
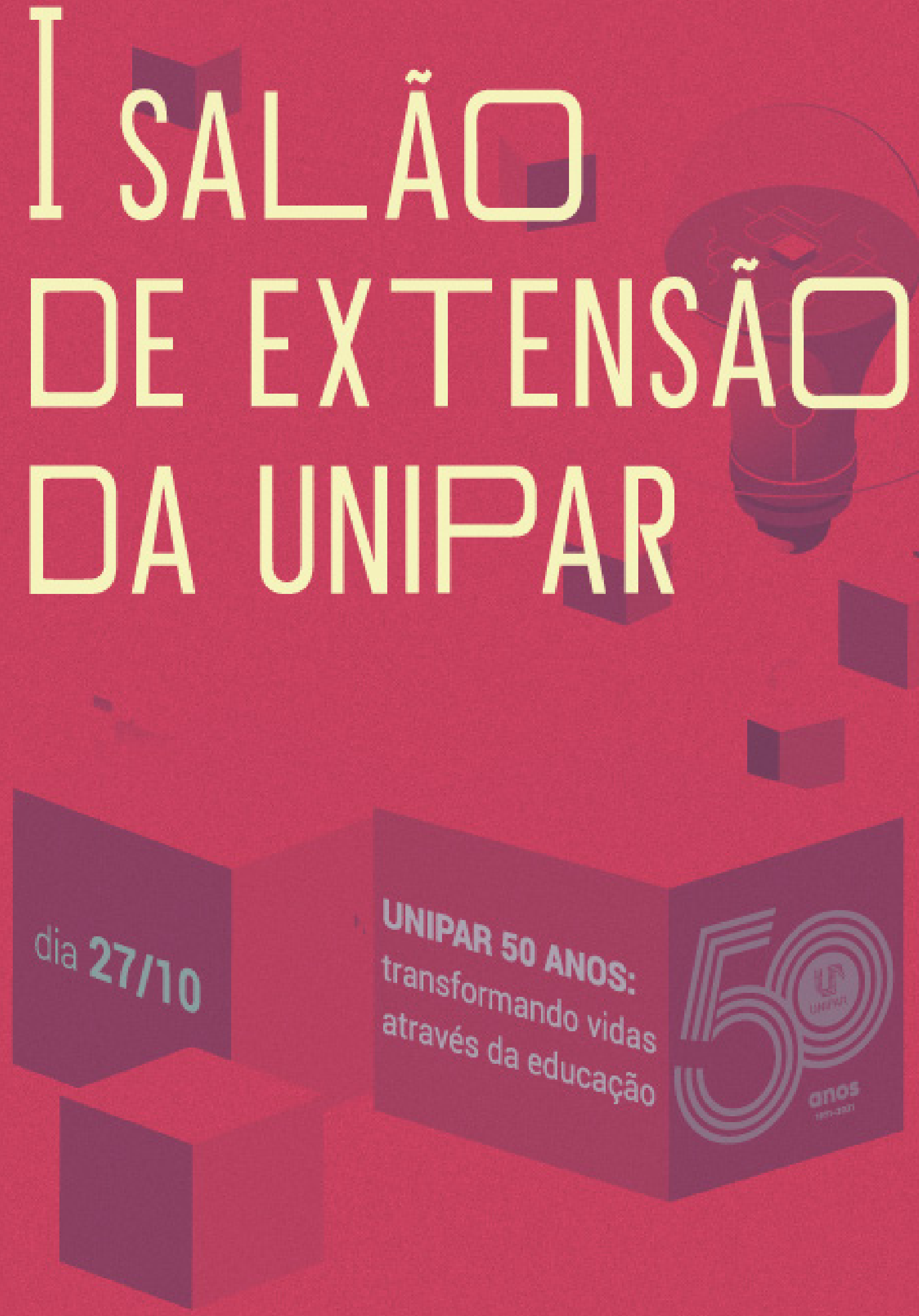


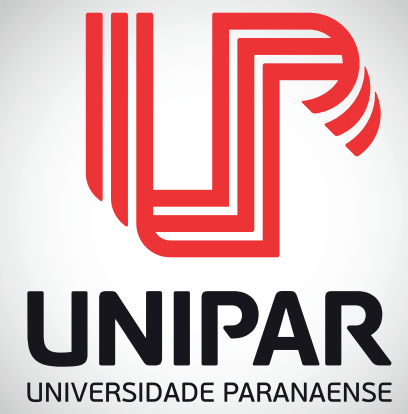




\section{UNIVERSIDADE PARANAENSE}

COORDENADORIA DE PESQUISA E EXTENSÃO

\section{RESUMOS EXPANDIDOS DO I SALÃO DE EXTENSÃO DA UNIPAR}

Departamento de Editoração e Divulgação Científica - DEDIC Umuarama - PR 2021 
Ficha Catalográfica

Bibliotecária Responsável: Inês Gemelli CRB 9/966

S161 Salão de Extensão da UNIPAR (1.: 2021: Umuarama, PR). Anais do I Salão de Extensão da UNIPAR, 27 outubro de 2021. - Umuarama: UNIPAR, 2021.

ISBN 978-65-87557-74-8

1. Pesquisa. I. Universidade Paranaense. II. Título.

(21.ed.) CDD: 001.4

DOI: $10.25110 /$ salaoextensaodaunipar.2021 


\title{
UNIVERSIDADE PARANAENSE
}

\section{Mantenedora}

ASSOCIAÇÃO PARANAENSE DE ENSINO E CULTURA - APEC

\author{
Reitor \\ Carlos Eduardo Garcia \\ Vice-Reitora Executiva \\ Neiva Pavan Machado Garcia \\ Chefe de Gabinete da Reitoria \\ Rogério Dutra
}

\begin{abstract}
Diretor Executivo de Gestão de Assuntos Comunitários Cássio Eugênio Garcia
\end{abstract}

Diretora Executiva de Gestão da Cultura e Divulgação Institucional Claudia Elaine Garcia Custódio

Diretora Executivo de Gestão de Planejamento Acadêmico Sônia Regina da Costa Oliveira

Diretor Executivo de Gestão de Recursos Financeiros Rui de Souza Martins

Diretor Executivo de Gestão das Relações Trabalhistas Janio Tramontin Paganini

Diretor Executivo de Gestão dos Assuntos Jurídicos

Lino Massayuki Ito

Diretora Executiva de Gestão e Auditoria de Bens Materiais Permanentes e de Consumo

Rosilamar de Paula Garcia

Diretora Executiva de Gestão da Educação a Distância Ana Cristina de Oliveira Cirino Codato

Diretor Executivo de Gestão da Dinâmica Universitária José de Oliveira Filho

Diretora Executiva de Gestão do Ensino Superior Maria Regina Celi de Oliveira

Coordenadora de Pesquisa e Extensão

Evellyn Claudia Wietzikoski Lovato

Coordenador de Pós-Graduação

Emerson Luiz Botelho Lourenço

Diretora Geral do Campus Umuarama

Fernanda Garcia Velasquez de Lima

Diretor Geral do Campus Toledo

Angelo Alfredo Sucolotti

Diretora Geral do Campus Paranavaí

Edwirge Vieira Franco

Diretor Geral do Campus Guaíra

Hugo Miranda Mendes da Silva

Diretora Geral do Campus Cianorte

Dieine Aparecida Cescon

Diretor Geral do Campus Cascavel

Gelson Luiz Uecker

Diretor Geral do Campus Francisco Beltrão

Claudemir José de Souza

\section{COMISSÃO ORGANIZADORA}

Prof. a Dr. ${ }^{a}$ Evellyn Claudia Wietzikoski Lovato

Prof. Dr. Rodrigo Oliva

\section{COMISSÃO JULGADORA CONCURSO CULTURAL}

Rodrigo Oliva - Doutor em Comunicação

Thiago Garcia Martins - Mestre em Comunicação e Linguagens

Bruno Silva Santos - Professor e Designer

Vanessa Mayumi Pereira - Especialista em Discurso Fotográfico

Guilherme Almeida - Publicitário

\section{COMISSÃO DE APOIO}

Edilaine de Souza Chinaglia Bogo COPEX

Eliane Cristina Ussifati

COPEX

Gabriela Fernanda Tozati

COPEX

COPEX

COPEX

DEDIC

DEDIC

A

DEDIC

DADS 


\section{CONSULTORES AD HOC}

ADRIANA DIAS MARTINS FERRAREZI

ADRIANA KUNEN

ADRIANO AUGUSTO MARTINS

ALESSANDRO RODRIGUES PERONDI

ALEXANDRE MAGNO AUGUSTO MOREIRA

ANA CLEIA DE OLIVEIRA CIRINO

ANA DANIELA LOPES

ANA PAULA TORQUETI GAVIOLI

ANDRE LUIZ URBANO

CAMILA CRISTIANE FORMAGGI SALES RIBEIRO

CAMILA PEREIRA GIROTTO

CESAR AUGUSTO HOFFMANN

CINTHIA THIESEN OTANI

CLEBER DE SOUZA RELLI

CLOVIS ULIANA

CRISTIANE CLAUDIA MEINERZ

DARIANE DOS SANTOS VIRGENS A DA SILVA

DEBORA TATIANE FEIBER GIRARDELLO

DENISE ALVES LOPES

DIANE GUZI FOMIN

DORA DE CASTRO AGULHON SEGURA

DURCELINA SCHIAVONI BORTOLOTI

EDSON GERONIMO

ELIANE CRISTINA USSIFATI

ELIZABETI DE MATOS MASSAMBANI

ELOUISE MILENI STECANELLA

ELYSSANDRO PIFFER

ERICA APARECIDA ROMERO ORTEGA

EVARISTO NUNES DE FARIAS

EVELLYN CLAUDIA WIETZIKOSKI LOVATO

EVERLEI CAMARA

FERNANDO RIGO BOTELHO

FILIPE CORREA PACHECO

FRANCIELE DO NASCIMENTO SANTOS ZONTA

GERVALDO RODRIGUES CAMPOS

GIOVANA MIOTO DE MOURA

HELTON ADRIANO DE SOUZA

IGO HENRIQUE SILVA NUNES

INDIOMARA BARATTO

IONE REGINA ESPERANCA

IRINEIA PAULINA BARETTA

JAQUELINE HOSCHEID

JOSE GASPAR FERRAREZI

JOSE LUIZ BORSATTO JUNIOR

KAREN LAURENE DALLA COSTA

LEDIANA DALLA COSTA
LUCAS GOMES DE OLIVEIRA

LUCYELENA AMARAL PICELLI

LUIS IRAJA NOGUEIRA DE SA JUNIOR

LUIZ AUGUSTO MUGNAI VIEIRA JUNIOR

MARCELO FIGUEIRO BALDI

MARCO AURELIO CUNHA DEL VECHIO

MARCOS JOSE ALVES DE

MARIA DO CARMO DE OLIVEIRA NOGUEIRA

MARIANA VITORIA GASPERIN

MARIANNA COSTA OLIVEIRA

MIRIAM FECCHIO CHUEIRI

PATRICIA AMARAL GURGEL VELASQUEZ

PATRIK AMERICO POLLIZELLO LOPES

PAULA MONTANHINI FAVETTA

PAULO CESAR DE SOUSA 4436233292

RAQUEL COSTA MACHADO

RENATA TORRI SALDANHA COELHO

RICARDO MARCELO ABRAO

RODRIGO LEITE ARRIEIRA

RODRIGO OLIVA

ROSILEY BERTON PACHECO

SUELLEN LAIS VICENTINO VIEIRA

TAISE SIGNORINI

TANIA HARUMI UCHIDA

TATIANA QUEIROZ BARDI AUGUSTO

THAIS CRISTINA GUTSTEIN NAZAR

THIAGO HENRIQUE DE BONA

VITOR HUGO RAMOS MACHADO

VOLMIR PITT BENEDETTI

ZILDA CRISTIANI GAZIM 


\section{APRESENTAÇÃO}

O I Salão de Extensão foi preparado com o objetivo de propiciar um espaço de socialização de ações voltadas à comunidade, mostrar a diversidade e a abrangência da extensão desenvolvida pela Instituição, na qual reafirma o compromisso social e acadêmico da UNIPAR, possibilitando a troca de experiências e a divulgação de conhecimentos produzidos por meio da Extensão Universitária.

Com uma programação diversificada o I Salão de Extensão contará com Sessão Virtual de Pôster Vídeo, Ciclo de Palestras, Concurso Cultural UPfotografei, Mostra Virtual de Fotografias e Conferência de Abertura, com a temática: "UNIPAR 50 anos: transformando vidas através da educação".

A heterogeneidade dos participantes permite uma ampla apresentação dos mais diversos assuntos relacionados as ações extensionistas desenvolvidas por professores, acadêmicos da graduação e pós-graduação, além de profissionais e demais interessados da própria instituição e de instituições externas.

Neste ano de 2021, o evento será realizado virtualmente, onde serão apresentados trabalhos na forma de pôster vídeo. Além desta atividade, os participantes poderão navegar e acessar todos os pôsteres vídeos exibidos no site do evento, interagir em chats com os autores, assistir ao Ciclo de Palestras, navegar pela Mostra Virtual de fotografias e assistir a Conferência de Abertura com apresentação artística a partir às $19 \mathrm{~h} 00 \mathrm{~min}$.

Participam da Comissão Organizadora a Coordenadoria de Pesquisa e Extensão e a Comissão de Avaliação de Projetos de Extensão - CAPE.

No intuito de estimular o interesse pela prática extensionistas em alunos de graduação, e desenvolver ações sociais que beneficiam a comunidade em geral, a UNIPAR criou Programas de Iniciação à Extensão: 1) Programa Institucional de Bolsas de Iniciação à Extensão - PIBEX; 2) Programa Externo de Bolsas de Iniciação à Extensão - PEBEX; e 3) Programa de Iniciação à Extensão - PEX. No PIBEX os acadêmicos recebem bolsas (40) oriundas de recursos da arrecadação da Universidade Paranaense. No PEBEX, as bolsas são custeadas por órgãos/agências de fomento externo, destacando-se a Fundação Araucária (2021/2022) 02 bolsas vigentes. Enquanto no PEX, no ano de 2021, são 960 acadêmicos da graduação presencial, semipresencial e da educação à distância, que participam dos projetos de extensão de forma voluntária.

O número de inscritos e de trabalhos apresentados no I Salão de Extensão da UNIPAR, encontram-se demonstrado no quadro a seguir:

\begin{tabular}{|c|c|c|c|}
\hline ANO & EVENTO & $\begin{array}{c}\mathbf{N}^{\mathbf{o}} \text {. DE } \\
\text { INSCRITOS }\end{array}$ & $\begin{array}{c}\mathbf{N}^{\mathbf{0}} \text {. DE } \\
\text { TRABALHOS }\end{array}$ \\
\hline 2021 & I Salão de Extensão da UNIPAR & 865 & 201 \\
\hline
\end{tabular}

Fonte: COPEX - UNIPAR.

A UNIPAR investe anualmente em professores, materiais de projetos de extensão e bolsas de iniciação à extensão de uma forma equitativa, no ano de 2021 são 187 professores extensionistas vinculados entre os cursos de graduação e pósgraduação. Em função disso, a maior parte da produção extensionista da UNIPAR concentra-se nas áreas de conhecimento de Ciências da Saúde, Ciências Humanas e Ciências Sociais Aplicadas, como podemos visualizar no quadro abaixo, mediante o número de trabalhos apresentados no I Salão de Extensão da UNIPAR:

\begin{tabular}{|l|c|}
\hline \multicolumn{1}{|c|}{ ÁREA DE CONHECIMENTO } & I SALÃO DE EXTENS ÃO \\
\hline Ciências Exatas e da Terra & 02 \\
\hline Ciências Biológicas & 12 \\
\hline Engenharias & 04 \\
\hline Ciências da Saúde & 140 \\
\hline Ciências Agrárias & - \\
\hline Ciências Sociais Aplicadas & 20 \\
\hline Ciências Humanas & 23 \\
\hline Linguística, Letras e Artes & - \\
\hline TOTAL & 201 \\
\hline
\end{tabular}

Fonte: COPEX - UNIPAR.

Certamente, a dedicação dos acadêmicos e professores tem impulsionado a prática extensionista da Universidade 
Paranaense. Parabenizamos docentes e acadêmicos extensionistas pelo compromisso e pelos resultados obtidos e agradecemos imensamente o apoio da Universidade Paranaense e da Fundação Araucária.

Prof. ${ }^{a}$ Dr. ${ }^{a}$ Evellyn Claudia Wietzikoski Lovato

Coordenadora de Pesquisa e Extensão 


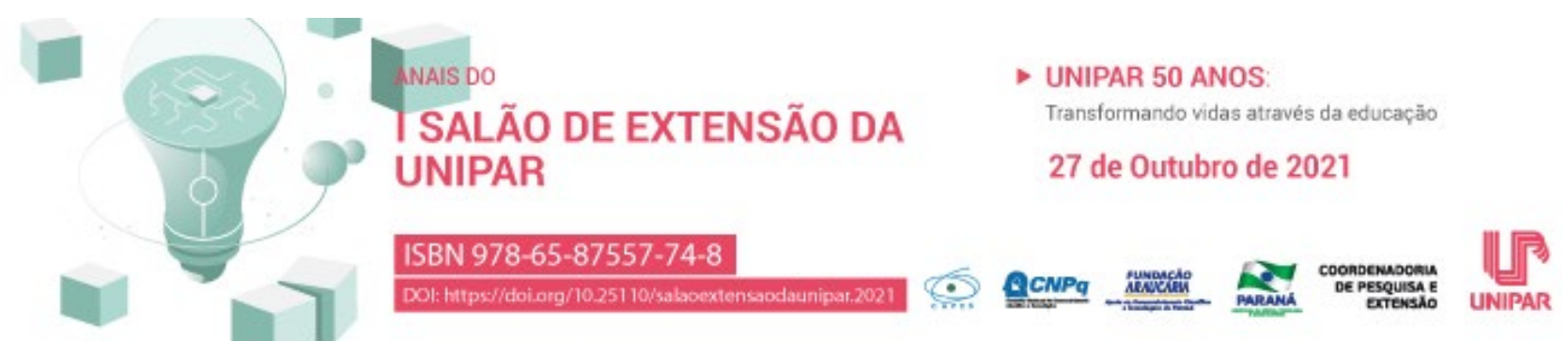

RAIVA NO BRASIL E EM REGIÕES FRONTEIRIÇAS

\author{
${ }^{1}$ MARCO AURELIO CUNHA DEL VECHIO, ${ }^{2}$ LAISA MARINA ROSA REY, ${ }^{3}$ FERNANDA SPESIA ANTONIO, ${ }^{4}$ LEILA ALVES DE \\ OLIVEIRA, ${ }^{5}$ LIDIANE NUNES BARBOSA, ${ }^{6}$ DANIELA DIB GONÇALVES
}

\author{
${ }^{1}$ Programa de Pós-Graduação em Ciência Animal, Taxista CAPES/PROSUP, UNIPAR \\ ${ }^{2}$ Programa de Pós-Graduação em Ciência Animal, Bolsista Fundação Araucária, UNIPAR \\ ${ }^{3}$ Discente de Medicina Veterinária, PIBIC, UNIPAR \\ ${ }^{4}$ Programa de Pós-Graduação em Ciência Animal, Taxista CAPES/PROSUP, UNIPAR \\ ${ }^{5}$ Docente de Medicina Veterinária e Programa de Pós-Graduação em Ciência Animal, UNIPAR \\ ${ }^{6}$ Docente de Medicina Veterinária e Programa de Pós-Graduação em Ciência Animal, UNIPAR
}

Introdução: A raiva é uma doença zoonótica, transmitida pela inoculação do vírus através da saliva de mamíferos infectados, sendo uma das vias a mordedura (OIE, 2016). A doença é causada por um vírus de RNA envelopado, do gênero Lyssavirus e família Rhabdoviridae (ICTV, 2014). No Brasil, a raiva é considerada endêmica e sua distribuição tem relação com variáveis socioeconômicas e culturais (MINISTÉRIO DA SAÚDE, 2015). Os morcegos hematófagos são considerados os principais transmissores da raiva no Brasil, entretanto, já foram encontrados espécimes não hematófagos com raiva (BRASIL, 2008).

Objetivo: Reunir informações epidemiológicas da literatura referentes a infecção por raiva no Brasil e regiões fronteiriças, compartilhando tais conhecimentos no Colégio Agrícola Estadual de Umuarama em formato de apresentação com painel e cartilhas educativas, a fim de contribuir no ensino destes alunos e na literatura científica.

Resultados: Em 1966 implantou-se o Plano de Combate à Raiva dos Herbívoros e atualmente denominado Programa Nacional de Controle da Raiva dos Herbívoros e outras Encefalopatias (PNCRH), que tem como objetivo diminuir a prevalência da doença nos herbívoros domésticos no País (Brasil, 2009). O Programa Nacional de Profilaxia da Raiva Humana (PNPR) foi instituído em 1973 visando reduzir o número de casos em humanos (SCHNEIDER et al., 1996). Destaca-se a importância de países fronteiriços realizarem controles e padronizações de sistemas de combate a zoonoses, já que alguns países como Bolívia e províncias de Puerto Quijarro e Suarez possuem vulnerabilidades refletindo diretamente na saúde pública e nos indicadores de vigilância sanitária (GADELHA; COSTA, 2007). O monitoramento da circulação do vírus, vacinação da população, medidas educacionais, controle de focos em locais de susceptibilidade ao vírus são formas de controle para esta zoonose (CEBALLOS et al., 2014). Em 2016 no município de Maringá/Paraná no Brasil, diagnosticado pelo Centro de Controle de Zoonoses foi confirmado um caso de raiva canina, na qual até então não possuía registros de diagnóstico para a doença (RONCADA et al., 2019). Segundo Cabral et al. (2018) apesar da prevenção através de vacinação a raiva continua sendo uma importante causa de mortalidade humana em muitos países, representando um grande desafio para as autoridades sanitárias. Casos confirmados de raiva felina e canina registrados em 2014 e 2015 no estado de São Paulo no Brasil, indicam que a doença está presente no país e que pode acometer os seres humanos e animais domésticos (CASTILHO et al., 2016). Mesmo nas áreas onde a raiva foi erradicada, esta pode ser reintroduzida por animais silvestres, se a população de cães não é imunizada de forma eficaz (LACERDA et al., 2020). De acordo com Rodrigues et al. (2017) em 2010, 2011 e 2015 no município de Campinas/São Paulo, não houveram campanhas de vacinação contra raiva, o que colabora com a não adesão da população pela vacina muito possivelmente pelo desconhecimento da mesma. Dória (2009) relata o quão fundamental é a vacinação antirrábica para a prevenção, proteger os animais, não permitir que os animais fiquem soltos nas ruas, manter latas de lixo fechadas para não atrair outros animais e manter distância de animais selvagens e desconhecidos. Para Lima e Gagliano (2014) está clara a necessidade em deixar a população informada sobre os reservatorios, modo de transmissão, agentes etiológicos e só assim será possível controlar esta doença.

Conclusão: Conclui-se que campanhas de vacinação de cães, gatos e seres humanos no Brasil e em países de fronteira se fazem necessárias, já que o controle epidemiológico é complicado em virtude de ser um vírus de fácil propagação. Ações de educação em saúde devem ser realizadas constantemente por Médicos Veterinários visando a prevenção desta e de outras doenças zoonóticas e o desenvolvimento de projetos de extensão trazendo informações a população podem colaborar quanto a conscientização da população.

\title{
Referências
}

BRASIL. Raiva humana, Brasil, 1986-2009. Coordenação de Vigilância das Doenças Transmissíveis por Vetores e Antropozoonoses, Coordenação Geral de Doenças Transmissíveis, Secretaria de Vigilância em Saúde, Ministério da Saúde. Umuarama, 24 jun. 2021. Disponível em: http://portal. saude.gov.br. Acesso em: 24 jun. 2021. 
BRASIL. Manual de Diagnóstico Laboratorial de Raiva. 1. ed. Brasília: Ministério da Saúde, 2008.

CASTILHO, J.G.; SOUZA, D. N.; OLIVEIRA, R. N.; CARNIELI, J. P.; BATISTA, H. B. C. R.; PEREIRA, P. M. C.; ACHKAR, S. M.; MACEDO, C. I. The epidemiological importance of bats in the transmission of rabies to dogs and cats in the state of São Paulo, Brazil, between 2005 and 2014. Zoonoses Public Health, v. 64, n. 6, p. 423-430, sep./nov. 2016.

CABRAL, K. C.; OLIVEIRA, M. A.; DINIZ, S. A.; HADDAD, J. P. A.; MATOS, J. C. C.; OLIVEIRA, T. M.; BICALHO G. C.; SILVA, M. X. Avaliação do tratamento antirrábico humano pós-exposição, associado a acidentes com cães. Arquivo Brasileiro de Medicina Veterinária e Zootecnia, v. 70, n. 3, p. 682-688, mai/jun. 2018.

CEBALLOS, Aréchiga N.; KARUNARATNA, D.; SETIÉN, Aguilar A. Control of canine rabies in developing countries: key features and animal welfare implications. Revue Scintifique et Technique Office International Epizootics, v. 33, n. 1, p. 311- 321, apr. 2014.

DÓRIA, José. A raiva ou Hidrofobia. Umuarama, 14 jun. 2021. Disponível em: http://www.vetbiblios.pt/artigos_tecnicos/Zoonoses/raiva_ou_hidrofobia.pdf. Acesso em: 14 jun. 2021.

GADELHA, Carlos Augusto Grabois.; COSTA, Laís. Integração de fronteiras: a saúde no contexto de uma política nacional de desenvolvimento. Cadernos de Saúde Pública, v. 23, n. 2, p. 214-226. 2007.

ICTV. Rabies Virus Taxonomy. Umuarama, 14 jun, 2021. Available from: http://www.ictvonline.org/ virusTaxonomy.asp/. Accessed: jun 9, 2021.

LACERDA, L., SANTOS, D., BARROS, E., ROSÁRIO, C., \& COIMBRA, V. Avaliação da Ocorrência de Raiva Canina no Estado do Maranhão no Período de 2010 a 2018. Ars Veterinaria, v.36, n. 3, p. 174-180, mai/ago. 2020.

MINISTÉRIO DA SAÚDE. Mapas da raiva no Brasil 2015. Umuarama, 14 jun. 2021. Disponível em: http://portalsaude.saude.gov.br/images/pdf/2015/junho/08/map as-atualizados-raiva-2015.pdf. Acesso em: 10 jun. 2021.

OIE. Rabies Portal. Umuarama, 14 jun, 2021. Available from: http://www.oie.int/en/ animal-health-in-the-world/rabiesportal/about-rabies/. Accessed: jun 11, 2021.

PUPULIM, Antônio Guilherme Roncada.; FONZAR, Udelysses Janete Veltrini.; LANGONI, Hélio. Raiva canina no município de Maringá-PR em 2016 - Relato de Caso. Veterinária e Zootecnia, v. 26, p. 1-5, jun. 2019.

RODRIGUES, Ricardo Conde Alves; ZUBEN, Andrea Paula Bruno Von; LUCCA, Tosca de; REICHMANN, Maria de Lourdes Aguiar Bonadia. Campanhas de vacinação antirrábica em cães e gatos e positividade para raiva em morcegos, no período de 2004 a 2014, em Campinas, São Paulo. Epidemiologia e Serviços de Saúde, v. 26, n. 3, p. 621-628, jul./sep. 2017.

Schneider, M. C.; Souza, L. M.; Moraes, N. B.; Diaz, R. C. Controle da raiva no Brasil de 1980 a 1990. Revista de Saúde Pública, v. 30, n. 2, p.196-203. 1996.

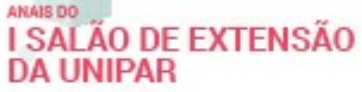

I SALÃO DE EXTENSÃO DA UNIPAR

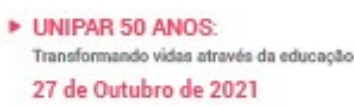
Traneformando videa atreves da educaçe
27 de Outubro de 2021

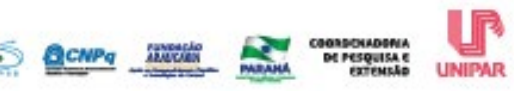




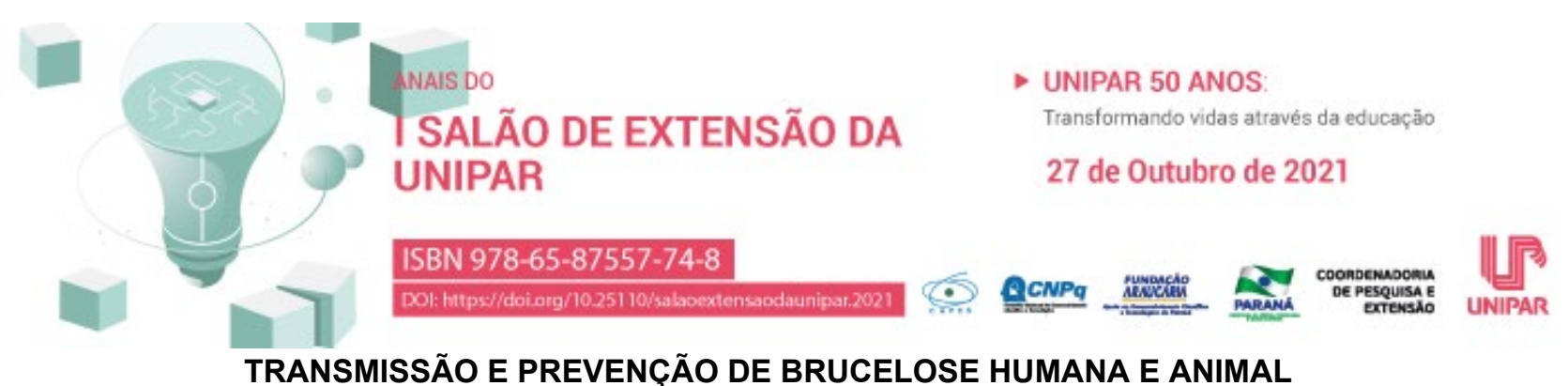

\author{
${ }^{1}$ FERNANDA SPESIA ANTONIO, ${ }^{2}$ LEILA ALVES DE OLIVEIRA, ${ }^{3}$ LAISA MARINA ROSA REY , ${ }^{4}$ MARCO AURÉLIO CUNHA \\ DEL VECHIO, ${ }^{5}$ ISABELA CARVALHO DOS SANTOS, ${ }^{6}$ DANIELA DIB GONÇALVES
}

\author{
${ }^{1}$ Discente Medicina Veterinária, bolsista PIBIC, UNIPAR \\ ${ }^{2}$ Pós-Graduandos do PPG em Ciência Animal, UNIPAR \\ ${ }^{3}$ Pós-Graduandos do PPG em Ciência Animal, UNIPAR \\ ${ }^{4}$ Pós-Graduandos do PPG em Ciência Animal, UNIPAR \\ ${ }^{5}$ Pós-Graduandos do PPG em Ciência Animal, UNIPAR \\ ${ }^{6}$ Docente da UNIPAR
}

Introdução: A brucelose é uma doença bacteriana, transmissível, causada por diferentes espécies da Brucellaspp.e por ser uma zoonose, é endêmica em muitos países, causando grandes perdas econômicas no sistema de produção e afetando gravemente a saúde única (BRASIL, 2006). Em todas as espécies de Brucella identificadas, B. melitensis, B. suis e B. abortus são caracterizadas como espécies lisas com alta patogenicidade, podendo causar doenças graves em caprinos, ovinos, suínos, bovinos, e inclusive no homem (CORBEL; ELBERG; COSIVI, 2006).

Objetivo: $O$ objetivo deste trabalho é realizar uma revisão de literatura sobre a transmissão e prevenção da brucelose humana e animal, buscando informações relevantes para serem compartilhadas no Colégio Agrícola Estadual de Umuarama, a fim de contribuir no ensino destes alunos através de apresentação e palestras com auxílio de painel e cartilhas educativas.

Desenvolvimento: A brucelose é uma zoonose de grande relevância mundial e, conforme a Organização Mundial da Saúde, ela é transmitida para os humanos por contato direto e/ou indireto com animais infectados ou seus subprodutos (WHO, 2006). Em humanos, as principais formas de transmissão são pelo contato direto com material contaminado, como feto abortado ou restos placentários, através de pele ferida e principalmente ingestão de produtos lácteos contaminados (MANTUR; AMARNATH; SHINDE, 2007; DEAN et al., 2012). Os sintomas mais comuns nos humanos são febre intermitente, dores musculares, articulares, cefaléia e sudorese noturna, sendo geralmente confundida com gripe recorrente (SILVA et al., 2005; AL DAHOUK et al., 2007). Sobre a prevenção humana, essa pode ser feita com medidas de higiene e de segurança, incluindo fatores como a pasteurização do leite ou seu uso fervido, o uso de roupas adequadas e equipamento de proteção individual quando da lida com os animais ou seus subprodutos, bem como a desinfecção de equipamentos, instrumentos e instalações (CORBEL; ELBERG; COSIVI, 2006; LAWINSKY et al., 2010; SANCHES, 2012). Já nos animais a melhor forma de controle e prevenção é o uso de vacinação de todas as fêmeas bovinas e bubalinas com idade entre três a oito meses de vida, com o uso da vacina (B19), podendo ser substituída pela vacina não indutora da formação de anticorpos aglutinantes, amostra RB51, ou eliminação dos animais positivos, e em casos positivos fazer o adequado destino dos animais por meio da notificação em órgão fiscalizador (BRASIL, 2016).

Conclusão: Neste sentido, sabe-se que a prevalência da doença no animal acompanha a prevalência da doença em humanos e constata-se que para a prevenção de brucelose humana se faz essencial manter uma boa higiene dos produtos e evitar o consumo de alimento lácteo cru e produtos lácteos não pasteurizados, bem como atentar-se ao uso de roupas e equipamentos que possam estar infectados. Assim, a prevenção vai desde o rebanho animal, da realização do protocolo vacinal dos animais de maneira adequada e da higiene dentro das propriedades no trato com os animais, realizando a eliminação de animais diagnosticados para a doença. Ações de educação em saúde para produtores e trabalhadores rurais, bem como para a população em geral são essenciais para disseminação de informações, como formas de transmissão e prevenção desta enfermidade zoonótica, por isso projetos de extensão à comunidade são imprescindíveis.

\title{
Referências
}

AL DAHOUK, S.; et al. Evaluation of Brucella MLVA typing for humanbrucellosis. Journal of MicrobiologicalMethods, v. 69, p.137 145, 2007.

BRASIL. Instrução Normativa no 19, de 10 de outubro de 2016. Diário Oficial da União, Brasília, n. 211, Seção 1, p. 7, 3 nov. 2016.

BRASIL. Programa Nacional de Controle e Erradicação da Brucelose e da Tuberculose Animal (PNCEBT). Brasília: MAPA/SDA/DSA, 2006.

CORBEL, M.J.; ELBERG S.S.; COSIVI, O. Brucellosis in humans and animals. Geneva: WHO Press, 2006.

DEAN, A. S.; et al. ClinicalManifestations of HumanBrucellosis: A SystematicReview and Meta-Analysis. PLOS Neglected 
Tropical Diseases, v. 6, n. 12, p. 1929, 2012.

LAWINSKY, M. L. DE. J.; et al. Estado da arte da brucelose em humanos. Revista Pan-AmazSaude, v. 1, n. 4, p. 75-84, 2010.

MANTUR, B. G., AMARNATH, S. K., SHINDE, R. S., Review of clinical and laboratoryfeatures of humanBrucellosis. Indian J Med Microbiol., v. 25, n. 3, p. 188-202, 2007.

SANCHES, L. M. G. Análise comparativa da evolução da brucelose humana e animal, em Portugal Continental de 2002 a 2011. Dissertação (Mestrado em Saúde Pública) - Universidade do Porto, Porto, 2012.

SILVA, F. L. et al. Brucelose bovina. Cadernos Técnicos de Veterinária e Zootecnia, n. 47, p. 1-12, 2005.

I SALÃOO DE EXTENSÃO

DA UNIPAR
- UNIPAR 50 ANOS

Transformando vides atravia da educaçso

27 de Outubro de 2021 


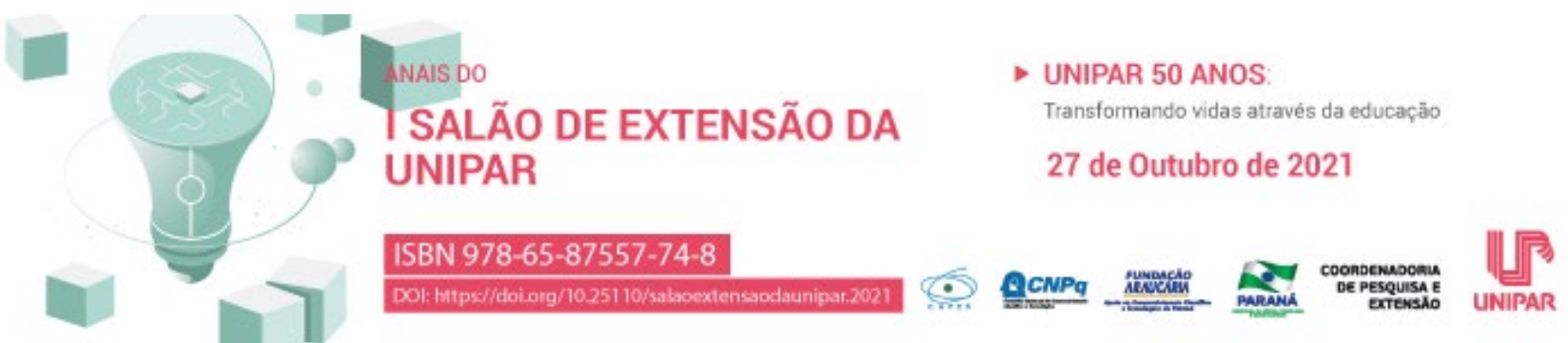 \\ FISIOTERAPIA NEUROLÓGICA: UM ESTÍMULO À NEUROPLASTICIDADE
}

\author{
${ }^{1}$ LETICIA FLOIS FERREIRA, ${ }^{2}$ ANA PAULA CAMPOS SANTANA, ${ }^{3}$ KARINE GREEF LAMB, ${ }^{4}$ DORA DE CASTRO AGULHON \\ SEGURA
}

\author{
${ }^{1}$ Acadêmica do Curso de Fisioterapia da UNIPAR \\ ${ }^{2}$ Acadêmica do Curso de Fisioterapia da UNIPAR \\ ${ }^{3}$ Acadêmica do Curso de Fisioterapia da UNIPAR \\ ${ }^{4}$ Docente da UNIPAR
}

Introdução: É notória a alta incidência de doenças neurológicas no mundo, sobretudo em países menos desenvolvidos. O mais agravante é que se trata de distúrbios que desencadeiam sequelas permanentes, incidindo em limitações físicas e cognitivas (UMPHRED, 2010). Assim, o diagnóstico precoce se torna decisivo para a recuperação funcional realizado por fisioterapeutas. Embora, após uma lesão neuronal ser constatada, e suas repercussões serem consideradas irreversíveis, o estímulo cerebral desencadeia áreas adjacentes à lesão provocando a migração de neurônios saudáveis com a finalidade de minimizar sequelas, fenômeno esse nominado de neuroplasticidade (STOKES, 2000). Para Umphred (2010), uma avaliação funcional precisa é fundamental para elaboração de uma conduta fisioterapêutica eficaz, voltada para normalização do tônus, melhora da força e flexibilidade, aquisição de habilidades motoras, e promoção de independência.

Objetivo: Através de um projeto de extensão promover conhecimento sobre a profissionalização da fisioterapia.

Resultados: Constatou-se que lesões neurológicas são as grandes causas de incapacidade funcional em indivíduos em qualquer faixa etária. No princípio, a ciência acreditava que após uma lesão no sistema nervoso, as conexões neurais jamais seriam reestabelecidas. Entretanto, com o avanço das pesquisas, evidenciou-se que o encéfalo compõe um conjunto de órgãos mutáveis e capazes de se reorganizarem para recuperar funções perdidas, ou treinar o corpo para desenvolver novas habilidades, mesmo que restritas, surfgindo assim, a fisioterapia neurológica, que comprova através da terapêutica que a neuroplasticidade é evidenciada na melhora das sequelas do indivíduo que sofreu um infortúnio neural (PARTRIDGE, 2006). Para Umphred (2010), embora a fisioterapia não possa reverter a lesão, seus métodos de tratamento previnem complicações e estimulam a aquisição funcional, melhorando a qualidade de vida dos pacientes. Um programa de reabilitação fisioterapêutico é composto por atividades que desenvolvem potencialidades sensório motoras, minimizando dor, melhorando a condição física, e treinando funções cotidianas, como o executar a marcha. Torna-se importante ressaltar que o tratamento é lento e deve ser gradativo, sendo muito relevante a divulgação dessa temática como forma de explanar as diversas áreas de atuação da fisioterapia

Considerações Finais: Concluiu-se que o projeto em questão é crucial para a divulgação da fisioterapia, neste caso, no âmbito da neurologia, facilitando o entendimento de quem procura por atendimento ou pessoas que pesquisam por uma área profissional bem sucedida.

\section{Referências}

PARTRIDGE, C. Fisioterapia Neurológica. 1. ed. São Paulo: Santos Editora, 2006.

STOKES, M. Neurologia para Fisioterapeutas. 1. ed. SãoPaulo: Premier, 2000.

UMPHRED, D. A. Reabilitação Neurológica. 5. ed. São Paulo: Elsevier, 2010.

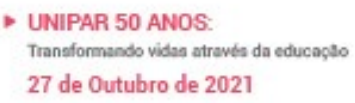

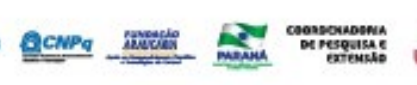




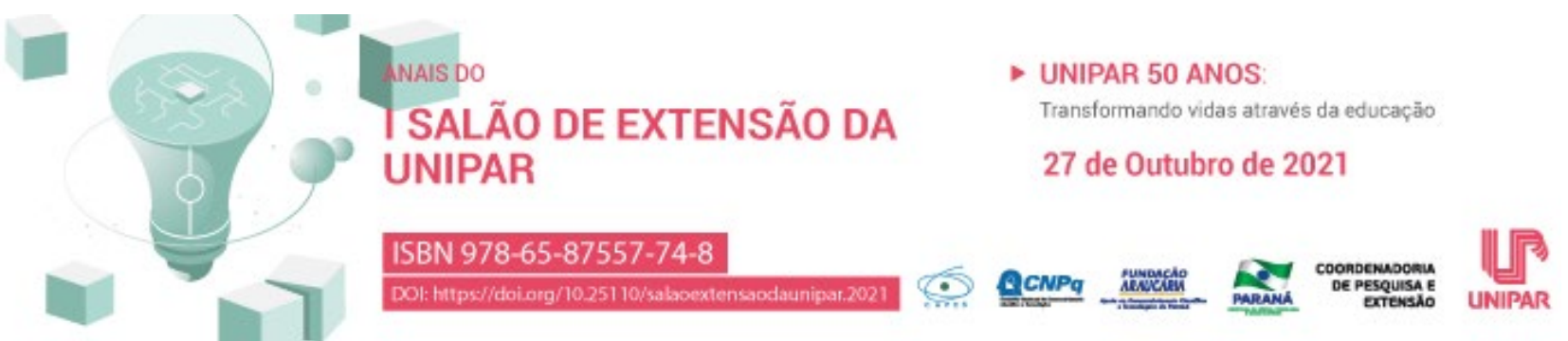 \\ RELAÇÃO DA OBESIDADE COM O ALTO CONSUMO DE ALIMENTOS ULTRAPROCESSADOS
}

\author{
${ }^{1}$ DEBORA TIEMI IGARASHI DOS SANTOS, ${ }^{2}$ BRUNA GAZETTA PEREIRA, ${ }^{3}$ KASSIELEN APARECIDA COELHO \\ MARYNOWSKI DA SILVA, ${ }^{4}$ MARTA ANDREIA CUSTODIO JORGE, ${ }^{5}$ MÔNICA DO VALE ASSIS GARCIA SANTINI, ${ }^{6}$ LIDIANE \\ NUNES BARBOSA
}

\author{
${ }^{1}$ Acadêmica de Nutrição e bolsista PIBEX (Programa Institucional de Bolsas de Extensão) \\ ${ }^{2}$ Acadêmica do Curso de Nutrição da UNIPAR e participante do PEX (Programa de Extensão) \\ ${ }^{3}$ Acadêmica do Curso de Nutrição da UNIPAR e participante do PEX (Programa de Extensão) \\ ${ }^{4}$ Acadêmica do Curso de Nutrição da UNIPAR e participante do PEX (Programa de Extensão) \\ ${ }^{5}$ Responsável Técnica pela Clínica de Nutrição da Unipar \\ ${ }^{6}$ Docente de Nutrição na UNIPAR
}

Introdução: Segundo o Guia Alimentar para a População Brasileira (BRASIL, 2014) os ultraprocessados são alimentos feitos exclusivamente pela indústria e que usam de ingredientes os quais conferem aroma, cor e sabor atraentes para o consumidor. Exemplos são so salgadinhos de pacote, balas, sucos em pó etc. Segundo Martins (2019) a alta intervenção sobre esta classe de alimentos altera a forma como interagem com o organismo do consumidor, pois torna-os viciantes, enquanto Martins (2018) alerta para a alta carga de gorduras e açúcares presentes nas composições. Também foi observada a ingestão elevada de ultraprocessados na dieta de pessoas com obesidade ou sobrepeso (OLIVEIRA et al., 2019) .

Objetivo: Analisar a relação da frequência de ingestão de alimentos ultraprocessados com as elevadas taxas de gordura corporal e os quadros de obesidade em pacientes atendidos na Clínica de Nutrição da Unipar.

Resultados: Todas as 64 anamneses usadas na coleta de dados são datadas de junho de 2020 a junho de 2021. Além disso, 52 dos atendidos (82\%) são mulheres e apenas 12 deles (próximo de 18\%) são do sexo masculino. Neste cenário, foi constatado que os pacientes em sua totalidade consumiam algum tipo de comida ultraprocessada, sendo que aproximadamente $86 \%$ deles (55 indivíduos) ingeriam 5 ou mais (ex: refrigerantes, chocolates etc.), geralmente, com frequência diária ou semanal. Paralelo a isso, 35 (cerca de 55\%) apontavam para algum grau de obesidade ou risco para desenvolver a mesma. Dadas as circunstâncias, 51 pessoas (perto de $80 \%$ dos analisados) estão com o percentual de gordura acima do ideal, mesmo aqueles com peso adequado, oferecendo maior risco para o desenvolvimento de doenças como dislipidemias, doença cardiovascular, inflamação, entre outras.

Considerações finais: Com a coleta de dados feita, conclui-se que o alto consumo de ultraprocessados está diretamente ligado à incidência de obesidade ou ao risco de desenvolvê-la, visto que essa categoria de alimentos, além de carregados de gordura, também são repletos de açúcares que são estocados na forma de gordura quando ultrapassam o limite que o corpo pode gastar. Sendo assim, cabe aos profissionais de saúde, em especial, nutricionistas, conscientizar sobre os males dos ultraprocessados à saúde e oferecer propostas de substituição por alimentos minimamente processados ou in natura, visando a prevenção e tratamento de quadros clínicos como os apresentados nos dados deste trabalho.

\section{Referências}

BRASIL, de outubro de 2014, disponível em https://bvsms.saude.gov.br/ . Acesso em 12. jul. 2021

MARTINS, Paula de Fátima Almeida. Alimentos ultraprocessados: uma questão de saúde pública. Comunicação em Ciências da Saúde, v. 29, n. 1, p. 14-17, 2018.

MARTINS, Susana Raquel Rodrigues. Alimentos ultraprocessados e saúde. 2019. https://repositorioaberto.up.pt/bitstream/10216/122211/2/350792.pdf acesso em 06/08/2021

OLIVEIRA, lara Katrynne Fonsêca et al. Consumo de alimentos ultraprocessados e obesidade abdominal em adolescentes universitários. Revista Eletrônica Acervo Saúde, v. 11, n. 16, p. e1574-e1574, 2019.

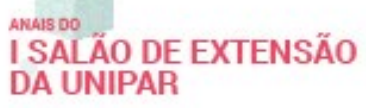

DA UNIPAR

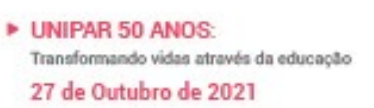

Traneformando videa stravies da educagto

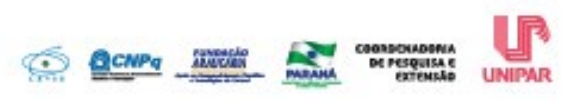




\title{
(1) \\ - UNIPAR 50 ANOS: \\ Transformando vidas através da educação \\ 27 de Outubro de 2021 \\ ISBN 978-65-87557-74-8 \\ . \\ Dol: hitps//doiong/10.251 10/salaoxtenssodaunipar.2021 \\ QCNPq A Axouctio

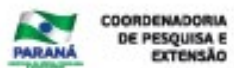

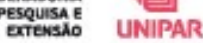 \\ OSTEOSSÍNTESE DE SÍNFISE MANDIBULAR E TRATAMENTO ENDODÔNTICO EM UM GATO RELATO DE CASO
}

\author{
${ }^{1}$ GUILHERME DONADEL, ${ }^{2}$ JOAO ANTONIO BERTA DE OLIVEIRA, ${ }^{3}$ SALVIANO TRAMONTIN BELETTINI
}

${ }^{1}$ Discente do Mestrado em Ciência Animal e Produtos Bioativos (PROSUP/CAPES),UNIPAR, Umuarama- PR

${ }^{2}$ Acadêmico do Curso de Medicina VeterinÃ iria da UNIPAR

${ }^{3}$ Docente da UNIPAR

Introdução: Atualmente pode-se contar com a possibilidade do tratamento de canal radicular, preservando-se o elemento dental em seu alvéolo, mantendo assim forma, função e estética da cavidade oral do animal (DUPONT, 2007). Com o avanço da medicina veterinária nos últimos 15 anos, surgiram as especialidades, dentre as quais a odontologia veterinária ocupa um lugar de destaque. A odontologia surgiu nos últimos vinte anos como uma parte distinta e significativa da clínica médica veterinária. A odontologia veterinária vem crescendo de forma extraordinária nestes últimos anos e hoje, vários profissionais atuam na área em todo o Brasil (BEZUIDENHOUT,2007). O tratamento baseia-se no tipo de fratura, no equipamento disponível, nos suprimentos, no conhecimento, nível de conforto e experiência do médico-veterinário (CUNHA et al.,2010).

Objetivo: Realizar o tratamento de restabelecimento da oclusão funcional por fixação que permita que o animal tenha uso suficiente da boca para se alimentar e ingerir líquidos após a redução e fixação.

Resultado: Foi atendido no hospital veterinário da Universidade Paranaense, um gato macho com um ano de idade, sem raça definida, pesando $4,3 \mathrm{~kg}$, não castrado, que possui acesso à rua e convive com outros dois animais, um cão e uma gata sem sinais de doença aparente. Durante anamnese a proprietária relatou sialorréia intermitente, tremores mandibulares, retração anormal da língua e vocalização. Notou-se que tratava-se de uma separação de sínfise mandibular simples sem fragmentos e comprometimento. Para correção da sínfise mandibular foi empregada a técnica de cerclagem simples com um fio ao redor da mandíbula (DUPONT, 2007). O procedimento odontológico escolhido para o tratamento dos três caninos foram os mesmos, já que os dentes afeccionados possuíam as mesmas características traumáticas. Os três possuíam polpa viva e viável e não apresentavam sinais de pulpite nem contaminação pulpar. Diante desse quadro optou-se pelo tratamento endodôntico aplicando a técnica de pulpectomia parcial seguida de restauração coronal (WOODBRIDGE; OWEN, 2013). A técnica de pulpectomia parcial e restauração dos dentes caninos com amálgama se mostraram resistentes e efetivas já que a proprietária relatou que o animal se alimentou e ingeriu água no mesmo dia em que foram realizados os procedimentos, não voltando a realizar as vocalizações e mimicas de dor durante estas atividades.

Conclusão: Conclui-se que as técnicas empregadas foram plenamente satisfatórias, possibilitando recuperação rápida do paciente.

\section{Referências}

BEZUIDENHOUT, A. J. Anatomia e histologia bucal aplicada In: SLATTER, D. Manual de cirurgia de pequenos animais. 3. ed, Barueri: Manole, 2007. 2630- 2637 p. v.2.

CUNHA, M. G. M. C. M. et al. Cerclagem com abraçadeira de náilon ou fio de aço no reparo de fraturas experimentais de sínfise mandibular em gatos. Acta Scientiae Veterinariae, v.38, n.4, Jul. 2010.

DUPONT, G. A. Odontologia restauradora. In: SLATTER, D. Manual de cirurgia de pequenos animais. 3. ed., Barueri: Manole, 2007. 2678-2686 p. v.2

WOODBRIDGE, N.; OWEN, M. Feline mandibular fractures: A significant surgical challenge. Journal of Feline Medicine and Surgery, v. 15, n. 3, p. $211218,2013$.

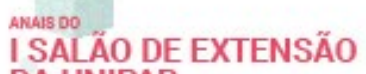

DA UNIPAR

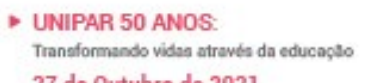

27 de Outubro de 2021

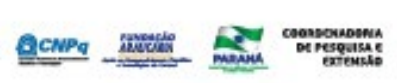




\title{
- E \\ SALÃO DE EXTENSÃO DA Transformando vidas através da educą̧̃o \\ UNIPAR \\ 27 de Outubro de 2021 \\ ISBN 978-65-87557-74-8

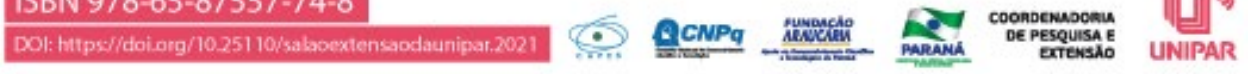 \\ PREVALÊNCIA DE CONSTIPAÇÃO INTESTINAL EM PACIENTES ATENDIDOS NA CLÍNICA ESCOLA DE NUTRIÇÃO DE UMUARAMA-PR
}

\begin{abstract}
${ }^{1}$ MARTA ANDREIA CUSTODIO JORGE, ${ }^{2}$ BRUNA GAZETTA PEREIRA, ${ }^{3}$ DEBORA TIEMI IGARASHI DOS SANTOS, ${ }^{4}$ KASSIELEN APARECIDA COELHO MARYNOWSKI DA SILVA, ${ }^{5}$ MONICA DO VALE ASSIS GARCIA SANTINI, ${ }^{6}$ LIDIANE NUNES BARBOSA
\end{abstract}

\author{
${ }^{1}$ Acadêmica de Nutrição e participante do PEX (Programa de Extensão) da Unipar \\ ${ }^{2}$ Acadêmica de Nutrição e participante do PEX (Programa de Extensão) da Unipar \\ ${ }^{3}$ Acadêmica de Nutrição e Bolsista PIBEX (Programa Institucional de Bolsas de Extensão) da UNIPAR \\ ${ }^{4}$ Acadêmica de Nutrição e participante do PEX (Programa de Extensão) da Unipar \\ ${ }^{5}$ Representante Técnica da Clínica Escola de Nutrição da Unipar \\ ${ }^{6}$ Docente de Nutrição da UNIPAR
}

Introdução: A Constipação Intestinal $(\mathrm{Cl})$ é uma doença que pode se manifestar de maneiras diferentes para cada pessoa, acometendo sempre as funções colônicas e anorretais (JUNIOR et al., 2005). Onde os principais sintomas consistem em dificuldades para evacuar, evacuação incompleta ou fezes petrificadas, que na maioria dos casos é causada por problemas de saúde, má alimentação, e consequências de pouca ingestão de líquidos (SANT et al., 2016).

Objetivo: O presente estudo teve como objetivo estimar a prevalência de Constipação Intestinal e seus sintomas em pacientes atendidos na Clínica Escola de Nutrição, da Unipar de Umuarama.

Resultados: Foram analisados os dados de 46 pacientes, sendo eles do sexo masculino e feminino com a faixa etária de idade entre 18 a 65 anos, após as suas respectivas consultas, sendo elas realizadas entre o período de Março à Novembro do ano de 2020. Os prontuários foram avaliados para identificação de queixas e sintomas característicos, relacionados a idade e aos hábitos alimentares. Desses pacientes $75 \%$ foram do sexo feminino, e $25 \%$ do sexo masculino. Houve associação a problemas de saúde, como a desnutrição e obesidade relacionados aos hábitos alimentares em $50 \%$ dos pacientes, sendo eles portadores de sintomas de constipação intestinal, sintomas esses sendo dificuldade de evacuar, distensão abdominal, gases e fezes com aspecto petrificado, relatados após serem adeptos a uma dieta pobre em fibras, vitaminas, minerais e probióticos que ajudam a manter a saúde do intestino e a flora intestinal.

Conclusão: Há prevalência de Constipação Intestinal em $50 \%$ dos pacientes, devido a problemas de saúde e aos hábitos alimentares. Por tanto, com uma boa orientação nutricional é possível implementar de forma prática e diretiva a construção de novos hábitos alimentares, como alimentar-se em horários regulares mastigando bem os alimentos, dar preferência a refeições variadas, ricas em fibras, vitaminas, minerais e probióticos, diminuir quantidade de gorduras na alimentação e fazer a ingestão de no mínimo 2 litros de água por dia, dessa forma é possível controlar os sintomas e prevenir futuras doenças relacionadas ao intestino (MORAIS; MAFFEI 2000).

\section{Referências}

JUNIOR, SANTOS; MONTEIRO, Júlio César. Constipação intestinal. Revista brasileira de colo-proctologia, p. 79-93, 2005.

MORAIS, Mauro Batista; MAFFEI, Helga Verena L. Constipação intestinal. Jornal de Pediatria, v. 76, n. 2, p. 147-156, 2000.

SANT, Mônica de Souza Lima et al. Prevalência de constipação intestinal no município de Viçosa/MG. Nutrição Brasil, v. 15, n. 1, p. 10-14, 2016.

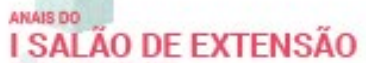
DA UNIPAR

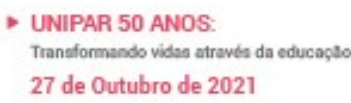

27 de Outubro de 2021

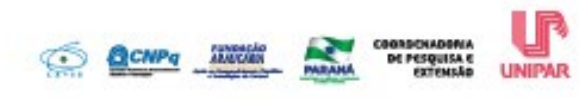




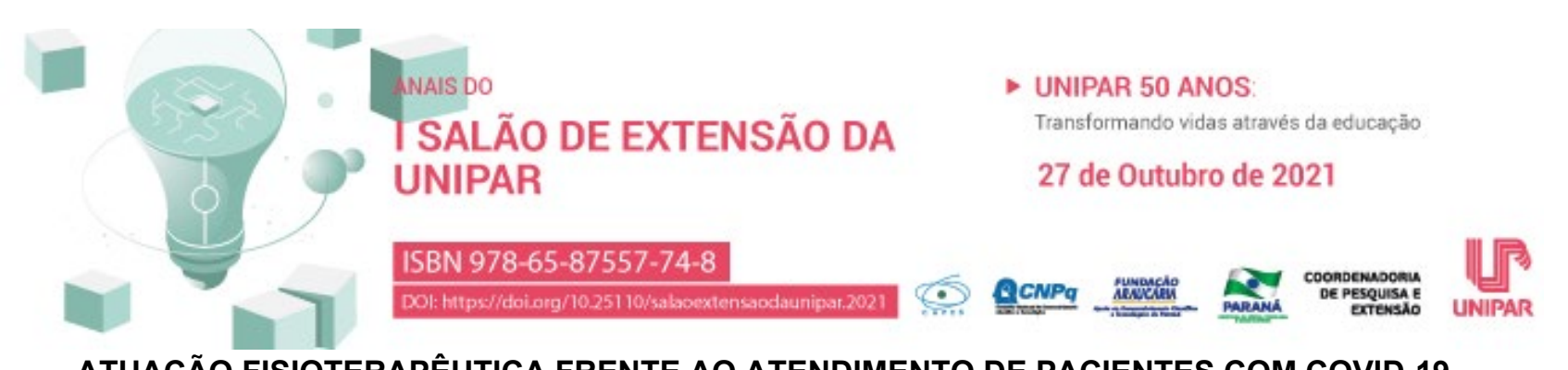

\title{
ATUAÇÃO FISIOTERAPÊUTICA FRENTE AO ATENDIMENTO DE PACIENTES COM COVID-19
}

\author{
1JESSICA FERNANDA BARBIERO, 2LORENA CASTAGNA ANGELIM COSTA, ${ }^{3}$ MARIANA GONCALVES DE OLIVEIRA, \\ ${ }^{4}$ FERNANDA PEGORINI PADILHA, ${ }^{5}$ DORA DE CASTRO AGULHON SEGURA
}

${ }^{1}$ acadêmico pic/unipar
${ }^{2}$ Acadêmica do Curso de Fisioterapia da UNIPAR
${ }^{3}$ Acadêmica do Curso de Fisioterapia da UNIPAR
${ }^{4}$ Acadêmica do Curso de Biomedicina da UNIPAR
${ }^{5}$ Docente da UNIPAR

Introdução: A COVID 19 é uma doença respiratória provocada pelo coronavírus (SARS-CoV-2), que teve início na China, em 2019, se alastrando para o mundo, tornando uma das pandemias com maior registro de óbitos. Os sintomas mais comuns são febre, tosse, dificuldade para respirar, dor generalizada no corpo e fadiga. Quando associada a outras comorbidades possui sintomatologia mais grave, incidindo em riscos. Decorrente da dificuldade respiratória e baixa oximetria, a indicação de ventilação se faz necessária, sendo, por muitas vezes o paciente encaminhado para tratamento na Unidade de Terapia Intensiva (MAGNO et al., 2020). De acordo com Guimarães (2020), o fisioterapeuta é um dos profissionais da linha de frente quanto a recuperação funcional, sendo imprescindivel no manejo dos parâmetros do ventilador mecânico, bem como, na aplicação de técnicas manuais para promover melhora da capacidade respiratória.

Objetivos: Através de um projeto de extensão promover conhecimento sobre a profissionalização da fisioterapia.

Resultados: Segundo Sales et al. (2020), a atuação do fisioterapeuta intensivista frente a COVID 19 possui uma abordagem individualizada voltada para as deficiências de cada paciente. As condutas são sucedidas por avaliações complexas e reavaliações frequentes. Diversos procedimentos podem ser realizados, desde auxílio a intubação, pronação, ajustes na ventilação mecânica, desmames, extubações a mobilizações motoras. A pandemia ressaltou que o fisioterapeuta deve ser considerado um profissional indispensável na busca por um bom prognóstico no tratamento da COVID 19, acarretando no reconhecimento da equipe multiprofissional, bem como da sociedade em geral e gestores em saúde. Muitos pacientes, mesmo após alta hospitalar, em virtude da gravidade da doença e das sequelas instaladas, necessitam do acompanhamento do profissional da fisioterapia de forma domiciliar ou ambulatorial, objetivando o retorno da habilidade motora e recuperação da mecânica respiratória efetiva, ressaltando que o tratamento não decorre somente na fase inicial da doença, bem como, na restauração da total qualidade de vida (GUIMARÃES, 2020; SALES et al., 2020).

Conclusão: Concluiu-se que o projeto em questão é crucial para a divulgação da fisioterapia, em todos seus aspectos, neste caso, evidenciando a necessidade da fisioterapia no tratamento de pacientes com COVID 19, seja assegurando a capacidade respiratória e a recuperação funcional.

\section{Referências}

GUIMARÃES, F. Atuação do fisioterapeuta em unidades de terapia intensiva no contexto da pandemia de COVID-19. Revista Fisioterapia em Movimento, v. 33, e0033001, p. 01-03, 2020.

MAGNO, L. et al. Desafios e propostas para ampliação da testagem e diagnóstico para COVID-19 no Brasil. Revista Ciência \& Saúde Coletiva, v. 25, n. 9, p. 3355-3364, 2020.

SALES, E. M. P. et al. Fisioterapia, funcionalidade e COVID-19: Revisão integrativa. Revista Científica da Escola de Saúde Pública do Ceará, v. 14, n. 1 p. 68 73, 2020.

I SALÃOO DE EXTENSÃO DA UNIPAR

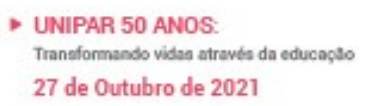

Traneformando vidas atravta da educaçto
27 de Outubro de 2021

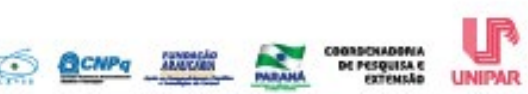




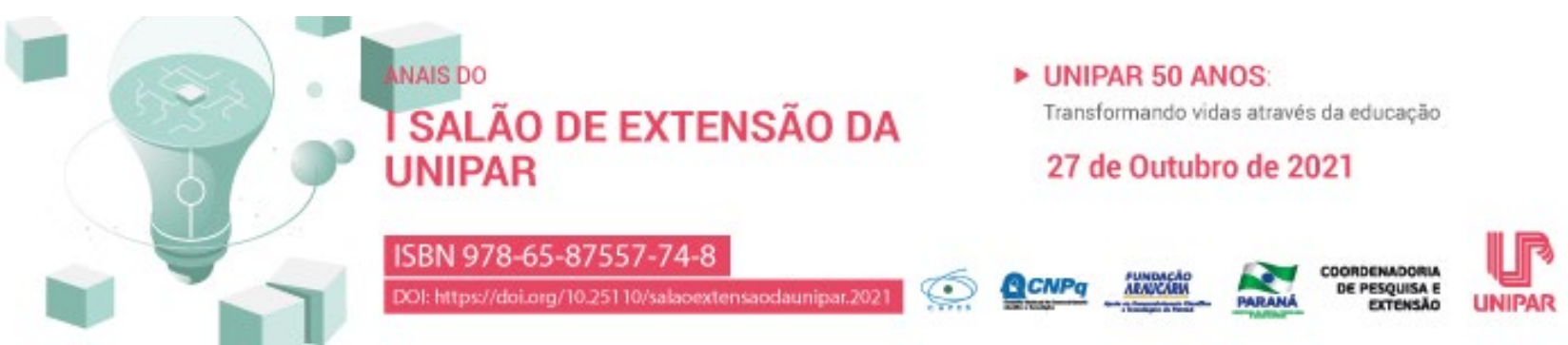 \\ FISIOTERAPIA DESPORTIVA: PREVENÇÃO E REABILITAÇÃO DE ATLETAS
}

\author{
${ }^{1}$ LAURA HEIS OLIVO, ${ }^{2}$ EDILAINE APARECIDA DA CRUZ, ${ }^{3}$ MARIA EDUARDA DE OLIVEIRA SPERANDIO, ${ }^{4}$ THAYNA PINTER \\ MENDES CAMPOS, ${ }^{5}$ DORA DE CASTRO AGULHON SEGURA
}

\begin{abstract}
${ }^{1}$ Acadêmica do Curso de Fisioterapia da UNIPAR
${ }^{2}$ Acadêmica do Curso de Fisioterapia da UNIPAR

${ }^{3}$ Acadêmica do Curso de Fisioterapia da UNIPAR

${ }^{4}$ Acadêmica do Curso de Fisioterapia da UNIPAR

${ }^{5}$ Docente da UNIPAR
\end{abstract}

Introdução: A fisioterapia desportiva é uma das áreas da fisioterapia voltadas a prevenção e reabilitação de atletas, promovendo segurança em relação a prática do esporte, favorecendo uma boa qualidade de vida, não somente nas funções motoras, bem como, na capacidade mental. O fisioterapeuta possui como função prevenir, tratar e recuperar funções osteomioarticulares prejudicadas, seja por uma prática irregular do esporte ou decorrente de lesões por traumatismos acidentais (SILVA et al., 2011). Para Almeida et al. (2009), um diagnóstico preciso é fundamental para seleção da conduta terapêutica oportuna, da fase aguda à crônica. Muitas técnicas são indicadas, mas a cinesioterapia, através de alongamentos e mobilizações, bem como posteriormente, ao treino resistido, asseguram melhores desempenhos.

Objetivos: Através de um projeto de extensão promover conhecimento sobre a profissionalização da fisioterapia.

Resultados: Inúmeros são os benefícios da fisioterapia desportiva, como promoção da longevidade na prática esportiva, melhor performance dos atletas, menor risco de lesões, dando mais auto confiança e controle mental. Trata-se do profissional que estará mais em contato com o atleta na fase de recuperação frente às lesões, alinhando treinamento e gradativamente gerando maior estímulo no desempenho das ações. Contudo, é importante que exista um bom conhecimento de fisiologia do exercício e compreensão do processo de recuperação dos diversos componentes que compõem o corpo humano (SANTOS; GREGUOL, 2016). A fisioterapia desportiva vem ganhando cada vez mais importância, trabalhando lado a lado com a medicina esportiva. Juntos trabalham pressionados pelo tempo, pois o retorno precoce e saudável dos atletas incide em custos para times e equipes, sendo que as lesões mais comuns são entorses, luxações e fraturas. Quanto mais se conhece sobre as diversas áreas da fisioterapia mais oportuno fica o auxílio aos indivíduos que necessitam da terapêutica, por isso justifica-se a explanação dessa temática (ALMEIDA et al., 2009).

Conclusão: Concluiu-se que o projeto em questão é crucial para a divulgação da fisioterapia, em todos seus aspectos, neste caso, abordando a fisioterapia desportiva, voltada à prevenção e reabilitação de atletas, assegurando um retorno precoce e efetivo a habilidade funcional de atletas profissionais e amadores.

\section{Referências}

ALMEIDA, Paulo Henrique Foppa et al. Alongamento muscular: Suas implicações na performance e na prevenção de lesões. Fisioterapia em Movimento, Curitiba, v. 22, n. 3, p. 335-43, jul./set. 2009.

SANTOS, Ariadne Maria; GREGUOL, Márcia. Prevalência de lesões em atletas jovens. Semina: Ciências Biológicas e da Saúde, Londrina, v. 37, n. 2, p. 115-124, jul./dez. 2016.

SILVA, Anderson et al. Análise do perfil, funções e habilidades do fisioterapeuta com atuação na área esportiva nas modalidades de futebol e voleibol no Brasil. Revista Brasileira de Fisioterapia, São Carlos, v. 15, n. 3, p. 219-26, jun. 2011.

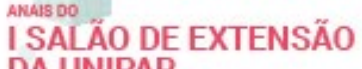

DA UNIPAR

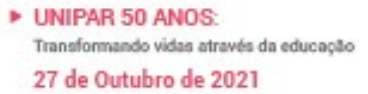

UNIPAR 50 ANOS:

27 de Outubro de 2021

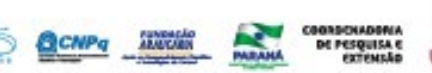

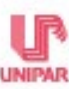




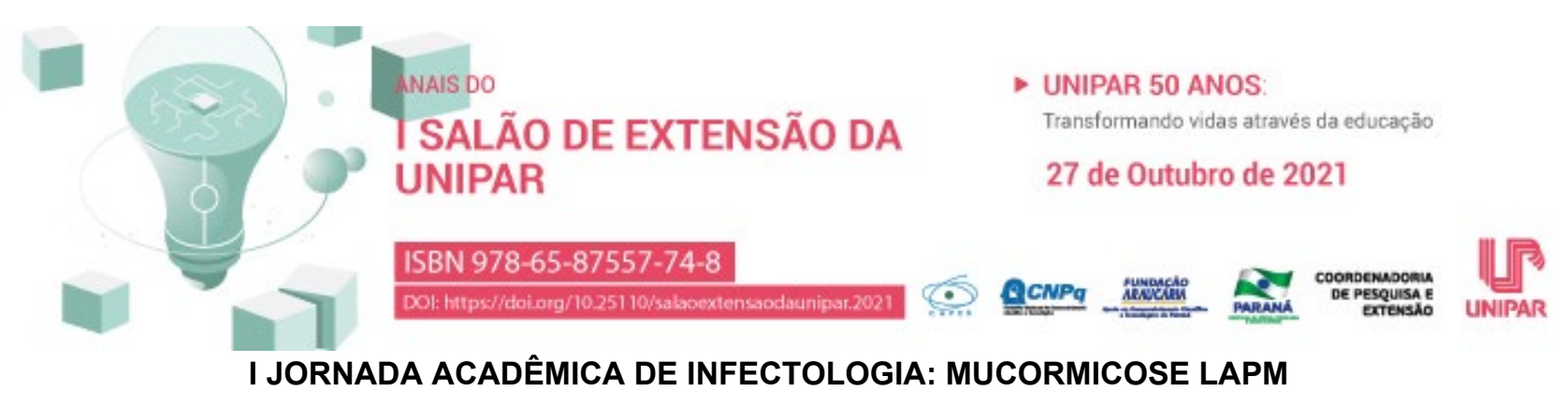

\author{
${ }^{1}$ LARISSA LOYOLA BARBOSA, ${ }^{2}$ CAROLINE VINTIGUERA PANCERA, ${ }^{3}$ TAIS DA SILVA SCHMIDT, ${ }^{4}$ CAROLINE ZAURA, \\ 5LUCIANA VIEIRA PINTO RIBEIRO, ${ }^{6}$ LUCIANO SERAPHIM GASQUES
}

\author{
${ }^{1}$ Acadêmica do Curso de Medicina da UNIPAR \\ ${ }^{2}$ Acadêmica do Curso de Medicina da UNIPAR \\ ${ }^{3}$ Acadêmica do Curso de Medicina da UNIPAR \\ ${ }^{4}$ Acadêmica do Curso de Medicina da UNIPAR \\ ${ }^{5}$ Docente da UNIPAR \\ ${ }^{6}$ Docente da UNIPAR
}

Introdução: A I Jornada Acadêmica de Infectologia foi baseada em mentorias que teve como objetivo ser um instrumento de aprendizagem para compreensão de diversos temas baseados na mesma área científica e institucional. Dessa forma, é possível analisar a interação de diversas equipes de alunos com inúmeros mentores para dar continuidade a uma área específica com diferentes assuntos (CONCEIÇÃO et al., 2017). Diante dessa situação, a Liga Acadêmica de Parasitologia Médica (LAPM) enquadrou-se como um dos organizadores e apresentadores do evento, juntamente, com o Dr. Raphael C. Biscaia Hartmann, apresentando a todos o tema Mucormicose, desde sua etiologia, englobando morfologia e seu funcionamento dentro do hospedeiro, até seu quadro clínico com a COVID-19.

Objetivo: Apresentar aos interessados em Parasitologia e outras doenças infecciosas, palestras abrangendo diversos assuntos sobre o tema, visando propagar o conhecimento.

Resultados: A Liga Acadêmica de Parasitologia Médica (LAPM), juntamente com a Liga Acadêmica de Doenças Infecciosas e Parasitárias (LADIP) da cidade de Pato Branco - Paraná, tiveram a ideia de reunir diversas ligas de várias estados diferentes, visando conceitualizar com auxílio de professores, médicos e doutores sobre discrepantes assuntos mas, com equivalente relevância entre os temas. Sem embargo, na área da tecnologia e do compartilhamento de informações, buscar por ensinos e apoios extraordinários se tornou uma necessidade para muitos alunos, professores e doutores de diversas universidades, e como explanado se tem uma relevante importância para a formação de alunos a participação dos mesmos nas mais conhecidas Jornadas Acadêmicas (SILVA; PAULINO; MACEDO, 2015). Diante disso, as Ligas realizaram parcerias com outras nove instituições, totalizando 320 inscritos, com diferentes parceiros para patrocínios e sorteios, com o intuito de promover a interação e o próprio interesse de ligantes e alunos. Foram realizadas dez palestras entre os dias 09 a 13 de agosto de 2021. Dessa maneira, notou-se uma elevada participação de acadêmicos com um crescimento profissional amplo diante de debates ricos e criativos.

Conclusão: Conclui-se que as jornadas acadêmicas são de extrema importância para a formação, participando como um instrumento inovador para o desempenho acadêmico e profissional de cada indivíduo. Abrangendo relações interpessoais com outros discentes como também o enriquecimento do conhecimento para atuação ocupacional.

\title{
Referências
}

CONCEIÇÃO, E. J. et al. A importância da monitoria acadêmica no processo de ensino e aprendizagem na formação dos alunos de fisioterapia e medicina. II CONGRESSO BRASILEIRO DE CIÊNCIA DE SAÚDE. Pernambuco, out. 2017.

SILVA, L. B; PAULINO, W. M; MACEDO, O. J. V. Contribuições da monitoria no processo de construção da identidade docente. II Congresso Nacional de Educação. Campina Grande, out. 2015.

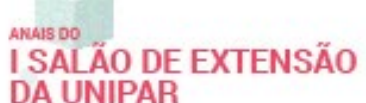

DA UNIPAR

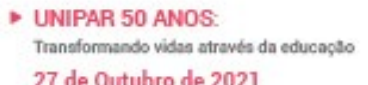

27 de Outubro de 2021

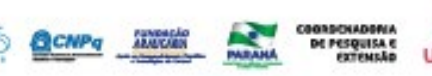




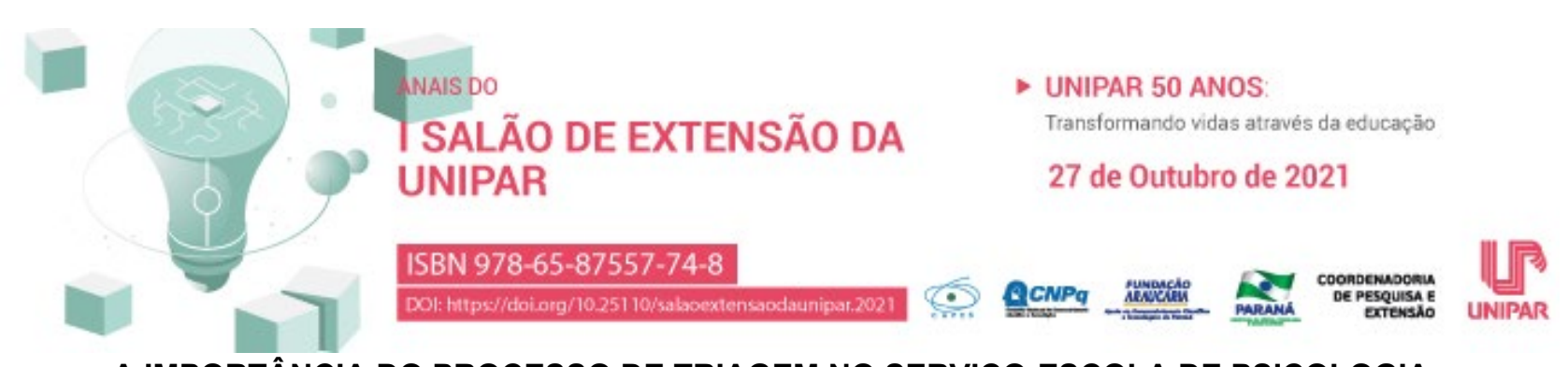

A IMPORTÂNCIA DO PROCESSO DE TRIAGEM NO SERVIÇO-ESCOLA DE PSICOLOGIA

\author{
${ }^{1}$ ANA MARIA CANZI, ${ }^{2}$ ANA PAULA GARGANTINI DA SILVA \\ ${ }^{1}$ Acadêmica Bolsista PIBEX/UNIPAR \\ ${ }^{2}$ Responsável Técnica
}

Introdução: A clínica escola tem como função criar um espaço de treinamento e atuação para os futuros profissionais e ofertar serviços psicológicos a comunidade, tendo em vista a grande demanda atual para atendimento psicológico. A porta de entrada para o atendimento na clínica escola se dá através da triagem, é a partir dela que se conhece a demanda e os motivos da procura pelo serviço (CAVALHEIRO et al, 2012). A triagem pode e deve ser mais que uma coleta de informações, através do acolhimento e escuta, ela irá permitir avaliar a real demanda e buscar o melhor caminho para o atendimento. Quando a triagem não tem um bom desfecho, pode acontecer de o paciente não retornar, nesse sentido, uma triagem feita com qualidade a partir da escuta e de um referencial técnico e teórico é de extrema importância. (PERFEITO E MELO, 2004).

Objetivo: $O$ presente artigo tem como objetivo demonstrar a importância da triagem psicológica como ferramenta nos atendimentos em clínica escola. Através desse instrumento se estabelece um processo mais aprofundado sobre o indivíduo e sobre suas vivências, papel fundamental para mediação das demandas e queixas que visam buscar um atendimento dentro das possibilidades reais da clínica escola (CAVALHEIRO et al, 2012).

Resultados: Através da pesquisa bibliográfica se percebeu a importância e a singularidade da triagem na clínica escola, sendo ela porta de entrada para o atendimento psicológico, podendo ser decisiva na continuidade do tratamento.

Conclusão: Buscou-se enfatizar o uso da triagem como ferramenta de intervenção psicológica, que muito além do levantamento de informações, tem ação terapêutica e auxilia o paciente a saber sobre suas dores e quais as causas (PERFEITO E MELO, 2004).

\title{
Referências
}

CAVALHEIRO, Nayara Cristina et al. Triagem interventiva: a caracterização de uma demanda. Revista da SBPH, Rio de Janeiro, v. 15, ed. 2, 2012. Disponível em: http://pepsic.bvsalud.org/scielo.php?script=sci_arttext\&pid=\$1516-08582012000200002. Acesso em: 12 ago. 2021.

PERFEITO, Hélvia Cristine Castro Silva; MELO, Sandra Augusta de. Evolução dos processos de triagem psicológica em uma clínica-escola. Estudos de Psicologia, Minas Gerais, 2004. Disponivel em: https://www.scielo.br/j/estpsi/a/jYCZCXssXHTXFpTgSQsRkyv/?lang=pt. Acesso em: 13 ago. 2021.

\section{SALĀO DE EXTENSÃO DA UNIPAR}

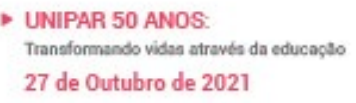

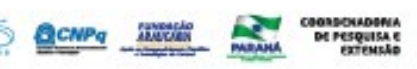




\title{
(1) $\begin{aligned} & \text { NaIs do } \\ & \text { SALÃO DE EXTENSÃO DA } \\ & \text { UNIPAR }\end{aligned}$ \\ - UNIPAR 50 ANOS: \\ Transformando vidas através da educą̧ào \\ 27 de Outubro de 2021

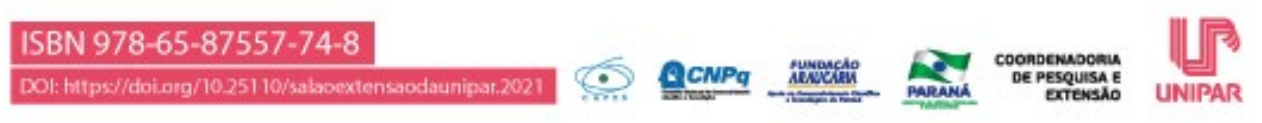 \\ SALA DE AULA INVERTIDA: UMA METODOLOGIA DE ENSINO-APRENDIZAGEM NA LIGA ACADÊMICA DE PARASITOLOGIA MÉDICA (LAPM)
}

\author{
${ }^{1}$ FERNANDA DE ABREU BRAGA, ${ }^{2}$ KEROLAINE MANTOVI COSTA, ${ }^{3}$ GABRIEL HENRIQUE DO PRADO GONCALVES, ${ }^{4}$ MARIA \\ EDUARDA DIAS BERGAMO, ${ }^{5}$ LUCIANO SERAPHIM GASQUES
}

\author{
${ }^{1}$ Acadêmico bolsista do PEBIC / Fundação Araucária \\ ${ }^{2}$ Acadêmica do Curso de Medicina da UNIPAR \\ ${ }^{3}$ Acadêmico do Curso de Medicina da UNIPAR \\ ${ }^{4}$ Acadêmica do Curso de Medicina da UNIPAR \\ ${ }^{5}$ Docente da UNIPAR
}

Introdução: A metodologia ativa de ensino, progressivamente, ganha espaço e notoriedade na formação acadêmica dos alunos na área da saúde. Estudos demonstram que o uso de tal método é uma estratégia relevante capaz de estimular no estudante a autonomia, a reflexão, a crítica e a capacidade de solucionar problemas, aproximando o conhecimento teórico e técnico da realidade (LIMA, 2017). Nesse contexto, a liga acadêmica de Parasitologia Médica (LAPM) da Unipar utiliza essa metodologia de ensino usando como base para as aulas a sala de aula invertida, que nada mais é do que um tipo de metodologia ativa em que o conteúdo é ensinado e administrado pelo próprio aluno, assim, assumindo o papel de protagonista do seu aprendizado.

Objetivo: Apresentar a metodologia da Sala de Aula Invertida aplicada na LAMP e seus benefícios, a fim de promover capacitação de seus membros.

Resultados: A liga de parasitologia médica (LAMP) da UNIPAR foi inaugurada durante o período da pandemia, devido à políticas públicas de distanciamento social e liberação de números restritos de pessoas em um mesmo lugar, tivemos que nos adaptar à nova realidade. À vista desse fato foi que surgiu a ideia de sala de aula invertida, a qual propõe inverter a metodologia tradicional de ensino. Ou seja, ao invés do aluno, tradicionalmente acostumado à condição passiva de receber e absorver as informações, o aluno passa a assumir o papel de protagonista do seu aprendizado, ganhando metas e responsabilidades no processo de construção de conhecimento (SCHNEIDERS, 2018; OLIVEIRA et al., 2020). Diante disso, a cada semana dois alunos da LAMP, tanto diretores, quanto ligantes, são responsáveis por preparar e organizar o conteúdo proposto, dessa forma, utilizavam-se de slides, estudo guiado por perguntas para estudar o material teórico, pesquisas científicas atualizadas, formulários com perguntas referente ao tema e até premiações para as melhores pontuações. Ainda, para uma maior flexibilidade e dinâmica, os alunos recebem o tema que será dado em sala antecipadamente, para que assim todos possam estudar o conteúdo e participar de debates no decorrer da reflexão sobre o tema. Como resultado, notou-se aulas menos extenuantes, um melhor desempenho dos alunos e debates mais ricos e criativos nas discussões em sala, atingindo o objetivo de formação dos acadêmicos com relação aos temas propostos.

Considerações Finais: Conclui-se que a sala de aula invertida é uma ferramenta inovadora que ajuda no desenvolvimento e desempenho dos alunos e na captação de informações, além de maior participação e debates enriquecedores.

\section{Referências}

LIMA, Valéria Vernaschi. Espiral construtivista: uma metodologia ativa de ensino-aprendizagem. Interface, v. 21, n. $61,2017$.

OLIVEIRA, João Lucas dos Santos Oliveira; LIMA, Priscila da Silva Neves; CARVALHO, Cedric Luiz; FONSECA, Amanda Vitória Silva. Sala de aula 4.0 uma proposta de ensino remoto baseado em sala de aula invertida, gamification e pbl. Revista Brasileira de Informática na Educação, v. 28, n.1, p.1-25, 2020.

SCHENEIDERS, Luís Antônio. O método da sala de aula invertida (flipped classroom). 1ed. Lajeado: Univates, 2018.

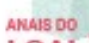

I SALÃO DE EXTENSÃO DA UNIPAR

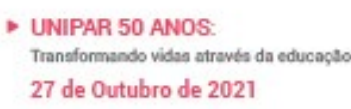

27 de Outubro de 2021

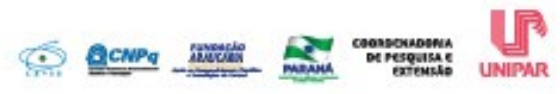




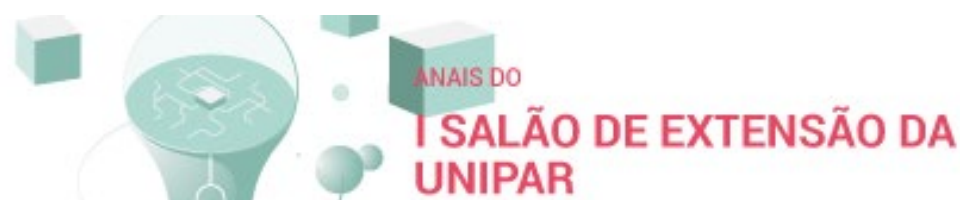 \\ - UNIPAR 50 ANOS: \\ Transformando vidas através da educação \\ 27 de Outubro de 2021

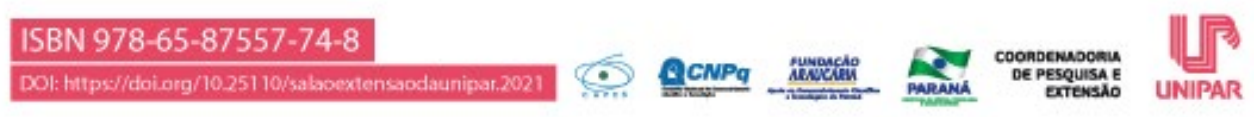 \\ REFLEXOS DO DISTANCIAMENTO SOCIAL NO AUMENTO DA VIOLÊNCIA CONTRA CRIANÇA E ADOLESCENTE NO BRASIL
}

\author{
${ }^{1}$ BEATRIZ SARTORI DOS SANTOS, ${ }^{2}$ MARICELES CRISTHINA FECCHIO
}

${ }^{1}$ Acadêmica do PEX/UNIPAR

${ }^{2}$ Docente da UNIPAR

Introdução: Um dos direitos básicos assegurados a todos os sujeitos e, em especial, à criança e ao adolescente é o direito ao respeito, abarcando a manutenção da integridade física, psíquica e moral. Sendo vedado qualquer tipo de castigo físico, de tratamento cruel ou degradante.

Objetivo: Analisar os impactos causados pela pandemia da covid-19 nas relações familiares, tendo como foco o aumento de casos de violência contra crianças e adolescentes.

Resultados: Os crimes nos ambientes domésticos e familiares apresentaram um notável crescimento, sobretudo com as circunstâncias excepcionais advindas da Pandemia da COVID-19. Segundo dados da ouvidoria Nacional de Direitos Humanos, em 2020, foram contabilizadas mais de 95 mil denúncias de maus-tratos contra crianças e adolescentes (GOV.BR, 2021). Sendo que a maioria dos casos de violência contra esse grupo é praticada por agressores da família ou por conhecidos (SANTOS, 2019), sobre os quais recaem o dever de proteção integral da criança e do adolescente, nos termos do artigo $4^{\circ}$ Lei $n^{\circ} 8.069 / 90$ (BRASIL, 1990). Verifica-se que o isolamento social provocado pela pandemia agravou ainda mais a vulnerabilidade das crianças e adolescentes dentro do ambiente doméstico, a falta da escola na rotina, o maior estresse dos familiares e a intolerância com os problemas contribuiu significativamente para o agravamento desse quadro. Denota-se que a violência contra a criança envolve a violência física, psíquica, sexual, bem como a negligência, maus tratos, castigos corporais e humilhação (ALKIMIN, 2016), sendo que tais atos podem impactar o desenvolvimento cognitivo e emocional, bem como a saúde física e mental dos indivíduos, de forma a ocasionar problemas clínicos, tais como uso de álcool ou drogas e depressão, podendo estas consequências evoluírem para transtornos mentais e fazer das vítimas futuros agressores, causando um fenômeno transgeracional (SANTOS, 2019). Assim, é importante saber identificar os sinais apresentados pela vítima, que podem ser físicos ou psicológicos, sendo certo que esse tipo de violência nem sempre é visível e poucos casos são denunciados perante a autoridade policial, Conselho Tutelar ou Ministério Público (ALKIMIN, 2016).

Conclusão: Destarte, a vulnerabilidade da criança e do adolescente os tornam vítimas em potencial de atos de violência, notadamente no âmbito doméstico, sendo que este quadro foi ainda mais agravado durante o cumprimento das medidas restritivas decorrentes do período pandêmico.

\section{Referências}

ALKIMIN, Maria Aparecida. Uma reflexão em torno da violência doméstica contra a criança e o adolescente diante dos aspectos controvertidos e lacunosos da Lei 13.010, de 26.06.2014 (lei da palmada). Revista Dos Tribunais | Vol. 964/2016 | P. $377-405$ | Fev / 2016.

BRASIL. Lei n 8.069, de 13 de julho 1990. Dispõe sobre o Estatuto da Criança e do Adolescente e dá outras providências. Brasília, 2015. Disponível em: . Acesso em: 11 ago. 2021.

GOV.BR. Disque 100 e Ligue 180 registram cerca 1 mil denúncias de violações de direitos humanos por dia em 2020. Disponivel em: < https://www.gov.br/mdh/pt-br/assuntos/noticias/2021/marco/disque-100-e-ligue-180-registram-cerca-1-mildenuncias-de-violacoes-de-direitos-humanos-por-dia-em-2020 >. Acesso em: 11 de ago. 2021.

SANTOS, Eliane Machado Dos. Rede de apoio social e afetiva de adolescentes vítimas de maus-tratos. Revista De Direito E Medicina | Vol. 4/2019 | Out - Dez / 2019.

\section{SALÃO DE EXTENSÃO DA UNIPAR}

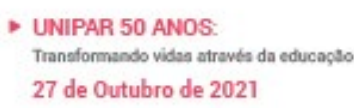

27 de Outubro de 2021

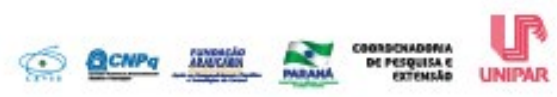




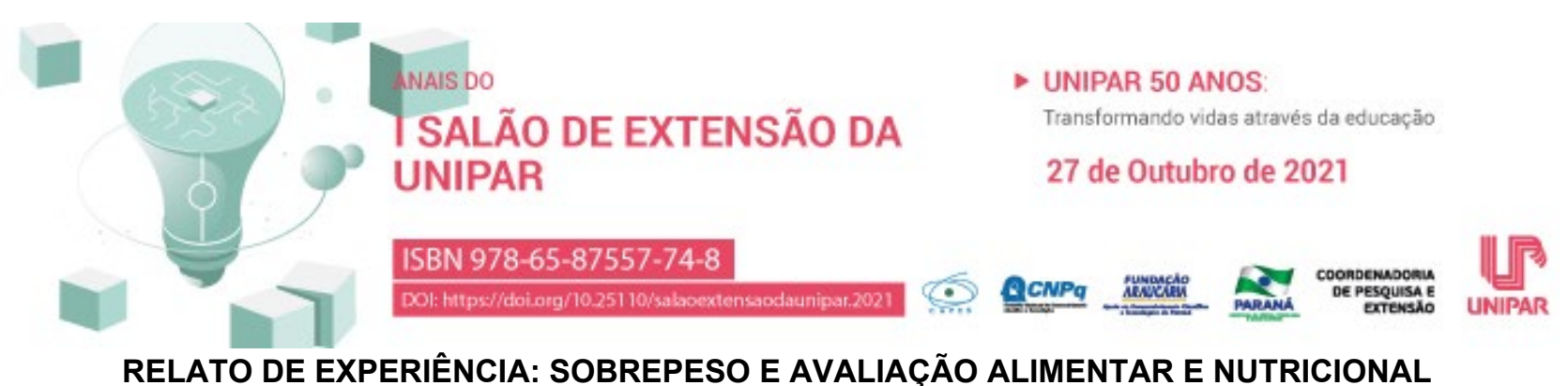

\author{
${ }^{1}$ LETICIA REGINA PEREZ, ${ }^{2}$ MARIANA HACHICHO ALMEIDA, ${ }^{3}$ MARIA BEATRIZ NAUFEL CARVALHO, ${ }^{4}$ MONICA DO VALE \\ ASSIS GARCIA SANTINI, 5 LIDIANE NUNES BARBOSA
}

${ }^{1}$ Acadêmica do curso de Nutrição da Unipar
${ }^{2}$ Acadêmica do Curso de Nutrição da UNIPAR
${ }^{3}$ Acadêmica do Curso de Nutrição da UNIPAR
${ }^{4}$ Docente da UNIPAR
${ }^{5}$ Docente da UNIPAR

Introdução: O sobrepeso e a obesidade na infância e na adolescência vem crescendo em todo o mundo, o que tem preocupado as autoridades públicas por terem relação com o surgimento de doenças crônicas e com a elevada taxa de morbidade e mortalidade (HRUBY, 2015). Tanto na infância, quanto na adolescência o excesso de peso pode estar relacionado com comorbidades, dentre elas, as mais comuns são, dislipidemias, resistência à insulina, diabetes mellitus-2, hipertensão arterial e esteatose hepática (NERI et al., 2017). Segundo o Instituto Brasileiro de Geografia e Estatística, 60,3\% dos indivíduos com 18 anos, têm excesso de peso, sendo maior no sexo feminino e uma em cada quatro pessoas nessa faixa de idade no Brasil apresenta obesidade (IBGE, 2019). De acordo com isso, a adolescência é uma etapa da vida crítica para o desenvolvimento da obesidade e que requer uma maior atenção para o surgimento de problemas metabólicos, ortopédicos, cardiovasculares, pulmonares e também de câncer na fase adulta (SBP, 2012). Estudos têm mostrado que os jovens possuem uma alimentação com uma grande quantidade de alimentos processados e ultraprocessados juntamente com a ausência de atividade física, o que pode contribuir para o ganho de peso e o desenvolvimento de síndrome metabólica e deficiência nutricional (ABESO, 2016; SOUZA et al., 2016). Por esses motivos, os adolescentes podem ser considerados um dos grupos com chances de apontarem problemas ligados à alimentação, visto que essa faixa etária no geral apresenta uma alimentação inadequada (ENES, 2010).

Objetivo: O presente trabalho, tem como objetivo relatar a atuação do profissional nutricionista na prática clínica associada com o sobrepeso em adolescentes. Bem como, destacar os principais pontos utilizados durante a intervenção nutricional de redução de peso dessa faixa etária.

Desenvolvimento: Foi avaliado o caso de uma paciente de 18 anos atendida na Clínica Escola de Nutrição da Unipar de Umuarama. Na primeira consulta, a mesma apresentou sobrepeso e riscos de doenças associadas à obesidade. Dessa forma, foram propostas mudanças nos hábitos alimentares nesse primeiro momento, tendo como objetivo a redução de peso, medidas, gordura corporal e modulação da microbiota intestinal, já que a paciente relatou constipação. A conduta foi elaborada com base em uma dieta hipocalórica de $1.800 \mathrm{kcal}$ por dia, sendo $45 \%$ de carboidrato, $30 \%$ de proteína e $25 \%$ de lipídio. Além disso, foi prescrito, um fracionamento de $6 \mathrm{x}$ ao dia e o aumento de alimentos ricos em fibras.

Resultados: A paciente apresentou resultados positivos após o primeiro mês de tratamento e, no retorno pode-se notar a perda de $1,5 \mathrm{~kg}$, redução do índice de massa muscular, redução das circunferências de braço, cintura, quadril e abdômen. Resultando em uma perda de $5 \%$ de gordura corporal. Dessa forma, a paciente também relatou uma alimentação rica em alimentos com fibras e aumento no consumo de água, obtendo assim uma melhora no trânsito intestinal e constipação.

Conclusão: Diante disso, conclui-se que foi possível atingir os resultados propostos pela paciente. O que reforça a importância do profissional da área de nutrição na intervenção de redução de peso e educação alimentar, principalmente nessa faixa etária.

\footnotetext{
Referências

ABESO. Associação Brasileira para Estudo da Obesidade e Síndrome Metabólica - ABESO. Diretrizes Brasileiras de Obesidade, 4.ed, São Paulo, p. 1-188, 2016.

ENES, C., SLATER, C. B. Obesidade na adolescência e seus principais fatores determinantes. Revista Brasileira de Epidemiologia, v. 13n. 1, p. 163-71, 2010.

HRUBY, A. H. F. B. The epidemiology of obesity: a big picture. Pharmacoeconomics, v. 33, p. 673-89, 2015.

SBP. Sociedade Brasileira de Pediatria. Obesidade na infância e adolescência. 2nd Ed. São Paulo: SBP; 2012.

SOUZA, A. M. et al. ERICA: intake of macro and micronutrients of Brazilian adolescents. Revista de Saúde Pública, v. 50, n.1, p. 1-15, 2016.

NERI, L.C.L. et al. Obesidade infantil. Barueri, SP: Manole, 2017.
}

IBGE. Pesquisa do IBGE mostra aumento da obesidade entre adultos. Disponível em: https://www.gov.br/ptbr/noticias/saude-e-vigilancia-sanitaria/2020/10/pesquisa-do-ibge-mostra-aumento-da-obesidade-entre-adultos. Acesso em: 
$19 / 08 / 2021$

ANaAs Do - UNIPAR 50 ANOS:

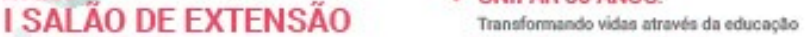

DA UNIPAR

27 de Outubro de 2021

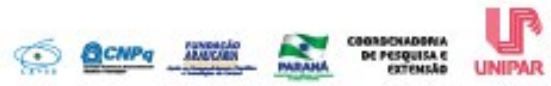




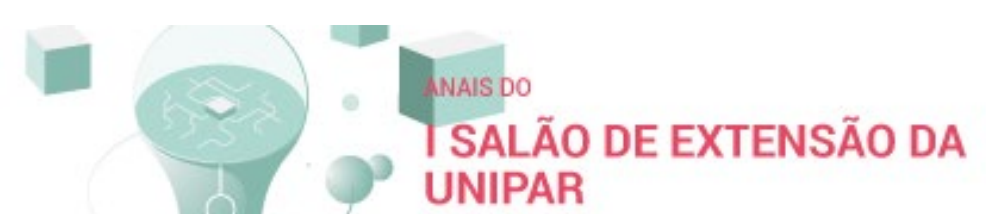

ISBN 978-65-87557-74-8

DOl: hitps//doing/10.251 10/saboextens

\section{CAMPANHA ABRIL VERDE SAÚDE E SEGURANÇA NO TRABALHO EM EMPRESA DE ENGENHARIA NA CIDADE DE IPORÃ}

\section{${ }^{1}$ LUIZ GUSTAVO MARTINS, ${ }^{2}$ AMABILLI ESCARANTE SILVA MASSAROTO, ${ }^{3}$ MICHELLE CRISTINA MASSIAS , ${ }^{4}$ TANIELLY CELLI JULIAO, ${ }^{5}$ EGUIMAR ROBERTO MARTINS}

\author{
${ }^{1}$ Discente do Curso de Medicina/UNIPAR \\ ${ }^{2}$ Acadêmica do Curso de Medicina da UNIPAR \\ ${ }^{3}$ Acadêmica do Curso de Medicina da UNIPAR \\ ${ }^{4}$ Acadêmica do Curso de Medicina da UNIPAR \\ ${ }^{5}$ Docente da UNIPAR
}

Introdução: O alcoolismo constitui um dos principais problemas de saúde pública em todo o mundo, gerando consequências negativas ao nível biopsicossocial do indivíduo. O consumo excessivo de álcool está relacionado a mais frequentes transgressões sociais, como brigas, acidentes de trânsito, problemas familiares, além de acidentes e abandono ao trabalho. $\mathrm{O}$ álcool reduz a expectativa de vida e está relacionado com aproximadamente $30 \%$ das internações psiquiátricas (BOZA et al., 2018). No que se diz respeito ao ambiente de laboral, o álcool gera diversos entraves como comprometer a qualidade do serviço, do produto final além de afetar a saúde do trabalhador, cuja sequelas desencadeiam situações que vão desde um simples atraso, falta, afastamentos, até acidentes de trabalho, rescisões de contrato e condições de óbito (FERNANDES et al., 2014).

Objetivo: Conscientizar os trabalhadores de uma empresa de engenharia na cidade de Iporã, Paraná, através de dados estatísticos sobre a importância de se prevenir quanto ao uso de álcool e seus malefícios. Além disso, foi realizado também aferição de pressão arterial e teste de glicemia, contribuindo assim para segurança no trabalho dos colaboradores.

Resultados: Por meio dessa atividade conseguimos difundir as informações mais importantes sobre os malefícios do uso do álcool e cessar as dúvidas referentes ao assunto, gerando uma reflexão aos trabalhadores sobre o que esse uso pode causar. Logo, a ação obteve como consequência final a contribuição de gerar uma reflexão sobre a redução do uso do álcool, principalmente por esse ser um dos fatores que influenciam nos acidentes de trabalho.

Conclusão: As campanhas de combate ao alcoolismo são de suma importância para toda a sociedade. Essas ações devem ser ampliadas e impulsionadas por todo o país na tentativa de reduzir o número de acidentes de trabalho causados por excesso de uso do álcool.

\section{Referências}

FERNANDES, M. F. F. F.; SANTOS, F. S. M.; SANTANA, K. W. C.; TELES, W. S.; SILVA, C. E.. Consumo de álcool e sua influência no ambiente de trabalho da construção civil. Scire Salutis, Aquidabã, v.4, n.2, p.28 - 46, 2014. DOI: http://dx.doi.org/10.6008/SPC2236-9600.2014.002.0004.

PENA BOZA, Rosario et al . Alcoholismo, repercusión social en la familia.CMF \# 8. Municipio Guisa. 2018. Multimed, Granma , v. 23, n. 4, p. 592-605, agosto 2019. Disponible en . accedido en 20 agosto 2021.

\section{SALĂOO DE EXTENSÃO DA UNIPAR}

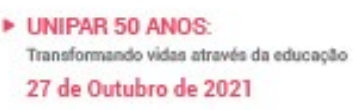

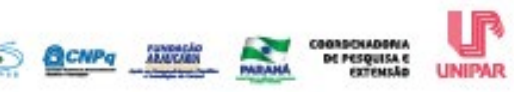




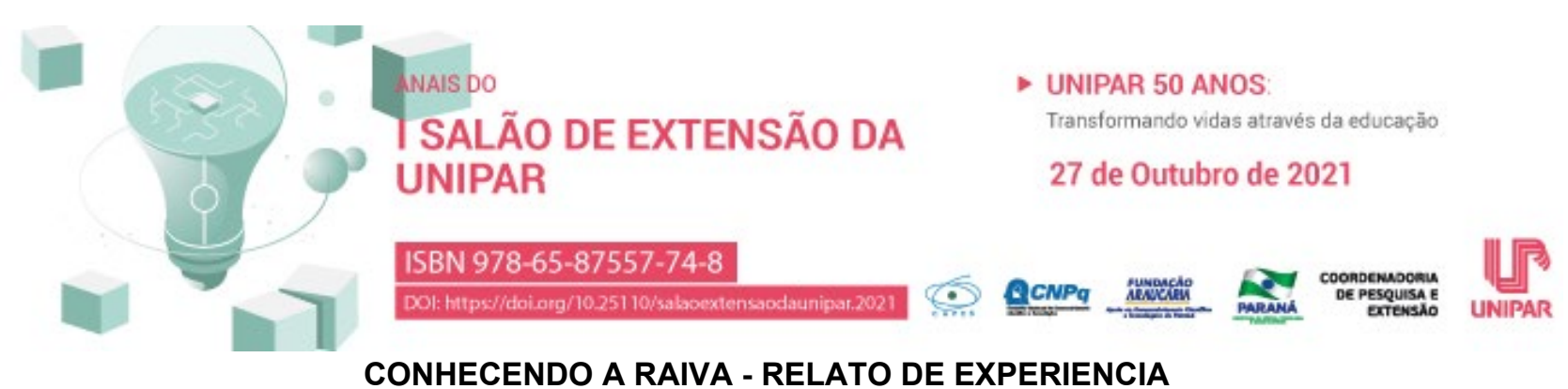

\author{
${ }^{1}$ TAYMILI ALVES DA SILVA, ${ }^{2}$ LAISA MARINA ROSA REY, ${ }^{3}$ DEBORA CRISTINA RIBEIRO, ${ }^{4}$ GEOVANA CRISTINA SARTORI \\ ANDRE, ${ }^{5}$ KELLY REGINA DE JESUS DUARTE PEREIRA, ${ }^{6}$ LILIANA DE SOUSA BAIA, ${ }^{7}$ DANIELA DIB GONÇALVES
}

\author{
${ }^{1}$ Acadêmico do Curso de Medicina Veterinária da UNIPAR \\ ${ }^{2}$ Acadêmico do Curso de Mestrado Em Ciencia Animal Com Enfase Em Produtos Bioativos - Turma Xv da UNIPAR \\ ${ }^{3}$ Acadêmica do Curso de Medicina VeterinÃ $\tilde{j}_{i}$ ria da UNIPAR \\ ${ }^{4}$ Acadêmica do Curso de Medicina VeterinÃ $\tilde{i}_{i}$ ia da UNIPAR \\ ${ }^{5}$ Acadêmica do Curso de Medicina VeterinÃjiria da UNIPAR \\ ${ }^{6}$ Acadêmica do Curso de Medicina VeterinÃ iria da UNIPAR \\ ${ }^{7}$ Docente da UNIPAR
}

Introdução: A raiva é uma zoonose letal em quase todos os casos, é causada por um vírus do gênero Lyssaviruse transmitida pelo contato direto do vírus contido na saliva do animal infectado, sendo a mordedura a forma de exposição mais frequente (OIE, 2016; VARGAS et al., 2019). O morcego hematófago contaminado com o agente é o principal transmissor de raiva urbana e rural. Consequentemente o contato direto com animais selvagens e domésticos é uma das principais transmissões para o ser humano (BENAVIDES et al., 2020). O controle pode ser realizado através da vacinação dos animais de estimação e de produção (BRASIL, 2009; SEAPA, 2020).

Objetivo:Relatar a experiência da disseminação do conhecimento sobre a raivanas redes sociais, tais como dos acadêmicos de medicina veterinária da UNIPAR envolvidos no projeto.

Metodologia: Um material informativo (folder digital) foi elaborado com as principais abordagens epidemiológicas da raiva e foi publicada nas redes sociais dos alunos do curso de Medicina Veterinária da UNIPAR com o intuito da popularização da ciência.

Resultados: O Programa Nacional de Controle da Raiva dos Herbívoros e outras Encefalopatias (PNCRH) foi criado com o objetivo de controlar o número de casos da doença no país (BRASIL, 2009). Uma das estratégias compostas para a prevenção da raiva inclui a conscientização da população sobre o problema (BATISTA et al., 2007). Considerando a importância de se disseminar o conhecimento desta zoonose como forma da popularização deste assunto para prevenção/controle da doença urbana e rural, graduandos e pós-graduandos do curso de medicina veterinária da UNIPAR divulgaram um folder digital nas redes sociais, alcançando um total de1.099 visualizações, 14 curtidas e cincocompartilhamentos.

Considerações Finais: Conclui-se que a prevenção é essencial para o controle da doença, tanto para o ciclo urbano quanto para o rural. Está clara a importância em deixar a população informada. Ações de educação devem ser realizadas constantemente por acadêmicos e profissionais de medicina veterinária, visando à prevenção desta doença. Projetos acadêmicos e divulgação de informações à população em geral podem colaborar quanto a conscientização da comunidade.

\title{
Referências
}

BATISTA, Helena Beatriz de Carvalho Ruthner et al. Raiva: uma breve revisão. Acta ScientiaeVeterinariae, Rio Grande do Sul, Brasil, v. 35, n. 2, p. 125-144, 2007.

BENAVIDES, Julio A. et al. Using Surveillance of Animal Bite Patients to Decipher Potential Risks of Rabies Exposure From Domestic Animals and Wildlife in Brazil. Frontiers in Public Health, Santiago, Chile, v. 8, p. 1-9, jul. 2020.

BRASIL. Raiva humana, Brasil, 1986-2009. Coordenação de Vigilância das Doenças Transmissíveis por Vetores e Antropozoonoses, Coordenação Geral de Doenças Transmissíveis, Secretaria de Vigilância em Saúde, Ministério da Saúde. Umuarama, 24 ago 2021. Disponível em: http://portal.saude.gov.br. Acesso em: 24 ago. 2021.

SEAPA. Raiva dos Herbívoros. Vacinação contra raiva é obrigatória em 121 municípios considerados de alto risco. Umuarama, 24 ago 2021. Disponível em: https://agricultura.go.gov.br. Acesso em: 24 ago. 2021.

VARGAS, Alexander et al. Human rabies in Brazil: a descriptive study, 2000-2017. Epidemiologia e Serviços de Saúde, v. 28, n. 2, p. 1-9, 2019.

OIE. Rabies Portal. Umuarama, 14 jun, 2021. Available from: http://www.oie.int/en/ animal-health-in-the-world/rabiesportal/about-rabies/. Accessed: jun 11, 2021. 


\section{(1) \\ ISBN 978-65-87557-74-8 \\ DOI: hitps/idoiorg/10.251 10/saboextenssodaunipar.2021 \\ A BRINCADEIRA NÃO PODE PARAR E SIM ADAPTAR-SE: RELATO DE EXPERIÊNCIA DAS ATIVIDADES LÚDICAS REMOTAS NA BRINQUEDOTECA DA UNIPAR}

${ }^{1}$ LUCYELENA AMARAL PICELLI, ${ }^{2}$ JOSE RICARDO SKOLMOVSKI DA SILVA, ${ }^{3}$ ISABELLI MARIA FAZOLIN, ${ }^{4}$ TAFNES BEDIM DE OLIVEIRA , ${ }^{5}$ LETICIA VITORIA DA SILVA, ${ }^{6}$ MICHELLE FABRIS PASSOS, ${ }^{7}$ DIENNYFER BARION , ${ }^{8}$ MARINA YARA RIBEIRO CRUZ DOS SANTOS, ${ }^{9}$ SABRINA CAIADO BARRETO GUEDES, ${ }^{10}$ THALITA AKEMI YNAMURA SOARES, ${ }^{11}$ CARLOS ANTONIO ZAGO , ${ }^{12}$ VITORIA CARDOSO DOS SANTOS, ${ }^{13}$ HEMYLLY CHRYSTIE MORAES DE OLIVEIRA, ${ }^{14}$ GIOVANNA MARIA KLUCK KNAP, ${ }^{15}$ VINICIUS DOS SANTOS JANUARIO , ${ }^{16}$ MARIA DO CARMO DE OLIVEIRA NOGUEIRA

${ }^{1}$ Docente da UNIPAR

2Docente da UNIPAR

${ }^{3}$ Acadêmica do Curso de Pedagogia da UNIPAR

${ }^{4}$ Acadêmica do Curso de Pedagogia da UNIPAR

${ }^{5}$ Acadêmica do Curso de Pedagogia da UNIPAR

${ }^{6}$ Acadêmica do Curso de Pedagogia da UNIPAR

${ }^{7}$ Acadêmica do Curso de Pedagogia da UNIPAR

${ }^{8}$ Acadêmica do Curso de Pedagogia da UNIPAR

${ }^{9}$ Acadêmica do Curso de Pedagogia da UNIPAR

${ }^{10}$ Acadêmico do Curso de Pedagogia da UNIPAR

${ }^{11}$ Acadêmico do Curso de Pedagogia da UNIPAR

${ }^{12}$ Acadêmica do Curso de Pedagogia da UNIPAR

${ }^{13}$ Acadêmica do Curso de Pedagogia da UNIPAR

${ }^{14}$ Acadêmico do Curso de Pedagogia da UNIPAR

${ }^{15}$ Acadêmico do Curso de Pedagogia da UNIPAR

${ }^{16}$ Docente da UNIPAR

Introdução: Diante da proibição de funcionamento dos estabelecimentos de ensino e de espaços que promovem recreações e aglomerações de crianças, a Brinquedoteca da UNIPAR, precisou rever sua forma de atender, para que o momento do brincar não ficasse fora da rotina infantil e que os Estágios Supervisionados não fossem prejudicados. Diante disso, reorganizou-se atividades e atendimentos com uso de aplicativos - vídeo chamadas entre Brinquedoteca, acadêmicos e crianças. Bem como, três propostas tiveram início em junho de 2020: a atividade Brink On-line pelo Hangout Meet, convidou-se as crianças a brincar com os funcionários através de jogos e atividades adaptados para interação on-line; a ação Brincar do quê? ,- com uso de infográfico prático e atraente com várias brincadeiras e sugestões, entre as crianças e seus responsáveis para promover o brincar único e singular em família; e o Brincando \& Cia com atividades semanais através do WhatsApp, onde crianças de um lado da tela, estagiários do outro, interagiram com dinâmicas, usufruíram da troca de saberes, a partir de jogos analógicos que possuem em suas residências ou que já vivenciaram na Brinquedoteca.

Objetivo: Apresentar um relato de experiência descrevendo as ações desenvolvidas no Projeto, em função das medidas necessárias para o enfrentamento da pandemia.

Resultados: O destaque foi o comportamento das crianças na curiosidade em saber como estavam seus lugares favoritos na Brinquedoteca. Outra observação foi seus olhares atentos, provando a verdade simbólica vivenciada nesta idade. Havia muita expectativa da equipe, de quantos e quem iria participar. Nas orientações com os acadêmicos sugeriu-se brincadeiras que não utilizassem muitos recursos materiais, com regras fáceis e com muita interação. Para o trabalho alimentou-se a plataforma Google Classroom, com diversas atividades lúdicas, para serem pesquisadas e utilizadas durante os encontros com as crianças.

Considerações finais: As aprendizagens mediante as atividades on-line foram inesperadas, porém, enxergar o brilho no olhar dos pequenos através das telas e notar expressiva dedicação dos acadêmicos ao preparar e praticar o que aprenderam na teoria, denotou a importância da existência de tal projeto. O brincar não parou, a proposta continuou consistente e embasada nas tecnologias, com as adaptações que se fizeram necessárias. As expectativas foram substituídas por sensação de êxito, devido ao grande empenho e dedicação de todos os envolvidos. 


\section{Referências}

Coronavírus e primeira Infância. Fundação Maria Cecilia Souto Vidigal. São Paulo. Disponível em: , acesso em: 15 de set. 2020.

CUNHA, Nylse Helena da Silva, Brinquedoteca: Um mergulho no brincar. São Paulo: Vetor, 2007.

HORN, Claudia Inês, et al. Pedagogia do brincar. $2^{\circ}$ ed. Porto Alegre: Mediação, 2014.

KISHIMOTO, Tizuko Morchida (org.). O brincar e suas teorias. São Paulo: Pioneira, 2002.

MEDEIROS, Michele Hirsch de. A importância dos jogos e brincadeiras para o desenvolvimento da criança pequena. Curitiba: XI Congresso Nacional de Educação EDUCERE. p. 23854-23865, 2013. Disponível em: , acesso em: 19 de set. 2020. SANTOS, S. M. P. dos. Brinquedoteca: o lúdico em diferentes contextos. Petrópolis: Vozes, 1997.

\section{SALÃOO DE EXTENSÃO}

DA UNIPAR
- UNIPAR 50 ANOS:

Transformando vides atravta da educagto

27 de Outubro de 2021

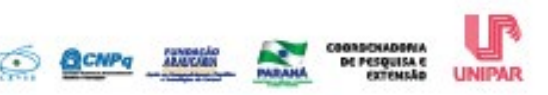




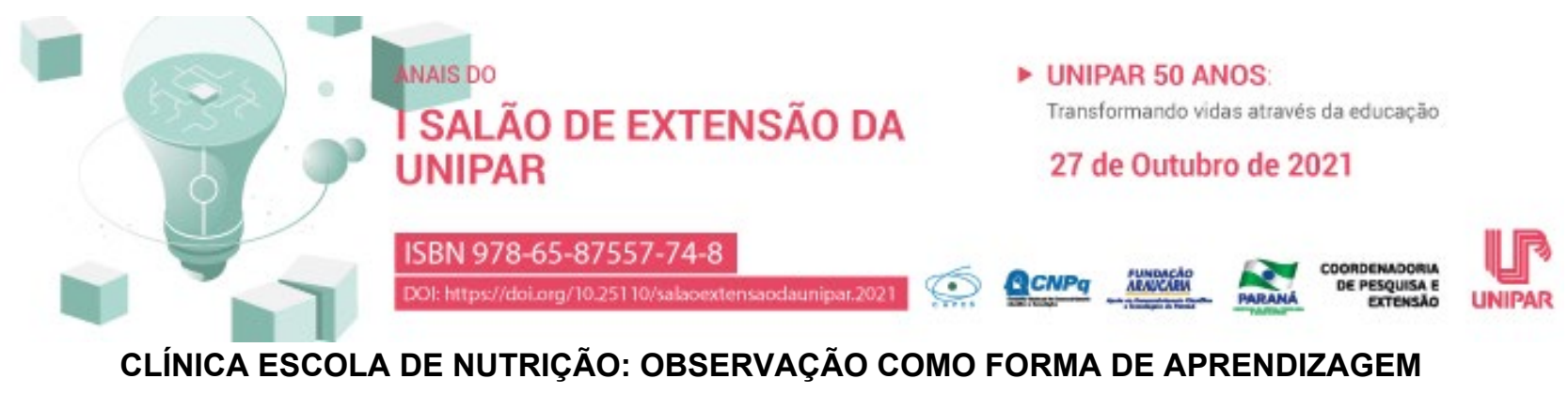

\author{
${ }^{1}$ ALINE MARA STRUB, ${ }^{2}$ EDIANE PISSAIA, ${ }^{3}$ KEILA MARIA MOREIRA, ${ }^{4}$ DANIELA EMILIO, ${ }^{5}$ SARAH ALESSANDRA \\ PASQUALETTO, ${ }^{6}$ PRISCILA DA SILVA ROKEMBACH AMARILHO, ${ }^{7}$ INDIOMARA BARATTO
}

${ }^{1}$ Acadêmica do Curso de Nutrição da Unipar
2Docente da UNIPAR
${ }^{3}$ Acadêmico do Curso de Nutriã£Ã£o da UNIPAR
${ }^{4}$ Acadêmica do Curso de NutriãßÃ£o da UNIPAR
${ }^{5}$ Acadêmica do Curso de NutriÃßÃ£o da UNIPAR
${ }^{6}$ Acadêmica do Curso de NutriãßÃ£o da UNIPAR
${ }^{7}$ Docente da UNIPAR

Introdução: A demanda por orientação alimentar e nutricional têm crescido significativamente face ao diagnóstico precoce das doenças, principalmente das doenças crônicas e ao reconhecimento da influência da alimentação sobre elas. Também, a consideração do sobrepeso e da obesidade como fatores de risco para doenças cardiovasculares, hipertensão, diabetes mellitus, osteoporose, câncer, dentre outras patologias, levam a procura crescente ao atendimento nutricional (SANTOS et al, 2017). Não há registros sobre o incremento e a dimensão atual dessa demanda, mas observa-se que ela tem aumentado tanto na rede básica de saúde, quanto em clínicas e consultórios. O aumento da demanda por orientação nutricional ou atendimento nutricional justifica a retomada do estudo ao aconselhamento dietético, como a orientação profissional individualizada para ajudar indivíduos ajustarem seu consumo diário de alimentos, a fim de atender as suas necessidades de saúde (MENDES, 2012). Considera-se que a ajuda para resolver problemas alimentares insere-se numa busca de âmbito maior por qualidade de vida. Esta ocorre em determinado momento crítico, no qual surge um problema, que por sua vez, também é fruto da história de vida. $O$ aconselhamento é uma estratégia educativa que precisa ser resgatada, a fim de redimensionar a atuação do nutricionista junto ao cliente/paciente que necessita mudar seu comportamento alimentar. O preparo de nutricionistas para essa modalidade de intervenção demanda estágios práticos e observacionais, supervisionados por profissionais da área, que os auxiliem a perceber a intersubjetividade no relacionamento com o cliente /paciente, e a explorar as possibilidades, compreender as limitações da comunicação verbal e não verbal, de forma a instrumentalizá-los para lidar com o inesperado e, sobretudo, com as próprias inseguranças.

Objetivo: Oportunizar aos acadêmicos do curso de graduação em nutrição através do projeto de extensão, a observação e a prática do acompanhamento e/ou atendimento nutricional na clínica escola de nutrição da Unipar, desenvolvendo capacidade para intervir na área de nutrição clínica ambulatorial e de educação nutricional por meio de atendimento à população.

Resultados: Na Clínica Escola de Nutrição, durante o desenvolvimento do projeto de extensão, os acadêmicos desenvolvem competências e habilidades correspondentes à profissão através da observação aos atendimentos ambulatoriais individuais, atendimento em grupos, oficinas e atividades de educação nutricional. O contato acadêmico/paciente contribui para a melhoria de vida da população pela oferta de consultas a preços populares e propicia a experiência da prática clínica ambulatorial aos estudantes, sendo essa atividade de extrema importância para a formação do Nutricionista. Além disso, o espaço Clínica Escola ainda dá bases a conhecimentos que vão além do atendimento nutricional tais como: administração de clínica, estratégias de marketing e captação de clientes, postura profissional e ética, contato com o cenário social econômico da população atendida, bem como o olhar para o futuro profissional pelas mudanças alimentares que causam impacto direto na atuação profissional, como por exemplo, dietas ।"da modal", restrição do consumo de produtos de origem animal, alergia e intolerância alimentar, introdução de alimentos não convencionais, entre outros. Os acadêmicos do curso ainda são capazes de observar e interagir com acadêmicos de outros anos e assim, juntos, analisarem, supervisionarem e avaliarem dietas e suplementos dietéticos para indivíduos sadios e enfermos, diagnosticarem e acompanharem o estado nutricional de indivíduos, elaborarem orientação nutricional voltada a alimentos e hábitos culturais regionais, promoverem, manterem e/ou recuperarem o estado nutricional de indivíduos e grupos populacionais, realizarem atividades de educação nutricional em indivíduos e coletividade, realizarem intervenções nutricionais em grupo e em família, realizarem prescrições dietoterápicas de forma terapêutica e preventiva em indivíduos e grupos populacionais.

Conclusão: Permitir que os acadêmicos desenvolvam habilidades para a execução de atividades de educação nutricional, reforcem os conhecimentos teóricos de sala de aula com a vivência prática da avaliação do estado nutricional dos clientes/ pacientes, valorizem a alimentação e a nutrição como fator essencial na promoção, prevenção e recuperação de saúde individual 
dos clientes / pacientes, pratiquem habilidades para a conduta e a prescrição nutricional, desenvolvam a capacidade para intervir na área de nutrição clínica, ambulatorial e de educação nutricional nos diferentes aspectos que contemplam essa atividade.

\section{Referências}

SANTOS, et al. Aconselhamento sobre alimentação e atividade física: prática e adesão de usuários da atenção primária. Revista Gaúcha de Enfermagem, Porto Alegre, p. 14-21, 2012.

MENDES, Eugênio Vilaça. O cuidado das condições crônicas na atenção primária à saúde: o imperativo da consolidação da estratégia de saúde da família. Organização Pan-Americana de Saúde: Brasília, 2012.

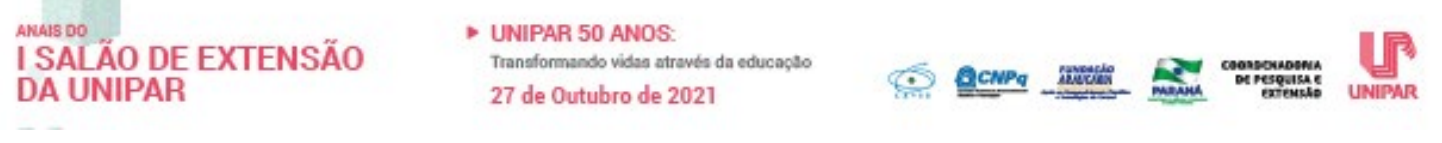




\section{(1) D UNIPAR 50 ANOS \\ SALÃO DE EXTENSÃO DA Transformando vidas através da educą̧̄o \\ UNIPAR \\ 27 de Outubro de 2021 \\ ISBN 978-65-87557-74-8

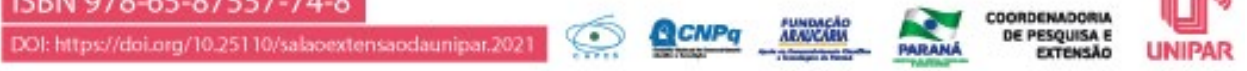 \\ LIGA ACADÊMICA DE ANGIOLOGIA E CIRURGIA VASCULAR: COMPARTILHANDO CONHECIMENTO ATRAVÉS DAS REDES SOCIAIS}

${ }^{1}$ DEBORAH TAVARES BIEZUS, ${ }^{2}$ ANA BEATRIZ PINHEIRO ZAUPA, ${ }^{3}$ ANA BEATRIZ DERENUSSON NELLI MARGATTO NUNES, ${ }^{4}$ BRUNA LUANA CHAPLA, ${ }^{5}$ CARLOS EDUARDO RUZZENE RODRIGUES, ${ }^{6}$ CAMILA MARIA ESCARDILLE YOSHITANI, ${ }^{7}$ DAVI CORREA PEREIRA, ${ }^{8}$ ESTER PELEGRINI SILVA, ${ }^{9}$ GABRIEL HENRIQUE BELLATO PALIN, ${ }^{10}$ GABRIELA CAROLINA CREMONESE VON BORSTEL, ${ }^{11}$ GABRIELA CORREA ALBERTI, ${ }^{12}$ JOLMAR LEONARDO PENAZZO MACHADO, ${ }^{13}$ JESSICA ZANQUIS FERREIRA, ${ }^{14}$ ADALBERTO CARLOS GIOVANINI NETO

${ }^{1}$ Acadêmica do Curso de Medicina da UNIPAR

${ }^{2}$ Acadêmica do Curso de Medicina da UNIPAR

${ }^{3}$ Acadêmica do Curso de Medicina da UNIPAR

${ }^{4}$ Acadêmica do Curso de Medicina da UNIPAR

${ }^{5}$ Acadêmico do Curso de Medicina da UNIPAR

${ }^{6}$ Acadêmica do Curso de Medicina da UNIPAR

${ }^{7}$ Acadêmico do Curso de Medicina da UNIPAR

${ }^{8}$ Acadêmica do Curso de Medicina da UNIPAR

${ }^{9}$ Acadêmico do Curso de Medicina da UNIPAR

${ }^{10}$ Acadêmica do Curso de Medicina da UNIPAR

${ }^{11}$ Acadêmica do Curso de Medicina da UNIPAR

${ }^{12}$ Acadêmico do Curso de Medicina da UNIPAR

${ }^{13}$ Acadêmica do Curso de Medicina da UNIPAR

${ }^{14}$ Docente da UNIPAR

Introdução: As ligas acadêmicas possuem atividades fundamentais no ambiente universitário, a partir de ações extracurriculares que alcançam o aluno, o meio em que se encontram e a sociedade (SILVA et al., 2015). Assim, a Liga Acadêmica de Angiologia e Cirurgia Vascular (LAACV) - UNIPAR, fundada em 2021, em um dos seus projetos de extensão, atua compartilhando informações através da rede social - Instagram -, na qual são realizadas postagens sobre assuntos relacionados à área médica vascular, além de vídeos gravados pelo preceptor, Dr. Adalberto Carlos Giovanini Neto, o qual compartilha seu vasto conhecimento com a sociedade, a fim de informá-los de forma precisa sobre temas relevantes para sua saúde vascular.

Objetivo: Descrever as atividades da LAACV do Campus UNIPAR por meio das postagens sobre os assuntos da área na rede social - Instagram - e os resultados alcançados por meio do compartilhamento de conhecimento com a população.

Resultados: A página da rede social Instagram, criada em 14 de novembro de 2020 conta com 1019 seguidores, 52 publicações no feed, somando um total de 2.432 likes e uma média de 46 curtidas por post. Ademais, desde o início, contabilizam-se 34.973 impressões e 25.633 alcances das publicações. Há postagens informativas sobre as mais diversas doenças no âmbito da Angiologia e da Cirurgia Vascular, contribuindo ainda mais para a expansão do conhecimento em favor da população através dessa rede. Além disso, a página da LAACV, teve a oportunidade de levar o conhecimento para outras cidades e estados, isso porque de acordo com os Insights da rede, dos 1019 seguidores até o momento, tem-se que o público atingido foi de $35,1 \%$ de cidadãos de Umuarama/PR, 6.1\% de Maringá, 3.7\% de Cascavel, 3.4\% Uberaba-SP, e 3.2\% da cidade de São Paulo.

Conclusão: É nítido, portanto, que por meio deste projeto conseguiu-se alcançar inúmeras pessoas de diversos locais, as quais apresentaram um engajamento notável frente às postagens e também acompanharam a progressão da liga acadêmica nessa rede social. Ademais, a população, ao acompanhar o conteúdo da LAACV no Instagram também fica por dentro de diversos assuntos voltados à cirurgia vascular, conhecendo melhor as principais ocorrências desta área, bem como informações que auxiliam na identificação de sinais e sintomas das afecções mais comuns.

\section{Referências}

SILVA, J. H. S. da et al.. Implantação de uma Liga Acadêmica de Anatomia: Desafios e Consquistas. Revista Brasileira de Educação Médica, 2015. Disponível em: https://doi.org/10.1590/1981-52712015v39n2e03012014 . Acesso em ago. 2021. 
- unIPAR 50 anos:

I SALAOO DE EXTENSÃO Transformando vidas atravies da educaģso

DA UNIPAR 


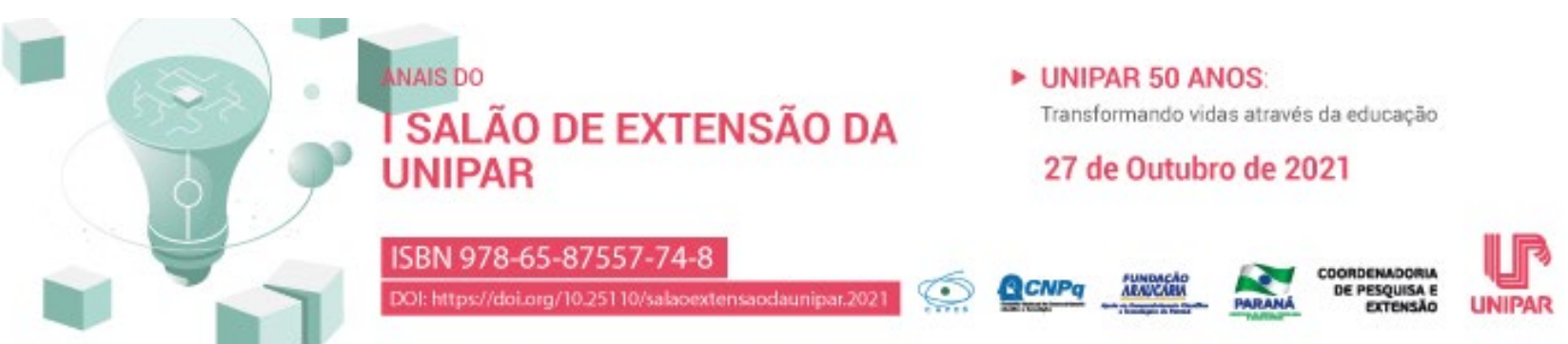 PROJETO DE EXTENSÃO FARMÁCIA VIVA DURANTE A PANDEMIA}

1BARBARA DE SOUZA ARCANJO, ${ }^{2}$ GABRIELLA SANTANA DE OLIVEIRA, ${ }^{3}$ GABRIELA CATUZO CANONICO SILVA, ${ }^{4}$ GABRIEL VIVIAN RODRIGUES, ${ }^{5}$ JUSLAINE KARINE BARBOSA DE OLIVEIRA, ${ }^{6}$ NAYANA ALMEIDA BELIATTO MARCONI, ${ }^{7}$ ANA CAROLINA DA SILVA, ${ }^{8}$ TATIANE SILVA CASTELLINI, ${ }^{9}$ MARISA CASSIA VIEIRA DE ARAUJO BENTO, ${ }^{10} \mathrm{GABRIEL}$ AUGUSTO RODRIGUES BEIRAO, ${ }^{11}$ BRUNA DE PAULA BELINI, 12ISABELLE LUIZ RAHAL, 13JULIANA APARECIDA MENDONCA , ${ }^{14}$ GABRIEL TRAMONTINI PEREIRA, ${ }^{15}$ ZILDA CRISTIANI GAZIM

${ }^{1}$ Bolsista do programa Institucional de Bolsas de Extensão Universitária PIBEX e discente do Curso de Enfermagem Universidade Paranaense

${ }^{2}$ Acadêmica do Curso de Nutrição da UNIPAR

${ }^{3}$ Acadêmica do Curso de Quimica Industrial da UNIPAR

${ }^{4}$ Acadêmico do Curso de Farmácia da UNIPAR

${ }^{5}$ Acadêmica do Curso de Farmácia da UNIPAR

${ }^{6}$ Docente da UNIPAR

${ }^{7}$ Acadêmica do Curso de Enfermagem da UNIPAR

${ }^{8}$ Acadêmica do Curso de Enfermagem da UNIPAR

${ }^{9}$ Acadêmica do Curso de Enfermagem da UNIPAR

${ }^{10}$ Acadêmico do Curso de Farmácia da UNIPAR

${ }^{11}$ Acadêmica do Curso de Nutrição da UNIPAR

${ }^{12}$ Acadêmica do Curso de Doutorado Em Biotecnologia Aplicada A Agricultura - Turma VIII da UNIPAR

${ }^{13}$ Acadêmica do Curso de Ciências Biologicas da UNIPAR

${ }^{14}$ Acadêmico do Curso de Farmacia da UNIPAR

${ }^{15}$ Docente dos cursos de Graduação e Pós-Graduação e Coordenadora do Projeto Farmácia Viva - UNIPAR Umuarama-PR

Introdução: Frente a realidade imposta pela pandemia do Covid-19, o distanciamento social exigiu que a sociedade mudasse seu modo de ser e viver. Em relação ao mundo acadêmico os impactos foram significativos, pois as instituições de ensino precisaram se reinventar modificando o ensino e suas metodologias aplicadas, aderindo então às plataformas virtuais como, Google Meet, Zoom, Google Classroom, etc. Ou seja, o tripé universitário ensino, pesquisa e extensão sofreu todas essas alterações, sendo que as práticas de extensão foram duramente atingidas e o contato direto com a comunidade ficou restrito (ALBERTI et al., 2020).

Objetivo: Levar a informação do uso de plantas medicinais à população através do ensino remoto.

Resultados: A maior dificuldade inicial foi planejar a execução de um projeto essencialmente presencial e social de forma remota, visto que, houve uma necessidade rápida de adaptação dos professores e alunos para esta modalidade de ensino. E com o projeto de extensão farmácia viva não foi diferente. Inicialmente o projeto foi divulgado em grupos de alunos das diferentes modalidades (presencial, semi-presencial, estágios e salas de aula), utilizando a única ferramenta disponível as redes sociais (email, grupos de whatsapp, facebook, instagram). Os interessados foram convidados a se inscreverem na plataforma institucional (classroom). A comunicação foi através de vídeos informativos sobre o cultivo, coleta e processamento das plantas medicinais; vídeos de oficinas de produtos artesanais confeccionadas a partir das plantas medicinais. Estes vídeos foram disponibilizados na plataforma classroom, juntamente com atividades para os participantes. 45 alunos dos cursos de farmácia, nutrição, biomedicina e ciências biológicas participaram do projeto. 30 vídeos foram gravados e dispostos na plataforma classroom. Respeitando as normas de biossegurança da Universidade Paranaense e do município de Umuarama, e mantendo o distanciamento de 1,5 metros, entre os dias 06 de outubro de 2020 á 11 de novembro de 2020, foram realizadas oficinas no laboratório de farmacotécnica, em grupos de no máximo 05 alunos por período.

Conclusão: Foi possível a realização de um projeto essencialmente presencial de forma remota sem comprometer os objetivos da extensão que é levar o conhecimento científico à comunidade.

\section{Referências}

ALBERTI, Graziela, Minas. et al. Desafios Da Extensão Universitária Em Época De Pandemia. Ed. 4, Anais do Salão de 
Extensão da FADISMA, Rio Grande do Sul, 2020. Disponível em: http://sites.fadismaweb.com.br/salaoextensao/anais/desafiosda-extensao-universitaria-em-epoca-de-pandemia/. Acesso em: 20 ago. 2021.

ANaIS DO

DA UNIPAR

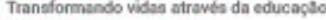

27 de Outubro de 2021

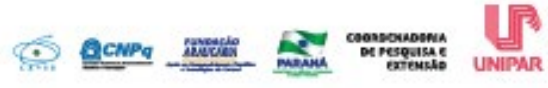




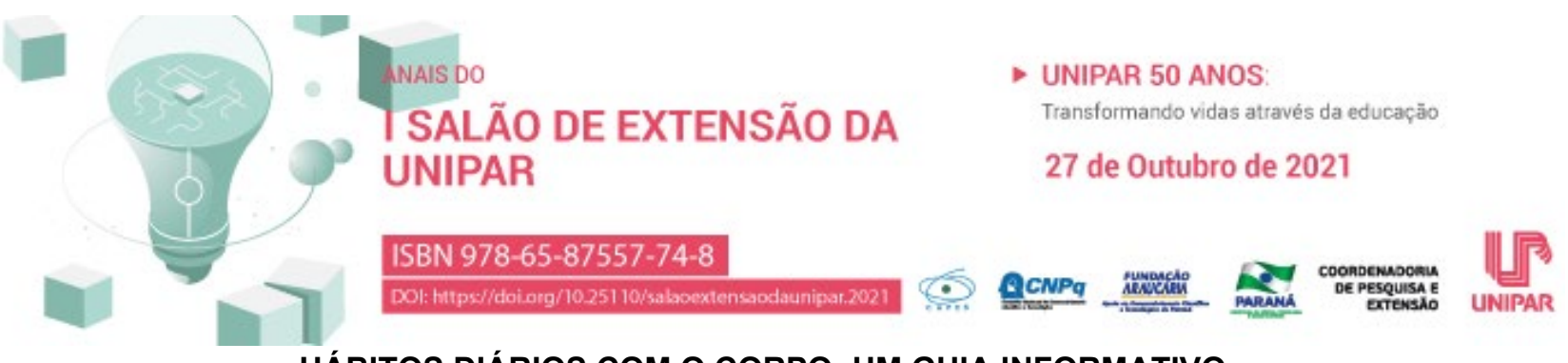 \\ HÁBITOS DIÁRIOS COM O CORPO: UM GUIA INFORMATIVO
}

\author{
${ }^{1}$ MILENA SCHREINER, ${ }^{2}$ JULIA GONZATTO ZEWICKER, ${ }^{3}$ KELLI KUHNEN, ${ }^{4}$ JULIANA PELISSARI MARCHI
}

${ }^{1}$ Acadêmica participante do Programa Institucional Centro de Estética e Cosmética Escola, do C.S.T. em Estética e Cosmética da UNIPAR.

${ }^{2}$ Acadêmica participante do Programa Institucional Centro de Estética e Cosmética Escola, do C.S.T. em Estética e Cosmética da UNIPAR.

${ }^{3}$ Responsável Técnica do Centro de Estética Escola do Curso Superior de Tecnologia em Estética e Cosmética da Universidade Paranaense, UNIPAR.

${ }^{4}$ Docente do C.S.T. em Estética e Cosmética da Universidade Paranaense, UNIPAR, Unidade de Francisco Beltrão.

Introdução: As atividades do projeto incluíram atendimentos estéticos (facial, corporal, capilar, terapias integrativas e imagem pessoal) e elaboração da cartilha Cuidados diários com o corpo que está sendo divulgada para a população. Os cuidados com o corpo são necessários para aumentar a autoestima e a autoconfiança, melhorar a qualidade de vida, evitar o surgimento de disfunções estéticas e manter a saúde (SANTOS, 2008; VAZ AMARAL, 2019).

Objetivo: Relatar a experiência de atividades desenvolvidas no Programa Institucional Centro de Estética e Cosmética Escola da UNIPAR.

Resultados: O projeto é de extrema importância, abre as portas do conhecimento a partir da relação teórico-prática, assim, favorece o enriquecimento curricular. Além disso, oportuniza a vivência e a experiência prática dos atendimentos, com uso de cosméticos multimarcas e equipamentos de altíssima qualidade. A elaboração da cartilha possibilitou ampliação do conhecimento e ainda despertou o interesse em transmitir informações de saúde e de estética para a comunidade. Com o desenvolvimento desta cartilha, podemos citar que os cuidados com o corpo incluem tanto o uso de cosméticos quanto os cuidados com os hábitos diários. São eles: uso de protetor solar, a fim de proteger a pele, prevenir câncer de pele e/ou fotoenvelhecimento; hidratação cutânea, ideal para manter a barreira cutânea íntegra e assim evitar o ressecamento da pele e o surgimento de disfunções (flacidez, estrias, ressecamento, descamação); uso de cosmético de tratamento quando há disfunções (gordura localizada, fibro edema ginóide, estrias, flacidez); esfoliação a fim de ativar a renovação tecidual e melhorar o aspecto da pele; evitar banhos quentes e exposição solar solar em horários inadequados (PINHEIRO, 2018; VAZ AMARAL, 2019; SANTOS, 2008). Hábitos diários como ingesta de água adequada, alimentação equilibrada, prática de exercícios físicos e sono adequado, são fundamentais tanto para o corpo quanto para a mente, assim, promove prevenção de doenças e de disfunções estéticas, melhora da qualidade de vida, da autoconfiança e da autoestima, contribuindo com a saúde (BRESSAN, 2009; SIQUEIRA, 2007).

Conclusão: Por meio do projeto, com os atendimentos à comunidade e com a pesquisa científica para elaboração da cartilha, conclui-se que a pesquisa deve estar presente no cotidiano profissional, pois, a teoria e prática devem estar relacionadas.

\section{Referências}

BRESSAN, Josefina et al. Impacto Hormonal e Inflamatório de Diferentes Composições Dietéticas: Ênfase em Padrões Alimentares e Fatores Dietéticos Específicos. Arq Bras Endocrinal Metab, 2009; 53/5. Disponível em: https://www.scielo.br/j/abem/a/Z7tLRGLkTMg9BbcsCBGdMqc/?lang=pt\&format=pdf. Acesso em: 17 ago. 2021.

PINHEIRO, Chloé. Dossie banho quente: ele traz prejuízos, mas dá para amenizar a situação. Revista saúde.abril.com.br. 20 de junho de 2018.

SANTOS, Ligia Amparo da Silva. O Corpo, o comer e a comida: um estudo sobre as práticas corporais e alimentares no mundo contemporâneo. Salvador, 2008. Disponível em: https://static.scielo.org/scielobooks/38m/pdf/santos-9788523209087.pdf. Acesso em: 17 Ago. 2021.

SIQUEIRA, Denise. Corpo, saúde e beleza: representação sociais nas revistas femininas. Revistacmc.espm.br; v.3, n.9, 2007. VAZ AMARAL, Karina Fabrícia. A Importância da hidratação cutânea para melhor tratamento das disfunções estéticas. Idonline.emnuvens.com.br; v.13, n. 48, 2019.

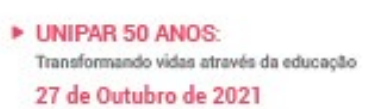

Transformando vidas atravis da educagto

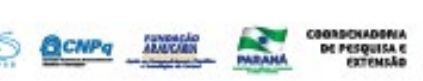




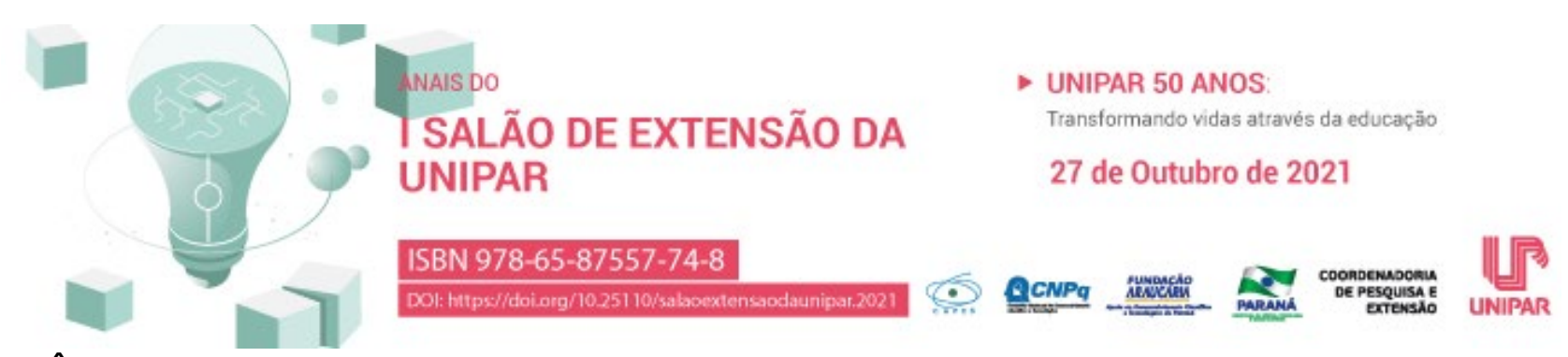

\section{LIGA ACADÊMICA DE OTORRINOLARINGOLOGIA: EXPANDINDO CONHECIMENTO COM PODCAST MEDTALKS UNIPAR}

${ }^{1}$ DEBORAH TAVARES BIEZUS, ${ }^{2}$ ARIELLA REGINA BRUSCHI, ${ }^{3}$ AUGUSTO FASSINI FONT, ${ }^{4}$ EDUARDO AUGUSTO PFAU , ${ }^{5}$ BERNARDO MUNHOZ LIMA, ${ }^{6}$ ESTER PELEGRINI SILVA, ${ }^{7}$ FABIANE ANGELICA DE PAIVA PAULA, ${ }^{8}$ FABIOLA COSTA TAKAKUA, 9 LUCAS ALEXANDRE GUBERT SCHIER, ${ }^{10}$ SIMARA RAISA DE BRITO MORAES, ${ }^{11}$ THALYTA CUSTODIO, ${ }^{12}$ VICTOR HUGO ONO SAKUMA DOLCI DOS SANTOS, ${ }^{13}$ FERNANDO CEZAR CARDOSO MAIA FILHO

${ }^{1}$ Acadêmica do Curso de Medicina da UNIPAR

${ }^{2}$ Acadêmica do Curso de Medicina da UNIPAR

${ }^{3}$ Acadêmico do Curso de Medicina da UNIPAR

${ }^{4}$ Acadêmico do Curso de Medicina da UNIPAR

${ }^{5}$ Acadêmico do Curso de Medicina da UNIPAR

${ }^{6}$ Acadêmica do Curso de Medicina da UNIPAR

${ }^{7}$ Acadêmica do Curso de Medicina da UNIPAR

${ }^{8}$ Acadêmica do Curso de Medicina da UNIPAR

${ }^{9}$ Acadêmico do Curso de Medicina da UNIPAR

${ }^{10}$ Acadêmica do Curso de Medicina da UNIPAR

${ }^{11}$ Acadêmica do Curso de Medicina da UNIPAR

${ }^{12}$ Acadêmico do Curso de Medicina da UNIPAR

${ }^{13}$ Docente da UNIPAR

Introdução: A liga acadêmica é uma associação civil sem fins lucrativos, com caráter educacional, extensionista, criada, organizada e gerida por discentes sob preceptoria de professor (ALMEIDA et al). Dessa maneira, a Liga Acadêmica de Otorrinolaringologia (LAORL) - UNIPAR, fundada em 2021, tem, em conjunto com professor preceptor Dr. Fernando Cezar Cardoso Maio Filho, um projeto de podcast, onde os ligantes têm oportunidade de compartilhar conhecimentos para sociedade, a fim de informá-los sobre temas de saúde relevantes.

Objetivo: Descrever a atividade da LAORL do Campus UNIPAR por meio de episódios em podcast sobre assuntos da área e compartilhamento com a população.

Resultados: O projeto do podcast MedTalks é uma iniciativa do Dr. Fernando Cezar Cardoso Maia Filho juntamente com mais membros da UNIPAR. Até esse momento, conta com 20 publicações e os três episódios sobre Câncer de Cabeça e Pescoço feitos com membros da LAORL foram executados, em média, 10 vezes, com concentração maior no Brasil (95\%), Paraguai $(2 \%)$, Itália $(<1 \%)$, Maldivas $(<1 \%)$, EUA $(<1 \%)$, Suíça $(<1 \%)$, Finlândia $(<1 \%)$ e Portugal $(<1 \%)$. Nesses episódios os participantes discutiram sobre câncer da cavidade oral, câncer de laringe e câncer da tireóide, bem como epidemiologia, os fatores de risco, prevenção, sinais e sintomas, diagnóstico e tratamento para cada uma dessas doenças. $O$ andamento da LAORL contará com mais participações dos ligantes no MedTalks e espera-se aumentar os números de episódios contemplando a área da otorrinolaringologia.

Conclusão: Com base no exposto, percebemos que a abrangência do projeto alcançou inúmeras pessoas, tanto dentro do território nacional, quanto internacional e que a população está informada sobre diversos assuntos relevantes da área da otorrinolaringologia.

\section{Referências}

ALMEIDA, Prof. Dr. André Quintão et al. Manual de Liga Acadêmica. Serviço Público Federal Ministério da Educação Universidade Federal de Sergipe Pró-reitoria de Extensão.
em: https://proex.ufs.br/uploads/page_attach/path/6620/Manual_das_Ligas_Acad_micas.pdf 


\title{
8 .
}

PROJETO SYNAPSE: APLICANDO INTELIGÊNCIA ARTIFICIAL EM UMA EDUCAÇÃO GAMIFICADA

\author{
${ }^{1}$ PEDRO VITOR NUNES ARRUdA, ${ }^{2}$ GABRIEL FELIPE BELLO, ${ }^{3}$ LUCAS CARDOZO, ${ }^{4}$ MATEUS ANDRE NUNES ARRUDA, \\ ${ }^{5}$ FERNANDO RIGO BOTELHO
}

${ }^{1}$ Acadêmico de Sistemas de Informação da Universidade Paranaense - UNIPAR; e-mail: pedro.nunes@edu.unipar.br; Cascavel PR.

${ }^{2}$ Acadêmico de Análise e Desenvolvimento de Sistemas da Universidade Paranaense - UNIPAR; e-mail: g.bello@edu.unipar.br; Toledo PR.

${ }^{3}$ Acadêmico de Engenharia da Computação da Universidade Paranaense - UNIPAR; e-mail: I.cardozo@edu.unipar.br; Cascavel PR.

${ }^{4}$ Acadêmico de Sistemas de Informação da Universidade Paranaense - UNIPAR; e-mail: mateus.andre@edu.unipar.br; Cascavel PR.

${ }^{5}$ Docente da Universidade Paranaense - UNIPAR, Coordenador projeto INOVATECH. fernandobotelho@prof.unipar.br; Toledo PR.

Introdução: Segundo projeções realizadas pela Brasscom (2019), o mercado brasileiro terá uma demanda de 70 mil profissionais de Tecnologia da Informação (TI) por ano até 2024, diante de uma oferta dos bancos universitários de 45 mil pessoas por ano. Diante disso, é necessário que a formação de profissionais deste ramo aumente consideravelmente e uma das estratégias é a familiarização da juventude com a área. Desenvolvido por alunos da Universidade Paranaense (UNIPAR), participantes do projeto de extensão INOVATECH, o projeto Synapse ajuda nisso por meio de um sistema de questionários online, onde uma Inteligência Artificial (IA) identifica e classifica as respostas dos usuários, que são realizadas por meio de gestos. Este é o grande diferencial da aplicação, que utiliza uma estratégia de gamificação para pontuar os participantes. Para o desenvolvimento do projeto, foi utilizado React JS (2013) no Frontend, Java com API Rest (SOUZA, 2018) no Backend, servidor Wildfly (2020), banco de dados MySQL (1995) e Inteligência Artificial com a biblioteca Python (1991) TensorFlow (2015a, 2015b). A gestão do código-fonte foi realizada por meio do GitHub (2008).

Objetivos: Despertar o interesse da juventude no âmbito da $\mathrm{Tl}$, demonstrando a ampla gama de possibilidades que a área possui por meio de um software interativo e de fácil entendimento visual que utiliza a Inteligência Artificial, uma das áreas mais comentadas atualmente.

Resultados: Foram atingidos todos os objetivos propostos, chegando a um sistema rápido, simples e dinâmico, características essenciais para o público-alvo e objetivo em questão. Atualmente, está na versão beta, fazendo o processo de cadastro da pergunta, criação de sala, acesso do usuário respondente, reconhecimento da resposta pelos gestos através da biblioteca TensorFlow e o registro no banco de dados.

Conclusão: Diante da necessidade da familiarização das crianças e adolescentes na $\mathrm{TI}$, o presente trabalho apresenta uma forma de ajudar a alcançar tal objetivo. Como a Inteligência Artificial é um tema crescente, que desperta interesse de jovens a adultos, o trabalho teve a função de mostrar sua aplicação em uma atividade lúdica e prática. Como próximo passo, é necessário a apresentação e uso deste para testes em escolas, públicas ou privadas, para validar o sistema e a estratégia adequada de uso em sala de aula.

\section{Referências}

BRASSCOM. Formação Educacional e Empregabilidade em TIC: Achados e Recomendações. São Paulo, 2019. Disponível em: $\quad$ https://brasscom.org.br/wp-content/uploads/2019/09/BRI2-2019-010-P02-Forma\%C3\%A7\%C3\%A3o-Educacional-eEmpregabilidade-em-TIC-v83.pdf. Acesso em: 11 jul. 2021.

MYSQL $\quad$ Chapter 1 General Information. Uppsala, 1995. Disponível em: https://dev.mysql.com/doc/refman/8.0/en/introduction.html. Acesso em: 16 ago. 2021.

PYTHON. Python. Amsterdã, 1991. Disponível em: https://www.python.org/. Acesso em: 09 ago. 2021.

REACT JS. React: Uma biblioteca JavaScript para criar interfaces de usuário. Carlsbad, 2013. Disponível em: https://ptbr.reactjs.org/. Acesso em: 09 ago. 2021.

SOUZA, Diogo. REST Tutorial: Primeiros passos com Serviços REST. Cascavel, 2018. Disponível em: https://www.devmedia.com.br/rest-tutorial/28912. Acesso em: 11 jul. 2021.

TENSORFLOW. Tensorflow - Object detection disponível no Github. Mountain View, 2015a. Disponível em: https://github.com/tensorflow/models/tree/master/research/object_detection. Acesso em: 11 jul. 2021. 
TENSORFLOW. Tensorflow - JS converter disponível no Github. Mountain View, 2015b. Disponível em: https://github.com/tensorflow/tfjs/tree/master/tfjs-converter. Acesso em: 11 jul. 2021.

WILDFLY. Wildfly documentation. Raleigh, 2010. Disponível em: https://docs.wildfly.org/20/. Acesso em: 11 jul. 2021. GITHUB. Github. São Francisco, 2008. Disponível em: https://github.com/. Acesso em: 21 ago. 2021.

I SALÃOO DE EXTENSÃO

DA UNIPAR
- UNIPAR 50 ANOS:

Transformando videa atreves da educages

27 de Outubro de 2021

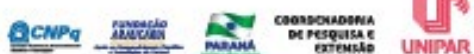




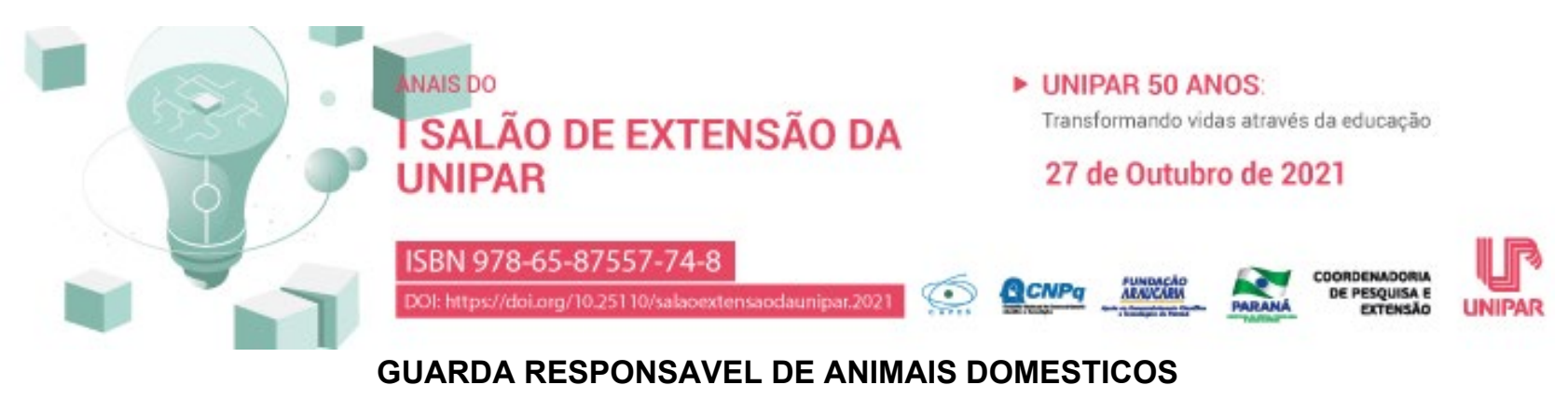

\author{
${ }^{1}$ DEBORA CRISTINA RIBEIRO, ${ }^{2}$ ADRIANO AUGUSTO MARTINS \\ ${ }^{1}$ Discente do Curso de Medicina Veterinária e bolsista PIBEX/UNIPAR \\ ${ }^{2}$ Docente da UNIPAR
}

Introdução: Guarda responsável é a garantia, pelo tutor, da manutenção do bem estar do animal, respeitando suas necessidades físicas e psicológicas (ISHIKURA et al., 2017). Segundo PLAZAZ et al (2014), o termo bem-estar animal tem como conceito que um animal deve estar em boas condições, saudável, confortável, bem alimentado, seguro e capaz de expressar sua forma inata de comportamento, sem dor ou medo. Ultimamente, o número de animais de companhia vem aumentando cada vez mais e com isso pode-se notar que muitos tutores tem um grande despreparo e desconhecimento sobre a responsabilidade de ter um animal, e com isso vem surgindo muitos problemas como superpopulação de animais e abandono nas ruas, levando à disseminação de doenças zoonóticas como leishmaniose, raiva, toxoplasmose e leptospirose. Um dos métodos mais eficazes para o controle da superpopulação animal é a castração cirúrgica dos animais. Por esses motivos, o tema guarda responsável tem sido abordado com mais frequência.

Objetivo: O objetivo deste trabalho é mostrar o que é a guarda responsável e conscientizar a população sobre a sua importância. Resultados: Os resultados de diversos estudos mostram que o abandono de animais traz problemas de saúde pública e ambientais, podendo afetar a sociedade brasileira como um todo, causando principalmente o aumento de infecções em animais, ataques a pedestres e motoristas devido à ferocidade de animais abandonados e legislação proteger os animais.

Conclusão: A guarda responsável, além de garantir o bem-estar animal, auxilia no controle da superpopulação e de doenças zoonóticas.

\title{
Referências
}

JORGE, S. S. et al. Guarda Responsável de Animais: Conceitos, ações e políticas públicas. Centro Científico Conhecer, Goiânia, v.15 n.28, 2018, DOI: 10.18677/EnciBio_2018B51.

ISHIKURA, J. I. et al. Mini-hospital Veterinário: guarda 23-30, 2017. Disponívelem: responsável, bem-estar animal, zoonoses e proteção à fauna exótica. Revista Brasileira de Extensão Universitária, v. 8, n. 1, p.

SILVA, M. N. G. et al. Projeto melhor amigo na conscientização de guarda responsável de animais de estimação. Rev. Ciênc. Ext. v. 9, n. 3, p. 43-52, 2013, ISSN 1679-4605.

SANTANA, L. R.; OLIVEIRA, T. P. Reflexões sobre a guarda responsável de animais de companhia no Brasil, dA. Derecho Animal (Forum of Animal Law Studies), v.11, n.2 fev./maio de 2020. DOI: https://doi.org/10.5565/rev/da.47.

SILVA, A. S. et al. Ações sobre bem-estar animal e zoonoses em escolas do sertão nordestino. Brazilian Journal of Animal and Environmental Research, Curitiba, v. 3, n. 1, p.286-289, jan./mar. 2020, ISSN 2595-573.

I SALÃO DE EXTENSÃO

DA UNIPAR
- UNIPAR 50 ANOS:

Transformando vidas atravta da educaçso

27 de Outubro de 2021

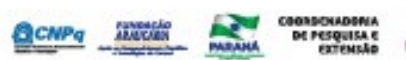

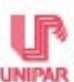




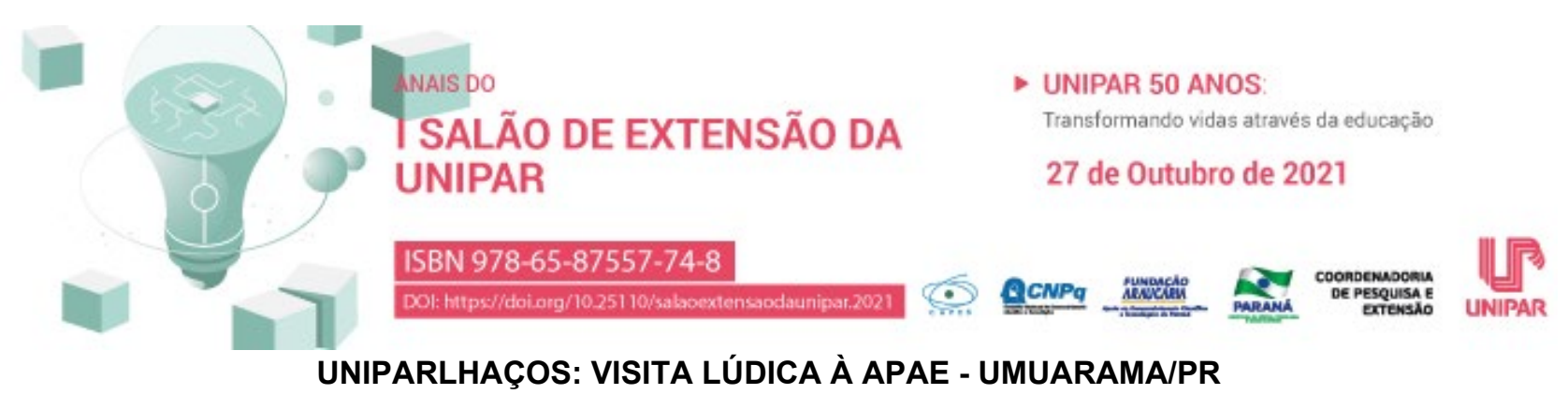

\begin{abstract}
${ }^{1}$ EMILLY CAETANO DE ANDRADE, ${ }^{2}$ HELOISA MIYKE PAINI, ${ }^{3}$ FERNANDA DE ABREU BRAGA, ${ }^{4}$ PRISCILA FREIRES LOPES , ${ }^{5}$ NATALIA FERNANDES DA SILVA, ${ }^{6}$ ANA BEATRIZ SILVESTRI RIBEIRO, ${ }^{7}$ ALANA CAROLINE OSTETTI BORGES, ${ }^{8}$ MARCIA ELIZA BAVARESCO TOZONI, ${ }^{9}$ ANA CAROLINA BONADIO, ${ }^{10}$ IZADORA MAITAN DO NASCIMENTO, ${ }^{11} \mathrm{GABRIELA}$ BARBOSA DE OLIVEIRA, ${ }^{12}$ MARIA EDUARDA BERLITZ DE SOUZA, ${ }^{13}$ CAMILE FERNANDA SQUISATTI, ${ }^{14}$ REBECCA VAN HATTEM, ${ }^{15}$ ISABELLA ARANTES TOBBIN, ${ }^{16}$ ELIZABETI DE MATOS MASSAMBANI
\end{abstract}

\begin{abstract}
${ }^{1}$ Acadêmica do Curso de Medicina da UNIPAR
${ }^{2}$ Acadêmica do Curso de Medicina da UNIPAR

${ }^{3}$ Acadêmica do Curso de Medicina da UNIPAR

${ }^{4}$ Acadêmica do Curso de Medicina da UNIPAR

${ }^{5}$ Acadêmica do Curso de Medicina da UNIPAR

${ }^{6}$ Acadêmica do Curso de Medicina da UNIPAR

${ }^{7}$ Acadêmica do Curso de Medicina da UNIPAR

${ }^{8}$ Acadêmica do Curso de Medicina da UNIPAR

${ }^{9}$ Acadêmica do Curso de Medicina da UNIPAR

${ }^{10}$ Acadêmica do Curso de Medicina da UNIPAR

${ }^{11}$ Acadêmica do Curso de Medicina da UNIPAR

${ }^{12}$ Acadêmica do Curso de Medicina da UNIPAR

${ }^{13}$ Acadêmica do Curso de Medicina da UNIPAR

${ }^{14}$ Acadêmica do Curso de Medicina da UNIPAR

${ }^{15}$ Acadêmica do Curso de Medicina da UNIPAR

${ }^{16}$ Docente da UNIPAR - Umuarama
\end{abstract}

Introdução: Palhaços-doutores são voluntários que adotam a arte do palhaço em atividades recreativas em ambientes hospitalares, proporcionando bem-estar físico, psicológico e social ao paciente internado (ARAÚJO; GUIMARÃES, 2009). Estes encontros no ambiente hospitalar apresentam melhora no bem-estar emocional tanto dos pacientes como de acompanhantes $\mathrm{e}$ funcionários (SATO et al., 2016). UNIPARLHAÇOS é um projeto de extensão com caráter multidisciplinar e conta com a participação de 30 acadêmicos que passaram por duas etapas de seleção e por oficinas e atividades para treinamento. $O$ exercício da medicina integrativa proporciona um cuidado integral e humanizado em saúde aos pacientes internados, transformando suas doenças ou limitações através de atividades lúdicas, além disso, o projeto contribui para a desenvoltura profissional dos acadêmicos, assim como envolvê-los em atividades fora da universidade, uma vez que esta é um local racional e para o desenvolvimento do conhecimento e das habilidades técnicas. A APAE (Associação de Pais e Amigos dos Excepcionais) de Umuarama recebeu a visita do projeto UNIPARLHAÇOS em evento para marcar a Semana Nacional da Pessoa com Deficiência Intelectual e Múltipla. A APAE desenvolve um trabalho de excelência no sentido de ensinar os integrantes com necessidades especiais, oportunizando o desenvolvimento das habilidades para que os mesmos sejam respeitados e valorizados em todos os espaços da sociedade.

Objetivo: Proporcionar atividades lúdicas aos integrantes da APAE de Umuarama/PR.

Resultados: O projeto UNIPARLHAÇOS desenvolveu atividades como brincadeiras, dança, confecção e entrega de balões em diversos formatos para alegrar os participantes. Os principais episódios de interação entre os palhaços-doutores com os integrantes da APAE e familiares que os acompanhavam envolveram risos e momentos de descontração. Estes puderam influenciar positivamente colocando à disposição do integrante o prazer de rir, e mostrando possibilidades do processo de sentirse bem.

Conclusão: A visita na APAE ocorreu de forma positiva, com muita receptividade por parte dos integrantes e demais participantes. É fundamental incentivar recursos de humanização no aspecto de proporcionar bem-estar, alegria e estímulo para que os portadores de necessidades especiais possam se sentir integrados, respeitados e valorizados na sociedade. E certamente, o ganho maior é dos acadêmicos que se enriquecem humanamente com estas atividades desenvolvidas em prol da 
comunidade e do próximo.

\section{Referências}

ARAÚJO, Tereza Cristina Cavalcanti Ferreira; GUIMARÃES, Tathiane Barbosa. Interações entre voluntários e usuários em oncoum estudo sobre os palhaços-doutores

REVSPSI.

Disponível

em: http://www.revispsi.uerj.br/v9n3/artigos/html/v9n3a06.html. Acesso: 11 ago. 2021.

SATO, Mariana, et al. Palhaços: uma revisão acerca do uso dessa máscara no ambiente hospitalar. INTERFACE: COMUNICAÇÃO SAÚDE EDUCAÇÃO, v. 20, n. 56, p.123-34. 2016. Disponível em: https://www.scielo.br/j/icse/a/dvyvCQfpZCcQB8ZLVkVdLhL/?lang=pt. Acesso em: 21 ago. 2021.

I SALÃOO DE EXTENSÃO

DA UNIPAR
> UNIPAR 50 ANOS:

Transformando vides atraves da educagto

27 de Outubro de 2021 


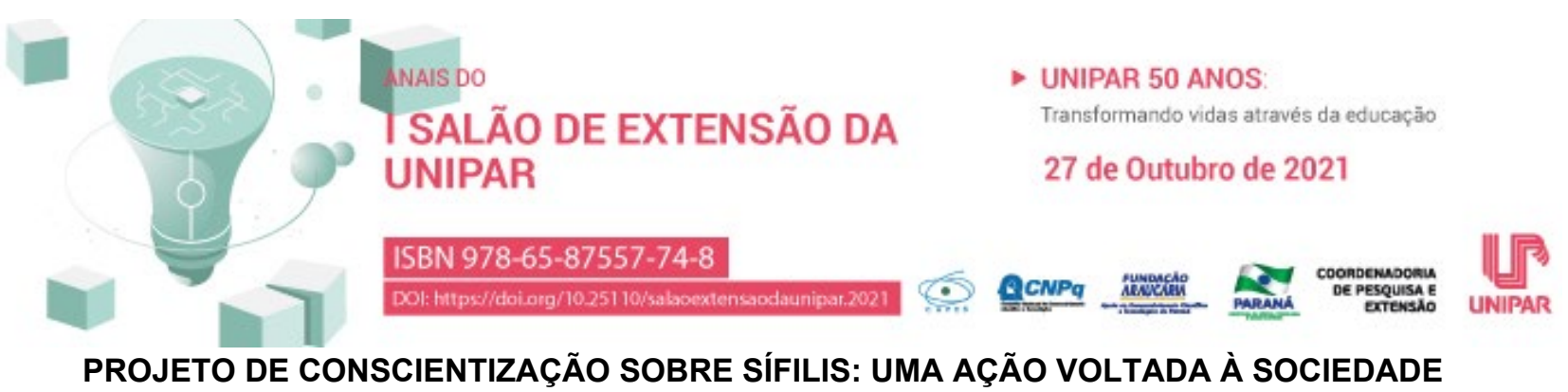

\begin{abstract}
${ }^{1}$ IZABEL PUZISKI ROSSATO, ${ }^{2}$ SABRINA SUEMY KATO TANAKA, ${ }^{3}$ THALYTA CUSTODIO, ${ }^{4}$ PAOLA LIS OCHIAL DE BARROS, ${ }^{5}$ CAUA VINICIUS RIBEIRO ALVES, ${ }^{6}$ LEANDRO MARTINS LIMA SOUZA, ${ }^{7}$ MARILIA YUKIE TAKAKI DE OLIVEIRA ALVES, ${ }^{8}$ AMANDA CAMPETTI RAIMUNDO, ${ }^{9}$ BRUNA FAVRETTO DA SILVA, ${ }^{10}$ ANA BEATRIZ SILVESTRI RIBEIRO, ${ }^{11}$ LAIS TEODORO LOPES, ${ }^{12}$ ALESSA CARONI OLIVEIRA DE SOUZA, ${ }^{13}$ MAYARA HILDA GUERINI, ${ }^{14}$ LEONARDO GARCIA VELASQUEZ
\end{abstract}

${ }^{1}$ Acadêmica do Curso de Medicina da UNIPAR/ ligante da Liga Acadêmica de Imunologia Clínica (LAIC)

${ }^{2}$ Acadêmica do Curso de Medicina da UNIPAR/ ligante da Liga Acadêmica de Imunologia Clínica (LAIC)

${ }^{3}$ Acadêmica do Curso de Medicina da UNIPAR/ ligante da Liga Acadêmica de Imunologia Clínica (LAIC)

${ }^{4}$ Acadêmica do Curso de Medicina da UNIPAR/ ligante da Liga Acadêmica de Imunologia Clínica (LAIC)

${ }^{5}$ Acadêmico do Curso de Medicina da UNIPAR/ ligante da Liga Acadêmica de Imunologia Clíncia (LAIC)

${ }^{6}$ Acadêmico do Curso de Medicina da UNIPAR/ ligante da Liga Acadêmica de Imunologia Clíncia (LAIC)

${ }^{7}$ Acadêmica do Curso de Medicina da UNIPAR/ ligante da Liga Acadêmica de Imunologia Clínica (LAIC)

${ }^{8}$ Acadêmica do Curso de Medicina da UNIPAR/ ligante da Liga Acadêmica de Imunologia Clínica (LAIC)

${ }^{9}$ Acadêmica do Curso de Medicina da UNIPAR/ ligante da Liga Acadêmica de Imunologia Clínica (LAIC)

${ }^{10}$ Acadêmica do Curso de Medicina da UNIPAR/ ligante da Liga Acadêmica de Imunologia Clínica (LAIC)

${ }^{11}$ Acadêmica do Curso de Medicina da UNIPAR/ ligante da Liga Acadêmica de Imunologia Clínica (LAIC)

${ }^{12}$ Acadêmica do Curso de Medicina da UNIPAR/ ligante da Liga Acadêmica de Imunologia Clínica (LAIC)

${ }^{13}$ Acadêmica do Curso de Medicina da UNIPAR/ ligante da Liga Acadêmica de Imunologia Clínica (LAIC)

${ }^{14}$ Docente do Curso de medicina da UNIPAR/ preceptor da Liga Acadêmica de Imunologia Clínica (LAIC)

Introdução: A sífilis é causada pelo agente etiológico Treponema pallidum, que é uma bactéria gram-negativa, que se apresenta em três fases: primária, secundária e terciária (FREITAS et al., 2020). Ela é trasmitida por meio de relações sexuais desprotegidas, uso compartilhado de materias perfuros cortantes e por transmissão vertical, ou seja, da mãe para o feto durante a gestação. (AVELLEIRA; BOTTINO, 2016). De acordo com a Secretaria de Vigilância em Saúde (2020), a taxa de incidência da forma congênita teve seu ápice no ano de 2018, com 9,0 casos por mil nascidos vivos, regredindo para 8,2 casos por mil nascidos vivos em 2019. Já a taxa de detecção de sífilis em gestantes foi de 21,5 casos por mil nascidos vivos em 2018, e em 2019 caiu para 20,8 por mil nascidos vivos. A adquirida, teve sua taxa de detecção aumentada de 34,1 casos por 100.000 habitantes em 2015 para 72,8 casos por 100.000 habitantes em 2019.

Objetivo: Realizar uma ação de conscientização voltada à sociedade sobre a sífilis, sua transmissão, prevenção e diagnóstico.

Resultados: A realização de projetos voltados à orientação da comunidade é fundamental para que doenças como a sífilis possam ser menos prevalentes. Ações como a que foi realizada no projeto, permitem evidenciar que a população necessita de informações acerca de doenças com a sífilis, como por exemplo nas formas de prevenção delas. Nesse contexto chama-se a atenção para o uso de preservativos, o que ainda é uma prática que apresenta certa resistência por parte da popuação. Assim, ações como esta impactam positivamente na queda dos casos de doenças como a síflis e outras infecções sexualmente transmissíveis.

Conclusão: A partir do exposto e estudado na preparação do projeto percebemos que ainda há problemas na conscientização e na adesão das medidas de prevenção. Dessa forma reforça-se a necessidade de ações que ofereçam informações a respeito do assunto para a população, principalmente quanto às formas de transmissão e proteção, na forma de educação em saúde.

\title{
Referências
}

AVELLEIRA, J. C. R.; BOTTINO, G. Sífilis: diagnóstico, tratamento e controle. Educação Médica Continuada. An. Bras Dermatol. v.81.p.111-26, 2006. Acesso em: 24 de agosto de 2021.

BRASIL. Ministério da saúde. Boletim epidemiológico de Sífilis, 2020. Disponível em>https://www.gov.br/saude/ptbr/assuntos/media/pdf/2020/outubro/29/BoletimSfilis2020especial.pdf

FREITAS, F. L. S. et al. Protocolo brasileiro para infecções sexualmente transmissíveis 2020: acquired syphilis. Consenso. Epidemiol. Serv. 2021. Acesso em: 24 de agosto de 2021. 
- unIPAR 50 anos:

I SALAOO DE EXTENSÃO Transformando vidas atravies da educaģso

DA UNIPAR 


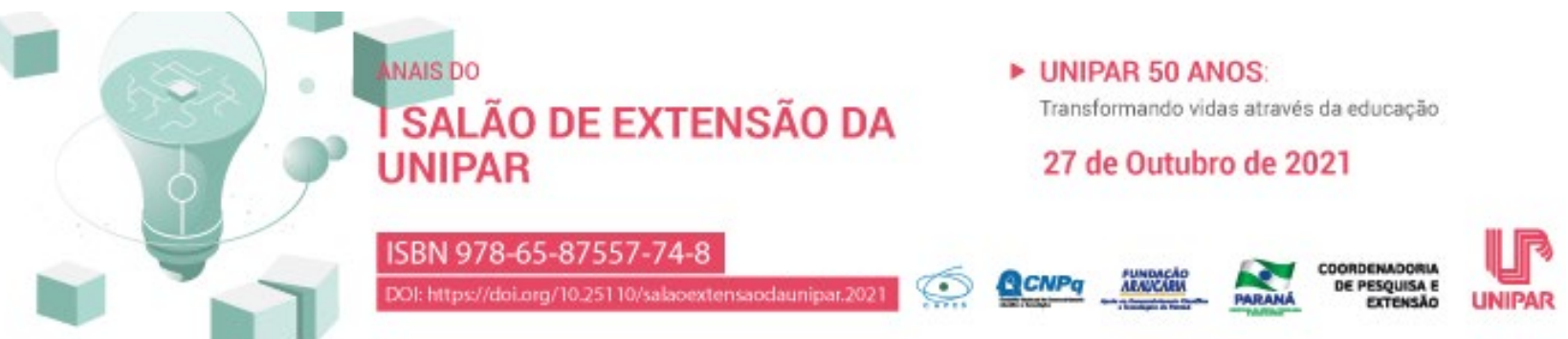 \\ COVID-19 E DISFUNÇÕES CUTÂNEAS: UM RELATO DE EXPERIÊNCIA
}

\author{
${ }^{1}$ PAMELA SZESKOSKI, ${ }^{2}$ KELLI KUHNEN, ${ }^{3}$ BRUNA ALVES SOBRINHO, ${ }^{4}$ POLLIANA BORGES DE ANDRADE, ${ }^{5}$ MAYNI \\ TRENTIN, ${ }^{6}$ MAYNI TRENTIN, ${ }^{7}$ JULIANA PELISSARI MARCHI
}

\begin{abstract}
${ }^{1}$ Acadêmica participante do Programa Institucional Centro de Estética e Cosmética Escola, do C.S.T. em Estética e Cosmética da UNIPAR.

${ }^{2}$ Responsável Técnica do Centro de Estética Escola do C.S.T. em Estética e Cosmética da Universidade Paranaense, UNIPAR.

${ }^{3}$ Acadêmica participante do Programa Institucional Centro de Estética e Cosmética Escola, do C.S.T. em Estética e Cosmética da UNIPAR.

${ }^{4}$ Acadêmica participante do Programa Institucional Centro de Estética e Cosmética Escola, do C.S.T. em Estética e Cosmética da UNIPAR.

${ }^{5}$ Acadêmica participante do Programa Institucional Centro de Estética e Cosmética Escola, do C.S.T. em Estética e Cosmética da UNIPAR.

${ }^{6}$ Acadêmica participante do Programa Institucional Centro de Estética e Cosmética Escola, do C.S.T. em Estética e Cosmética da UNIPAR.

${ }^{7}$ Docente do C.S.T. em Estética e Cosmética da Universidade Paranaense, UNIPAR, Unidade de Francisco Beltrão.
\end{abstract}

Introdução: Com as atividades práticas do projeto percebemos um grande número de disfunções cutâneas, ao avaliá-las e confrontá-las à literatura, averiguamos que há mais de 2000 artigos científicos citando dermatologia e COVID-19. As disfunções cutâneas estão relacionadas ao estresse e a ansiedade desse período, e também, como efeito secundário da COVID19 e dos tratamentos (SBD, 2021). Para tanto, a pesquisa foi base para a elaboração de uma cartilha informativa Alterações de pele pós COVID-19 , que está sendo divulgada para profissionais da saúde e para a população.

Objetivo: Relatar a experiência de atividades desenvolvidas no Programa Institucional Centro de Estética e Cosmética Escola da UNIPAR.

Resultados: Os atendimentos nos permitiram aperfeiçoar a prática, visualizar disfunções cutâneas e indagar sobre a necessidade de novas pesquisas para melhor atender à população, fortalecendo, inclusive, os relacionamentos humanos e a empatia. Ainda nos exigiu aptidão para agir em situações inesperadas, estimulando-nos a ter ideias e a apresentar soluções rápidas. A cartilha nos mostrou que a pesquisa deve estar em evidência. Um exemplo disso é que a COVID-19 afeta inicialmente a parte respiratória. Como efeito secundário pode comprometer diversos outros sistemas, dentre eles, o cutâneo (HUANG et al, 2020; MARZANO et al, 2020). Diversas são as disfunções cutâneas encontradas em indivíduos infectados, dentre elas, destacase: Erupção Urticariforme que tem relação com agentes bacterianos e virais (IMBALZANO et al, 2016). Erupções Eritematosas, Maculopapulares e Morbiliformes afetam tronco e membros (CASAS et al, 2020). Exantema Papulovesicular são lesões semelhantes a varicela (MARZANO et al, 2020). Padrão Acral é a segunda manifestação cutânea mais frequente, induzida por vírus ou pela anormalidade na coagulação (COLONNA et al, 2020). Padrão Livedo Reticularis/Racemosa apresenta manchas escuras, estreitas e simétricas ou anéis maiores, irregulares e assimétricos (GRIFFITHS, 2016; KARACA, 2020).

Conclusão: As atividades do projeto são extremamente importantes para o desenvolvimento acadêmico e pessoal. Ao longo dos dias e com as experiências que vivenciamos em contato com a população, percebemos a necessidade de atualização acerca de temas novos, que carecem grandemente de informações e estudos, representando uma falha em termos de possibilidades de diagnósticos e tratamentos. Sugere-se novas pesquisas sobre as disfunções cutâneas e a COVID-19.

\section{Referências}

CASAS, C. G. et al. Classification of the cutaneous manifestations of COVID-19: a rapid prospective nationwide consensus study in Spain with 375 cases. Br J Dermatol. v. 183, n. 1, Abril, $2020 . \quad$ Disponível em: https://www.ncbi.nlm.nih.gov/pmc/articles/PMC7801998/. Acesso em: 16 ago. 2021.

COLONNA, Cristiana. et al. Surto de lesões acrais semelhantes a frieiras em crianças na área metropolitana de Milão, Itália, durante a pandemia de COVID-19. Jornal da Academia Americana de Dermatologia, v. 83, n. 3, 2020. Disponível em: https://www.ncbi.nlm.nih.gov/pmc/articles/PMC7801998/. Acesso em: 16 ago. 2021.

GRIFFITHS, Christopher et al. (Ed.). Livro didático de dermatologia de Rook . John Wiley \& Sons. 9 Ed. Reino Unido: WileyBlackwell, 2016, 4992 pp.

HUANG, Chaolin et al. Características clínicas de pacientes infectados com novo coronavírus de 2019 em Wuhan, China. A 
lanceta , v. 395, n. 10223, 2020. Disponível em: https://www.ncbi.nlm.nih.gov/pmc/articles/PMC7801998/. Acesso em: 16 ago. 2021.

IMBALZANO, Egídio et al. Associação entre urticária e infecções por vírus: uma revisão sistemática. In: Allergy Asthma Proc. v. 37, n. 1, 2016. Disponível em: https://www.ncbi.nlm.nih.gov/pmc/articles/PMC7801998/. Acesso em: 16 ago. 2021.

KARACA, Zeynep; YAYLI, Savaş; ÇALIŞKAN, Okan. Erupção cutânea purpúrica unilateral em paciente com infecção por COVID - 19. Terapia dermatológica, v. 33, n. 4, 2020. Disponível em: https://www.ncbi.nlm.nih.gov/pmc/articles/PMC7801998/. Acesso em: 16 ago. 2021.

MARZANO, Angelo Valerio et al. Manifestações cutâneas em pacientes com COVID - 19: uma revisão preliminar de um problema emergente. British Journal of Dermatology, v. 183, n. 3, 2020. Disponível em: https://www.ncbi.nlm.nih.gov/pmc/articles/PMC7801998/. Acesso em: 16 ago. 2021.

SBD - SOCIEDADE BRASILEIRA DE DERMATOLOGIA. Nota Técnica SBD. MANIFESTAÇÕES CUTÂNEAS ASSOCIADAS À COVID-19 CONFORME LITERATURA PUBLICADA ATÉ 30/04/21. 2021. Disponível em: https://www.sbd.org.br/mm/cms/2021/05/27/nota-tecnicasbd.pdf. 10 p. Acesso em: 29 jul 2021.

I SALÄ́O DE EXTENSÃOO

DA UNIPAR
- UniPAR 50 anOs:

Traneformento videa atrewta da educageto

27 de Outubro de 2021

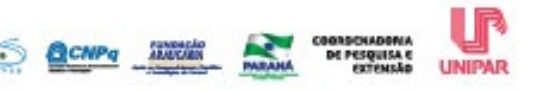




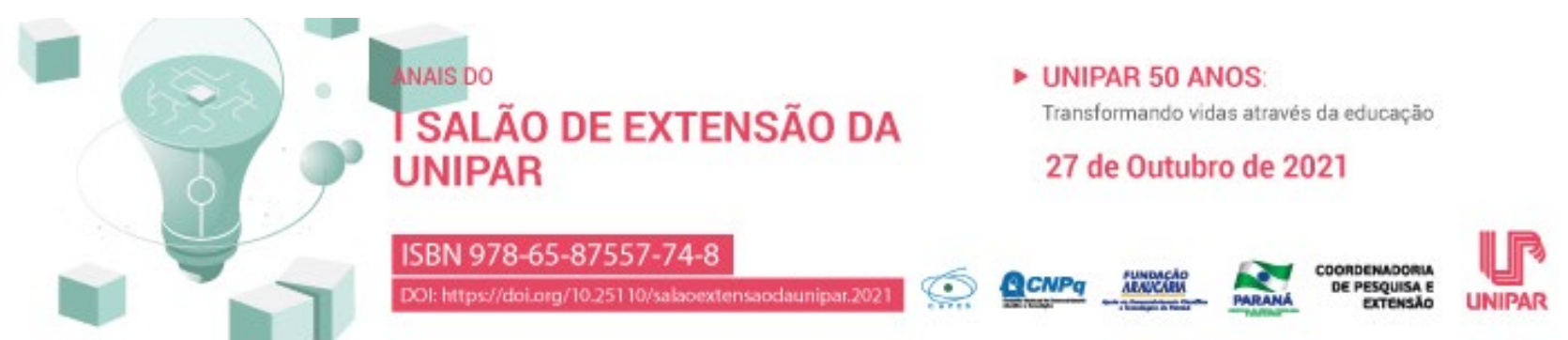

ABORDAGEM INICIAL A PACIENTES QUEIMADOS

\author{
${ }^{1}$ LUMA MAZIERI, ${ }^{2}$ FERNANDA ANDRADE FORMIGHIERI, ${ }^{3}$ CAMILA MORENO GIAROLA, ${ }^{4}$ THIAGO AUGUSTO RIBEIRO IRIA
}

\begin{abstract}
${ }^{1}$ Discente do curso de Medicina da Universidade Paranaense
${ }^{2}$ Discente do curso de Medicina da Universidade Paranaense

${ }^{3}$ Discente do curso de Medicina da Universidade Paranaense

${ }^{4}$ Docente do curso de medicina da UNIPAR
\end{abstract}

Introdução: As queimaduras caracterizam-se por lesões cutâneas ocasionadas pela ação direta ou indireta de traumas térmico, elétrico, químico ou radioativo, que vão resultar em efeitos físicos nas camadas da epiderme e derme. Mesmo com o progresso da medicina no tratamento de queimados, as taxas de mortalidade ainda são elevadas devido às complicações que elas causam, como infecções, sepse e desnutrição. Quanto à classificação, são avaliadas de acordo com a profundidade que alcançam. As de primeiro grau afetam somente a epiderme e apresentam vermelhidão, dor, edema e descamação em 4 a 6 dias, porém não formam bolhas. Já as de segundo grau atingem a epiderme e parte da derme, evoluindo para bolhas ou flictenas. As de terceiro grau afetam a epiderme, derme e estruturas profundas e possuem textura coriácea, juntamente com uma placa esbranquiçada ou enegrecida (MOORE et al., 2009).

Objetivo: delimitar a abordagem a pacientes queimados.

Desenvolvimento: A reabilitação de queimaduras difere-se de acordo com o tipo, se iniciando movendo a vítima para uma área de segurança, e em seguida, protegendo a coluna cervical e garantindo a permeabilidade das vias respiratórias, conferindo o ABCD do trauma. Para Mélega (2011), a reposição volêmica mantém o paciente hidratado e com uma boa diurese, utilizando cristaloides. O cálculo é feito nas primeiras 24 horas e deve-se ministrar $4 \mathrm{~mL} / \mathrm{kg} / \%$ de área queimada com solução de Ringer com lactato, sendo os primeiros $50 \%$ nas primeiras 8 horas e o restante nas próximas 16 horas subsequentes. O débito urinário deve ser mantido em 0,5-1,0 mL/kg/h no adulto (PIERINI \& ASSUNÇÃO, 2014). Em caso de lesões de vias respiratórias, realiza a dosagem de carboxi-hemoglobina, gasometria arterial e raio $X$ de tórax. A broncoscopia pode ser realizada, e a intubação do paciente é feita se necessário, seguindo o conceito de que há alto risco de obstrução das vias respiratórias de 24 a 36 horas após a queimadura. A cabeceira deve estar elevada a $30^{\circ}-45^{\circ}$ para diminuir o edema de vias respiratórias e a pressão abdominal sobre o diafragma. (MÉLEGA, 2011). Para o controle da dor, não há esquema analgésico único. Em queimaduras leves a moderadas, recomenda-se inicialmente mergulhar a área em água fria, reduzindo a formação de edema, pode ser útil medicações como paracetamol e dipirona, por via oral, deve-se evitar a aspirina pelo seu efeito anticoagulante. Associar o uso de drogas ansiolíticas é de grande valia em casos de pacientes emocionalmente abalados, estes ajudaram a melhorar a tolerância à dor, usualmente associa-se o midazolam, por via sublingual ou intranasal (MÉLEGA, 2011). Em grandes queimados, usa-se opiáceos. As opções de medicamentos são: morfina; tramadol, tem menor efeito de depressão respiratória; metadona. Após a fase aguda, a dor pode ser regulada com o uso de fentanil transdérmico, codeína oral, antidepressivos, anti-histamínicos e sedativos (MÉLEGA, 2011). De acordo com Mélega, a área queimada se torna um local propício a infecções. O local acometido permanece estéril por pouco tempo, sendo colonizado por bactérias horas após a lesão. A antibioticoterapia profilática não previne a infecção, não devendo ser realizada. Os antibióticos devem ser administrados na primeira hora após a suspeita de infecção na queimadura ou sinais clínicos (hipertermia, hipotermia, agitação, distensão abdominal, taquipneia, taquicardia, diarreia, oligúria, retenção de líquidos, modificação do aspecto da lesão). A antibioticoterapia empírica deve ser realizada imediatamente após coleta de exames diagnósticos (MÉLEGA, 2011). O suporte nutricional é de extrema importância, considerando o fato que o queimado grave apresenta hipermetabolismo (SALES \& NUNES, 2015). Deve ser iniciada nas primeiras 6 horas, por via oral ou através de sonda. A fórmula de Curreri ( $25 \mathrm{kcal} \times \mathrm{P}(\mathrm{kg})+40 \mathrm{kcal} \times \mathrm{SCQ})$ é utilizada para a sapiência da quantidade ideal de calorias para a vítima. A nutrição deve incluir substratos tróficos para o intestino (glutamina e fibras) e proteínas (MÉLEGA, 2011). Ao exame diário do paciente queimado, é utilizado o checklist FAST HUG: I"Fl" refere a feeding, analisando a nutrição; ।"Al" é analgesis, controlando a dor; ।"SI" de sedação, minimizando o estresse; ।"TI" analisa o tromboembolismo, que apresenta risco aumentado após queimadura; ।"H।" de head, devendo manter a cabeceira elevada; ।"U।" de úlceras gástricas; e I"GI" referente a glicemia (WAINWRIGHT, 2009).

Conclusão: Todos os cuidados estabelecidos têm por finalidade diminuir os riscos de complicações e sequelas, ajudando na melhora do doente. Além disso, foi possível compreender a necessidade de assistência adequada e contínua, e como isso pode contribuir efetivamente no processo de cura e reabilitação do paciente. A vítima de queimadura precisa de uma unidade hospitalar com atendimento especializado e equipe multidisciplinar. $O$ tratamento fisioterapêutico atua também de forma complementar nas cirurgias, principalmente as enxertias, apresentando condutas importantes em todas as fases, da internação 


\section{Referências}

MOORE, M. L.; DEWEY, W. S.; RICHARD, R. L. Rehabilitation of the burned hand. Hand Clin, v. 25, n. 4, p. 529-41, 2009.

PIERINI, E.; ASSUNCÃO, F. F. O. Recursos estéticos aplicados ao tratamento das queimaduras: revisão de literatura. MTP \& RehabJournal, n. 12, p. 218-233, 2014.

SALES, M. S. C.; NUNES, R. D. Abordagem fisioterapêutica em queimados: um estudo revisão no âmbito da terapia intensiva. Revista Amazônica Science \& Health, v. 3, n. 2, p. 30-35, 2015.

MÉLEGA, J. M.; VITERBO, F.; MENDES, F. H. Cirurgia plástica: os princípios e a atualidade. 1ed. Rio de Janeiro: Guanabara Koogan, 2011.

WAINWRIGHT, D. J. Burn reconstruction: the problems, the techniques, and the applications. Clin Plast Surg, v. 36, n. 4, p. 687700, 2009.

\section{SALĀO DE EXTENSÃO}

DA UNIPAR
- UNIPAR 50 ANOS:

Traneformando vides atravea da educaces

27 de Outubro de 2021

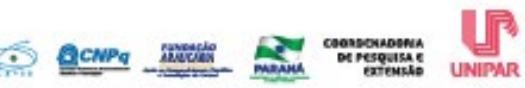




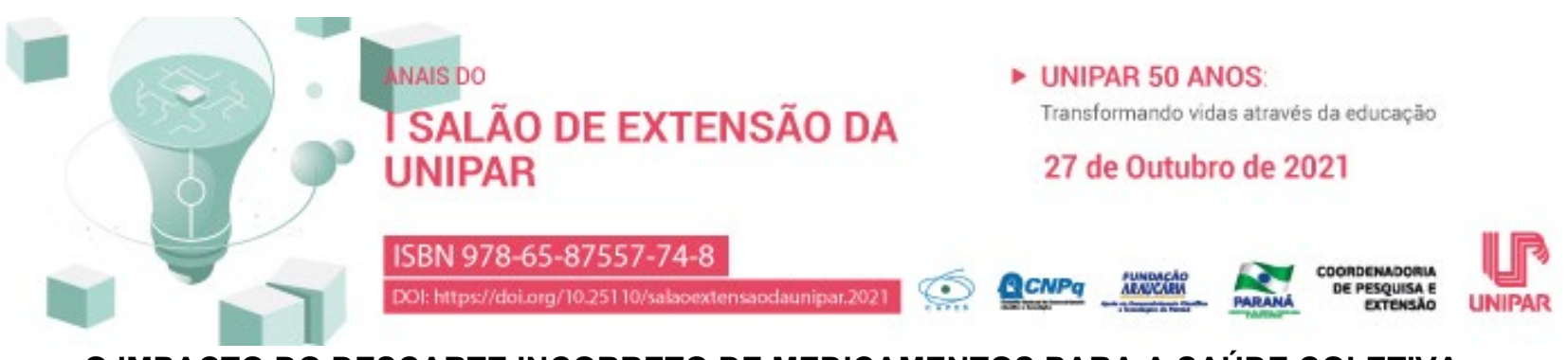 \\ O IMPACTO DO DESCARTE INCORRETO DE MEDICAMENTOS PARA A SAÚDE COLETIVA
}

\author{
${ }^{1}$ NATALIA NAMIE MIZUGUCHI, ${ }^{2}$ PAULA MONTANHINI FAVETTA, ${ }^{3}$ WESLEY ALVES TRINDADE, ${ }^{4}$ ANDREIA ASSUNCAO \\ SOARES
}

${ }^{1}$ Discente do curso de Enfermagem PIBIC e PEX/UNIPAR

${ }^{2}$ Discente Doutoranda no PPG em Ciência Animal com Ênfase em Produtos Bioativos da UNIPAR - Bolsista PROSUP- CAPES

${ }^{3}$ Discente Doutorando no PPG em Ciência Animal com Ênfase em Produtos Bioativos, Taxista PROSUP- CAPES/UNIPAR

${ }^{4}$ Docente da UNIPAR

Introdução: O Brasil é o sétimo país que mais consome medicamentos no mundo, e pode chegar a quinta posição até 2023 (INTERFARMA, 2020). E o descarte de medicamentos causa preocupação relacionada à poluição na água e solo, e seus potenciais efeitos adversos para a saúde humana e para o meio ambiente (JOÃO, 2011). Nesse cenário, a logística reversa é um instrumento que tem como objetivo o retorno do produto para a indústria para ser descartado corretamente ou reutilizado (MUELLER, 2005).

Objetivo: Relatar o impacto do descarte incorreto de medicamentos para a saúde coletiva

Resultados: A dispensação de medicamentos em maior quantidade do que o tratamento, a distribuição de amostras-gratis e o gerenciamento inadequado são alguns dos fatores que causam a sobra de medicamentos (JOÃO, 2011) e tem como consequência, a maior produção de resíduos sólidos, aumento de descarte incorreto, o uso sem necessidade ou sem indicação, falta de efetividade do tratamento, reações adversas, a contaminação e intoxicação para a população e para o meio ambiente. (ROSA et al., 2021; PIVETA et al., 2015 ). Sendo as principais vias de descarte de medicamentos em desuso ou vencidos, o lixo comum, o vaso sanitário ou a pia (esgoto) (VAZ, FREITAS, CIRQUEIRA, 2011; SILVA et al., 2014). As fórmulas tem alguns componentes que são prejudiciais, já que não deterioram com o passar do tempo podendo assim contaminar a superfície terrestre e a água (ROSA et al., 2021). Isso ocorre, devido a falta de conhecimento da população sobre o assunto e a falta de postos de coleta de medicamentos (KALINKE, JUNIOR, 2014). Com isso, é importante ressaltar que a efetivação de um sistema de gerenciamento de resíduos contribui diretamente para a redução de riscos à saúde e ao meio ambiente (SILVA et al., 2014).

Conclusão: $O$ descarte incorreto de medicamentos causam diversos impactos negativos para a saúde coletiva e para o meio ambiente. Desse modo, é fundamental a conscientização da população sobre a correta destinação final de medicamentos e as suas consequências, a implantação de uma estratégia com o objetivo de minimizar o acúmulo de fármacos nas residências, e a realização do sistema de logística reversa, que regulamentam o descarte de modo que os estabelecimentos que vendem, também aceitem a devolução de unidades usadas, vencidas ou em desuso.

\section{Referências}

INTERFARMA. Guia 2020. Disponível em: Acesso: 22 jul. 2021.

JOÃO, W. D. S. J. Descarte de medicamentos. Pharmacia Brasileira, n. 82, p. 14-16, 2011. Disponível em: . Acesso: 23 jul. 2021.

KALINKE, A. C.; MARTINS JUNIOR, L. Descarte de medicamentos: situação atual, impactos e conhecimento da população. Revista Saúde e Pesquisa, v. 7, n. 3, p. 525-530, 2014. Disponível em: . Acesso: 23 jul. 2021.

MUELLER, C. F. Logística Reversa Meio-ambiente e Produtividade. Grupo de Estudos Logísticos, Universidade Federal de Santa Catarina, v. 7, n. 3, p. 1 - 6, 2005. Disponivel em: Acesso: 25 jul. 2021.

PIVETA, L. N. et al. Armazenamento e descarte de medicamentos por acadêmicos da área da saúde de uma universidade pública paranaense. Semina: Ciências Biológicas e da Saúde, v. 36, n. 1, p. 55-66, 2015. Disponível em: . Acesso: 23 jul. 2021.

ROSA, P. D. S. R et al. Descarte de medicamentos de forma correta: proposta de material de divulgação. Revista Saúde em Foco, v.13, p. 2-8, 2021. Disponível em: . Acesso: 23 jul. 2021.

SILVA, A. L. E. et al. Posicionamento das farmácias e a logística reversa no controle dos medicamentos em desuso. Santa Cruz do Sul: Revista Eletrônica em Gestão, Educação e Tecnologia Ambiental REGET, v. 18, n.1, p. 1-9, 2014 Disponível em: Acesso: 22 jul. 2021.

VAZ, K. V.; FREITAS, M. M.; CIRQUIERA, J. Z. Investigação sobre a forma de descarte de medicamentos vencidos. Cenarium

Pharmacêutico, n. 4, p. 3-27, 2011. Disponível em: . Acesso: 23 jul. 2021. 
- unIPAR 50 anos:

I SALAOO DE EXTENSÃO Transformando vidas atravies da educaģso

DA UNIPAR 


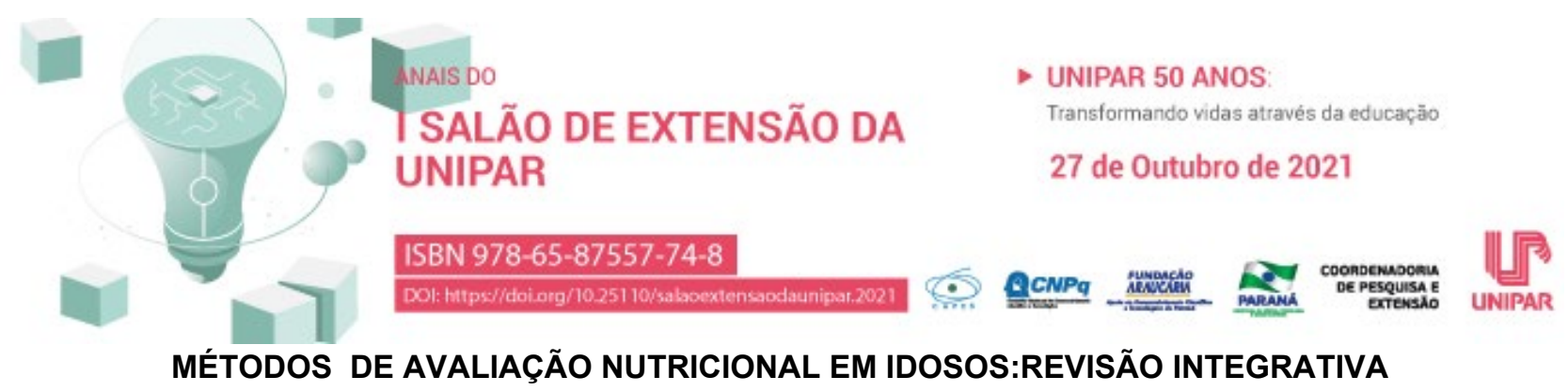

\section{${ }^{1}$ MAIARA CRISTINA SCHREINER, ${ }^{2}$ INDIOMARA BARATTO}

${ }^{1}$ Acadêmica do Curso de Nutrição da Unipar

${ }^{2}$ Docente da UNIPAR

Introdução: Bem-estar nutricional é um componente da saúde e da qualidade de vida e da independência de idosos. Estima-se que aproximadamente $75 \%$ dos idosos no mundo apresentam uma ou mais doenças que poderiam ser prevenidas ou controladas com alimentação adequada, que pelo menos $50 \%$ apresentam problemas de saúde que exigem intervenção nutricional e em torno de 20 a $40 \%$ estão em risco nutricional. A identificação da condição nutricional desse grupo pode ser uma alternativa para mudanças nesse cenário epidemiológico (ROEDIGER et al., 2019).

Objetivo: Realizar uma revisão integrativa sobre a importância da avaliação física e nutricional de pessoas a partir de 60 anos de idade.

Desenvolvimento: Segundo Tavares et al. (2015), entre os problemas de saúde pública no país atualmente, a maioria está relacionada com o estado nutricional. Há uma crescente demanda de saúde atrelada à dupla carga de doenças - doenças não transmissíveis como obesidade, diabetes e doenças coronarianas; e fome/desnutrição e anemia. Esse cenário díspar e complexo está relacionado com outra particularidade: o envelhecimento populacional. Dentro deste contexto, a avaliação nutricional em idosos é fundamental para detectar a necessidade de uma intervenção dietética, a fim de prevenir a presença de comorbidades, que interferem no bem-estar e na expectativa e qualidade de vida destes indivíduos com idade avançada (CARDOZO et al., 2017). Cabe ressaltar que o envelhecimento populacional é uma realidade nos países em desenvolvimento, o que traz grandes desafios para a sociedade e especialmente para o setor saúde. No Brasil, esse processo é acelerado e se dá de maneira desigual entre as diferentes regiões do país. Dessa forma, torna-se premente o desenvolvimento de ações intersetoriais articuladas de assistência e estímulo à inserção social de idosos para a promoção de envelhecimento ativo (TAVARES et al., 2015). Na velhice, ocorrem alterações fisiológicas nos ossos, nas articulações, nos músculos e nos sistemas respiratório, cardíaco e digestório que comprometem o condionamento físico e a composição corporal dos idosos. Somadas a fatores de risco como tabagismo, sedentarismo, alcoolismo e maus hábitos alimentares, podem levar ao aparecimento das doenças crônicas, à complicações nas atividades de vida diárias, ao aumento das quedas e à sarcopenia na população idosa (FERREIRA; SILVA; PAIVA, 2020).

Considerações Finais: Diante do que foi exposto, constata-se que a avaliação nutricional em idosos é fundamental para o combate a doenças físicas e mentais, assim como para a promoção do bem-estar e da qualidade de vida desta população.

\section{Referências}

CARDOZO, Natalia Rodrigues et al. Estado nutricional de idosos atendidos por unidades de saúde da família na cidade de Pelotas-RS. 2017. Disponível em: http://www.braspen.com.br/home/wp-content/uploads/2017/04/16-AO-Estado-nutricional-deidosos.pdf. Acesso em: 11 jun. 2021.

FERREIRA, Laura Fernandes; SILVA, Cátria Milena; PAIVA, Aline Cardoso de. Importância da avaliação do estado nutricional de idosos. Braz. J. Hea. Rev., Curitiba, v. 3, n. 5, p. 14712-14720, set/out. 2020 . Disponível em: https://www.brazilianjournals.com/index.php/BJHR/article/view/18506/14905. Acesso em: 10 jun. 2021.

ROEDIGER, Manuela de Almeida et al. Revisão sistemática de métodos de triagem nutricional para idosos brasileiros domiciliados. Ciência \& Saúde Coletiva, v. 24, n.6, pp. 2307-2316, 2019. Disponível em: https://www.scielosp.org/pdf/csc/2019.v24n6/2307-2316/pt. Acessível em: 09 jun. 2021.

TAVARES, Elda Lima et al. Avaliação nutricional de idosos: desafios da atualidade. Rev. Bras. Geriatr. Gerontol., Rio de Janeiro, v. 18, n. 3, pp. 643-650, 2015. Disponível em: https://www.scielo.br/j/rbgg/a/gs9jQ8cX3QbDvPGZPZPK9Fb/? lang=pt\&format=pdf. Acesso em: 09 jun. 2021.

\section{SALĂOO DE EXTENSÃO} DA UNIPAR

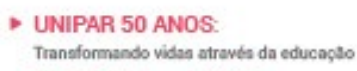

27 de Outubro de 2021

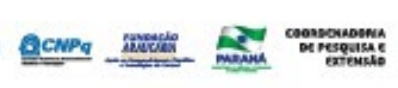

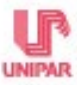




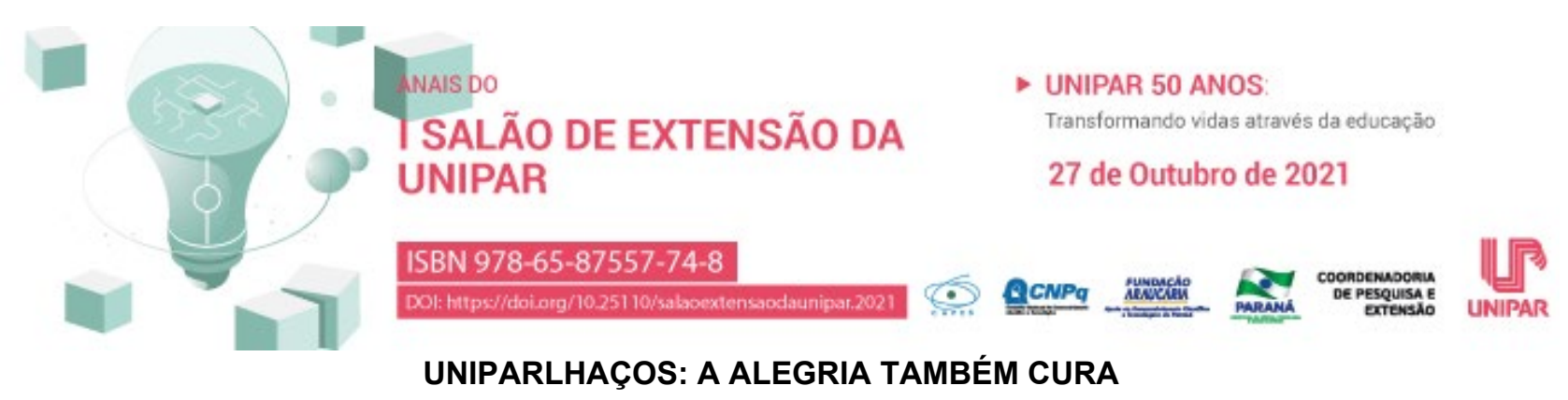

\begin{abstract}
${ }^{1}$ MAYCON JORGE BRANDOLIM, ${ }^{2}$ MAURICIO SPRICIGO, ${ }^{3}$ SILVANO FARIAS DIAS JUNIOR, ${ }^{4}$ JULIA BEATRIZ PINTO ARAUJO, 5 JOAO THOMAZ TERRA PRADO BORGES, ${ }^{6}$ MARCOS CARRILLO GARCIA NETO, 7 VICTOR SOUZA DACROCE, ${ }^{8}$ MARIANE RODRIGUES TEZA, ${ }^{9}$ RAISA LENHANI, ${ }^{10}$ TANIELLY CELLI JULIAO, ${ }^{11}$ THALYTA CUSTODIO, ${ }^{12}$ ISABELA CARVALHO LOPES, ${ }^{13}$ LORENA DE FATIMA MORETTO, ${ }^{14}$ MILENA DE SOUZA HELLER, ${ }^{15}$ CARLOS EMANUEL LOBATO, ${ }^{16}$ ELIZABETI DE MATOS MASSAMBANI
\end{abstract}

\footnotetext{
${ }^{1}$ Acadêmico PIC/Unipar - Umuarama

${ }^{2}$ Acadêmico do Curso de Medicina da UNIPAR

${ }^{3}$ Acadêmico do Curso de Medicina da UNIPAR

${ }^{4}$ Acadêmica do Curso de Medicina da UNIPAR

${ }^{5}$ Acadêmico do Curso de Medicina da UNIPAR

${ }^{6}$ Acadêmico do Curso de Medicina da UNIPAR

${ }^{7}$ Acadêmico do Curso de Medicina da UNIPAR

${ }^{8}$ Acadêmica do Curso de Medicina da UNIPAR

${ }^{9}$ Acadêmica do Curso de Medicina da UNIPAR

${ }^{10}$ Acadêmica do Curso de Medicina da UNIPAR

${ }^{11}$ Acadêmica do Curso de Medicina da UNIPAR

${ }^{12}$ Acadêmica do Curso de Medicina da UNIPAR

${ }^{13}$ Acadêmica do Curso de Medicina da UNIPAR

${ }^{14}$ Acadêmica do Curso de Medicina da UNIPAR

${ }^{15}$ Acadêmico do Curso de Medicina da UNIPAR

${ }^{16}$ Docente da UNIPAR - Umuarama
}

Introdução: O ambiente hospitalar é paradoxal, porque ao mesmo tempo em que é visto como um local de cura, ele carrega um estigma de dor e sofrimento (DIAS CRUZ, 2016). Uma das formas de se minimizar esta situação é inserir a figura do palhaçodoutor dentro do ambiente hospitalar como paródia do médico para deixar as fragilidades dos pacientes mais leves, fazendo com que de maneira lúdica o ambiente hospitalar se torne menos hostil e promova o bem-estar (CAVALCANTE, GUIMARÃES, 2009). Este trabalho realizado no mundo todo tem uma proporção muito grande, mostra que o palhaço, elemento humanizante das relações, tem suas origens fincadas na ingenuidade e na pureza. Ele coloca à disposição do paciente o prazer de rir, amplia sua perspectiva de vida, Ihe mostra outras possibilidades do processo de sentir-se bem, podendo influenciar positivamente no tratamento de pacientes hospitalizados. UNIPARLHAÇOS é um projeto de extensão com caráter multidisciplinar e conta com a participação de 30 acadêmicos que passaram por duas etapas de seleção e por oficinas e atividades para treinamento. Em duplas ou trios, realizarão visitas quinzenalmente aos hospitais, e futuramente a outras entidades da comunidade de Umuarama, previamente agendados, desenvolvendo atividades como música, malabarismos, leitura de histórias, truques de mágica a depender da faixa etária do paciente, procurando sempre deixar mensagens de conforto, esperança e alegria ao internado. Este projeto está fundamentado no respeito e na valorização à pessoa e oportuniza ao acadêmico se aproximar do paciente sem a obrigação de desempenhar o papel de profissional, e além de construir conhecimento e interação da Universidade com a sociedade, ele será sensibilizado para a importância do exercício da cidadania.

Objetivo: Proporcionar o cuidado integral em saúde ao paciente internado, transformando a doença ou limitação do mesmo através de atividades lúdicas realizadas pelos palhaços-doutores.

Resultados: Este projeto é jovem, e como resultados já foram realizadas as fases de treinamentos dos acadêmicos participantes com oficinas ministradas por um palhaço profissional na área hospitalar para desenvolverem as técnicas da arte da palhaçaria para ambientes de saúde. E como apresentação piloto foi realizada uma visita a APAE de Umuarama em data alusiva à Semana Nacional da Pessoa com Deficiência Intelectual e Múltipla. As visitas aos ambientes hospitalares já estão sendo viabilizadas.

Conclusão: As atividades e recursos utilizados trarão benefícios ao paciente e aos acadêmicos participantes, pois a alegria pode ser uma forma de abordagem e de humanização das relações entre paciente e profissional, onde toda visita será uma 
experiência nova e estarão praticando e desenvolvendo o ato de confortar, alegrar, acolher melhor e principalmente dar esperança aos pacientes.

\section{Referências}

CAVALCANTE, Tereza Cristina; GUIMARÃES, Tathiane Barbosa. Interações entre voluntários e usuários em onco-hematologia um estudo sobre os palhaços-doutores .

Revispsi. 2009.

Disponível

em: http://www.revispsi.uerj.br/v9n3/artigos/html/v9n3a06.html. Acesso em: 06 ago. 2021.

DIAS CRUZ, Daniel. A inserção do palhaço no ambiente hospitalar: experiências de um projeto de extensão. Em Extensão, v. 15, n. 1, p. 133-140, 25 jul. 2016. Disponível em: http://www.seer.ufu.br/index.php/revextensao/article/view/31110. Acesso em: 06 ago. 2021.

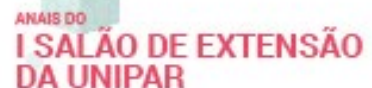

DA UNIPAR
- UNIPAR 50 ANOS:

Transformando vides atraves da educagaso

27 de Outubro de 2021

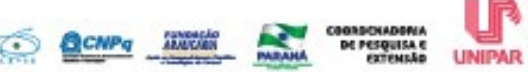




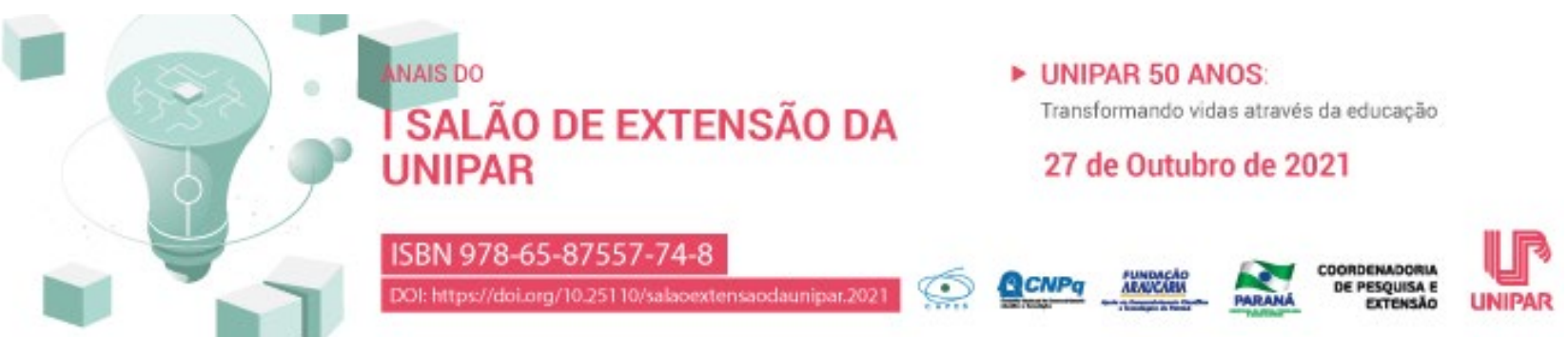 \\ MEDTALKS: PODCAST SOBRE SAÚDE COMO FORMA DE AUXILIAR A POPULAÇÃO}

${ }^{1}$ DANILLO PRECHLAK DE SOUZA, ${ }^{2}$ DAVI CORREA PEREIRA, ${ }^{3}$ GIOVANA TOLOTTI, ${ }^{4}$ GLESIE BERTULUCI MARTINS, ${ }^{5}$ KARINA DETOFOL, ${ }^{6}$ NARA RUBIA GONCALVES, ${ }^{7}$ MARINA CHAVES ORBEN, ${ }^{8}$ PAULA MOSCOVITS QUEIROZ, ${ }^{9}$ VIDA PASCHOAL, ${ }^{10}$ BRUNO GUILHERME DE CASTRO OLIVEIRA, ${ }^{11}$ FERNANDO CEZAR CARDOSO MAIA FILHO, ${ }^{12}$ RAPHAEL CHALBAUD BISCAIA HARTMANN

\footnotetext{
${ }^{1}$ Acadêmico do curso de Medicina da UNIPAR e membro do projeto de extensão MedTalks

${ }^{2}$ Acadêmico do curso de Medicina da UNIPAR e membro do projeto de extensão MedTalks

${ }^{3}$ Acadêmica do Curso de Medicina da UNIPAR e membro do projeto de extensão MedTalks

${ }^{4}$ Acadêmica do Curso de Medicina da UNIPAR e membro do projeto de extensão MedTalks

${ }^{5}$ Acadêmica do Curso de Medicina da UNIPAR e membro do projeto de extensão MedTalks

${ }^{6}$ Acadêmica do Curso de Medicina da UNIPAR e membro do projeto de extensão MedTalks

${ }^{7}$ Acadêmica do Curso de Medicina da UNIPAR e membro do projeto de extensão MedTalks

${ }^{8}$ Acadêmica do Curso de Medicina da UNIPAR e membro do projeto de extensão MedTalks

${ }^{9}$ Acadêmica do Curso de Medicina da UNIPAR e membro do projeto de extensão MedTalks

${ }^{10}$ Docente da UNIPAR

${ }^{11}$ Docente da UNIPAR

${ }^{12}$ Docente da UNIPAR
}

Introdução: Este trabalho mostra um Projeto de Extensão da Universidade Paranaense (UNIPAR), conhecido como Medtalks, que surgiu com a intenção de auxiliar a população sobre informações de saúde por meio de Podcast, que na palavra de Luiz (2014, p. 13) são programas de áudio ou vídeo que tem como particularidade a distribuição direta e atemporal de transmissão de arquivos radiofônicos on-line.

Objetivo: O objetivo deste estudo é mostrar como a Unipar por meio de seus professores e alunos de medicina difundiram informações sobre saúde através de Podcast, com a finalidade de auxiliar a população, dando ênfase à transmissão sobre hepatite.

Resultados: Cada vez mais o mundo se vê integrado a novas tecnologias e todas as áreas devem se conectar para estarem em conformidade com essas novas plataformas digitais, assim também é a área de medicina. Desse modo, a Unipar por meio do Medtalks encontrou uma forma de contribuir com a população e através de Podcast realizou transmissões sobre doenças que são do interesse da comunidade, disponíveis no Spotify. Como o mês de julho é considerado o mês da luta contra as hepatites virais, doenças causadas por cinco tipos de vírus, $A, B, C, D$ (Delta) e E, foi realizada uma gravação para informar à população sobre esta doença infectocontagiosa. Abordou-se as formas de prevenção de contágio e a importância de se realizar diagnóstico precoce. Demonstrou-se que as hepatites virais podem ser transmitidas por contaminação fecal-oral; pela relação sexual desprotegida; pelo contato com sangue contaminado; da mãe para o filho durante a gravidez (transmissão vertical); por meio de transfusão de sangue ou hemoderivados (BRASIL, 2021). Esclareceu que a hepatite infecta as células do fígado e que os sintomas, quando presentes, podem se manifestar através de cansaço, febre, mal-estar, tontura, enjoo, vômitos, dor abdominal, pele e olhos amarelados, urina escura e fezes claras (BRASIL, 2020). E que uma excelente forma de prevenção é a vacinação contra hepetite $A$ e $B$, disponibilizada pelo SUS. A transmissão deste Podcast alcançou um número de noventa e nove ouvintes, demonstrando que este novo formato de transmissão de informação é uma excelente forma de esclarecer a população sobre saúde.

Conclusão: Diante do exposto, observa-se a importância de se utilizar ferramentas digitas como meio de informar a população sobre doenças, como a hepatite, para que possa haver a prevenção do contágio, principalmente nestes tempos difíceis da pandemia.

\section{Referências}

BRASIL. Ministério da Saúde. BVSMS - Biblioteca Virtual em Saúde. Julho Amarelo: Mês de luta contra as hepatites virais. Disponível em: https://bvsms.saude.gov.br/julho-amarelo-mes-de-luta-contra-as-hepatites-virais/. Acesso: 21 ago. 2021.

BRASIL. Ministério da Saúde. Secretaria de Vigilância em Saúde. Departamento de Doenças de Condições Crônicas e Infecções Sexualmente Transmissíveis. A B C D E das hepatites virais para agentes comunitários de saúde / Ministério da Saúde, 
Secretaria de Vigilância em Saúde, Departamento de Doenças de Condições Crônicas e Infecções Sexualmente Transmissíveis. 2. ed. Brasília: Ministério da Saúde, 2020.

LUIZ, Lucio. Reflexões sobre o podcast. Rio de Janeiro: Marsupial Editora, 2014.

ANals Do " UNIPARAR 50 ANOS:

DA UNIPAR 


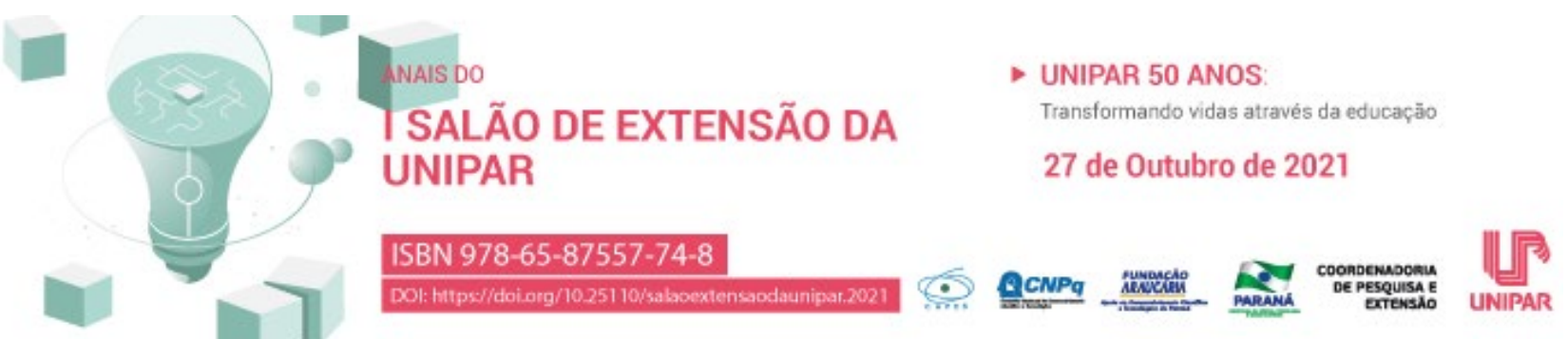

A EXTENSÃO COMO PRÁXIS NA PSICOLOGIA: PROJETO AMPLIANDO HORIZONTES

\author{
${ }^{1}$ LUANI AKEMI FURYAMA, ${ }^{2}$ ISABELA SATO ROSSI, ${ }^{3}$ FRANCIELE PICINATO CARVALHO, ${ }^{4}$ LAIS SILVERIO DE LIMA, \\ ${ }^{5}$ LAUANE VALDIVIESO, ${ }^{6}$ CLAUDIA LOPES PERPETUO
}

${ }^{1}$ Acadêmica do Curso de Psicologia da Unipar
${ }^{2}$ Acadêmica PIBEX da UNIPAR
${ }^{3}$ Acadêmica do Curso de Psicologia da UNIPAR
${ }^{4}$ Acadêmica do Curso de Psicologia da UNIPAR
${ }^{5}$ Acadêmica do Curso de Psicologia da UNIPAR
${ }^{6}$ Docente da UNIPAR

Introdução: O presente trabalho apresentará de forma breve o andamento do Projeto de Extensão nomeado: Ampliando Horizontes. Tal projeto se justifica devido a abrangência de áreas de atuação da Psicologia e do pouco conhecimento dos alunos a respeito dessas áreas. $O$ projeto de extensão tem a pretensão de produção de práxis, ou seja, proporcionar aos alunos o deslocamento de um lugar de produto para um lugar de tomada de consciência sobre suas intervenções na realidade de forma que possam ser promotoras de mudanças, segundo Vygotsky (2007) é nas relações produzidas na cultura que o indivíduo transforma e é transformado por elas. Sendo assim, pretende-se além de trazer conhecimentos sobre campos de atuações plurais, uma forma que as extensionistas também se engajem em um processo transformador, bem como, possam refletir e fazer refletir sobre uma prática psicológica crítica, social e de responsabilização. Essa prática engajada se dará com o levantamento da demanda através de um formulário sobre as áreas que mais irrompem dúvidas entre os alunos, com a posse desses dados haverá a possibilidade de elaboração de rodas de conversas, cartilhas contendo informações e referências para estudo sobre a temática, bem como, áudios/podcast que poderão ser disponibilizados para os alunos.

Objetivo: Desenvolver uma práxis que contribua com a formação de alunos na graduação de Psicologia, a fim de que possam conhecer e engajar-se em áreas na qual a Psicologia atua.

Resultados: Até o momento do estudo foram coletados dados parciais através do formulário e as extensionistas percorrem pelo processo de análise das dúvidas mais emergentes sobre as diferentes áreas de conhecimento da Psicologia: Licenciatura em Psicologia; Psicologia Jurídica; Psicologia do Esporte; Psicologia Hospitalar; Psicologia Organizacional e do Trabalho entre outras. Sendo assim, ao término do preenchimento do formulário pelos alunos, que se dará na última semana de setembro, em posse de todas as respostas, os dados serão compilados, e a partir destes dados serão elaboradas cartilhas, rodas de conversa que possibilitem sanar as dúvidas trazidas pelos mesmos.

Conclusão: Mediante o exposto, nota-se a importância de abordar temáticas da Psicologia nos anos iniciais do curso, tendo em vista as poucas informações a respeito da dimensão do campo Psicológico enquanto ciência e profissão. Vislumbra-se através deste projeto, que os alunos possam nortear suas práticas de forma engajada desde o começo do curso, podendo assim, se tornarem mais comprometidos ética e politicamente nos processos de transformação social.

\section{Referências}

VYGOTSKY, Lev. Formação social da mente. 4. ed. São Paulo: Martins Fontes, 1991. Disponível em http://www.egov.ufsc.br/portal/sites/default/files/vygotsky-a-formac3a7c3a3osocial-da-mente.pdf. Acesso em: 21 ago. 2021.

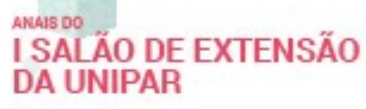

I SALÃO DE EXTENSÃO DA UNIPAR

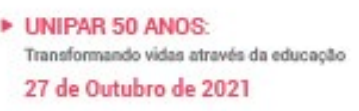

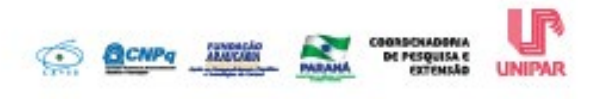




\title{
(1) DUISDO UNPAR 50 ANOS \\ SALÃO DE EXTENSÃO DA Transformando vidas através da educaçẵo UNIPAR ACADÊMICA DE PARASITOLOGIA SOBRE A MALÁRIA NO BRASIL
}

\author{
${ }^{1}$ GABRIELA KAROLAINE TEIXEIRA, ${ }^{2}$ LUIS FERNANDO DELAZARI VALERIO, ${ }^{3}$ VANESSA MARCONDES BRASILEIRO \\ FREDERICO, ${ }^{4}$ RAPHAEL CHALBAUD BISCAIA HARTMANN
}

\author{
${ }^{1}$ Acadêmico do Curso de Medicina da UNIPAR \\ ${ }^{2}$ Acadêmico do Curso de Medicina da UNIPAR \\ ${ }^{3}$ Acadêmica do Curso de Medicina da UNIPAR \\ ${ }^{4}$ Docente da UNIPAR
}

Introdução: o MedTalks é um podcast do curso de Medicina da Unipar que está nas principais mídias de streaming de áudio como o Spotify, para criar conteúdo não só para os acadêmicos de Medicina, mas para toda comunidade, tem se mostrado uma ferramenta efetiva de comunicação para os estudantes de medicina desta Universidade. Segundo Saidelles et al, 2018, é notável a preocupação de pesquisadores, de diferentes áreas do saber, em buscar novas formas de agregar as tecnologias no contexto educaciona. Desse modo, o uso do podcast, pode ser utilizado de maneira que interaja concomitantemente como uma ferramenta educacional e de divulgação de temas e trabalhos científicos, sendo cada vez mais utilizado, no cenário universitário, como uma forma inovadora de propagação de conhecimento. (OLIVEIRA JÚNIOR, 2020).

Objetivo: Apresentar e informar a comunidade acadêmica o panorama da Malária no Brasil, apresentando dados epidemiológicos do ano de 2020, com a intenção de propagar conhecimento através do uso de instrumentos de mídia de streaming.

Resultados: Segundo Saidelles et al, 2018: A cada ano, fica perceptível que os alunos buscam novas formas de informação em tecnologias, e se tornam cada vez mais desmotivados para os métodos tradicionais de ensino. Segundo Oliveira Júnior, 2020: $O$ Medtalks contribuiu com a Liga Acadêmica de Parasitologia Médica (LAPM), pois mostrou aos alunos um entendimento do ensino como uma forma de desenvolver novas capacidades, dando autonomia e compartilhando conhecimentos com os usuários. Houve também uma nova percepção dos alunos diante da experiência do podcast, tendo um entendimento do processo de criação como uma nova forma para o treinamento de linguagem do profissional com o ouvinte, exercendo uma reflexão sobre qual a melhor maneira de se emitir uma informação clara ao paciente.

Conclusão: É de suma importância notarmos que o podcast deve ser visto como uma forma de propagar conhecimento, porém com liberdade criativa e de linguagem, tornando-o um método de aprendizado de fácil adesão e propagação, visto que o material pode ser propagado em meios comuns e populares, como celulares e computadores, além de poderem ser acessados a qualquer momento do dia. (OLIVEIRA JÚNIOR, 2020). Outro aspecto importante notado por alunos e professores participantes de podcasts, é de que há um treinamento de linguagens e comunicação entre o comunicador e o ouvinte. A partir desse ponto, é possível realizar uma análise sobre seu desempenho individual e coletivo, ajudando o aluno a transmitir seu próprio saber e compartilhá-lo com o usuário do podcast. (OLIVEIRA JÚNIOR, 2020).

\section{Referências}

SAIDELLES, Tiago et al. A utilização do podcast como uma ferramenta inovadora no contexto educacional. $23^{\circ}$ seminário internacional de educação, tecnologia e sociedade, p. 1-10, 2018.

OLIVEIRA , J, R, M. Elaboração de podcast como ferramenta educacional para estudantes de medicina. Dissertação de Mestrado. Universidade Federal do Rio Grande do Norte. 2020

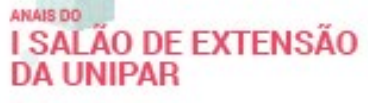

I SALÃO DE EXTENSÃO DA UNIPAR

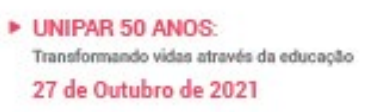

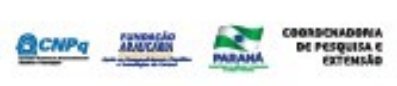

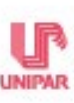




\section{NaIs Do
SALÃO DE EXTENSÃO DA
UNIPAR \\ ISBN 978-65-87557-74-8

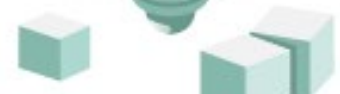 \\ DOI: Hitpsi/doiorg/10.251 10issaboest \\ - UNIPAR 50 anOS \\ Transformando vidas através da educą̧ào \\ 27 de Outubro de 2021 \\ RELATO DE EXPERIÊNCIA: A INTEGRAÇÃO DE ENSINO-SERVIÇO NA CAMPANHA DE IMUNIZAÇÃO CONTRA INFLUENZA}

${ }^{1}$ Gracy Schroeder, ${ }^{2}$ DHONSILLY GABRIELLY DOMINGOS FREIRE, ${ }^{3}$ DIOGO ALEXANDRE RIBEIRO, ${ }^{4}$ EMILY VITORIA GONCALVES, ${ }^{5}$ GABRIELA MARIA KEMFER, ${ }^{6}$ HAYANI SANCHES, ${ }^{7}$ LUCAS SANTIAGO SAGAZ, ${ }^{8}$ DAISY CRISTINA RODRIGUES, ${ }^{9}$ JADY FERNANDA DA CRUZ DE LIMA, ${ }^{10}$ CAMILA CRISTIANE FORMAGGI SALES RIBEIRO, ${ }^{11}$ JULIANA CARISSIMI, ${ }^{12}$ LAUANA EMANUELLY FERREIRA, ${ }^{13}$ MARIA GABRIELE TAVARES MOURA, ${ }^{14}$ PEDRO HENRIQUE RODRIGUES DE LIMA, ${ }^{15}$ SARA LAMBARDOZI GALDINO DA SILVA, ${ }^{16}$ DEBORA TATIANE FEIBER GIRARDELLO

${ }^{1}$ Docente da Unipar

${ }^{2}$ Acadêmica do Curso de Enfermagem da UNIPAR

${ }^{3}$ Acadêmico do Curso de Enfermagem da UNIPAR

${ }^{4}$ Acadêmica do Curso de Enfermagem da UNIPAR

${ }^{5}$ Acadêmica do Curso de Enfermagem da UNIPAR

${ }^{6}$ Docente da UNIPAR

${ }^{7}$ Acadêmico do Curso de Enfermagem da UNIPAR

${ }^{8}$ Docente da UNIPAR

${ }^{9}$ Acadêmica do Curso de Enfermagem da UNIPAR

${ }^{10}$ Docente da UNIPAR

${ }^{11}$ Acadêmica do Curso de Enfermagem da UNIPAR

${ }^{12}$ Acadêmica do Curso de Enfermagem da UNIPAR

${ }^{13}$ Acadêmica do Curso de Enfermagem da UNIPAR

${ }^{14}$ Acadêmico do Curso de Enfermagem da UNIPAR

${ }^{15}$ Acadêmica do Curso de Enfermagem da UNIPAR

${ }^{16}$ Docente da UNIPAR

Introdução: Anualmente ocorrem cerca de 3 a 5 milhões de agravamento de casos de influenza no mundo, ocasionando em aproximadamente 500 mil óbitos, seguido de um grande aumento de internações hospitalares. Em contrapartida, a vacinação é um recurso eficiente na prevenção da influenza diminuindo os casos graves e o nível de internações (SOUZA et al, 2019, p.3148). O indício de contaminação pelo vírus ocorre pela transmissão através de gotículas sendo reconhecido pelas manifestações dos sintomas específicos como início súbito de febre alta, mialgia, cefaleia e coriza que afeta as vias aéreas superiores sendo capaz de se estender para regiões inferiores agravando mais a doença. Um fator preocupante são suas complicações como a pneumonia que muitas vezes é responsável pelas internações e/ou óbitos (SOUZA et al, 2016, p.214).

Objetivo: Estudo descritivo, do tipo relato de experiência, que tem por objetivo descrever a experiência dos acadêmicos de enfermagem sobre a integração ensino e serviço durante a campanha de imunização contra influenza.

Resultados: Em decorrência a imunização contra a covid 19 com uma grande demanda nas unidades de saúde, simultaneamente com a imunização geral da população e o início da campanha contra a influenza, foram ampliados os acessos com postos volantes de vacinação. O centro de saúde escola da universidade paranaense teve a participação de alunos do $1^{\circ}$ ao $5^{\circ}$ ano de enfermagem, totalizando em: 04 enfermeiros docentes, 03 enfermeiros responsáveis técnicos e 48 discentes do curso de bacharelado em enfermagem. O público alvo na universidade atingiu crianças a partir dos 3 anos, adultos e idosos no qual obteve percentuais excelentes de vacinações. A campanha proporcionou aos acadêmicos a integração de ensino e serviço na prática de imunização.

Conclusão: A experiência descrita proporcionou aos acadêmicos vivenciar a integração ensino-serviço no planejamento e implementação de ações na cobertura vacinal da população durante a Campanha Nacional de Vacinação contra a Influenza, concebendo uma grande oportunidade de aprendizado e gerando um importante suporte no serviço de saúde. 
produzido em 2016. Revista Eletrônica de Comunicação, Informação \& Inovação em Saúde, Rio de Janeiro, v. 15, n. 1, p. 211-220, jan./Mar. 2021. Disponível em: https://doi.org/10.29397/reciis.v15i1.2014.

SOUZA, Tiago Pereira et al. Fatores associados à aceitação da vacina influenza entre trabalhadores de saúde: conhecimento, atitude e prática. Revista Ciência \& Saúde Coletiva, 24(8):3147-3158, 2019. Disponível em: DOI: 10.1590/141381232018248.21912017.

I SALĂOO DE EXTENSÃ́O " UNIPAR 50 ANOS:

DA UNIPAR
27 de Outubro de 2021

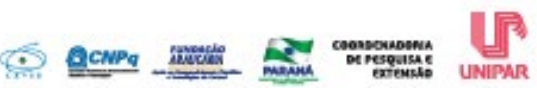




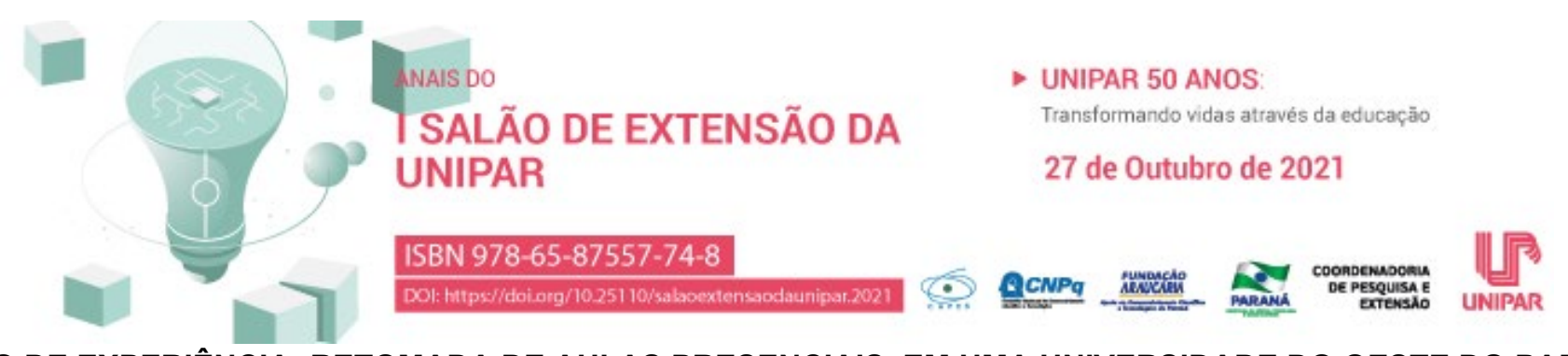

\title{
RELATO DE EXPERIÊNCIA: RETOMADA DE AULAS PRESENCIAIS EM UMA UNIVERSIDADE DO OESTE DO PARANÁ
}

\begin{abstract}
${ }^{1}$ Gracy Schroeder, ${ }^{2}$ DAIANA MAYDANA RODRIGUES, ${ }^{3}$ THALIA DA SILVA CAMARGO , ${ }^{4}$ AMANDA DA ROCHA MARTINS, ${ }^{5}$ EDUARDA CRISTINA PEREIRA MARQUES LOURO, ${ }^{6}$ MAIARA SANTOS, ${ }^{7}$ GABRIELA MARIA KEMFER, ${ }^{8}$ MALVINA DA SILVA VIEIRA SOUZA, ${ }^{9}$ ALUANA MORAES, ${ }^{10}$ CARLA REJANE DE OLIVEIRA, ${ }^{11}$ AMANDA JOSIANE GARCIA MUGNAI VIEIRA, ${ }^{12}$ BRUNA FELTES CAMARGO, ${ }^{13}$ LUCAS SANTIAGO SAGAZ, ${ }^{14}$ TAINARA MACHADO DE OLIVEIRA, ${ }^{15}$ JESSICA CORDEIRO VIDAL DOS SANTOS BALISKI, ${ }^{16}$ DEBORA TATIANE FEIBER GIRARDELLO
\end{abstract}

\footnotetext{
${ }^{1}$ Docente Unipar

${ }^{2}$ Acadêmica do Curso de Biomedicina da UNIPAR

${ }^{3}$ Acadêmico do Curso de Enfermagem da UNIPAR

${ }^{4}$ Acadêmica do Curso de Enfermagem da UNIPAR

${ }^{5}$ Acadêmica do Curso de Enfermagem da UNIPAR

${ }^{6}$ Acadêmica do Curso de Enfermagem da UNIPAR

${ }^{7}$ Acadêmica do Curso de Enfermagem da UNIPAR

${ }^{8}$ Acadêmica do Curso de Enfermagem da UNIPAR

${ }^{9}$ Docente da UNIPAR

${ }^{10}$ Docente da UNIPAR

${ }^{11}$ Docente da UNIPAR

${ }^{12}$ Acadêmico do Curso de Enfermagem da UNIPAR

${ }^{13}$ Acadêmico do Curso de Enfermagem da UNIPAR

${ }^{14}$ Acadêmica do Curso de Enfermagem da UNIPAR

${ }^{15}$ Acadêmico do Curso de Enfermagem da UNIPAR

${ }^{16}$ Docente da UNIPAR
}

Introdução: A síndrome respiratória aguda 2 (SARS-COV-2), originado pela COVID-19 responsável pela atual pandemia, repercutiu profundamente na saúde da população decorrente ao seu alto grau de contaminação. Com isso, culminou em uma grande repercussão em outros casos, como no setor da educação. Tamanha implicação percorre por um processo de adaptação nas instituições de ensino, como nas universidades, principalmente em cursos da área de saúde (BASTOS et al, 2020). No Brasil o número de contaminação pelo Covid 19 é elevado, entretanto foram criadas medidas prioritárias para diminuição dos números de transmissão do vírus que requer o afastamento social, diminuindo o fluxo constante de pessoas. Contudo, é primordial entender que mesmo considerando as adequações educacionais mediante a pandemia para a continuidade da formação acadêmica, em cursos da área da saúde não se pode abrir mão de recursos que promovam a interação entre pessoas. Pois é perfil prático da profissão, por trabalhar com o processo saúde-doença que exige o desenvolvimento e aperfeiçoamento de habilidades específicas do processo do cuidar (BASTOS et al., 2020).

Objetivo: Estudo descritivo, do tipo relato de experiência, tem por objetivo descrever as medidas implementadas no centro de saúde escola (CSE) e na instituição de ensino de uma universidade privada do Oeste do Paraná, para retomada das atividades de forma segura atendendo as necessidades sanitárias previstas em normas e decretos em vigor neste momento de pandemia.

Resultados: Em virtude com a atual situação pandêmica que vivenciamos, diversas medidas foram implantadas para a segurança dos usuários na isntituição de ensino e no centro de saúde escola. No primeiro momento foi realizado a retomada gradual dos funcionários /colaboradores dos sentores e dos cursos, num segundo momento a retomada gradual das atividades práticas e atualmente a retomada gradual e segura dos acadêmicos para as aulas teóricas em ambiente intituicional, sendo monitorado e podendo sofrer alterações quando necessário para ajustes de condutas ou mesmo quando necessário a obediência a normas e decretos e medidas expedidas pelos poderes Municipal, Estadual e Federal. Ressaltado que cada curso possui um Protocolo Operacional padrão (POP), com orientações específicas, para combate e prevenção ao Novo Coronavirus (SARS-CoV2), e este fica disponível nas coordenações para orientação de acadêmicos, pacientes, clientes, visitantes e funcionários. Todos os acadêmicos foram orientados que caso apresentem sintomas como tosse, febre, coriza, dor de garganta, dificuldade de respirar, fadiga, tremores e calafrios, dor muscular, dor de cabeça, perda recente do olfato ou paladar, deve comunicar 
imediatamente a instituição. Em caso suspeito ou confirmado de covid 19 os acadêmicos, funcionários/ colaboradores e professores são orientados a seguir o protocolo do município de origem do mesmo, afastar imediatamente das atividades presenciais. Para manter o acesso ao CSE é imprescindível o uso de máscara de proteção, manter o distanciamento de 1 metro, realizar a higienização das mãos com preparação alcoólica a $70 \%$ e a aferição da temperatura corporal com valores inferior a $37,1^{\circ} \mathrm{C}$. O enfermeiro(a) responsável e/ou acadêmicos incumbido de prestar atendimento realizam a higienização das mãos conforme as normativas de biossegurança, a utilização de óculos de proteção ou protetor facial, uso constante de mascará cirúrgica, uso de luvas de acordo com o atendimento prestado. A realização de higiene das superfícies e do ambiente conforme protocolo de segurança.

Conclusão: A implementação caracterizada descreve a importância do cuidado na prestação do serviço aos usuários, alunos e professores, mantendo o ambiente seguro para melhor atendê-los mediante a situação pandêmica que nos encontramos.

\section{Referências}

BASTOS, Milena de Camargo et al. Ensino Remoto Emergencial na Graduação em Enfermagem: Relato de Experiência na Covid-19. REME - Rev Min Enferm, 2020. Disponível em: 1415-2762-reme-24-e1335.pdf (bvs.br) Acesso em: 31 ago. 2021. 


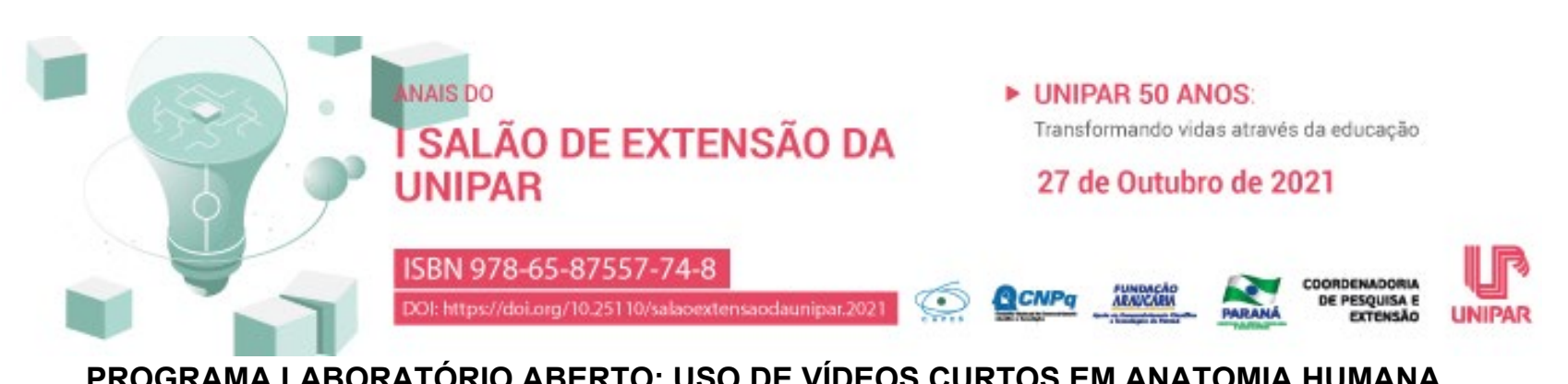

\title{
PROGRAMA LABORATÓRIO ABERTO: USO DE VÍDEOS CURTOS EM ANATOMIA HUMANA
}

\author{
${ }^{1}$ TAILINI PAGNONCELLI LAZARIN, ${ }^{2}$ MATHEUS JOSE CESARI, ${ }^{3}$ JULIA BEATRIZ PANSERA, ${ }^{4}$ STEPHANY BITENCOURT \\ LEITE, ${ }^{5}$ FRANCIELE DO NASCIMENTO SANTOS ZONTA, ${ }^{6}$ LUCIANA PELLIZZARO
}

1Acadêmica do Curso de Enfermagem, Unipar-Francisco Beltrão.
${ }^{2}$ Acadêmico do Curso de Enfermagem da UNIPAR
${ }^{3}$ Acadêmica do Curso de Odontologia da UNIPAR
${ }^{4}$ Acadêmica do Curso de Odontologia da UNIPAR
${ }^{5}$ Orientadora, Professora da Unipar.
${ }^{6}$ Orientadora, Professora da Unipar.

Introdução: A Anatomia Humana estuda as estruturas de um organismo e relações entre suas partes (COLARES et al., 2019). Seu aprendizado normalmente inclui a prática em laboratório e as peças anatômicas. Atualmente os estudantes estão bastante familiarizados com as ferramentas tecnológicas, o que possibilita uma abordagem com novas práticas de ensino, a exemplo do audiovisual (MACHRY; DIAS; ANDRADE, 2018), como os vídeos, usados de forma cada vez mais frequente como ferramentas de aprendizagem (DAMAZIO et al., 2016). Assim, buscando contribuir com o estudo de Anatomia Humana é possível gravar pequenos vídeos em laboratório próprio, como apoio para alunos que desejam aprofundar seus conhecimentos. Essa estratégia foi feita pelos alunos do Programa Laboratório Aberto, durante o período pandêmico.

Objetivo: Descrever o uso de vídeos curtos de Anatomia Humana no Programa Laboratório Aberto.

Desenvolvimento: O Programa de Extensão Laboratório Aberto objetiva oferecer atividades práticas em várias áreas, incluindo Anatomia Humana, a alunos de Ensino Fundamental e Médio das escolas de Francisco Beltrão e região. Tendo em vista o período pandêmico, visitas à Unipar foram desaprovadas. Assim, para cumprir o objetivo, os acadêmicos participantes gravaram pequenos vídeos usando peças anatômicas sintéticas relacionads aos sistemas esquelético, nervoso, cardiovascular, respiratório, digestório e linfático, apresentando suas estruturas. Cada parte foi identificada e apontada pelo acadêmico, que descreveu sua posição e características. Antes da gravação, houve o preparo do conteúdo pelos acadêmicos. Os vídeos foram gravados com celulares e cada um deles possui, no máximo, três minutos de duração. Os vídeos foram encaminhados a professores de Ciências e Biologia das escolas da região para usarem na sua prática e aos acadêmicos da instituição que cursam Anatomia, como forma de reforçar o conteúdo.

Conclusão: Os vídeos de curta duração são bons instrumentos para aprender Anatomia Humana. Acadêmicos participantes beneficiaram-se melhorando seu conhecimento a respeito do tema, assim como aqueles que os receberam.

\section{Referências}

COLARES, Maria Alice Mendes; MELLO, Josiane Medeiros; VIDOTTI, Ana Paula; SANTANA, Débora de Mello Gonçalves. Metodologias de Ensino de Anatomia Humana: Estratégias para diminuir as dificuldades e proporcionar um melhor processo de ensino-aprendizagem. Arq. MUDI, v. 23, n. 3, p. 140-60, 2019.

DAMÁZIO, Laila Moreira. Vídeo-aulas no ensino de Anatomia Humana. Rev. Experiência, v. 2, n. 2, p. 4-14, 2016.

MACHRY, Paulo Henrique; DIAS, Daniel Ventura; ANDRADE, João Cleber Theodoro. Utilização de Vídeos de Anatomia Humana como Ferramenta de Apoio para o Estudo/Aprendizagem de Anatomia Prática. Rev. Educ., Cult. Soc, v. 8 n.1, p. 357-68, 2018.

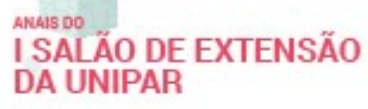

I SALÃO DE EXTENSÃO

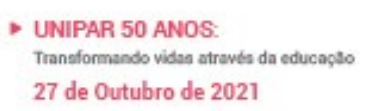
da educaçlo
27 de Outubro de 202

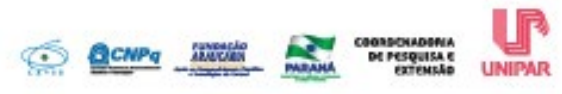




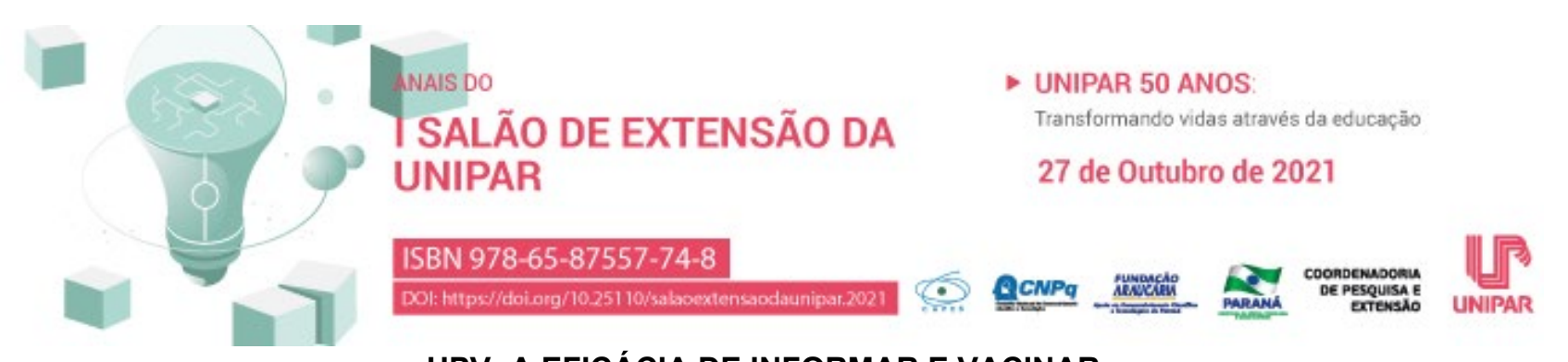

HPV: A EFICÁCIA DE INFORMAR E VACINAR

\title{
${ }^{1}$ JULIANA TADEU THOME, ${ }^{2}$ KATIA BIAGIO FONTES
}

\author{
${ }^{1}$ Acadêmica do Curso de Medicina da UNIPAR \\ ${ }^{2}$ Docente da UNIPAR
}

Introdução: De acordo com a OPAS (2021), em 2020, mais de meio milhão de mulheres tiveram câncer de colo de útero e cerca de 342 mil morreram em consequência.

Objetivo: Descrever a importância da vacina contra o HPV e os fatores relacionados a não adesão da vacinação pela população. Desenvolvimento: O Papilomavírus Humano (HPV) é uma das infecções sexualmente transmissíveis mais frequentes no mundo (MOURA et al., 2020). É a causa de vários tipos de câncer: colo de útero, de vulva, vagina, pênis, ânus e orofaringe, bem como de verrugas anogenitais. Estima-se que $99 \%$ dos casos de câncer de colo do útero estão ligados ao HPV, que é evitável com testes de triagem regulares e vacinas para HPV. A Organização Mundial de Saúde (OMS) recomenda o uso da vacina contra HPV, prioritariamente para a população de meninas de 9 a 14 anos, antes que se tornem sexualmente ativas (CARVALHO et al., 2018). No Brasil a vacina é distribuída pelo SUS, fazendo parte do calendário nacional de vacinação em 2 doses, com intervalo de 6 meses entre as doses, nas meninas de 9 a 14 anos e nos meninos de 11 a 14 anos. Pessoas de 9 a 26 anos, vivendo com HIV/Aids, transplantados de órgãos sólidos e de medula óssea e pacientes oncológicos, 3 doses da vacina com necessidade de prescrição médica para este grupo. Apesar dos benefícios apontados, resultados de estudo conduzido no Brasil por Moura et al. (2020), demonstrou sucesso na cobertura vacinal da primeira dose, porém, o mesmo não ocorreu na segunda, sugerindo a necessidade do planejamento de estratégias pelos gestores estaduais. Diversos fatores têm sido apontados na literatura associados à baixa cobertura vacinal de HPV, especialmente, baixo nível educacional, baixa renda, baixo acesso à informação e aos serviços de saúde, residência em zona rural e barreiras interpostas por dogmas religiosos. Carvalho et al., (2018), apontam também o baixo risco percebido de infeç̧ão pelo HPV, raça, crenças e valores quanto ao comportamento sexual.

Conclusão: Pode-se concluir que a vacina contra HPV é distribuída gratuitamente a população e eficaz na prevenção do câncer de colo de útero. Contudo, a maioria dos fatores relacionados à baixa adesão estão atrelados à desinformação, sugerindo a necessidade de informar e estimular a população, como forma de desmistificar e simplificar os aspectos relacionados à vacina, no sentido de promover o sucesso na cobertura das 2 doses recomendadas.

\section{Referências}

Brasil. Ministério da Saúde. Calendário Nacional de Imunização. ANEXO V INSTRUÇÃO NORMATIVA REFERENTE AO CALENDÁRIO NACIONAL DE VACINAÇÃO 2020. Disponível em: https://www.gov.br/saude/pt-br/assuntos/saude-de-a-az/c/calendario-de-vacinacao Acesso em: 13 ago. 2021.

CARVALHO, AMC et al. Adesão à vacina HPV entre os adolescentes: revisão integrativa. Texto \& Contexto - Enfermagem [ONLINE]. v. 28, 2019. Disponível em: SciELO - Brasil - HPV VACCINE ADHERENCE AMONG ADOLESCENTS: INTEGRATIVE REVIEW HPV VACCINE ADHERENCE AMONG ADOLESCENTS: INTEGRATIVE REVIEW. Acesso em 12 ago. 2021.

MOURA, LL et al. Cobertura da vacina Papilomavírus Humano (HPV) no Brasil: heterogeneidade espacial e entre coortes etárias. Revista Brasileira de Epidemiologia [online]. v.24, 2021. Disponível em: SciELO - Brasil - Cobertura da vacina papilomavírus humano (HPV) no Brasil: heterogeneidade espacial e entre coortes etárias Cobertura da vacina papilomavírus humano (HPV) no Brasil: heterogeneidade espacial e entre coortes etárias. Acesso em: 12 ago. 2021.

Organização Pan-Americana da Saúde. Novas recomendações de rastreio e tratamento para prevenir o câncer do colo do útero. Jul, 2021. Disponível em:

https://www.paho.org/pt/noticias/6-7-2021-novas-recomendacoes-rastreio-e-tratamento-para-prevenir-cancer-do-colo-do-utero. Acesso em 18 ago. 2021.

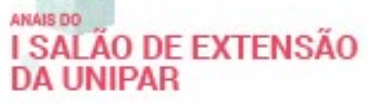

I SALÄO DE EXTENSÃO
DA UNIPAR

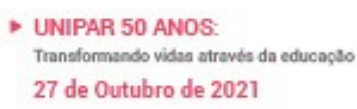

Transeformando vides atrawbs da educaçso
27 de Outubro de 2021

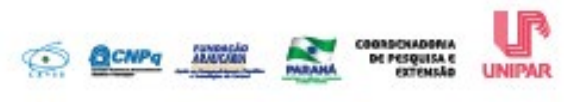




\title{
(1) \\ ISBN 978-65-87557-74-8

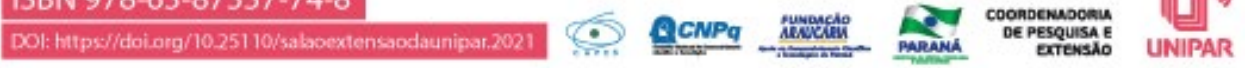 \\ INTERFERÊNCIA DOS PROCEDIMENTOS ESTÉTICOS NA AUTOESTIMA E AUTOIMAGEM DE MULHERES ATENDIDAS PELO PROJETO ESTÉTICA NA COMUNIDADE
}

\author{
${ }^{1}$ HELEN CRISTINA DA SILVA, ${ }^{2}$ ANALICE GALVAO DE MEIRA MENDONCA, ${ }^{3}$ GABRIELI BENTO DE FREITAS , ${ }^{4}$ ESTEFANI \\ CAROLINE DAHLEM MORE, ${ }^{5}$ LUCIANA PELLIZZARO, ${ }^{6}$ KELLI KUHNEN, ${ }^{7}$ JULIANA PELISSARI MARCHI
}

\begin{abstract}
${ }^{1}$ Acadêmica participante do Projeto de Extensão Estética na Comunidade, do C.S.T. em Estética e Cosmética da UNIPAR.
${ }^{2}$ Acadêmica participante do Projeto de Extensão Estética na Comunidade, do C.S.T. em Estética e Cosmética da UNIPAR.

${ }^{3}$ Acadêmica participante do Projeto de Extensão Estética na Comunidade, do C.S.T. em Estética e Cosmética da UNIPAR.

${ }^{4}$ Acadêmica participante do Projeto de Extensão Estética na Comunidade, do C.S.T. em Estética e Cosmética da UNIPAR.

${ }^{5}$ Docente do C.S.T. em Estética e Cosmética da Universidade Paranaense, UNIPAR, Unidade de Francisco Beltrão.

${ }^{6}$ Responsável Técnica do Centro de Estética Escola do C.S.T. em Estética e Cosmética da Universidade Paranaense, UNIPAR.

${ }^{7}$ Docente do C.S.T. em Estética e Cosmética da Universidade Paranaense, UNIPAR, Unidade de Francisco Beltrão.
\end{abstract}

Introdução: A estética é uma prática que esteve sempre associada à vaidade, hoje já se sabe que os cuidados com a aparência e o bem-estar guardam estreita ligação com a saúde (EDUARDO; FERREIRA, 2019). A autoestima é o sentimento positivo ou negativo que as pessoas têm para consigo mesmas (ANDRADE; SOUZA, 2010). Já a autoimagem é a percepção que a pessoa tem de si e de seu reflexo diante do retorno de sentimentos ou ações em seus relacionamentos interpessoais (FLORIANI; MARCANTE; BRAGGIO, 2010). Diferentes estudos apontam os resultados positivos em estados e motivações emocionais de pessoas submetidas às cirurgias e procedimentos estéticos (EDUARDO; FERREIRA, 2019). Com base nisso, o projeto "Estética na comunidade"realizou no dia 22 de junho, nos laboratórios da UNIPAR, procedimentos de design de sobrancelhas, hidratação facial e capilar num grupo de mulheres.

Objetivo: Relatar a experiência de atividades realizadas com um grupo de mulheres, pelo Projeto de Extensão Estética na Comunidade.

Resultados: Durante a execução dos atendimentos de design de sobrancelhas, hidratação facial e capilar, foi estabelecido um diálogo com as mulheres, visando o atendimento em estética humanizada. Com isso, foi possivél receber alguns relatos dessas mulheres, dentre eles, nos impactou o fato de que a grande maioria das mulheres envolvidas na atividade, não haviam realizado procedimentos estéticos anteriormente, sendo as atividades do projeto o primeiro contato com o universo da beleza e saúde estética. Baseando-se nos relatos e comentários dessas mulheres, foi perceptível que os procedimentos realizados as deixaram com amor-próprio e autoconfiança elevada. Sabe-se que a pele e os cabelos, são os principais elementos do nosso corpo na avaliação da imagem corporal, tendo impacto direto no autoconceito e autoestima, bem como sabe-se que a autoestima está diretamente relacionada ao bem-estar emocional (BORBA; THIVES, 2011). O cuidado com a saúde da pele e dos cabelos vai além da beleza, colaboram diretamente com a saúde, pois, oportunizam uma experiência proveitosa e benéfica, exaltam os traços de beleza, melhoram a qualidade de vida e o bem-estar (FLORIANI; MARCANTE; BRAGGIO, 2010).

Conclusão: Muitas pessoas não têm acesso aos procedimentos estéticos ou cosméticos, por isso, as atividades do projeto são essenciais e contribuem para ressaltar a beleza, com isso, aumentam a confiança e melhoram a vida social, contribuindo diretamente com a saúde.

\section{Referências}

ANDRADE, Edson Ribeiro; SOUZA, Edinilsa Ramos. Autoestima como expressão de saúde mental e dispositivo de mudanças na cultura organizacional da polícia. Psic. Clin., Rio de Janeiro, vol.22, n.2, p.179 195, 2010.

BORBA, J. Tamila; THIVES, Fabiana Marin. Uma reflexão sobre a Influência da estética na auto-estima, automotivação e bem estar do ser humano. 2011. Universidade do Vale do Itajaí - UNIVALI, Balneário Camboriú, SC. Disponível em: http://siaibib01.univali.br/pdf/Tamila\%20Josiane\%20Borba.pdf. Acesso em: 19 ago. 2021.

EDUARDO, Maria Aparecida; FERREIRA, Keila Suzzete. A Relevância dos Cuidados Corporais para a Autoestima das Pessoas: Uma Revisão da Leitura. 2019. UNIFASC, Itumbiara-GO. Disponível em: https://unifasc.edu.br/wpcontent/uploads/2019/05/A-relev\%C3\%94ncia-dos-Cuidados-Corporais-Maria-Aparecida-1.pdf

FLORIANI, Flavia Monique; MARCANTE, Márgara Dayana da Silva; BRAGGIO, Laércio Antônio. Auto-estima e auto-imagem: a relação com a estética. 2010. Universidade do Vale do Itajaí - UNIVALI, Balneário Camboriú, SC. Disponível em: http://siaibib01.univali.br/pdf/Flavia\%20Monique\%20Floriani,\%20M\%C3\%A1rgara\%20Dayana\%20da\%20Silva\%20Marcante.pdf. 
- unIPAR 50 anos:

I SALAOO DE EXTENSÃO Transformando vidas atravies da educaģso

DA UNIPAR 


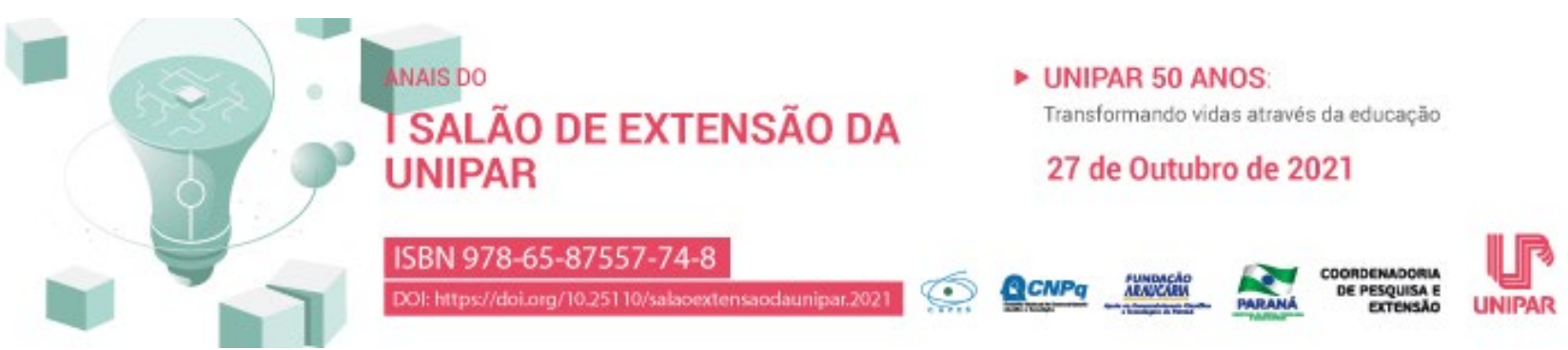 \\ UM RELATO DE EXPERIÊNCIA SOBRE A AROMATERAPIA NA QUALIDADE DE VIDA
}

\author{
${ }^{1}$ IARA FRANCISQUET, ${ }^{2}$ CINTIA THALIA FROIS, ${ }^{3}$ KELLI KUHNEN, ${ }^{4}$ HELLEN JANAINA GALVAN, ${ }^{5}$ SIMONE CASTAGNA \\ ANGELIM COSTA, ${ }^{6}$ RAQUEL COSTA MACHADO, ${ }^{7}$ GIOVANA MIOTO DE MOURA, ${ }^{8}$ JULIANA PELISSARI MARCHI
}

\begin{abstract}
${ }^{1}$ Acadêmica participante do Programa Institucional Centro de Estética e Cosmética Escola, do C.S.T. em Estética e Cosmética da UNIPAR.

${ }^{2}$ Acadêmica participante do Programa Institucional Centro de Estética e Cosmética Escola, do C.S.T. em Estética e Cosmética da UNIPAR.

${ }^{3}$ Responsável Técnica do Centro de Estética Escola do C.S.T. em Estética e Cosmética da Universidade Paranaense, UNIPAR.

${ }^{4}$ Acadêmica participante do Programa Institucional Centro de Estética e Cosmética Escola, do C.S.T. em Estética e Cosmética da UNIPAR.

${ }^{5}$ Docente do C.S.T. em Estética e Cosmética da Universidade Paranaense, UNIPAR.

${ }^{6}$ Docente do C.S.T. em Estética e Cosmética da Universidade Paranaense, UNIPAR.

${ }^{7}$ Docente do C.S.T. em Estética e Cosmética da Universidade Paranaense, UNIPAR.

${ }^{8}$ Docente do C.S.T. em Estética e Cosmética da Universidade Paranaense, UNIPAR.
\end{abstract}

Introdução: Durante as atividades práticas do projeto observamos que as pessoas envolvidas não sabiam a forma correta de uso da aromaterapia. Isso nos levou a elaborar uma cartilha informativa Formas de uso da aromaterapia: Melhore sua qualidade de vida , que foi disponibilizada para a população em geral. A aromaterapia consiste na aplicação de óleos essenciais por diversas vias, dentre elas, destaca-se a via tópica ou olfativa, objetivando a prevenção ou tratamento de disfunções (GASPAR, 2004). Os óleos essenciais são compostos orgânicos de origem vegetal (flores, folhas, sementes, frutos e raízes) de plantas aromáticas, que apresentam vários benefícios e efeitos fisiológicos (FARRER-HALLS, 2016; HOARE, 2010).

Objetivo: Relatar a experiência de atividades desenvolvidas no Programa Institucional Centro de Estética e Cosmética Escola da UNIPAR.

Resultados: As atividades práticas auxiliaram a aperfeiçoar a prática, diminuir a insegurança e fortalecer a relação profissionalcliente, contribuindo para o aperfeiçoamento profissional. Elaborar a cartilha foi interessante e agregou conhecimentos, além disso, beneficiou a população com informações importantes: seus principais meios de uso são pelo olfato (inalar, difusor de ambiente, difusor pessoal) e pela via cutânea (diluído em base biocompatível, banhos aromáticos, escalda pés, banhos de assento, compressas, massagens) (STEVENSON, 2018; HOARE, 2010). A aromaterapia é terapêuticamente efetiva, pois, apresenta potencial terapêutico e farmacológico por diferentes propriedades biológicas, fisiológicas e psicológicas (STEVENSON, 2018; TISSERAND, 1993). De modo geral, a aromaterapia atua de maneira holística, tanto na prevenção quanto no controle de disfunções (MAIA; ZOGHBI; ANDRADE, 2001). Portanto, a aromaterapia promove mudanças positivas de humor, reduz a ansiedade e o estresse, ativa o relaxamento, energiza e equilibra, gera o bem-estar e com isso melhora a qualidade de vida das pessoas (STEVENSON, 2018; GASPAR, 2004).

Conclusão: As atividades práticas do projeto levaram a busca pelo aperfeiçoamento teórico, a partir da pesquisa científica e elaboração da cartilha. Portanto, o projeto contribuiu para a relação teórico-prático acerca da aromaterapia na qualidade de vida, e suas formas de aplicação.

\section{Referências}

FARRER-HALLS, Gill. A bíblia da aromaterapia: o guia definitivo para o uso terapêutico dos óleos essenciais. São Paulo: Pensamento. 2016.

GASPAR. Eneida Duarte, Aromaterapia uso terapêutico das essências vegetais. Rio de Janeiro: Editora Pallas. 2004.

HOARE, Joana. Guia completo de aromaterapia: um curso estruturado para alcançar a excelência profissional. São Paulo: Pensamento. 2010.

MAIA, José Guilherme Soares; ZOGHBI, Maria das Graças Bichara; ANDRADE, Eloisa Helena de Aguiar. Plantas Aromáticas na Amazônia e seus Óleos Essenciais, Belém: Museu Paraense Emílio Goeldi, 2001.

STEVENSON, Judy, Guia Definitivo dos Óleos Essenciais: Domine Todos os Benefícios Secretos da Aromaterapia e Tenha Mais Qualidade de Vida. São Paulo, 2018.

TISSERAND, Robert. A arte da aromaterapia. 13.ed. São Paulo: Roca, 1993. 
- unIPAR 50 anos:

I SALAOO DE EXTENSÃO Transformando vidas atravies da educaģso

DA UNIPAR 


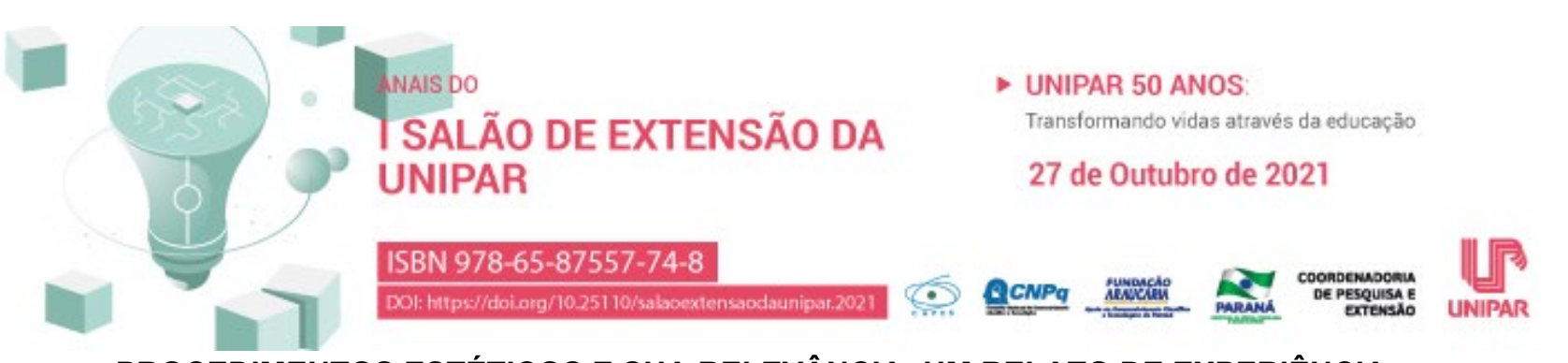

PROCEDIMENTOS ESTÉTICOS E SUA RELEVÂNCIA: UM RELATO DE EXPERIÊNCIA

\author{
${ }^{1}$ ThAis GABRIELI ROSANELI, ${ }^{2}$ RAFAELA GEOVANA MELlE, ${ }^{3}$ CAMILA CHIAPETTI, ${ }^{4}$ LUANA dOS SANTOS, ${ }^{5}$ ANA JULIA \\ GONCALVES, ${ }^{6}$ KELLI KUHNEN, ${ }^{7}$ LUCIANA PELLIZZARO, ${ }^{8}$ JULIANA PELISSARI MARCHI
}

\begin{abstract}
${ }^{1}$ Acadêmica participante do Projeto de Extensão Estética na Comunidade, do C.S.T. em Estética e Cosmética da Universidade Paranaense, UNIPAR.

${ }^{2}$ Acadêmica participante do Projeto de Extensão Estética na Comunidade, do C.S.T. em Estética e Cosmética da Universidade Paranaense, UNIPAR.

${ }^{3}$ Acadêmica participante do Projeto de Extensão Estética na Comunidade, do C.S.T. em Estética e Cosmética da Universidade Paranaense, UNIPAR.

${ }^{4}$ Acadêmica participante do Projeto de Extensão Estética na Comunidade, do C.S.T. em Estética e Cosmética da Universidade Paranaense, UNIPAR.

${ }^{5}$ Acadêmica participante do Projeto de Extensão Estética na Comunidade, do C.S.T. em Estética e Cosmética da Universidade Paranaense, UNIPAR.

${ }^{6}$ Responsável Técnica do Centro de Estética Escola do C.S.T. em Estética e Cosmética da Universidade Paranaense, UNIPAR.

${ }^{7}$ Docente do C.S.T. em Estética e Cosmética da Universidade Paranaense, UNIPAR.v

${ }^{8}$ Docente do C.S.T. em Estética e Cosmética da Universidade Paranaense, UNIPAR.
\end{abstract}

Introdução: As atividades do Projeto correlacionam a teoria com a prática. No dia 22 de junho de 2021 no período vespertino, nos laboratórios da UNIPAR, foram realizados atendimentos de design de sobrancelhas, hidratação facial e capilar, num grupo de mulheres. Durante a prática foram repassadas instruções sobre os procedimentos realizados e orientações gerais sobre os cuidados com a pele e cabelo: não usar água quente para a higienização, usar cosméticos adequados ao biotipo e realizar hidratação periodicamente (AMARAL; SOUZA, 2019; DAMAZIO; MAKINO, 2017).

Objetivo: Relatar a experiência de atividades realizadas com um grupo de mulheres, pelo Projeto de Extensão Estética na Comunidade.

Resultados: Os atendimentos favoreceram a inter-relação entre teoria e prática, permitiram vivenciar na prática o atendimento humanizado, favoreceram o diálogo com mulheres de diferentes faixas etárias, etnias e classe social, além de permitir o contato com diferentes tipos de pele e cabelo. Além disso, ampliaram a bagagem teórica, uma vez que o estudo científico foi necessário antes da realização da prática. O procedimento de design de sobrancelhas promove destaque dos traços de beleza individuais, eleva a autoestima e a autoconfiança das mulheres (KAMIZATO, 2013). Os procedimentos cosméticos realizados promoveram hidratação cutânea e capilar, com isso, ressaltaram os traços de beleza individuais. Na pele o tratamento fortalece e restaura a camada hidrolipídica, deposita ativos hidratantes e nutritivos, restabelece o equilíbrio cutâneo, ativa a normalidade do tecido e melhora o aspecto cutâneo. Nos cabelos, o procedimento deposita ativos hidratantes e nutritivos, fecha a cutícula dos fios e forma um filme protetor. Assim, o procedimento de hidratação deixou tanto a pele quanto os cabelos, protegidos contra variações das condições ambientais e às agressões físicas, mantendo-os saudáveis e protegidos. Por fim, os procedimentos contribuíram com o bem-estar e qualidade de vida das pessoas envolvidas (BENY, 2013; RIBEIRO, 2010; DAMAZIO; MAKINO, 2017).

Conclusão: $O$ atendimento estético deve ser humanizado contribuindo diretamente com a saúde, uma vez que esses procedimentos promovem acolhimento, ressaltam a beleza, elevam a autoestima e a autoconfiança, garantem o bem-estar físico e mental e portanto, melhoram a qualidade de vida.

\title{
Referências
}

AMARAL, Karina Fabrícia Vaz; SOUZA, Rafaela Brito Arêas. A Importância da Hidratação Cutânea para melhor tratamento das Disfunções Estéticas. Id on Line Rev. Mult. Psic. v.13, n. 48, 2019. Disponível em: https://idonline.emnuvens.com.br/id/article/view/2284/3505. Acesso em: 20 ago. 2021.

BENY, Mariana. Histologia e Fisiologia da Pele (Série Fundamento de Cosmetologia), Cosmetics \& Toiletries Brasil, São Paulo SP, v. 25, n. 2, p. 34-40, mar./abr. 2013.

DAMAZIO, Marlene Gabriel; MAKINO, Rosa de Fátima Lago. Terapia Capilar:Uma Abordagem Inter e Multidisciplinar. RED, 2017.

KAMIZATO, Karina Kiyoko. Imagem pessoal e visagismo. Érica, 2013.

RIBEIRO, Cláudio. Cosmetologia aplicada a Dermoestética. 2. ed. LMC - Pharmabooks, 2010. 
- unIPAR 50 anos:

I SALAOO DE EXTENSÃO Transformando vidas atravies da educaģso

DA UNIPAR 


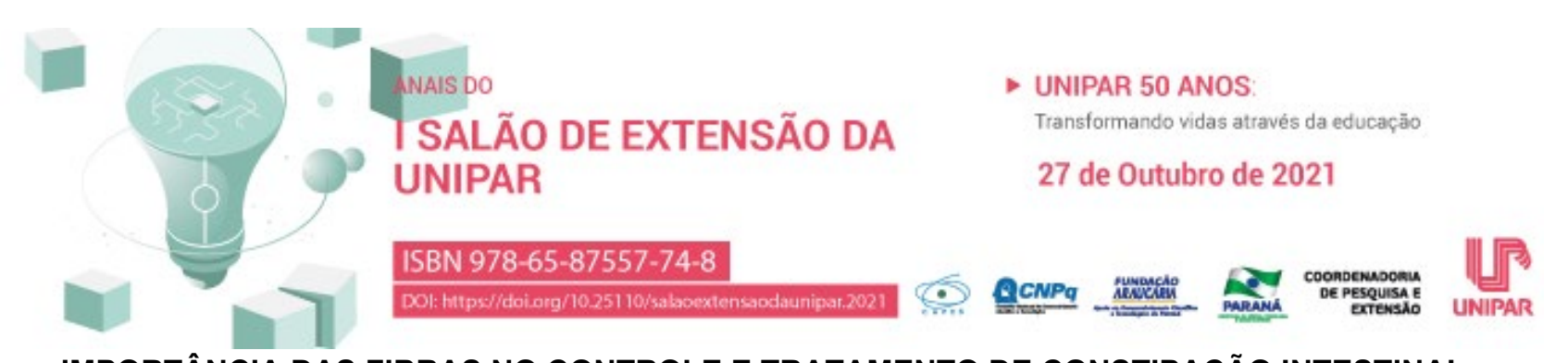

\title{
IMPORTÂNCIA DAS FIBRAS NO CONTROLE E TRATAMENTO DE CONSTIPAÇÃO INTESTINAL
}

\author{
${ }^{1}$ RENATA CAROLINA DELLA RIVA, ${ }^{2}$ ANA LETICIA MIKA YASSUE, ${ }^{3}$ MONICA DO VALE ASSIS GARCIA SANTINI, ${ }^{4}$ LIDIANE \\ NUNES BARBOSA
}

${ }^{1}$ Discente do curso de Nutrição e Participante do Programa de Iniciação a Extensão - PEX/UNIPAR

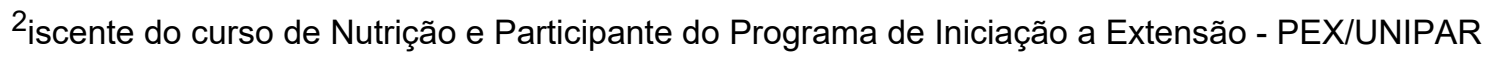

${ }^{3}$ Responsável técnica da Clínica de Nutrição da Unipar

${ }^{4}$ Docente da UNIPAR

Introdução: A constipação intestinal é a queixa digestiva mais comum na população em geral e costuma ser tratada com base na impressão do paciente sobre existir uma alteração no funcionamento do seu intestino (OLIVEIRA; SILVA, 2018). Entretanto, esse termo apresenta significados variados para pessoas diferentes, desde fezes endurecidas ou em pouca quantidade para alguns até a evacuação difícil, incompleta ou infrequente para outros (OLIVEIRA; SILVA, 2018). Assim, a constipação intestinal pode ser definida como uma frequência de evacuações menor do que três vezes por semana (OLIVEIRA; SILVA, 2018). O consumo de fibras pode melhorar os sintomas de pacientes constipados, elas estão disponíveis em vários alimentos e suplementos alimentares, tendo em vista que os suplementos de fibras apresentam baixo custo, além de serem fáceis e seguros de usar, costumam ser primordialmente empregados no manejo da constipação intestinal, em detrimento aos medicamentos (OLIVEIRA; SILVA, 2018). Diante disso, foi verificada uma conduta a fim de auxiliar no tratamento da constipação intestinal .

Objetivo: Relatar o caso de um paciente, atendido na clínica de nutrição da Unipar, tratado com $35 \mathrm{~g}$ de fibras na dieta para a melhora da constipação intestinal.

Resultados: A estratégia abordada nesse caso foi o manejo de uma dieta rica em fibras, no qual foi ofertado $35 \mathrm{~g} / \mathrm{dia}$ (Escott, 2011), associado a ingestão adequada de água. Foi aumentada a biodisponibilidade de nutrientes na alimentação, adicionando mais alimentos integrais, frutas, verduras, legumes e baixo consumo de alimentos ultraprocessados e foi adicionado também, a ameixa preta seca, que é um ótimo alimento para ajudar com esse problema intestinal. A paciente possuía sobrepeso e não praticava atividade física, seu GEB era de $1470 \mathrm{kcal}$, e seu GEB de $2050 \mathrm{kcal}$, então foi aplicado a fórmula de VENTA e foi ofertado uma dieta hipocalórica com $1600 \mathrm{kcal}$ para que houvesse o emagrecimento. Após 20 dias de tratamento, com o mesmo plano alimentar, a paciente já relatou a melhora na consistência e frequência de evacuações, e além disso relatou a melhora do sono, do cabelo, eliminou $1,5 \mathrm{~kg}$ e estava se sentindo bem melhor.

Conclusão: A importância de um acompanhamento nutricional individualizado é essencial para garantir bons resultados no tratamento de patologias. A dieta personalizada rica em fibras e nutrientes necessários para o problema e queixa do paciente, foi a forma mais eficaz na intervenção da constipação intestinal, nota-se que a conduta nutricional apresentou excelentes resultados no tratamento da constipação intestinal, sugerindo que uma dieta rica em fibras é a melhor alternativa para o tratamento de constipação intestinal.

\section{Referências}

ESCOTT, Sylvia Stump. Nutrição relacionada ao diagnóstico e tratamento. 6 ed, pg 418 e 594 - Barueri Sp, 2011. OLIVEIRA, Aline Marcadenti. SILVA, Flávia Moraes. Dietoterapia das doenças do adulto. 1. ed. Rio de Janeiro: Rubio, 2018.

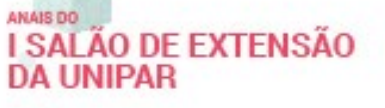

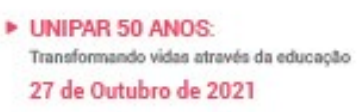

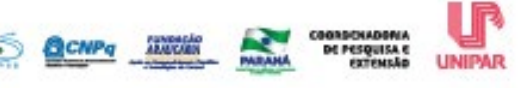




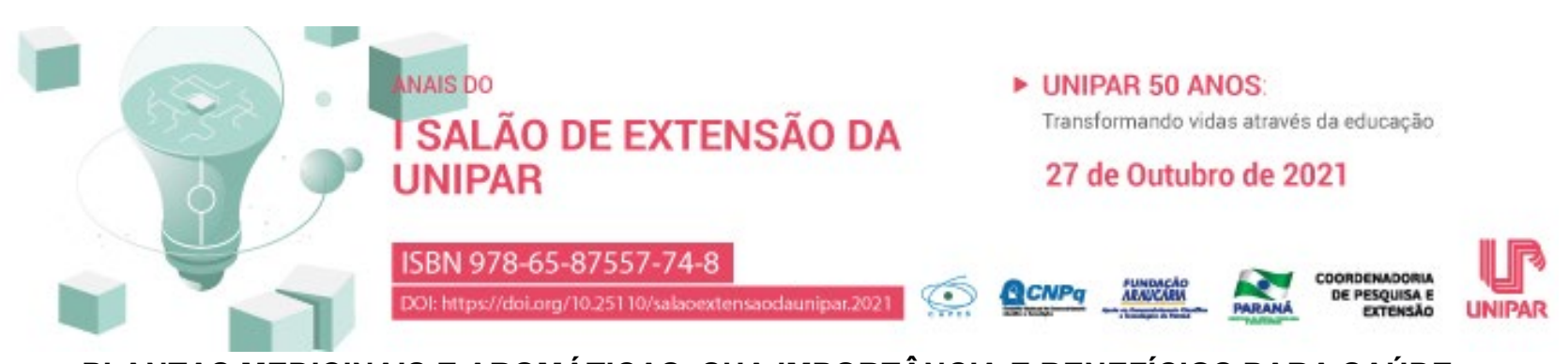

\title{
PLANTAS MEDICINAIS E AROMÁTICAS: SUA IMPORTÂNCIA E BENEFÍCIOS PARA SAÚDE
}

\author{
${ }^{1}$ ALESSANDRA TOBIAS DOS SANTOS, ${ }^{2}$ CAMILA GONCALVES DE BARROS, ${ }^{3}$ MARIANA RAFAELLY PIGOZZO RAMOS, \\ ${ }^{4}$ LUANA PILAR GRONDONA, ${ }^{5}$ KELLI KUHNEN, ${ }^{6}$ SIMONE CASTAGNA ANGELIM COSTA, ${ }^{7}$ RAQUEL COSTA MACHADO, \\ ${ }^{8}$ ROMIR RODRIGUES, ${ }^{9}$ JULIANA PELISSARI MARCHI
}

\begin{abstract}
${ }^{1}$ Acadêmica participante do Programa Institucional Centro de Estética e Cosmética Escola, do C.S.T. em Estética e Cosmética da UNIPAR.

${ }^{2}$ Acadêmica participante do Programa Institucional Centro de Estética e Cosmética Escola, do C.S.T. em Estética e Cosmética da UNIPAR.

${ }^{3}$ Acadêmica participante do Programa Institucional Centro de Estética e Cosmética Escola, do C.S.T. em Estética e Cosmética da UNIPAR.

${ }^{4}$ Acadêmica participante do Programa Institucional Centro de Estética e Cosmética Escola, do C.S.T. em Estética e Cosmética da UNIPAR.

${ }^{5}$ Responsável Técnica do Centro de Estética Escola do C.S.T. em Estética e Cosmética da Universidade Paranaense, UNIPAR.

${ }^{6}$ Docente do C.S.T. em Estética e Cosmética da Universidade Paranaense, UNIPAR.

${ }^{7}$ Docente do C.S.T. em Estética e Cosmética da Universidade Paranaense, UNIPAR.

${ }^{8}$ Docente do C.S.T. em Estética e Cosmética da Universidade Paranaense, UNIPAR.

${ }^{9}$ Docente do C.S.T. em Estética e Cosmética da Universidade Paranaense, UNIPAR.
\end{abstract}

Introdução: O uso de plantas medicinais e fitoterápicos se dá a partir de uma luta que remonta à época anterior à criação do Sistema Único de Saúde (SUS), em que diversas classes, como pesquisadores, gestores, profissionais de saúde e usuários tiveram papel fundamental (BRASIL, 2011). O Brasil tem uma rica história de uso das plantas medicinais para tratamento na saúde da população, o seu uso está construído com base na experiência e transmitido de forma oral (TISSERAND, 1993). Com base nisso, realizamos a gravação de um vídeo sobre o uso de plantas medicinais em terapias integrativas que está sendo divulgado por meios digitais.

Objetivo: Relatar a experiência de atividades desenvolvidas no Programa Institucional Plantas Medicinais e Aromáticas: sua importância e benefícios para a saúde da UNIPAR.

Resultados: A gravação do vídeo foi realizada no dia 05 de agosto, no laboratório de terapia capilar da Universidade Paranense e consistiu em duas etapas: a primeira etapa foi a de preparação do sal para o escalda pés, abordando cada um dos elementos utilizados: sal grosso, plantas (alecrim e erva-doce), óleos essenciais de erva-doce (Foeniculum vulgare) e hortelã pimenta (Mentha piperita); a segunda etapa consistiu na aplicação da técnica de escalda pés: iniciou com a preparação da pele (higienização e esfoliação), depois com a preparação do material (água morna, esferas de vidro, sal já preparado, rodelas de limão e laranja), execução do procedimento e a finalização deste com massagem nos pés, para isso utilizou-se um creme neutro com adição dos óleos essenciais de erva-doce (Foeniculum vulgare) e hortelã pimenta (Mentha piperita). A divulgação do vídeo para a população em geral contribuiu com informações científicas, dicas e orientações sobre o uso de plantas medicinais e óleos essenciais nos cuidados home care, com segurança, uma vez que estes possuem doses adequadas, indicações e contra indicações (ROSE, 1995; BRUNING.; MOSEGUI.; VIANNA, 2012; SACCO; FERREIRA, 2015). A técnica de escalda pés melhora a circulação sanguínea e linfática, diminui o edema e a dor, promovendo bem-estar e relaxamento, assim, melhorando a qualidade de vida (AGUIR et al., 2020).

Conclusão: Com a atividade realizada, obtivemos resultados na diminuiçao do edema local, relaxamento e promoção do bemestar. Também pudemos compartilhar conhecimentos e beneficiar a população com os benefícios do escalda pés e uso de plantas medicinais e óleos essenciais, favorecendo assim, que eles obtenham equilíbrio físico, mental e energético com o uso correto e seguro desta técnica.

\section{Referências}

AGUIR, Fernanda Soares de; et al. Escalda-pés e os benefícios à saúde no processo de cuidado de enfermagem. Salão do Conhecimento Unijuí 2020, Santo Angelo, 2020. Disponível em: https://www.publicacoeseventos.unijui.edu.br/index.php/salaoconhecimento/article/view/18363/17097. Acesso em: 23 ago. 2021. BRASIL. Agência Nacional de Vigilância Sanitária. Formulário de Fitoterápicos da Farmacopeia Brasileira. Brasília: Anvisa, 2011. Disponível em www.anvisa.gov.br. Acesso em: 23 ago. 2021. 
BRUNING, Maria Cecilia Ribeiro; MOSEGUI, Gabriela Bittencourt Gonzalez; VIANNA, Cid Manso de Melo; A utilização da fitoterapia e de plantas medicinais em unidades básicas de saúde nos municípios de Cascavel e Foz do Iguaçu-Paraná: a visão dos profissionais de saúde. Ciência e Saúde coletiva, v. 17, n. 10, p. 2.675-2.685, 2012. Disponível em: http://www.scielosp.org/pdf/csc/v17n10/17.pdf. Acesso em: 23 ago. 2021.

ROSE, Jeanne. O livro da Aromaterapia: aplicações e inalações. Rio de Janeiro: Campus; 1995.

SACCO, Patrine Roman; FERREIRA, Graziele Cristina Garcia Bernardino; SILVA, Ana Claudia Calazans; da Aromaterapia no auxílio do combate ao estresse: bem-estar e qualidade de vida. Revista Científica da FHO|UNIARARAS, Araras, v. 3, n. 1, 2015. TISSERAND, Robert. A arte da Aromaterapia. São Paulo: Roca; 1993.

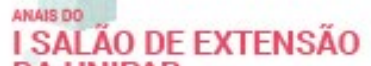

DA UNIPAR
- UNIPAR 50 ANOS:

Traneformando vidas atrevela da educapto

27 de Outubro de 2021

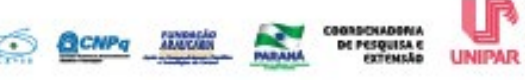




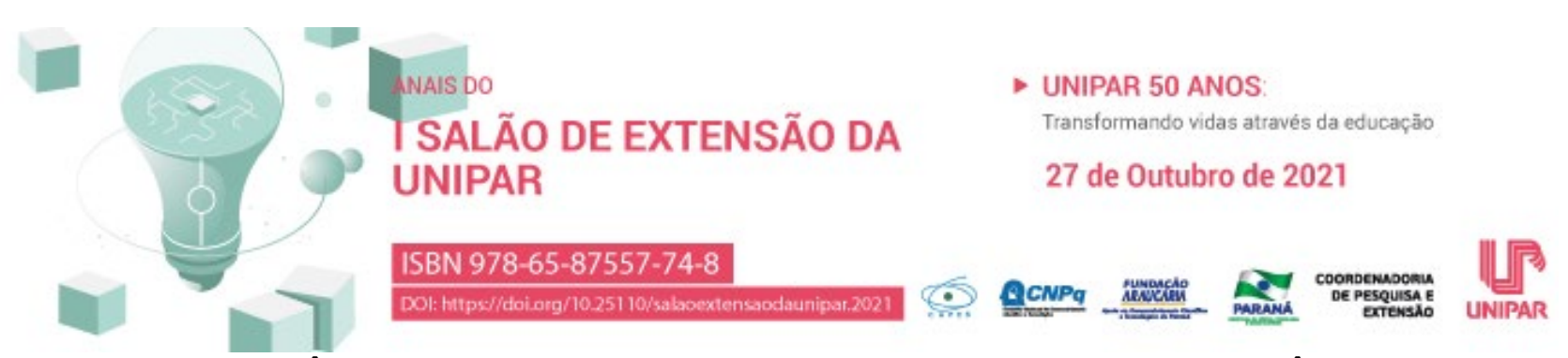

A IMPORTÂNCIA DO USO DO PROTETOR SOLAR: UM RELATO DE EXPERIÊNCIA

\author{
${ }^{1}$ ANA CAROLINA HUNHOFF, ${ }^{2}$ DANIELI DA SILVA ROSA, ${ }^{3}$ LUCINEIA CRISTIANE SCHMIDT, ${ }^{4} \mathrm{KELLI} \mathrm{KUHNEN,}{ }^{5}$ RAQUEL \\ COSTA MACHADO, ${ }^{6}$ SIMONE CASTAGNA ANGELIM COSTA, ${ }^{7}$ JULIANA PELISSARI MARCHI
}

\begin{abstract}
${ }^{1}$ Acadêmica participante do Programa Institucional Centro de Estética e Cosmética Escola, do C.S.T. em Estética e Cosmética da UNIPAR.

${ }^{2}$ Acadêmica participante do Programa Institucional Centro de Estética e Cosmética Escola, do C.S.T. em Estética e Cosmética da UNIPAR.

${ }^{3}$ Acadêmica participante do Programa Institucional Centro de Estética e Cosmética Escola, do C.S.T. em Estética e Cosmética da UNIPAR.

${ }^{4}$ Responsável Técnica do Centro de Estética Escola do C.S.T. em Estética e Cosmética da Universidade Paranaense, UNIPAR.

${ }^{5}$ Docente do C.S.T. em Estética e Cosmética da Universidade Paranaense, UNIPAR.

${ }^{6}$ Docente do C.S.T. em Estética e Cosmética da Universidade Paranaense, UNIPAR.

${ }^{7}$ Docente do C.S.T. em Estética e Cosmética da Universidade Paranaense, UNIPAR.
\end{abstract}

Introdução: No decorrer dos atendimentos no projeto, observamos que muitos dos clientes não utilizavam protetor solar diariamente, sabemos que a incidência do câncer de pele tem aumentado nos últimos anos devido ao aumento da radiação ultravioleta (UV) penetrando na superfície terrestre com facilidade. Para nos protegermos destes raios UV temos uma gama de fatores de proteção solar, que reduzem a quantidade de raios absorvidos pela pele (DE ARAÚJO; SOUZA., 2008). Com intuito informativo, foi elaborada e divulgada para o público geral uma cartilha que retrata como avaliar o protetor solar na hora da compra e como utilizá-lo.

Objetivo: Relatar a experiência de atividades desenvolvidas no Programa Institucional Centro de Estética e Cosmética Escola da UNIPAR, além de abordar o tema indagado na cartilha.

Resultados: Aperfeiçoar a prática, visualizar disfunções cutâneas e indagar sobre a necessidade de elaborar e divulgar materiais informativos sobre cuidados com a pele, prevenção de patologias e disfunções cutâneas. A pesquisa bibliográfica para elaboração da cartilha mostrou, que o sol tem um papel fundamental na vida do ser humano, trazendo muitos benefícios a ele, mas a exposição excessiva à radiação pode trazer muitos malefícios, sendo necessário evitar exposição solar prolongada, bem como evitar se expor entre as $10 \mathrm{~h} 00$ às $16 \mathrm{~h} 00$, usar protetor solar, chapéu, roupas protetoras (SCHALKA, et al., 2014). O protetor solar é o meio de proteção mais comum, ele atua tanto na absorção quanto na dissipação dos raios UV na pele, devido possuir filtros orgânicos e/ou inorgânicos, assim, protege a pele de queimaduras e eritemas, do câncer de pele e do fotoenvelhecimento (FLOR; DAVOLOS; CORREA, 2007; DIDIER; BRUM; AERTS, 2014). A base cosmética (creme, loção, emulsão, gel creme, sérum) deve ser escolhida de acordo com o biotipo cutâneo. Outro fator importante a ser avaliado é o FPS (medida de proteção contra os raios UVB) e o PPD (medida de proteção contra raios UVA) (FLOR; DAVOLOS; CORREA, 2006). A aplicação do protetor solar deve ser feita em todo o corpo, e reaplicado a cada $2 \mathrm{~h}$ em quantidade adequada. $\mathrm{O}$ uso de protetor solar é de suma importância para a saúde e proteção da pele (PIACENTINI et al., 2011).

Conclusão: Com os atendimentos realizados e com a elaboração da cartilha, concluímos que é papel do esteticista orientar a população quanto ao uso correto de protetor solar, para isso se faz necessário elaboração de materiais informativos e orientações.

\title{
Referências
}

DE ARAÚJO, Tatiana Santos; DE SOUZA, Susana Oliveira. Protetores solares e os efeitos da radiação ultravioleta. Scientia plena, v. 4, n. 11, 2008.

DIDIER, Flávia Barreto Campello Walter; BRUM, Lucimar Filot da Silva; AERTS, Denise Rangel Ganzo de Castro. Hábitos de exposição ao sol e uso de fotoproteção entre estudantes universitários de Teresina, Piauí. Epidemiologia e Serviços de Saúde, 23: 487-496, 2014.

FLOR, Juliana; DAVOLOS, Marian Rosaly; CORREA, Marcos Antonio. Protetores solares. Química nova, v. 30, p. 153-158, 2007.

SCHALKA, Sérgio; STEINER, Denise; RAVELLI, Flávia Naranjo; STEINER, Tatiana; TERENA, Aripuanã Cobério; MARÇON, Carolina Reato;AYRES, Eloisa Leis; ADDOR, Flávia Alvim Sant'anna; MIOT, Helio Amante; DUARTE, Humberto Ponziolda; NEFFÁ, Jane; DA CUNHA, José Antônio; BOZA, Juliana Catucci; SAMORANO, Luciana de Paula; CORREAA, Marcelo de Paula; 
MAIA, Marcus; NASSER, Nilton; LEITE, Olga Maria Rodrigues Ribeiro; LOPES, Otávio Sergio; OLIVEIRA, Pedro Dantas; MEYER, Renata Leal Bregunci; CESTARI, Tânia; DOS REIS, Vitor Manuel Silva; REGO, Vitória Regina Pedreira de Almeida. Brazilian consensus on photoprotection. Anais brasileiros de dermatologia, v. 89, p. 1-74, 2014.

PIACENTINI, Rubén; SALUM, Graciela Marisa; FRAINDENRAICH, Naum; TIBA, Chigueru. Extreme total solar irradiance due to cloud enhancement at sea level of the NE Atlantic coast of Brazil. Renewable Energy, v. 36, n. 1, p. 409-412, 2011.

I SALÃO DE EXTENSÃO " UNIPAR 50 ANOS:

DA UNIPAR 


\title{
Pre
}

\author{
${ }^{1}$ JULIA LORRANE BRAZ SILVA, ${ }^{2}$ JOSE ANTONIO JUNIOR FIGUEREDO, ${ }^{3}$ GUILHERME ZAN MENEGUIM, ${ }^{4}$ MARIA EDUARDA \\ SOARES, ${ }^{5}$ ANA PAULA TORQUETI GAVIOLI
}

\author{
${ }^{1}$ Acadêmico bolsista PIBEX/UNIPAR \\ ${ }^{2}$ Acadêmico do Curso de Arquitetura e Urbanismo da UNIPAR \\ ${ }^{3}$ Acadêmico do Curso de Arquitetura e Urbanismo da UNIPAR \\ ${ }^{4}$ Acadêmica do Curso de Arquitetura e Urbanismo da UNIPAR \\ ${ }^{5}$ Docente da UNIPAR
}

Introdução: Dentro da extensão os alunos devem adquirir habilidades da profissão, compreender a prática de maneira conectada com o mundo real. Vivemos em uma sociedade cada vez mais digital e interconectada. Muitos escritórios hoje apresentam e vendem serviços e produtos através das redes sociais. A plataforma Instagram foi idealizada com o intuito de compartilhar fotos e vídeos com pessoas do mundo todo e firmar amizades. Porém a ferramenta popularizou-se e recentemente tem se tornado uma profissão para muitas pessoas que criam conteúdo (MORAIS et al, 2020. Segundo Hunt (2010), as empresas estão utilizando as redes sociais para formar uma base, se conectarem com pessoas e alcançarem clientes em potencial.

Objetivo: apresentar os resultados da atividade Criação de Conteúdo para o Instagram, desenvolvida pelo projeto de extensão Escritório Modelo de Arquitetura e Engenharia EMAE de Cianorte.

Resultados: As atividades aconteceram da seguinte maneira: seleção dos temas, elaboração dos materiais (imagens e texto) e postagem no perfil. Todas as etapas foram supervisionadas pela professora responsável. $O$ aprendizado aconteceu em 4 esferas: pesquisa, imagem/criação de artes, escrita e planejamento. Na esfera pesquisa, o aluno seleciona um assunto e faz uma pesquisa sobre ele. Na esfera imagem o aluno seleciona uma imagem de banco de imagens ou elabora uma arte utilizando a ferramenta Canva, a qual aprendem a usar no EMAE - Cianorte. Nesta esfera, tanto ao buscar pela imagem quanto ao utilizar o Canva é possível treinar o olhar do aluno para cor, equilíbrio e demais elementos de composição. Pela escrita o aprendizado acontece ao elaborarem a redação, o texto que acompanhará a imagem. E por último o planejamento: os alunos aprendem a planejar as postagens/conteúdos. Destaca-se que o ensino/aprendizagem acontece não só para os alunos que estão produzindo, mas também para todos que acessarem o material na rede social.

Conclusão: Observa-se que o aprendizado acontece de maneira multidisciplinar, envolvendo criação de arte, pesquisa, escrita e organização. Acontece um processo de produção. Além disso, por ser digital, o conteúdo produzido pelos alunos consegue chegar até a comunidade de maneira eficiente e rápida.

\section{Referências}

HUNT, Tara. O poder das redes sociais. São Paulo: Editora Gente, 2010.

NORAIS, Natallya Silva Dantas; BRITO, Max Leandro de Araújo. Marketing digital através da ferramenta Instagram. Revista EAcadêmica, Vargem Grande Paulista, v. 1, n. 1, e3, 2020.

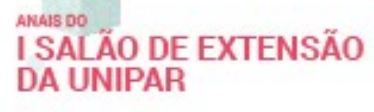

I SALÁO DE EXTENSÃO DA UNIPAR
- UNIPAR 50 ANOS: Transformando vidas atravis da educaça 27 de Outubro de 2021

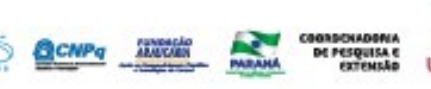




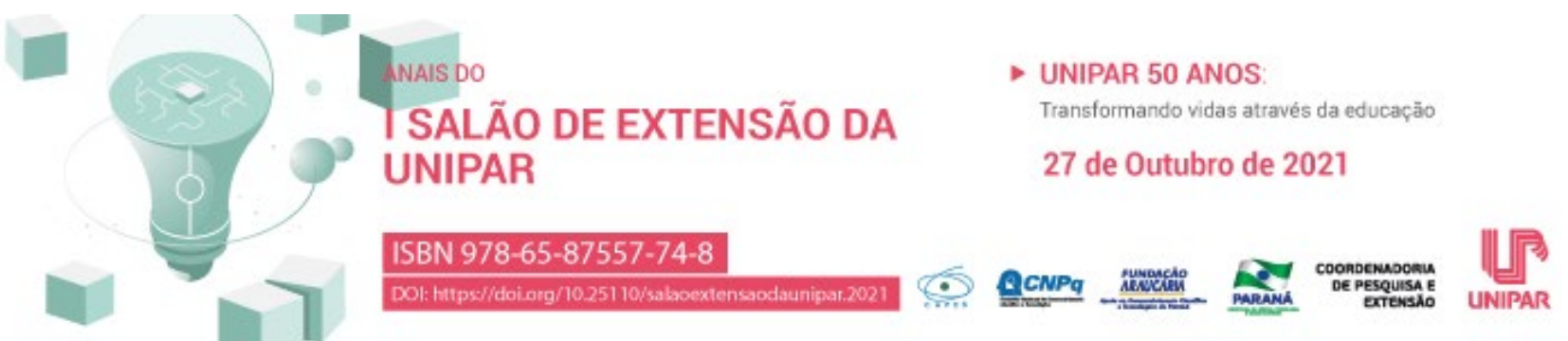 \\ ALEITAMENTO MATERNO: UMA RESPONSABILIDADE DA COMUNIDADE}

1'LARA MARIA SOUZA MARCONDES COLOGNESI, ${ }^{2}$ DANILLO PRECHLAK DE SOUZA, ${ }^{3}$ HELOUYZE CHRYSTHYNAH ALBANO ASSIS DOS SANTOS, ${ }^{4}$ ISABELA TONON LAINO, ${ }^{5}$ LUISA BATISTA DORNELLES, ${ }^{6}$ NARA RUBIA GONCALVES, ${ }^{7}$ ANA BEATRIZ DOS SANTOS SERRAGLIO, ${ }^{8}$ THAYNE ZIMERMANN DURIGON, ${ }^{9}$ ANA BEATRIZ DOS SANTOS SERRAGLIO, ${ }^{10}$ LAUHANY PAULA HENZ, ${ }^{11}$ RENAN CORADIN, ${ }^{12}$ RAYANE BIOLCHI, ${ }^{13}$ ISABELLA ACACIO FERREIRA DE SOUZA, ${ }^{14}$ KARINA DETOFOL, ${ }^{15}$ ANA MARIA MIYAWAKI PAULINO, ${ }^{16}$ EZEQUIEL MATTEI

${ }^{1}$ Acadêmico do curso de Medicina da UNIPAR

${ }^{2}$ Acadêmico do Curso de Medicina da UNIPAR

${ }^{3}$ Acadêmica do Curso de Medicina da UNIPAR

${ }^{4}$ Acadêmica do Curso de Medicina da UNIPAR

${ }^{5}$ Acadêmica do Curso de Medicina da UNIPAR

${ }^{6}$ Acadêmica do Curso de Medicina da UNIPAR

${ }^{7}$ Acadêmica do Curso de Medicina da UNIPAR

${ }^{8}$ Acadêmica do Curso de Medicina da UNIPAR

${ }^{9}$ Acadêmica do Curso de Medicina da UNIPAR

${ }^{10}$ Acadêmica do Curso de Medicina da UNIPAR

${ }^{11}$ Acadêmico do Curso de medicina da UNIPAR

${ }^{12}$ Acadêmica do Curso de Medicina da UNIPAR

${ }^{13}$ Acadêmica do Curso de Medicina da UNIPAR

${ }^{14}$ Acadêmica do Curso de Medicina da UNIPAR

${ }^{15}$ Acadêmica do Curso de Medicina da UNIPAR

${ }^{16}$ Docente da UNIPAR

Introdução: O aleitamento materno proporciona vantagens imediatas e futuras à saúde da mulher, bem como é a forma mais efetiva e acessível para promover prevenção da morbidade e mortalidade infantil (FEBRASGO, 2021). Ressalta-se que o aleitamento é fundamental para o estabelecimento do vínculo entre a mãe e o bebê, levando ao recém-nascido a sensação de segurança e estabilidade (PIRES et al., 2012). O aleitamento também auxilia na redução do sangramento uterino pós-parto, pela maior liberação de ocitocina (REA, 2004). De acordo com o presidente do Departamento Científico de Aleitamento Materno da Sociedade Brasileira de Pediatria (SBP), Dr. Luciano Borges Santiago, a mulher precisa ter a proteção do aleitamento em todos os âmbitos, seja em casa, com a família e, até mesmo, os vizinhos; no trabalho, amparada pelas leis; na imprensa, com a divulgação de informações corretas sobre o assunto (SBP, 2021). Diante disso, a Liga Acadêmica de Ginecologia e Obstetrícia (LAGO) considera imprescindível estimular a doação de leite e a compreensão da população sobre o papel do aleitamento materno.

Objetivo: Divulgar e apoiar a campanha do Agosto Dourado de 2021, enfatizando a importância do aleitamento materno, assim como seu incentivo.

Resultados: A LAGO participou ativamente na divulgação da Campanha Agosto Dourado 2021, realizada pela Associação Beneficente de Saúde do Noroeste do Paraná (Norospar), cujo tema foi Proteja a amamentação: uma responsabilidade compartilhada , idealizado pela Aliança Mundial para Ação de Aleitamento Materno. Além da conscientização, a campanha teve como objetivo a arrecadação de leite materno. Uma das ferramentas utilizadas para a divulgação da campanha foi a participação do Dr. Ezequiel Mattei no programa MedTalks, evento em que foi explicado a importância do tema à população. Ademais, a Liga Acadêmica de Medicina da Família e Comunidade juntamente com a Secretaria Municipal de Saúde realizaram uma campanha de arrecadação de frascos de vidro para o armazenamento do leite doado, a qual a LAGO também participou por meio de divulgações.

Conclusão: $O$ aleitamento materno é a principal fonte de nutrição e proteção disponível, além de ser uma forma econômica e eficiente, a qual auxilia na redução da morbidade e mortalidade infantil. $O$ benefício se estende até a mãe, evidenciando a 
necessidade de incentivo e proteção do aleitamento materno.

\section{Referências}

Federação Brasileira das Associações de Ginecologia e Obstetrícia - FEBRASGO. Aleitamento materno. Protocolo FEBRASGOObstetrícia, n. 13/Comissão Nacional Especializada em Aleitamento Materno. São Paulo: FEBRASGO, 2021.

PIRES, M. M. S. et al. Manual de orientação do departamento de nutrologia: alimentação do lactente, do pré-escolar, do escolar, do adolescente e na escola. $3^{a}$ edição. Rio de Janeiro. Sociedade Brasileira de Pediatria, p. 41, 2012.

REA, Marina F. Os benefícios da amamentação para a saúde da mulher. Jornal de pediatria, v. 80, p. s142-s146, 2004. Sociedade Brasileira de Pediatria - SBP. SMAM 2021 exalta que a amamentação deve ser compreendida como uma responsabilidade compartilhada. 2021. Disponível em: www.sbp.com.br/imprensa/detalhe/nid/smam-2021-exalta-que-aamamentacao-deve-ser-compreendida-como-u ma-responsabilidade-compartilhada. Acesso em: 20 ago. 2021.

ANA1S Do

I SALÃO DE EXTENSÃO

DA UNIPAR
- UNIPAR 50 ANOS:

Traneformando vidas atraves da educacto

27 de Outubro de 2021

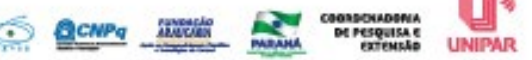




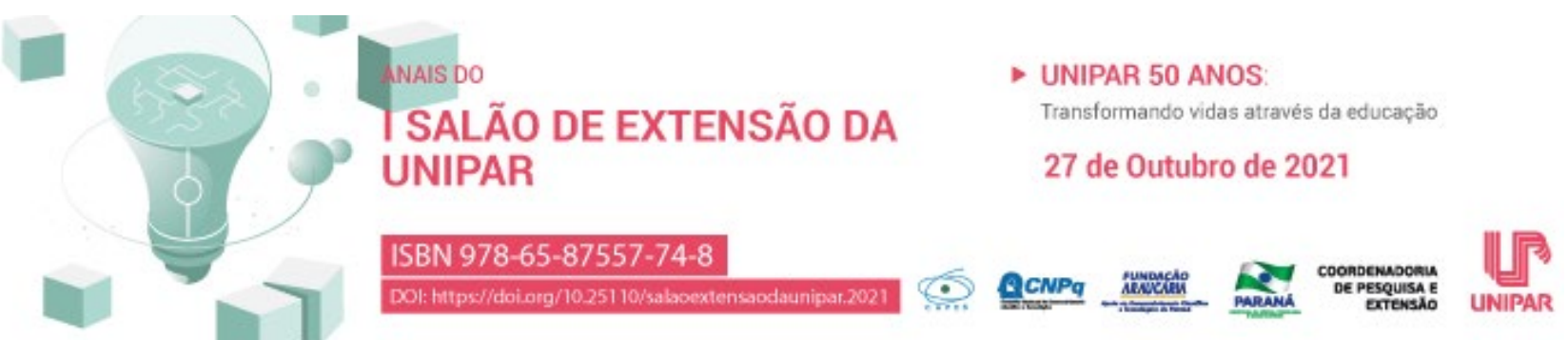 \\ CUIDADOS DIÁRIOS COM OS CABELOS: UMA CARTILHA INFORMATIVA
}

\author{
${ }^{1}$ TAIS dOS SANTOS GUMIERO, ${ }^{2}$ SIMONE CASTAGNA ANGELIM COSTA, ${ }^{3}$ RAQUEL COSTA MACHADO, ${ }^{4}$ GIOVANA MIOTO \\ DE MOURA, ${ }^{5}$ THAYNARA KLEINERT DE SOUZA, ${ }^{6}$ BRUNA HINDERSMANN BOLICO, ${ }^{7}$ TAIARA FABIAN, ${ }^{8}$ KELLI KUHNEN, \\ ${ }^{9}$ JULIANA PELISSARI MARCHI
}

\begin{abstract}
${ }^{1}$ Acadêmica participante do Programa Institucional Centro de Estética e Cosmética Escola, do C.S.T. em Estética e Cosmética da UNIPAR.

${ }^{2}$ Docente do C.S.T. em Estética e Cosmética da Universidade Paranaense, UNIPAR.

${ }^{3}$ Docente do C.S.T. em Estética e Cosmética da Universidade Paranaense, UNIPAR.

${ }^{4}$ Docente do C.S.T. em Estética e Cosmética da Universidade Paranaense, UNIPAR.

${ }^{5}$ Acadêmica participante do Programa Institucional Centro de Estética e Cosmética Escola, do C.S.T. em Estética e Cosmética da UNIPAR.

${ }^{6}$ Acadêmica participante do Programa Institucional Centro de Estética e Cosmética Escola, do C.S.T. em Estética e Cosmética da UNIPAR.

${ }^{7}$ Acadêmica participante do Programa Institucional Centro de Estética e Cosmética Escola, do C.S.T. em Estética e Cosmética da UNIPAR.

${ }^{8}$ Responsável Técnica do Centro de Estética Escola do C.S.T. em Estética e Cosmética da Universidade Paranaense, UNIPAR. ${ }^{9}$ Docente do C.S.T. em Estética e Cosmética da Universidade Paranaense, UNIPAR.
\end{abstract}

Introdução: Por meio do projeto realizamos atendimentos em estética (facial, corporal, capilar, imagem pessoal e terapias integrativas) à comunidade (interna e externa) e elaboramos uma cartilha intitulada Cuidados diários com os cabelos , divulgada para o público em geral.Algumas atitudes rotineiras podem impactar na saúde dos fios, e incomodam muito as mulheres que prezam a beleza dos cabelos, é importante ter os cuidados diários para qualquer tipo de cabelo, desde os mais saudáveis até os extremamente danificados, com os devidos cuidados é possível repor a água, devolver o brilho e a maciez dos fios (HERNANDEZ, 1999).

Objetivo: Relatar a experiência de atividades desenvolvidas no Programa Institucional Centro de Estética e Cosmética Escola da UNIPAR.

Resultados: As atribuições do projeto concederam experiência teórico-prática, por meio do conhecimento científico e atendimento ao público. Com a cartilha pudemos repassar orientações para a população, ressaltando que antes de adotar uma rotina para o cabelo, é importante levar em consideração o biotipo (seco, oleoso, misto ou normal), pois cada um demanda cuidados específicos. Para um bom resultado, além dos cuidados, é interessante associá-los a um cronograma capilar semanal, que inclui hidratação, nutrição, cauterização ou reconstrução dos fios, sempre levando em conta a necessidade de cada um (MANSUR, 2004). Produtos como shampoo, condicionador, máscaras e tônicos não podem faltar nessa rotina (GOMES; GABRIEL, 2006). Alimentação balanceada e a ingestão adequada de água é essencial para manter o ciclo de crescimento do cabelo em boas condições (HALAL, 2012). O hábito de dormir com os cabelos molhados traz danos ao couro cabeludo, pois a retenção de água no local gera um acúmulo de fungos e bactérias (LYON, 2015). A aplicação excessiva de calor pode desnaturar a queratina, proteína responsável pela elasticidade e resistência dos fios. Assim, é ideal evitar fontes de calor, como secadores, chapinhas e babyliss, ou aplicar algum protetor térmico antes de utilizá-los (NAKANO, 2006). Ademais, o ideal é lavar os fios com água morna ou fria e nunca quente (DOS SANTOS, 2017).

Conclusão: $O$ objetivo era auxiliar a comunidade sobre os cuidados diários com os cabelos. Observamos uma grande melhora na mudança de hábitos e a rotina dos cuidados essenciais para o bom funcionamento da saúde capilar.

\section{Referências}

DOS SANTOS, Andreza Carneiro. Fibra Capilar, Agentes de Coloração e Descoloração: Química, Mecanismos de Ação e Danos Oxidativos. 2017.

GOMES, Rosaline Kelly; DAMAZIO, Marlene Gabriel. Cosmetologia: descomplicando os princípios ativos. São Paulo: Livraria Médica Paulista, 2009.

HALAL, John. Tricologia e a química cosmética capilar. São Paulo: Cengage Learning, 2013.

HERNANDEZ, Micheline; FRESNEL, M. M. Manual de cosmetologia. Rio de Janeiro: Revinter, 1999.

LYON, Sandra; SILVA, Rozana Castorina da. Dermatologia estética: Medicina e Cirurgia Estética, Rio de Janeiro: MedBook, 
2015.

MANSUR, Cristina et al. Aprimoramentos no transplante de cabelo com laser de CO2: apresentação de três casos clínicos. Anais brasileiros de dermatologia, v. 79, n. 2, p. 199-204, 2004.

NAKANO, Adelino Kaoru et al. Comparação de danos induzidos em cabelos de três etnias por diferentes tratamentos. 2006.

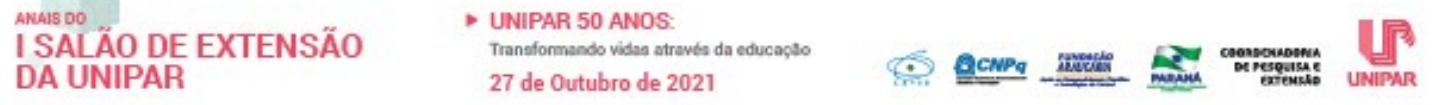




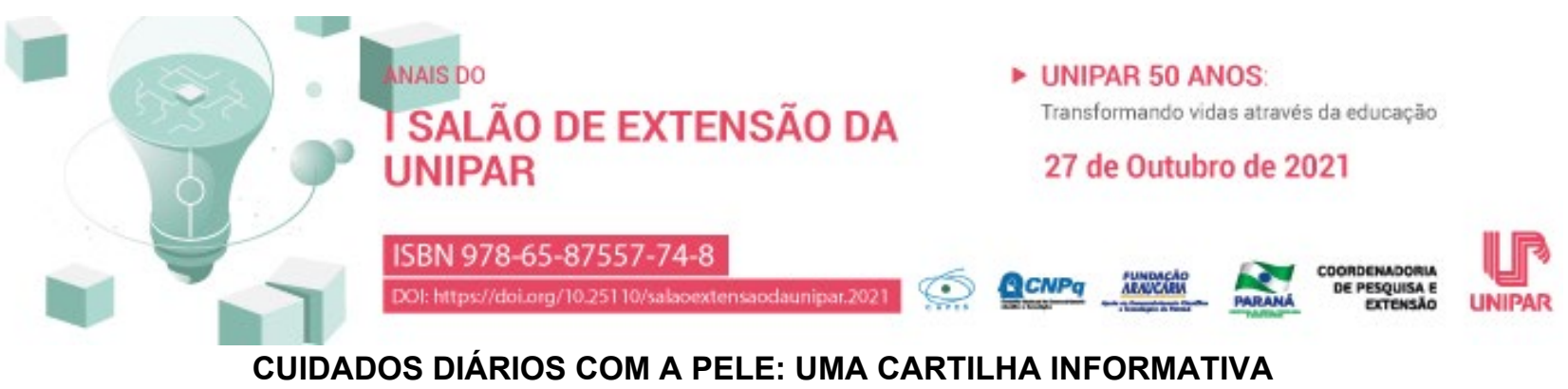

\author{
${ }^{1}$ VICTORIA RIBEIRO CEZAR, ${ }^{2}$ ANA ALINE SONZAVO, ${ }^{3}$ DEISE DA SILVEIRA DA VEIGA, ${ }^{4}$ NATALY DENDENA, ${ }^{5} \mathrm{KELLI}$ \\ KUHNEN, ${ }^{6}$ SIMONE CASTAGNA ANGELIM COSTA, ${ }^{7}$ RAQUEL COSTA MACHADO, ${ }^{8}$ GIOVANA MIOTO DE MOURA, ${ }^{9}$ JULIANA \\ PELISSARI MARCHI
}

\author{
1 1Acadêmica participante do Programa Institucional Centro de Estética e Cosmética Escola, do C.S.T. em Estética e Cosmética \\ da UNIPAR. \\ ${ }^{2}$ Acadêmica participante do Programa Institucional Centro de Estética e Cosmética Escola, do C.S.T. em Estética e Cosmética da \\ UNIPAR. \\ ${ }^{3}$ Acadêmica participante do Programa Institucional Centro de Estética e Cosmética Escola, do C.S.T. em Estética e Cosmética da \\ UNIPAR. \\ ${ }^{4}$ Acadêmica participante do Programa Institucional Centro de Estética e Cosmética Escola, do C.S.T. em Estética e Cosmética da \\ UNIPAR. \\ ${ }^{5}$ Responsável Técnica do Centro de Estética Escola do C.S.T. em Estética e Cosmética da Universidade Paranaense, UNIPAR. \\ ${ }^{6}$ Docente do C.S.T. em Estética e Cosmética da Universidade Paranaense, UNIPAR. \\ ${ }^{7}$ Docente do C.S.T. em Estética e Cosmética da Universidade Paranaense, UNIPAR. \\ ${ }^{8}$ Docente do C.S.T. em Estética e Cosmética da Universidade Paranaense, UNIPAR. \\ ${ }^{9}$ Docente do C.S.T. em Estética e Cosmética da Universidade Paranaense, UNIPAR.
}

Introdução: As atividades do programa institucional oportunizou o contato com diversos biotipos e fototipos de pele, fato esse que despertou o interesse de pesquisa e nos levou a elaboração da cartilha Cuidados diários com a pele: Uma cartilha informativa , com o intuito de levar para a população informações básicas sobre os esses cuidados e contribuir com a autoestima e bem-estar da população. Segundo Bohjanen (2017) e Costa (2006), a pele serve como barreira protetora contra microorganismos, traumatismos e contusões, além de possuir função termorreguladora e imunológica. $O$ tecido cutâneo pode ser classificado em: normal, oleoso, misto, seco e sensível, sendo que cada qual possui suas particularidades específicas.

Objetivo: Relatar a experiência de atividades desenvolvidas no Programa Institucional Centro de Estética e Cosmética Escola da UNIPAR, Campus Unidade de Francisco Beltrão.

Resultado: A vivência nesse programa institucional oportunizou o contato com diversos biotipos, fototipos cutâneos e disfunções estéticas, o que propiciou amadurecimento profissional, enriquecimento curricular e evolução. Ainda ressaltou a necessidade de pesquisa e o interesse em levar informação profissional em uma linguagem adequada para a população através da elaboração da cartilha. Durante a pesquisa foi notável a importância da adesão desses cuidados diários para uma pele saudável, a qual traz benefícios tanto para a questão estética, quanto para o equilíbrio da pele. Há uma sequência de cuidados, como higienizar, esfoliar, tonificar, hidratar e fazer o uso de filtro solar. A diferença de cada skincare estará em suas formulações (GERSON, 2011; KEDE e SABATOVICH, 2004). Uma pele oleosa precisará de substâncias seborreguladoras. A pele normal apresenta um equilíbrio hídrico e lipídico, sendo indicado cosméticos neutros. A pele seca apresenta carência de água, necessitando de cosméticos hidratantes. A pele mista, por sua vez, é oleosa na zona $\mathrm{T}$ do rosto e seca em região zigomática, podendo usar cosméticos adstringentes e hidratantes. Por fim, a pele sensível é uma subclassificação caracterizada por sua fácil irritabilidade, usa-se cosméticos calmantes (BEZERRA, 2001; GOMES, 2009).

Conclusão: Com a experiência de atendimento no centro de estética, foi notável a ausência de conhecimento com os cuidados diários dos clientes para seu biotipo cutâneo. Cabe, portanto, ao profissional de estética realizar essa orientação, levando em consideração as particularidades de cada um.

\section{Referências}

BEZERRA, Sandra Vasconcelos. Guia de produtos cosméticos. São Paulo: Ed. SENAC, 2001.

BOHJANEN, Kimberly. Estrutura e funções da pele. Dermatologia Clínica. Seção I Bases para diagnóstico e tratamento. 2017 COSTA, Claudia Rejane Lima de Macedo. Proposta de caracterização fotoacústica do Nível de Oleosidade da Pele. Orientador: Paulo Roxo Barja. 2006. Dissertação apresentada ao Programa de Pós-graduação em Bioengenharia do Instituto de Pesquisa e Desenvolvimento. Universidade do Vale do Paraíba, São José dos Campos-SP, 2006.

GERSON, Joel Fundamentos de Estética 4Milady`sStandart São Paulo: Cengagelearninig; 2011.

GOMES, Rosaline Kelly. Cosmetologia descomplicando os princípios ativos. 3.ed. São Paulo: Livraria Médica Paulista, 2009. 
KEDE, Maria Paulino Vilarejo.; SABATOVICH, Oleg. Dermatologia estética. 3.ed, São Paulo: Atheneu, 2004.

ANALA DO D UNIPAR 50 ANOS:

I SALÃO DE EXTENSÃO Traneformando vidas atravia da educageto

DA UNIPAR

27 de Outubro de 2021

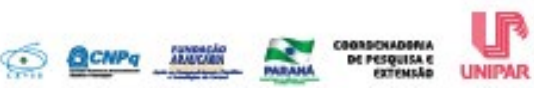




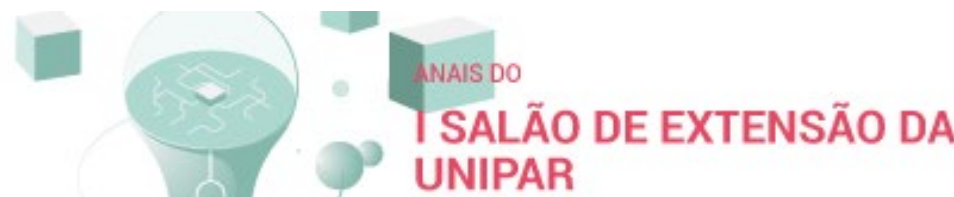 \\ - UNIPAR 50 ANOS \\ Transformando vidas através da educação \\ 27 de Outubro de 2021 \\ ISBN $978-65-87557-74-8$ \\ . \\ Dol: hitps//doiorg/10.251 10/saboextensadaunipar.2021 \\ QCNPq Awectin

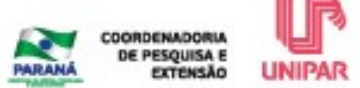 \\ FISIOTERAPIA DERMATOFUNCIONAL: ASSOCIAÇÃO DA DRENAGEM LINFÁTICA MANUAL E LINFOTAPING NO PÓS- OPERATÓRIO DE CIRURGIAS PLÁSTICAS
}

\author{
${ }^{1}$ LAYANE VITORIA MOLOGNI, ${ }^{2}$ DORA DE CASTRO AGULHON SEGURA
}

${ }^{1}$ Acadêmica de Fisioterapia da Unipar
${ }^{2}$ Docente da UNIPAR

Introdução: O Brasil é o segundo país que mais realiza cirurgias plásticas no mundo, sendo que as intervenções estéticas mais comum entre as mulheres são a abdominoplastia, lipoaspiração e mamoplastia (COUTINHO et al., 2006; MACEDO; OLIVEIRA, 2017). A atuação do fisioterapeuta na assistência à cirurgia plástica, através de inúmeras técnicas, tem crescido muito, em decorrência da contribuição significativa no processo do pós-operatório. Após passar por uma intervenção cirúrgica, com deslocamento ou corte do tecido, as células e os vasos sanguíneos são rompidos, gerando edema local. Sendo indicada a drenagem linfática manual para a recuperação rápida e eficaz (ZANELLA; RUCKL; VELOSZIN, 2011). O linfotaping se tornou uma das técnicas inovadoras de aplicação das bandagens elásticas para o tratamento fisioterapêutico no pós-operatório de cirurgias estéticas, estimulando a circulação sanguínea e linfática para uma melhor recuperação. Os protocolos de drenagem linfática manual com o linfotaping revelam resultados competentes (PEREIRA; SANTOS, 2016).

Objetivo: Promover conhecimento sobre a atuação e a importância da fisioterapia no pós-operatório de cirurgias plásticas.

Resultados: $\mathrm{O}$ atendimento fisioterapêutico frente às cirurgias plásticas obteve um grande crescimento nos últimos anos. $\mathrm{O}$ conhecimento científico sobre a área permitiu uma ampliação das condutas terapêuticas para o desenvolvimento do tratamento pós-operatório. A drenagem linfática manual é uma técnica muito utilizada no pós-operatório, por sua eficácia frente a recuperação do paciente. O método promove redução do edema proporcionado um maior conforto, age de forma antiinflamatória, melhora a circulação sanguínea, exerce um efeito calmante e sedativo (MARTINS et al., 2021). A técnica de bandagem elástica linfática tem grande repercussão no controle de linfedemas, sendo muito utilizada em casos de edemas graves e equimoses pós-operatória. O processo de colagem da bandagem elástica sobre a pele acaba promovendo drenagem fisiológica do organismo, além da reabsorção de equimoses de forma mais rápida e segura (PEREIRA; SANTOS, 2016).

Conclusão: Concluiu-se que o projeto em questão é de extrema importância para o conhecimento sobre a atuação do fisioterapeuta nas diversas áreas de atuação, neste caso, no tratamento pós-operatório de cirurgias plásticas frente as novas técnicas que facilitam e aceleram o processo de recuperação.

\section{Referências}

COUTINHO, M. M. et al. A importância da atenção fisioterapêutica na minimização do edema nos casos de pós-operatório de abdominoplastia associada à lipoaspiração de flancos. Revista Fisioterapia Ser, v. 4, n. 1, p. 1-8, 2006.

MACEDO, A. C. B.; OLIVEIRA, S. M. A atuação da fisioterapia no pré e pós-operatório de cirurgia plástica corporal: Uma revisão de literatura. Cadernos da Escola de Saúde, v. 1, n. 4, p. 185-201, 2017.

MARTINS, M. et al. Fisioterapia no pré-operatório, intraoperatório e pós-operatório de cirurgias faciais. In: Manual de condutas e práticas em fisioterapia dermatofuncional: Atuação no pré e pós-operatório de cirurgias plásticas. Campo Grande: Editora UFMS, 2021.

PEREIRA, M. S.; SANTOS, M. D. Efeitos da aplicação do linfotaping como técnica coadjuvante no pós-operatório cirurgias plásticas abdominais. Visão Universitária, v. 2, n. 1, p. 159-176, 2016.

ZANELLA, B. I.; RUCKL, S.; VELOSZIN, M. A importância da drenagem linfática manual no pós-operatório da abdominoplastia. $19 \mathrm{f}$. Trabalho de Conclusão de Curso (Curso de Cosmetologia e Estética) - Universidade do Vale do Itajaí, Balneário Camboriú-SC, 2011.

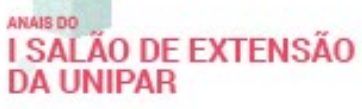

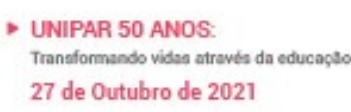

27 de Outubro de 2021

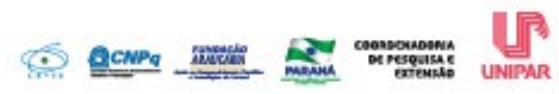




\section{8 \\ CIDADANIA VERDE: UM DESAFIO DE CONSCIENTIZAÇÃO AMBIENTAL?}

${ }^{1}$ KATILA DE AVILA RIBEIRO, ${ }^{2}$ ALINE BRUNA BIANCHINI FELTRIN, ${ }^{3}$ SADRAQUE CAETANO DA SILVA, ${ }^{4}$ FLAVIA EMMANUELLE PELEGRIN, ${ }^{5}$ ALANA ZENILDA THOMAZ SACHT, ${ }^{6}$ ANA CLARA ELEUTERIO PRETO, ${ }^{7}$ ALINE FONSECA PERRUT, ${ }^{8}$ SARAH LEITE TRINDADE, ${ }^{9}$ MARIANA ZANOTELLI SCHMIDT, ${ }^{10}$ HEMERSON DE CAMPOS, ${ }^{11}$ VIVIAN YATIYO MITUI GONCALVES, ${ }^{12}$ RAFAELA CHEFFER MODESTO, ${ }^{13}$ STEPHANIE AKEMI SATO VAILOES, ${ }^{14}$ FERNANDO EUGENIO ZIMMERMANN DORNE , ${ }^{15}$ NATIELY SEGALLA FAQUINETI, ${ }^{16}$ LUIZ AUGUSTO MUGNAI VIEIRA JUNIOR

\footnotetext{
${ }^{1}$ Acadêmica do Curso de Biomedicina e PEX da UNIPAR

${ }^{2}$ Acadêmica do Curso de Arquitetura e Urbanismo e PEX da UNIPAR

${ }^{3}$ Acadêmico do Curso de Arquitetura e Urbanismo e PEX da UNIPAR

${ }^{4}$ Acadêmica do Curso de Arquitetura e Urbanismo e PEX da UNIPAR

${ }^{5}$ Acadêmica do Curso de Odontologia e PEX da UNIPAR

${ }^{6}$ Acadêmica do Curso de Odontologia e PEX da UNIPAR

${ }^{7}$ Acadêmica do Curso de Arquitetura e Urbanismo e PEX da UNIPAR

${ }^{8}$ Acadêmica do Curso de Arquitetura e Urbanismo e PEX da UNIPAR

${ }^{9}$ Acadêmica do Curso de Arquitetura e Urbanismo e PEX da UNIPAR

${ }^{10}$ Acadêmico do Curso de Psicologia e PEX da UNIPAR

${ }^{11}$ Acadêmica do Curso de Direito e PEX da UNIPAR

${ }^{12}$ Acadêmica do Curso de Arquitetura e Urbanismo e PEX da UNIPAR

${ }^{13}$ Acadêmica do Curso de Arquitetura e Urbanismo e PEX da UNIPAR

${ }^{14}$ Acadêmico do Curso de Direito e PEX da UNIPAR

${ }^{15}$ Acadêmica do Curso de Odontologia e PEX da UNIPAR

${ }^{16}$ Docente e Orientador do PEX da UNIPAR
}

Introdução: Recentemente, o meio ambiente ganhou espaço, destaque e repercussão no Brasil e no mundo. Grande parte dessa reverberação é devido à forma como o Brasil e o mundo têm tratado as questões que envolvem o meio ambiente. As mídias digitais têm se mostrado frequentemente um parâmetro de opinião pública (VIEIRA JUNIOR; PELÚCIO, 2020) e tem se observado que há um foco de se repensar o meio ambiente, fundamentalmente, pelas gerações mais jovens por uma política verde como também por uma economia que tem se baseado cada vez mais na ideia de sustentabilidade, mas, sobretudo numa cidadania verde. Segundo Thomas Marshall (1967) a cidadania corresponde à conquista de três direitos: o civil, o político e o social.

Objetivos: O projeto de extensão Cidadania verde: ação e conscientização psicossociais do meio ambiente iniciado em 2020 e em continuação em 2021 têm como objetivos o esclarecimento e a conscientização sobre a cidadania verde, uma vez que, há uma dificuldade social de entendimento sobre cidadania e mais ainda quanto à cidadania ambiental.

Resultados: Tal situação se deve por falta de informações e políticas públicas mais efetivas de cidadania sobre o meio ambiente. Devido o momento pandêmico atual foi realizada uma consulta preliminar por meio digital com a comunidade externa no qual mostrou que $87 \%$ dos consultados desconheciam sobre o direito ao meio ambiente. Esses dados preliminares vêm em consonância com os objetivos do projeto que consistem em conscientizar e promover conhecimento por meio de cartilha ilustrativa sobre o meio ambiente como um direito de cidadania.

Considerações finais: Discutir o meio ambiente enquanto cidadania é pensar uma educação socioambiental (MIRANDA; ZANETI, 2020) promotora de melhor qualidade de vida (DELBONO, 2016); ir além dos aspectos não somente biofísico e de preservação ambiental (GIDDENS, 1997), fundamentalmente, propor um olhar de empatia, de pensar no outro e na coletividade por meios políticos e econômicos de sustentabilidade da prática humana em harmonia com a natureza.

\section{Referências}

DELBONO, B. D.F. Responsabilidade social e ambiental. Londrina: Educacional S.A., 2016.

GIDDENS, A. Risco, Confiança, Reflexividade. In: BECK, U.; GIDDENS, A. \& LASH, S. (eds). Modernização Reflexiva. São 
Paulo: UNESP, 1997.

MARSHALL, Thomas Humphrey. Cidadania, classe social e status. Rio de Janeiro. Zahar Editores, 1967.

MIRANDA, D.B. ; ZANETI, I.C.B.B. A abordagem socioambiental na educação em ciências como caminho para a construção da cidadania na sociedade de risco. Revista Ensaio | Belo Horizonte | v.22 | e19811 | 2020.

VIEIRA JUNIOR, L. A Mugnai; PELUCIO, Larissa. Memes, fake news e pós-verdade ou como a teoria de gênero vira uma ideologia perigosa . Estud. sociol. Araraquara v.25 n.48 p.87-113 jan.-jun, 2020.

$\begin{array}{ll}\text { Anuis do } & \text { UNIPAR } 50 \text { ANOS: } \\ \text { I SALAOO DE EXTENSÃO } & \text { Tranaformando vides atravis da educagto } \\ \text { DA UNIPAR } & 27 \text { de Outubro de } 2021\end{array}$




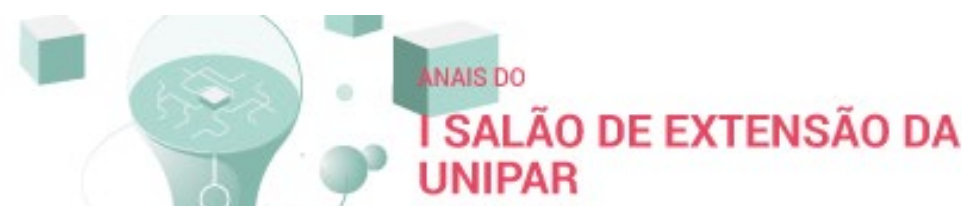 \\ - UNIPAR 50 ANOS \\ Transformando vidas através da educação \\ 27 de Outubro de 2021 \\ ISBN 978-65-87557-74-8 \\ DOI: hitps//doiorg/1025110/sabosxtensadaunipar.2021 \\ QCNPq N nevocti

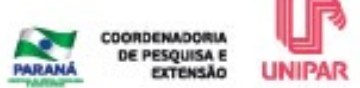

USO DAS PRÁTICAS INTEGRATIVAS E COMPLEMENTARES NA PROMOÇÃO DA SAÚDE E BEM ESTAR

${ }^{1}$ SAYHURY SHIMADA PULGATTI, ${ }^{2}$ SAMILY FABIOLA DA COSTA CRUZ, ${ }^{3}$ MAYSA LUCIANA BIRKHEUER, ${ }^{4}$ ALINE TEZOLIN CASARIL, ${ }^{5}$ NATHALIA BRUNO DE SOUZA, ${ }^{6}$ MAYARA FERNANDA DE SOUZA MARQUES, ${ }^{7}$ RAFAELA FRANCIOZI HOLSBACH, ${ }^{8}$ TIFANI VITORIA DE ARAUJO DE SOUZA DALLABENETTA, ${ }^{9}$ BARBARA FERNANDA FERREIRA, ${ }^{10}$ CAROLINE MERCURIO SANCHES PERACI, ${ }^{11}$ GEOVANA DOS SANTOS LOPERA, ${ }^{12}$ JEFERSON HENRIQUE BUENO ANDERSON, ${ }^{13} \mathrm{JULIA}$ BARBOSA GUIMARAES, ${ }^{14}$ KAMILA PIRES SALDANHA, ${ }^{15}$ CRISTIANE CLAUDIA MEINERZ, ${ }^{16}$ SIMONE CASTAGNA ANGELIM COSTA

${ }^{1}$ Acadêmica do PEX UNIPAR

${ }^{2}$ Acadêmica do PEX UNIPAR

${ }^{3}$ Acadêmica do PEX UNIPAR

${ }^{4}$ Acadêmica do PEX UNIPAR

${ }^{5}$ Acadêmica do PEX UNIPAR

${ }^{6}$ Acadêmica do PEX UNIPAR

${ }^{7}$ Acadêmica do PEX UNIPAR

${ }^{8}$ Acadêmica do PEX UNIPAR

${ }^{9}$ Acadêmica do PEX UNIPAR

${ }^{10}$ Acadêmica do PEX UNIPAR

${ }^{11}$ Acadêmica do PEX UNIPAR

${ }^{12}$ Acadêmico PEX UNIPAR

${ }^{13}$ Acadêmica do PEX UNIPAR

${ }^{14}$ Acadêmica do PEX UNIPAR

${ }^{15}$ Docente da UNIPAR do Curso de Tecnologia em Estética e Cosmética UNIPAR/Guaíra

${ }^{16}$ Docente da UNIPAR do Curso de Tecnologia em Estética e Cosmética UNIPAR/Guaíra

Introdução: A Organização Mundial de Saúde (OMS) afirma que a saúde é um estado de completo bem-estar físico, mental e social e não apenas a ausência de doença ou enfermidade. Sendo assim, para se ter saúde é necessário possuir qualidade de vida e bem estar físico, mental, emocional e social. Utilizar as práticas integrativas e complementares são recursos simples e naturais que podem recuperar a saúde, diminuir o consumo de medicamentos, resgatar vidas e principalmente o autoconhecimento (BRASIL, 2006). Com a pandemia e tempos incertos, agravou-se ainda mais os sentimentos de insegurança, medo, depressão e ansiedade. Implantar o projeto de extensão auto cuidado através da medicina complementar e alternativa na promoção da saúde e bem estar, na UNIPAR, unidade de Guaíra propicia desenvolver técnicas de meditação, musicoterapia, aromaterapia, cromoterapia que ajudam a enfrentar e superar traumas antigos, presentes e futuros.

Objetivo: Reduzir os impactos na saúde mental que a pandemia exacerbou.

Resultados: O projeto é realizado uma vez por semana, com quatorze participantes divididos em dois grupos, na qual adentram na sala preparada e aromatizada com óleo essencial de bergamota (Citrus bergamia), iniciando o processo terapêutico aromático. As moléculas aromáticas dos óleos essenciais penetram nas narinas e são captadas pelo sistema olfativo que estimulam as células receptoras presentes na mucosa olfativa, gerando impulsos nervosos que são encaminhados ao cérebro pelo nervo olfativo, estimulando reações químicas e elétricas produzindo resposta terapêutica (AMARAL, 2015). Segundo estudo de Rombolà et al., (2017) o óleo essencial de bergamota (Citrus bergamia) apresentou efeitos ansiolíticos e relaxante no comportamento de ratos que foram submetidos a testes de campo aberto, nado forçado e labirinto em cruz elevado. A eficácia do óleo essencial de bergamota para respostas aos níveis de estresse, ansiedade, depressão vem sendo estudado e citado pesquisas como de Navarra et al., (2015), Watanabe et al., (2015), podendo ser uma opção natural aos pacientes que não querem fazer uso de medicamentos químicos. No ambiente também são usadas cores que induzem o relaxamento, como a azul e verde. Essas cores tranquilizam, induzindo o cérebro a secretar hormônios neurotransmissores que possuem ação calmante (WALKER, 1995). A meditação guiada faz parte da sessão e é utilizada para que o participante esteja com atenção plena em si, fazendo uma integração e auto regulação da mente e corpo. A prática da meditação, realizada com regularidade apresenta 
redução dos sintomas do transtorno de ansiedade generalizada e transtorno do pânico (GALVIN et al., 2006).

Conclusão: As práticas integrativas empregadas no projeto, visam oferecer aos participantes, benefícios como relaxamento, autocuidado e autoconhecimento, que favorecem a diminuição de alterações como medo, insegurança e ansiedade, e também contribuem para a promoção de saúde e bem estar.

\section{Referências}

AMARAL, Fernando. Técnicas de aplicação de óleos essenciais. 1ª ed. São Paulo: Cengage Learning, 2015, 235 p. BRASIL. Ministério da Saúde. Secretaria de Atenção à Saúde. Departamento de Atenção Básica. Política Nacional de Práticas Integrativas e Complementares no SUS, Brasília: Ministério da Saúde. (Série B. Textos Básicos de Saúde). 2006. 92 p.

GALVIN, Jennifer A; et al. The relaxation response: reducing stress and improving cognition in healthy aging adults. Complement Ther Clin Pract. v. 12, n. 3, p. 186-191, 2006. Disponível em: doi10.1016/j.ctcp.2006.02.004. Acesso em: 05 set 2021.

NAVARRA, Michele; et al. Citrus bergamia essential oil: from basic research to clinical application. Front Pharmacol. v. 6, n. 36, p. 1-6, 2015. Disponível em: https://doi.org/10.3389/fphar.2015.00036. Acesso em: 31 ago 2021.

ROMBOLÀ, Laura; et al. Corasaniti, Giacinto Bagetta e Luigi A. Morrone 2017. Bergamot Essential Oil Attenuates Anxiety-Like Behavior in Rats. Molecules, v. 22, n. 614, p. 1-11, 2017. Disponível em: https://doi.org/10.3390/molecules22040614. Aceso em: 02 set 2021.

WALKER, Morton. 0 poder das cores: as cores melhorando a sua vida. Tradução de Denise Cavalcante. São Paulo: Saraiva; 1995.

WATANABE Eri; et al. Effects of bergamot (Citrus bergamia (Risso) Wright \& Arn.) essential oil aromatherapy on mood states, parasympathetic nervous system activity, and salivary cortisol levels in 41 healthy females. Forsch Komplementmed, v. 22, n. 1, p. 43 49, 2015. Disponível em: DOI: 10.1159/000380989. Acesso em: 30 ago 2021.

$$
\text { I SALÃOO DE EXTENSÃ̃O }
$$$$
\text { DA UNIPAR }
$$

- UNIPAR 50 anos:

Traneformanso vides atrewta da educagse

27 de Outubro de 2021

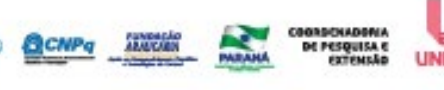




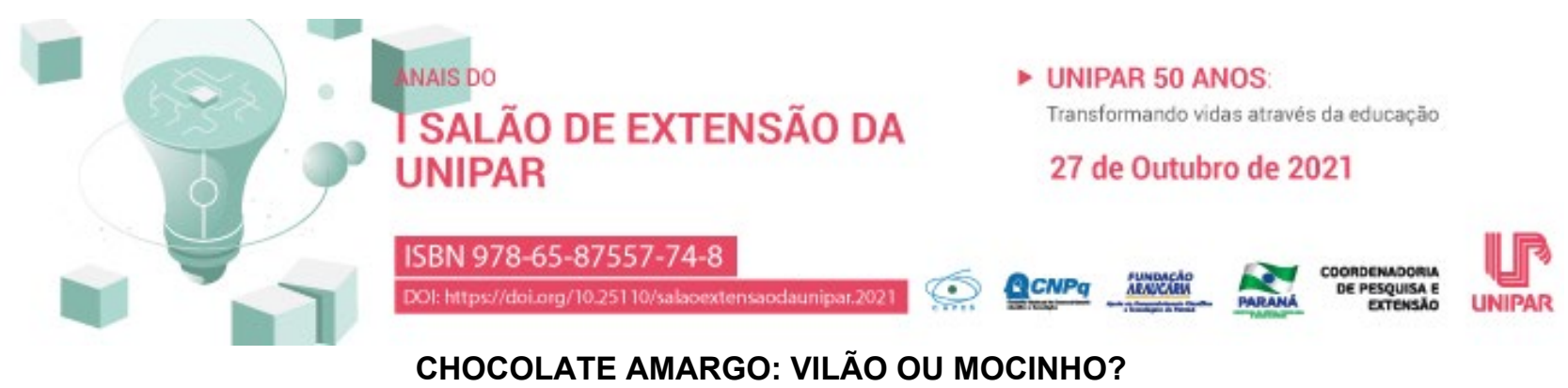

\title{
${ }^{1}$ CARLOS EDUARDO RUZZENE RODRIGUES, ${ }^{2}$ LUCIANA DOLORES PACHECO, ${ }^{3}$ NEUSA VIANA LOPES, ${ }^{4}$ RITA DE CÁCIA BELTRAME RUZZENE RODRIGUES, ${ }^{5}$ KATIA BIAGIO FONTES
}

\author{
${ }^{1}$ Acadêmico do Curso de Medicina da UNIPAR \\ ${ }^{2}$ Enfermeira da UNIPAR \\ ${ }^{3}$ Enfermeira da UNIPAR \\ ${ }^{4}$ Nutricionista. Formada na Universidade Tuiuti do Paraná. \\ ${ }^{5}$ Docente da UNIPAR
}

Introdução: Estudos têm demonstrado que o consumo de chocolate amargo está relacionado à cardioproteção. Assim, há evidências que tal alimento melhore a função plaquetária, aumente a sensibilidade à insulina e, por fim, controle a pressão arterial. Dito isso, a menor prevalência da Hipertensão Arterial Sistêmica tem como base a ação vasodilatadora dos flavonóides, composto encontrado em maiores quantidades no chocolate amargo.

Objetivo: Revisar na literatura sobre o uso de chocolate meio amargo na redução da pressão arterial sistêmica.

Desenvolvimento: A priori, no cacau são encontrados flavonóides, os quais possuem bioatividade. Sabe-se que a concentração plasmática desses compostos são dose-dependente. Nesse contexto, $10 \mathrm{~g}$ resultam em uma biodisponibilidade suficiente para notar efeitos. Tal substância atinge maior concentração plasmática 2 a 3 horas após o consumo, sendo observado uma concentração alta, ainda, 8 horas após a ingestão. A interferência sistêmica acontece por estímulo da enzima óxido nítrico sintase, que produz óxido nítrico. A vasodilatação, então, leva a redução da pressão arterial. Resultados de estudo demonstraram que o cacau presente em $100 \mathrm{~g}$ de chocolate por dia, por 15 dias, reduz a pressão arterial e resistência à insulina, além de melhorar os efeitos de anti-hipertensivos. No entanto, não é necessário uma grande quantidade para tal efeito, conforme resultado apresentado em outro estudo onde $6 \mathrm{~g}$ reduziu a prevalência de hipertensão na amostra. Observou-se mudanças vasculares duas horas após o consumo, culminando em redução da pressão arterial. O consumo melhorou na claudicação intermitente em pacientes com doença arterial periférica, o que indica importante vasodilatação endotélio-dependente. Outros estudos demonstraram uma melhora no quadro lipídico. Assim, frente ao paciente pré-hipertenso, além da recomendação de mudanças no estilo de vida, é interessante adotar uma quantidade de flavonoides que se encaixe na dieta, uma vez que tal alimento já demonstrou redução de hipertensos grau I para quadros de pré-hipertensão. Não foram encontrados efeitos adversos, senão o aumento de peso, eis a importância de adequar a porção e a frequência com base na quantidade de calorias necessárias por dia.

Conclusão: Pode-se concluir que a presença de flavonóides no chocolate amargo pode reduzir a pressão arterial de forma aguda, duas horas após a ingestão do chocolate amargo. Neste sentido, seu uso pode ser grande aliado ao combate de cardiopatias, quando consumido de forma constante, já que seus efeitos cardioprotetores já foram comprovados.

\section{Referências}

FARIDI, Zubaiada et al. Acute dark chocolate and cocoa ingestion and endothelial function: a randomized controlled crossover trial. Am J Clin Nutr, v. 88, n. 1, p. 58-63, 2008.

FLAMMER, Andreas et al. Cardiovascular effects of flavanol-rich chocolate in patients with heart failure. Eur Heart J, v. 33, n. 17 , p. 2172-2180, 2012.

GRASSI, Davide et al. Cocoa reduces blood pressure and insulin resistance and improves endothelium-dependent vasodilation in hypertensives. Hypertension, v. 46, n. 2, p. 398-405, 2005.

GRASSI, Davide et al. Short-term administration of dark chocolate is followed by a significant increase in insulin sensitivity and a decrease in blood pressure in healthy persons. Am J Clin Nutr, v. 81, n. 3, p. 611-614, 2005.

HEISS, Christian et al. Impact of cocoa flavanol intake on age-dependent vascular stiffness in healthy men: a randomized, controlled, double-masked trial. Age (Dordr), v. 37, n. 3, p. 9794, 2015.LOFFREDO, L.; et al. Dark chocolate acutely improves walking autonomy in patients with peripheral artery disease. J Am Heart Assoc, v. 3, n. 4, 2014.

MONAHAN, Kevin et al. Dose-dependent increases in flow-mediated dilation following acute cocoa ingestion in healthy older adults. J Appl Physiol, v. 111, n. 6, p. 1568-1574, 2011.

PAZZINATO, Karolina et al. Efeitos dos flavonoides do cacau na prevenção e no tratamento de doenças cardiovasculares: uma revisão de literatura. Rev Ciênc Med, v. 28, n. 2, p. 85-98, 2019.

SANSONE, Roberto et al. Cocoa flavanol intake improves endothelial function and Framingham Risk Score in healthy men and 
women: a randomised, controlled, double-masked trial: the Flaviola Health Study. Br J Nutr, v. 114, n. 8, p. 1246-1255, 2015. SUDARMA, Verawati et al. Effect of dark chocolate on nitric oxide serum levels and blood pressure in prehypertension subjects. Acta Med Indones, v. 43, n. 4, p. 224-228, 2011.

I SALÃO DE EXTENSÃO

DA UNIPAR
- UNIPAR 50 ANOS: Traneformanso vides atravts da educaçso

27 de Outubro de 2021

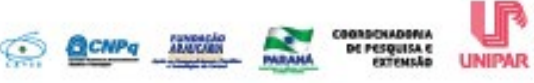




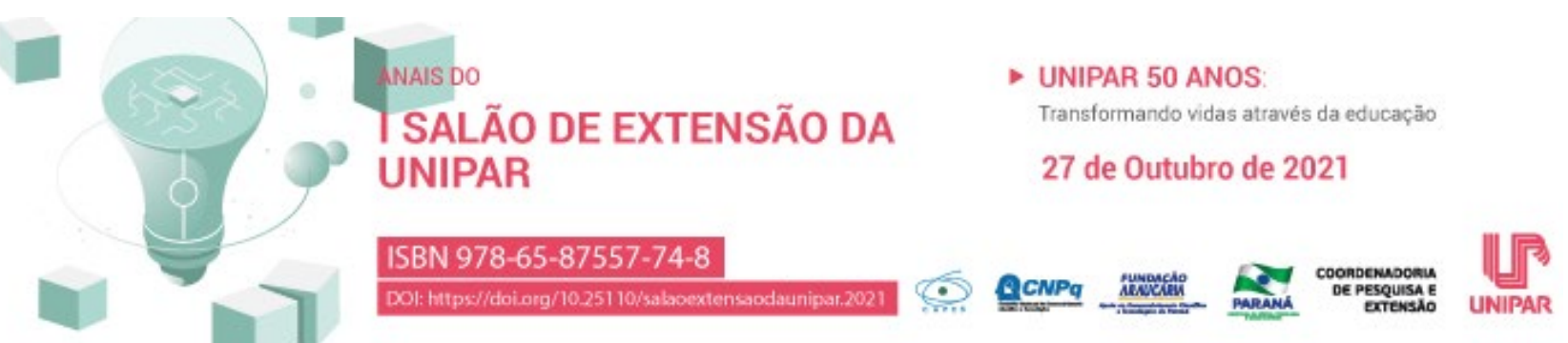

CARTILHAS INFORMATIVAS, UM INSTRUMENTO AUXILIAR NO PROCESSO DE APRENDIZADO

\author{
${ }^{1}$ NATANIELLY VITORIA DALCERO CASSOL, ${ }^{2}$ EDUARDA REGINA KIELING, ${ }^{3}$ ALINE DE BORTOLI, ${ }^{4}$ CAROLINA DE \\ OLIVEIRA, ${ }^{5}$ LUCIANA PELLIZZARO, ${ }^{6}$ KELLI KUHNEN, ${ }^{7}$ JULIANA PELISSARI MARCHI
}

\begin{abstract}
${ }^{1}$ Acadêmica participante do Projeto de Extensão Estética na Comunidade, do C.S.T. em Estética e Cosmética da Universidade Paranaense, UNIPAR.

${ }^{2}$ Acadêmica participante do Projeto de Extensão Estética na Comunidade, do C.S.T. em Estética e Cosmética da Universidade Paranaense, UNIPAR.

${ }^{3}$ Acadêmica participante do Projeto de Extensão Estética na Comunidade, do C.S.T. em Estética e Cosmética da Universidade Paranaense, UNIPAR.

${ }^{4}$ Acadêmica participante do Projeto de Extensão Estética na Comunidade, do C.S.T. em Estética e Cosmética da Universidade Paranaense, UNIPAR.

${ }^{5}$ Docente do C.S.T. em Estética e Cosmética da Universidade Paranaense, UNIPAR.

${ }^{6}$ Responsável Técnica do Centro de Estética Escola do C.S.T. em Estética e Cosmética da Universidade Paranaense, UNIPAR.

${ }^{7}$ Docente do C.S.T. em Estética e Cosmética da Universidade Paranaense, UNIPAR.
\end{abstract}

Introdução: A cartilha é um instrumento linguístico, podendo ser definida como pequenos textos impressos, os quais podem ser usados para a disseminação de ideias e conceitos, visando auxiliar e facilitar a compreensão de determinados assuntos (DIAS, 2018). Trata-se de um material didático com o objetivo de esclarecer temas com uma maior facilidade, utilizando de uma linguagem simples, didática e ilustrada, fazendo com que determinados assuntos tornem-se de fácil entendimento para uma melhor interpretação do leitor (VIEIRA, 2017; SCHLICKMANN, 2001; SANTOS; SANTOS; MACEDO, 2012). Com base neste referencial foi elaborada uma cartilha informativa, intitulada Estruturação e importância do Tecido Cutâneo com objetivo de levar informações para estudantes, profissionais e população em geral, por meio da sua estrutura explicativa e ilustrativa.

Objetivo: Relatar a experiência da elaboração de uma cartilha informativa no Projeto de Extensão Estética na Comunidade.

Resultados: A cartilha Estruturação e importância do Tecido Cutâneo , contém 12 páginas, foi estruturada a partir de levantamento bibliográfico (livros e artigos científicos) sobre fisiologia e anatomia do sistema tegumentar, foi elaborada com as ferramentas do site Canva para criação da arte. A mesma foi desenvolvida no formato online contendo as informações escritas juntamente com ilustrações, visando facilitar a compreensão do assunto abordado na mesma e está sendo divulgada por meios eletrônicos. A cartilha é destinada ao público em geral, com ênfase no público estudantil, uma vez que auxilia os acadêmicos a reforçar e aprimorar o conhecimento sobre o conteúdo. Os alunos do ensino fundamental e ensino médio que receberam essas cartilhas, também aproveitam para aprimorar e ampliar os seus conhecimentos. Os professores ao receber essas cartilhas, conseguem reforçar o conteúdo com os alunos, pois a cartilha serve como material de estudo, facilita e fixa a aprendizagem (DIAS, 2018; CONCEIÇÃO; BEZERRA; SOUZA, 2019).

Conclusão: A elaboração da cartilha contribuiu com o enriquecimento curricular, desenvolveu habilidades criativas, oportunizou o trabalho em equipe e contribuiu com a formação dos estudantes de nível médio e superior, bem como para com os docentes que poderão usar essa cartilha como recurso auxiliar e complementar.

\title{
Referências
}

CONCEIÇÃO, Ewerton Henrique da; BEZERRA, Levi Araujo; SOUZA, Luiz Carlos Alves de. A produção e uso de uma Cartilha educativa como recurso didático no ensino do ciclo da água. Pernambuco, 2019. Disponível em: https://cointer.institutoidv.org/inscricao/pdv//uploadsAnais2020/A-COFEC\%C3\%87\%C3\%83O-DE-UMA-CARTILHA-EDUCATIVAPARA-O-ENSINO-DO-CICLO-DA-\%C3\%81GUA.pdf. Acesso em: 08 ago. 2021.

DIAS, Isabella Cristina Galvan. $O$ uso de Cartilha como Ferramenta para promover a Educação ambiental no Ensino da Ciência. Dois $\quad$ Vizinhos, 2018.2 Disponível em: http://repositorio.utfpr.edu.br:8080/jspui/bitstream/1/11122/1/DV_COBIO_2018_2_09.pdf. Acesso em: 07 ago. 2021.

SANTOS, Erika Dias; SANTOS, Miliede Borges Adalberto; MACEDO, Vanessa dos Santos. O método das Cartilhas. Sergipe, 2012. Disponível em: https://ri.ufs.br/bitstream/riufs/10173/24/23.pdf. Acesso em: 07 ago. 2021.

SCHLICKMANN, Maria. As Cartilhas no processo de alfabetização. v. 2, n. 1, 2001 . Disponível em: http://portaldeperiodicos.unisul.br. Acesso em: 06 ago. 2021.

VIEIRA, Zeneide Paiva Pereira. Cartilhas de alfabetização no Brasil: um estudo sobre trajetória e memória de ensino e 
aprendizagem da língua escrita. Bahia, 2017. Disponível em: http://www2.uesb.br/ppg/ppgmls/wp-content/uploads/2017/09/TeseZeneide-Paiva-Pereira-Vieira.pdf. Acesso em: 10 ago. 2021.

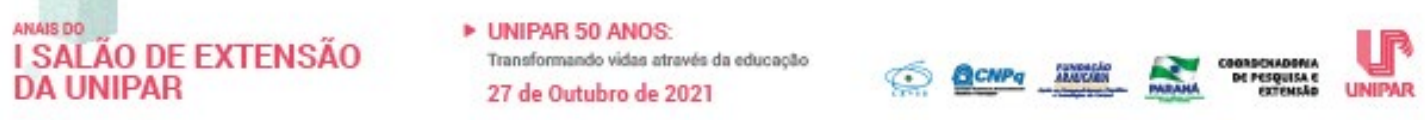




\title{
(1) DUNIPAR 50 ANOS \\ SALÃO DE EXTENSÃO DA Transformando vidas através da educą̧̧̃o UNIPAR

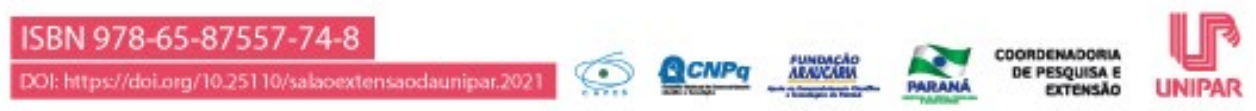 \\ AROMATERAPIA COMO RECURSO TERAPÊUTICO NO TRATAMENTO DO EFLÚVIO TELÓGENO EM CLIENTES PÓS COVID-19
}

\author{
${ }^{1}$ ERICA DAIANE RODRIGUES FERREIRA, ${ }^{2}$ EVELLYN GABRIELLY DE OLIVEIRA, ${ }^{3} \mathrm{KELLI} \mathrm{KUHNEN,}{ }^{4}$ JESSICA TAVARES DE \\ OLIVEIRA, ${ }^{5}$ RAQUEL COSTA MACHADO, ${ }^{6}$ JULIANA PELISSARI MARCHI, ${ }^{7}$ GIOVANA MIOTO DE MOURA, ${ }^{8}$ CRISTIANE \\ CLAUDIA MEINERZ, ${ }^{9}$ SIMONE CASTAGNA ANGELIM COSTA
}

\author{
${ }^{1}$ Acadêmica do PEX UNIPAR \\ ${ }^{2}$ Acadêmica Bolsista do PIBEX UNIPAR \\ ${ }^{3}$ Responsável Técnica do Centro de Estética da UNIPAR unidade Francisco Beltrão \\ ${ }^{4}$ Responsável Técnica do Centro de Estética da UNIPAR unidade Guaíra \\ ${ }^{5}$ Docente da UNIPAR do Curso de Tecnologia em Estética e Cosmética UNIPAR \\ ${ }^{6}$ Docente da UNIPAR do Curso de Tecnologia em Estética e Cosmética UNIPAR \\ ${ }^{7}$ Docente da UNIPAR do Curso de Tecnologia em Estética e Cosmética UNIPAR \\ ${ }^{8}$ Docente da UNIPAR do Curso de Tecnologia em Estética e Cosmética UNIPAR \\ ${ }^{9}$ Docente da UNIPAR do Curso de Tecnologia em Estética e Cosmética UNIPAR
}

Introdução: O eflúvio telógeno difuso ou intenso, conhecido como queda de cabelo, tem sido uma das principais queixas dos pacientes que chegam ao Centro de estética da Unipar, da unidade de Guaíra. Estes pacientes ao realizarem a ficha de anamnese, relataram que já tiveram a COVID-19 e que a quantidade de fios perdidos por dia é motivo de preocupação, ansiedade, estresse e baixa autoestima. O eflúvio telógeno segundo Kede e Sabatovich (2015) acontece após uma doença sistêmica crônica, estresse emocional, gestação, febre alta prolongada ou quadros de infecção. A busca por tratamentos alternativos têm crescido no pós-pandemia e a aromaterapia é uma destas opções, pois trata o emocional e o dermatológico ao mesmo tempo.

Objetivo: Fazer com que as acadêmicas entendam a importância de conhecer as patologias para utilizar os recursos alternativos da aromaterapia de forma correta e segura no tratamento da queda de cabelo, tratando ao mesmo tempo o físico e emocional.

Resultados: Tratar pacientes que chegam até o Centro de Estética, permitiu às acadêmicas entenderem melhor a doença, suas sequelas e complicações, fazendo com que buscassem meios alternativos para tratar, tornando os atendimentos mais humanizados e personalizados. A COVID-19 acelera a fase catágena do ciclo capilar, fazendo com que a fase telógena se instale precocemente e permaneça por um tempo maior que a fisiológica (ROSSI et al., 2021). Para Olds et al., (2020) o eflúvio telógeno está ligado ao estresse fisiológico durante a doença, modificando todo o ciclo capilar, interrompendo a fase anágena e catágena, evoluindo rapidamente para a telógena, que é a fase que caracteriza o eflúvio telógeno. Esse sintoma parece afetar cerca de um terço dos indivíduos infectados pela doença, no qual os sintomas surgem após a recuperação da COVID-19 (IZUMI, 2021). A aromaterapia é uma terapia que utiliza os compostos aromáticos voláteis de origem vegetal, isto é, os óleos essenciais. Esses óleos tratam o organismo de forma natural, buscando restabelecer o equilíbrio tanto no nível fisiológico como emocional (MACHADO, 2011). Pode ser empregada como terapia complementar, para restabelecer o equilíbrio do corpo e da mente (PRICE, 2010).Os óleos essenciais utilizados no protocolo de queda de cabelo pós COVID-19 são: óleo essencial de alecrim (Rosmarinus officinalis), que estimula a circulação periférica no local; óleo essencial de melaleuca (Melaleuca alternifolia) que atua no sistema imunológico; o óleo essencial de ylang ylang (Cananga odorata) que confere brilho aos cabelos e no ambiente em um difusor elétrico o óleo essencial de litsea (Litsea cubeba) que alivia o estresse, promove relaxamento, sono reparador e é um excelente antidepressivo (AMARAL, 2015).

Conclusão: $O$ uso da aromaterapia no tratamento do eflúvio telógeno tem apresentado resultados que demonstram uma melhora, num período menor, na queda de cabelo e no estado emocional dos clientes que realizam o tratamento.

\section{Referências}

AMARAL, Fernando. Técnicas de aplicação de óleos essenciais. $1^{\text {a }}$ ed. São Paulo: Cengage Learning, 2015, 235 p.

KEDE, Maria Paulina Villarejo; SABATOVICH, Oleg. Dermatologia Estética. $3^{\mathrm{a}}$ Ed. Atheneu, 2015, $1320 \mathrm{p}$.

IZUMI, Marcella de Oliveira; BRANDÃO, Bryon José Figueiredo. Tratamento do eflúvio telógeno Pós-Covid 19. BWS Journal.

Maio; v. 4: p. 1-8. 2021. Disponível em: file:///C:/Users/Alexandre/Downloads/165-Texto\%20do\%20artigo-652-2-1020210519\%20(1).pdf. Acesso em: 02 set 2021.

ROSSI, Alfredo; et al. Telogen Effluvium after SARS-CoV-2 Infection: A series os cases and possible pathogenetic mechanisms. 
Skin Appendage Disord. 2021; 21: 1-5. Publicado em 8 de julho de 2021. DOI: 10.1159. Disponível em https://www.ncbi.nlm.nih.gov/pmc/articles/PMC8339054/. Acesso em: 02 set 2021.

OLDS, Hailey et al. Telogen effluvium associated with COVID-19 infection . Dermatol Ther. v. 34, n. 2, 2021. DOI 10.1111. Disponível em: https://www.ncbi.nlm.nih.gov/pmc/articles/PMC7883200/\#dth14761-bib-0003. Acesso em: 02 set 2021

PRICE, Shirley. Aromaterapia e as emoções Como usar óleos essenciais para equilibrar o corpo e a mente. Tradução Marcia Frazão; $3^{\text {a }}$ Edição, Rio de Janeiro, Editora Bertrand Brasil, 2010.

MACHADO, Bruna Fernanda Murbach Teles; FERNANDES Júnior, Ary. Óleos essenciais: aspectos gerais e usos em terapias naturais. Cadernos acadêmicos, Tubarão, v. 3, n. 2, p. 105-127, 2011. Disponível em: http://www.portaldeperiodicos.unisul.br/index.php/Cadernos_Academicos/article/view/718/671. Acesso em 02 set 2021.

ANGas DO " UNIPAR 50 ANOS:

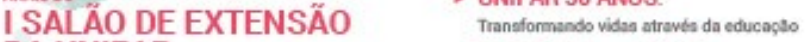

DA UNIPAR
27 de Outubro de 2021

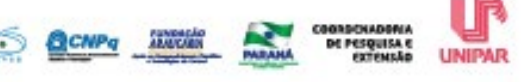




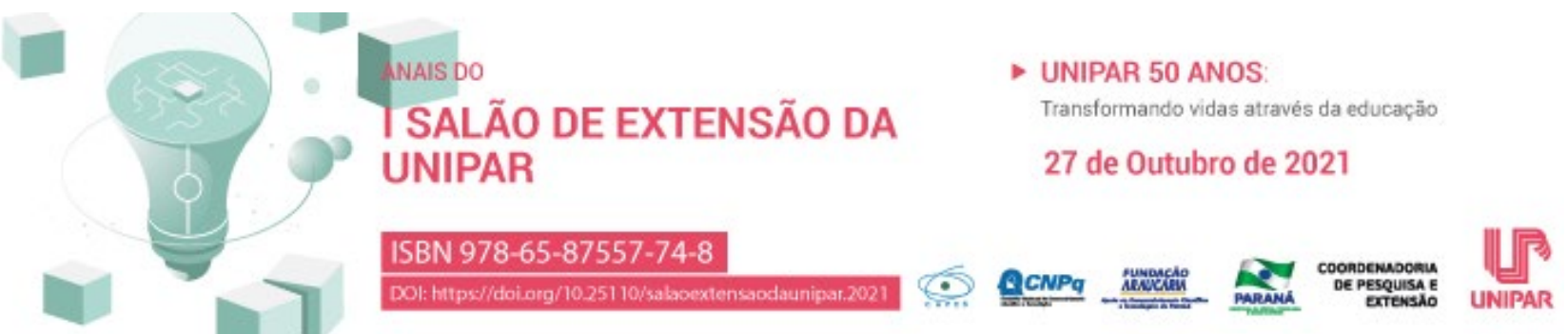 \\ PLANTAS MEDICINAIS: DO CULTIVO SUSTENTÁVEL À UTILIZAÇÃO SEGURA E EFICAZ
}

\author{
${ }^{1}$ ANDREIA TEONILA FUHR DOS SANTOS, ${ }^{2}$ JAQUELINE HOSCHEID
}

\author{
${ }^{1}$ Acadêmico Bolsista do PIBEX/UNIPAR \\ ${ }^{2}$ Docente da UNIPAR
}

Introdução: Desde o início da civilização humana as plantas medicinais são utilizadas com finalidades distintas e através de pesquisas ao longo dos anos comprovou-se que os princípios ativos produzidos pelas plantas trazem benefícios ao organismo, por isso passaram a ser utilizadas como remédios, substâncias aromáticas e condimentares, sendo a tradição familiar a base para seu consumo (COSTA, 2014). O cultivo destas espécies era mais comum em áreas rurais, no entanto, algumas práticas facilitaram a criação de pequenas hortas nas cidades mesmo em locais pequenos, sendo montadas nos quintais domésticos ou por meio de hortas verticais que otimizam o espaço disponível e assim se tornam uma forma prática, eficiente e de baixo custo para acesso às propriedades destas plantas (PERNA; FERREIRA, 2015), principalmente pela possibilidade de reutilização de materiais recicláveis, o que ajuda a minimizar os problemas e impactos provenientes do acúmulo de lixo no meio ambiente, sendo uma forma simples de transformar a natureza, afinal, reduz a quantidade de resíduos destinados aos aterros sanitários, prolongando assim a vida útil destes locais (ARRUDA; MARQUES; REIS, 2017). Desta forma, o cultivo de plantas medicinais é um meio de preservar o conhecimento dos antepassados sobre a flora, de lazer, de sustentabilidade e de consumo seguro das plantas, desde que observadas todas as orientações.

Objetivo: Disponibilizar informações sobre o cultivo sustentável e o uso seguro de plantas medicinais para a população em geral. Resultados: A implantação da horta mostrou ser um projeto simples e de baixo custo, o que se justifica pela utilização de materiais recicláveis como garrafas pet, pneus e pallets para a confecção dos canteiros e pelo fato de a maioria das plantas utilizadas se adaptarem bem ao solo e clima da região. Além disso, é possível o uso de inseticidas naturais elaborados com ingredientes da cozinha tradicional.

Conclusão: $O$ uso racional das plantas medicinais não apresenta riscos ao organismo e ainda possibilita baixo custo de produção quando voltada ao próprio consumo. Desta forma, a construção do conhecimento proporcionado tem o intuito de promover a saúde e a prevenção de doenças por fornecer à comunidade condições para obter das plantas os efeitos desejados, tendo o devido cuidado com a identificação, origem, época e local de plantio, armazenamento, conservação, uso das plantas, suas restrições e possíveis efeitos adversos.

\section{Referências}

ARRUDA, Raul Ferraz; MARQUES, Milene Reis; REIS, Januária Telis. Implantação de horta escolar utilizando materiais recicláveis como alternativa de ensino de educação ambiental. Interdisciplinary Scientific Journal. ISSN: $2358-8411 \mathrm{~N}^{\circ} 3$,

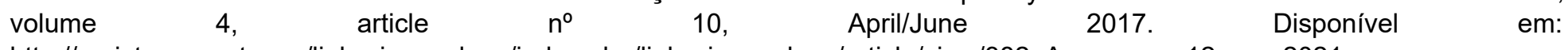
http://revista.srvroot.com/linkscienceplace/index.php/linkscienceplace/article/view/382. Acesso em 12 ago. 2021.

Brasil. MINISTÉRIO DA SAÚDE. Secretaria de Ciência, Tecnologia e Insumos Estratégicos. Departamento de Assistência Farmacêutica. Política nacional de plantas medicinais e fitoterápicos. Brasília: Ministério da Saúde, 2006. 60 p. Disponível em: https://bvsms.saude.gov.br/bvs/publicacoes/politica_nacional_fitoterapicos.pdf. Acesso em 05 ago. 2021.

BRASILEIRO, Beatriz Gonçalves. et al. Plantas medicinais utilizadas pela população atendida no Programa de Saúde da Família , Governador Valadares, MG, Brasil. Revista Brasileira de Ciências Farmacêuticas, vol. 44, n. 4, out./dez., 2008. Disponivel em: https://www.scielo.br/j/rbcf/a/TwBRyGvxZsHRXKvSBgdBYPc/?format=pdf\&lang=pt. Acesso em: 30 jul. 2021.

COSTA, Eronita de Aquino. Nutrição e fitoterapia: tratamento alternativo através de plantas. 3. ed. Petrópolis: Vozes, 2014.

JACOMASSI, Ezilda. Horto Medicinal do Campus 2 da Unipar: cultivando o bem-estar com a implantação de hortas comunitárias nas Unidades de Saúde. Umuarama: UNIPAR, 2017.

LIMA, Cristina Peitz de. Ensino das plantas medicinais: histórico e conceitos. Curitiba: Contentus, 2021.

PEDROSO, Reginaldo dos Santos; ANDRADE Géssica; PIRES, Regina Helena. Plantas medicinais: uma abordagem sobre o uso seguro e racional. Physis: Revista de Saúde Coletiva, jul., 2021. Disponível em: https://doi.org/10.1590/S010373312021310218. Acesso em: 03 ago. 2021.

PERNA, Tania Aparecida; FERREIRA, Ana Paula do Nascimento Lamano. Revisão Bibliométrica Sobre o Cultivo de Plantas Medicinais em Quintais Urbanos em Diferentes Regiões do Brasil (2009-2012). São Paulo: Journal of Health Sciences, v. 16 n. 1 (2014). Disponível em: https://journalhealthscience.pgsskroton.com.br/article/view/567. Acesso em 13 ago. 2021. 
- unIPAR 50 anos:

I SALAOO DE EXTENSÃO Transformando vidas atravies da educaģso

DA UNIPAR 


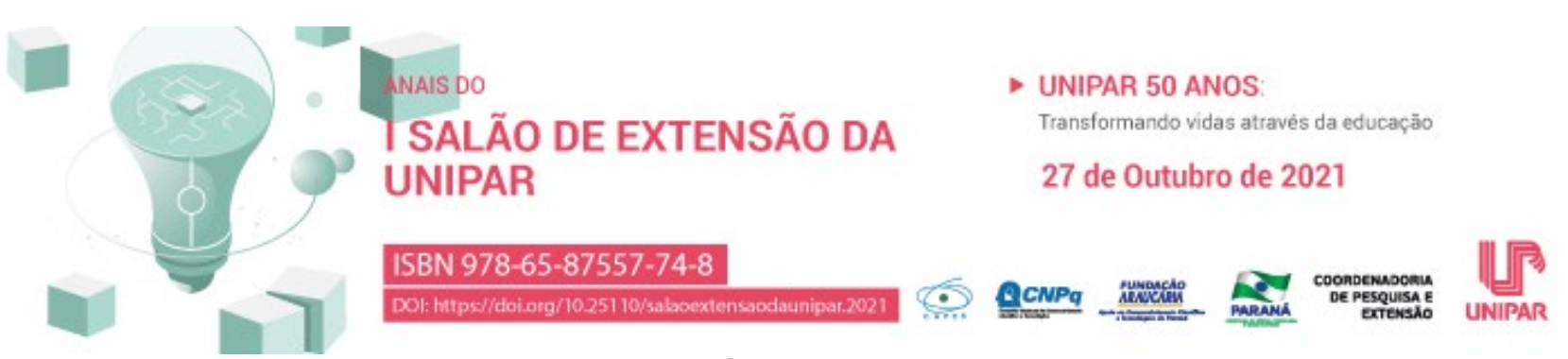

\title{
ARGILAS: USO E BENEFÍCIOS NO SKIN CARE FACIAL
}

\author{
${ }^{1}$ AMANDA KAROLINE DE MELO, ${ }^{2}$ LARISSA CRISTIANE DE LIMA CORDOVA, ${ }^{3} \mathrm{HELOUIZA} \mathrm{DA} \mathrm{SILVA} \mathrm{GUIMARAES,}{ }^{4}$ SIMONE \\ MARCIA ALBERTI, ${ }^{5}$ KELLI KUHNEN, ${ }^{6}$ RAQUEL COSTA MACHADO, ${ }^{7}$ SIMONE CASTAGNA ANGELIM COSTA, ${ }^{8}$ JULIANA \\ PELISSARI MARCHI
}

\author{
${ }^{1}$ Acadêmica participante do Programa Institucional Centro de Estética e Cosmética Escola, do C.S.T. em Estética e Cosmética da \\ UNIPAR. \\ ${ }^{2}$ Acadêmica participante do Programa Institucional Centro de Estética e Cosmética Escola, do C.S.T. em Estética e Cosmética da \\ UNIPAR. \\ ${ }^{3}$ Acadêmica participante do Programa Institucional Centro de Estética e Cosmética Escola, do C.S.T. em Estética e Cosmética da \\ UNIPAR. \\ ${ }^{4}$ Acadêmica participante do Programa Institucional Centro de Estética e Cosmética Escola, do C.S.T. em Estética e Cosmética da \\ UNIPAR. \\ ${ }^{5}$ Responsável Técnica do Centro de Estética Escola do C.S.T. em Estética e Cosmética da Universidade Paranaense, UNIPAR. \\ ${ }^{6}$ Docente do C.S.T. em Estética e Cosmética da Universidade Paranaense, UNIPAR. \\ ${ }^{7}$ Docente do C.S.T. em Estética e Cosmética da Universidade Paranaense, UNIPAR. \\ ${ }^{8}$ Docente do C.S.T. em Estética e Cosmética da Universidade Paranaense, UNIPAR.
}

Introdução: No presente estudo realizado no projeto centro de estética e cosmética da unipar, objetivou-se levar informações sobre o uso das argilas no skin care facial, pois desde a antiguidade as mesmas são aliadas aos procedimentos estéticos faciais e corporais. Através da nossa experiencia vivenciada em atendimento ao publico do projeto iniciamos a elaboração da cartilha:

Argilas: uso e benefícios no skin care facial . Aliados dos procedimentos estéticos faciais e corporais desde a antiguidade, as argilas são consideradas multifuncionais, seus efeitos incluem: limpeza, adstringência, ação tensora, ativadora ou calmante, isso se dá de acordo com sua cor e composição, uma vez que a cor está associada a presença de minerais específicos (RIBEIRO, 2010).

Objetivo: Relatar a experiência de atividades desenvolvidas no Programa Institucional Centro de Estética e Cosmética Escola da UNIPAR.

Resultados: O contato com clientes, funcionários, acadêmicas e professoras é de extrema importância para nossa bagagem profissional e pessoal, permitindo o amadurecimento e o enriquecimento na formação. O desenvolvimento da cartilha informativa trouxe conhecimento teórico para nossa vida profissional e levou o conhecimento acadêmico para a sociedade, numa linguagem adequada, simples e de fácil compreensão. Um exemplo disso, é o uso da argila que pode ser aplicado em tratamento estético e terapêutico profissional ou como tratamento skin care, visando uma pele mais bonita e saudável de uma forma natural. Sua ação depende da cor que apresenta, como: argila branca para peles sensíveis e tratamentos de discromias; argila verde para controle da oleosidade; argila rosa com ação hidratante e suavizante, sendo ideal para peles sensíveis; argila preta é detoxificante, purificante e ativadora; argila vermelha com ação ativadora da microcirculação e controle de flacidez; argila amarela atua na reconstituição celular e purificadora, assim, é recomendada para rejuvenescimento e revitalização; argila roxa promove nutrição celular e ação ativadora (HEIDEMANN, 2018; AMORIM; PIAZZA, 2010). As argilas são aplicadas na estética facial sob a forma de máscaras, para isso são diluídas em base biocompatível, como a água filtrada, água thermal, óleo vegetal, soro fisiológico, hidratante neutro de acordo com o biotipo cutâneo e o objetivo do tratamento (AMORIM; PIAZZA, 2010; NARDIL; ROCATELLI; BLANCO, 2019).

Conclusão: $O$ estudo científico deve estar presente na trajetória profissional. Além disso, é responsabilidade do esteticista repassar as orientações skin care para seus clientes, para que os mesmos dêem continuidade ao tratamento, potencializando os resultados. Com isso, conseguimos resultados satisfatorios, entre eles o controle da oleosidade, a hidrataçao cutanea e a melhora na flacidez tissular.

\section{Referências}

AMORIM, Monthana Imai de; PIAZZA, Fátima Cecília Poleto. Uso das Argilas na Estética Facial e Corporal, Itajaí, 2010. Disponível em: http://siaibib01.univali.br/pdf/monthana\%20imai\%20de\%20amorim.pdf . Acesso em: 17 ago 2021.

HEIDEMANN, Morgana Schmoller. O uso da argila nos tratamentos estéticos faciais: uma revisão integrativa. Ciências da Saúde: Tubarão, v. 32, junho, 2018. Disponível em: Acesso em: 02 ago. 2021. 
NARDIL, Cínthia Romagna, ROCATELLI, Larissa Aleixo , BLANCO, Priscilla Hellen Martinez. Argila: Propriedades e benefícios para a pele. XI Encontro Internacional de Produção Científica. Centro Universitário de Maringá UNICESUMAR. 2019. Disponível em: http://rdu.unicesumar.edu.br/bitstream/123456789/3839/1/LARISSA\%20ALEIXO\%20ROCATELLI.pdf . Acesso em: 17 ago. 2021.

RIBEIRO, Cláudio de Jesus. Cosmetologia aplicada à Dermoestética. 2 ed. São Paulo, Pharmabooks, 2010.

I SALALOO DE EXTENSÃO " UNIPAR 50 ANOS:

DA UNIPAR
Transtormanso vides atroutes da educagato

27 de Outubro de 2021

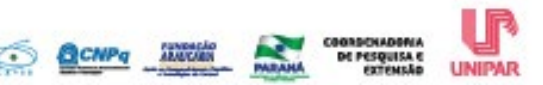




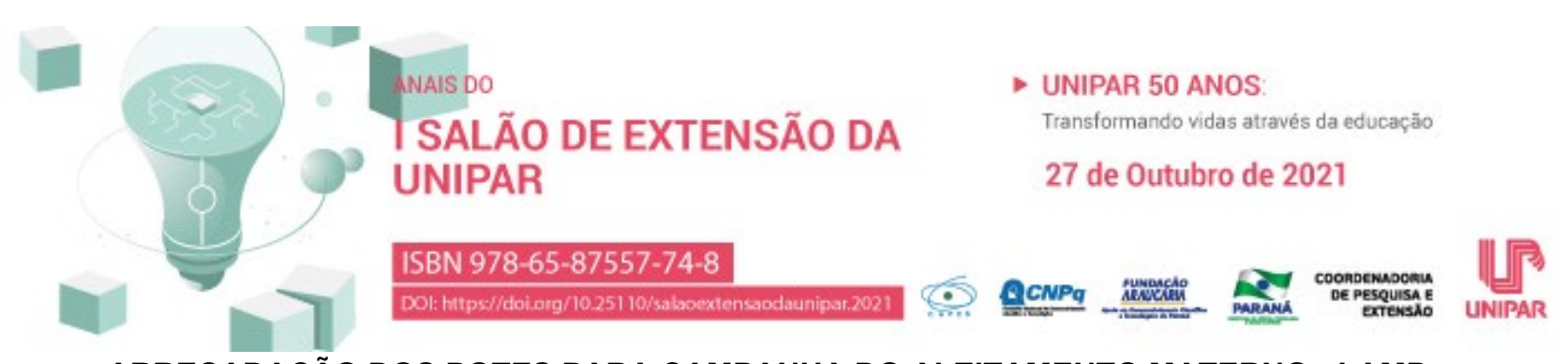

\section{ARRECADAÇÃO DOS POTES PARA CAMPANHA DO ALEITAMENTO MATERNO - LAMP}

${ }^{1}$ BEATRIZ PASCOALI CUNHA, ${ }^{2}$ BARBARA TEREZA LAVAGNINI, ${ }^{3}$ ANA BEATRIZ PINHEIRO ZAUPA, ${ }^{4}$ ANTONIO CARLOS FERREIRA DE OLIVEIRA FILHO, ${ }^{5}$ JULIA MARIA KROHLING BERTE, ${ }^{6}$ EDUARDA LUIZA MERTZ, ${ }^{7}$ EDHILA ASSUNCAO PINHEIRO, ${ }^{8}$ HELOISA GOMES MANZZANO, ${ }^{9}$ LETICIA NOGUEIRA ALVES DA SILVA, ${ }^{10}$ MARIA AUGUSTA NATALE FIORELLI, ${ }^{11}$ NATALLY GABRIELLY MARTIN FERNANDES, ${ }^{12} \mathrm{KELSON} \mathrm{RUDI} \mathrm{FERRARINI}$

${ }^{1}$ Discente do curso de Medicina - UNIPAR/Participante do Programa de Iniciação Científica - PIC/UNIPAR

${ }^{2}$ Discente do curso de Medicina - UNIPAR/Participante do Programa de Iniciação Científica - PIC/UNIPAR

${ }^{3}$ Discente do curso de Medicina - UNIPAR/Bolsista do PEBIC/UNIPAR

${ }^{4}$ Discente do Curso de Medicina da UNIPAR

${ }^{5}$ Discente do Curso de Medicina da UNIPAR

${ }^{6}$ Discente do Curso de Medicina da UNIPAR

${ }^{7}$ Discente do Curso de Medicina da UNIPAR

${ }^{8}$ Discente do Curso de Medicina da UNIPAR

${ }^{9}$ Discente do Curso de Medicina da UNIPAR

${ }^{10}$ Discente do Curso de Medicina da UNIPAR

${ }^{11}$ Discente do Curso de Medicina da UNIPAR

${ }^{12}$ Docente da UNIPAR

Introdução: A Liga Acadêmica de Medicina Pediátrica (LAMP) da UNIPAR teve sua fundação no dia 30 de abril de 2018, trazendo como objetivos a ampliação do conhecimento teórico-prático acerca da medicina pediátrica, bem como o incentivo a uma medicina mais humanizada, incluindo ações que enfatizem a importância do aleitamento materno. Dessa forma, como o mês de agosto é conhecido como Agosto dourado , destinado ao incentivo à amamentação, a LAMP participou de uma campanha de arrecadação de potes para armazenamento do leite materno. Sabe-se que a amamentação é a maneira natural de alimentar o bebê nos primeiros meses de vida, apresentando muitas vantagens. A primeira delas é que o leite materno possui uma composição de nutrientes específica que acompanha as necessidades da criança durante o seu desenvolvimento. Além disso, o leite materno contém agentes imunológicos que protegem a criança de doenças infecciosas. Portanto, alimentar a criança com o leite materno possibilita que ela cresça com todo o potencial que nasceu e que herdou da família. (CTENAS; VITOLO, 1999).

Objetivo: Abordar a importância, relevância e necessidade do arrecadamento de potes de vidro para a campanha Agosto Dourado durante o mês de conscientização sobre a amamentação.

Resultados: A campanha Agosto Dourado, realizada pela Secretaria de Saúde de Umuarama, com o apoio da LAMP e outras instituições, teve como objetivo arrecadar potes de vidro para armazenar leite materno doado destinado às crianças prematuras internadas em UTIs. A doação ocorreu na COVISA (Secretaria de Saúde de Umuarama), no dia 30 de agosto, totalizando uma arrecadação de mais de 100 potes de vidro. Posteriormente, esses potes foram destinados ao Posto de Coleta do Hospital Norospar, local onde estão internados os prematuros. Como forma de incentivo, a campanha contava com um certificado de quatro horas complementares para cada 10 potes doados pelos alunos, sendo esses de $250 \mathrm{ml}$ com ou sem tampa, devendo estar previamente higienizados. A campanha foi de extrema importância, tendo em vista que o leite materno constitui-se como alimento exclusivo até os 6 meses de vida, corroborando sua necessidade aos prematuros.

Conclusão: Dado o exposto, a LAMP por meio da Campanha Agosto Dourado realizada pela Secretaria de Saúde de Umuarama, contribuiu ajudando diversos pacientes pediátricos que necessitam de leite materno para sobreviver e as mães que não podem amamentar por conta do estado crítico que seus filhos se encontram.

\section{Referências}

CTENAS, M. L. B., VITOLO, M. R. Crescendo com Saúde: o guia de crescimento da criança. São Paulo: C2 Editora e Consultoria em Nutrição, 1999. 


\section{8 \\ BENEFÍCIOS DE ATENDIMENTOS ESTÉTICOS EM MULHERES PÓS CÂNCER DE MAMA}

${ }^{1}$ MARIANA GARCIA DE OLIVEIRA, ${ }^{2}$ ANA JULIA LUCHETTI BARAGATTI, ${ }^{3}$ CAMILLY CRISTINA DE LIMA, ${ }^{4}$ DAIANI APARECIDA AGUERO, ${ }^{5}$ IZABELA CRISTINA COMAR, ${ }^{6}$ AMANDA CAROLINE MARCOMINI DA SILVA, ${ }^{7}$ LARISSA DE FARIA MELO, ${ }^{8}$ SIMONE CASTAGNA ANGELIM COSTA, ${ }^{9}$ ANA BEATRIZ PENASSO DA SILVA, ${ }^{10}$ MILENA CAROLINE DE SOUZA ROCHA, ${ }^{11}$ MARIA EDUARDA LONGHI, ${ }^{12}$ NATALIA DE OLIVEIRA SOUZA, ${ }^{13}$ JULIANA PELISSARI MARCHI, ${ }^{14}$ RAQUEL COSTA MACHADO, ${ }^{15}$ SIMONE TRINDADE GONZAGA APPOLINARIO, ${ }^{16} \mathrm{GIOVANA} \mathrm{MIOTO}$ DE MOURA

\footnotetext{
${ }^{1}$ Acadêmica do Curso de Estética e Cosmética - UNIPAR - Cianorte

${ }^{2}$ Acadêmica do Curso de Estética e Cosmética da UNIPAR

${ }^{3}$ Acadêmica do Curso de Estética e Cosmética da UNIPAR

${ }^{4}$ Acadêmica do Curso de Estética e Cosmética da UNIPAR

${ }^{5}$ Acadêmica do Curso de Estética e Cosmética da UNIPAR

${ }^{6}$ Acadêmica do Curso de Estética e Cosmética da UNIPAR

${ }^{7}$ Acadêmica do Curso de Estética e Cosmética da UNIPAR

${ }^{8}$ Docente da UNIPAR

${ }^{9}$ Acadêmica do Curso de Estética e Cosmética da UNIPAR

${ }^{10}$ Acadêmica do Curso de Estética e Cosmética da UNIPAR

${ }^{11}$ Acadêmica do Curso de Estética e Cosmética da UNIPAR

${ }^{12}$ Acadêmico do Curso de Estética e Cosmética da UNIPAR

${ }^{13}$ Docente da UNIPAR

${ }^{14}$ Docente da UNIPAR

${ }^{15}$ Acadêmica do Curso de Estética e Cosmética da UNIPAR

${ }^{16}$ Docente da UNIPAR
}

Introdução: O câncer de mama é uma doença maligna que caracteriza-se pelo crescimento de células de forma desordenada, acometendo as glândulas mamárias, que se proliferam defeituosamente, criando nódulos na área e na região axilar (SOCIEDADE BRASILEIRA DE PATOLOGIA, 2016). Com incidência descrita pelo INCA (2021) no topo dos tumores que acometem as mulheres, tendo 66.280 novos casos. Sabe-se que é um tipo de doença que afeta o fisiológico e psicológico dessas pessoas, como descrito no estudo de Martins et al., (2016), onde mulheres relatam seus sentimentos de tristeza, angústia e esperança, desde o momento que receberam a notícia, durante o tratamento de quimioterapia e radioterapia, e após essa fase, olhando no espelho e observando o corpo sem uma das mamas. Com essa visão de contribuir para o embelezamento, autocuidado, e oferecer às essas pessoas momentos de conforto e relaxamento após toda essa fase difícil, o Projeto do Centro de Estética e Cosmética Escola realiza alguns procedimentos estéticos nessas mulheres, como estímulo do aumento da autoestima e qualidade de vida.

Objetivo: Explanar sobre os benefícios dos atendimentos estéticos para mulheres após o câncer de mama.

Resultados: Uma vez por semana um grupo de mulheres que tiveram câncer de mama, mastectomizadas ou não, previamente autorizados pelos seus médicos, recebem procedimentos estéticos como: design de sobrancelha, hidratação facial, corporal e capilar, spa das mãos e pés. Onde é possível perceber que algumas delas durante a sessão preferem ficar mais quietas, outras conversam durante o atendimento falando sobre diversos assuntos, inclusive o câncer, como se fosse minutos de desabafo, ou mesmo de atenção exclusiva para ela. Mas ao final de cada sessão, independente da técnica estética recebida, o sorriso no rosto que expressa felicidade e gratidão pelo momento, é visível, além das palavras de elogios e de agradecimentos. O semblante facial de cada uma delas antes e após o atendimento é perceptível que se altera, porém, muda para melhor, podendo ser observado que procedimentos estéticos podem contribuir positivamente na vida dessas mulheres.

Conclusão: Os atendimentos estéticos realizados em mulheres após o tratamento de câncer de mama, podem contribuir para a melhora da autoestima e promoção de qualidade de vida das mesmas, através de estímulos realizados por meio de técnicas de embelezamento e de relaxamento, que fazem dessas sessões um momento exclusivo e único para cada uma delas. 


\section{Referências}

INSTITUTO NACIONAL DO CÂNCER - MINISTÉRIO DA SAÚDE. Estatísticas do câncer. Publicação editada em 10 de julho de 2021. Disponível em: https://www.inca.gov.br/numeros-de-cancer. Acesso em: 01 set. 2021.

MARTINS, M. M. B.; FARIAS, M. D. B. S.; SILVA, I. S. Sentimentos pós mastectomia em mulheres atendidas em uma associação de apoio às pessoas com câncer. Rev. Gest.Saúde(Brasília) Vol.07, Nº. 02, Ano 2016.p 596-07. Disponível em: odicos.unb.br/index.php/rgs/article/view/3510. Acesso em: 01 set. 2021.

SOCIEDADE BRASILEIRA DE PATOLOGIA. Câncer de mama. Publicação realizada em 19 de julho de 2016. Disponível em: http://www.sbp.org.br/cancer-de-mama/? gclid=CjOKCQjwssyJBhDXARIsAK98ITQYRe6WYYw5gooWWAnTqjVO5d6yQaEFQgaCXU6In9JGMwqgsc9MpMaAgTEEALw_wcB. Acesso em: 31 ago. 2021.

I SALĂOO DE EXTENSÃO

DA UNIPAR
- UNIPAR 50 anos:

Transtormanso vides atrewtes da educagegto

27 de Outubro de 2021

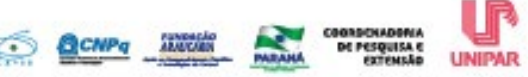




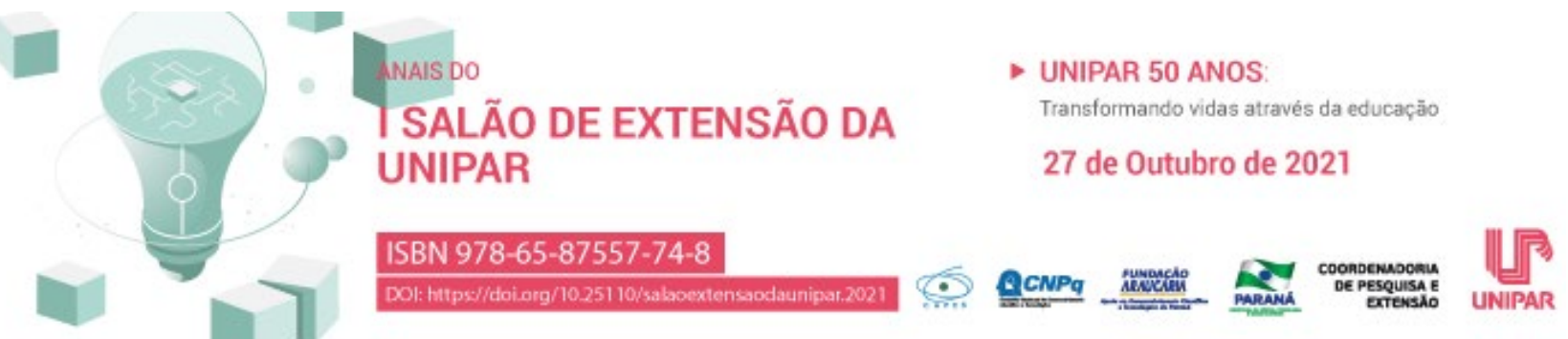 \\ ESCOLHA DE COSMÉTICOS PARA SKIN CARE: UM RELATO DE EXPERIÊNCIA
}

\author{
${ }^{1}$ THAIS APARECIDA HART RIBEIRO, ${ }^{2}$ DANIELA MILENA DIAS, ${ }^{3}$ MARINA CENTENARO, ${ }^{4}$ CARLA EDUARDA \\ ZAMBENEDETTI DE OLIVEIRA, ${ }^{5}$ KELLI KUHNEN, ${ }^{6}$ SIMONE CASTAGNA ANGELIM COSTA, ${ }^{7}$ GIOVANA MIOTO DE MOURA, \\ ${ }^{8}$ RAQUEL COSTA MACHADO, 9 JULIANA PELISSARI MARCHI
}

\begin{abstract}
${ }^{1}$ Acadêmica participante do Programa Institucional Centro de Estética e Cosmética Escola, do C.S.T. em Estética e Cosmética da UNIPAR.

${ }^{2}$ Acadêmica participante do Programa Institucional Centro de Estética e Cosmética Escola, do C.S.T. em Estética e Cosmética da UNIPAR.

${ }^{3}$ Acadêmica participante do Programa Institucional Centro de Estética e Cosmética Escola, do C.S.T. em Estética e Cosmética da UNIPAR.

${ }^{4}$ Acadêmica participante do Programa Institucional Centro de Estética e Cosmética Escola, do C.S.T. em Estética e Cosmética da UNIPAR.

${ }^{5}$ Responsável Técnica do Centro de Estética Escola do C.S.T. em Estética e Cosmética da Universidade Paranaense, UNIPAR.

${ }^{6}$ Docente do C.S.T. em Estética e Cosmética da Universidade Paranaense, UNIPAR.

${ }^{7}$ Docente do C.S.T. em Estética e Cosmética da Universidade Paranaense, UNIPAR.

${ }^{8}$ Docente do C.S.T. em Estética e Cosmética da Universidade Paranaense, UNIPAR.

${ }^{9}$ Docente do C.S.T. em Estética e Cosmética da Universidade Paranaense, UNIPAR.
\end{abstract}

Introdução: As atividades do projeto se consolidam como uma rica oportunidade de relacionamento entre teoria e prática. Durante a execução das atividades práticas verificou-se que a maioria das pessoas não conhecem o seu biotipo cutâneo e nem sabem escolher cosméticos ideais para os cuidados diários com a pele, ressaltando assim a necessidade de instrução profissional. Com isso, elaboramos a cartilha intitulada A escolha ideal de cosméticos para skin care , que foi disponibilizada para profissionais e para a população, com intuito de orientá-los quanto a forma correta de cuidar da pele. A pele é o maior órgão do corpo humano, está classificada em biotipos e apresenta características individuais, assim, reflete a saúde e o bem-estar do indivíduo, sendo necessário reconhecer essas características individuais para determinação dos cuidados diários adequados a fim de mantê-la saudável (URURAHY, 2015).

Objetivo: Relatar a experiência de atividades desenvolvidas no Programa Institucional Centro de Estética e Cosmética Escola da UNIPAR.

Resultados: As atividades nos permitiram desenvolver habilidades práticas, compreender a realidade e estabelecer reflexões acerca das condutas que devem ser realizadas de forma ética e humanizada. A pesquisa e elaboração da cartilha nos mostrou que devemos como profissionais intensificar a pesquisa e transmitir conhecimentos científicos, para tanto, com essa cartilha levamos informações importantes do skin care adequado. Para iniciar os cuidados com a pele é necessário a identificação dos biotipos cutâneos (normal, seca, oleosa, mista), análise das características individuais (fototipo, sensibilidade) e presença de disfunções estéticas, que serão avaliadas pelo profissional esteticista, ao qual irá aconselhar o uso ativos e bases cosméticas corretas para cada situação (PINHEIRO, 2016; FERNANDES; RAMALHINHO; NASCIMENTO, 2012). Num geral os cuidados diários incluem etapas (higienização, esfoliação, tonificação, hidratação, tratamento e fotoproteção), visando equilíbrio hídrico e sebáceo, prevenção e controle de disfunções estéticas a fim de manter a pele íntegra, equilibrada e saudável, para isso é necessário respeitar a individualidade (LIBERALI; VIEIRA, 2017).

Conclusão: Concluiu-se que a vivência no projeto teve grande importância na formação acadêmica e desenvolvimento pessoal. Além disso, contribuiu com o desenvolvimento de habilidades profissionais, capacitou-nos a atuar de forma personalizada.

\section{Referências}

FERNANDES Adriana Isabel Palhares; RAMALHINHO, Isabel Maria Pires Sebastião; NASCIMENTO, Tânia Isabel Martins do. Cuidados dermocosméticos para uma pele saudável: aconselhamento farmacêutico nos casos mais comuns. 2012. Monografia (Mestrado Integrado em Ciências Farmacêuticas) - Universidade do Algarve Faculdade de Ciências e Tecnologia, 2012.

LIBERALI, Rafaela; VIEIRA, Simone A. P. Cosmetologia III. Indaial: UNIASSELVI, 2017, 235 pp.

OLIVEIRA, Daniela Benedetti de; DORNELLAS, Eliane. Pele madura: a utilização de óleo de rosa mosqueta em produtos cosméticos. Revista Acadêmica Osvaldo Cruz, v. 3, n. 19, jul/set. 2018 . Disponível em: 
http://revista.oswaldocruz.br/Content/pdf/Edicao_19_DANIELA_BENEDETTI_DE_OLIVEIRA.pdf. Acesso em 16 ago. 2021. URURAHY, Gilberto. Os cuidados com a sua pele. Med.Rio: Check-up - Sempre a frente. 20 f. Rio de Janeiro, 2016. Disponível em: https://medriocheck-up.com.br/wp-content/uploads/2018/07/2015.pdf. Acesso em 17 ago. 2021.

ISALALOAOO DE EXTENSÃO

DA UNIPAR
- UNIPAR 50 anOS:

Traneformando vidas atraves da educaçso

27 de Outubro de 2021

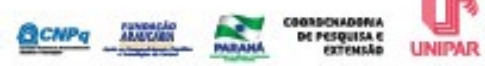




\title{
UNAIPAO DE EXTENSÃO DA \\ - UNIPAR 50 ANOS: \\ Transformando vidas através da educą̧ão \\ 27 de Outubro de 2021 \\ ISBN 978-65-87557-74-8 \\ ORIENTAÇÃO PROFISSIONAL PARA ADOLESCENTES E PANDEMIA: UM RELATO DE EXPERIÊNCIA
}

\author{
${ }^{1}$ ALYNE GUARDA BASSANESI, ${ }^{2}$ THAIS CRISTINA GUTSTEIN NAZAR
}

\author{
${ }^{1}$ Acadêmica do PEX do curso de Psicologia/Unipar \\ ${ }^{2}$ Docente do curso de Psicologia da Universidade Paranaense UNIPAR, campus de Francisco Beltrão/PR.
}

Introdução: A Orientação Profissional tem como objetivo auxiliar os indivíduos tanto na situação de primeira escolha profissional, quanto na reescolha ou na readaptação a novas profissões (Moura, 2004). A partir de um acompanhamento breve, mas bem focado, poderá ajudar a descobrir a oportunidade de carreira mais acertada para seguir auxiliando o adolescente na busca pelo reconhecimento das carreiras mais adequadas ao seu perfil e, ao mesmo tempo, esclarecer dúvidas existentes. Nos últimos meses, a partir do contexto social e de saúde enfrentados pela sociedade, a Psicologia precisou também ampliar as possibilidades de intervenções visando atingir o público a partir de diferentes propostas de trabalho. Com o intuito de alcançar a população, mas principalmente os jovens, e ampliar seus conhecimentos sobre Orientação Profissional, foi criado uma série de conteúdos para as redes sociais sobre o tema, cada um deles baseados no programa de Orientação Profissional sob enfoque da Análise do Comportamento (Moura, 2004).

Objetivo: Descrever os procedimentos realizados sobre Orientação profissional a partir da criação de conteúdos para redes sociais direcionados a adolescentes que estão vivenciando o momento da escolha profissional.

Material e métodos: A metodologia utilizada para esta proposta, foi realizada inteiramente de forma virtual, através das plataformas de mídias Facebook e Instagram. Inicialmente fora criada uma página denominada como Habilidades para a Vida em que foram feitas postagens intercaladas, com frequência de duas vezes a cada semana, totalizando 07 inserções. $O$ conteúdo abordado em cada postagem foi criado com o objetivo de disponibilizar informações e tornar acessível aos adolescentes, sendo as temáticas referente à autoconhecimento, conhecimento das profissões e tomada de decisões. Devido ao contexto da Pandemia, é perceptível a mudança e avanço tecnológico, já que por sua vez, é uma ferramenta dominada pelos jovens. Por meio do ambiente virtual, o alcance de pessoas se torna mais significativo, ampliando a zona de conhecimento.

Resultados: Com o engajamento nas redes sociais, as postagens despertaram o interesse do público em analisar as dúvidas sobre tomada de decisões, mostrando a importância de falar mais sobre o assunto, e também, em incentivar os jovens a ir em busca de desbravar suas incertezas, assim obtendo um resultado positivo. Baseando-se nos resultados do projeto, muitas pessoas se interessaram pelos temas abordados, como por exemplo, a importância de se ouvir e não tomar decisões baseadas nas opiniões alheias, muitos compartilharam em seus perfis nas redes, onde nos fez alcançar ainda mais pessoas.

Discussão: Durante as intervenções foram analisados pontos sobre o significativo número de pessoas que se encontram em modo de indecisão, o que nos incentivou ainda mais a produzir conteúdos que pudessem abranger as mais variadas dúvidas. Além disso, devido a este novo cenário de Pandemia, o ambiente virtual constituiu-se como um auxílio na autonomia e liberdade de escolha dos jovens (MAUCH; COSTA; SILVA; ANDRADE; ALMEIDA; ARAUJO; SOUZA; NUNES; SOUZA, 2020). Mas há os obstáculos predominantes, muitas pessoas têm sofrido com este novo método de aprendizagem, onde tudo é de forma digital e a distância. Houve o aumento da exigência, tanto em produzir mais quanto em administrar, gerando sobrecarga, estresse e ansiedade.

Conclusão: A proposta de intervenção apresentada contribuiu para o avanço da ciência psicológica na interlocução com a comunidade, especificamente com adolescentes que estão enfrentando o momento da escolha profissional no contexto da Pandemia. Sugerem-se novas e futuras intervenções voltadas a essa temática mostrando a psicologia de diferentes maneiras e possibilidades, especificamente neste contexto aprofundando e direcionando o olhar acerca da Orientação Profissional e a utilização das redes sociais digitais no cuidado com os adolescentes.

\section{Referências}

MOURA, Cynthia Borges de. Orientação Profissional Sob o Enfoque Da Análise Do Comportamento. $1^{a}$ ed. Campinas, SP: Editora Alínea, 2004.

MAUCH, Ana Gabriela; COSTA, Jéssica Emanoeli; SILVA, Kelly Mangabeira; ANDRADE, Lorena Bianca; ALMEIDA, Lucas; ARAÚJO, Sarah; NUNES, Tâmara; SOUZA, Vanessa. A utilização das redes sociais digitais no cuidado psicossocial infantojuvenil, diante da pandemia por Covid-19. Vol. 1, Distrito Federal, 28 abril. 2020. Disponível em: https://escsresidencias.emnuvens.com.br/hrj/article/view/12/17 



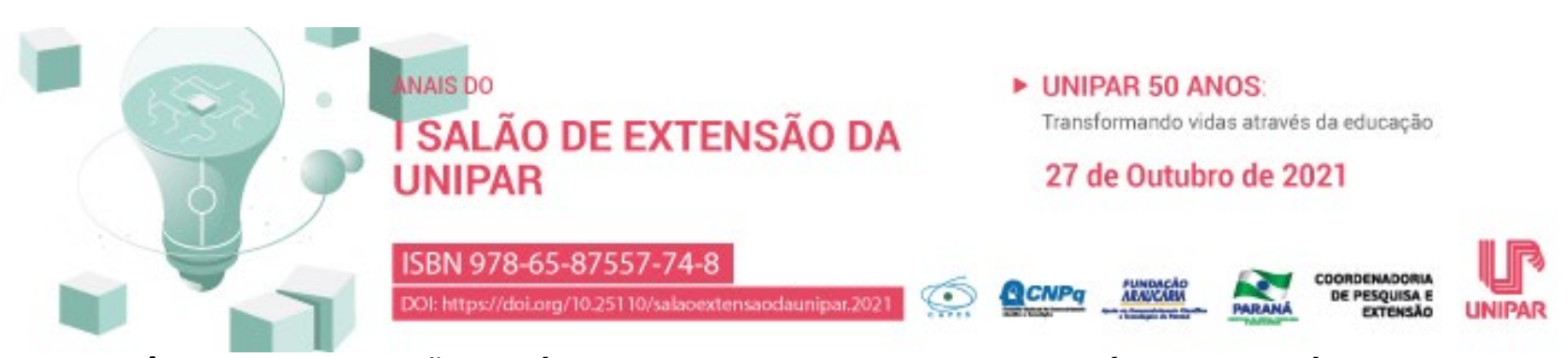

IMPORTÂNCIA DA INGESTÃO DE ÁGUA PARA OS TRATAMENTOS ESTÉTICOS E SAÚDE DA PELE

\author{
${ }^{1}$ ANGELA JULIA PFEIFER, ${ }^{2}$ CLAUDIA DE QUADROS, ${ }^{3}$ ISADORA MILENA ROCHA KRIGER, ${ }^{4}$ LORHUAMA DE OLIVEIRA, \\ ${ }^{5}$ SIMONE CASTAGNA ANGELIM COSTA, ${ }^{6}$ RAQUEL COSTA MACHADO, ${ }^{7} \mathrm{KELLI} \mathrm{KUHNEN,}{ }^{8}$ JULIANA PELISSARI MARCHI
}

\begin{abstract}
1 Acadêmicas participantes do Programa Institucional Centro de Estética e Cosmética Escola, do Curso Superior de Tecnologia em Estética

${ }^{2}$ Acadêmica participante do Programa Institucional Centro de Estética e Cosmética Escola, do C.S.T. em Estética e Cosmética da UNIPAR.

${ }^{3}$ Acadêmica participante do Programa Institucional Centro de Estética e Cosmética Escola, do C.S.T. em Estética e Cosmética da UNIPAR.

${ }^{4}$ Acadêmica participante do Programa Institucional Centro de Estética e Cosmética Escola, do C.S.T. em Estética e Cosmética da UNIPAR.

${ }^{5}$ Docente do C.S.T. em Estética e Cosmética da Universidade Paranaense, UNIPAR.

${ }^{6}$ Docente do C.S.T. em Estética e Cosmética da Universidade Paranaense, UNIPAR.

${ }^{7}$ Responsável Técnica do Centro de Estética Escola do C.S.T. em Estética e Cosmética da Universidade Paranaense, UNIPAR.

${ }^{8}$ Docente do C.S.T. em Estética e Cosmética da Universidade Paranaense, UNIPAR.
\end{abstract}

Introdução: As atividades práticas desse programa institucional são desenvolvidas no Centro de Estética e Cosmética Escola da UNIPAR. Durante o período de março a agosto os clientes relataram baixa ingestão de água, ao questioná-los percebeu-se que ainda possuem falta de conhecimento sobre seus benefícios. A partir desse dado, realizamos uma pesquisa e elaboramos a cartilha intitulada Importância da ingesta de água para os tratamentos estéticos e saúde da pele , que está sendo divulgada para a população. O consumo de água é fundamental tanto para a saúde quanto para a estética, uma vez que auxilia nos processos metabólicos e mantém o organismo hidratado (ISRAEL, 2015).

Objetivo: Descrever a experiência de atividades desenvolvidas no Programa Institucional Centro de Estética e Cosmética Escola da UNIPAR, além de abordar o tema indagado na cartilha.

Resultados: O organismo humano é composto de $70 \%$ de água, a todo instante acontece a eliminação de água, por isso é necessário a reposição constante (aproximadamente 2 litros de água por dia, pode variar de acordo com a idade, nível de atividade física e temperatura do ambiente) a fim de manter o tecido hidratado (SANTOS, 2018; BORTOLI, 2016; EARLE; VARTULI, 2020). Apesar da pele possuir um fator natural de hidratação, este ainda não é suficiente, pois existem vários fatores ambientais que influenciam na redução de água da pele. Quando está hidratada apresenta-se com aspecto suave ao toque, macia e uniforme, já uma pele seca a sua perda da suavidade é notória, com aparência áspera, opaca e descamativa. Para um bom andamento dos procedimentos estéticos, o profissional deve estar atento aos níveis de hidratação cutânea, pois a partir do mecanismo de hidratação da pele que obtém resultados satisfatórios, além disso, estará colaborando para uma pele saudável, macia, com flexibilidade e elasticidade (AMARAL; SOUZA, 2019). A vivência nesse programa institucional é de grande importância, pois, desenvolve a autoconfiança o que possibilita a aplicação das atividades práticas com segurança. Ainda, agrega conhecimento preparando o acadêmico para exercer a profissão com segurança e domínio. A cartilha possibilitou o desenvolvimento teórico acerca do tema.

Conclusão: A hidratação corporal é de suma importância para a fisiologia humana, proveniente da ingestão diária de água, que contribui com uma pele saudável e com os resultados de tratamentos estéticos. Além do líquido, a orientação e uso de cosméticos hidratantes pelo profissional de estética são indispensáveis.

\footnotetext{
Referências

AMARAL, Karina Fabrícia Vaz; SOUZA, Rafaela Brito Arêas. A Importância da Hidratação Cutânea para melhor tratamento das Disfunções Estéticas/The Importance of Skin Hydration for Better Treatment of Aesthetic Dysfunctions. ID on line REVISTA DE PSICOLOGIA, v. 13, n. 48, p. 763-771, 2019.

BORTOLI, Jaqueline De. Qualidade físico-química e microbiológica da água utilizada para consumo humano e dessedentação animal em propriedades rurais produtoras de leite na região do Vale do Taquari/RS. Orientador: Claudete Rempel. 2016. 152 f. Dissertação (Mestrado em ambiente e desenvolvimento) - Centro Universitário UNIVATES, Lajeado, 2016. EARLE, Liz; VARTULI, Michele A. Menopausa bem vivida: o guia definitivo para se sentir bem e radiante na prémenopausa, na menopausa e depois dela. Editora Senac, São Paulo, 2020.
} 
ISRAEL, Doris. Detox já: Mude seus hábitos, emagreça e conquiste saúde, vitalidade e disposição. HarperCollins Brasil, 2015.

SANTOS, Thalyta Monte Batalha dos. Necessidade humana básica de hidratação dos profissionais de enfermagem de uma unidade de terapia intensiva. Orientadora: Flávia Danyelle Oliveira Nunes. 2018. 55 f. Monografia (graduação em Enfermagem) - Universidade Federal do Maranhão, São Luís, 2018.

I SALALO DE EXTENSÃO " UNIPAR 50 ANOS:

DA UNIPAR
27 de Outubro de 2021

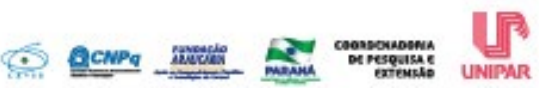




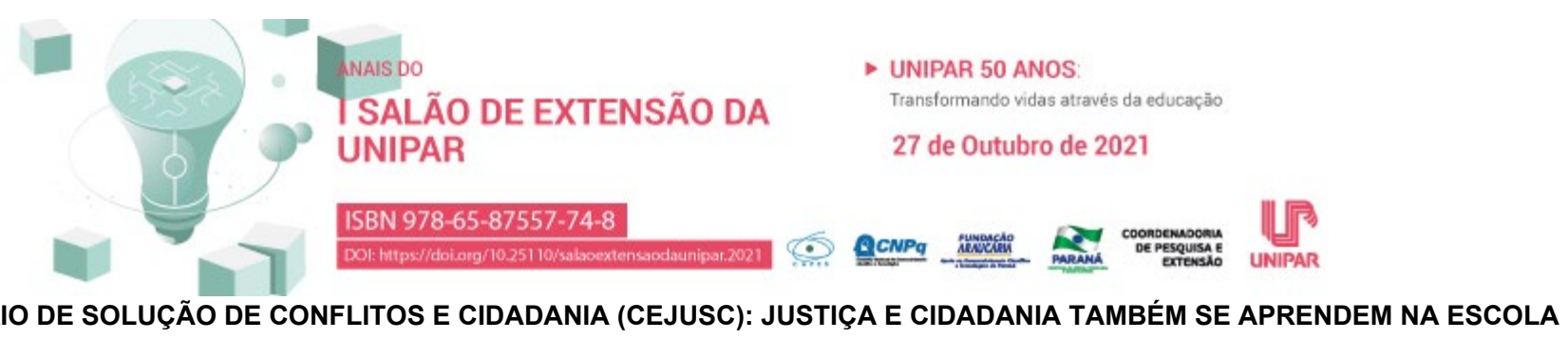

\author{
${ }^{1}$ CAMILA CRISTINA HENRIQUE SCHULZE, ${ }^{2}$ ANA CAROLINE CORREIA, ${ }^{3}$ ALEXANDRE MAGNO AUGUSTO MOREIRA
}

\author{
${ }^{1}$ Responsável Técnica do Curso de Direito da Unipar - Unidade de Francisco Beltrão \\ ${ }^{2}$ Acadêmica do Curso de Direito da UNIPAR \\ ${ }^{3}$ Docente da UNIPAR
}

Introdução: O CEJUSC consiste em um programa de extensão do Curso de Direito da Universidade Paranaense Unidade de Francisco Beltrão vinculado ao TJPR. Em parceria com a $2^{2}$ Vice-Presidência do Tribunal, é desenvolvido o programa Justiça e Cidadania Também Se Aprendem Na Escola que, mediante respaldo técnico dos professores e responsáveis técnicos, conta com a participação dos acadêmicos do Curso de Direito. O presente projeto possui como finalidade oferecer noções básicas de cidadania e justiça aos alunos da rede pública municipal de ensino de Francisco Beltrão. Em um primeiro momento, por meio de cartilhas didáticas, são repassados para os alunos alguns conhecimentos acerca das funções do Estado e dos Poderes Legislativo, Executivo e Judiciário, assim como são apresentados direitos e deveres dos cidadãos. Em um segundo momento, os alunos realizam uma visita nas dependências do Fórum de Justiça, com o propósito de oportunizá-los a conhecer os espaços ocupados pelos integrantes do Poder Judiciário. Ao final, o projeto é encerrado com a realização de um júri simulado com a participação ativa das crianças e com uma produção cultural, ocasião em que são elaborados cartazes referentes aos temas trabalhados, com premiação para os primeiros colocados.

Objetivo: Com a realização dessa atividade, pretende-se contribuir no processo de formação dos futuros jovens cidadãos de Francisco Beltrão, estimulando dessa forma o desenvolvimento cívico por meio de reflexões sobre cidadania e justiça. Além disso, procura-se contribuir com a formação acadêmica e pessoal dos acadêmicos do Curso de Direito, com a provocação de debates, reflexões e conhecimento acerca de diversos contextos sociais. Resultados: Nas ocasiões em que foram desenvolvidas as atividades, foram possíveis verificar reflexões e questionamentos acerca dos assuntos abordados. Ao final, ainda, observou-se, a partir da elaboração dos cartazes e a realização do júri simulado, a assimilação dos temas apresentados por parte das crianças.

Conclusão: Depreende-se que a idealização do programa pelo Tribunal de Justiça contribui com a formação cívica das crianças em desenvolvimento, assim como oportuniza, por meio da visita realizada nas dependências do Fórum de Justiça, o conhecimento de diversas carreiras profissionais que podem ser almejadas pelos alunos em um futuro próximo.

\title{
Referências
}

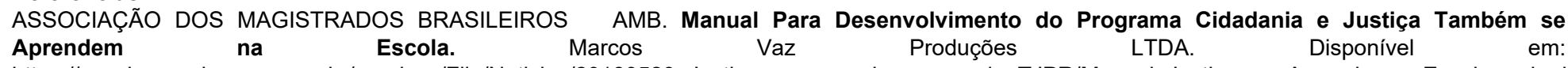
https://escolasuperior.mppr.mp.br/arquivos/File/Noticias/20180529_Justica_se_aprende_na_escola_TJPR/Manual_Justiaa_se_Aprende_na_Escola_red.pdf. Acesso em: 05 set. 2021.

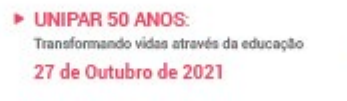

- UNIPAR 50 ANOS:
Tranefformando vides atreves da educagaso
27 de Outubro de 2021

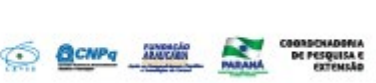




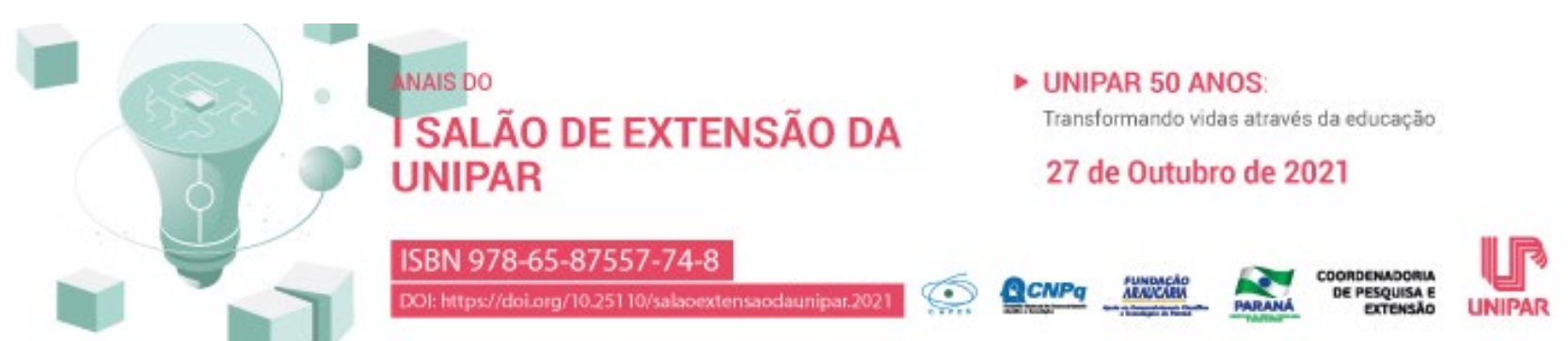

\title{
AÇÕES DA LIGA ACADÊMICA DE ENDOCRINOLOGIA DA UNIPAR NA SEMANA INTERNACIONAL DA TIREOIDE 2021
}

\author{
1VANESSA MARCONDES BRASILEIRO FREDERICO, ${ }^{2}$ AMANDA PINHEIRO PRADO, ${ }^{3}$ MARIO MARQUES PEREIRA FILHO, \\ ${ }^{4}$ MICHELE AYUMI CHAVES, ${ }^{5}$ BRUNA MONTEIRO SANCHES, ${ }^{6}$ SUELEN STEFANONI BRANDAO, ${ }^{7}$ VINICIUS PAIE MARQUES \\ DOS REIS, ${ }^{8}$ MIGUEL FRANCISCO FERREIRA BATISTA, ${ }^{9}$ LUCAS ALEXANDRE GUBERT SCHIER, ${ }^{10}$ GABRIELA ALVES DE \\ OLIVEIRA, ${ }^{11}$ PATRICIA RODRIGUES HAUCK PRANTE
}

\footnotetext{
${ }^{1}$ Acadêmica do curso de Medicina da UNIPAR

${ }^{2}$ Acadêmica de Medicina da UNIPAR

${ }^{3}$ Acadêmico do Curso de Medicina da UNIPAR

${ }^{4}$ Acadêmica do Curso de Medicina da UNIPAR

${ }^{5}$ Acadêmica do Curso de Medicina da UNIPAR

${ }^{6}$ Acadêmica do Curso de Medicina da UNIPAR

${ }^{7}$ Acadêmico do Curso de Medicina da UNIPAR

${ }^{8}$ Acadêmico do Curso de Medicina da UNIPAR

${ }^{9}$ Acadêmico do Curso de Medicina da UNIPAR

${ }^{10}$ Acadêmica do Curso de Medicina da UNIPAR

${ }^{11}$ Docente da UNIPAR
}

Introdução: A tireóide é uma glândula cuja função é o controle do metabolismo corporal, agindo em órgãos importantes como o coração, cérebro, fígado e rins. Interfere, também, no crescimento e desenvolvimento das crianças e adolescentes, na regulação dos ciclos menstruais e na fertilidade, no peso, na memória, na concentração e até no controle emocional. É fundamental que a glândula esteja em perfeito estado de funcionamento para garantir o equilíbrio e a harmonia de todos os sistemas do organismo. Nos casos de hipotireoidismo, o qual se caracteriza pela falta do hormônio da tireóide, se desenvolvem sintomas como astenia, alterações de memória, pele seca, sonolência, intolerância ao frio, voz arrastada e constipação intestinal. Entretanto, muitos pacientes são assintomáticos ou oligossintomáticos ao diagnóstico, sobretudo aqueles com doença menos intensa ou de menor duração, sendo detectados, muitas vezes em exames de rotina( VILAR,2021). Por outro lado, o hipertireoidismo decorre da produção excessiva de hormônios tireoidianos e pode se manifestar com palpitações, agitação, sudorese e perda de peso.

Objetivo: Estimular a prevenção, por meio da informação contida em panfletos ofertados à comunidade, acerca de sintomas, diagnóstico e tratamento das patologias tireoidianas mais prevalentes.

Resultados: Um dos achados mais frequentes da tireóide são os nódulos, que na maior parte dos casos não manifestam sintomas específicos. Estima-se que $60 \%$ da população brasileira tenha nódulos na tireoide em algum momento da vida, não necessariamente malignos e que apenas $5 \%$ destes sejam cancerosos (SBEM,2021). A identificação precoce dos nódulos pode reduzir a morbi mortalidade na eventualidade de uma lesão maligna . Para isso, utiliza-se o exame clínico com uma palpação criteriosa da glândula tireóide. Este exame é simples, fácil de ser feito e pode mudar a história de uma pessoa. Uma vez identificada a presença do nódulo, é importante que o endocrinologista solicite uma série de exames complementares para confirmar a presença ou não do câncer. Dada a importância da glândula tireóide para o desempenho de funções homeostáticas, foi realizada uma atividade envolvendo a comunidade a fim de alertá-la quanto aos sinais do nosso corpo. O projeto ocorreu na semana de 24 a 28/05/2021, pois o dia 25/05 é marcado como Dia Internacional da Tireóide" e foi realizado pelos integrantes da Liga Acadêmica de Endocrinologia e Metabolismo (LAEM) da Universidade Paranaense (UNIPAR) da sede de Umuarama-PR. No projeto em questão, os integrantes da liga acadêmica realizaram durante o período de uma semana, a distribuição de panfletos com informações sobre as principais doenças que acometem a glândula tireóide e seus principais sinais e sintomas. Com isso, foi possível realizar a conscientização da população em geral a respeito da importância da glândula tireóide, da atenção aos sintomas e da investigação regular da saúde tireoidiana para assim, prevenir, diagnosticar e tratar precocemente os casos de disfunções da glândula tireóide.

Considerações Finais: A Liga de Endocrinologia e Metabolismo da UNIPAR (LAEM) conclui que a entrega dos panfletos foi efetiva e correspondeu às expectativas, pois fez-se a entrega de 1000 panfletos, além de esclarecer dúvidas da população. Entretanto sabe-se que há muito ainda a ser feito para que as pessoas tenham conhecimento das doenças tireoidianas que mais afetam a população, como palestras nas Unidades Básicas de Saúde para funcionários e usuários. 


\section{Referências}

SBEM,Sociedade Brasileira de Endocrinologia e

Metabologia, 2021. Tireoide. Disponível em:https://www.endocrino.org.br/tireoide/. Acesso em 30 de ago.2021.

FREITAS, Maria da Conceição, LIMA, Helena. Diagnóstico e Tratamento do Hipotireoidismo. In: VILAR, Lúcio. Endocrinologia Clínica.Rio de Janeiro: Guanabara Koogan, 2021.313-325.

I SALÄO DE EXTENSÃ́O " UNIPAR 50 ANOS:

DA UNIPAR
27 de Outubro de 2021
.5. PCNPQ 告) 


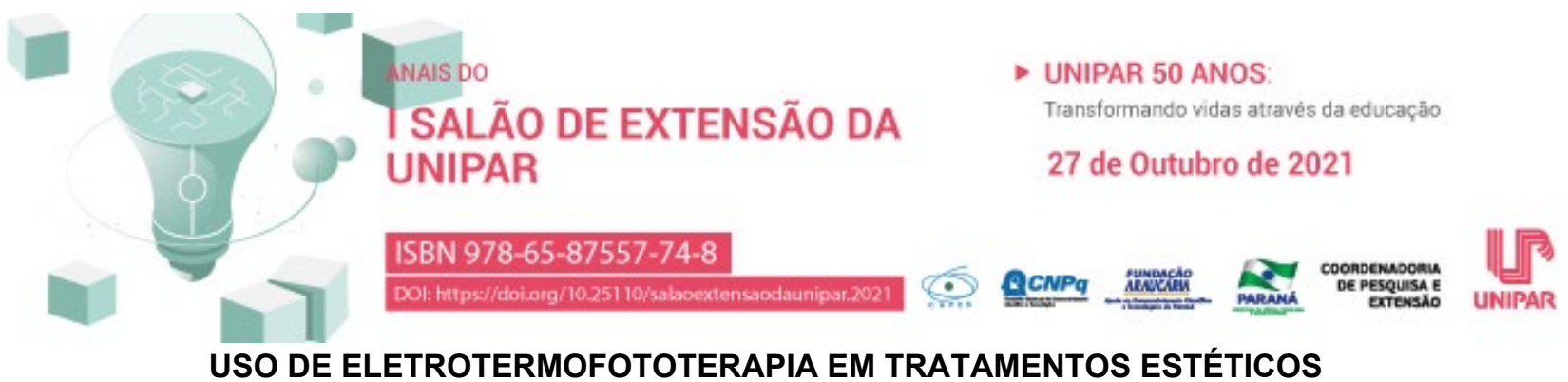

${ }^{1}$ LAYS CAROLINE MACENTE, ${ }^{2}$ SANDY ROBERTA VICENTE , ${ }^{3}$ SABRINA PIVATO VERSUTI, ${ }^{4}$ JULIA GABRIELLA PENASSO SANTOS, ${ }^{5}$ AMANDA MARIA BUENO MARQUES, ${ }^{6}$ THAINARA GOMES DE FREITAS, ${ }^{7}$ CAMILA CAROLINE SIQUEIRA, ${ }^{8}$ JESSICA DE SOUZA LIMA, ${ }^{9}$ PALLOMA GIOVANA MORETTI, ${ }^{10}$ PAOLLA FERNANDA MORALES FLORES, ${ }^{11}$ SHIRLAINE RIBEIRO DA SILVA, ${ }^{12}$ VERA LUCIA BATISTA SOARES DE ARAUJO, ${ }^{13}$ SIMONE CASTAGNA ANGELIM COSTA, ${ }^{14}$ JULIANA PELISSARI MARCHI, ${ }^{15}$ RAQUEL COSTA MACHADO, ${ }^{16}$ GIOVANA MIOTO DE MOURA

\footnotetext{
${ }^{1}$ Acadêmica do Curso de Estética e Cosmética da UNIPAR - Cianorte

${ }^{2}$ Acadêmica do Curso de Estética e Cosmética da UNIPAR

${ }^{3}$ Acadêmica do Curso de Estética e Cosmética da UNIPAR

${ }^{4}$ Acadêmica do Curso de Estética e Cosmética da UNIPAR

${ }^{5}$ Acadêmica do Curso de Estética e Cosmética da UNIPAR

${ }^{6}$ Acadêmica do Curso de Estética e Cosmética da UNIPAR

${ }^{7}$ Acadêmica do Curso de Estética e Cosmética da UNIPAR

${ }^{8}$ Acadêmica do Curso de Estética e Cosmética da UNIPAR

${ }^{9}$ Acadêmica do Curso de Estética e Cosmética da UNIPAR

${ }^{10}$ Acadêmica do Curso de Estética e Cosmética da UNIPAR

${ }^{11}$ Acadêmica do Curso de Estética e Cosmética da UNIPAR

${ }^{12}$ Acadêmica do Curso de Estética e Cosmética da UNIPAR

${ }^{13}$ Docente da UNIPAR

${ }^{14}$ Docente da UNIPAR

${ }^{15}$ Docente da UNIPAR

${ }^{16}$ Docente da UNIPAR
}

Introdução: Os fundamentos e aplicabilidade da eletroterapia faz parte da atuação clínica de um profissional de estética, isso é justificável pelo uso de tecnologias que potencializam os resultados dos tratamentos que visam saúde e beleza (AGNE, 2019). As tecnologias inseridas nos equipamentos estéticos, auxiliam na reabilitação fisiológica do organismo como, aumento da circulação sanguínea e linfática, estímulo da síntese de colágeno e elastina, além de contribuir com o mecanismo de lipólise, relacionando os resultados com a melhora do contorno corporal, redução de edema, e contribuindo com a saúde do indivíduo (GUIRRO; GUIRRO, 2004). Devido a isso, realizou-se uma análise comparativa do mês de maio e do mês de agosto de 2021, em relação a porcentagem do uso de equipamentos durante as sessões estéticas, realizadas no Projeto de Extensão do Centro de Estética Escola - UNIPAR - Unidade de Cianorte.

Objetivo: Expor a incidência de atendimentos estéticos que usaram a eletrotermofototerapia no mês de maio e agosto.

Resultados: Foram coletados dados e analisados através do programa de Excel $₫$, onde a intenção foi analisar e comparar a porcentagem de atendimentos que utilizaram a eletroterapia durante a sessão, tais atendimentos foram realizados no Centro de Estética - Unipar - Cianorte. A coleta foi referente ao mês de maio, na qual as atividades do projeto foram realizadas durante 30 dias, e do mês de agosto, último mês observado do projeto em andamento. Tendo em vista que em maio foram realizados 120 procedimentos estéticos, contemplando as terapias corporais, faciais, alternativas e capilares, onde $56(46,6 \%)$ utilizaram a eletrotermofototerapia. Já no mês de agosto, em um total de 141 procedimentos, sendo que $72(51 \%)$ deles também fizeram uso dessas tecnologias. Observando assim, um aumento de $5 \%$ da indicação e aplicação de recursos que auxiliam na ação fisiológica do organismo, potencializa os resultados, e entrega ao paciente os resultados esperados.

Conclusão: $O$ uso da eletrotermofototerapia em procedimentos estéticos teve uma crescente, quando comparados os meses de maio e agosto, observando um aumento de $5 \%$. Podendo essa elevação estar relacionada a maior indicação das eletroterapias pelos seus benefícios no organismo, e a contribuição para os bons resultados alcançados durante as sessões, ou também pela maior busca por tratamentos estéticos quando as estações mais quentes do ano se aproximam.

\section{Referências}


AGNE, J. D. Eletrotermofototerapia. 6 ed. Santa Maria: O Autor, 2019.

GUIRRO, Elaine Caldeira de Oliveira; GUIRRO, Rinaldo Roberto de J.. Fisioterapia dermato-funcional: fundamentosrecursos-patologias . 3 ed., rev. e ampl.. Barueri: Editora Manole, 2004.

ISALÄO DE EXTENSÃO " UNIPAR 50 ANOS:

DA UNIPAR 


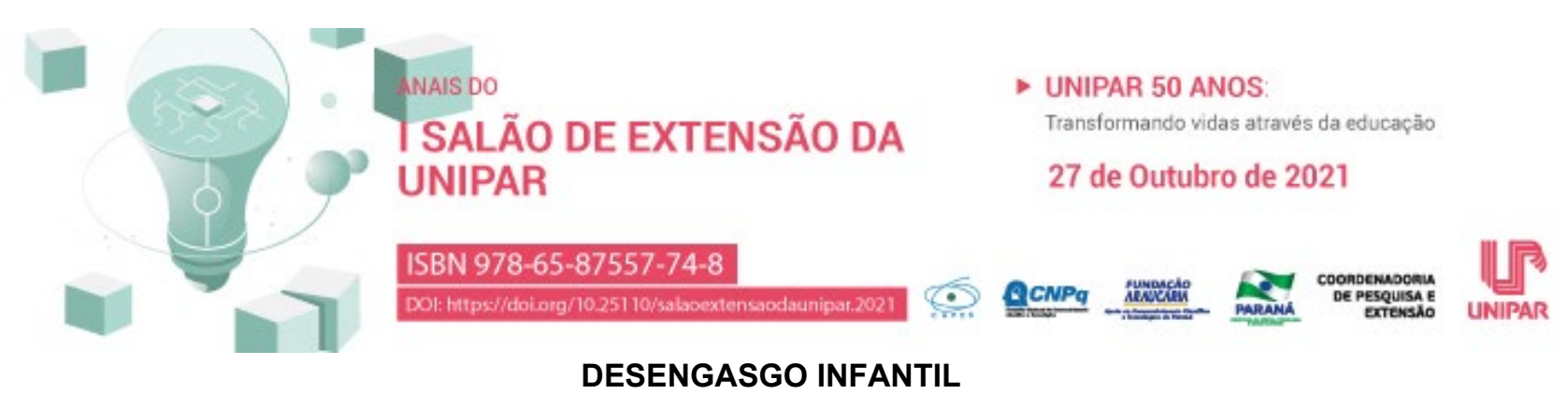

${ }^{1}$ LUIZA MAYUMI CAZELOTO SILVA, ${ }^{2}$ VICTOR FAJARDO BORTOLI, ${ }^{3}$ MONICA MICHELI ALEXANDRE , ${ }^{4}$ KARINA SPOSITO NEGRINI, ${ }^{5}$ RAFAELA DIAS DE ARAUJO, ${ }^{6}$ EGUIMAR ROBERTO MARTINS, ${ }^{7}$ GIULIANA ZARDETO SABEC, ${ }^{8}$ GABRIELA ALVES DE OLIVEIRA, ${ }^{9}$ LUCAS MATEUS SMANIOTTO, ${ }^{10}$ BRUNA MONTEIRO SANCHES, ${ }^{11}$ IARA HENRIQUE ROCHA, ${ }^{12}$ KENGO MATSUGUMA JUNIOR, ${ }^{13}$ ANA BEATRIZ DERENUSSON NELLI MARGATTO NUNES, ${ }^{14}$ REINALDO HIGASHI YOSHII

\footnotetext{
${ }^{1}$ Acadêmica do curso de Medicina da UNIPAR

${ }^{2}$ Acadêmico do Curso de Medicina UNIPAR

${ }^{3}$ Acadêmica do Curso de Medicina da UNIPAR

${ }^{4}$ Acadêmica do Curso de Medicina da UNIPAR

${ }^{5}$ Acadêmica do Curso de Medicina da UNIPAR

${ }^{6}$ Docente da UNIPAR

${ }^{7}$ Docente da UNIPAR

${ }^{8}$ Acadêmica do Curso de Medicina da UNIPAR

${ }^{9}$ Acadêmico do Curso de Medicina da UNIPAR

${ }^{10}$ Acadêmica do Curso de Medicina da UNIPAR

${ }^{11}$ Acadêmica do Curso de Medicina da UNIPAR

${ }^{12}$ Acadêmico do Curso de Medicina da UNIPAR

${ }^{13}$ Acadêmica do Curso de Medicina da UNIPAR

${ }^{14}$ Docente da UNIPAR
}

Introdução: No Brasil, a Aspiração de Corpo Estranho (ACE) é uma das principais causas de mortes acidentais na faixa etária pediátrica, especialmente em menores de quatro anos, pois as crianças, em seus primeiros anos de vida, tendem a utilizar a via oral (explorando pequenos objetos e comidas) para se relacionar com o mundo real, podendo então levar a aspiração de corpos estranhos e consequentemente, a possível obstrução de vias aéreas, devido vulnerabilidade em relação fisiológica, fragilidade de defesa e a limitação na comunicação (MELO; SANTOS, 2020). De acordo com FERREIRA et al. (2018), na obstrução das vias aéreas por aspiração de corpo estranho parcial, a vítima consegue tossir, emitir sons e respirar com dificuldade; já na obstrução total, a vítima não consegue emitir nenhum desses sinais, além de não realizar os movimentos respiratórios, podendo evoluir para uma parada cardiorrespiratória (PCR) após asfixia. É possível desobstruir as vias aéreas superiores imediatamente utilizando a manobra de Heimlich.

Objetivo: Orientar o público leigo a respeito da Manobra de Heimlich em crianças e lactentes e sobre o reconhecimento de uma obstrução de vias aéreas superiores devido a Aspiração de Corpo Estranho em Umuarama-PR, a fim de diminuir o número de morbidade e mortalidade.

Resultados: Devido ao agosto dourado, foi realizada uma parceria com a secretaria municipal de Umuarama-PR, onde foram empregadas palestras teórico-práticas em seis Unidades Básicas de Saúde (UBS) do município no mês de agosto, sendo realizadas no período matutino, pelos discentes da liga de urgência e emergência, e estes foram orientados pelos doutores Reinaldo e Eguimar. Desse modo, foi possível o compartilhamento de conhecimento acerca da Manobra de Heimlich em crianças e lactentes para a população que está diretamente ligada a esse grupo. Nos dias das ações após a explicação das técnicas e sua relevância, as mesmas conseguiram simular por meio de bonecas, e com isso puderam aprender a sequência correta das ações necessárias para se realizar a técnica de forma correta e eficaz.

Conclusão: Com a relevância do número de casos de engasgo infantil atendidos na região de Umuarama, concluímos que a ação realizada é de extrema importância de ser aplicada tanto para os pais quanto para a população em geral. A Manobra de Heimlich é de fácil execução e pode salvar vidas, quando aplicada de forma correta, desse modo, através dessa ação a população ficou apta para possíveis emergências.

\section{Referências}

FERREIRA, Noélia Lourenço Martins; MEDEIROS, Luiza Sátyro Morais; BONFIM, Célio da Rocha; BARBOSA, Ana Beatriz Alves; 
MARTINS, Edmara Nóbrega Xavier; FERREIRA, Allan Martins. Primeiros socorros na educação infantil. João Pessoa, 2018. Disponível em: https://temasemsaude.com/wp-content/uploads/2018/10/fip201802.pdf. Acesso em 02 set. 2021.

MELO, Adriano Almeida Melo; SANTOS, Paulo Ubiratan Silva. Orientadora: Prof(a). Divinamar Pereira. Conhecimento dos pais quanto a procedimentos realizados diante do engasgo na criança. Trabalho de conclusão de curso. Curso de Enfermagem. Centro Universitário do Planalto Central Apparecido dos Santos. Brasília-DF, 2019.

I SALÃO DE EXTENSÃO

DA UNIPAR
- UNIPAR 50 ANOS:

Transformando vidas atravis da educaço

27 de Outubro de 2021

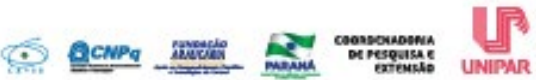




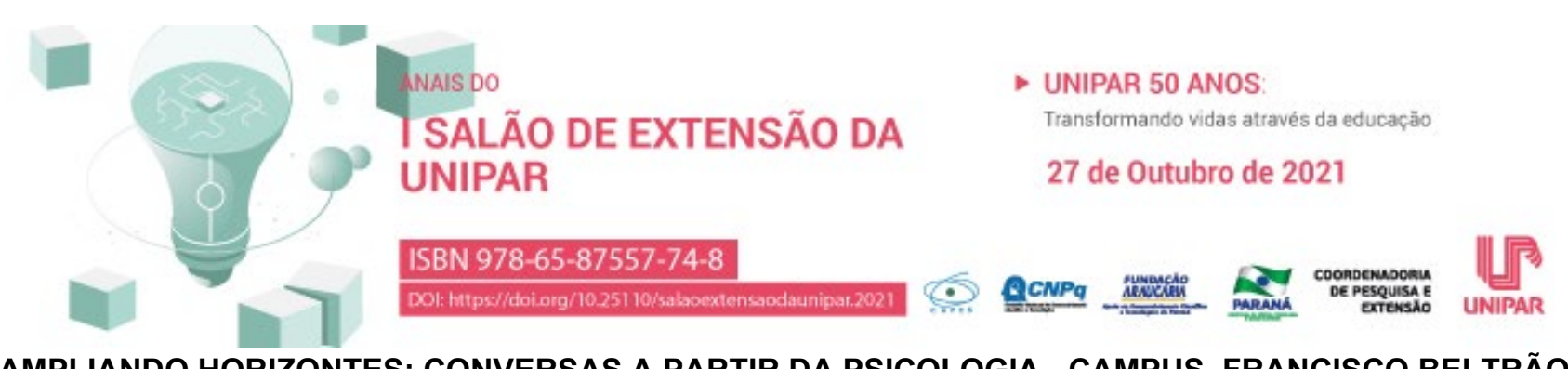

AMPLIANDO HORIZONTES: CONVERSAS A PARTIR DA PSICOLOGIA - CAMPUS FRANCISCO BELTRÃO

\author{
${ }^{1}$ MARCIA HELLMANN TONIAZZO, ${ }^{2}$ TAINARA OLIVEIRA VALDAMERI, ${ }^{3}$ ISADORA GAGLIOTTO GALVAN, ${ }^{4}$ VIVIANE SAGIN, \\ ${ }^{5}$ HELOISA SANTOLIN DA SILVA, ${ }^{6}$ MATEUS JOAO CORDEIRO SCHMOELLER DE LIMA, ${ }^{7}$ TAISE SIGNORINI
}

\begin{abstract}
Responsável Técnica do cu
${ }^{2}$ Docente da UNIPAR

${ }^{3}$ Acadêmica do Curso de Psicologia da UNIPAR

${ }^{4}$ Acadêmica do Curso de Psicologia da UNIPAR

${ }^{5}$ Acadêmica do Curso de Psicologia da UNIPAR

${ }^{6}$ Acadêmico do Curso de Psicologia da UNIPAR

${ }^{7}$ Docente da UNIPAR
\end{abstract}

11 Discentes do curso de Psicologia da Universidade Paranaense

Introdução: Difundir os saberes da Psicologia é uma tendência na contemporaneidade, onde se faz necessário ampliar os olhares para as transformações sociais, de forma coerente com as questões históricas e atuais. O Projeto Ampliando Horizontes tem como intuito aprofundar temáticas e tecer discussões relevantes à ciência psicológica, através da elaboração de material didático. O tema que está sendo abordado, nesse ano, é o compromisso social do psicólogo. De acordo com Yamamoto $(2007 ; 2012)$, as discussões acerca do compromisso social do psicólogo, vão além das discussões de abrangência e abertura de mercado de trabalho, estão relacionadas ao nosso papel de transformação social. Para isso, segundo Dantas (2010), a Psicologia precisa se abrir aos problemas da sociedade, rompendo com as práticas que determinam como o sujeito deve ser, pensar e agir e refletindo desde a formação, continuamente, sobre nossas possibilidades e limites de atuação.

Objetivo: Ampliar o conhecimento dos acadêmicos do curso de psicologia sobre o compromisso social do psicólogo, por meio de revisão bibliográfica, levantamento de dados, produção de cartilhas e rodas de conversas. Sendo assim, as primeira orientações do projeto foram realizadas através de discussões de livros e artigos científicos que abordavam o tema. Em seguida elaboramos um formulário online, que foi enviado a $1^{\mathrm{a}}$ e $2^{\mathrm{a}}$ série do curso de Psicologia, a fim de coletarmos dados sobre o conhecimento que possuiam acerca da temática. Para então darmos início a elaboração de cartilhas explicativas e rodas de conversas, com intuito de sanar as dúvidas e fazer esclarecimentos sobre o compromisso social do psicólogo.

Resultados: Através da revisão bibliográfica e discussões em orientação, observou-se que o psicólogo apesar de ter ampliado seu espaço de inserção profissional, continua a reproduzir a tradicional prática clínica, o que em muitos espaços não corresponde as reais necessidades de transformação social e melhorias nas condições de vida, estabelecidas pelo compromisso social do psicólogo. A partir disso e considerando que através do levantamento feito pelo formulário, observou-se que os acadêmicos ao adentrar na graduação possuem pouco conhecimento sobre a temática. Ressalta-se a necessidade de aprofundarmos essas discussões em torno do compromisso social do psicólogo.

Conclusão: Contudo, notou-se que a realização de rodas de conversa e cartilhas explicativas ajudam no entendimento do psicólogo como sujeito ativo e dinâmico em processo de recriação de sua identidade, em busca de novos caminhos de inserção nos mais diversos campos de trabalho. Esse movimento contínuo da Psicologia em criar novos saberes, adaptando-os sobre as dinâmicas da sociedade, reforçam o compromisso ético e político com os sujeitos, as transformações sociais, as condições de vida e suas particularidades.

\title{
Referências
}

DANTAS, Jurema Barros. Formar Psicólogos: Por quê? Para quê? Fractal: Revista de Psicologia, v. 22, n. 3, p. 621-636, set/dez. 2010.

YAMAMOTO, Oswaldo Hajime. Políticas sociais, I"terceiro setorl" e ।"compromisso sociall": perspectivas e limites do trabalho do Psicólogo. Psicologia e Sociedade, v. 19, n. 1, p. 30-37, jan/abr. 2007.

YAMAMOTO, Oswaldo Hajime. 50 Anos de profissão: Responsabilidade social ou projeto ético-político? Psicologia: Ciência e Profissão [online] , v. 32, n. spe., p. 6-17. 2012. Disponível em: . Epub 08 Nov 2012. ISSN 1982-3703. https://doi.org/10.1590/S1414-98932012000500002. Acesso em: 18 ago. 2021.

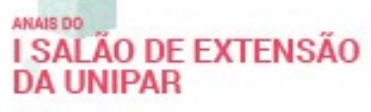

I SALĀO DE
DA UNIPAR
- UNIPAR 50 ANOS: Traneformando vidas atrevts da educacto 27 de Outubro de 2021

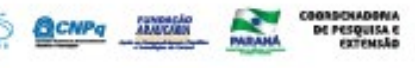




\title{
(1) \\ - UNIPAR 50 ANOS: \\ Transformando vidas através da educaçào \\ 27 de Outubro de 2021 \\ ISBN 978-65-87557-74-8 \\ .

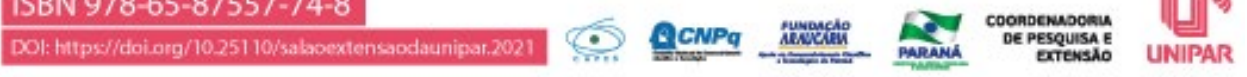 \\ SEXUALIDADE NA ADOLESCÊNCIA: A IMPORTÂNCIA DA ABORDAGEM CONSCIENTE E A ABERTURA PARA O DIÁLOGO
}

\author{
${ }^{1}$ GESSICA PAULA BATTISTI, ${ }^{2}$ HILDA CARLA FERREIRA ESPANIOL , ${ }^{3}$ AGHATA POSSATTO, ${ }^{4}$ JULYA FERREIRA \\ SILIPRANDI DOS SANTOS, ${ }^{5}$ ROSANE TEREZINHA RODRIGUES OLDONI, ${ }^{6}$ FRANCIELE DO NASCIMENTO SANTOS \\ ZONTA, ${ }^{7}$ LEDIANA DALLA COSTA
}

\author{
${ }^{1}$ Acadêmica do PEX - Curso de Enfermagem - Unidade de Francisco Beltrão \\ ${ }^{2}$ Acadêmica do Curso de Enfermagem da UNIPAR \\ ${ }^{3}$ Acadêmico do Curso de Enfermagem da UNIPAR \\ ${ }^{4}$ Acadêmica do Curso de Enfermagem da UNIPAR \\ ${ }^{5}$ Acadêmica do Curso de Enfermagem da UNIPAR \\ ${ }^{6}$ Docente da UNIPAR \\ ${ }^{7}$ Docente da UNIPAR
}

Introdução: As intervenções de educação em saúde podem contribuir para o diálogo e questionamentos relacionados à vivência dos adolescentes, pois exercer a sexualidade sem conhecimento é um fator de risco, além da carência de comunicação dos meios em que vive, podendo ser o escolar e ou familiar (FRANCO, 2020).

Objetivo: Promover uma reflexão sobre a abordagem da sexualidade na adolescência, explicitando a importância da orientação e educação em saúde.

Resultados: A adolescência se caracteriza como a fase de transição entre a infância e a idade adulta, marcada por muitas transformações e a busca por sua própria identidade, evidenciando por parte deles, uma maior vulnerabilidade ao comportamento sexual nocivo e infecções sexualmente transmissíveis (IST's) (COSTENARO, 2020). A princípio, o ambiente escolhido para o debate deve ser descontraído, que passe confiabilidade, ter a escola como cenário principal dessa abordagem pode deixar os adolescentes mais à vontade, pois se trata de um ambiente do cotidiano, em que passam a maior parte do tempo e desenvolvem suas relações afetivas, por isso é essencial a implementação de estratégias educativas que se valham de metodologias participativas, como as oficinas e ilustrações, para incentivar a comunicação e a conscientização dos adolescentes de forma sutil, mas que atentem para os riscos da omissão dos cuidados (CARNEIRO, 2015). O profissional da enfermagem pode promover um elo entre família e escola, fornecendo subsídios para capacitação e orientação quanto à sexualidade para educandos, pais e professores, desde o ensino do uso do preservativo, prevenção de IST's e gravidez na adolescência, até formas de identificar violências sexuais (COSTENARO, 2020; NERY, 2014). A enfermagem atua como mediadora do conhecimento, bem como, facilitadora da saúde, e promotora do diálogo, além de instituir ações que podem contribuir para otimizar o comportamento sexual desses adolescentes, prevenindo agravos e salientando a importância desse trabalho multidisciplinar entre saúde e educação (SANTOS, 2017; RIBEIRO, 2018).

Conclusão: A educação sexual e o acesso à informação são essenciais para prevenção de IST's, gravidez indesejada e a busca para o enfrentamento da violência sexual, além do necessário diálogo e orientação voltada ao respeito e à diversidade. Ademais, enfatiza-se o papel do enfermeiro enquanto educador e promotor da saúde frente a essa temática.

\section{Referências}

CARNEIRO, Rithianne Frota et al. EDUCAÇÃO SEXUAL NA ADOLESCÊNCIA: UMA ABORDAGEM NO CONTEXTO ESCOLAR. Sanare. Rev. de Políticas Públicas. São Luiz-MA, v.14, 1-5, n.1, jan./jun., 2015. Disponível em: https://sanare.emnuvens.com.br/sanare/article/view/617. Acesso em: 29 Ago. 2021.

COSTENARO, Regina Gema Santiniet al. EDUCAÇÃO SEXUAL COM ADOLESCENTES: PROMOVENDO SAÚDE E SOCIALIZANDO BOAS PRÁTICAS SOCIAIS E FAMILIARES. Brazilian Journal of Development, Curitiba-PR, v.6, 1-17, n.12, nov., 2020. Disponível em: https://www.brazilianjournals.com/index.php/BRJD/article/view/21960. Acesso em: 29 Ago. 2021.

FRANCO, Maurilio de Souzaet al. EDUCAÇÃO EM SAÚDE SEXUAL E REPRODUTIVA DO ADOLESCENTE ESCOLAR. Rev.

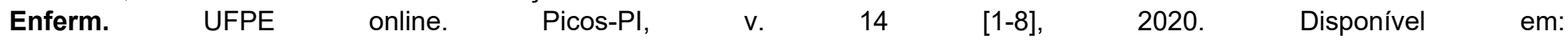
https://periodicos.ufpe.br/revistas/revistaenfermagem/article/view/244493/36298. Acesso em: 29 Ago. 2021.

NERY, Inez Sampaio et al. ABORDAGEM DA SEXUALIADE NO DIÁLOGO ENTRE PAIS E ADOLESCÊNTES. Acta Paul Enferm. Teresina-PI, v.28, 287-291, n.3, mai./jun., 2015. Disponível em: http://dx.doi.org/10.1590/1982-0194201500048. Acesso em: 29 Ago. 2021. 
RIBEIRO, Daniele Knoppet al. EXPERIENNCIA DE ESTUDANTES DE ENFERMAGEM EM UM PROJETO DE EDUCAÇÃO EM SAÚDE E SEXUALIDADE NA ESCOLA. Revista Guará, Vitória-ES, n. 09, 85-96, jun., 2018. Disponível em: https://doi.org/10.30712/guara.v6i9.15624. Acesso em: 29 Ago. 2021

SANTOS, Vaneska Ribeiro Perfeito et al. OS DESAFIOS DA EDUCAÇÃO SEXUAL NO CONTEXTO ESCOLAR: O PAPEL DA ENFERMAGEM. Rev. Eletrônica Debates em Educação Científica e Tecnológica. Vitória-ES, v. 7, 187-207, n. 03, dez., 2017. Disponível em:https://ojs2.ifes.edu.br/index.php/dect/article/view/677. Acesso em: 29 Ago. 2021.

$\begin{array}{ll}\text { Anats do } & \text { UNIPAR } 50 \text { ANOS: } \\ \text { I SALÄO DE EXTENSÃO } & \text { Transformando vidas atravia da educagto } \\ \text { DA UNIPAR } & 27 \text { de Outubro de } 2021\end{array}$




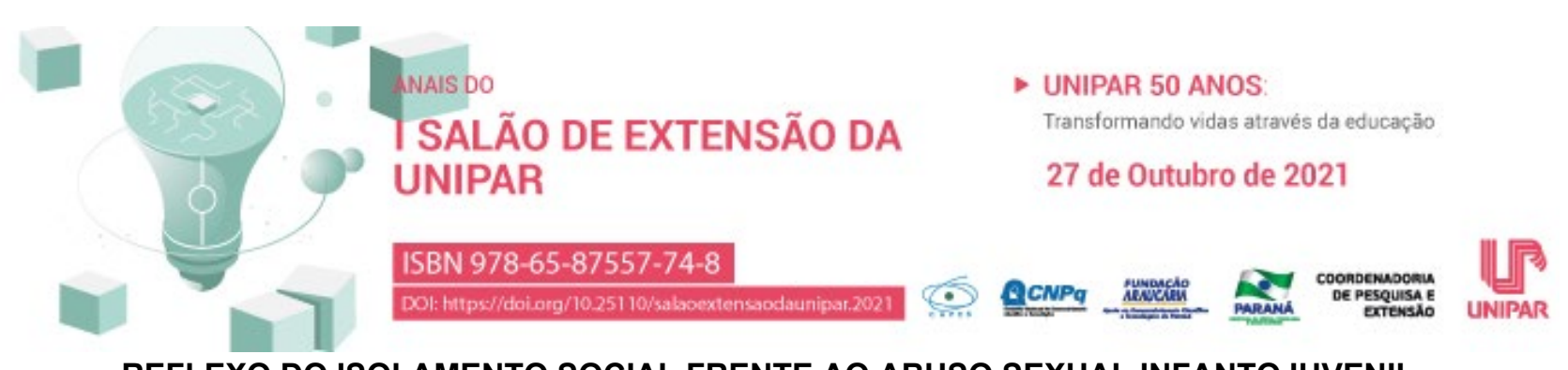

REFLEXO DO ISOLAMENTO SOCIAL FRENTE AO ABUSO SEXUAL INFANTOJUVENIL

\author{
${ }^{1}$ ALINE APARECIDA BARTNISKI, ${ }^{2}$ CAROLINE XAIANE STEFAINSKI, ${ }^{3}$ EDUARDA DOS SANTOS BARCELLOS, ${ }^{4}$ JULIA ROSIN \\ , ${ }^{5}$ LAURA BALESTRIN WARLITZER, ${ }^{6}$ FRANCIELE DO NASCIMENTO SANTOS ZONTA, ${ }^{7}$ LEDIANA DALLA COSTA
}

${ }^{1}$ Acadêmica do PEX - Curso de Enfermagem - Unidade de Francisco Beltrão
${ }^{2}$ Acadêmica do PEX - Curso de Enfermagem - Unidade de Francisco Beltrão
${ }^{3}$ Acadêmica do PEX - Curso de Enfermagem - Unidade de Francisco Beltrão
${ }^{4}$ Acadêmica do PEX - Curso de Enfermagem - Unidade de Francisco Beltrão
${ }^{5}$ Acadêmica do PEX - Curso de Enfermagem - Unidade de Francisco Beltrão
${ }^{6}$ Docente da UNIPAR
${ }^{7}$ Docente da UNIPAR

Introdução: A pandemia causada pelo novo Coronavírus intensificou a dificuldade no enfretamento do abuso sexual, principalmente sob grupos vulneráveis, como crianças e adolescentes. No Brasil, ocorrem 3 violações sexuais a cada uma hora, acometendo essa faixa etária, índices crescentes foram observados no período de isolamento social, a partir do maior contato dessa população com o agressor, visto que, na maioria dos casos, configura-se como familiar da vítima (SANTOS; FUMAGALI, 2021).

Objetivo: Descrever os impactos do isolamento social em período de pandemia, frente aos índices de abuso sexual infantojuvenil.

Desenvolvimento: A cada oito adolescentes, um relata que já foi vítima de abuso, os quais, tendem a manifestar transtornos biopsicossociais, ressaltando a necessidade de atenção especializada, sendo nítido o agravamento periodicamente nos últimos semestres, sobretudo em ocasiões, em que o abusador caracteriza-se como membro familiar (CRUZ et al, 2021; FONTES; CONCEIÇÃO; MACHADO, 2017). A convivência em âmbito escolar favorece a identificação dos sinais de abuso e encaminhamento para os órgãos competentes, porém, em período de isolamento social, resultante em fechamento de escolas, comércios e indústrias, crianças e adolescentes tornaram-se vulneráveis ao abuso sexual dentro de suas casas, resultando em aumentos dos casos, impossibilitando intervenções (BRASIL, 2020). Estudo divulgado pelo Ministério da Mulher, Família e Direitos Humanos constatou em $73 \%$ dos casos a ocorrência na casa vítima e $40 \%$ destes, cometidos pelo pai ou padrasto. Outros dados evidenciam 86,8 mil denúncias de violações de direitos infanto-juvenis em 2019 , sendo a violência sexual $11 \%$ dos casos (BRASIL, 2020). Já durante o período de pandemia em 2020, observou-se aumento de casos, com 95.200 denúncias, sendo 14.621, violência sexual (BRASIL, 2020). Observa-se a necessidade de implementação da educação sexual ao decorrer da formação básica, permitindo compreensão de situações de violência, juntamente com maior adequação à proteção e acolhimento infanto-juvenil através da busca ativa, com resolutiva de casos (SANTOS; FUMAGALI, 2021). Esse projeto é desenvolvido em parceria com o Núcleo Regional de Educação, até o momento foram realizados treinamentos dos componentes do grupo, e assim que houver liberação das escolas estaduais para atendimento presencial, as oficinas serão realizadas in loco.

Considerações finais: $O$ isolamento social dispôs de impactos negativos frente ao abuso sexual infanto-juvenil, resultando em crescimento dos índices, por inacessibilidade de identificação dos casos, onde o familiar configura-se como principal abusador. Com isso, torna-se imprescindível a evolução de diretrizes de segurança e acolhimento das vítimas.

\title{
Referências
}

BRASIL. Ministério da Mulher, da Família e dos Direitos Humanos. Ministério divulga dados de violência sexual contra crianças e adolescentes. Brasil, agosto, 2020a. Disponivel em: https://www.gov.br/mdh/pt-br/assuntos/noticias/20202/maio/ministerio-divulga-dados-de-violencia-sexual-contra-criancas-e-adolescentes. Acesso em: 17/08/2021.

BRASIL. Fundo das Nações Unidas para a Infância. Pandemia dificulta denúncia de violência sexual contra crianças e adolescentes no estado de São Paulo. Brasil, dez, 2020b. Disponível em https://www.unicef.org/brazil/comunicados-deimprensa/pandemia-dificulta-denuncia-de-violencia-sexual-contra-criancas-e-adolescentes-em-sp. Acesso em:16/08/2021.

BRASIL. Ministério da Mulher, da Família e dos Direitos Humanos. Abuso Sexual conta Crinaças e Adolescentes Abordagem de casos concretos em uma perspectiva multidisciplinar e insterinstitucional. Brasil. 2021c. Disponível em: https://www.gov.br/mdh/pt-br/assuntos/noticias/2021/maio/CartilhaMaioLaranja2021.pdf. Acesso em 17/08/2021.

CRUZ, Moniky Araújo da, GOMES, Nardilene Pereira, CAMPOS, Luana Moura, ESTRELA, Fernanda Matheus, WHITAKER, Maria Carolina Ortiz, LíRIO, Josinete Gonçalves dos Santos. Repercussões do abuso sexual vivenciado na infância e 
adolescência: revisão integrativa. Ciência \& Saúde Coletiva, Rio de Janeiro, v. 26, n. 4, p. 1369-1380, abril, 2021. Disponível em: https://www.scielosp.org/article/csc/2021.v26n4/1369-1380. Acesso em: 16/08/2021.

FONTES, Luiz Felipe Campos, CONCEIÇÃO, Otavio Canozzi, MACHADO, Sthefano. Violência sexual na adolescência, perfil da vítima e impactos sobre a saúde mental. Ciência \& Saúde Coletiva, Rio de Janeiro, v. 22, n. 9, p. 2919-2928, 2017. Disponível em: https://www.scielosp.org/article/csc/2017.v22n9/2919-2928/pt/. Acesso em: 17/08/2021.

SANTOS, Cibelle Christiane Ato, FUMAGALLI, Ellen de Oliveira. Abuso sexual de crianças e adolescentes no Brasil em tempos de COVID-19: A educação como forma de prevenção. Portal de Periódicos, Grupo Tiradentes, Aracaju, v. 6, n. 3, p. 171-184, mar, 2021. Disponível em: https://periodicos.set.edu.br/cadernohumanas/article/view/9994/4436. Acesso em: 15/08/2021.

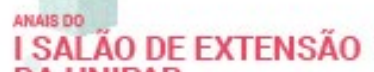

DA UNIPAR
- UNIPAR 50 ANOS:

Traneformendo vidas atravta da educacto

27 de Outubro de 2021

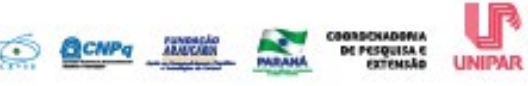




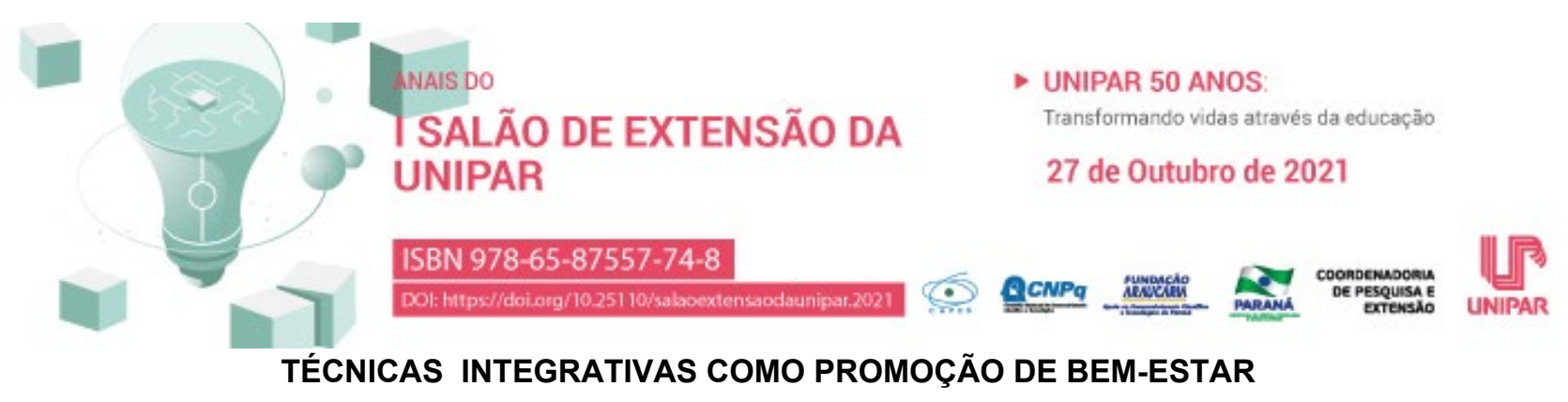

\author{
${ }^{1}$ ANA PAULA MARIOTI, ${ }^{2}$ ALESSANDRA TOBIAS DOS SANTOS, ${ }^{3}$ BRUNA BATTISTI MORAIS , ${ }^{4}$ JESSICA AUTO DE \\ OLIVEIRA, ${ }^{5}$ KELLI KUHNEN, ${ }^{6}$ SIMONE CASTAGNA ANGELIM COSTA, ${ }^{7}$ RAQUEL COSTA MACHADO, ${ }^{8}$ JULIANA PELISSARI \\ MARCHI
}

${ }^{1}$ Acadêmica participante do Programa Institucional Centro de Estética e Cosmética Escola, do C.S.T. em Estética e Cosmética da UNIPAR.

${ }^{2}$ Acadêmica participante do Programa Institucional Centro de Estética e Cosmética Escola, do C.S.T. em Estética e Cosmética da UNIPAR.

${ }^{3}$ Acadêmica participante do Programa Institucional Centro de Estética e Cosmética Escola, do C.S.T. em Estética e Cosmética da UNIPAR.

${ }^{4}$ Acadêmica participante do Programa Institucional Centro de Estética e Cosmética Escola, do C.S.T. em Estética e Cosmética da UNIPAR.

${ }^{5}$ Responsável Técnica do Centro de Estética Escola do Curso Superior de Tecnologia em Estética e Cosmética

${ }^{6}$ Docente do C.S.T. em Estética e Cosmética da Universidade Paranaense, UNIPAR.

${ }^{7}$ Docente do C.S.T. em Estética e Cosmética da Universidade Paranaense, UNIPAR.

${ }^{8}$ Docente do C.S.T. em Estética e Cosmética da Universidade Paranaense, UNIPAR.

Introdução: $O$ projeto do Centro de Estética oportuniza aos acadêmicos a realização de atendimentos à comunidade, e a experiência prática dos conteúdos teóricos de cada disciplina. Através desse projeto é possivel criar também uma cartilha para a comunidade intitulada I"Técnicas integrativas como promoção de bem estar . A elaboração dessa cartilha é uma atividade desafiadora no sentido de planejar, colocar no papel de forma clara e objetiva informações científicas, que a população pudesse ter um entendimento facilitado. Não somente de forma escrita, mas as terapias integrativas tem sido colocado em prática nos atendimentos estéticos realizados no Programa Institucional Centro de Estética e Cosmética Escola (PAUL, 2013; SAMPAIO, FERREIRA, 2009).

Objetivo: Relatar a experiência de atividades desenvolvidas no Programa Institucional Centro de Estética e Cosmética Escola da UNIPAR.

Resultados: Os atendimentos em estética facial, corporal, capilar, imagem pessoal e de terapias integrativas, realizados neste programa institucional possibilitaram o aperfeiçoamento da prática, bem como a inter-relação entre teoria e prática. Além disso, favorece o desenvolvimento de habilidades para um atendimento humanizado e holístico, proporcionando a cada cliente um atendimento individualizado. A pesquisa bibliográfica e a elaboração da cartilha nos mostra que a pesquisa científica deve estar em evidência e no cotidiano profissional. Um exemplo disso é que as Práticas Integrativas e Complementares (PICS) são tratamentos que utilizam recursos terapêuticos baseados em conhecimentos tradicionais (BRASIL, 2018). A partir dessas práticas é possível tratar o indivíduo como um todo, desde os sinais/sintomas até a causa destes, assim, a área de terapia integrativa pode ser trabalhada como técnica isolada (terapêutica) ou como técnica complementar aos atendimentos de estética e de saúde (SCHEFFER, 2011). As PICS visam melhoria da condição de saúde do indivíduo, ou seja, atuam como recursos profiláticos que promovem o reequilíbrio do organismo e previnem doenças. Ainda atuam como recursos auxiliares no tratamento, quando um quadro patológico já está instalado (FISCHBORN, 2016; GALLI, 2012). A interligação de corpo, mente e visualização do paciente como um ser biopsicossocial afirmam a necessidade de abordagens que trabalhem com sua totalidade (GALLI, 2012).

Conclusão: A vivência neste programa institucional contribuiu com o enriquecimento curricular e prepara os acadêmicos para o mercado de trabalho, trouxe segurança e confiança. Além disso, reforça a necessidade de capacitação profissional e novas pesquisas.

\title{
Referências
}

BRASIL MS. Glossário Temático: Práticas Integrativas e Complementares em Saúde, Projeto de Terminologia da Saúde. Brasília, 2018. Disponível em:http://bvsms-bases.saude.bvs.br Acesso em:17 ago. 2021

FISCHBORN, Aline Fernanda et al. A Política das Práticas Integrativas e Complementares do sus: o relato da implementação em uma unidade de ensino e serviço de saúde. Cinergis, v. 17, 2016.Disponivel em:https://docs.bvsalud.org Acesso em:17 ago. 2021

GALLI, Kiciosan da Silva Bernardi et al. Saúde e equlíbrio através das terapias integrativas: relato de experiência. Revista de 
Enfermagem, v. 8, n. 8, p. 245-255, 2012.Disponivel em:http://repositorio.unis.edu.br Acesso em:17 ago. 2021

PAUL, Patrick. Saúde e transdisciplinaridade. São Paulo: Edusp, 2013.Disponivel em:https://sistema.atenaeditora.com.br Acesso em:17 ago. 2021

SAMPAIO, R. P. A. FERREIRA, R. F. Beleza, Identidade e Mercado. Psicologia em Revista, Belo Horizonte, v. 15, n. 1, p.120140, 2009.Disponivel em:http://pepsic.bvsalud.org Acesso em:17 ago. 2021

SCHEFFER, M. Terapia floral do Dr. Bach: teoria e prática. 13. ed. São Paulo: Pensamento, 2011. Disponível em:https://repositorio.unesp.br Acesso em:17 de agosto.2021.

I SALÃOO DE EXTENSÃO

DA UNIPAR
- UNIPAR 50 ANOS:

Transformando vidas atrevesa da educacto

27 de Outubro de 2021

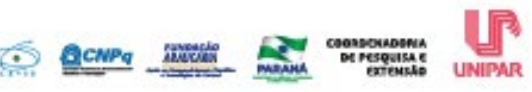




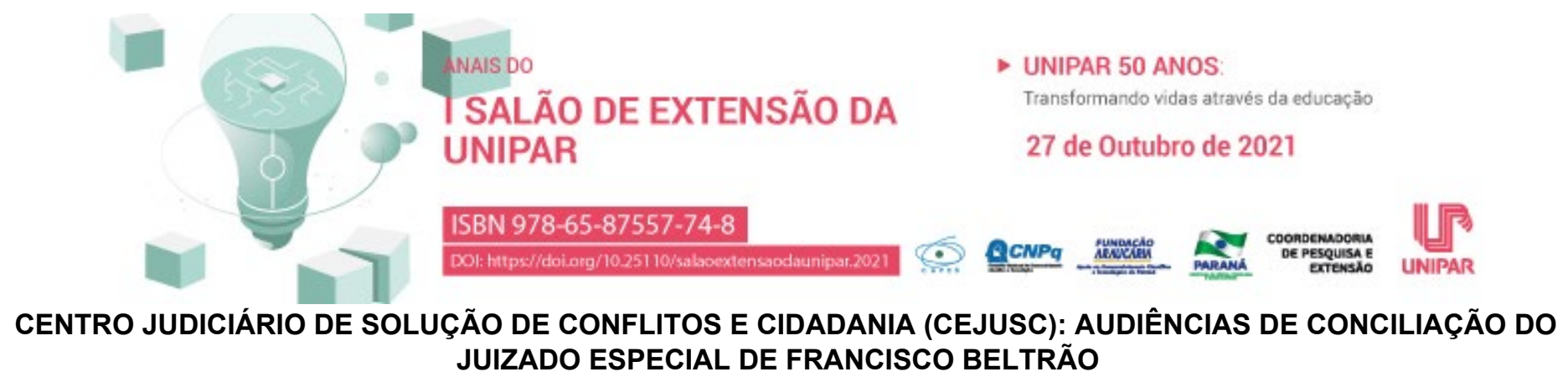

\author{
${ }^{1}$ CAMILA CRISTINA HENRIQUE SCHULZE, ${ }^{2}$ ANA CAROLINE CORREIA, ${ }^{3}$ ALEXANDRE MAGNO AUGUSTO MOREIRA, \\ 4JOAO PEDRO LYRA PIOVESAN
}

\author{
${ }^{1}$ Responsável Técnica do Curso de Direito da Unipar - Unidade de Francisco Beltrão \\ ${ }^{2}$ Acadêmica do Curso de Direito da UNIPAR \\ ${ }^{3}$ Docente da UNIPAR \\ ${ }^{4}$ Acadêmico do Curso de Direito da UNIPAR
}

Introdução: O CEJUSC consiste em um programa de extensão do Curso de Direito da Universidade Paranaense Unidade de Francisco Beltrão vinculado ao TJPR na forma da Resolução n. 125 CNJ. Por meio desse programa, são desenvolvidas as audiências de conciliação cíveis designadas pelo Juizado Especial de Francisco Beltrão por meio de um Responsável Técnico com auxílio dos acadêmicos do curso de Direito. Essas audiências têm como escopo a solução pacífica de conflitos, oportunizando às pessoas envolvidas a possibilidade de autocomposição. Além de favorecer a solução pacífica através de um ambiente colaborativo, no qual as pessoas se dispõem a dialogar de modo a desenvolver a própria autonomia, as audiências promovidas pela Lei $n^{\circ}$. 9.099/95 e pelo Código de Processo Civil de 2015 consistem em uma importante ferramenta para se promover o acesso à justiça, pois permitem a obtenção de uma resposta ao conflito de forma mais célere, eficiente, adequada e gratuita (TARTUCE, 2018, p. 99-122).

Objetivo: Objetiva-se colaborar com a comunidade atendida pela Comarca de Francisco Beltrão, auxiliando o Poder Judiciário na efetivação do acesso à justiça para que as controvérsias trazidas pelos cidadãos sejam solucionadas a contento pelas partes envolvidas, assim como proporcionar aos acadêmicos a experiência de presenciar audiências judiciais e de desenvolver técnicas adequadas para a soluções de conflitos.

Resultados: Em 2020, as atividades permaneceram suspensas por conta da pandemia de COVID-19. No corrente ano, por autorização do Juízo titular do Juizado as atividades foram retomadas de forma remota, com a celebração de 9 acordos do total de 91 audiências realizadas até o mês de agosto. Em 2019, foram realizadas 421 audiências, nas quais obtidas 56 acordos, enquanto 283 restaram prejudicadas pela ausência de uma das partes e 82 infrutíferas. Desde o ano de 2016, foram realizadas 1.733 audiências.

Conclusão: Depreende-se da realização dessas audiências uma contribuição favorável com a comunidade, ante o auxílio ao Poder Judiciário na efetivação do acesso à justiça. Além disso, é possível verificar uma contribuição positiva na formação acadêmica e pessoal dos acadêmicos participantes. No entanto, é possível também observar que a ausência da parte em audiência impede o diálogo a ser oportunizado, demonstrando de certa forma a necessidade de se fomentar nos ambientes sociais, familiar e escolar, a prática cotidiana de soluções pacíficas por meio de uma cultura de paz.

\section{Referências}

BRASIL. Lei $n^{\circ} .9 .099$ de 26 de setembro de 1995. Dispõe sobre os Juizados Especiais Cíveis e Criminais e dá outras providências. Diário Oficial da União, Brasília, Seção 1, p. 15033, 27 set. 1995.

BRASIL. Lei nº 13.105 de 16 de março de 2015. Código de Processo Civil. Diário Oficial da União, Brasília, Seção 1, p. 1 e 51, 17 mar. 2015.

CONSELHO NACIONAL DE JUSTIÇA. Resolução n. 125 de 29 de novembro de 2010. Dispõe sobre a Política Judiciária Nacional de tratamento adequado dos conflitos de interesses no âmbito do Poder Judiciários e dá outras providências. Diário da Justiça Eletrônico do Conselho Nacional de Justiça: ${ }^{\circ}$ 2019/2010, de $1^{\circ}$ dez. 2010, p.2-14.

TARTUCE, Fernanda. Mediação nos Conflitos Civis. 4. ed. Rio de Janeiro: Forense; São Paulo: Método, 2018, p. 99-122.

\section{SALÃOO DE EXTENSÃO} DA UNIPAR

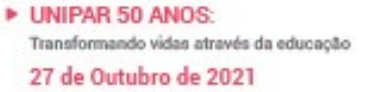

27 de Outubro de 2021

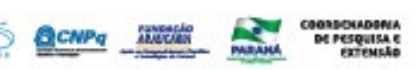

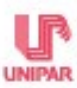




\section{(1) DUNIPAR 50 ANOS \\ SALÃO DE EXTENSÃO DA Transformando vidas através da educą̧̧̄o \\ UNIPAR \\ 27 de Outubro de 2021 \\ ISBN $978-65-87557-74-8$

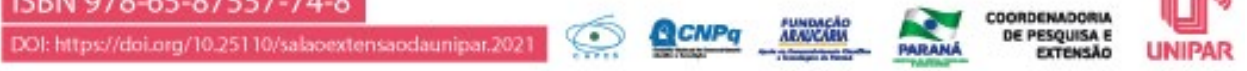 \\ PROJETO DE EXTENSÃO ELEUTÉRIO RODRIGUEZ NETO: ESTIMULANDO O PROTAGONISMO EM ACADÊMICOS DA SAÚDE}

${ }^{1}$ GEOVANA LUCIA BARBACOVI, ${ }^{2}$ LUCIANA PELLIZZARO, ${ }^{3}$ ANA CAROLINA SCHIO, ${ }^{4}$ ALAN CESAR DREY, ${ }^{5}$ YASMIN MENDONCA RODRIGUES BORGES, ${ }^{6}$ DIANE MIRELLY DICKEL, ${ }^{7}$ GABRIELA MACAGNAN, ${ }^{8}$ GIOVANA CRISTINA CICHOSKI TONELLO, ${ }^{9}$ RAPHAELA BOLIGON, ${ }^{10}$ GABRIEL CAMINI, ${ }^{11}$ ALESSANDRO RODRIGUES PERONDI

${ }^{1}$ Discente do Programa de Iniciação a Extensão da Universidade Paranaense UNIPAR/Francisco Beltrão-PR,

2Docente da UNIPAR

${ }^{3}$ Acadêmica do Curso de Enfermagem da UNIPAR

${ }^{4}$ Acadêmico do Curso de Psicologia da UNIPAR

${ }^{5}$ Acadêmica do Curso de Enfermagem da UNIPAR

${ }^{6}$ Acadêmica do Curso de Enfermagem da UNIPAR

${ }^{7}$ Acadêmica do Curso de Enfermagem da UNIPAR

${ }^{8}$ Acadêmica do Curso de Enfermagem da UNIPAR

${ }^{9}$ Acadêmica do Curso de Enfermagem da UNIPAR

${ }^{10}$ Acadêmico do Curso de Enfermagem da UNIPAR

${ }^{11}$ Docente da UNIPAR

Introdução: A publicação das diretrizes curriculares nacionais fomentou modificações nos currículos dos cursos da saúde no Brasil, estabelecendo a formação generalista, humanista, crítica e reflexiva, para atuar em todos os níveis de atenção à saúde, com base no rigor técnico e científico (MOURA et al., 2012). Nessa perspectiva, a extensão universitária desempenha um papel relevante na formação de profissionais, tendo em vista ser a ligação entre a universidade e a sociedade (SILVA, 2019).

Objetivo: Trata-se de um relato de experiência do projeto de extensão universitária Eleutério Rodriguez Neto, que propicia vivências em realidades distintas das encontradas no entorno da universidade, visando estimular o protagonismo em acadêmicos da saúde, integrando formação, prática assistencial e noções de cidadania.

Resultados: $O$ projeto, vinculado ao Curso de Enfermagem da Universidade Paranaense, foi desenvolvido de forma interprofissional, com a participação de três professores e 38 acadêmicos dos últimos anos dos cursos de Enfermagem, Nutrição, Psicologia, Farmácia, Odontologia, Ciências Biológicas, Educação Física e Estética e cosmética. Foi realizado no município de Laranjal, localizado na Região Centro-sul do Paraná, com 6.205 habitantes e baixo IDH 0,585 (PINTO; COSTA; MARQUES, 2013). Inicialmente, os professores realizaram uma visita à secretaria de saúde do município, para identificar problemas e demandas relevantes. Com base nesses problemas e demandas, os acadêmicos elaboraram atividades a serem desenvolvidas e produziram materiais como folders, cartilhas e manuais, com acompanhamento dos professores. As atividades foram planejadas de forma a fomentar o exercício da clínica ampliada. A equipe permaneceu no município por quatro dias, alojada em uma escola local, desenvolvendo atividades grupais, educação em saúde nas escolas, visitas domiciliares, atendimentos relacionados à saúde da criança, saúde da mulher, saúde mental e pacientes crônicos (diabéticos e hipertensos). Atividades de educação em saúde foram conduzidas de forma participativa, exigindo dos acadêmicos criatividade diante de situações inesperadas.

Conclusão: Ao final do projeto, os acadêmicos manifestaram gratidão pela oportunidade de interagir e aprender com uma comunidade aberta e com muitos desafios. Além de requerer formas diferentes de fazer saúde, a experiência proporcionou novas visões sobre o modo de viver em sociedade, com o exercício da humildade, cooperação e solidariedade.

\section{Referências}

MOURA, Lúcia de Fátima Almeida de Deus et al. Impacto de um projeto de extensão universitária na formação profissional de egressos de uma universidade pública. Revista de Odontologia da UNESP, v. 41, p. 348-352, 2012.

PINTO, Daniela Gomes Coordenação; COSTA, Marco Aurélio Coordenação; MARQUES, Maria Luiza de Aguiar Coordenação. 0 índice de desenvolvimento humano municipal brasileiro. 2013.

SILVA, Luciane Fontana Matoso. Assessoria executiva em arquivos: relato das percepções acadêmicas de um projeto de extensão universitária. Revista de Gestão e Secretariado, v. 10, n. 1, p. 73-90, 2019. 
- unIPAR 50 anos:

I SALAOO DE EXTENSÃO Transformando vidas atravies da educaģso

DA UNIPAR 


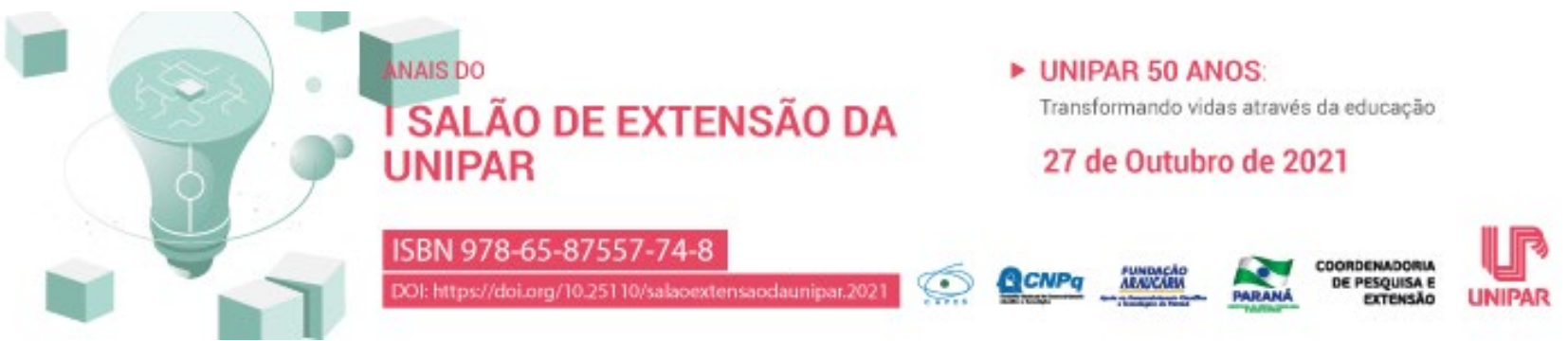 \\ COBERTURA VACINAL CONTRA O PAPILOMAVÍRUS HUMANO: DESAFIOS E ESTRATÉGIAS
}

\author{
${ }^{1}$ DJULIA RAISSA SEITZ, ${ }^{2}$ JULIANE DA COSTA, ${ }^{3}$ KASSIANY CARVALHO GUTERVIL, ${ }^{4}$ MYRIAN IOTHI, ${ }^{5}$ FRANCIELE DO \\ NASCIMENTO SANTOS ZONTA, ${ }^{6}$ LEDIANA DALLA COSTA
}

\author{
${ }^{1}$ Acadêmica do PEX - Curso de Enfermagem - Unidade de Francisco Beltrão \\ ${ }^{2}$ Acadêmica do Curso de Enfermagem da UNIPAR \\ ${ }^{3}$ Acadêmica do Curso de Enfermagem da UNIPAR \\ ${ }^{4}$ Acadêmica do Curso de Enfermagem da UNIPAR \\ ${ }^{5}$ Docente da UNIPAR \\ ${ }^{6}$ Docente da UNIPAR
}

Introdução: A vacina contra o Papilomavírus Humano (HPV) possui prioritariamente como público alvo, meninas com idade entre nove e quatorze anos, antes da iniciação sexual e meninos com faixa etária entre onze e quatorze anos. Entretanto, ainda existem barreiras importantes que dificultam a adequada cobertura vacinal (LOBÃO, 2018).

Objetivo: Descrever os desafios e estratégias relacionadas à cobertura vacinal contra o HPV, por meio de uma revisão de literatura.

Resultados: A infecção causada pelo HPV, é considerada uma infecção sexualmente transmissível, que pode levar ao câncer de colo uterino, vagina, vulva, pênis, neoplasias malignas do trato genital e não genital, além de verrugas genitais e cutâneas (CARVALHO et al., 2019). Diante disso, a vacinação foi desenvolvida como uma estratégia preventiva, demonstrando eficácia e segurança em adolescentes (SILVA et al., 2009). A vacina quadrivalente contra o vírus HPV está disponível pelo Programa Nacional de Imunização (PNI), oferecendo imunidade contra os sorotipos 6,11,16 e 18 (ALMEIDA et al., 2020). Estudos demonstram que desde a implementação no calendário do PNI, a cobertura vacinal anti-HPV está abaixo do recomendado, entre os motivos da baixa adesão a vacinação, destacam-se a falta de conhecimento sobre a eficácia e necessidade da vacina, receio de efeitos colaterais, dificuldade no acesso, crença de que a vacina promove o início da atividade sexual precoce e a convicção de que o exame citopatológico uterino é suficiente para prevenção do HPV (LOBÃO, 2018). Além disso, a falta de adesão está relacionada também ao movimento anti-vacina, responsável por disseminar informações equivocadas que refutam a eficácia e segurança das vacinas, considerado um dos maiores problemas de saúde pública global (ALMEIDA et al., 2020). A implementação de programas de educação em saúde em ambiente escolar, com a disseminação de conhecimento sobre a vacina contra o HPV para o público-alvo, junto a informações sobre os riscos da infecção, sintomas, confiabilidade e benefícios da vacinação podem influenciar a conscientização da população e permitir uma tomada de decisão, sendo portanto, uma estratégia eficaz para aumentar o alcance da vacinação (INTERAMINENSE et al., 2016). Trata-se de um projeto em parceria com o Núcleo Regional de Eduacação, o qual foi desenvolvido por meio de treinamentos para os acadêmicos, as oficinas nas escolas serão realizadas no $2^{\circ}$ semestre a partir da liberação do Núcleo devido a organização do calendário escolar de retorno às aulas presenciais.

Conclusão: É necessário a implementação de estratégias com foco em educação em saúde, com objetivo de transmitir maiores informações sobre a vacina, esclarecer dúvidas e reiterar a necessidade e eficácia da vacinação, conscientizando a população e possibilitando assim a ampliação da cobertura vacinal.

\section{Referências}

ALMEIDA, Rafaela Cristina Alves Altino et al. Cobertura Vacinal ANTI-HPV e motivos de não vacinação. Revista Eletrônica Acervo Enfermagem. $\quad$ v.2, p.e2600, Fev, $2020 . \quad$ Disponível em: https://acervomais.com.br/index.php/enfermagem/article/view/2600. Acesso em: 05 de setembro de 2021.

CARVALHO, Ayla Maria Calixto, et al. Adesão à vacina HPV entre os adolescentes: Revisão integrativa da literatura. Texto \& Contexto Enfermagem, 2019. v.28, n.1, p.e20180257, nov, 2019. Disponível em: https://www.scielo.br/j/tce/a/LxgbWPXJyD8ZCSGwhMbtZRw/?format=pdf\&lang=pt. Acesso em: 05 de Setembro de 2021. INTERAMINENSE, Iris Nayara da Conceição Souza et al. Tecnologias educativas para promoção da vacinação contra o papilomavírus humano: Revisão integrativa da literatura. Texto \& Contexto Enfermagem, 2016. v.25, n.2, p.:e2300015, Fev, 2016. Disponível em: https://www.scielo.br/j/tce/a/HKXSCtBvdhd6jdktK5GxW4d/?lang=pt. Acesso em: 06 de setembro de 2021. LOBÃO, William Mendes. Avaliação da aceitação parental da vacina HPV após sua introdução no programa nacional de imunização. Orientador: Edson Duarte Moreira Junior. 2018. 94 f. Tese (Doutorado em Biotecnologia em Saúde e Medicina Investigativa) Instituto Gonçalo Moniz, Fundação Oswaldo Cruz, Salvador, 2018. 
SILVA, Maria José Penna Maisonnette de Attayde et al. A eficácia da vacina profilática contra o HPV nas lesões HPV induzidas. Femina, Rio de Janeiro, v.37, n.10, p.519-526, Out, 2009. Disponível em: http://www.hu.ufsc.br/projeto_hpv/A\%20eficacia\%20da\%20vacina\%20profilatica\%20contra\%20o\%20HPV.pdf. Acesso em: 05 de Setembro de 2021.

I SALALS DO DE EXTENSÃOO " UNIPAR 50 ANOS:

DA UNIPAR
27 de Outubro de 2021
5 AcNPQ 


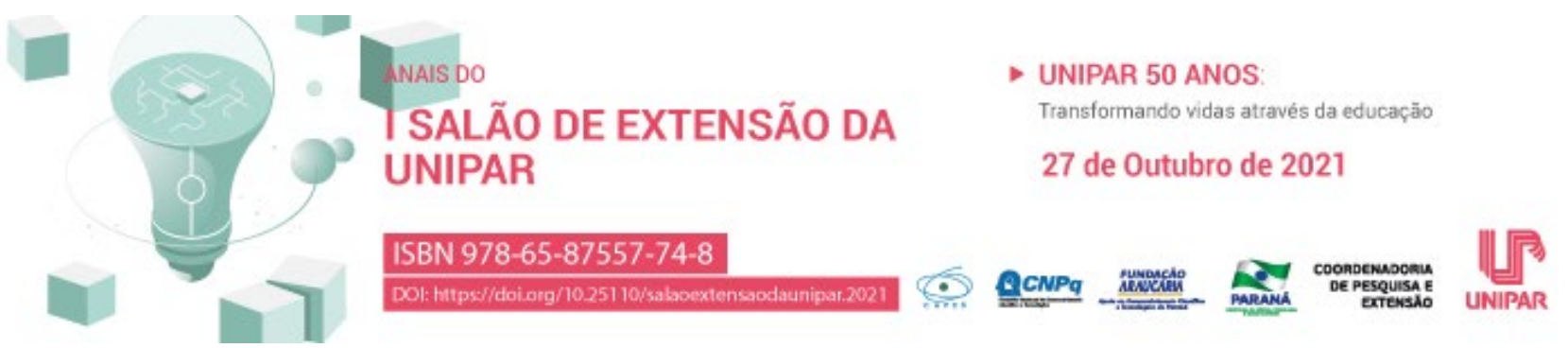 \\ RODAS DE CONVERSA SOBRE ESCOLHA DA PROFISSÃO EM TEMPOS DE PANDEMIA
}

\author{
${ }^{1}$ GABRIELA GOMES LUIZ, ${ }^{2}$ CAMILA CONEGLIAN FREITAS , ${ }^{3}$ ANA JULIA DA SILVA CANTO, ${ }^{4}$ BEATRIZ DE ARAUJO \\ TIMOTEO, ${ }^{5}$ VANESSA CAROLINA ALMEIDA DE JESUS, ${ }^{6}$ MELISSA JHULLY GUTIERREZ, ${ }^{7}$ MARIA ADELAIDE PESSINI
}

\begin{abstract}
${ }^{1}$ Acadêmica do Curso de Psicologia da UNIPAR
${ }^{2}$ Acadêmica do Curso de Psicologia da UNIPAR

${ }^{3}$ Acadêmica do Curso de Psicologia da UNIPAR

${ }^{4}$ Acadêmica do Curso de Psicologia da UNIPAR

${ }^{5}$ Acadêmica do Curso de Psicologia da UNIPAR

${ }^{6}$ Acadêmica do Curso de Psicologia da UNIPAR

${ }^{7}$ Docente da UNIPAR
\end{abstract}

Introdução: Esse trabalho representa o projeto de extensão universitária intitulado projeto de vida orientação profissional e de carreira, se justifica por oportunizar espaço de aprendizagem aos acadêmicos no campo da orientação profissional, e aos jovens do ensino médio, estreitar seus laços com sua futura profissão, fazendo-os refletir os aspectos que estão implicados na escolha da profissão. Desde o início de dezembro de 2019 a descoberta do vírus Sars-Cov-2 se propagou muito rapidamente, impossibilitando vivências cotidianas, transformando totalmente o cenário mundial. Com as restrições estabelecidas, foi necessário repensar uma outra modalidade da prática de orientação profissional que vinha sendo realizada através de atendimentos em grupo. Ressignificou-se esta prática, por meio das ferramentas do Google Meet, utilizando-se da metodologia de rodas de conversa, que se caracteriza como estratégia participativa que favorece a construção de uma prática dialógica, e possibilita o exercício de pensar compartilhado, cuja participação é espontânea. Questionamentos como: O que eu vou ser? e

Será que vou fazer a escolha correta? são recorrentes em diálogos entre jovens do ensino médio, e o processo de conversa sobre a decisão, não somente ajuda no próprio entendimento, mas também apresenta outras situações similares vividas por diferentes estudantes, assim promovendo um sentimento de pertencimento e identificação, aspectos que são de importância para a construção de um grupo.(BECHELLI, SANTOS, 2004).

Objetivo: Facilitar a comunicação e a interação dos participantes, garantindo maior disponibilidade para ouvir, do que para falar sobre todas as variáveis pessoais, profissionais e da tomada de decisão, presentes no momento da escolha de uma profissão.

Resultados: Foram atendidas dezessete pessoas com o nível de escolaridade do $1^{\circ}$ ao $3^{\circ}$ ano do ensino médio de escolas públicas e privadas., de Umuarama, São Jorge do Patrocínio e Douradina. São demandas trabalhadas: insegurança, escolhas erradas, ansiedade frente ao vestibular, pressão familiar e autocobrança.

Conclusão: Considera-se fundamental, oportunizar aos acadêmicos experiências que reforçam a importância da inter relação teoria e prática no campo da orientação profissional e aos participantes facilitar o momento da escolha profissional, auxiliando-os a compreender sua situação específica, no qual estão incluídos aspectos pessoais, familiares, sociais, culturais e econômicos.

\section{Referências}

BECHELLI, Luiz Paulo de C.; SANTOS, Manoel Antônio dos. Psicoterapia de grupo: como surgiu e evoluiu. Revista LatinoAmericana de Enfermagem, Ribeirão Preto, v. 12, p. 242-249, fev. 2004.

\section{SALĀO DE EXTENSÃO} DA UNIPAR

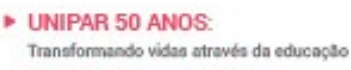

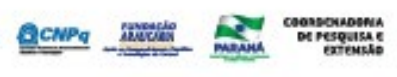

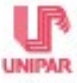




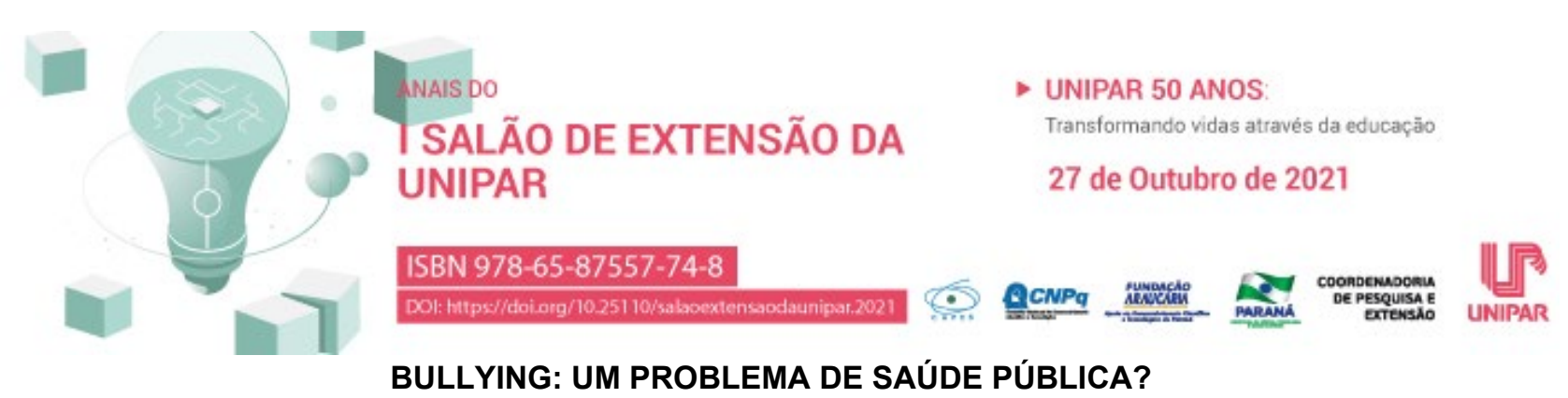

\begin{abstract}
${ }^{1}$ VERONICA DE MORAES, ${ }^{2}$ RAFAELA MATOS RODRIGUES, ${ }^{3}$ CAMILLY SCHAEFERS LUIZ, ${ }^{4}$ BELMIRO CHIELE JUNIOR, ${ }^{5}$ ANA LIVIA MACHADO TRES, ${ }^{6}$ MAISA DA ROSA DE TONI, ${ }^{7}$ LISLENE CRISTINA FARIA DE OLIVEIRA, ${ }^{8}$ ANA CLARA MILHAREZI DE SOUZA, ${ }^{9}$ BRUNA DENZER THOLKEN, ${ }^{10}$ ANNA JULIA HEBERLE BOSI, ${ }^{11}$ LAIANA RAFAELA CATTANI, ${ }^{12}$ LUIZ AUGUSTO MUGNAI VIEIRA JUNIOR
\end{abstract}

\footnotetext{
${ }^{1}$ Acadêmica do curso de Odontologia - PEX - UNIPAR

${ }^{2}$ Acadêmica do Curso de Psicologia - PEX da UNIPAR

${ }^{3}$ Acadêmica do Curso de Odontologia - PEX da UNIPAR

${ }^{4}$ Acadêmico do Curso de Odontologia - PEX da UNIPAR

${ }^{5}$ Acadêmica do Curso de Odontologia - PEX da UNIPAR

${ }^{6}$ Acadêmica do Curso de Odontologia - PEX da UNIPAR

${ }^{7}$ Acadêmica do Curso de Odontologia - PEX da UNIPAR

${ }^{8}$ Acadêmica do Curso de Psicologia - PEX da UNIPAR

${ }^{9}$ Acadêmica do Curso de Odontologia - PEX da UNIPAR

${ }^{10}$ Acadêmica do Curso de Odontologia - PEX da UNIPAR

${ }^{11}$ Acadêmica do Curso de Odontologia - PEX da UNIPAR

${ }^{12}$ Docente e Orientador PEX da UNIPAR
}

Introdução: Observa-se que o bullying tem se mostrado um problema de saúde pública no Brasil e no mundo (ORGANIZAÇÃO MUNDIAL DA SAÚDE, 2008). O bullying é compreendido como todas as formas de atitudes agressivas que podem ser realizadas de forma voluntária e repetitiva e que muitas vezes podem ter ou não motivação evidente. Ainda, de acordo com a Associação Brasileira Multiprofissional de Proteção à Infância e à Adolescência ABRAPIA (2000) o bullying é uma prática que geralmente é adotada por um ou mais estudantes contra outro (s) e que causa dor e angustia, pois envolve dentro de uma relação desigual de poder. Tal agressão tem sido cada vez mais frequente nos ambientes escolares e tem gerado diversos problemas de saúde.

Objetivo: Pensando nesse aspecto de proporcionar o enfrentamento do bullying como uma ação de cidadania e, por conseguinte, alertar o quanto o bullying pode acarretar em diversos problemas de saúde graves como ansiedade e depressão; o projeto de extensão Lição de cidadania nas escolas: bullying, tô fora! tem como objetivo proporcionar esclarecimento e conhecimento sobre o bullying com a finalidade de desconstruir a ideia que a sua prática seja uma brincadeira.

Resultados: Assim, e de maneira preliminar foi realizada uma consulta digital com parte da comunidade escolar. A pergunta consistia se o bullying é um problema de saúde? A maioria consultada respondeu que o bullying é um problema de saúde; sendo 92\% dos estudantes e $95 \%$ dos professores. Para as pesquisadoras Pimentel; Méa; Patias (2020) as vítimas de bullying possuem uma prevalência de sintomas depressivos, ansiedade, estresse e ideação suicida.

Conclusão: Tais dados vêm confirmar a fala frequente de pesquisadores de que o bullying não é uma brincadeira. É preciso tratá-lo com responsabilidade e trazê-lo para o debate junto da escola, comunidade, família e outros espaços sociais com o objetivo de desmistificar de que se trata de uma prática normal e natural da fase escolar.

\title{
Referências
}

ASSOCIAÇÃO BRASILEIRA MULTIPROFISSIONAL DE PROTEÇÃO À INFÂNCIA E À ADOLESCÊNCIA. ABRAPIA. Pesquisa sobre bullying. Disponível em: http://www.ripsa.org.br/lis/resource/446\#.YTV3F1VKi1s. Acesso em: 10 dez. 2000.

ORGANIZAÇÃO MUNDIAL DA SAÚDE. Desigualdades na saúde dos jovens: principais conclusões do Health Behavior in School-Age Children (HBSC) 2005/2006 ficha técnica da pesquisa. Copenhagen: Organização Mundial da Saúde; 2008.

PIMENTEL, Fernanda de Oliveira; MÉA, Cristina Pilla Della; PATIAS, Naiana Dapieve. Victims of bullying, symptoms of depression, anxiety and stress, and suicidal ideation in teenagers. Acta Colombiana de Psicología, 23(2), 205-216, 2020.

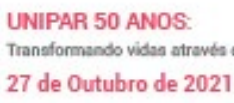

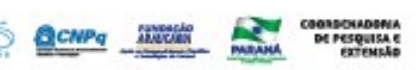




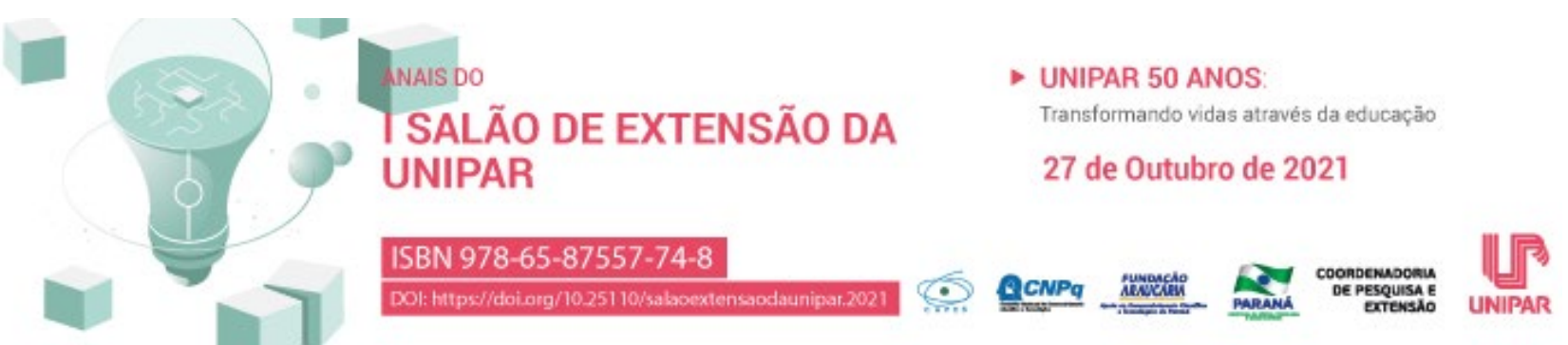 \\ BULLYING EM TEMPOS PANDÊMICOS: O AUMENTO DO CYBERBULLING}

${ }^{1}$ ISABELA RAMOS LESNIEWSKI, ${ }^{2}$ EMANUELE TONET DE SOUZA, ${ }^{3}$ GIOVANA GUOLLO TOZIM, ${ }^{4}$ JULIA CHIAMENTI, ${ }^{5}$ EDUARDA OLIVEIRA DA SILVEIRA, ${ }^{6}$ FERNANDA LIMA, ${ }^{7}$ EDER TREVISAO, ${ }^{8}$ LETICIA SILVEIRA DE ALMEIDA, ${ }^{9}$ GABRIELLA FORNARI, ${ }^{10}$ VANESSA PEREIRA DOS SANTOS, ${ }^{11}$ LUIZ AUGUSTO MUGNAI VIEIRA JUNIOR

${ }^{1}$ Acadêmica do Curso de Odontologia - PEX da UNIPAR

${ }^{2}$ Acadêmica do Curso de Odontologia - PEX da UNIPAR

${ }^{3}$ Acadêmica do Curso de Psicopedagogia e PEX da UNIPAR

${ }^{4}$ Acadêmica do Curso de Odontologia - PEX da UNIPAR

${ }^{5}$ Acadêmica do Curso de Psicologia - PEX da UNIPAR

${ }^{6}$ Acadêmica do Curso de Odontologia - PEX da UNIPAR

${ }^{7}$ Acadêmico do Curso de Odontologia - PEX da UNIPAR

${ }^{8}$ Acadêmico do Curso de Odontologia - PEX da UNIPAR

${ }^{9}$ Acadêmica do Curso de Odontologia - PEX da UNIPAR

${ }^{10}$ Acadêmica do Curso de Odontologia - PEX da UNIPAR

${ }^{11}$ Docente e Orientador PEX da UNIPAR

Introdução: O bullying não tem tradução para a língua portuguesa, pois é uma palavra da língua inglesa bully que significa valentão ou valentona , entretanto, poderia ser muito próximo do que seria um assédio moral ou uma perseguição repetitiva. O bullying compreende todas as atitudes agressivas, verbais ou físicas, intencionais com características, principalmente, de repetição, intimidação e agressão sem que a pessoa alvo dela possa se defender havendo dessa forma desigualdade de forças e abuso de poder (BORGES, 2015). Podemos observar que o cyberbullying seria um desdobramento do bullying e de acordo com Mason (2008) faz o uso da Internet e de outras tecnologias, sobretudo, das redes sociais digitais uma nova forma de agressão e ameaça entre alunos.

Objetivo: Desconstruir as visões distorcidas sobre o bullying e proporcionar o debate sobre a prática que, muitas vezes, desenrola no cyberbulling.

Resultados: Segundo United Nations International Children's Emergency Fund - UNICEF (2019) um em cada três jovens de trinta países diferentes afirmaram ter sido vítimas de cyberbullying. Ainda, segundo outra pesquisa da UNICEF (2020) a pandemia aumentou a exposição à agressões online. Em consonância com tais dados, o projeto de extensão Lição de cidadania nas escolas: bullying, tô fora! realizou uma prévia consulta com duas escolas de Cascavel-PR por meio digital que perguntou: se a pandemia fez aumentar a prática do cyberbullying? Dos estudantes que responderam; $93 \%$ afirmam que sim, $5 \%$ não e $2 \%$ não sabe.

Conclusão: Os números levantados pela consulta online impressionaram os participantes do projeto de extensão, o que confirmou a necessidade de um olhar mais atento do bullying no digital, e principalmente, para desconstruir a ideia ainda muito presente de que na internet não há limite e lei e que se pode tudo nela.

\section{Referências}

BORGES, Tahiana Andrade. Memórias do Bullying. São Paulo: Novo Século, 2015.

FUNDO DAS NAÇÕES UNIDAS PARA A INFÂNCIA (UNICEF). Pesquisa do UNICEF: Mais de um terço dos jovens em 30 países relatam ser vítimas de bullying online. Disponível em: https://www.unicef.org/brazil/comunicados-de-imprensa/mais-de-umterco-dos-jovens-em-30-paises-relatam-ser-vitimas-bullying-online. Acesso em: 04 set. 2019.

FUNDO DAS NAÇÕES UNIDAS PARA A INFÂNCIA (UNICEF). UNICEF alerta: situação de crianças e adolescentes se agravou consideravelmente após nove meses de pandemia. Disponível em: https://www.unicef.org/brazil/comunicados-deimprensa/unicef-alerta-situacao-de-criancas-e-adolescentes-se-agravou-consideravelmente-apos-nove-meses-pandemia. Acesso em: 11 dez. 2020.

MASON, Kimberly Lynn. CyberBullying (intimidação psicológica com a ajuda da tecnologia): Avaliação preliminar no ambiente escolar. Psychology in the Schools, Universidade Estadual de Cleveland, v.45, n.4, 2008. 
- unIPAR 50 anos:

I SALAOO DE EXTENSÃO Transformando vidas atravies da educaģso

DA UNIPAR 


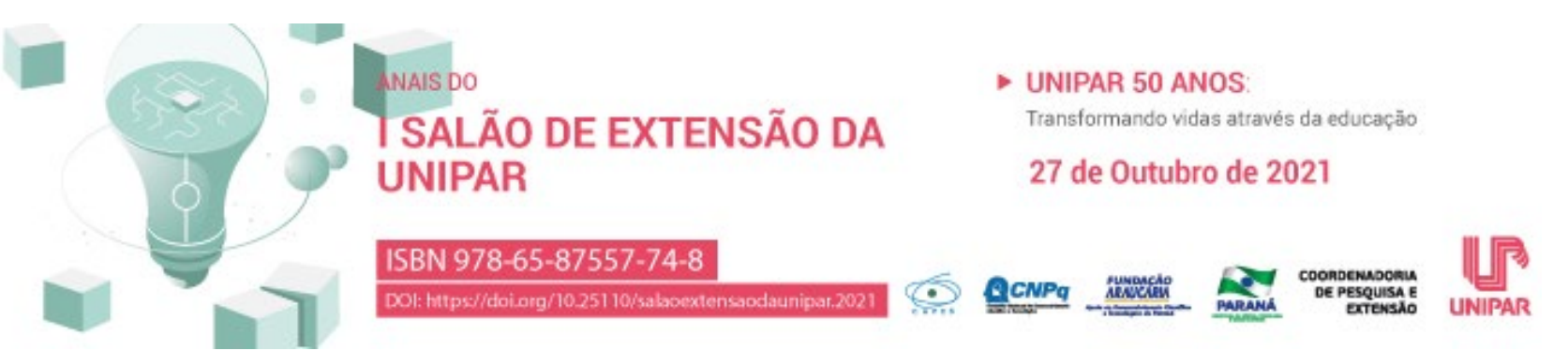

ARQUITETANDO SOLIDARIEDADE: UMA PROPOSTA DE AÇÕES QUE VISE O COMBATE A MISÉRIA E A FOME

${ }^{1}$ EDUARDO GABRIEL GEMNICZAK, ${ }^{2}$ EMEROIDES DE FREITAS MOTTA, ${ }^{3}$ ELOISA BEATRIZ FIORESI VAZ, ${ }^{4}$ JULIA KLEIN, ${ }^{5}$ RAFAELA CHEFFER MODESTO, ${ }^{6}$ KAOANY VITORIA ALBERTI, ${ }^{7}$ FERNANDA PELEGREFI THOME, ${ }^{8}$ ALINE FONSECA PERRUT, ${ }^{9}$ STEPHANIE AKEMI SATO VAILOES, ${ }^{10}$ ALINE BRUNA BIANCHINI FELTRIN, ${ }^{11}$ AMANDA RAFAELA RODRIGUES CARDOSO DA SILVA, ${ }^{12}$ HENZO GERARDI NETO, ${ }^{13}$ MARIANA ZANOTELLI SCHMIDT, ${ }^{14}$ SADRAQUE CAETANO DA SILVA , ${ }^{15}$ FLAVIO HENRIQUE DA ROSA UREN

\footnotetext{
${ }^{1}$ Acadêmico UNIPAR

${ }^{2}$ Acadêmico do Curso de Arquitetura e Urbanismo da UNIPAR

${ }^{3}$ Acadêmica do Curso de Arquitetura e Urbanismo da UNIPAR

${ }^{4}$ Acadêmica do Curso de Arquitetura e Urbanismo da UNIPAR

${ }^{5}$ Acadêmica do Curso de Arquitetura e Urbanismo da UNIPAR

${ }^{6}$ Acadêmica do Curso de Arquitetura e Urbanismo da UNIPAR

${ }^{7}$ Acadêmica do Curso de Arquitetura e Urbanismo da UNIPAR

${ }^{8}$ Acadêmica do Curso de Arquitetura e Urbanismo da UNIPAR

${ }^{9}$ Acadêmica do Curso de Arquitetura e Urbanismo da UNIPAR

${ }^{10}$ Acadêmica do Curso de Arquitetura e Urbanismo da UNIPAR

${ }^{11}$ Acadêmica do Curso de Arquitetura e Urbanismo da UNIPAR

${ }^{12}$ Acadêmico do Curso de Arquitetura e Urbanismo da UNIPAR

${ }^{13}$ Acadêmica do Curso de Arquitetura e Urbanismo da UNIPAR

${ }^{14}$ Acadêmico do Curso de Arquitetura e Urbanismo da UNIPAR

${ }^{15}$ Docente da UNIPAR
}

Introdução: Agenda 2030 da Organização das Nações Unidas fomenta ação para as pessoas, para o planeta e para a prosperidade priorizando o desenvolvimento sustentável do mundo. A Agenda traz 17 objetivos de Desenvolvimento Sustentável e 169 metas. Eles se constroem sobre o legado dos Objetivos de Desenvolvimento do Milênio

Este convite é para todos os países e todas as partes interessadas, atuando em parceria colaborativa e com isso, articulando a proposição de uma formação integradora, constituída no Projeto Pedagógico do curso de Arquitetura e Urbanismo da UNIPAR e a carência de várias ações sociais em nossa cidade, faz-se compreender a importância do Projeto Arquitetando Solidariedade. É um projeto que se propõem articular ações que estejam comprometidas com o bem comum, em específico da comunidade que a Universidade Paranaense está inserida, e atrelada a um dos objetivos da agenda que é acabar com a pobreza em todas as suas formas, em todos os lugares e acabar com a fome. De fato, o projeto não tem pretensão de atender a macrorregião de Cascavel, porém de forma pontual propomos ações que promovam tais embates e acima de tudo que articule em nossos alunos os princípios de altruísmo e articule habilidade sobre relacionamento interpessoal.

Devido ao sucesso deste projeto na fase 1 no ano de 2019 e na fase 2 em 2020 é que se propõe novamente para atender outras entidades.

Objetivo geral: Propor ações que estejam apropriadas a qualidade de vida digna para todos os envolvidos, quando interagidos com pessoas em estado vulnerável. Objetivos Específicos: Integrar comunidade e Universidade. Propor ações que resgate os valores e a cultura em específico quando interagidos com crianças,

Propor ações que suplante a dignidade e o altruísmo quando interagidos com pessoas sem poder aquisitivo. Propor ações que promova a reflexão do alunado frente as demandas sociais de nossa cidade, compreendendo e articulando a formação profissional com a formação cidadã Garantir o trabalho integrado a outras áreas do conhecimento;

Aguçar a criticidade e a criatividade dos alunos como ferramenta para uma formação consolidada e mais humana. Aguçar a necessidade de participação e relação nos projetos de extensão e ensino do curso.

Resultados: $1^{\text {a }}$ Ação- Doação de donativos para escola Jose Bonifácio, distrito de Rio do Saldo na cidade de Cascavel. Esta ação envolve uma campanha com a comunidade acadêmica com a sensibilização de ajuda ao próximo. (Ação concluida). $2^{\mathrm{a}}$ Ação- para o Centro POP - Serviço especializado para pessoas em situação de rua prevê a Doação de donativos para os usuários da Casa. (Ação concluida). $3^{a}$ Ação - ACIPA Associação Cidadã de Proteção aos Animais. Esta ação que é 
semelhante as anteriores, visa também uma campanha de ajuda aos animais deste centro que encontram-se em estado de precariedade. (Ação em andamento)

Considerações Finais: O Projeto Arquitetando Solidariedade, na sua parte três é um projeto que se propõem articular ações que estejam comprometidas com o bem comum, em específico da comunidade que a Universidade está inserida, e atrelada a um dos objetivos da agenda da ONU que é acabar com a pobreza e a miséria em todas as suas formas, em todos os lugares e acabar com a fome.

\section{Referências}

NAÇÕES UNIDAS NO BRASIL- ONU BR. A Agenda 2030. Disponível em: https://nacoesunidas.org/pos2015/agenda2030/. Acesso em: 13 jun. 2021.

TERESA, MADRE. Amor maior não há. Universo dos Livros Editora Ltda, São Paulo, 2017.

GONZÁLEZ-BALADO, J. L. Madre Teresa de Calcutá Um amor sem fronteiras, Editorial Franciscana, Braga, 2003.

SPINK, K. Madre Teresa de Calcutá. Missionária da Caridade, Editorial A. O. e Edições Loyola, Braga, São Paulo, 1984.

I SALÃOO DE EXTENSÃO

DA UNIPAR
- UNIPAR 50 ANOS:

Traneformando vides atreves da educapes

27 de Outubro de 2021

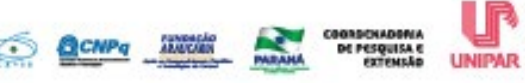




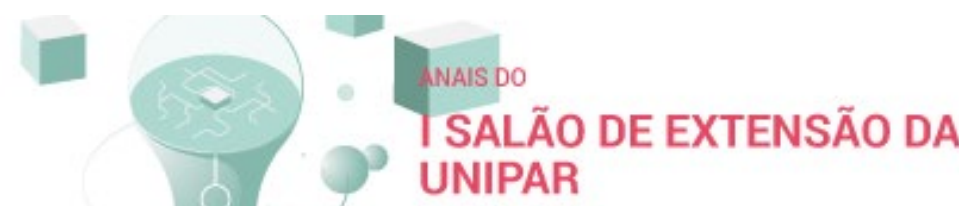 \\ - UNIPAR 50 ANOS: \\ Transformando vidas através da educação \\ 27 de Outubro de 2021

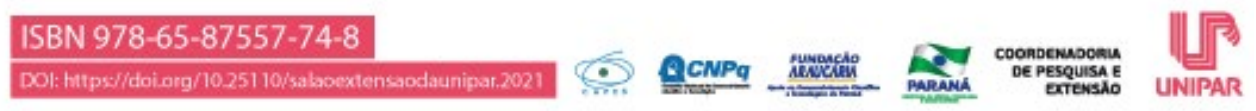 \\ INFLUÊNCIA DOS RESPONSÁVEIS SOBRE A SAÚDE BUCAL DE CRIANÇAS: ASPECTOS RELACIONADOS À CÁRIE NA PRIMEIRA INFÂNCIA
}

\author{
${ }^{1}$ ALICIA GIOVANA ROCHA, ${ }^{2}$ AMANDA FERREIRA TETILIA, ${ }^{3}$ CAMILA DA SILVA BUFETI, ${ }^{4}$ ISADORA MACIEL SANTOS, \\ ${ }^{5}$ JULIA IRMA DA SILVA ESGLÓ, ${ }^{6}$ JULIANA SAMPAIO SILVA, ${ }^{7}$ KARLA MILENA OLIVEIRA, ${ }^{8}$ MILENA CAMPOS OLIVEIRA, \\ ${ }^{9}$ LETICIA VAZ DE CAMARGO, ${ }^{10}$ PAULA GABRIELE CUNHA PERUSSO, ${ }^{11}$ ANA CAROLINA SOARES FRAGA ZAZE
}

\footnotetext{
${ }^{1}$ Acadêmico do curso de Odontologia UNIPAR

${ }^{2}$ Acadêmico do curso de Odontologia UNIPAR

${ }^{3}$ Acadêmico do curso de Odontologia UNIPAR

${ }^{4}$ Acadêmico do curso de Odontologia UNIPAR

${ }^{5}$ Acadêmico do curso de Odontologia UNIPAR

${ }^{6}$ Acadêmico do curso de Odontologia UNIPAR

${ }^{7}$ Acadêmico do curso de Odontologia UNIPAR

${ }^{8}$ Acadêmico do curso de Odontologia UNIPAR

${ }^{9}$ Acadêmico do curso de Odontologia UNIPAR

${ }^{10}$ Acadêmico do curso de Odontologia UNIPAR

${ }^{11}$ Docente da UNIPAR
}

Introdução: Quando a cárie acomete a primeira infância, está relacionada a hábitos que foram instituídos na rotina da criança, na maioria das vezes desde os primeiros meses de vida. Sabe-se que são os responsáveis pelo bebê que influenciam na dieta e formação do paladar, bem como na rotina de higienização bucal de seus filhos.

Objetivo: Compreender a influência dos responsáveis na saúde bucal de crianças, sobre os aspectos relacionados à cárie dentária, como hábitos de higiene, dietéticos e características individuais.

Resultados: Os fatores relacionados ao desenvolvimento da cárie são amplamente discutidos pela literatura, entretanto, informações apresentadas à população são pouco voltadas às características inerentes de cada faixa etária. Para a primeira infância, é necessário ressaltar que as consequências de escolhas e hábitos indesejáveis para a manutenção da saúde bucal são observadas na criança, mas quem determina isso são os adultos responsáveis por ela. Algumas características são determinadas geneticamente e sobre elas, não existe muito controle, como anatomia dos dentes e características salivares. Todavia, a maioria dos fatores etiológicos da cárie está relacionada a hábitos, definidos no decorrer da vida de cada pessoa, e que são iniciados nos primeiro ano de vida. A dieta rica em carboidratos, principalmente a sacarose, serve de substrato para microrganismos, favorecendo a presença dos cariogênicos. O tempo de permanência do substrato na boca e o momento no qual os alimentos são ingeridos alteram a cariogenicidade deles, portanto, informações inerentes à remoção do substrato e do biofilme devem ser disponibilizadas para responsáveis de bebês, mesmo antes do nascimento dos primeiros dentes. Desde a gestação até a infância, ocorrem diversos processos de desenvolvimento na criança, e uma nutrição adequada é de extrema importância para a saúde geral e bucal. Alguns estados carenciais e a ingestão de componentes alimentares específicos influenciam na formação e erupção dental. Estudos relatam que crianças que apresentam cárie na primeira infância podem ter crescimento mais lento, quando comparadas às livres de cárie, sendo que algumas podem apresentar baixo peso devido à associação da dor ao ato de comer.

Conclusão: A educação em saúde voltada à responsáveis por bebês favorece a presença de hábitos alimentares e de higiene mais saudáveis, o que permite a manutenção da saúde bucal, e consequentemente uma melhor saúde geral.

\section{Referências}

BATISTA, Luciana et al. Alimentação, estado nutricional e condição bucal da criança. Revista de Nutrição, v. 20, n. 2, p. 191196, dez., 2006.

FEIJÓ , Isadora et al. Cárie e dieta alimentar. Uningá Review Journal, v. 19, n. 3, p. 44-50, set., 2014.

LIMA, José et al. Cárie dentária: um novo conceito. Revista Dental Press: Ortodontia e Ortopedia facial, v. 12, n. 6, p. 119130, ago. 2008.

LOSSO, Estela et al. Cárie precoce e severa na infância: uma abordagem integral. Jornal de Pediatria, v. 85, n.. 4, p. 295-300, nov. 2008. 
- unIPAR 50 anos:

I SALAOO DE EXTENSÃO Transformando vidas atravies da educaģso

DA UNIPAR 


\section{DNAIS DO UNIPAR 50 ANOS \\ SALÃO DE EXTENSÃO DA Transformando vidas através da educaçäo \\ UNIPAR \\ 27 de Outubro de 2021 \\ ISBN 978-65-87557-74-8

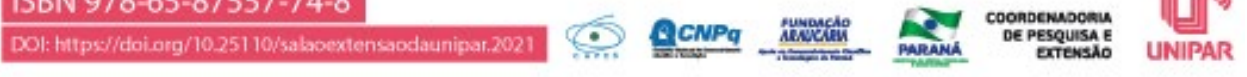 \\ LIGA ACADÊMICA DE HEPATOLOGIA, DOAÇÃO E TRANSPLANTE DE ÓRGÃOS: CONSCIENTIZAÇÃO PARA DOAÇÃO DE ÓRGÃOS E TECIDOS}

${ }^{1}$ GABRIELA CORREA ALBERTI, ${ }^{2}$ RAFAEL RODRIGUES CORREA, ${ }^{3}$ GABRIEL HENRIQUE BELLATO PALIN, ${ }^{4}$ CARLOS EDUARDO RUZZENE RODRIGUES, ${ }^{5}$ DAVI CORREA PEREIRA, ${ }^{6}$ JOLMAR LEONARDO PENAZZO MACHADO, ${ }^{7}$ ESTER PELEGRINI SILVA, ${ }^{8}$ BEATRIZ MORETTO DE PAULA, ${ }^{9}$ MARIANA VITORIA GASPERIN

${ }^{1}$ Acadêmico do Curso de Medicina da UNIPAR

${ }^{2}$ Acadêmico do Curso de Medicina da UNIPAR

${ }^{3}$ Acadêmico do Curso de Medicina da UNIPAR

${ }^{4}$ Acadêmico do Curso de Medicina da UNIPAR

${ }^{5}$ Acadêmico do Curso de Medicina da UNIPAR

${ }^{6}$ Acadêmico do Curso de Medicina da UNIPAR

${ }^{7}$ Acadêmica do Curso de Medicina da UNIPAR

${ }^{8}$ Acadêmica do Curso de Medicina da UNIPAR

${ }^{9}$ Docente da UNIPAR

Introdução: Projetos de extensão auxiliam na formação do profissional, além de levar conhecimento à comunidade. As ligas acadêmicas agregam conhecimento científico, utilizando-se deste para esclarecer assuntos importantes para a população. A doação de órgãos é mistificada, pelo receio em se falar sobre a morte e, consequentemente, sobre a doação de órgãos (QUINTANA; ARPINI, 2009).

Objetivo: Descrever as atividades desenvolvidas pela Liga Acadêmica de Hepatologia, Doação de Órgãos e Transplante (LAHDOT) durante o mês de setembro em divulgação ao "Setembro Verdel". O foco do projeto foi a divulgação de informações referentes à importância da doação de órgãos esclarecendo dúvidas da comunidade e alunos do curso de medicina da Unipar.

Resultados: Os alunos diretores da LAHDOT trabalharam em conjunto a 26 alunos voluntários no projeto. Foram elaborados 1.500 panfletos contendo verdades e mitos sobre doação de órgãos a serem entregues em conjunto a laço de cetim verde (símbolo da doação de órgãos) e uma bala. Nos dias 13 e 14 de setembro de 2021 será realizada a entrega dos panfletos. Outros alunos da Unipar também serão abordados, na intenção de divulgar o tema e incentivar a se tornarem doadores. Em 15 de setembro de 2021 fecharemos o projeto com uma palestra sobre conscientização de doação de órgãos e tecidos tendo como alvo os estudantes do curso de medicina da Universidade. Será realizada inscrição solidária e cada inscrito deverá levar um quilo de alimento ou dois itens de higiene pessoal para a doação ao Projeto Restauração . A palestrante será a Doutora Mariana Vitória Gasperin, que explicará sobre como ser um doador, em que situações é realizada a doação, descreverá o processo de doação e outros assuntos relevantes ao setembro verde. Por fim, o vídeo de incentivo a doação de órgãos confeccionado pelos alunos será postado em nosso Instagram no intuito de alcançar e incentivar o maior número de pessoas a doação de órgãos e tecidos.

Conclusão: Diante do exposto, é notório a intenção do projeto, que é influenciar de maneira significativa a doação de órgãos. $O$ intuito é alcançar não só a comunidade mas também os futuros egressos, a respeito deste nobre ato de doação de órgãos que salva vidas.

\section{Referências}

QUINTANA, Alberto Manuel; ARPINI, Dorian Mônica. Doação de órgãos: possíveis elementos de resistência e aceitação. Boletim de psicologia, v. 59, n. 130, p. 91-102, 2009.

SCHEIDEMANTEL, Sheila Elisa; KLEIN, Ralf; TEIXEIRA, Lúcia Inês. A importância da extensão universitária: o Projeto Construir. In: Congresso Brasileiro de Extensão Universitária. 2004. p. 1-6.

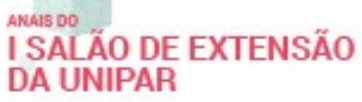

DA UNIPAR

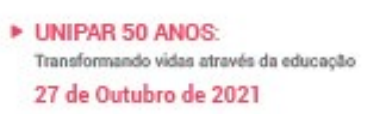

27 de Outubro de 2021

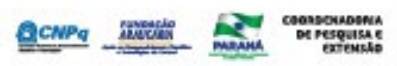




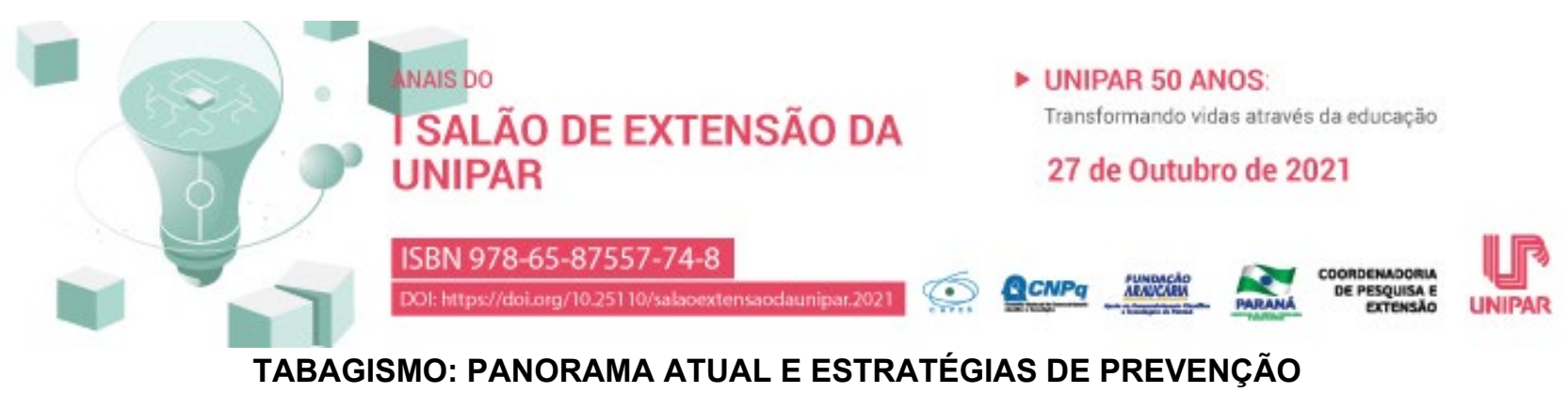

\section{${ }^{1}$ SARAH JULIA SANTOS DE CARVALHO ROSA, ${ }^{2}$ KATIA BIAGIO FONTES}

${ }^{1}$ Discente do Curso de Enfermagem na universidade Paranaense- Unipar

${ }^{2}$ Docente da UNIPAR

Introdução: Apesar do amplo conhecimento da sociedade de como o tabaco pode acarretar dependência através da nicotina e o desenvolvimento de doenças graves e fatais para quem o utiliza, sendo considerado como um problema de saúde pública. Nos últimos 30 anos, mais de 200 milhões de pessoas morreram devido ao uso do tabaco. Em 2019, mais de 1 bilhão de pessoas fumam regularmente e quase 8 milhões de pessoas morreram por fumar, representando $20,2 \%$ das mortes entre os homens (PEREIRA et al., 2021).

Objetivo: Identificar na literatura científica estratégias de prevenção para o controle do tabagismo.

Resultado: É notório que a maioria dos países em desenvolvimento, apresentam as políticas para o controle do tabagismo incipientes, gerando concorrência para a expansão das transnacionais de tabaco, fazendo necessário o aumento dos impostos sobre o cigarro, para que assim diminua cada vez mais a sua demanda. É perceptível que o número de jovens fumantes vem crescendo a cada dia, grande parte por se tratar de moda da época. A prevalência do tabagismo ativo entre os jovens na maioria dos países ainda é alta, o que está relacionado ao aumento do uso de e-cigarros e produtos vaporizados (PEREIRA et al., 2021). Entre os alunos que fumam, $15 \%$ relataram terem fumado pela primeira vez antes dos 14 anos e, apenas $3 \%$ dos adolescentes fumantes admitem fumar após os 16 anos (FILHO et al., 2010). Com isso, faz-se necessário criar programas de educação de controle do tabagismo nas escolas e restringir o acesso ao tabaco aos jovens, para assim, cessar aos poucos essa

febre que acomete muitos indivíduos. Além disso, o Brasil vem se destacando, sendo o primeiro país a proibir o uso de descritores nas embalagens e o segundo a inserir advertências com frases e imagens nas embalagens, além de ser um dos poucos países que restringem a publicidade e vetam vendas na indústria de alimentos para simular derivados do tabaco. Todas essas estratégias são propostas pela Convenção-Quadro para o Controle do Tabaco (SILVA et al., 2014).

Conclusão: Pode-se concluir que as estratégias de prevenção apontadas na literatura foram aumentar os impostos sobre o cigarro; proibir o uso de descritores de embalagem; inserir advertências com frases e imagens nas embalagens e vetar vendas nas indústrias alimentícias. Com isso em mente, é necessário a prontificação de toda a sociedade, para que, de pouco em pouco, possa cada vez mais ser encarado e desenvolvido essa doença tão fatal.

\section{Referências}

PEREIRA, Marilyn; NETO, Herberto; SOLÉ, Dirceu. Controle do tabagismo em jovens e adultos: O Brasil fez sua lição de casa?. J Bras Pneumol, v. 47, n. 05, 2021. Disponível em:

https://cdn.publisher.gn1.link/jornaldepneumologia.com.br/pdf/2021_47_5_3577_portugues.pdf, Acesso: 31 ag. 2021.

SILVA, Sandra et al. Combate ao tabagismo no Brasil: a importância estratégica das ações governamentais. Rio de Janeiro-RJCiênc. saúde coletiva, v. 19, n. 02, 2014. Disponível em:

https://www.scielo.br/j/csc/a/Wq3hFwwN8m8JBfZ3sd4nCvF/?lang=pt\&format=html, Acesso: 31 ag. 2021.

FILHO, Victor et al. Tabagismo e câncer no Brasil: evidências e perspectivas. Rev Bras Epidemiol, v.13, n. 02, 2010. Disponível em:

https://www.scielosp.org/article/ssm/content/raw/?resource_ssm_path=/media/assets/rbepid/v13n2/01.pdf, Acesso: 31 ag. 2021.

> UNIPAR 50 ANOS:

Transeformando vides atraves da educaçlo

27 de Outubro de 2021

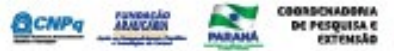

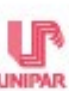




\title{
ADEQUAÇÃO DO SISTEMA DE FORNECIMENTO DE ÁGUA E ALIMENTO DE GALINHAS POEDEIRAS CRIADAS A PASTO DE ACORDO COM A HUMAN
} FARM ANIMAL CARE

\begin{abstract}
${ }^{1}$ GIOVANA DANTAS GROSSI, ${ }^{2}$ NATIELLI BELOTTI PAIE, ${ }^{3}$ ANA KARLA FAVORETTO, ${ }^{4}$ GUSTAVO MARCOS FAGIANI, ${ }^{5}$ SARAH LISSONI COBO, ${ }^{6}$ RAPHAELA FLOES DÁVILA, ${ }^{7}$ VICTORIA DOS REIS VOLPATTO, ${ }^{8}$ GEYSIANE MOREIRA GEROTTI, ${ }^{9}$ MATHEUS BASILIO MARCAL, ${ }^{10}$ ANA LUISA CANO, ${ }^{11}$ HELOYSA PIRES, ${ }^{12}$ VINICIUS AUGUSTO SILVA DIAS, ${ }^{13}$ LEILA ALVES DE OLIVEIRA, ${ }^{14}$ RANULFO PIAU JUNIOR, ${ }^{15}$ LUCIANA KAZUE OTUTUMI FARIAS
\end{abstract}

\author{
${ }^{1}$ Acadêmica do Curso de Medicina Veterinária, UNIPAR, bolsista PIBIC/UNIPAR, PEX/UNIPAR \\ ${ }^{2}$ Acadêmica do Curso de Medicina Veterinária, UNIPAR, bolsista PIBIC/UNIPAR, PEX/UNIPAR \\ ${ }^{3}$ Acadêmica do Curso de Medicina Veterinária, UNIPAR, bolsista PIBIC/UNIPAR, PEX/UNIPAR \\ ${ }^{4}$ Acadêmico do Curso de Medicina Veterinária, UNIPAR, PEX/UNIPAR \\ ${ }^{5}$ Acadêmica do Curso de Medicina Veterinária, UNIPAR, PEX/UNIPAR \\ ${ }^{6}$ Acadêmica do Curso de Medicina Veterinária, UNIPAR, PEX/UNIPAR \\ ${ }^{7}$ Acadêmica do Curso de Medicina Veterinária, UNIPAR, PEX/UNIPAR \\ ${ }^{8}$ Mestranda em Ciência Animal com Ênfase em Produtos Bioativos da UNIPAR, taxista PROSUP/CAPES \\ ${ }^{9}$ Mestrando em Ciência Animal com Ênfase em Produtos Bioativos da UNIPAR, taxista PROSUP/CAPES \\ ${ }^{10}$ Acadêmica do Curso de Medicina Veterinária, UNIPAR, PEX/UNIPAR \\ ${ }^{11}$ Acadêmica do Curso de Medicina Veterinária, UNIPAR, PEX/UNIPAR \\ ${ }^{12}$ Acadêmico do Curso de Medicina Veterinária, UNIPAR, bolsista PIBIC/UNIPAR, PEX/UNIPAR \\ ${ }^{13}$ Doutoranda em Ciência Animal com Ênfase em Produtos Bioativos, UNIPAR, taxista PROSUP/CAPES \\ ${ }^{14}$ Professor do curso de Medicina Veterinária e do Programa de Pós-Graduação em Ciência Animal, UNIPAR \\ ${ }^{15}$ Professora do curso de Medicina Veterinária e do Programa de Pós-Graduação em Ciência Animal, UNIPAR
}

Introdução: A Humane Farm Animal Care é uma organização sem fins lucrativos que tem como missão melhorar a vida dos animais de produção, estabelecendo padrões viáveis e confiáveis adequadamente monitorados para a produção humanitária de alimentos, garantindo aos consumidores que produtos certificados atendam a esses padrões (HFAC, 2018). Os três maiores produtores de ovos no Brasil no ano de 2020 foram São Paulo (29,83\%), Espírito Santo (10,39\%) e Minas Gerais (10,11\%) (ABPA, 2021), ficando o estado do Paraná na sexta posição com 5,44\% da produção do Brasil. De acordo com Amaral et al. (2016), o ovo de galinha é um alimento nutritivo e barato, comercializado em casca ou industrializado, com diversas aplicações na indústria alimentícia e que tem apresentado nos últimos anos, um aumento da preocupação com o bem-estar dos animais. Isso tem provocado mudanças no setor de produção de ovos, com a União Européia e parte dos Estados Unidos regulamentando a eliminação da produção de ovos de galinhas confinadas em gaiolas, o que tem trazido uma oportunidade de negócio para a criação no sistema sem gaiolas (RUSSO, 2021). Isso ocorre porque as galinhas, em condições naturais, são criadas em melhores condições de bem-estar e passam boa parte do tempo ciscando a procura de insetos e sementes, tomam banhos de areia, tem um lugar mais alto para alçar pequenos voos ou fugir de aves dominantes, esticar as asas, espojar-se, bicar objetos e forragear, comportamentos considerados importantes para as galinhas poedeiras (SILVA; ABREU; MAZZUCO, 2020).

Objetivo: O objetivo do trabalho foi avaliar a adequação do sistema de fornecimento de água e alimento de galinhas poedeiras criadas a pasto do Colégio Agrícola Estadual de Umuarama de acordo com o padrão estabelecido pelo Human Farm Animal Care (HFAC).

Resultado: Foram realizadas visitas no Colégio Agrícola Estadual de Umuarama a fim de avaliar o sistema de fornecimento de água e alimento de galinhas poedeiras criadas no sistema a pasto. Atualmente no setor de galinhas poedeiras estavam alojadas 140 aves. O fornecimento de ração era feito duas vezes ao dia, de manhã e de tarde. Como as aves já estavam na fase de produção de ovos, era fornecido aproximadamente 100 gramas de ração/ave/dia. As aves tinham acesso a dois piquetes de aproximadamente 16,5 metros de comprimento por nove metros de largura $\left(148,5 \mathrm{~m}^{2}\right)$. A área coberta, destinada para o fornecimento de água e ração e descanso dos animais no período noturno, apresentava 5,8 metros de comprimento por seis metros de largura $\left(34,8 \mathrm{~m}^{2}\right)$. $\mathrm{Na}$ área coberta havia cinco comedouros tubulares, sendo que três apresentavam capacidade de até $10 \mathrm{~kg}(125 \mathrm{~cm}$ espaço) e dois com capacidade de até três kg (84 $\mathrm{cm}$ de espaço). Havia ainda um comedouro de calha feito com cano PVC o qual ficava situado no meio dos outros comedouros e bebedouros e apresentavam três metros de comprimento. Em relação ao sistema de fornecimento de água, havia três bebedouros pendulares, que eram lavados e higienizados duas vezes ao dia. Como o objetivo era avaliar o sistema de fornecimento de água e ração para atender o estabelecido pela HFAC para galinhas poedeiras criadas a pasto, verificou-se que a quantidade de bebedouros estava adequada (recomendação de um bebedouro pendular para cada 100 galinhas). A recomendação de espaçamento de comedouro por ave de acordo com a HFAC é de quatro centímetros por ave para comedouro tubular e cinco centímetros por ave para comedouro com acesso de dois lados. Levando-se em consideração a quantidade de galinhas alojadas e a quantidade de comedouros, verificou-se que o espaço linear total era de $418 \mathrm{~cm}$ para comedouros tubulares e $300 \mathrm{~cm}$ para comedouro PVC. Esses valores permitem atender 104 galinhas nos comedouros tubulares e 60 galinhas no comedouro de PVC, atendendo dessa forma, a recomendação da HFAC. Quanto ao posicionamento dos comedouros e bebedouros, a recomendação é que as galinhas não devem se deslocar mais de $7,3 \mathrm{~m}$ para al cançar o alimento e a água, atendendo também a recomendação. De acordo com Silva, Abreu e Mazzuco (2020), os bebedouros do tipo pendular, devem sem higienizados pelo menos uma vez ao dia. O procedimento realizado no Colégio era de limpeza duas vezes ao dia, uma de manhã e outra no período da tarde, atendendo a recomendação.

Conclusão: Conclui-se que a criação de galinhas a pasto do Colégio Agrícola Estadual de Umuarama, atende as recomendações de espaçamento de bebedouro e comedouro, e deslocamento dos animais para ter acesso à alimentação.

\section{Referências}

ABPA Associação Brasileira de Proteína Animal. Relatório anual 2021. Disponivel em: http://abpa-br.org/abpa-lanca-relatorio-anual-2021/ Acesso em: 22 ago. 2021.

AMARAL, Gisele Ferreira et al. Avicultura de postura: estrutura da cadeia produtiva, panorama do setor no Brasil e no mundo e o apoio do BNDES.

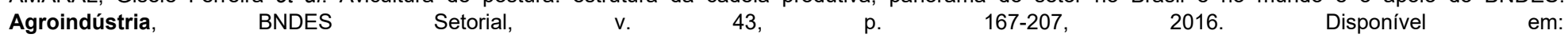
https://web.bndes.gov.br/bib/jspui/bitstream/1408/9579/3/BS\%2043\%20Avicultura\%20de\%20postura_estrutura\%20da\%20cadeia\%20produtiva_corrigido_P_BD.pdf Acesso em: 22 ago. 2021.

HUMAN FARM ANIMAL CARE HFAC. Referencial de HFAC de galinhas poedeiras. Middleburg: HFAC. 2018. 48p. 
RUSSO, J. C. Tudo o que você precisa saber sobre o sistema de produção de ovos. 2021. Agroceres Multimix. Disponível em: https://www.aviculturaindustrial.com.br/imprensa/tudo-que-voce-g-saber-sobre-os-\%20sistemas-de-producao-de-ovos/20190326-113131-t740 Acesso em: 22 ago. 2021.

SILVA, I. J de O.; DE ABREU, P. G.; MAZZUCO, H. Manual de boas práticas para o bem-estar de galinhas poedeiras criadas livres de gaiola. Embrapa Suínos e Aves-Fôlder/Folheto/Cartilha (INFOTECA-E), 2020. Disponível em: https://ainfo.cnptia.embrapa.br/digital/bitstream/item/222488/1/Man-Rev6.pdf Acesso em: 01 ago. 2021.

I SALÃOO DE EXTENSÃO

DA UNIPAR
- Unipar 50 anos:

deven da educagato

27 de Outubro de 2021
5 AcNpg 


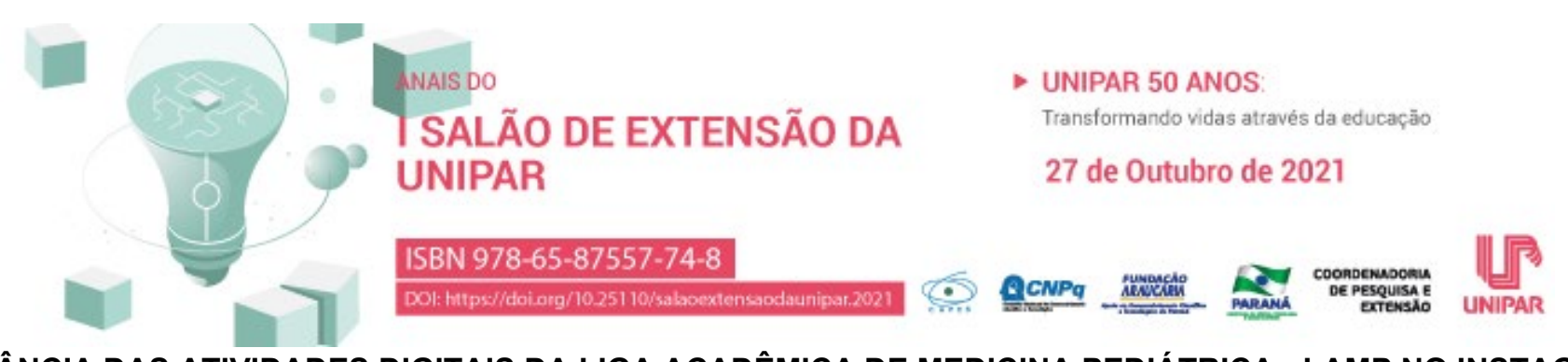

\title{
RELEVÂNCIA DAS ATIVIDADES DIGITAIS DA LIGA ACADÊMICA DE MEDICINA PEDIÁTRICA - LAMP NO INSTAGRAM
}

\author{
${ }^{1}$ LETICIA CASALLI COUTO, ${ }^{2}$ YASMIN NAVA SINHORIN, ${ }^{3}$ JAINE THAIS GABRIEL, ${ }^{4}$ KAREN RAMOS MARIN, ${ }^{5}$ JESSICA \\ ZANQUIS FERREIRA, ${ }^{6}$ VITORIA MARIA RAUBER MARCELINO, ${ }^{7}$ ISADORA GIACOMINO ALVES, ${ }^{8}$ JULIANA ROSA \\ BOAMORTE, ${ }^{9}$ MAYUMI REGINA ANDO,${ }^{10} \mathrm{GIOVANA} \mathrm{LUCACIN} \mathrm{FRANCA,}{ }^{11} \mathrm{KELSON}$ RUDI FERRARINI
}

${ }^{1}$ Acadêmica do Curso de Medicina da UNIPAR

${ }^{2}$ Acadêmica do Curso de Medicina da UNIPAR

${ }^{3}$ Acadêmica do Curso de Medicina da UNIPAR

${ }^{4}$ Acadêmica do Curso de Medicina da UNIPAR

${ }^{5}$ Acadêmica do Curso de Medicina da UNIPAR

${ }^{6}$ Acadêmica do Curso de Medicina da UNIPAR

${ }^{7}$ Acadêmica do Curso de Medicina da UNIPAR

${ }^{8}$ Acadêmica do Curso de Medicina da UNIPAR

${ }^{9}$ Acadêmica do Curso de Medicina da UNIPAR

${ }^{10}$ Acadêmica do Curso de Medicina da UNIPAR

${ }^{11}$ Docente da UNIPAR

Introdução: Ligas acadêmicas são associações civis e científicas livres, de duração indeterminada, sem fins lucrativos, com sede e foro na cidade da instituição de ensino que a abriga, possuem atividades fundamentais no ambiente universitário, a partir de ações extracurriculares que alcançam o acadêmico e a sociedade em geral (SILVA et al., 2015). Assim, a Liga Acadêmica de Medicina Pediátrica (LAMP) foi fundada em 30 de abril de 2018, apresentando por finalidades a ampliação de conhecimento dos ligantes no eixo da medicina pediátrica e desenvolvendo a vivência teórico-prática nessa área. Também promove ações de caráter social, como o compartilhamento de informações através da rede social Instagram, por meio de enquetes interativas e publicações autoexplicativas com base científica e que abrange temas da área pediátrica para o benefício da sociedade em geral. Objetivo: Abordar a relevância das atividades digitais da LAMP-UNIPAR, na rede social Instagram e descrever os resultados obtidos por meio de postagens na temática da especialização da liga.

Resultados: A página do instagram da LAMP foi criada em 12 de maio de 2019 e possui 444 seguidores e 48 publicações, além de um total de 1.830 curtidas em publicações, sendo em média, 23 curtidas por postagem. As postagens são referentes a temas básicos relacionados à puericultura, aleitamento materno, vacinas, introdução alimentar, crescimento infantil e também os mais complexos como desenvolvimento de doenças neonatais e pediátricas, como as doenças do TORCH. Além disso, são enfatizadas Campanhas Locais e Nacionais de Saúde, bem como dias comemorativos que englobam a vida das crianças como o Dia do Combate ao Abuso e Exploração Sexual Infantil. Ademais, contribui com o conhecimento de outras cidades e países, de acordo com os Insights da rede, conclui que $67,3 \%$ dos seus seguidores são de Umuarama, 2,6\% de Iporã, 1,9\% de Maringá, $1,9 \%$ de Cascavel e 1,6\% de Assis Chateaubriand, além de $0,3 \%$ de seguidores no Canadá.

Conclusão: Este projeto contribuiu com o conhecimento da população alcançada, em diversas localidades, resultando em um engajamento bilateral, beneficiando tanto a população leiga, como a progressão das redes sociais da LAMP. Dessa forma, o compartilhamento de assuntos voltados à área pediátrica, com conhecimentos básicos, informações que irão auxiliar na identificação de sinais e sintomas das patologias mais comuns na infância e na observação dos marcos do desenvolvimento infantil.

\section{Referências}

SILVA, J. H. S. da et al.. Implantação de uma Liga Acadêmica de Anatomia: Desafios e Consquistas. Revista Brasileira de Educação Médica, v. 39, n. 2, p. 310-315, 2015. Disponível em: https://doi.org/10.1590/1981-52712015v39n2e03012014. Acesso em 24 ago. 2021. 


\title{
8 . \\ INTERVENÇÕES PSICOLÓGICAS NO VÍNCULO MÃE-BEBÊ: UMA LEITURA PSICANALÍTICA
}

\author{
${ }^{1}$ MATEUS JOAO CORDEIRO SCHMOELLER DE LIMA, ${ }^{2}$ CLAUDIA ANTONIOLI REZENDE, ${ }^{3}$ RENATA DOS SANTOS DA \\ CUNHA, ${ }^{4}$ TAISE SIGNORINI
}

\author{
${ }^{1}$ Acadêmico do Curso de Psicologia da UNIPAR \\ ${ }^{2}$ Acadêmica do Curso de Psicologia da UNIPAR \\ ${ }^{3}$ Acadêmica do Curso de Psicologia da UNIPAR \\ ${ }^{4}$ Docente da UNIPAR
}

Introdução: Sabe-se que a relação vincular entre mãe-bebê é fundamental para a constituição psíquica do sujeito (NASIO, 2017), ou seja, é a partir dos acontecimentos ocorridos entre a mãe e seu filho que vai originar a estrutura subjetiva do rebento (CECHINATO, 2008). Desta forma, entender como essa relação está sendo estruturada no cotidiano, bem como se dá a apresentação a função materna e, consequentemente, a possível introdução da função paterna são essenciais para o bom andamento psíquico do bebê (NASIO, 2007). A primeira infância se revela em uma fase crucial para o desenvolvimento de aspectos subjetivos, acompanhar essa mãe/figura materna e possibilitar-Ihe intervenções psicológicas, de acordo com suas dificuldades, podem tornar a organização psíquica mais condizente e menos propícia a sofrimentos (DOR, 2011)

Objetivo: Observar a interação vincular entre mãe-bebê e proporcionar, a partir, a partir dessa observação, intervenções que possam efetivar o vínculo a ser estabelecido, visualizando a constituição subjetiva.

Resultados: Em função da pandemia, considerando que o público alvo da intervenção, é mais vulnerável, as intervenções ficaram prejudicadas, pois o público entendeu que seria arriscado se fazer presente para as intervenções. Assim, foram realizadas buscas e apanhados bibliográficos a respeito do tema previsto e estabelecidas as temáticas que serão trabalhadas assim que for possível os encontros presenciais. Evidenciando-se a importância desse tipo de trabalho a ser realizado a partir do vínculo mãe-bebê, pois essa interação afetiva deixa traços na estruturação da personalidade do rebento (NASIO, 2007), ou seja, o bebê é intensamente afetado pela mãe (relação materna) e isso balizará, posteriormente, as suas outras relações estabelecidas (DOR, 2011).

Conclusão: As intervenções psicológicas junta ao vínculo mãe-bebê são fortuitas para melhor qualidade de vida de ambos os parceiros dessa relação, pois pode-se afirmar que é o desenrolar dessa relação que estrutura psiquicamente o sujeito. Neste sentido, priorizar o entendimento de como essa relação está sendo estabelecida é importante para prever ações psicológicas, principalmente para essa mãe/figura materna.

\section{Referências}

CHECCHINATO, Durval. et al. A Clínica da Psicose. $2^{\mathrm{a}}$ ed. Campinas: Papirus, 2008.

DOR, Joel. O pai e sua função em psicanálise. Rio de Janeiro: Jorge Zahar, 2011.

NASIO, Juan David. Édipo: o complexo do qual nenhuma criança escapa. Rio de Janeiro: Jorge Zahar, 2007.

NASIO, Juan David. Lições sobre os 7 conceitos cruciais da Psicanálise. Rio de Janeiro: Jorge Zahar, 2017.

Anals Do

I SALÃO DE EXTENSÃO

DA UNIPAR

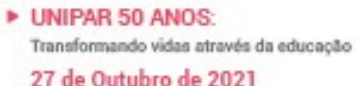

27 de Outubro de 2021

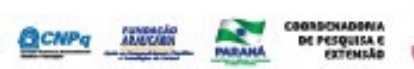

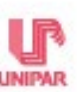




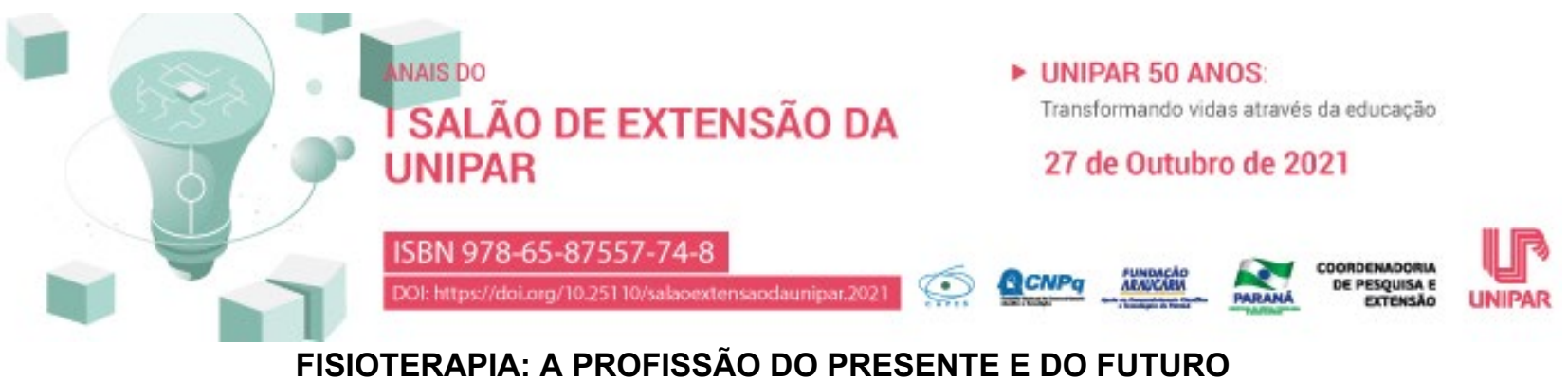

\author{
${ }^{1}$ CLARA EDUARdA MATtOS ROSSA, ${ }^{2}$ ANA PAULA BORTOLOTO SANTOS, ${ }^{3}$ ALINE FREDO, ${ }^{4}$ VANESSA GABRIELE \\ ENDLER, ${ }^{5}$ DORA DE CASTRO AGULHON SEGURA
}

\begin{abstract}
${ }^{1}$ Academica do Curso de Fisioterapia da Unipar
${ }^{2}$ Acadêmica do Curso de Fisioterapia da UNIPAR

${ }^{3}$ Acadêmica do Curso de Fisioterapia da UNIPAR

${ }^{4}$ Acadêmica do Curso de Fisioterapia da UNIPAR

${ }^{5}$ Docente da UNIPAR
\end{abstract}

Introdução: A fisioterapia é uma profissão considerada muito nova, com apenas 52 anos de regulamentação. Evoluiu de forma muito lenta entre as décadas de 1970 e 1980, mas com o crescente número de universidades, disponibilizando o curso de graduação, atingiu exponencial crescimento em meados do ano 2000. É considerada de suma importância a inserção deste profissional como membro da equipe multiprofissional que atua na área da saúde, nos âmbitos da prevenção e reabilitação (BISPO JÚNIOR, 2009).

Objetivos: Através de um projeto de extensão promover conhecimento sobre a profissionalização da fisioterapia.

Resultados: A fisioterapia compõe uma profissão da área da saúde que esteve estagnada por muitas décadas, com profissionais vinculados ao atendimento voltado somente à reabilitação após uma doença já instalada e evoluída. Os locais de atendimento se limitavam a clínicas, consultórios e centros de reabilitação, muitas vezes atendendo somente no modelo privado. Muito era ofertado em relação aos distúrbios musculoesqueléticos (MEYER; COSTA; GICO, 2006). Entretanto, após décadas de uma luta árdua, a profissão avançou de forma impressionante, sendo hoje, primordial e insubstituível, com profissionais em diferentes áreas de especialização, que compreende da prevenção à recuperação, na fisioterapia ortopédica, desportiva, cardiológica, respiratória, pediátrica, geriátrica, neurológica e dermatológica funcional, tanto em locais privados quanto públicos, vinculados ao sistema único de saúde. O fisioterapeuta está inserido em hospitais, clínicas, empresas, academias, escolas, sendo um campo promissor no mercado de trabalho. Muitos são os procedimentos executados por este profissional, englobando atendimentos na fisioterapia aquática, equoterapia, osteopatia, microfisioterapia, acupuntura, terapia manual, método pilates, entre outros diversos métodos (SILVA; ROS, 2007).

Conclusão: Concluiu-se que o projeto em questão é crucial para a divulgação da fisioterapia, em todos seus aspectos, facilitando a população quanto a procura do auxílio de atendimento, bem como a escolha certeira da profissão quando em época estudantil.

\section{Referências}

BISPO JÚNIOR, J. P. Formação em fisioterapia no Brasil: Reflexões sobre a expansão do ensino e os modelos de formação. História, Ciências e Saúde, Manguinhos, v. 16, n. 3, p. 655-668, 2009.

MEYER, P. F.; COSTA, I. C. C.; GICO, V. V. Ciências sociais e fisioterapia: Uma aproximação possível. História, Ciênciase Saúde, Manguinhos, v. 13, n. 4, p. 877-890, 2006.

SILVA, D. J.; ROS, M. A. Inserção de profissionais de fisioterapia na equipe de saúde da família e Sistema Único de Saúde: Desafios na formação. Ciência \& Saúde Coletiva, Rio de Janeiro, v. 12, n. 6, p. 1673-1681, 2007.

\section{ANGals Do \\ I SALÃO DE EXTENSÃO}

DA UNIPAB

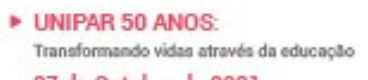

27 de Outubro de 2021

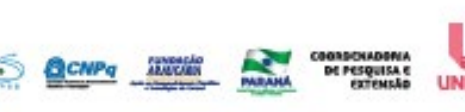




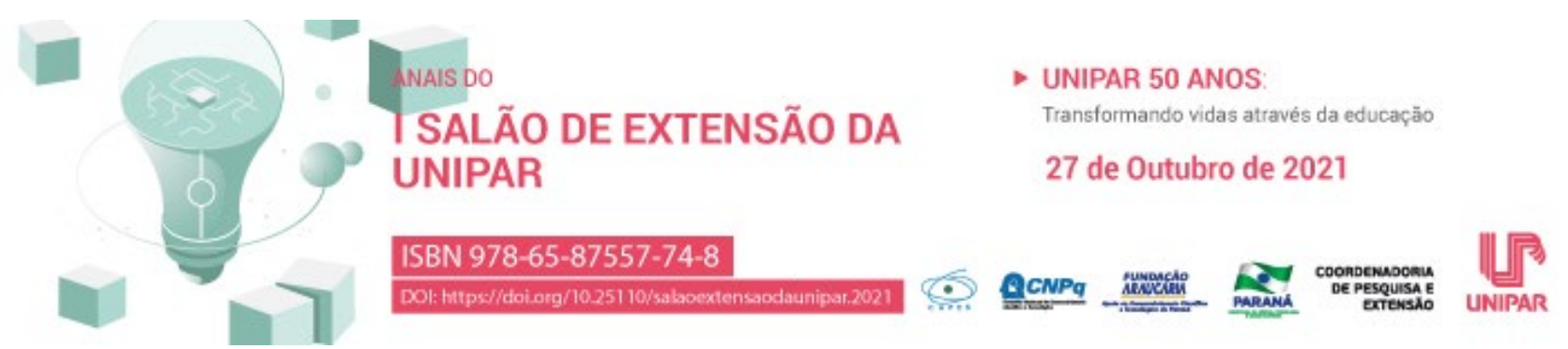

\title{
AVALIAÇÃO DO CONSUMO DE SAL, AÇÚCAR E ÓLEO E SEU IMPACTO A SAÚDE
}

\author{
${ }^{1}$ BRUNA GAZETTA PEREIRA, ${ }^{2}$ KASSIELEN APARECIDA COELHO MARYNOWSKI DA SILVA, ${ }^{3}$ MARTA ANDREIA CUSTÓDIO \\ JORGE, ${ }^{4}$ DEBORA TIEMI IGARASHI DOS SANTOS, ${ }^{5}$ MONICA DO VALE ASSIS GARCIA SANTINI, ${ }^{6}$ LIDIANE NUNES \\ BARBOSA
}

\author{
${ }^{1}$ Discente de Nutrição e do Programa de Iniciação a Extensão da Unipar \\ ${ }^{2}$ Acadêmica do Curso de Nutrição e do Programa de Iniciação a Extensão da Unipar \\ ${ }^{3}$ Acadêmica do Curso de Nutrição e do Programa de Iniciação a Extensão da Unipar \\ ${ }^{4}$ Acadêmica do Curso de Nutrição e bolsista do Programa de Iniciação a Extensão da Unipar \\ ${ }^{5}$ Responsável técnica da Clínica de Nutrição da Unipar \\ ${ }^{6}$ Docente da UNIPAR
}

Introdução: Nos dias de hoje, o consumo de alimentos com alto teor de sal, açúcar e gorduras vem crescendo cada vez mais e consequentemente os riscos à saúde também tem aumentado. Esses ingredientes são usados para temperar e melhorar o sabor das comidas, mas é necessário ser usado com moderação, pois podem causar e agravar algumas doenças, como, insuficiência renal, AVC, hipertensão arterial, doenças cardíacas, entupimento de veias do coração, obesidade e diabetes (MILL et al., ano 2019). O açúcar é uma fonte de energia, mas seu consumo não deve ser exagerado. O sal é um ingrediente indispensável na dieta, desde que usado com moderação. Já o óleo, tem uma grande importância quando são ricos em ácidos graxos insaturados e pobre em ácidos graxos saturados, podendo ser um fornecedor de energia (TORREZAN; NEVES; REIS, 2017).

Objetivo: Avaliar o consumo de sal, óleo e açúcar dos pacientes da Clínica de Nutrição da Unipar e os impactos desse consumo à saúde.

Resultados: Foi avaliado o consumo de sal, óleo e açúcar de pacientes atendidos na Clínica Escola de Nutrição no período de julho de 2020 a julho de 2021. Para isso, foram analisadas 65 anamneses e os dados foram exibidos em consumo diário por pessoa (g ou mL/ dia). Segundo a Organização Mundial da Saúde (OMS) o consumo recomendado por dia de sal é de $5 \mathrm{~g}, 25 \mathrm{~g}$ de açúcar e de $16 \mathrm{~mL}$ óleo. De acordo com os resultados, $27,68 \%$ dos pacientes da clínica tiveram um consumo elevado de óleo, cerca de $52,3 \%$ estão dentro da recomendação indicada e $20 \%$ não souberam responder quantidades exatas. Sobre o consumo do sal $27,69 \%$ dos pacientes estão consumindo uma quantidade acima do recomendado, $49,2 \%$ estão dentro das recomendações e $23 \%$ não souberam responder. E por fim, 32,3\% consomem mais açúcar que o recomendado, $46,1 \%$ estão dentro das recomendações e $21,5 \%$ não souberam responder. O consumo da população brasileira vem diminuindo nos últimos anos, mas ainda sim os números são altos. De acordo com o Instituto Brasileiro de Geografia e Estatística- IBGE 53,5\% da população ingere sódio acima do limite (IBGE, 2021). Esse consumo exagerado desses alimentos podem trazer impactos negativos à saúde, como, insuficiência renal, AVC, hipertensão arterial, doenças cardíacas, entupimento de veias do coração, obesidade e diabetes (MILL et al., ano 2019). Considerando o consumo observado nas anamneses, e os impactos negativos que este consumo em pode gerar à saúde, se faz necessária novas intervenções, bem como a inserção de condutas nutricionais que possibilitem a redução do uso de sal, óleo e açúcar na rotina destes pacientes, com a indicação de outras alternativas, como o uso de temperos naturais.

Conclusão: Embora tenhamos uma considerável porcentagem de indivíduos que apresentam bons hábitos alimentares associados ao uso desses três ingredientes, é notório que a orientação por parte dos acadêmicos para com os pacientes devem continuar, para que estes indivíduos tenha informações qualificadas a respeito dos bons hábitos de vida e o impacto que eles geram em sua saúde.

\section{Referências}

IBGE. O consumo de gorduras saturadas cai em dez anos, mas a ingestão de açúcar e sal ainda é alta. Disponível em: https://agenciadenoticias.ibge.gov.br/agencia-noticias/2012-agencia-de-noticias/noticias/28647-consumo-de-gorduras-saturadascai-em-dez-anos-mas-ingestao-de-acucar-e-sal-ainda-e-alta. Acesso em: 06 ago. 2021.

MILL, José Geraldo et al. Estimativa do consumo de sal pela população brasileira: resultado da Pesquisa Nacional de Saúde 2013. Revista Brasileira de Epidemiologia, v. 22, p. E190009. SUPL. 2, 2019.

OMS. Organização Mundial de Saúde. Disponível em: https://www.imparcial.com.br/noticias/acucar-oms-recomenda-consumodiario-de-apenas-25-g,35932. Acesso em: 06 ago. 2021

TORREZAN, Renata; NEVES, Laisa Stefani da Silva; REIS, Carlla Cristhina de Oliveira Pedroza Bindi. Orientações para a redução do consumo de sódio, açúcar e gorduras. Embrapa Agroindústria de Alimentos-Documentos (INFOTECA-E), 2017. 
- unIPAR 50 anos:

I SALAOO DE EXTENSÃO Transformando vidas atravies da educaģso

DA UNIPAR 


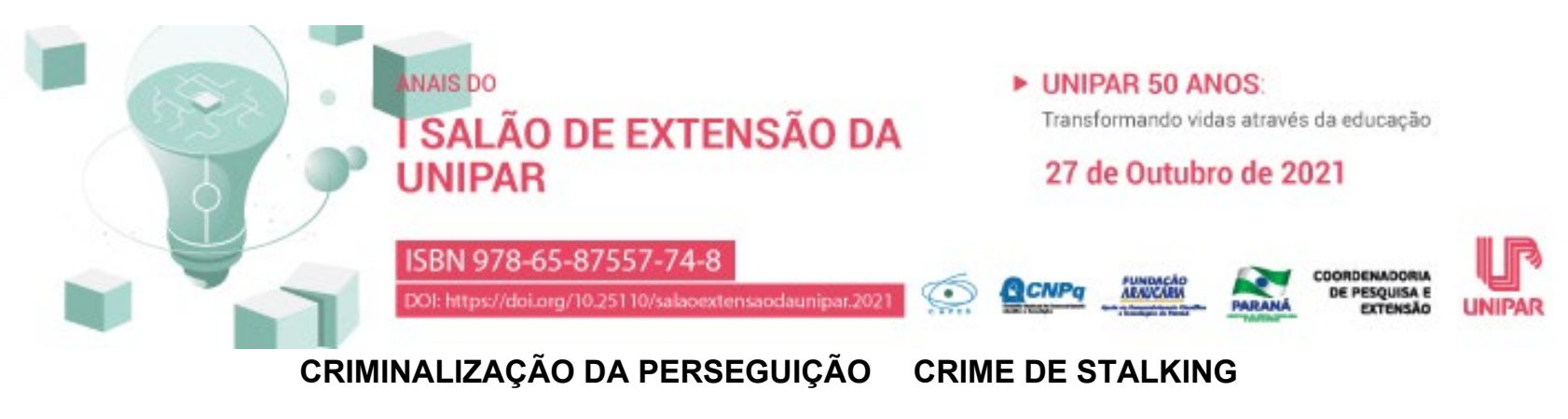

\author{
${ }^{1}$ IVANILDA VAZ BATISTA DE OLIVEIRA, ${ }^{2}$ MARICELES CRISTHINA FECCHIO
}

${ }^{1}$ Acadêmica do curso de Direito da UNIPAR

${ }^{2}$ Docente da UNIPAR

Introdução: A prática da perseguição tem ocorrido não somente por meio físico, mas também, e de forma crescente, em ambiente virtual, e, até mesmo com o auxílio de terceiros, prejudicando assim a vida das vítimas bem como de seus familiares, logo é necessário que haja a devida sanção para os que cometem tal crime.

Objetivo: Apresentar os subsídios de desenvolvimento do novo tipo penal denominado como crime de perseguição ou crime de stalking, assim como a normativa que regulamenta a matéria em âmbito penal como forma de tratamento e prevenção da disseminação da prática desse tipo de crime.

Desenvolvimento: O crime de perseguição também conhecido como crime de stalking, antes de março de 2021 era classificado apenas como contravenção penal, agora com a instituição da prática da perseguição como crime o art.147-A do Código Penal dispõe que práticas reiteradas de atos de perseguição que confiram riscos psíquicos ou físicos ou ainda de alguma forma restrinja a liberdade da pessoa, estão sujeitos à pena de seis meses a dois anos e multa (Brasil 2021). Os atos que visam a perseguição da vítima, seja de forma física ou psicológica, poderão por meio de representação, levar o agente a responder em esfera penal, por tratar-se de um crime de ação pública condicionada. Como é cada vez mais difícil viver no anonimato, tanto na vida, quanto na rede de convivência, bem como na rotina, as pessoas se tornam alvos diretos e fáceis para a prática do crime de perseguição, pois estão cada vez mais expostas. São fatos notórios e diários, notícias das consequências do crime de perseguição em redes sociais, que muitas vezes se dá não de forma direta entre o agente e a vítima, mas por intermédio de outras pessoas, pela rede de disseminação de notícias falsas ou impactantes que acabam abalando de forma irreparável a vida de quem é vítima, portanto, tal prática poderá ser responsabilizada como cometida em concurso de pessoas (M.P/PR 2021). Dentre os elementos que instigam a perseguição nas suas mais variadas formas, podem se originar por questões pessoais, por pessoas alheias ao convívio da vítima, pelos denominados stalkers das redes, ou ainda, por pessoas que de alguma forma tentam chamar a atenção da vítima.

Considerações Finais: Assim sendo, foi relevante a criminalização da prática dos atos de perseguição, vez que gera maior conforto e segurança às vítimas e acaba por inibir e impedir que vivam à margem da lei àqueles que normalizam tal prática.

\title{
Referências
}

BRASIL. Lei $n^{\circ}$ 14.132, de março de 2021. Disponível em: < http://www.planalto.gov.br/ccivil_03/_ato20042006/2006/lei//11340.htm>. Acesso em: 14 ago. 2021.

Lei que tipifica a conduta de perseguição (stalking) é sancionada. Ministério Público do Paraná. 2021. Disponível em: https//direito.mppr.br/2021/04/172/Lei-que-tipifica-a-conduta-de-perseguicao-stalking-e-sancionada.html\#. Acesso em: 10 ago. 2021.

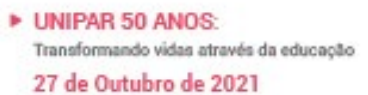

27 de Outubro de 2021

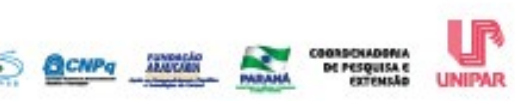




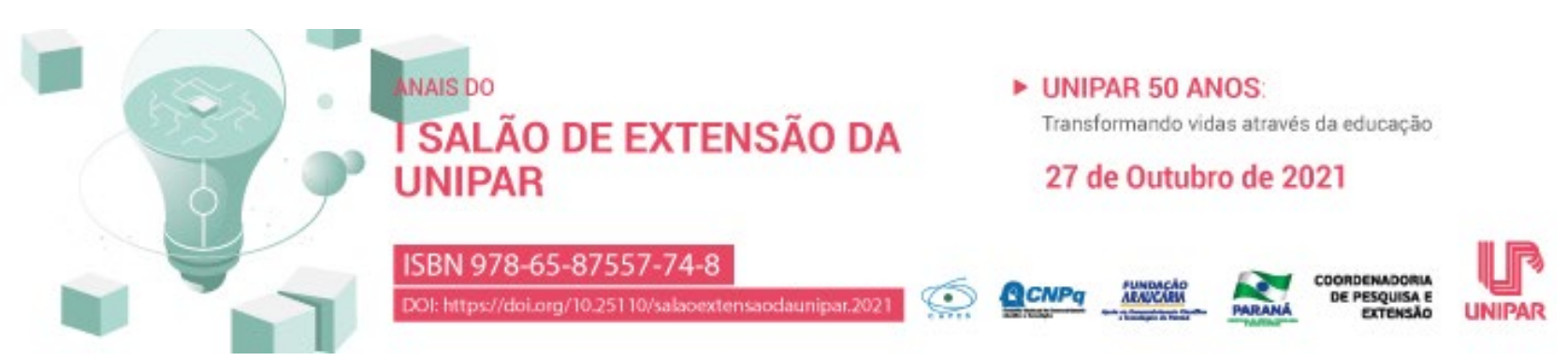

ABUSO SEXUAL DE CRIANÇAS E ADOLESCENTES

\author{
${ }^{1}$ BEATRIZ PAIXAO DO CARMO , 2LUCAS VALENTIN GIROTTO, ${ }^{3}$ MARICELES CRISTHINA FECCHIO
}

\author{
${ }^{1}$ Acadêmica do PEX/UNIPAR \\ ${ }^{2}$ Acadêmico do PEX/UNIPAR \\ ${ }^{3}$ Docente da UNIPAR
}

Introdução:É de conhecimento geral que o abuso sexual é uma forma ampla para categorizar atos de violação sexual a que não há consentimento da outra parte. Segundo dados do Ministério da Saúde, a maior parte das vitimas são crianças e adolescentes. Objetivo:Este trabalho visa orientar e identificar sinais de violência sexual contra crianças e adolescentes, crime este de difícil suspeita e complicada confirmação.

Resultados:A Violência sexual contra crianças e adolescentes possui variadas características que se reveste de uma complexidade e gravidade devastadoras às vítimas. O abuso sexual é entendido como toda ação em que se utiliza da criança para fins sexuais ou para estimulação sexual do agente ou do terceiro. Os levantamentos do Sistema de Informações de Agravos de Notificação, mostram que há uma prevalência absoluta de meninas vitimadas, representando o percentual de $85,3 \%$ e $14,7 \%$ restantes são de meninos, notificações contra pessoas de 0 a 19 anos, acumuladas pela pasta entre 2013 e 2017. Com a criação da Lei 8.069/90 Estatuto da Criança e do Adolescente, foi estabelecido um conjunto de normas que tem como objetivo a proteção integral da criança e do adolescente. Pesquisas realizadas em 2011 ao primeiro semestre de 2019, registram mais de 200 mil denúncias de violência sexual contra crianças e adolescentes no Disque 100,e afirmam que apenas $10 \%$ dos casos são notificados às autoridades. Com a pandemia o isolamento social passa a ser um fator de risco para as crianças, e as relações de poder do autor do crime e a vítima contribuem para silenciar os casos de abuso sexual com o aumento e as sub notificações. É dever de todos velar pela dignidade da criança e do adolescente, pondo-o salvo de qualquer tratamento desumano, violento, aterrorizante, vexatório ou constrangedor (FULLER,2018). Os instrumentos aptos a receber denuncias de abuso sexual praticado contra criança e adolescente, são: o Disque 100, o Conselho Tutelar, o Ministério Público ou os canais da Polícia. É importante fazer a denúncia. O registro é para iniciar uma investigação de que se houve ou não o abuso sexual.

Conclusão:Conforme o exposto, verifica-se que, apesar dos canais existentes para que seja feita a denúncia de abuso sexual de crianças e adolescentes, muitos ainda há que ser feito, vez que o aumento do índice de casos é extremamente significativo.

\title{
Referências
}

BRASIL.Decreto Lei $\mathbf{n}^{\circ}$ 2.848, de 07 de dezembro de 1940.Código Penal. Disponível em: https://www.jusbrasil.com.br/topicos/10612010/artigo-213-do-decreto-lei-n-2848-de-07-de-dezembro-de-1940. Acesso em:10 ago. 2021.

BRASIL.Lei $n^{\circ}$ 8.069, de 13 de julho de 1990.Estatuto da Criança e do Adolescente.Código Civil. Disponível em: http://www.planalto.gov.br/ccivil_03/leis//8069.htm. Acesso em: 10 ago. 2021.

BRASIL. Boletim Epidemiológico, julho 2018. Ministério da Saúde. Disponível em: https://antigo.saude.gov.br/images/pdf/2018/junho/25/2018-024.pdf. Acesso: 10 ago. 2021.

GOV.BR.Sinan, Sistema de Informação de Agravos de Notificação. Ministério Da Saúde.Brasília, 2017. Disponível em:https://portalsinan.saude.gov.br/. Acesso:10 ago. 2021.

FULLER.P.H.A.. Estatuto da Criança e do Adolescente Comentado - Ed.2018. Revista dos Tribunais, 2018.

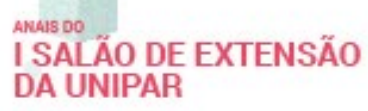

I SALÃO DE EXTENSÃO DA UNIPAR

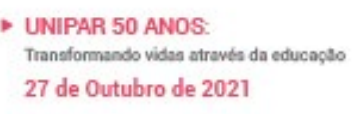

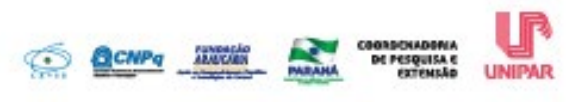




\section{0}

\section{${ }^{1}$ MARIANA FELIPE MARQUES, ${ }^{2}$ KATIA BIAGIO FONTES}

${ }^{1}$ Discente do Curso de Enfermagem na universidade Paranaense- Unipar ${ }^{2}$ Docente da UNIPAR

Introdução: A assistência ao período gestacional, conhecida como pré-natal, é oferecida pelo sistema único de saúde (SUS) e toda gestante tem o direito por lei de ser atendida em suas consultas. Ela constitui-se em um conjunto de ações que são simultaneamente preventivas, promotoras de saúde, diagnósticas e curativas, visando o bom desfecho da gestação para a mulher e seu filho(s) ( LEAL et al., 2020).

Objetivo: Identificar na literatura científica os desafios encontrados e as condutas necessárias para a qualidade da assistência no pré-natal.

Resultados: Estudos demonstraram falhas na atenção pré-natal, evidenciadas por questões como dificuldades no acesso ao atendimento, início das consultas após 12 semanas de gestação, realização incompleta dos procedimentos recomendados, solicitação inadequada de exames laboratoriais e de imagem e insuficiência de informações acerca dos direitos das gestantes e familiares (SEHNEM et al., 2019). Esses fatores acabam originando muitos desafios à implantação de ações qualificadas ao cuidado gestacional. Para uma excelência nos cuidados ao pré-natal, é preciso iniciar o pré-natal o mais precocemente possível com a realização da $1^{a}$ consulta, acolher a mulher e abordar os seus medos, ideias e expectativas, ou seja, realizar a anamnese, cadastrar a gestante no sistema de informação, preencher o cartão da gestante. Como também, efetuar avaliação nutricional, exame físico geral e específico, solicitação de exames e explicar a rotina do acompanhamento pré-natal. (MINISTÉRIO DA SAÚDE, 2016). Portanto, a gestante precisa se sentir acolhida, confortável e informada, pois o período gestacional representa no universo familiar, um processo de profundas transformações, aprendizagens, expectativas, anseios e inseguranças perante o que será vivenciado, incluindo a aquisição de novos papéis e responsabilidades (SEHNEM et al., 2019).

Conclusão: Pode-se concluir que os desafios para uma assistência qualificada no pré-natal compreenderam início tardio, abandono de procedimentos, falta de informações, requisição inadequada de exames. Contudo, para uma boa assistência ao período gestacional é necessário que seja realizado enfermeiro e pelo médico de forma humanizada, qualificada e esclarecedora.

\section{Referências}

MINISTÉRIO DA SAÚDE. Protocolos da atenção básica: Saúde das mulheres. Brasília/DF, 1a edição, n. 04, abril, 2016. Disponível em: https://bvsms.saude.gov.br/bvs/publicacoes/protocolos_atencao_basica_saude_mulheres.pdf. Acesso em: 30 ag. 2021.

LEAL, Maria et al. Assistência pré-natal na rede pública do Brasil. Revista de saúde pública, v.54, n.20, janeiro, 2020. Disponivel em: https://www.scielosp.org/article/rsp/2020.v54/08/pt/\# . Acesso em: 30 ag. 2021.

SEHNEM, Graciela et al. Consulta de pré-natal na atenção primária à saúde: gragilidades e potencialidades da intervenção de enfermeiros brasileiros. Revista de Enfermagem Referência v.5, n. 23, junho, 2021. Disponível em: https://www.redalyc.org/jatsRepo/3882/388263105017/388263105017.pdf . Acesso em: 30 ag. 2021.
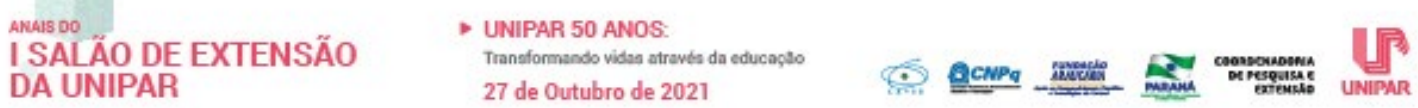


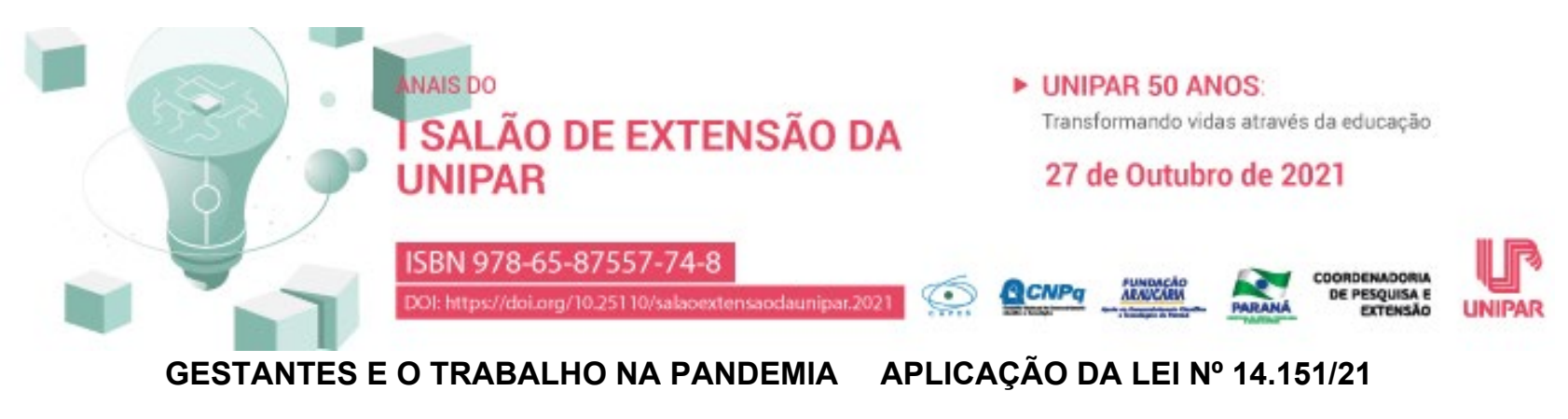

\author{
${ }^{1}$ PATRICIA CARNEIRO PERAL MORO, ${ }^{2}$ VALERIA BONONI GONCALVES DE SOUZA
}

${ }^{1}$ Discente da UNIPAR

${ }^{2}$ Docente da UNIPAR

Introdução: Com o novo normal que assolou o mundo no ano de 2020, por consequência do coronavírus, repercutiu nas relações de trabalho.A nova legislação trouxe à baila que a funcionária gestante deve permanecer em trabalho remoto, enquanto perdurar o estado de calamidade pública.

Objetivo: Demonstrar a repercussão nas relações de emprego após a aprovação da Lei 14.151/21.

Resultados: A Lei 14.151/21 aprovada no mês de maio de 2021 determina que todas as gestantes deverão exercer seus trabalhos pela modalidade de teletrabalho, ou seja, homeoffice, sem prejuízo salarial, com intuito de assegurar a saúde da mãe e do feto, enquanto perdurar a emergência de saúde pública. A questão da prevenção está vinculada a noção de dignidade da pessoa humana, a valorização do trabalho e ao direito à saúde (BELMONTE, 2020). Ocorre que a lei possui apenas um artigo e um parágrafo, não fornecendo opção ao empregador, a não ser afastar a gestante do ambiente de trabalho, independente se a própria gestante quer ou não ser afastada, atendendo ao princípio da irrenunciabilidade de direitos trabalhistas, já que trata de obrigação e não de uma faculdade. Desta forma, surgiram dúvidas sobre a aplicação da lei, pois há empregos em que não há possibilidade de ser executado de forma remota. Então caberá à hermenêutica do direito ocupar-se de como se dará essa aplicação. A fim de combater e regulamentar o texto da Lei 14.151/21, tramita no plenário o Projeto de Lei 2.058/21, que prevê, no caso do trabalho exercido pela gestante, quando não puder ser efetuado de forma remota, o empregador poderá suspender 0 contrato de trabalho e caberá aos programas governamentais o pagamento do salário. De igual modo, também prevê que a gestante já vacinada contra o coronavírus poderá exercer sua atividade laboral normalmente.

Conclusão: Embora as medidas adotadas pelo Governo sejam controversas, é certo que elas refletem sua preocupação com a manutenção dos empregos, geração de renda e a diminuição em uma possível discriminação na contratação do sexo feminino.

\title{
Referências
}

BELMONTE, Alexandre Agra. O Direito do trabalho na crise da COVID-19. Salvador: JusPodivm, 2020.

JANARY, Júnior. Projeto disciplina afastamento de empregadas grávidas do trabalho. Brasília, 07 jun. 2021. Disponível em: https://www.camara.leg.br/noticias/782432-projeto-disciplina-afastamento-de-empregadas-gravidas-do-trabalho. Acesso em: 15 ago. 2021

BRASIL. Lei $n$. 14.151 de 12 de maio de 2021. Dispõe sobre o afastamento da empregada gestante das atividades de trabalho presencial durante a emergência de saúde pública de importância nacional decorrente do novo coronavírus. Disponível em: http://www.planalto.gov.br/ccivil_03/_ato2019-2022/2021/lei/L14151.htm. Acesso em 25 de ago. de 2021.

\section{SALÃO DE EXTENSÃO} DA UNIPAR

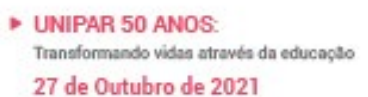

Transformando vides atravts
27 de Outubro de 2021

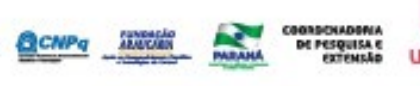




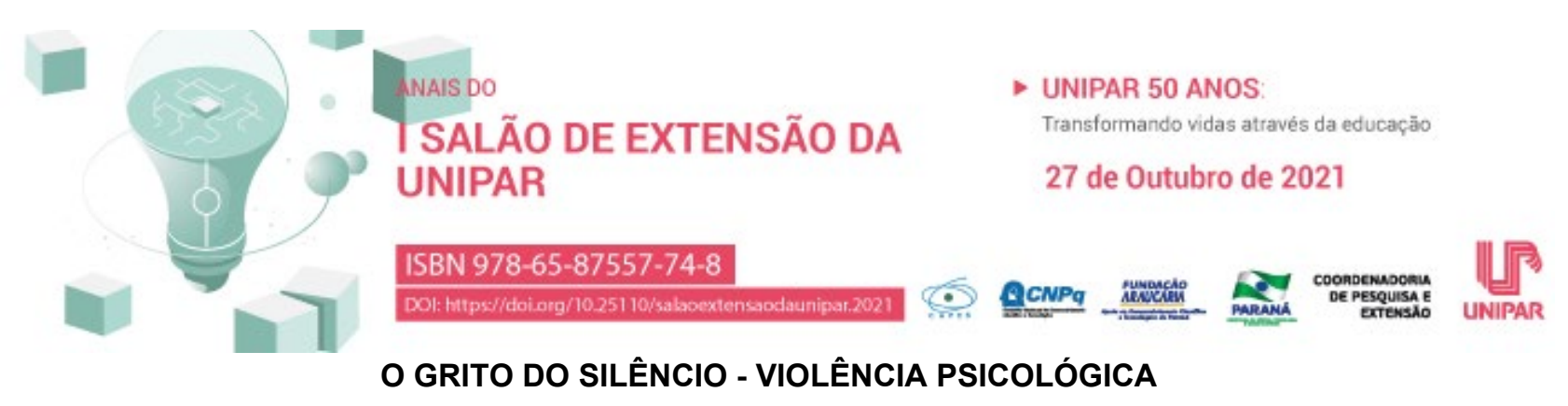

\title{
${ }^{1}$ PATRICIA CARNEIRO PERAL MORO, ${ }^{2}$ MARICELES CRISTHINA FECCHIO, ${ }^{3}$ MIRIAM FECCHIO CHUEIRI
}

\author{
${ }^{1}$ Discente da UNIPAR \\ ${ }^{2}$ Docente da UNIPAR \\ ${ }^{3}$ Docente da UNIPAR
}

Introdução: A sociedade evolui a cada dia e com ela os tipos de crime que interferem no direito do outro. É necessário que haja leis que acompanhem tal evolução.

Objetivo: Demonstrar a aplicação da Lei 14.188/21 no tocante à violência psicológica.

Resultados: A violência psicológica é uma forma que o agressor encontra para fragilizar a mulher por meio de palavras ou atitudes. As ameaças representam uma forma comum de violência psicológica, que restringe a autonomia da vontade da vítima. Essa violência pode se caracterizar da forma mais sutil à mais grave, conforme preceitua Sirvinskas Merece, no entanto, especial destaque a violência psicológica. Pode-se notar que o rol é extenso e qualquer atitude, por menor que seja, poderá caracterizar essa modalidade de violência, especialmente quando o marido ridicularizar a mulher por brincadeira, por exemplo (pg. 112). Com números cada vez maiores de casos de violência doméstica, recentemente foi sancionada a Lei 14.188/21 que tipifica o crime de violência psicológica contra a mulher, com previsão no art. $7^{\circ}$ da Lei Maria da Penha e agora também expresso no art. $147 \quad$ B do Código Penal, que regula: Causar dano emocional à mulher que a prejudique e perturbe seu pleno desenvolvimento ou que vise a degradar ou a controlar suas ações, comportamentos, crenças e decisões, mediante ameaça, constrangimento, humilhação, manipulação, isolamento, chantagem, ridicularizarão, limitação do direito de ir e vir ou qualquer outro meio que cause prejuízo à sua saúde psicológica e autodeterminação . Observa-se, que o legislador, preocupado com as consequências que essa violência causa na vida da mulher, estabeleceu que o agressor poderá receber pena de prisão de seis meses a dois anos, se comprovado o ato delitivo. A nova Lei também alterou a modalidade da pena do crime de lesão corporal simples praticada contra a mulher, que passou a ser de um a quatro anos de prisão, além de criar o Programa Sinal Vermelho que possibilita à vítima que esteja sob perigo faça um $X$ em uma das mãos, na cor vermelha, que representará uma denúncia de violência doméstica e poderá mostrá-las a agentes de órgãos públicos e alguns da rede privada para que sejam tomadas as providências cabíveis.

Conclusão: Contudo, o regimento é recente e muitas pessoas/mulheres ainda não sabem da nova tipificação. Então caberá as políticas públicas informar a população, a fim de cessar todas as formas de violências praticadas contra o sexo feminino.

\section{Referências}

SIRVINSKAS, Luis Paulo. SIRVINSKAS, Luis Paulo. Aspectos polêmicos sobre a Lei n. ${ }^{0} 11.340$, de 7 de agosto de 2006, que cria mecanismos para coibir a violência doméstica e familiar contra a mulher. Revista Jurídica, ano $55, n^{\circ}{ }^{\circ} 351$, Porto Alegre: Nota Dez/Fonte do Direito, p. 107/129, jan. 2007, p. 112.

Planalto. Decreto-lei $n^{\circ} 2.848$, de 7 de dezembro de 1940. Disponível em: http://www.planalto.gov.br/ccivil_03/DecretoLei/Del2848.htm. Acesso em: 18 ago. 2021.

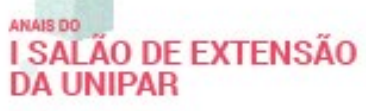

I SALÃO DE EXTENSÃO DA UNIPAR

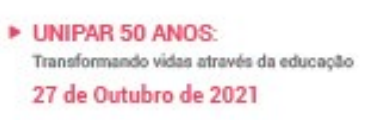

27 de Outubro de 2021

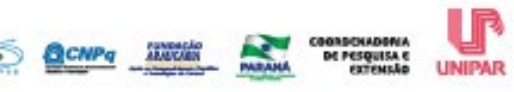




\title{
ASSISTÊNCIA À MULHER EM SITUAÇÃO DE VIOLÊNCIA DOMÉSTICA E FAMILIAR COMO BUSCA DA PREVENÇÃO DE FEMINICÍDIO
}

\author{
${ }^{1}$ BEATRIZ SARTORI DOS SANTOS, ${ }^{2}$ IVANILDA VAZ BATISTA DE OLIVEIRA, ${ }^{3}$ MARICELES CRISTHINA FECCHIO
}

\author{
${ }^{1}$ Acadêmica do PEX/UNIPAR \\ ${ }^{2}$ Acadêmica do PEX/UNIPAR \\ ${ }^{3}$ Docente da UNIPAR
}

Introdução: Usualmente, nos crimes de feminicídio verifica-se o histórico de agressões sofridas pelas vítimas, que normalmente ocorrem em um ciclo dividido em três fases, sendo elas: aumento de tensão, o ataque violento e lua de mel. Portanto, é necessário romper este ciclo de agressão para assim evitar consequências maiores.

Objetivo: Analisar as medidas de assistência à mulher em situação de violência doméstica previstas na Lei 11.340/2006, tendo como foco a sua atuação na busca da prevenção de feminicídio.

Resultados: No ciclo de violência, constata-se que com o transcorrer do tempo, os intervalos entre uma agressão e outra se tornam cada vez menores, sendo que em alguns casos somente cessam com o feminicídio. Essa foi a realidade de 1.350, mulheres no ano de 2020, no Brasil, de acordo com dados do Anuário Brasileiro de Segurança Pública (FÓRUM BRASILEIRO DE SEGURANÇA PÚBLICA, 2021). Nesse contexto, a Lei 11.340/2006 foi criada visando a proteção da vítima de violência doméstica e familiar, prevendo mecanismos para reprimir qualquer tipo de violência. Dentre as principais medidas protetivas, destacam-se o afastamento do agressor do lar, ou local de convivência com a vítima; proibição de contato, por qualquer meio de comunicação; restrição ou suspensão de visitas aos filhos; prestação de alimentos provisórios e o comparecimento do agressor a programas de recuperação (BRASIL, 2006). Além disso, a legislação ofertou instrumentos para proporcionar proteção à vítima e para garantir assistência social, bem como resguardar seus direitos patrimoniais e familiares. Nesse sentido, o artigo $9^{\circ}$ da Lei 11.340/2006 determinou que as principais portas de entrada para assistência às vítimas em situação de violência são: as unidades de saúde, as unidades de assistência social e a polícia. Desse modo, a eficácia do combate e prevenção da violência de gênero depende de uma boa articulação entre o Poder Judiciário e os serviços de atendimento à vítima, devendo a mulher ofendida ser devidamente orientada sobre seus direitos e os procedimentos, sejam eles judiciais ou não, para em seguida a encaminharem para a instituição condizente com o caso (MELLO; PAIVA, 2020).

Conclusão: Destarte, para a efetivação da assistência à mulher vítima de violência doméstica, deve haver um canal aberto das instituições que compõem o sistema de justiça com as áreas de saúde e serviço social, atuando de forma integrada e acolhedora.

\section{Referências}

BRASIL. Lei $\mathbf{n}^{\circ}$ 11.340, de 7 de agosto de 2006. Brasília, 2015. Disponível em: < http://www.planalto.gov.br/ccivil_03/_ato20042006/2006/lei/l11340.htm>. Acesso em: 12 ago. 2021.

FÓRUM BRASILEIRO DE SEGURANÇA PÚBLICA. Anuário Brasileiro de Segurança Pública Atualizado em 15.07.2021. São Paulo: Fórum Brasileiro de Segurança Pública, 2021. Disponível em: < https://forumseguranca.org.br/wpcontent/uploads/2021/07/anuario-2021-completo-v6-bx.pdf >. Acesso em: 14 ago. 2019.

MELLO, Adriana Ramos de; PAIVA, Lívia de Meira Lima. Lei Maria da Penha na Prática. Revista dos Tribunais. 2020.

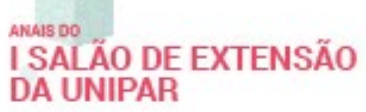

DA UNIPAR

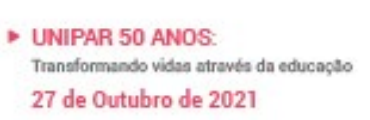

Transformando vides atravis da educagto

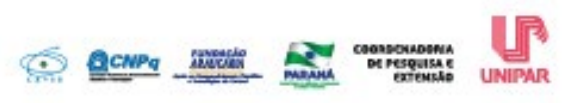




\title{
28
}

\author{
${ }^{1}$ Taiane Aparecida Ribeiro Nepomoceno, ${ }^{2}$ IRENE CARNIATTO
}

${ }^{1}$ Doutoranda em Desenvolvimento Rural Sustentável/Unioeste

${ }^{2}$ Pesquisadora e docente da Universidade Estadual do Oeste do Paraná. Doutora em Ciências Florestais pela UFPR.

Introdução: O tema das mudanças climáticas se tornou uma constante, quer nos espaços acadêmicos, meios de comunicação, debates políticos ou mesmo nas conversas particulares, especialmente, quando se pensa nos desastres inerentes ao meio ambiente. Contudo, a maioria dessas discussões desconsideram o impacto social e a sociedade continua a compreender esses processos como fenômenos naturais, desconsiderando o contexto econômico predatório, que construiu tais externalidades (GAUDINO; CARTEA; PÉREZ, 2020). Nesse sentido, a educação e a comunicação ambiental passam a ser decisivos, para evitar a construção de ideias fragmentadas e errôneas.

Objetivo: Refletir sobre os principais desafios da Educação Ambiental na emergência climática, no século XXI.

Resultados: $O$ modelo capitalista vigente visa a obtenção de lucro e não considera a capacidade de resiliência do planeta. Nesse sentido, revisitar o papel da Educação Ambiental é condição indispensável para a comunicação da emergência climática que assola o mundo. Uma tarefa proposta à Educação Ambiental diz respeito à reorientação prática dos currículos, principalmente sobre o esclarecimento do cenário em que as mudanças climáticas estão colocadas. As informações midiáticas lançam os danos para o futuro. Isso, acaba por evidenciar que ainda há tempo hábil para iniciar as mudanças atitudinais. E não há! (CARTEA, 2013). Os principais desafios da Educação Ambiental na emergência climática, relacionam-se com a comunicação para a tomada de decisões responsáveis, bem informadas; evidenciando os impactos, mas também soluções e estratégias; utilização de canais confiáveis de informação, a fim de que dados e conceitos não sejam distorcidos; levando em consideração o contexto social das práticas ambientais e a valorização dos envolvidos (CARIDE; CARTEA, 2020). Partindo da ideia de que todo processo representa a (des)construção de saberes, as noções acerca da emergência climática resultam de um conjunto de fatores, elaborados ao longo da vida. Assim, defende-se uma Educação Ambiental holística, permanente e participativa.

Conclusão: A tarefa da Educação Ambiental está no processo de reaprender a aprender, a todo instante, individual ou coletivamente. O desafio, hoje, em termo nacionais é a disrupção ocorrida na Educação Ambiental, que amparada na Constituição Nacional (BRASIL, 1988, Art. 225, § 1º, VI) deve ser executada efetiva e sistemicamente, comunicando numa lógica de enfrentamento, mas também de esperança.

\section{Referências}

BRASIL. Constituição da República Federativa do Brasil de 1988. Brasília: Centro Gráfico, 1988.

CARIDE, José Antônio; CARTEA, Pablo Ángel Meira. La educación ambiental en los límites, o la necesidad cívica y pedagógica de respuestas a una civilización que colapsa. Revista Interuniversitaria, v. 36, n. 1, p. 21-34, 2020.

CARTEA, Pablo Ángel Meira. Problemas ambientales globales y educación ambiental: Una aproximación desde las representaciones sociales del cambio climático. Revista Integra Educativa, v. 6, n. 3. p. 29-64, 2013.

GAUDINO, Édgar J. González; CARTEA, Pablo Ángel Meira; PÉREZ, José Gutiérrez. ¿cómo educar sobre la complejidad de la crisis climática? Revista Mexicana de Investigación Educativa, v. 25, n. 87, p. 843-872, 2020.

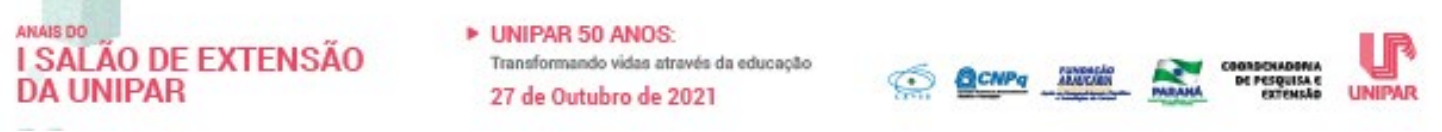




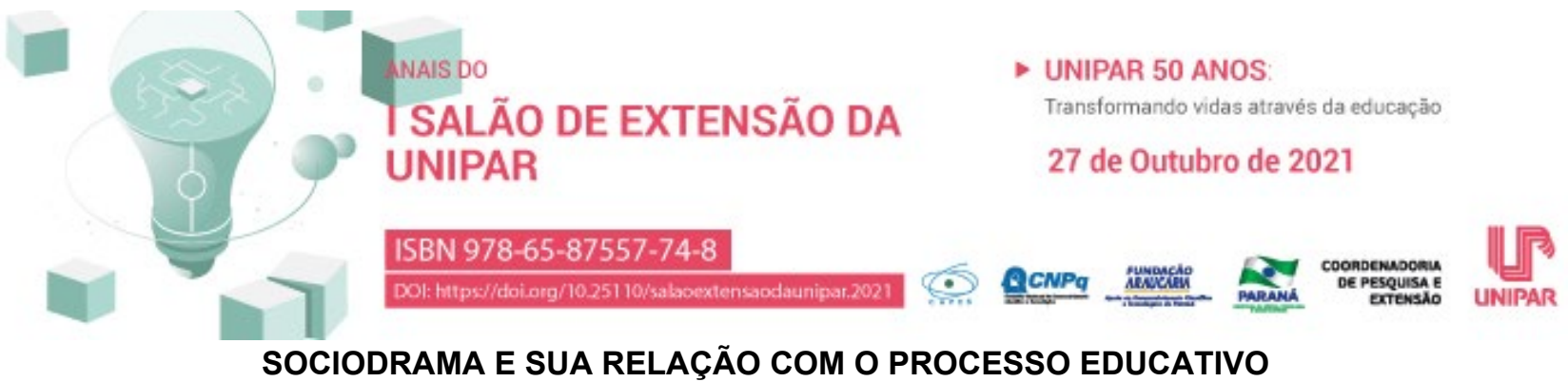

${ }^{1}$ Taiane Aparecida Ribeiro Nepomoceno, ${ }^{2}$ NAIN NOGÁRA

${ }^{1}$ Doutoranda em Desenvolvimento Rural Sustentável/Unioeste

${ }^{2}$ Mestranda em Desenvolvimento Rural Sustentável/Unioeste

Introdução: Em diversos contextos de formação discutem-se sobre temas emergentes, no entanto, na maioria das vezes, quando esses são incorporados nas práticas pedagógicas, eles são trabalhados de forma pontual, fragmentada e descontextualizada da realidade dos alunos. Portanto, a abordagem e sensibilização significativa sobre temáticas deste caráter deve ser um dos pilares da educação. Neste sentido, o sociodrama e suas diversas técnicas, apresentam-se como pertinentes aos processos educativos, visto que podem favorecer a aprendizagem ativa, a construção de saberes e o desenvolvimento de ações, atitudes e posturas críticas (SILVA; BERNARDES; DUTRA, 2019), frente a um tema ou assunto específico.

Objetivo: Apresentar o sociodrama enquanto abordagem metodológica para a educação básica.

Resultados: O sociodrama trata-se de uma metodologia ativa ainda pouco explorada no processo de ensino e aprendizagem. É definida também como uma abordagem terapêutica que se fundamenta na partilha coletiva de papéis sociais e culturais (MORENO, 2013). Ele possibilita a interação entre os participantes, trabalha com a expressividade criativa e a espontaneidade. Em função de sua abrangência em diferentes áreas do conhecimento, organizações e segmentos, constitui-se importante ferramenta de articulação e atribuição de maior sentido ao contexto social dos envolvidos. Envolve, sobretudo, um paradigma de construção coletiva, novas aprendizagens, que segundo Marra (2004) interfere diretamente na mudança e transformação dos conflitos, troca de informações e conjugação do saber popular e científico. O sociodrama, possui três fases principais, a citar: aquecimento, dramatização e compartilhamento (MORENO, 2013), com técnicas específicas e bem delineadas. Em vista disso, deve ser desenvolvido por profissionais especializados, com formação inerente. Essa técnica pode proporcionar oportunidades para reflexão crítica, desmistificando temáticas, transformando relações, atitudes, habilidades; gerando, novas formas de conviver, aprender e ensinar.

Conclusão: O sociodrama quando utilizado no contexto educativo, para a abordagem de diferentes conteúdos curriculares, pode representar um importante instrumento terapêutico, de formação humana. Em função de suas características reflexivas e emocionais, ele, também retrata dinâmicas muito próximas da realidade do aluno, permite que ele desmitifique crenças sobre os temas, tornando o conteúdo ainda mais significativo a eles.

\section{Referências}

MARRA, Marlene Magnabosco. O agente social que transforma: o sociodrama na organização de grupos. São Paulo: Ágora, 2004.

MORENO, Jacob Levy. Psicodrama. 16 ed. São Paulo: Cultrix, 2013.

SILVA, Harrysson Luiz; BERNARDES, Márcia Pereira; DUTRA, Rita de Cássia. Sociodrama como recurso pedagógico para educação ambiental em áreas de risco. In: SENHORAS, Elói Martins. Enfoque interdisciplinar na educação ambiental 2. Ponta Grossa: Atena Editora, 2019. p. 89-100.

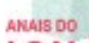

I SALÃO DE EXTENSÃO DA UNIPAR

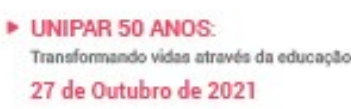

27 de Outubro de 2021

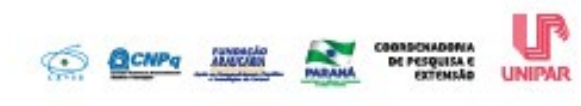




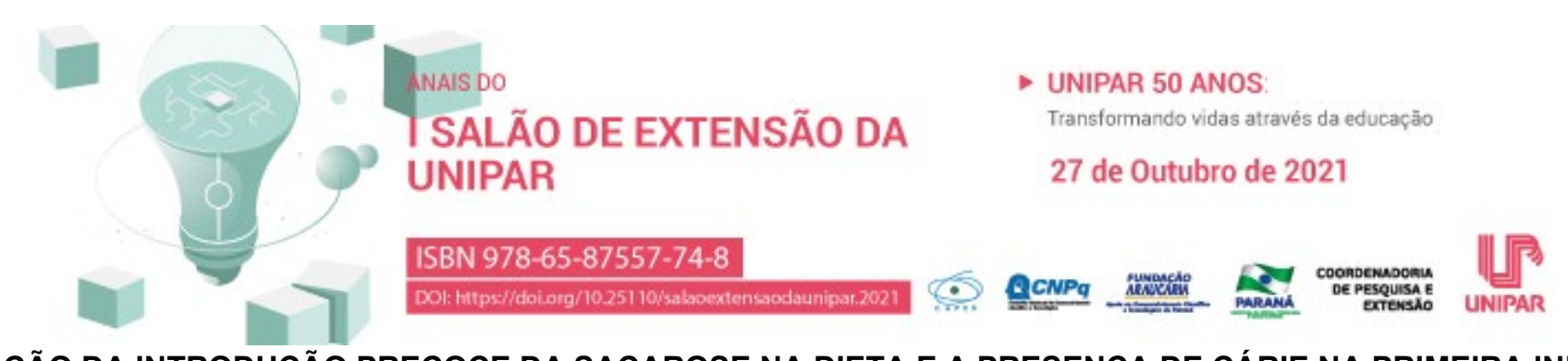

A RELAÇÃo DA INTRODUÇÃO PRECOCE DA SACAROSE NA DIETA E A PRESENÇA DE CÁRIE NA PRIMEIRA INFÂNCIA

\author{
${ }^{1}$ MATHEUS CAZARIN MALDONADO GARCIA, ${ }^{2}$ BEATRIZ CAVICHIOLI TINTI, ${ }^{3}$ ISABELLA CARDOSO MARTINS, ${ }^{4}$ LAVINIA \\ PRADO HERNANDES, ${ }^{5}$ RAFAELA VILALTA ESVERCUTTI, ${ }^{6}$ MARIA FERNANDA PRIETO NOGUEIRA, ${ }^{7}$ ANA CAROLINA \\ SOARES FRAGA ZAZE
}

${ }^{1}$ Acadêmico do Curso de Odontologia da UNIPAR
${ }^{2}$ Acadêmica do Curso de Odontologia da UNIPAR
${ }^{3}$ Acadêmica do Curso de Odontologia da UNIPAR
${ }^{4}$ Acadêmica do Curso de Odontologia da UNIPAR
${ }^{5}$ Acadêmica do Curso de Odontologia da UNIPAR
${ }^{6}$ Acadêmica do Curso de Odontologia da UNIPAR
${ }^{7}$ Docente do curso de Odontologia da UNIPAR/ Umuarama

Introdução: Doença multifatorial, infecciosa e transmissível, a cárie está claramente relacionada a introdução da sacarose na dieta, sendo uma das principais doenças na infância, tendo como um dos fatores primários os hábitos alimentares. A Organização Mundial da Saúde (OMS) define saúde como um bem-estar físico, mental e social, logo, saúde bucal é um agregado de práticas que promovem, recuperam, e mantêm a integridade das estruturas da cavidade bucal. Sendo assim, o cuidado odontológico deve ser feito cada vez mais cedo, começando na odontologia para bebês, com o objetivo de se tornar uma odontologia preventiva.

Objetivo: Por meio de uma revisão de literatura, correlacionar o contato precoce da sacarose na dieta de bebês e o desenvolvimento de cárie dentária na primeira infância.

Resultados: A dieta tem um papel essencial no desenvolvimento da cárie em crianças, sendo afetada pela família, assim como pela escola e também pela mídia. A sacarose é o elemento mais cariogênico da dieta, sendo substrato para a produção de ácidos pelas bactérias cariogênicas e subsequente desmineralização do esmalte dentário, fazendo com que a sacarose tenha o maior potencial cariogênico em relação a outros açúcares. Maus hábitos alimentares, especialmente, a partir do primeiro ano de vida, é a variável de comportamento com maior relação no aparecimento de cárie na primeira infância, sendo a implementação de hábitos saudáveis de extrema importância no combate ao desenvolvimento de cárie. Portanto, quando se trata de educação em saúde bucal, é imprescindível a abordagem de temas relacionados ao aspecto nutricional e as consequências da inserção precoce do açúcar na dieta de bebês, por meio de programas de educação e prevenção em saúde, a fim de reduzir a prevalência de cárie dental na primeira infância e oferecer uma melhor condição de saúde, tanto bucal quanto geral.

Conclusão: A introdução precoce da sacarose na dieta na primeira infância tem alta relação com o desenvolvimento de cárie dentária, salientando a importância de educação em saúde tanto bucal quanto nutricional para bebês, para a promoção de saúde e melhoria da qualidade de vida.

\title{
Referências
}

AMADO, Thais Santana; BARRETO, Mara Augusta Cardoso. Estudo da doença cárie em bebês e sua relação com os hábitos alimentares-uma revisão de literatura. Orientadora: Mara A. C. Barreto. 2019. 11 f. Monografia (Trabalho de conclusão de curso) - Universidade Tiradentes, Aracajú, 2012. Disponível em: http://openrit.grupotiradentes.com:8080/xmlui/handle/set/2346. Acesso em: 06 set. 2021.

ASSIS DE PAULA, B.; FREIRE-MAIA, J.; ANTÔNIO MARTINS JÚNIOR, P.; BARTOLOMEO FREIRE-MAIA, F. Introdução precoce da sacarose está associada à presença de cárie dentária em bebês. Arquivos em Odontologia, v. 55, n.12, p. 1- 7 , março, 2019.

MACAMBIRA, Dírlia Silva Cardoso; CHAVES, Emilia Soares; COSTA, Edmara Chaves. Conhecimento de pais/cuidadores sobre saúde bucal na infância, Saúde e pesqui. (Impr.), v.10, n.3, p. 463-472, dezembro, 2017.

MACIEL, Shirley Suely Veras Vieira et al. Prevalência da cárie precoce na infância em crianças de 6 a 36 meses em creches públicas de Caruaru/PE. Pesq. Bras. Odontopediatria. Clín. Integr. , v. 7, n. 1, p. 59-65, abril, 2007.

PAIM dos Santos, S.; VIEIRA, Graciete Oliveira; SCAVUZZI, Ana Isabel Fonseca; SUZART.; GOMES FILHO, Isaac Suzart, 
Práticas alimentares e cárie dentária - uma abordagem sobre a primeira infância, Rev. Assoc. Paul. Cir. Dent., v.70, n.1 p. 12-8, fevereiro, 2016.

SANTOS, Susana; VIEIRA, Graciete Oliveira; SCAVUZZI, Ana Isabel Fonseca; FILHO, Isaac Suzart Gomes. Práticas alimentares e cárie dentária-uma abordagem sobre a primeira infância. Rev. Assoc. Paul. Cir. Dent. , v. 70, n. 1, p. 12-18, janeiro, 2016.

SCALIONI, Flávia Almeida Ribeiro et al. Hábitos de dieta e cárie precoce da infância em crianças atendidas em faculdade de odontologia brasileira. Pesq. Bras. Odontopediatria. Clín. Integr., v. 12, n. 3, p. 399-404, setembro, 2012.

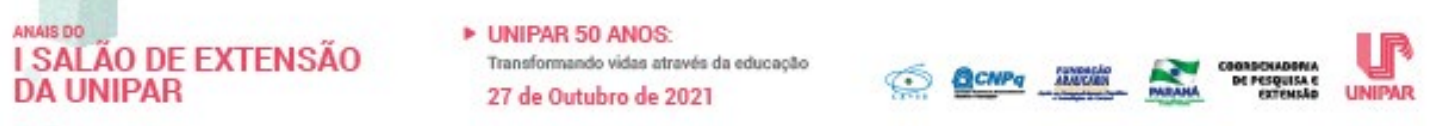




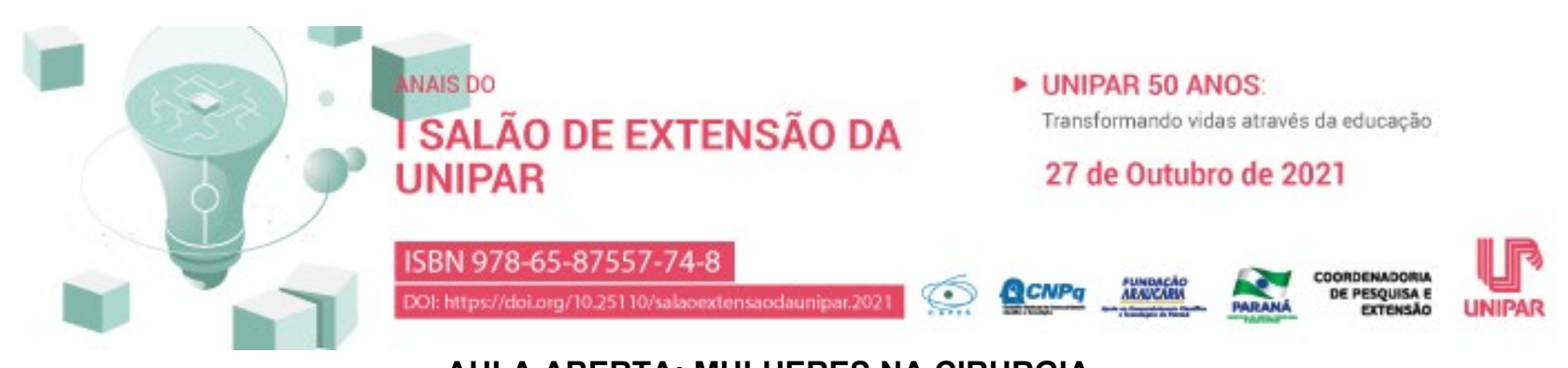

AULA ABERTA: MULHERES NA CIRURGIA

${ }^{1}$ HELOUYZE CHRYSTHYNAH ALBANO ASSIS DOS SANTOS, ${ }^{2}$ MARIA LUIZA CORREA PONTALTI, ${ }^{3}$ BARBARA TEREZA LAVAGNINI, ${ }^{4}$ PAULA MOSCOVITS QUEIROZ, ${ }^{5}$ LUCAS PINTO DE OLIVEIRA, ${ }^{6}$ LUCAS MANGIALARDO PERINI, ${ }^{7}$ MARINA CHAVES ORBEN, ${ }^{8}$ LUISA BATISTA DORNELLES, ${ }^{9}$ THAYNE ZIMERMANN DURIGON, ${ }^{10}$ RAFAEL LEONARDI JANEIRO, ${ }^{11}$ YASMIN LARISSA SPRICIGO, ${ }^{12}$ GEORGIA BAGGIO, ${ }^{13}$ KAREN RAMOS MARIN, ${ }^{14}$ NATHALIA HEVELLYN SCHERER, ${ }^{15}$ VICTOR FAJARDO BORTOLI, ${ }^{16}$ FERNANDO EDUARDO PAULATTI FREDERICO

\footnotetext{
${ }^{1}$ Acadêmica do Curso de Medicina da UNIPAR

${ }^{2}$ Acadêmica do Curso de Medicina da UNIPAR

${ }^{3}$ Acadêmica do Curso de Medicina da UNIPAR

${ }^{4}$ Acadêmica do Curso de Medicina da UNIPAR

${ }^{5}$ Acadêmica do Curso de Medicina da UNIPAR

${ }^{6}$ Acadêmica do Curso de Medicina da UNIPAR

${ }^{7}$ Acadêmica do Curso de Medicina da UNIPAR

${ }^{8}$ Acadêmica do Curso de Medicina da UNIPAR

${ }^{9}$ Acadêmica do Curso de Medicina da UNIPAR

${ }^{10}$ Acadêmica do Curso de Medicina da UNIPAR

${ }^{11}$ Acadêmica do Curso de Medicina da UNIPAR

${ }^{12}$ Acadêmica do Curso de Medicina da UNIPAR

${ }^{13}$ Acadêmica do Curso de Medicina da UNIPAR

${ }^{14}$ Acadêmica do Curso de Medicina da UNIPAR

${ }^{15}$ Acadêmica do Curso de Medicina da UNIPAR

${ }^{16}$ Docente da UNIPAR
}

Introdução: As Ligas Acadêmicas fazem parte do ambiente universitário, representando associações civis e científicas livres, sem fins lucrativos, com duração ilimitada e cujas atividades abrangem tanto o ensino acadêmico como a inserção dos alunos no meio social (SILVA et al. 2015). A Liga Acadêmica de Cirurgia Geral (LACG), fundada em 19 de fevereiro de 2019, possui por finalidades ampliar o conhecimento no eixo da área cirúrgica, promovendo atividades teórico-práticas, além de possuir importante papel nas realizações de caráter social a fim de contribuir para o bem da população e promover conhecimento. Dessa forma, a LACG desenvolveu uma aula aberta a respeito do tema Mulheres na Cirurgia para seus ligantes e todos aqueles que buscam conhecimento. Além de aproveitar o momento para realizar uma ação social.

Objetivo: Abordar a relevância, importância e necessidade da palestra Mulheres na cirurgia promovida pela Liga Acadêmica de Cirurgia Geral (LACG) e relatar o impacto proporcionado à comunidade.

Resultados: Realizou-se no dia 02 de setembro de 2021, uma aula aberta na Universidade Paranaense - UNIPAR, com o tema:

Mulheres na Cirurgia , ministrada pela Doutora Marcela Frederico, ginecologista e obstetra, para os ligantes da Liga Acadêmica de Cirurgia Geral e para demais interessados. Dessa forma, com a frase chave da aula Mulher pode ser Cirurgiã de verdade? , a Dra. relatou toda sua trajetória acadêmica até o ingresso na residência e, após residente, seus desafios nas especializações cirúrgicas que veio a realizar. Desafios esses que muitas vezes teve que enfrentar sozinha por ser a única mulher dentro de um centro cirúrgico, juntamente com a necessidade de se provar eficiente e capaz a todo momento por pertencer ao sexo feminino. Foi abordado ainda, o histórico de mulheres cirurgiãs que iniciaram toda essa luta, e como exemplo de uma entre várias, Angelita Gama, primeira mulher a fazer residência em Cirurgia Geral, no Hospital das Clínicas da FMUSP, além de ser a primeira a chefiar o Departamento de Cirurgia do mesmo hospital. A entrada ao evento foi efetuada por meio da doação de 1 (um) quilo de alimento não perecível, com o escopo de auxiliar a comunidade. Os alimentos arrecadados na aula foram, junto a Liga de Neurologia e Neurocirurgia, doados a Associação de Senhoras de Umuarama - PR (conhecida popularmente como Abrigo Tia Lili), que tem como finalidade o acolhimento institucional de crianças e adolescentes.

Conclusão: Com base no exposto, evidencia-se o importante papel representado pelas ligas acadêmicas, as quais permitem a associação de aprendizados sobre temas de extrema relevância, que nem sempre são abordados na graduação, com a 
oportunidade de exercer, além de tudo, o bem social, no caso, com a doação de alimentos não perecíveis.

\section{Referências}

SILVA, J. H. S. da et. al. Implantação de uma Liga Acadêmica de Anatomia: Desafios e Consquistas. Revista Brasileira de Educação Médica, v. 39, n. 2, p. 310-315, 2015.
I SALĀO DE EXTENSÃO
- UNIPAR 50 anOS.
DA UNIPAR
27 de Outubro de 2021

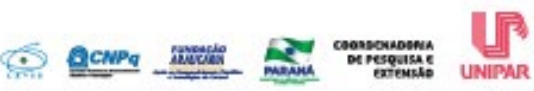




\title{
(1) \\ - UNIPAR 50 ANOS \\ Transformando vidas através da educação \\ 27 de Outubro de 2021

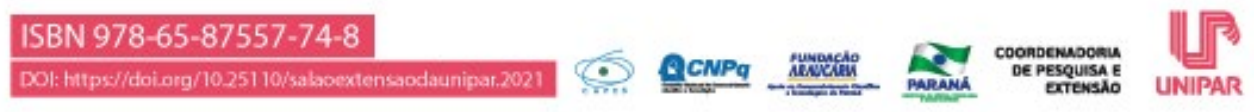 \\ QUE TAL CUIDAR DE VOCÊ? : RELATO DE EXPERIÊNCIA SOBRE INTERVENÇÃO PSICOLÓGICA PARA PROFESSORES
}

\author{
${ }^{1}$ FERNANDA PEGORARO, ${ }^{2}$ GABRIELA TOASSI BRITO, ${ }^{3}$ THAIS CRISTINA GUTSTEIN NAZAR
}

\author{
${ }^{1}$ Academica PEX do curso de Psicologia da Unipar \\ ${ }^{2}$ Acadêmica PEX do Curso de Psicologia da UNIPAR \\ ${ }^{3}$ Doudorado em Educação (UFPR), Docente do curso de Psicologia da UNIPAR
}

Introdução: No atual contexto pandêmico, causado pelo novo Coronavírus (SARS-CoV-2), a rotina do mundo precisou transformar-se, o espaço escolar precisou adaptar-se para o estabelecimento de medidas preventivas, os professores precisaram de forma emergente aprender a lidar com as Tecnologias de Informação e Comunicação (TICs) e mais do que nunca ser um local de acolhida, adaptação e de promoção de saúde mental geral. Visto todas as demandas, processos de luto, perdas, desemprego, desigualdade, desafios que a pandemia elucidou sabe-se que a profissão de docente é considerada uma das mais estressantes devido à precarização das condições de trabalho, excesso de tarefas, baixa remuneração e valorização do trabalho. (GUIMARÃES; VIANA,2021, p.8). Frente ao atual cenário mostra-se de suma importância trabalhar metodologias de prevenção e promoção de saúde mental com os profissionais de educação que estão inseridos em um contexto demasiadamente alterado desde o começo da pandemia da Covid-19.

Objetivo: O objetivo do presente trabalho foi proporcionar aos profissionais da educação, promoção e possível prevenção de saúde mental com intervenções objetivas e remotas no contexto de pandemia.Ademais proporcionar um espaço de troca de experiências para fortalecimento, conceder informações de quando, como e onde procurar ajuda no quesito de saúde mental, desenvolver as habilidades para a vida no cotidiano, tanto do trabalho quanto na vida pessoal.

Material e métodos: Participaram dos encontros seis docentes, todos da Rede Pública de Ensino. Foram trabalhadas diversas temáticas de Habilidades Para a Vida, por exemplo, o manejo de estresse e ansiedade, autoconhecimento, relacionamento interpessoal, empatia, resolução de problemas, pensamento crítico. Foram propostos no total, seis encontros quinzenais, com duração aproximada de $1 \mathrm{~h}$ cada, e foram abordadas também aspectos como autoconhecimento, autocuidado, estresse, entre outros, visando apresentar estratégias de manejo, relaxamento e métodos que auxiliassem e tornassem o cotidiano facilitado para o trabalho que realizam.

Resultados: Durante os encontros, conforme o andamento das atividades, a adesão e vínculo do grupo se mostrou crescente, aumentando a participação durante os encontros. Os resultados das intervenções demonstraram que os professores sentem-se cansados ao se deparar com demandas novas no contexto de pandemia que exigem uma certa improvisação, como por exemplo preparar materiais inéditos e recursos de apoio. A partir das vivências e intervenções e consonante ao andamento dos encontros, o grupo mostrou uma maior participação que foi observado no aumento de relatos pessoais, exemplos sobre o tema tratado e identificação.

Discussão: De maneira geral o grupo se mostrou produtivo e importante. Notaram-se queixas relevantes como a inexistência de território demarcado entre o trabalho e o lar, onde muitos demonstraram estar sobrecarregados justamente por não conseguir diferenciar estes espaços. Na maioria dos contextos, os professores precisam sistematizar leituras, providenciar materiais inéditos e recursos de apoio, estarem à disposição para dúvidas, produzirem vídeo-aulas e transmissões ao vivo. Muitos docentes, de acordo com relatos, além de não ter o preparo para tal atividade, recebem cobranças para melhorar linguagem, dinamismo, e se ater mais ao tema da aula. Além disso, as escolas têm atendido cada vez mais os pedidos dos pais, reforçando ainda mais a visão mercadológica da educação (ZAJAC, 2020).O estresse causado por essa extrema mudança de rotina desencadeia ou agrava diversas outras doenças, podendo ser físicas ou mentais, como: ansiedade, depressão, dor muscular e insônia. (GUIMARÃES; VIANA,2021, p.8). Assim fazendo-se necessário trabalhar as Habilidades Para a Vida com esse público.

Conclusão: Os encontros foram feitos de forma breve, facilitando a adesão ao projeto e contribuindo para a escuta e acolhida. $O$ presente estudo contribuiu em várias frentes, tanto na aprendizagem de novas formas de lidar com as problemáticas e habilidades cotidianas quanto no esforço realizado pelos participantes de estar dedicando tempo a sua saúde mental e espaço de fala e acolhida. Sugerem-se a continuidade de estudos e intervenções direcionadas a este público e temática.

\section{Referências}

GUIMARÃES, Fernanda Pacheco Viana. A pandemia (COVID-19):Consequências para a saúde mental dos professores. Hilma Aparecida Brandão. 2021. 25p. Pós Graduação (Latu- sensu). Instituto Federal Goiano - Ifgoaiano. Ipameri. 2021. Disponível em: https://repositorio.ifgoiano.edu.br/handle/prefix/1859. Acesso em: 13 de Setembro de 2021.

ZAJAC. Danilo. Ensino remoto na educação básica e Covid 19:Um agravo ao direito a educação e outros impasses, 2020 , 
Disponível em: https://epufabc.proec.ufabc.edu.br/ensino-remoto-na-educacao-basica/. Acesso em: 13 set. 2021.

ANaAs DO - UNIPAR 50 ANOS:

I SALÃO DE EXTENSÃO Transformando vides atraves da educoces

DA UNIPAR 27 de Outubro de 2021

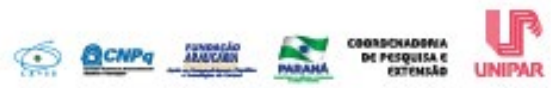




\title{
(1) $\begin{aligned} & \text { NaIs Do } \\ & \text { SALÃO DE EXTENSÃO DA } \\ & \text { UNIPAR }\end{aligned}$ \\ - UNIPAR 50 ANOS: \\ Transformando vidas através da educação \\ 27 de Outubro de 2021 \\ ISBN 978-65-87557-74-8

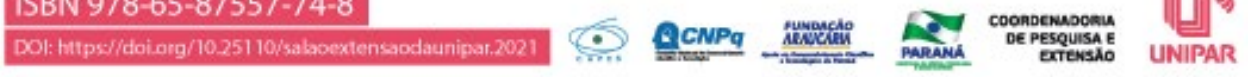 \\ PROMOÇÃO DA CAMPANHA DO AGASALHO 2021 NO MUNICÍPIO DE UMUARAMA EM ASSOCIAÇÃO COM AS LIGAS ACADÊMICAS DE MEDICINA
}

${ }^{1}$ GABRIELA BERTONI FERNANDES, ${ }^{2}$ ISABELA CARVALHO LOPES, ${ }^{3}$ NAGYLA OLIVA FERREIRA, ${ }^{4}$ BARBARA HELENA
SIOLARI DE MICO ROBERTO, ${ }^{5}$ EGUIMAR ROBERTO MARTINS

\begin{abstract}
${ }^{1}$ Acadêmica do Curso de Medicina da UNIPAR
${ }^{2}$ Acadêmica do Curso de Medicina da UNIPAR

${ }^{3}$ Acadêmica do Curso de Medicina da UNIPAR

${ }^{4}$ Acadêmica do Curso de Medicina da UNIPAR

${ }^{5}$ Docente da UNIPAR
\end{abstract}

Introdução: As ligas acadêmicas para a sociedade atual são de fundamental importância. Entre os propósitos de uma liga, está o eixo de demandas sociais, onde os acadêmicos realizam ações e campanhas voltadas em beneficiar a comunidade local (MOREIRA et al., 2021). As atividades de extensão universitárias devem estar imersas em um contexto de realidades políticas, econômicas e sociais da comunidade a qual pertence. A extensão, nesse contexto, está relacionada ao processo de integração entre a Instituição de Ensino Superior e a sociedade civil visando desenvolver atividades e campanhas onde o principal beneficiário seja a comunidade civil (CARBONARI E PEREIRA, 2015). Desse modo, vemos a importância das atividades desenvolvidas pelas ligas acadêmicas visando suprimir as necessidades da comunidade local, onde as campanhas sociais contribuem de modo significativo para melhoria da qualidade de vida dos mais necessitados (TORRES et al., 2008).

Objetivo: Promover e coordenar a arrecadação de roupas, agasalhos e cobertores para destinar à população carente do município de Umuarama-PR.

Resultados: A atividade Campanha do Agasalho 2021 foi idealizada pela Liga Acadêmica de Medicina da Família e Comunidade (LAMFC), onde se buscou parceria com 21 ligas locais do curso de medicina. A atividade se desenvolveu no período de 31/05 a 14/06, tendo três pontos de arrecadações dentro do domínio da Universidade Paranaense de Umuarama. Foi arrecadado um total de 780 peças, entre elas roupas, cobertores e calçados. Toda a arrecadação foi destinada a duas instituições de apoio à comunidade local, sendo, a Associação de Apoio à Promoção Profissional (APROMO) e Associação de Pais e Amigos dos Excepcionais (APAE).

Conclusão: Desse modo, verifica-se que é de extrema importância as campanhas de doação de roupas e agasalhos, em essencial no inverno, devido às altas taxas de mortalidades relacionadas a baixa temperatura tanto para moradores de rua, quanto para a população carente, sendo uma ação de grande impacto para a comunidade local.

\section{Referências}

CARBONARI, M. E. E.; PEREIRA, A. C. A extensão universitária no Brasil, do assistencialismo à sustentabilidade. Revista de Educação, v.10, n.10, 2007. Disponível em: https://revista.pgsskroton.com/educ/article/view/2133. Acesso em: 26 ago. 2021.

MOREIRA, L. M. et al. Ligas Acadêmicas e Formação Médica: Estudo Exploratório numa Tradicional Escola de Medicina. Revista Brasileira de Educação Médica [online]. 2019, v. 43, n. 1 [Acessado 26 Agosto 2021] , pp. 115-125. Disponível em: . ISSN 1981-5271. https://doi.org/10.1590/1981-52712015v43n1RB20170141.

TORRES, A. R. et al. Ligas Acadêmicas e formação médica: contribuições e desafios. Interface - Comunicação, Saúde, Educação [online]. 2008, v. 12, n. 27 [Acessado 26 Agosto 2021] , pp. 713-720. Disponível em: . Epub 31 Ago 2012. ISSN 18075762. https://doi.org/10.1590/S1414-32832008000400003.

\section{SALÄO DE EXTENSÃO DA UNIPAR}

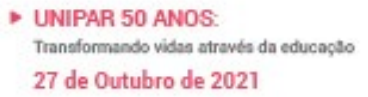

Traneformando vidas atrevta da educaço
27 de Outubro de 2021

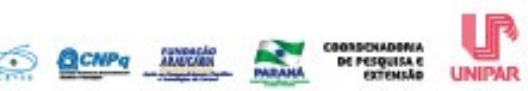




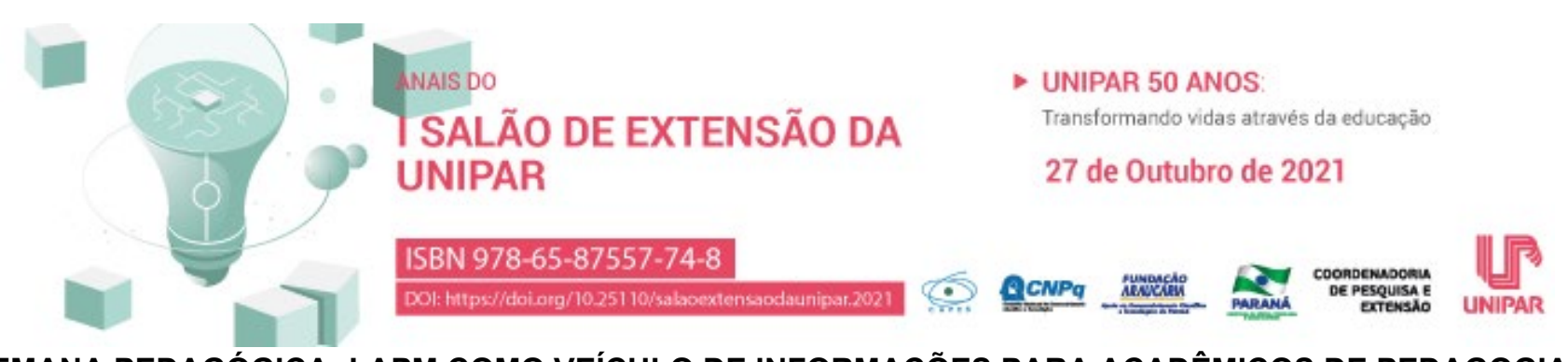

SEMANA PEDAGÓGICA: LAPM COMO VEÍCULO DE INFORMAÇÕES PARA ACADÊMICOS DE PEDAGOGIA

\author{
${ }^{1}$ Leticia CASAlLI COUto, ${ }^{2}$ ISABElle LAgUILIO FIALHO, ${ }^{3}$ LUCAS PARIZI ALVES, ${ }^{4}$ HELOISA GURALESKI SIQUEIRA, \\ 5LUCIANO SERAPHIM GASQUES
}

${ }^{1}$ Acadêmica do Curso de Medicina da UNIPAR
${ }^{2}$ Acadêmica do Curso de Medicina da UNIPAR
${ }^{3}$ Acadêmico do Curso de Medicina da UNIPAR
${ }^{4}$ Acadêmica do Curso de Medicina da UNIPAR
${ }^{5}$ Docente da UNIPAR

Introdução: O profissional da educação, além de ensinar, deve sempre estar atento aos acontecimentos da sociedade como um todo. Ademais, é de extrema importância que o docente reflita sobre a influência que pode exercer como profissional e desenvolver-se não somente nesse âmbito, mas também pessoalmente (RODRIGUES, 2017). Uma liga acadêmica busca aprofundar os conhecimentos de acadêmicos de diversas séries por base do tripé: ensino, pesquisa e extensão (BOTELHO, FERREIRA, SOUZA, 2013). Dessa forma, a união da Liga Acadêmica de Parasitologia Médica (LAMP) com o curso de Pedagogia-Unipar-Umuarama, busca por meio da semana pedagógica orientar futuros professores sobre doenças parasitológicas que mais acometem pessoas em idade escolar.

Objetivo: Apresentar informações sobre as parasitoses intestinais mais comuns em idade escolar e a profilaxia, visto que é um cenário ao qual os acadêmicos e profissionais de pedagogia estão inseridos.

Resultados: A semana pedagógica dos acadêmicos do curso de pedagogia está prevista para que ocorra no mês de novembro. Portanto, os integrantes da LAPM estão desenvolvendo aulas de uma forma lúdica e compreensível com informações sobre as principais parasitoses que acometem as crianças em idade pré-escolar e escolar. É importante ressaltar que as parasitoses intestinais são consideradas um problema de saúde pública e normalmente são tratadas na Atenção Primária à Saúde. As mais comuns são ascaridíase, tricuríase, infecções por ancilostomídeos e helmintíases intestinais, listadas entre as doenças negligenciadas ou doenças tropicais negligenciadas (ANDRADE, et al., 2010). Os alunos da liga envolvidos na atividade se mostraram muito interessados na atividade proposta, ao compreender a dinâmica que tem por intuito levar os conhecimentos adquiridos nas atividades teóricas e práticas da liga desenvolvidas durante todo o ano vigente aos acadêmicos e profissionais de pedagogia. Por estarem em contato direto com crianças de distintas idades e classes sociais, é preciso que o profissional pedagogo saiba prevenir e observar os possíveis sinais e sintomas das patologias selecionadas para serem apresentadas pelos acadêmicos de medicina, visando evitar a contaminação das crianças ou até mesmo dos adultos.

Conclusão: A atividade que está em desenvolvimento, proporciona aos alunos de medicina a experiência da docência e a oportunidade de aprimorar suas habilidades, tanto no âmbito da comunicação, quanto nos conhecimentos da parasitologia. Foram produzidos materiais de apoio lúdicos e objetivos para que a compreensão seja otimizada. Espera-se observar um benefício mútuo para os alunos de ambos os cursos, tanto de Medicina, quanto de Pedagogia, que na prática precisam atuar em sinergia para promover a saúde das crianças em idade pré-escolar e escolar.

\title{
Referências
}

ANDRADE, Elisabeth Campos. et al. Parasitoses intestinais: uma revisão sobre seus aspectos sociais, epidemiológicos, clínicos e terapêuticos. Revista Atenção Primária à Saúde: Juiz de Fora, v. 13, n. 2, p. 231-240, 2010.

BOTELHO, Nara Macedo; FERREIRA, lago Gonçalves; SOUZA, Luis Eduardo Almeida. Ligas acadêmicas de medicina: artigo de revisão. Revista paranaense de medicina: v. 27, n. 4, 2013.

RODRIGUES, Sirlei. A semana pedagógica como formação continuada de professores: um olhar a partir do método de instrução ao sósia. 2017. Dissertação de Mestrado. Universidade Tecnológica Federal do Paraná.

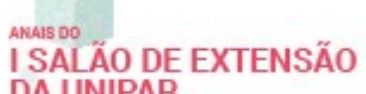

I SALAO DE
DA UNIPAR

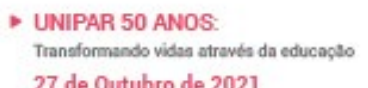

27 de Outubro de 2021

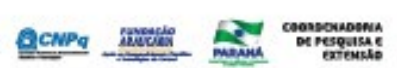




\title{
BALANÇO INVENTARIADO: INSTRUMENTO PARA IMPLANTAÇÃO DA CONTABILIDADE EM MICRO E PEQUENOS NEGÓCIOS
}

\author{
${ }^{1}$ GABRIEL DENKE MACHADO, ${ }^{2}$ JOSE LUIZ BORSATTO JUNIOR
}

\author{
${ }^{1}$ Acadêmico do curso de Ciências Contábeis - Pesquisador do PIC e Participante do PEX - Universidade Paranaense. \\ ${ }^{2}$ Docente da UNIPAR
}

Introdução: A informação se faz importante em qualquer tipo de organização, para se fazer análises, mensurar resultados e subsidiar a tomada de decisão. Toda empresa é movida por decisões, sejam estas boas ou ruins. A Contabilidade é considerada a linguagem dos negócios, porém nem todos os gestores utilizam-se da Contabilidade como meio formal para a condução dos negócios. Logo, o método do balanço inventariado surge como uma alternativa útil para os pequenos negócios, para se levantar e agrupar informações relevantes para elaboração de demonstrativos contábeis e corroborar com o processo de tomada de decisão. Os autores deste resumo estão desenvolvendo, em projetos de PEX e PIC, uma versão do Balanço Perguntado mais abrangente em relação à realidade organizacional de micro e pequenas empresas (MPES) e atualizada à realidade contábil, o que culminará em um instrumento mais adequado para a obtenção de informações contábeis voltadas para diagnósticos, tomada de decisão e controle.

Objetivo: Descrever o processo de adaptação da metodologia do balanço inventariado para implantação de contabilidade básica para MPES e posterior diagnóstico, tomada de decisão e controle.

Resultados: Com a pesquisa dos autores à respeito do balanço inventariado, percebe-se que boa parte da base teórica desse assunto advém do trabalho de Kassai e Kassai (2001) que destaca que o método do balanço inventariado ou perguntado consiste na elaboração de perguntas para o dono da empresa por meio de um questionário previamente elaborado, com intuito de se elaborar demonstrações contábeis e para analisar a situação econômica financeira. Com base nesta metodologia, os autores buscaram por meio da literatura modelos conceituais de aplicação deste balanço e ainda, se propuseram a desenvolver uma versão balanço perguntado tendo em vista a Resolução ITG 1000 do Conselho Federal de Contabilidade, ao qual, configurase como o modelo de contabilidade para micro e pequenas empresas. Atrelado a isso, está em estágio de aplicação esta ferramenta em uma empresa de pequeno porte no intuito de, posteriormente, servir de base para elaboração de análise de indicadores financeiros e contábeis. Até o presente momento, algumas dificuldades foram apresentadas na elaboração de demonstrativos contábeis, justificados pelo fator do tratamento e disponibilidade da informação apresentada pois, nem todas as informações obtidas são concretas e disponíveis para aplicação da metodologia, bem como, pela determinação de critérios específicos para estas informações, uma vez que, a ausência de critérios adequados a cada realidade empresarial possibilitaria distorções relevantes à realidade do negócio. Tais dificuldades e tratativas serão destacadas após findado todo processo de pesquisa e aplicação metodológica, servindo como tema para estudos futuros. Ainda assim, Fernandes, Leite, Tavares e Azevedo (2019) destacam que o uso da metodologia do balanço perguntado possibilita o levantamento de informações para elaboração dos demonstrativos contábeis, bem como, a análise da situação econômico-financeira das micro e pequenas empresas. Considerando isso, o aprimoramento deste estudo corrobora para as empresas que não possuem uma contabilidade formal tenha um parâmetro de implementação mais adequado, possibilitando condição de melhoria pelo método do balanço inventariado, alternativa que atende a geração de informações para demonstrativos da contabilidade gerencial e tomada de decisões, contribuindo sobretudo, com o empreendedorismo.

Conclusão: Com base na literatura, o balanço perguntado ou inventariado mostra-se viável para levantar e agrupar informações para elaboração das demonstrações econômico-financeiras, auxiliando os gestores no processo decisório. Tendo em vista a preocupação dos autores em atualizar esta método de inventariação contábil, a contribuição que este estudo traz consiste não somente na constatação de dificuldades inerentes ao processo de aplicação, mas também na proposição de uma versão para MPES em conformidade com as resoluções e práticas contábeis adequadas.

\section{Referências}

KASSAI, J. R.; KASSAI, S.; Balanço perguntado: solução para as pequenas empresas. In Anais do Congresso Brasileiro de Custos-ABC - 2001.

FERNANDES, R. B.; LeITE, I. F.; TAVARES, A. L.; AZEVEDO, Y. G. P. Balanço Perguntado: Um Instrumento para Análise Econômico-financeira de Micro e Pequenas Empresas - REMIPE Revista de Micro e Pequenas Empresas e Empreendedorismo - FATEC- Osasco, São Paulo - V. 5 Nº1 jan.-jun. 2019. 
- unIPAR 50 anos:

I SALAOO DE EXTENSÃO Transformando vidas atravies da educaģso

DA UNIPAR 


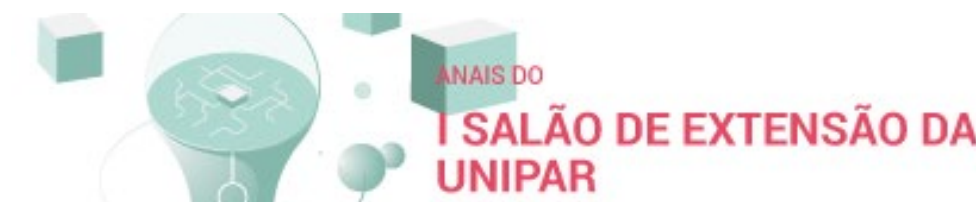 \\ - UNIPAR 50 anOS: \\ Transformando vidas através da educaçäo \\ 27 de Outubro de 2021

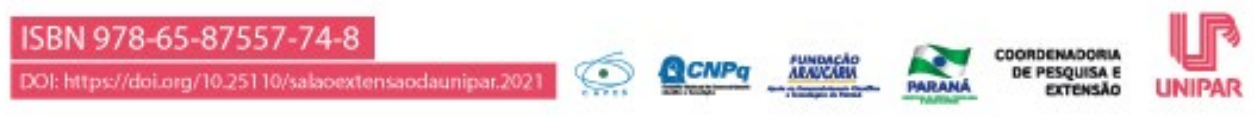 \\ CAMPANHA DE CONSCIENTIZAÇÃO NAS REDES SOCIAIS SOBRE O USO DE CINTO DE SEGURANÇA NOS AUTOMÓVEIS
}

\author{
${ }^{1}$ CAROLINE ZAURA, ${ }^{2}$ YASMIN LARISSA SPRICIGO, ${ }^{3}$ JOSE CARLOS RIBEIRO NETO, ${ }^{4}$ BEATRIZ CORREA CERNKOVIC, \\ ${ }^{5}$ ARTHUR LORHAN CALDEIRA, ${ }^{6}$ LUIGGI VASCONCELOS VITO, ${ }^{7}$ JORGE ANTONIO RIGONI JUNIOR
}

\author{
${ }^{1}$ Acadêmica do Curso de Medicina da UNIPAR \\ ${ }^{2}$ Acadêmica do Curso de Medicina da UNIPAR \\ ${ }^{3}$ Acadêmico do Curso de Medicina da UNIPAR \\ ${ }^{4}$ Acadêmica do Curso de Medicina da UNIPAR \\ ${ }^{5}$ Acadêmico do Curso de Medicina da UNIPAR \\ ${ }^{6}$ Acadêmico do Curso de Medicina da UNIPAR \\ ${ }^{7}$ Docente da UNIPAR
}

Introdução: Os acidentes de trânsito foram responsáveis por 3.400 óbitos diariamente no mundo, em 2012, segundo a Organização Mundial da Saúde (OMS) (MALTA, 2016). Além dos óbitos, os acidentes são responsáveis por muitos traumatismos, estima-se que cerca de 20 a 50 milhões de traumatismos não mortais ocorram por ano no mundo (NARVÁEZ, 2017). Durante os acidentes as lesões nos ocupantes dos veículos são produzidas por traumas oriundos da projeção destes que podem ocorrer através do embate dos ocupantes traseiros com dianteiros ou ejeção de ocupantes ao meio externo. (DURÃO; LUCAS, 2015). Um estudo mostrou que o uso do cinto de segurança reduz o risco de fraturas de face e que o número de fraturas nos ocupantes do banco traseiro sem cinto é muito alto, levando a crer que a utilização do cinto de segurança reduziria este fato (FONSECA, 2007).

Objetivo: O objetivo do projeto é a conscientização da população sobre o uso do cinto de segurança.

Resultados: No mês de setembro de 2021, ocorreu a divulgação do projeto. A disseminação ocorreu através do Instagram, pelo perfil da Liga Acadêmica de Ortopedia e Traumatologia da Universidade Paranaense que tem como usuário @laot.unipar. Na campanha foram feitas três postagens que abordam os objetivos, consequências e motivos do uso do cinto de segurança de uma forma dinâmica e de fácil interpretação para que assim possa conscientizar pessoas de todas as idades, visando disseminar um conhecimento seguro e de qualidade. A escolha da divulgação pela rede social foi devido ao grande grupo que podemos estender essa campanha de conscientização, levando em conta que até o dia 22 de setembro de 2021 as postagens tiveram um alcance de 176 visualizações, dentre as pessoas que visualizaram em sua maioria foram estudantes de medicina da Universidade Paranaense, porém seguem sendo divulgadas pelos integrantes da liga para que possam concientizar um público ainda maior.

Conclusão: Com o desenvolvimento do projeto ficou evidente que os acidentes de trânsito podem causar diversos traumatismos e até levar à morte. A velocidade excessiva é um grande fator entre as múltiplas causalidades. Em relação a isso, o uso do cinto de segurança, como foi observado, diminui as chances de trauma e até mesmo de morte.

\section{Referências}

DURÃO, Carlos Henriques; LUCAS, Francisco Manuel. Interpretação das lesões ortopédicas dos ocupantes dos veículos na reconstrução forense dos acidentes de viação. Revista Portuguesa de Ortopedia e Traumatologia, v. 23, n. 4, p. 298-309, 2015. Disponível em: http://www.scielo.pt/pdf/rpot/v23n4/v23n4a03.pdf Acesso em: 08 set 2021.

FONSECA, Alexandre Siqueira Franco et al. Seating position, seat belt wearing, and the consequences in facial fractures in car occupants. Clinics, v. 62, p. 289-294, 2007. Disponível em: https://www.scielo.br/j/clin/a/M9pqWynQdpfkWTHjkshkN9Q/?lang=en Acesso em: 08 set 2021.

MALTA, Deborah Carvalho et al. Lesões no trânsito e uso de equipamento de proteção na população brasileira, segundo estudo de base populacional. Ciência \& Saúde Coletiva, v. 21, p. 399-410, 2016. Disponível em: https://www.scielo.br/j/csc/a/TnRQ33rzhVWytpKVGbDWF5d/?lang=pt Acesso em: 08 set 2021.

NARVÁEZ YV, Sierra VP, Martínez JIV, González BZ, Cárdenas FP, Ramos LR, et al. Prevalencia del uso del cinturón de seguridad en vehículos automotor: un estudio observacional urbano. Journal Health NPEPS, v.2, n.1, p.194-205, 2017. Disponível em: https://periodicos.unemat.br/index.php/jhnpeps/article/view/1803 Acesso em: 08 set 2021. 
- unIPAR 50 anos:

I SALAOO DE EXTENSÃO Transformando vidas atravies da educaģso

DA UNIPAR 


\section{TMAIS DO UNIPAR 50 ANOS \\ SALÃO DE EXTENSÃO DA Transtormando vidas attravés da educaçăo UNIPAR \\ LIGA ACADÊMICA DE OTORRINOLARINGOLOGIA: COMPARTILHANDO CONHECIMENTO E DESPERTANDO O CUIDADO COM O PRÓXIMO}

${ }^{1}$ SIMARA RAISA DE BRITO MORAES, ${ }^{2}$ ESTER PELEGRINI SILVA, ${ }^{3}$ LUCAS ALEXANDRE GUBERT SCHIER, ${ }^{4}$ EDUARDO AUGUSTO PFAU, ${ }^{5}$ MARIO MARQUES PEREIRA FILHO, ${ }^{6}$ THALYTA CUSTODIO, ${ }^{7}$ ARIELLA REGINA BRUSCHI, ${ }^{8}$ FABIOLA COSTA TAKAKUA, ${ }^{9}$ AUGUSTO FASSINI FONT, ${ }^{10} \mathrm{VICTOR}$ HUGO ONO SAKUMA DOLCI DOS SANTOS, ${ }^{11}$ FABIANE ANGELICA DE PAIVA PAULA, ${ }^{12}$ BERNARDO MUNHOZ LIMA, ${ }^{13}$ DEBORAH TAVARES BIEZUS, ${ }^{14}$ FERNANDO CEZAR CARDOSO MAIA FILHO

${ }^{1}$ Acadêmica do curso de Medicina da UNIPAR

${ }^{2}$ Acadêmica do Curso de Medicina da UNIPAR

${ }^{3}$ Acadêmico do Curso de Medicina da UNIPAR

${ }^{4}$ Acadêmico do Curso de Medicina da UNIPAR

${ }^{5}$ Acadêmico do Curso de Medicina da UNIPAR

${ }^{6}$ Acadêmica do Curso de Medicina da UNIPAR

${ }^{7}$ Acadêmica do Curso de Medicina da UNIPAR

${ }^{8}$ Acadêmica do Curso de Medicina da UNIPAR

${ }^{9}$ Acadêmico do Curso de Medicina da UNIPAR

${ }^{10}$ Acadêmico do Curso de Medicina da UNIPAR

${ }^{11}$ Acadêmica do Curso de Medicina da UNIPAR

${ }^{12}$ Acadêmico do Curso de Medicina da UNIPAR

${ }^{13}$ Acadêmica do Curso de Medicina da UNIPAR

${ }^{14}$ Docente da UNIPAR

Introdução: As ligas acadêmicas, uma junção científica livre, possui como objetivo complementar a formação acadêmica em uma área específica da medicina. Assim, agrega valores e conhecimento, dando a oportunidade dos alunos participarem de atividades fora do ambiente institucional acadêmico abrangendo atividades voltadas para ensino, pesquisa e extensão (TAVARES et al., 2020). Dessa maneira, as implantações das ligas contribuem para promoção a saúde expressando a importância da atuação junto a sociedade (INÁCIO et. al., 2021). Visando isso, a liga acadêmica de otorrinolaringologia (LAORL), além de compartilhar conhecimento, teve o intuito de contribuir com a comunidade por meio de arrecadações de doações e posterior entrega, auxiliando as políticas públicas locais.

Objetivo: Descrever ação de extensão realizada pela LAORL a qual contemplou uma palestra elaborada pela Liga na Sede UNIPAR associada à arrecadação de doações para o Abrigo Tia Lili no município de Umuarama-PR.

Resultados: A palestra intitulada como Emergências em Otorrinolaringologia foi ministrada pela Dra Sandra Abou Rahal, de forma presencial, no campus sede da Unipar em Umuarama no dia 04 de agosto de 2021. Participaram da palestra um total de 25 (vinte e cinco) pessoas que ao processo de inscrição realizaram a doação de materiais de higiene pessoal e alimento. Atrelada a difusão do conhecimento dentro da área da otorrinolaringologia, a liga buscou além de atuar com a atividade de extensão dentro do público acadêmico do curso de medicina, realizar uma ação social, sendo arrecadados diversos produtos como pasta de dente, escovas dentais, fio dental, sabonetes e leite, que foram destinados a doação para o abrigo da tia Lili localizado no município de Umuarama.

Conclusão: Considerando que a LAORL foi recentemente implementada dentro de um período atípico com a presença da pandemia do COVID que exigiu necessidades como o cumprimento de cuidados com o distanciamento social, a atividade desenvolvida através da aula expositiva de uma renomada médica especialista, possibilitou a comunidade acadêmica um conhecimento agregado fundamental para formação dos futuros profissionais de medicina. Adicionado a isso, mesmo que com números reduzidos de recursos adquiridos através dessa ação de extensão, o sentimento de poder ajudar ao próximo através das doações recebidas por esse evento foi despertado nos participantes da Liga e com certeza servirá de estímulo para os novos eventos.

\section{Referências}


INÁCIO, Giovana Porto et. al. Liga Acadêmica de Medicina Integrada à Saúde da Comunidade: reflexões sobre a sua criação. Brazilian Journal of Health Review, Curitiba, v.4, n.3, p. 14330-14335 maio./jun. 2021. Disponível em: http://dx.doi.org/10.34119/bjhrv4n3-363. Acesso em: 04 set. 2021.

TAVARES, Dione Fernandes; ANDRADE, Marco Antônio Vieira; TEIXEIRA, Thiago Rhangel Gomes. Contribuições das ligas acadêmicas na formação médica brasileira. Revista Eletrônica Científica Da UERGS, v. 6, n.3, p. 289-292, dez. 2020. Disponível em: https://doi.org/10.1590/S1414-32832008000400003. Acesso em: 04 set. 2021.

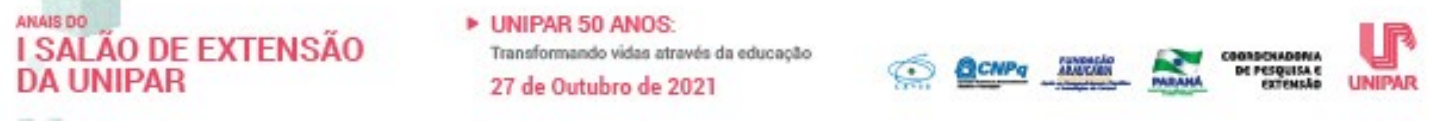




\title{
D E \\ SALÃO DE EXTENSÃO DA Transformando vidas através da educą̧̄o \\ UNIPAR \\ 27 de Outubro de 2021 \\ ISBN 978-65-87557-74-8

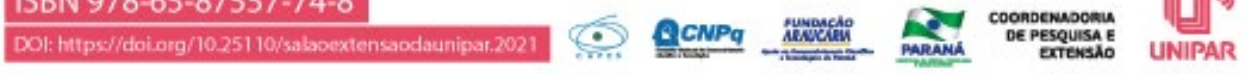 \\ USO DE VÍDEOS CURTOS EM ANATOMOFISIOLOGIA HUMANA NO PROGRAMA LABORATÓRIO ABERTO
}

\author{
${ }^{1}$ DANIELE CRISTINE ROSA DE SOUZA, ${ }^{2}$ JOSE EDUARDO IZABEL BERKENBROCK, ${ }^{3}$ MARIA EDUARDA MACIEL DE \\ SOUSA, ${ }^{4}$ PAMELA GROLLI, ${ }^{5}$ MONICA CASA, ${ }^{6}$ LUCIANA PELLIZZARO
}

1Acadêmica do curso de Educação Física da UNIPAR
${ }^{2}$ Acadêmico do Curso de Educação Física da UNIPAR
${ }^{3}$ Acadêmica do Curso de Educação Física da UNIPAR
${ }^{4}$ Acadêmica do Curso de Educação Física da UNIPAR
${ }^{5}$ Acadêmica do Curso de Farmácia da UNIPAR
${ }^{6}$ Orientadora, Professora da Unipar, Francisco Beltrão.

Introdução: Existem diversas novas estratégias usadas atualmente para estudo da Anatomofisiologia Humana, incluindo a gravação de pequenos vídeos, que são materiais audiovisuais de curta duração. Entre os métodos passivos de estudo, gravamos cerca de $20 \%$ do que ouvimos, $30 \%$ do que vemos e quando articulamos os dois, cerca de $50 \%$ (GLASSER, 2001). Já, entre os métodos ativos, nas discussões absorvemos cerca de $70 \%$ e ao ensinarmos, cerca de 95\% (OLIVEIRA; SANTOS, 2020). Assim, quando um vídeo é assistido contribui para a aprendizagem, e mais ainda quando está sendo preparado, onde é necessária a explicação. O Programa de Extensão Laboratório Aberto da Unipar fez uso desta estratégia para contribuir com o estudo de Anatomofisiologia.

Objetivo: Descrever o uso de vídeos curtos de Anatomofisiologia Humana no Programa de Extensão Laboratório Aberto.

Desenvolvimento: O Programa de Extensão Laboratório Aberto recebe na Unipar alunos de Ensino Fundamental e Médio de Francisco Beltrão e região com intuito de diversificar a sua aprendizagem prática em diversas áreas, incluindo Anatomofisiologia. Por conta das restrições impostas pela pandemia de Covid, visitações não foram possíveis. Então, para cumprir o programa, acadêmicos envolvidos fizeram vídeos curtos sobre os conteúdos. As gravações ocorreram após encontros entre os acadêmicos proponentes, para revisar os assuntos e sistematizar o que cada um gravaria. Foram usadas peças sintéticas do Laboratório de Anatomia da Unipar durante a gravação. Os vídeos gravados foram editados e enviados para professores de Ciências e Biologia dos colégios da região para que pudessem usá-los com seus alunos, e para os demais acadêmicos dos cursos da saúde da Unipar. Jaffar (2012), afirma que um número significativo de estudantes utiliza e depende da internet como meio de auxílio para estudo, incluindo sites, bibliotecas virtuais e plataformas de vídeos, desta forma, as gravações tiveram sua contribuição.

Conclusão: Muitos estudantes assistem a vídeos para auxiliar em seu estudo e complementar aulas tradicionais. A atividade contribuiu para o enriquecimento de conteúdo dos acadêmicos envolvidos no projeto, tendo em vista a oportunidade de explicar os assuntos de Anatomofisiologia.

\section{Referências}

GLASSER, William. Pirâmide de aprendizagem. 2001. Disponível em: http://www.abntouvancouver.com.br/2016/11/a-piramidede-aprendizagem-de-william.html. Acesso em 04 set. 2018.

JAFFAR, Akram Abood. YouTube: An Emerging Tool in Anatomy Education. Anat Sci Educ, v. 5, pp. 158-64, 2012.

OLIVEIRA, Layara Karuenny Oliveira; SANTOS, Ernani Martins. Metodologias Ativas e suas contribuições para os processos de ensino e aprendizagem. Congresso Nacional de Educação, 7, out. 2020. Anais... Edição On-line. Campina Grande: Realize, 2020., Disponível em: https://editorarealize.com.br/index.php/artigo/visualizar/68873. Acesso em: 23 ago. 2021.

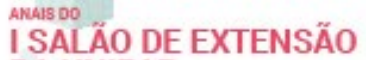

DA UNIPAR

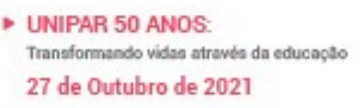

27 de Outubro de 2021

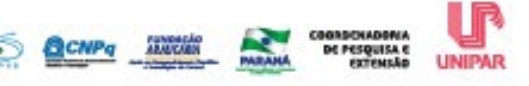




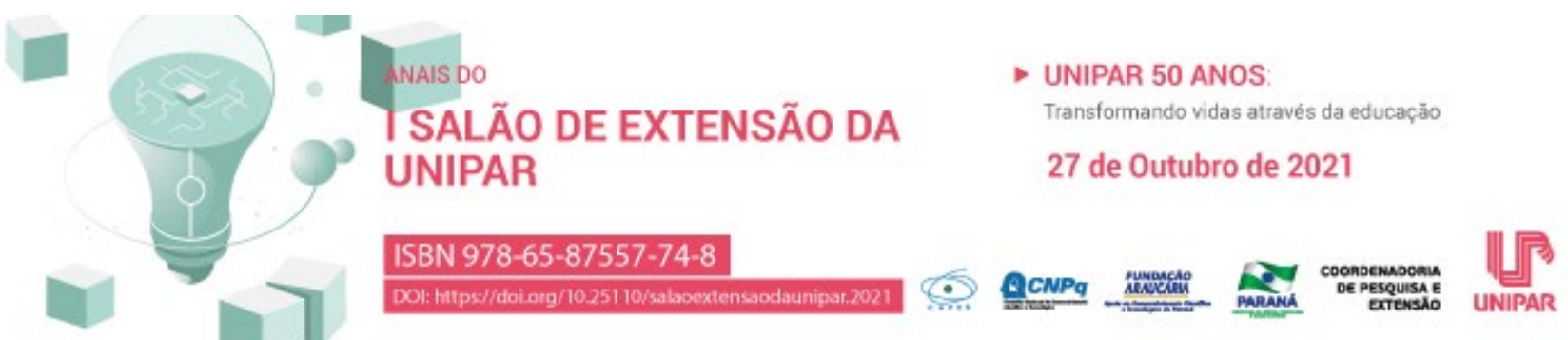 \\ REFORMA TRIBUTÁRIA: UMA ANÁLISE DO IMPOSTO DE RENDA PESSOA FÍSICA
}

\author{
${ }^{1}$ IDAIR EDSON MARCELLO, ${ }^{2}$ TAINARA CORTESE FOIATO, ${ }^{3}$ FLAVIO HENRIQUE ROHLING
}

${ }^{1}$ Docente do Curso de Ciências Contábeis

${ }^{2}$ Acadêmica do Curso de CiÃãncias Cont $\tilde{A}_{j}$ beis da UNIPAR

${ }^{3}$ Acadêmico do Curso de Ci $\tilde{A ̃}^{a}$ ncias Cont $\tilde{i}$ beis da UNIPAR

Introdução: O Imposto de Renda (IR) é regido pelo Decreto no 9.580/2018. A Câmara dos Deputados aprovou o Projeto de Lei $\mathrm{n}^{\circ}$ 2.337/2021, que traz mudanças nas faixas do IR, o que deve aumentar em mais de 5 milhões o número de contribuintes isentos do imposto. Este projeto ainda tem que passar pelo Senado que poderá concordar ou sugerir modificações sobre o textobase desta reforma tributária. Todas as faixas de IR deverão ser beneficiadas, e, com a redução tributária, pretende-se aumentar a disponibilidade de recursos para a população em geral, contribuindo assim, com a economia do país.

Objetivo: Analisar o impacto das alterações propostas pela Câmara dos Deputados no Projeto de Lei $n^{\circ} 2.337 / 2021$, na legislação do Imposto de Renda, precipuamente nas faixas de IR em relação à pessoa natural.

Resultados: A fim de de se verificar como seriam os resultados alcançados pela mudança na tabela do imposto de renda da pessoa física (TIRPF), foi realizada uma análise descritiva, tendo como base salários mensais brutos, visando uma relação com as 5 (cinco) faixas salariais dispostas na TIRPF. Com a incidência de um valor salarial de $R \$ 2.500,00$, constata-se que na versão ATUAL da TIRPF, teríamos 6,8 milhões de contribuintes na faixa 2 da tabela, enquanto que na tabela NOVA, teríamos 16,3 milhões de contribuintes na faixa 1 . Ao se verificar o salário de R $\$ 3.500,00$, na versão ATUAL da TIRPF, teríamos 3,7 milhões de contribuintes na faixa 3 , e na NOVA, 3,6 milhões de contribuintes, igualmente na faixa 3 . Já com um salário de R\$ $5.000,00$ teríamos na ATUAL 6,9 milhões de contribuintes na faixa 5, e na NOVA, 2,2 milhões na faixa 4. Por fim, o valor de R\$ $8.000,00$ teríamos na versão ATUAL 6,9 milhões de contribuintes na faixa 5 , e na NOVA, 6,3 milhões de contribuintes, na faixa 5.

Considerações Finais: Com a NOVA tabela do IR já aprovada pela Câmara dos Deputados, os contribuintes das faixas 1 e 2 serão os mais beneficiados com a mudança, sendo que, somente na faixa 1 , haverá um aumento dos casos de isenção do tributo em 5,6 milhões de contribuintes. Nas faixas 3, 4 e 5 da nova tabela, quem nelas se enquadrarem, terão valores menores de IR a ser recolhido ao governo federal. Já o valor do IR, com base em salários mensais acima de $R \$ 5.000,00$ permanecerão pagando valores semelhantes aos que já pagam na tabela ATUAL, pois o valor da declaração simplificada que era de $20 \%(R \$ 16.754 .34)$ cairá para $\mathrm{R} \$ 10.563,60$, anulando neste sentido, a diminuição do desconto mensal do IR proposta pela nova tabela.

\section{Referências}

BRASIL. Decreto no 9.580, de novembro de 2018. Regulamenta a tributação, a fiscalização, a arrecadação e a administração do Imposto sobre a Renda e Proventos de Qualquer Natureza. Diário Oficial da União, Brasília, v. 225, n. 1, p. 57, 23 nov. 2018. Disponível em: Acesso em: 09 set 2021.

BRASIL. Projeto de Lei no 2337, de Junho de 2021. Altera a legislação do Imposto sobre a Renda e Proventos de Qualquer Natureza das Pessoas Físicas e das Pessoas Jurídicas e da Contribuição Social sobre o Lucro Líquido. Disponível em: Acesso em: 10 set 2021.

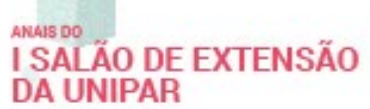
I SALÃO DE EXTENSÃO
DA UNIPAR

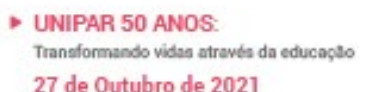

27 de Outubro de 2021

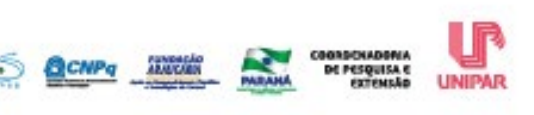




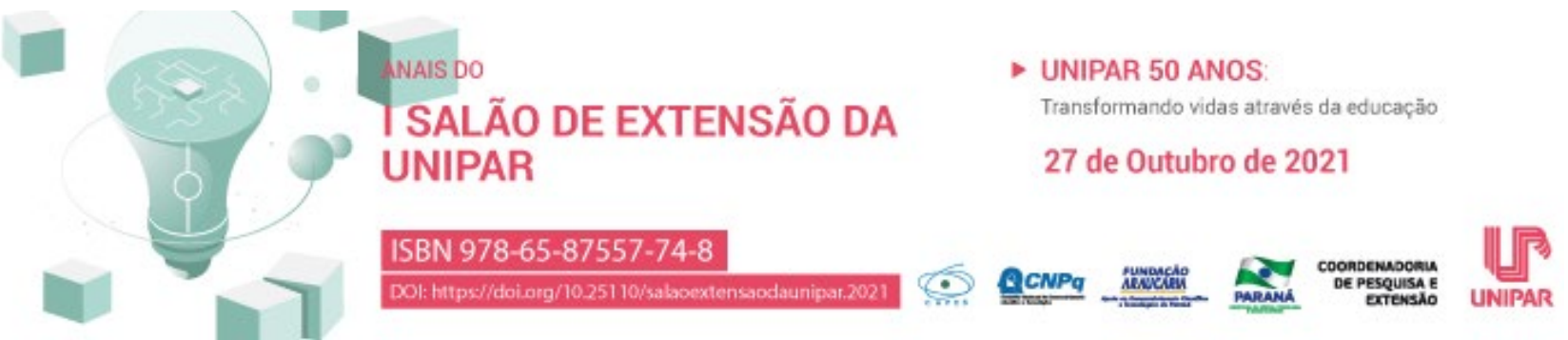 \\ FISIOTERAPIA AQUÁTICA: RECUPERAÇÃO FUNCIONAL NA ÁGUA
}

\author{
${ }^{1}$ MARIA VICTORIA VECCHIETTI, ${ }^{2}$ PAOLLA TAGLIATELLA, ${ }^{3}$ LETICIA IGNEZ DE OLIVEIRA, ${ }^{4} J$ JesSICA JUSSARA \\ SCHENKNECHT, ${ }^{5}$ DORA DE CASTRO AGULHON SEGURA
}

\begin{abstract}
${ }^{1}$ Acadêmica do Curso de Fisioterapia da UNIPAR
${ }^{2}$ Acadêmica do Curso de Fisioterapia da UNIPAR

${ }^{3}$ Acadêmica do Curso de Fisioterapia da UNIPAR

${ }^{4}$ Acadêmica do Curso de Fisioterapia da UNIPAR

${ }^{5}$ Docente da UNIPAR
\end{abstract}

Introdução: A fisioterapia aquática é uma das áreas de reabilitação que utiliza das propriedades da água para promover efeitos físicos funcionais em diversas doenças osteomioarticulares. Diversas são as desordens corporais que se beneficiam com essa técnica, desde lesões neurológicas, a casos ortopédicos e desportivos, bem como afecções geriátricas e pediátricas (RESENDE; RASSI; VIANA, 2008). A temperatura aquecida da água e sua mobilidade promovem diminuição da tensão muscular e estímulo das habilidades motoras, bem como treina o equilíbrio e a coordenação. Compõe um ambiente agradável e relaxante que entusiasma os pacientes a frequentarem as clínicas de fisioterapia (SACCHELLI; ACCACIO; RADI, 2007).

Objetivos: Através de um projeto de extensão promover conhecimento sobre as áreas de atuação da fisioterapia, neste momento, sobre a fisioterapia aquática.

Resultados: Para Candeloro e Caromano (2007), a fisioterapia aquática, também nominada de hidroterapia, é um dos diversos tipos de tratamento funcional desenvolvido e executado por fisioterapeutas. Em ambiente hídrico, através de uma piscina aquecida, uma variedade de exercícios é proposta, objetivando minimizar dor, promover relaxamento, melhorar amplitudes de movimento, tornando possível a realização de algumas atividades que em solo se tornam mais difíceis de serem executadas. Além de ser um ambiente que propicia socialização, sendo mais um componente para melhora da qualidade de vida dos pacientes. A modalidade pode ser desempenhada de forma individual ou em grupos de enfermidades com quadro clínico semelhante, trata-se de um meio que viabiliza segurança, por não ter risco de quedas. Também vale ressaltar que o corpo submerso em água, possui menos peso, o que incide em menor risco de lesões provocadas por impacto. Conhecimentos divulgados acerca do tratamento da fisioterapia em meio aquático se fazem de suma importância para direcionar pacientes a conduta terapêutica mais adequada as suas disfunções, bem como promove conhecimentos aos estudantes da fisioterapia que podem aprofunar o conhecimento clínico (FACCI; MARQUETTI; COELHO, 2007).

Conclusão: Concluiu-se que o projeto em questão é crucial para a divulgação da fisioterapia, em todos seus aspectos, neste caso, abordando a fisioterapia aquática, que reproduz diversos benefícios através das propriedades da água, sendo um excelente meio de recuperação funcional.

\section{Referências}

CANDELORO, J. M.; CAROMANO, F. A. Elaboração, aplicação e avaliação de um programa de ensino de adaptação ao meio aquático para idosos. Acta Fisiátrica, v. 14, n. 3, p.170-75, 2007.

FACCI, L. M.; MARQUETTI, R.; COELHO, K. C. Fisioterapia aquática no tratamento da osteoartrite de joelho: Série de casos. Fisioterapia em Movimento, v. 20, n. 1, p. 26-31, 2007.

RESENDE, S. M.; RASSI, C. M.; VIANA, F. P. Efeitos da hidroterapia na recuperação do equilíbrio e prevenção de quedas em idosas. Revista Brasileira de Fisioterapia, v. 12, n. 1, p. 57-63, 2008.

SACCHELLI, T.; ACCACIO, L. M. P.; RADI, A. L. M. Fisioterapia aquática. São Paulo: Manole, 2007

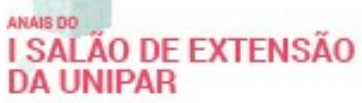

DA UNIPAR

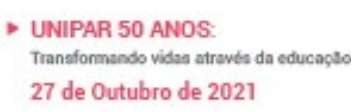

Transformando vidas atraves da educagso

27 de Outubro de 202

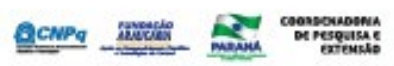

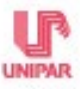




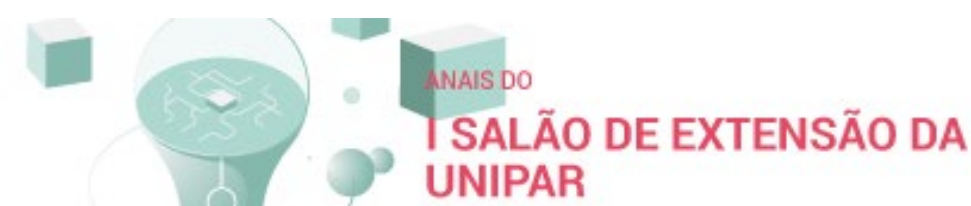 \\ - UNIPAR 50 ANOS \\ Transformando vidas através da educaçāo \\ 27 de Outubro de 2021 \\ ISBN 978-65-87557-74-8 \\ DOI: hitps/idoiorg/10.251 10/saboextenssodaunipar.2021 \\ QCNPq Auscetio

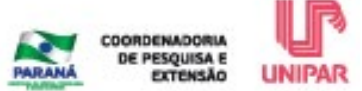 \\ HORTO MEDICINAL DO CAMPUS 2 DA UNIPAR: ATENDENDO A COMUNIDADE DE UMUARAMA E REGIÃO}

${ }^{1}$ MIGUEL FRANCISCO FERREIRA BATISTA, ${ }^{2}$ MATHEUS MARQUEZINI DE ANDRADE, ${ }^{3}$ ALYNE FERNANDA LEUCH DE SOUZA, ${ }^{4}$ GABRIEL SABATINI PEREIRA, ${ }^{5}$ ELIZABETH DANTAS, ${ }^{6}$ GABRIELA RAMPAZZO SANCHES BELTER, ${ }^{7}$ DANILO FELIPE SARAN, ${ }^{8}$ JULIANA TRENTINI MASCHIETTO, ${ }^{9}$ ALESSANDRO TENCA, ${ }^{10}$ DANIELA DE CASSIA FAGLIONI B CERANTO, ${ }^{11}$ ODAIR ALBERTON, ${ }^{12}$ EMERSON LUIZ BOTELHO LOURENCO, ${ }^{13}$ EZILDA JACOMASSI

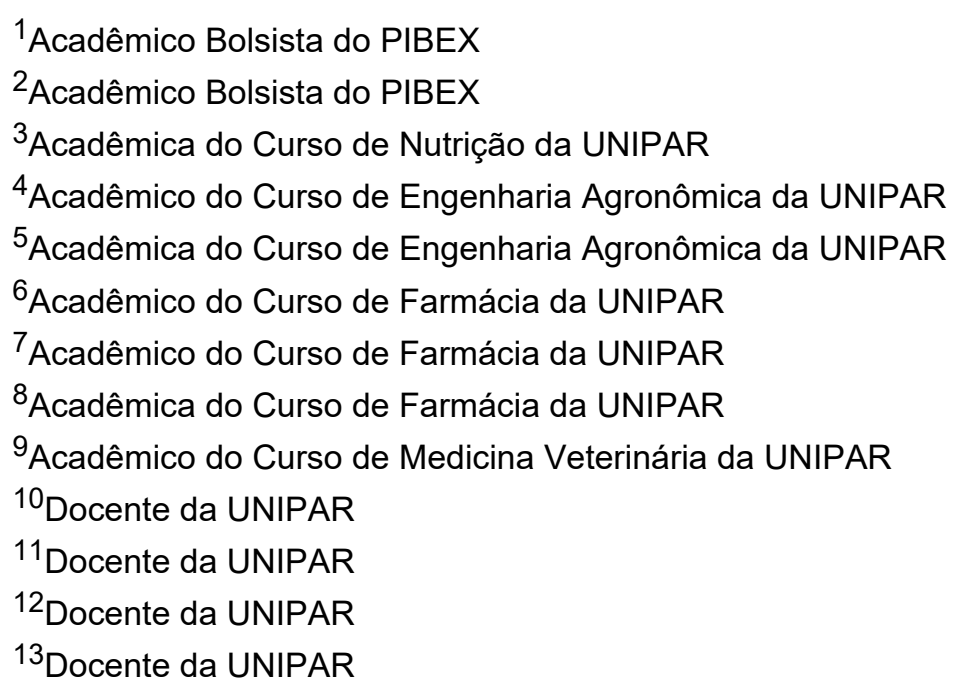

Introdução: O Horto Medicinal do Campus 2 da Universidade Paranaense (UNIPAR), situado em Umuarama/PR, foi implantado em 1996, em uma área de $30.000 \mathrm{~m}^{2}$, tornando-se um referencial de extrema importância para a comunidade local e regional, acadêmica ou não (CANZI et al.). Este espaço, considerado um laboratório vivo, permite a vivência de experiências que são compartilhadas dentro do universo que envolve as plantas medicinais.

Objetivo: Mostrar a importância do Horto Medicinal como um recurso terapêutico para a comunidade local e regional.

Resultados: Atualmente o Horto Medicinal conta com uma coletânea com cerca de 500 espécies, entre medicinais, tóxicas, comestíveis e ornamentais, onde, predominantemente, são plantas com propriedades terapêuticas. $O$ projeto proporciona o desenvolvimento de diversas atividades relacionadas ao Ensino, Pesquisa e Extensão desenvolvidas na UNIPAR. Dentre tantas atividades, podemos citar: visitas monitoradas que devem ser previamente agendadas; palestras e oficinas em escolas e Unidades Básicas de Saúde, quando solicitadas; produção de mudas para doação às hortas comunitárias, bem como a comercialização; produção de material biológico para aulas práticas dos cursos de graduação e pós-graduação da UNIPAR; catalogação de espécies presentes no Horto; produção de matéria prima para o desenvolvimento de teses, monografias, dissertações, projetos de iniciação científica e outros projetos de extensão. Sendo assim, atendendo inúmeras necessidade da UNIPAR e, inclusive, de outras Instituições situadas na região que buscam apoio para realizar trabalhos com plantas medicinais. Segundo Badke (2019) o desenvolvimento de projetos dessa natureza, oportuniza o resgate e a valorização do uso de plantas com propriedades terapêuticas entre docentes, discentes e comunidade, contribuindo, especialmente, para o cuidado compartilhado na melhoria e qualidade de vida de todos.

Conclusão: Apesar da situação pandêmica, o Horto Medicinal tem atendido a comunidade que vem a procura de maiores conhecimentos sobre este valioso recurso terapêutico representado pelas plantas medicinais. Por fim, o sucesso deste projeto de quase 26 anos, é resultado de um trabalho em equipe multidisciplinar, aliado ao incentivo e investimento constantes por parte da UNIPAR.

\section{Referências}

CANZI, et al. Levantamento florístico do Horto Medicinal do Campus 2 da Universidade Paranaense (UNIPAR) Umuarama/PR. Arquivos de Ciências da Saúde da UNIPAR (Impresso). , v.16, p.123 - 137, 2012.

BADKE, Marcio Rossato et al. Construção e implementação de um horto medicinal: um projeto de extensão universitária. Revista Brasileira em Promoção da Saúde, v. 32, 2019. 
- unIPAR 50 anos:

I SALAOO DE EXTENSÃO Transformando vidas atravies da educaģso

DA UNIPAR 


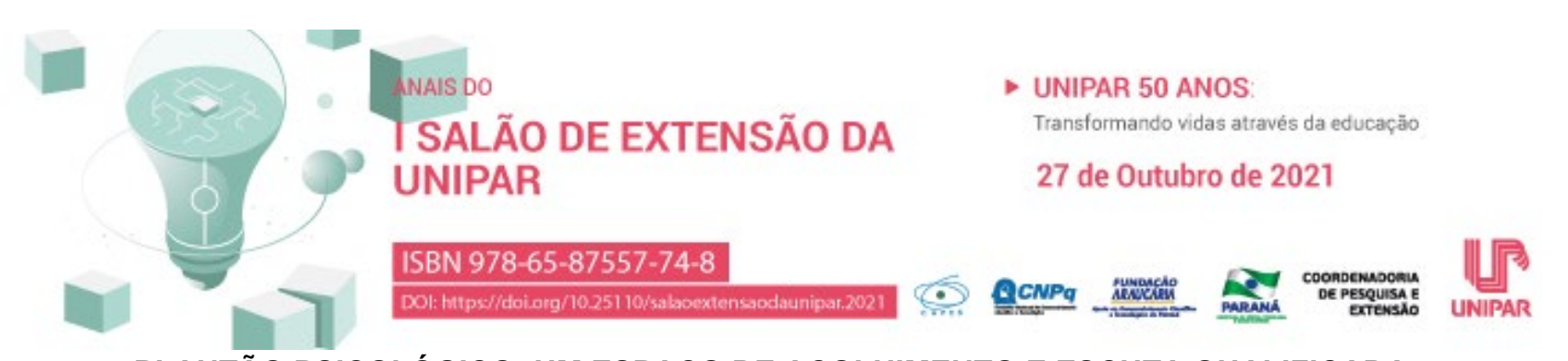

\title{
PLANTÃO PSICOLÓGICO: UM ESPAÇO DE ACOLHIMENTO E ESCUTA QUALIFICADA
}

\author{
${ }^{1}$ FLAVIA MARANEZI BRANDAO , ${ }^{2}$ MARIA ANDRESSA BLOCHENSKI, ${ }^{3}$ VALENTINA DIAS PEREIRA BERNARDES, ${ }^{4}$ LETICIA \\ IZABEL SANDRI, ${ }^{5}$ ARIANE DIOANE CARVALHO BARBOSA, ${ }^{6}$ ANA MARIA CANZI, ${ }^{7}$ ANA PAULA GARGANTINI DA SILVA
}

${ }^{1}$ Acadêmica do Curso de Psicologia UNIPAR

${ }^{2}$ Acadêmica do Curso de Psicologia da UNIPAR

${ }^{3}$ Acadêmica do Curso de Psicologia da UNIPAR

${ }^{4}$ Acadêmica do Curso de Psicologia da UNIPAR

${ }^{5}$ Acadêmica do Curso de Psicologia da UNIPAR

${ }^{6}$ Acadêmica do Curso de Psicologia da UNIPAR

${ }^{7}$ Psicóloga Responsável Técnica do Serviço-Escola de Psicologia

Introdução: O plantão psicológico se configura enquanto uma modalidade de atendimento psicológico, tendo como objetivo atender as demandas emergenciais que são trazidas pelos usuários (GOMES, 2008). Furigo et al (2008) apontam que na prática de plantão psicológico, é importante que sejam realizados os encaminhamentos necessários para a condução de cada caso. No plantão psicológico realizado no Serviço-Escola de Psicologia, após avaliação do caso, o atendimento poderia ser estendido até cinco sessões. Se a decisão fosse encaminhamento para outros serviços, uma possibilidade que contribuiu para o projeto, foi o encaminhamento para Psicólogos egressos da Instituição, através do convênio firmado com o Serviço-Escola de Psicologia UNIPAR Campus Cascavel.

Objetivos: O plantão psicológico visa a promoção de saúde mental nas mais variadas demandas apresentadas pelos indivíduos. A escuta qualificada e o acolhimento foram indispensáveis para a prática do plantão, antes de avaliar quais as melhores possibilidades de encaminhamentos do caso.

Resultados: Em geral, foi possível perceber que o usuário esperava encontrar alguém para ouvi-lo em seu momento de sofrimento e com isso oferecer ajuda para amenizá-lo. Para todas as demandas que chegaram até o plantão foram realizados encaminhamentos. Acredita-se que para uma boa adesão do plantão psicológico é necessária uma cultura bem estabelecida na instituição e região, para que as pessoas passem a procurar mais por esse serviço.

Cosiderações Finais: O presente artigo teve como intuito compartilhar sobre o plantão psicológico realizado no Serviço-Escola de Psicologia da UNIPAR Campus Cascavel. Sendo uma forma de intervenção psicológica que objetiva acolher o sujeito no momento de sua urgência, oferecendo-lhe acolhimento e escuta qualificada.

\section{Referências}

GOMES, F. M. D. Plantão psicológico: novas possibilidades em saúde mental. 2008. Disponível em: . Acesso em: 21 ago. 2021. FURIGO, R. C. P. L.; SAMPEDRO, K. M.; ZANELATO, L. S.; FOLONI, R. F.; BALLALAI, R. C.; ORMROD, T. 2008. Plantão psicológico: uma prática que se consolida. Disponível em: . Acesso em: 20 ago. 2021.

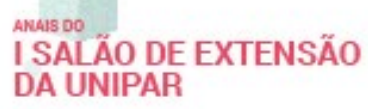

DA UNIPAR

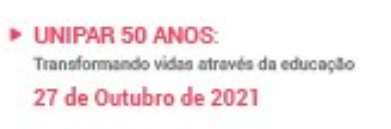

UNIPAR 50 ANOS:
Tranoformando vidas atravis da educagto
27 de Outubro de 2021

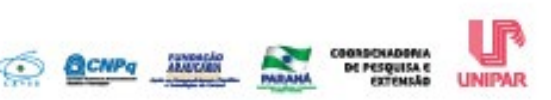




\title{
(1) DNAIS DO UNIPAR 50 ANOS \\ SALÃO DE EXTENSÃO DA Transformando vidas através da educą̧ăo UNIPAR \\ ISBN 978-65-87557-74-8

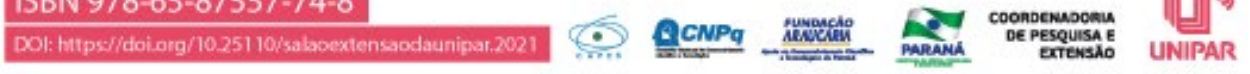 \\ COBERTURA VACINAL DO ROTAVíRUS NA $12^{\mathrm{a}}$ REGIONAL DE SAÚDE DO ESTADO DO PARANÁ, ENTRE OS ANOS DE 2015 A 2019
}

\section{${ }^{1}$ ELIANE SANTOS CARDOSO, ${ }^{2} \mathrm{KATIA}$ BIAGIO FONTES}

\author{
${ }^{1}$ Discente do Curso de Enfermagem da UNIPAR
}

${ }^{2}$ Docente do Curso de Enfermagem da UNIPAR

Introdução: O Rotavírus é um vírus de RNA pertencente à família reoviridae, responsável por diarreia aguda, principalmente em crianças com menos de cinco anos. A diarreia causada pelo Rotavírus representa um problema de saúde pública mundial, gerando um grande impacto na morbimortalidade infantil, sendo responsável por $70 \%$ das internações e por $20 \%$ a $30 \%$ dos óbitos por diarreia (WHO, 2013). A vacina previne da diarreia por Rotavírus, sendo composta pelo vírus atenuado. Foi adotada pelo Programa Nacional de Imunizações (PNI) do Brasil desde 2006, sendo administrada em duas doses, via oral, com intervalo recomendado de 60 dias entre as doses, sendo que, a $1^{a}$ dose deve ministrada até o $3^{\circ}$ mês de vida (PARANÁ, 2021). Os indicadores de cobertura vacinal representam um importante instrumento para a tomada de decisão nas diferentes esferas de gestão, uma vez que somente com coberturas adequadas é possível alcançar o controle ou manter em condição de eliminação ou erradicação as doenças imunopreveniveis (PALUDO, 2019, p. 5).

Objetivo: Analisar os indicadores de cobertura vacinal de Rotavírus da $12^{\mathrm{a}}$ regional se saúde do estado do Paraná, Brasil, entre os anos de 2015 a 2019.

Materiais e método: Trata-se de um estudo epidemiológico de análise descritiva que utilizou como fonte de dados o Sistema de Avaliação do Programa de Imunizações (API) e a base de dados do Departamento de Informática do SUS (DATASUS), referentes ao período entre 2015 e 2019. Os dados disponíveis são oriundos do Sistema de Avaliação do Programa de Imunizações - API, sistema este gerido pela Coordenação Geral do Programa Nacional de Imunizações - CGPNI, do Departamento de Vigilância Epidemiológica, Secretaria de Vigilância em Saúde, do Ministério da Saúde, em conjunto com as Secretarias Estaduais de Saúde, suas regionais e as Secretarias Municipais de Saúde.

Resultados: No período entre 2015 e 2019 a cobertura vacinal do Rotavírus analisados da $12^{\mathrm{a}}$ regional de saúde do estado do Paraná foi de $87,76 \%$, a média do estado foi de $85,33 \%$, enquanto a média nacional nesse período foi de $64,66 \%$. A maior cobertura vacinal apresentada na $12^{\mathrm{a}}$ região de saúde foi no ano de 2015 , com $98,67 \%$, o ano com menor cobertura foi no ano de 2019 , com $63,41 \%$. Por meio da análise das coberturas vacinais foi possível observar que apenas os anos de 2016 e 2019 , foram inferiores a $90 \%$.

Discussão: A cobertura vacinal é um importante indicador de saúde das populações (MIRANDA et al., 1995, p. 212). Um dos grandes desafios do PNI é o alcance das metas de vacinação (ROCHA et al., 2010). A vacinação do Rotavírus é essencial para a diminuição das taxas de internação infantil por diarreia cadastradas no Sistema Único de Saúde do Estado do Paraná. Um estudo realizado por Masukawa et al. (2015), no período de janeiro de 2000 a dezembro de 2009, observaram uma redução significativa nas taxas de hospitalização por diarreias agudas provocadas por Rotavírus, sugerindo que o uso da vacina e outros fatores associados podem reduzir os casos. A cobertura vacinal somente é alcançada quando a criança toma as duas doses da vacina, nisso o PNI tem como meta vacinar $90 \%$ das crianças com as duas doses em crianças menores de 6 meses. Porém, essa relação não é observada nas coberturas vacinais do Rotavírus na $12^{\mathrm{a}}$ regional de saúde do Paraná entre os anos de 2015 a 2019, assim como, no próprio estado do Paraná e no Brasil, podendo aumentar as taxas de diarreia aguda provocada por Rotavírus. Assim, é necessária a compreensão dos fatores associados à não-vacinação e das diferenças regionais, estaduais e municipais para a elaboração de estratégias específicas para cada contexto e território (OLIVEIRA et al., 2020, p. 16).

Conclusão: Comparando a média do estado do Paraná e do Brasil, a $12^{\mathrm{a}}$ região de saúde apresenta maior cobertura vacinal do Rotavírus. Entretanto observou-se uma diminuição significativa no ano de 2019, sendo necessários mais estudos para compreender as peculiaridades envolvidas na não-vacinação, com o propósito de melhorar as estratégias de imunização, permitindo a elaboração de politicas públicas mais específicas e eficazes.

\section{Referências}

OLIVEIRA, Guilherme da Silva et al. Cobertura vacinal: uma análise comparativa entre os estados da região norte do Brasil. Revista de Patologia do Tocantins, v. 7, n. 1, p. 14-17, 2020.

MASUKAWA, Maria de Lourdes Teixeira et al. Impacto da vacina oral de Rotavírus Humano nas taxas de hospitalizações em crianças. Acta Paulista de Enfermagem, v. 28, n. 3, p. 243-249, 2015. 
MIRANDA, Alcides S. de et al. Avaliação da cobertura vacinal do esquema básico para o primeiro ano de vida. Rev. Saúde publica, v. 29, n. 3, p. 208-214, 1995.

PALUDO, Elenice. Análise comparativa da cobertura vacinal da febre amarela no município de Veranópolis em relação à sua região de saúde. 2019. 33f. Trabalho de conclusão de curso (Especialização de gestão em saúde) - Universidade Federal do Rio Grande do Sul, Escola De Administração, Programa De Pós-graduação em Administração, Porto Alegre, 2019.
PARANÁ.
Programa
Estadual
de Imunização.
[online].
2021.
Disponível em: https://www.saude.pr.gov.br/Pagina/Vacinas Acesso em: 6 jul. 2021.

ROCHA, Ruben et al. Fatores associados ao não cumprimento do Programa Nacional de Vacinação e das vacinas pneumocócica conjugada heptavalente e contra o Rotavírus. Acta Pediátrica Portuguesa, v. 41, n. 5, p. 195- $200,2010$.

WORLD HEALTH ORGANIZATION (WHO). Rotavirus vaccines WHO position paper:January 2013. Vaccine, v. 31, n. 52, p. 6701, 2013. Disponível em: https://pubmed.ncbi.nlm.nih.gov/23746456/ Acesso em: 7 jul. 2021.

I SALĂO DE EXTENSÃO

DA UNIPAR
- UNIPAR 50 ANOS.

Transformando vidas atravela da educacto

27 de Outubro de 2021
5 ACNPQ

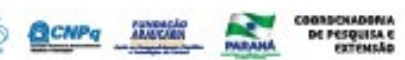




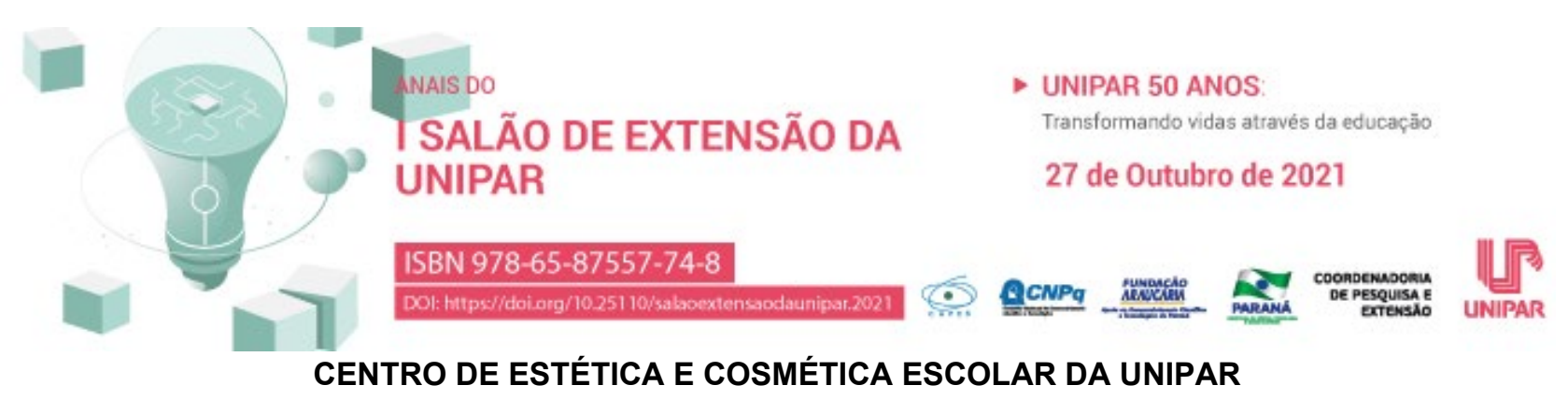

\author{
${ }^{1}$ GEANE DE LIMA MEDEIROS, ${ }^{2}$ LILIA APARECIDA MORENO DOS SANTOS, ${ }^{3}$ NATHANI FANTINE DE SA CERANTO, \\ ${ }^{4}$ TAMIRES PLACIDO MARIOTTI, ${ }^{5}$ SHEILA CRISTINA VIRGINIA DA PAZ DO NASCIMENTO, 6 LAIZA MARIA DA SILVA \\ OLIVEIRA, ${ }^{7}$ CAROLINE STEFANY MANZOLI BARBOSA, ${ }^{8}$ VANESSA ROSALINE COSTA OLIVEIRA
}

\author{
${ }^{1}$ Projeto COPEX \\ ${ }^{2}$ Acadêmica do Curso de Estética e Cosmética da UNIPAR \\ ${ }^{3}$ Acadêmica do Curso de Estética e Cosmética da UNIPAR \\ ${ }^{4}$ Acadêmica do Curso de Estética e Cosmética da UNIPAR \\ ${ }^{5}$ Acadêmica do Curso de Estética e Cosmética da UNIPAR \\ ${ }^{6}$ Acadêmica do Curso de Estética e Cosmética da UNIPAR \\ ${ }^{7}$ Acadêmica do Curso de Estética e Cosmética da UNIPAR \\ ${ }^{8}$ Docente da UNIPAR
}

Introdução: Este Programa Institucional Centro de Estética e Cosmética é uma proposta da Universidade para oportunizar a vivência do acadêmico com a realidade de sua profissão. Este projeto esta presente em todas as Unidades Universitárias de nossa Instituição. São realizados atendimentos estéticos nas seguintes terapias: Estética Capilar, Estética Facial, Estética Corporal, Terapias Alternativas e Imagem Pessoal e Maquiagem. O horário de atendimento é de segunda a sexta no período matutino das $07: 30 \mathrm{~h}$ às 12:00 e no período vespertino das 13:30h às 17:00h. O atendimento é realizado pelas acadêmicas da 3 Série sob supervisão da Responsável Técnica e da Professora Orientadora. $O$ atendimento ao cliente é realizado por um agendamento com a Secretária e em seguida as acadêmicas realizam avaliação um importante passo para o conhecimento de seu cliente e reconhecimento das afeç̧ões, para posteriormente elaborarmos o tratamento. A escola é um espaço importante para o desenvolvimento acadêmico. Sendo um aprendizado na construção de valores pessoais, crenças, conceitos e uma maneira de conhecer na prática o mundo na sua produção social e da saúde ampliando seu senso crítico e político (BRASIL, 2009).

Objetivos: O objetivo deste trabalho é observarmos a importância do desenvolvimento acadêmico perante os atendimentos realizados no Centro de Estética.

Resultados: Foi perguntado para as acadêmicas como foi a experiência quando entrou no Centro até os dias atuais no ano de 2021 e foi explicitado da seguinte forma: Através do projeto de extensão foi possível adquirir a experiência vivida entre profissional e paciente, que é algo a ser priorizado devido a sua significativa relevância pois é através desse contato que se estabelece um vínculo com o paciente a fim de conquistar sua segurança e intimidade para melhor atendê-lo, bem como possibilitar o preparo para a carreira profissional por meio da constante aprendizagem para exercer a profissão com autoconfiança e destreza.

Conclusão: O Projeto de Extensão do Centro de Estética é uma proposta para o desenvolvimento acadêmico na prática onde foi possível: Adquirir experiência vivida, melhora da aptidão em relação aos procedimentos estéticos, aprendizado na prática o que é ensinado em sala na teoria, aumento da confiança e o diálogo com o paciente atendido.

\title{
Referências
}

BRASIL, Ministério da Saúde. Secretaria de Atenção à Saúde. Departamento de Atenção Básica. Saúde na escola. Brasília, n. 24 p. 96. 2009.

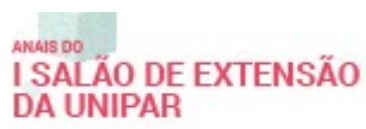

I SALẤO DE EXTENSÃO DA UNIPAR

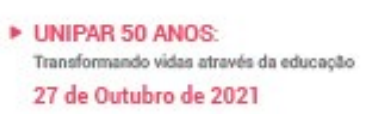

27 de Outubro de 2021
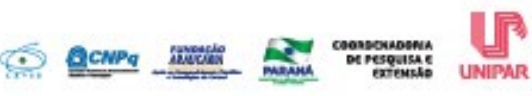


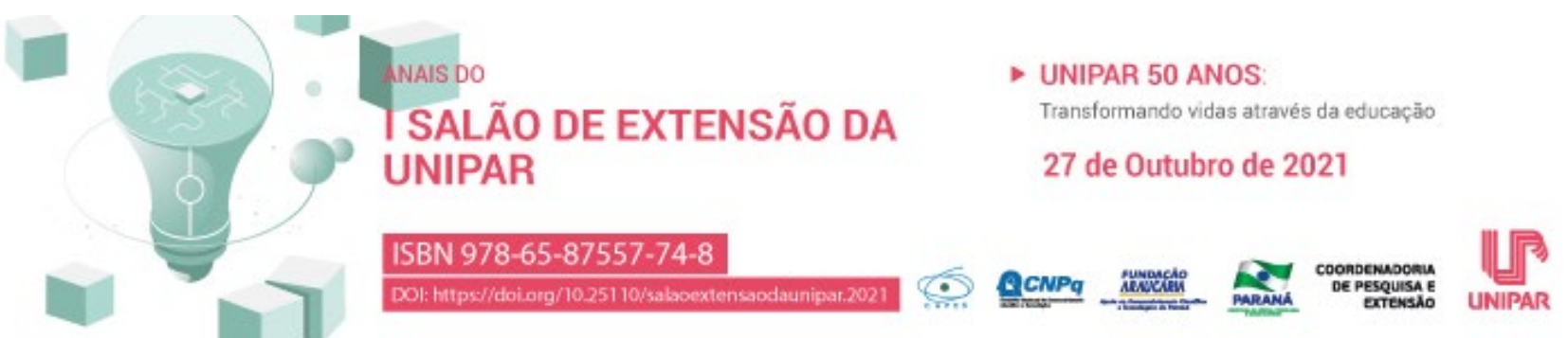 \\ DISTRIBUIÇÃO DE PRESERVATIVOS E FOLHETOS INFORMATIVOS SOBRE IST'S}

1JOAO THOMAZ TERRA PRADO BORGES, ${ }^{2}$ LAIS TEODORO LOPES, ${ }^{3}$ EDSON MEDINE SEREJO NETO, ${ }^{4}$ NATALIA COLCETTA, ${ }^{5}$ DEBORA KUCMANSKI, ${ }^{6}$ GABRIELE JUSSIANI CAETANO, ${ }^{7}$ EULLER CONDE FERNANDES, ${ }^{8}$ ISABELA SILVA TRODORFE, ${ }^{9}$ CRISTIANO JOSE DA SILVA, ${ }^{10}$ KEROLAINE MANTOVI COSTA, ${ }^{11}$ SABRINA SUEMY KATO TANAKA, ${ }^{12}$ INGRIDY RHAIANY PARREIRA MENEGASSI, ${ }^{13}$ CAMILA LOPES DIAS ARROYO, ${ }^{14}$ MARINA GIMENES

${ }^{1}$ Acadêmico do curso de medicina UNIPAR

${ }^{2}$ Acadêmica do Curso de Medicina da UNIPAR

${ }^{3}$ Acadêmico do Curso de Medicina da UNIPAR

${ }^{4}$ Acadêmica do Curso de Medicina da UNIPAR

${ }^{5}$ Acadêmica do Curso de Medicina da UNIPAR

${ }^{6}$ Acadêmica do Curso de Medicina da UNIPAR

${ }^{7}$ Acadêmico do Curso de Medicina da UNIPAR

${ }^{8}$ Acadêmica do Curso de Medicina da UNIPAR

${ }^{9}$ Acadêmico do Curso de Medicina da UNIPAR

${ }^{10}$ Acadêmica do Curso de Medicina da UNIPAR

${ }^{11}$ Acadêmica do Curso de Medicina da UNIPAR

${ }^{12}$ Acadêmica do Curso de Medicina da UNIPAR

${ }^{13}$ Acadêmica do Curso de Medicina da UNIPAR

${ }^{14}$ Docente da UNIPAR

Introdução: As Infeç̧ões Sexualmente Transmissíveis (IST) são frequentes e recorrentes mundialmente e refletem um problema de saúde pública que acomete principalmente os jovens (SPINDOLA et al., 2021). São causadas por vírus, bactérias, fungos e protozoários e transmitidas pelo contato sexual sem uso de preservativo, verticalmente, contato com secreções corporais contaminadas, transfusão sanguínea e contato com objetos perfurocortantes compartilhados (PEREIRA et al., 2021). A epidemiologia das IST's elucida que cerca de $25 \%$ das infecções são diagnosticadas em indivíduos com menos de 25 anos, estando ligadas a fatores biológicos, culturais e socioeconômicos (SPINDOLA et al., 2021). No Brasil, foram registrados em 2017 42.420 novos casos de infecção por HIV, com predomínio entre 20 a 29 anos, compatível com a faixa etária universitária (PEREIRA et al., 2021). Nesse contexto, a Liga Acadêmica de Epidemiologia e Saúde Coletiva (LAESC) da Unipar com base nos achados de literatura, identificou a população universitária como a de maior risco de exposição devido ao fato de serem socialmente e sexualmente mais ativos, mudança de parceiros, consumo de álcool e outras drogas, práticas sexuais desprotegidas e falta de educação sexual relacionada à prevenção e consciência coletiva em saúde, fatores que apontam para a necessidade de profilaxia nessa faixa etária (PEREIRA et al., 2021; DA FONTE et al., 2018). Considerando a importância do tema, a LAESC promoveu a distribuição de preservativos e panfletos informativos sobre IST's no intuito de conscientizar acadêmicos em relação ao seu contágio e prevenção na UNIPAR, Campus III, no dia 02 de setembro de 2021, em parceria com o Ambulatório de Doenças Infecciosas do Municipio, que contribuiu com os materiais para a campanha, camisinhas, feminina e masculina e folders.

Objetivo: Promover educação em saúde sexual a fim de prevenir Infecções Sexualmente Transmissíveis a nível Universitário.

Resultados: Foi entregue aos acadêmicos da UNIPAR, homens e mulheres, presevativos femininos e masculinos e panfletos, atingindo 180 acadêmicos.

Conclusão: As IST's são um grande problema de saúde pública, sendo necessário intensificar práticas de educação sexual incluindo formas de contágio e prevenção, em especial, à população acadêmica. Esta foi uma das primeiras campanhas da LAESC e espera-se dar continuidade na busca de prevenção das IST's entre os jovens.

\section{Referências}

DA FONTE, Vinícius Rodrigues Fernandes et al. Conhecimento e percepção de risco em relação às infecções sexualmente transmissíveis entre jovens universitários. Cogitare Enfermagem, v. 23, n. 3, 2018.

PEREIRA, Rejane et al. Infecções sexualmente transmissíveis entre acadêmicos da área da saúde. Revista Eletrônica Acervo 
Científico, v. 19, p. e5960-e5960, 2021.

SPINDOLA, Thelma et al. A prevenção das infecções sexualmente transmissíveis nos roteiros sexuais de jovens: diferenças segundo o gênero. Ciência \& Saúde Coletiva. v. 26, p. 2683-2692, 2021.

I SALÃO DE EXTENSÃO

DA UNIPAR
- UNIPAR 50 ANOS:

Traneformando vidas atravis da educaces

27 de Outubro de 2021
C.5 ACNPG 


\section{(1) DUNIPAR 50 ANOS \\ SALÃO DE EXTENSÃO DA Transformando vidas através da educą̧̧̃o \\ UNIPAR \\ 27 de Outubro de 2021 \\ ISBN 978-65-87557-74-8

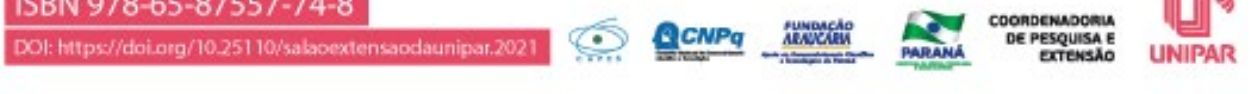 \\ LIGA ACADÊMICA DE OTORRINOLARINGOLOGIA: COMPARTILHANDO CONHECIMENTOS E DESENVOLVENDO COMPETÊNCIAS COMUNICATIVAS NOS MEIOS VIRTUAIS}

${ }^{1}$ LUCAS ALEXANDRE GUBERT SCHIER, ${ }^{2}$ SIMARA RAISA DE BRITO MORAES, ${ }^{3}$ THALYTA CUSTODIO, ${ }^{4}$ BERNARDO MUNHOZ LIMA, ${ }^{5}$ MARIO MARQUES PEREIRA FILHO, ${ }^{6}$ FABIOLA COSTA TAKAKUA, ${ }^{7}$ AUGUSTO FASSINI FONT, ${ }^{8} \mathrm{VICTOR}$ HUGO ONO SAKUMA DOLCI DOS SANTOS, ${ }^{9}$ FABIANE ANGELICA DE PAIVA PAULA, ${ }^{10}$ DEBORAH TAVARES BIEZUS, ${ }^{11}$ ESTER PELEGRINI SILVA, ${ }^{12}$ EDUARDO AUGUSTO PFAU, ${ }^{13}$ ARIELLA REGINA BRUSCHI, ${ }^{14}$ FERNANDO CEZAR CARDOSO MAIA FILHO

${ }^{1}$ Acadêmica do Curso de Medicina da UNIPAR

${ }^{2}$ Acadêmica do Curso de Medicina da UNIPAR

${ }^{3}$ Acadêmica do Curso de Medicina da UNIPAR

${ }^{4}$ Acadêmico do Curso de Medicina da UNIPAR

${ }^{5}$ Acadêmico do Curso de Medicina da UNIPAR

${ }^{6}$ Acadêmica do Curso de Medicina da UNIPAR

${ }^{7}$ Acadêmico do Curso de Medicina da UNIPAR

${ }^{8}$ Acadêmico do Curso de Medicina da UNIPAR

${ }^{9}$ Acadêmica do Curso de Medicina da UNIPAR

${ }^{10}$ Acadêmica do Curso de Medicina da UNIPAR

${ }^{11}$ Acadêmica do Curso de Medicina da UNIPAR

${ }^{12}$ Acadêmico do Curso de Medicina da UNIPAR

${ }^{13}$ Acadêmica do Curso de Medicina da UNIPAR

${ }^{14}$ Docente da UNIPAR

Introdução: As ligas acadêmicas representam uma entidade cooperativa científica livre, cujo enfoque é complementar a formação acadêmica, com atividades de ensino, pesquisa e extensão direcionadas a uma área específica, porém dentro do contexto da formação generalista em medicina. Dessa maneira, os acadêmicos participantes de ligas corroboram não somente informações, como também integram habilidades e competências caras à formação médica, como acontece na esfera comunicacional. Por conseguinte, é possível prestar serviço à comunidade, ainda que não nos ambientes intramuros da instituição de ensino de origem (TAVARES et al., 2020). Portanto, entende-se que as implantações das ligas contribuem para promoção à saúde demonstrando a relevância da atuação junto a sociedade (INÁClO et. al., 2021). Nesse contexto, a Liga Acadêmica de Otorrinolaringologia (LAORL), no exercício da sua função informativa, produz periodicamente conteúdos úteis tanto para o corpo acadêmico quanto para a comunidade de uma maneira geral, utilizando a plataforma do Instagram como via de integração.

Objetivo: Descrever a ação de extensão, no formato de publicações realizadas via Instagram, pela Liga Acadêmica de Otorrinolaringologia (LAORL) da Universidade Paranaense (UNIPAR) - Umuarama e o impacto ocasionado pelo alcance virtual das informações prestadas.

Resultados: A conta da Liga Acadêmica de Otorrinolaringologia (LAORL) foi criada em Abril de 2021, contando atualmente, no total, com 21 publicações, 301 seguidores em diversas cidades do Paraná, e soma um total de 460 curtidas, com um aumento expressivo no número de contas alcançadas a cada publicação, partindo de menos de 80 contas em publicações de Agosto, e mais de 240 publicações de Setembro. Em adição, conta-se, desde a sua fundação, com mais de 2.446 impressões. Estas, incluem informações acerca do quadro clínico, diagnóstico, tratamento e fisiopatologia das principais afecções otorrinolaringológicas a serem dominadas pelos estudantes, tendo como perspectiva a formação generalista e as patologias mais prevalentes na prática clínica. Além disso, a página serve como instrumento de comunicação acerca de atividades extracurriculares proporcionadas pela liga em questão, tais como palestras, aulas abertas e campanhas de doação na Universidade Paranaense (UNIPAR). Para a sociedade, a principal vantagem é o oferecimento ao paciente a oportunidade de uma busca conjunta com o profissional pela performance ativa do mesmo ante ao seu organismo e respectivo tratamento, partindo do pressuposto que a informação que lhe é prestada seja segura, viável e dentro dos parâmetros daquilo que é recomendado pela medicina (TAMOIO et al., 2020). Em adicional, o conteúdo postado, com planejamento mensal, visa contribuir 
para o estudo de colegas estudantes, e profissionais da área da saúde.

Conclusão: Destarte, o desenvolvimento de habilidades comunicacionais, especificamente no meio acadêmico, envolve também as facetas virtuais, dada sua importância no contexto globalizado. A interação da liga com a comunidade acadêmica e com a sociedade umuaramense produz diretamente um impacto positivo no que tange à busca, respectivamente, pelo aprimoramento do serviço em saúde e pelas informações que levam o indivíduo a reconhecer em si processos patológicos e a procurar assistência otorrinolaringológica.

\section{Referências}

TAVARES, Dione Fernandes; ANDRADE, Marco Antônio Vieira; TEIXEIRA, Thiago Rhangel Gomes. Contribuições das ligas acadêmicas na formação médica brasileira. Revista Eletrônica Científica Da UERGS, v. 6, n.3, p. 289-292, dez. 2020. Disponivel em: https://doi.org/10.1590/S1414-32832008000400003. Acesso em: 04 set. 2021.

TAMOTO, Paula; et al. Aprendizagem da geração millenial na graduação médica. Revista Bioética, v28, n.4, p 683-692.

INÁCIO, Giovana Porto et. al. Liga Acadêmica de Medicina Integrada à Saúde da Comunidade: reflexões sobre a sua criação.

Brazilian Journal of Health Review, Curitiba, v.4, n.3, p. 14330-14335 maio./jun. 2021. Disponível em: http://dx.doi.org/10.34119/bjhrv4n3-363. Acesso em: 04 set. 2021.

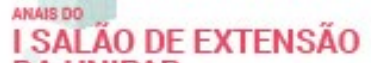

DA UNIPAR
> UNIPAR 50 ANOS:

Traneformando vides atravia da educaglo

27 de Outubro de 2021

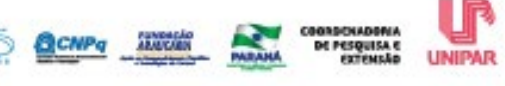




\title{
(1) \\ - UNIPAR 50 anOS \\ Transformando vidas através da educą̧ão \\ 27 de Outubro de 2021

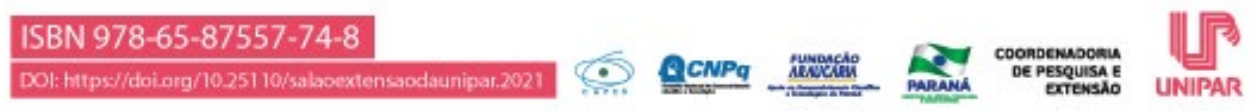 \\ ANÁLISE DA POTABILIDADE DE ÁGUA DE FONTES E POÇOS DESTINADOS A CONSUMO HUMANO EM PROPRIEDADES RURAIS DO MUNICÍPIO DE FRANCISCO BELTRÃO PR
}

\author{
${ }^{1}$ CASSIANE PARIZOTTO, ${ }^{2}$ JULIA COMACHIO FAVRETTO, ${ }^{3}$ NATIELE CHAVES DA SILVA, ${ }^{4}$ PRISCILA YANO RUTES, \\ ${ }^{5}$ BRUNA FREITAS BIEZUS, ${ }^{6}$ VOLMIR PITT BENEDETTI
}

\begin{abstract}
${ }^{1}$ Discente de Farmácia, PIBEX/Unipar - Francisco Beltrão PR
${ }^{2}$ Discente de Farmácia, PEX/Unipar- Francisco Beltrão PR

${ }^{3}$ Discente de Farmácia, PEX/Unipar- Francisco Beltrão PR

${ }^{4}$ Discente de Farmácia, PEX/Unipar- Francisco Beltrão PR

${ }^{5}$ Departamento de Vigilância em Saúde Secretaria Municipal de Saúde -Francisco Beltrão PR

${ }^{6}$ Docente da UNIPAR
\end{abstract}

Introdução: A água é um dos recursos naturais de maior importância para o planeta, sendo assim necessária para todos os seres vivos (MARQUES et al., 2008). Ela não é usada somente para beber, mas também é utilizada na preparação dos alimentos, para a higiene pessoal, limpeza, para regar as plantas, tratar animais, entre outras (MELGAÇO et al., 2008). Segundo a resolução do Conselho Nacional do Meio Ambiente (CONAMA) 357/2005, a qualidade da água, deve atender padrões de potabilidade, garantindo que estejam dentro dos padrões recomendados pela organização mundial da saúde (CUNHA et al., 2013). No Brasil, de acordo com Portaria n. 518, de 2004, do Ministério da Saúde / ANVISA, para uma água ser considerada potável ao consumo humano, sob parâmetros microbiológicos, deve estar de acordo com a seguinte conformidade: ausência de coliformes totais e ausência de Escherichia Coli. Os parâmetros preestabelecidos de natureza fisico-quimicas envolvem as seguintes analitos: alumínio, amônia, cloreto, cor, dureza total, ferro total, manganês, sódio, sólidos totais dissolvidos, sulfato, sulfeto, surfactante, zinco, turbidez e determinação de $\mathrm{PH}$, e parâmetros parasitológicos: ausência de enteroparasitas (BRASIL, 2004). Segundo Calheiros et al. (2004), para evitar a contaminação da água, medidas preventivas devem ser tomadas para que as fontes sejam preservadas, como, por exemplo, toda a área em volta da nascente deve ser cercada para evitar a entrada de animais, homem, veículos e produtos químicos.

Objetivo: Este projeto de extensão possui como objetivo analisar o índice de potabilidade para águas de fontes de propriedades rurais do município de Francisco Beltrão PR.

Metodologia: Para isso foram realizadas análises de 9 (nove) amostras de água de fonte ou poços que eram utilizadas para consumo humano em propriedades rurais do município de Francisco Beltrão PR. Foram analisados parâmetros físico-químico, microbiológico e parasitológico, seguindo as exigências de potabilidade segundo a PORTARIA № 2.914, 12/12/2011 do Ministério da Saúde (BRASIL, 2011). Paralelamente, foi aplicado um checklist para avaliar os fatores de risco para a contaminação das águas por agentes químicos ou biológicos. Para a determinação dos parâmetros microbiológicos foi utilizada a metodologia do meio de cultura Colitest $₫$. Os parâmetros físico-químicos foram realizados segundo o que está descrito na portaria, e para as análises parasitológicas será empregado a metodologia preconizada por Faust et al. (1939).

Resultados: Nesse projeto observou-se que das amostras analisadas, $66,6 \%$ positivaram para coliformes totais e para Escherichia Coli, 100\% mostraram-se ausente para enteroparasitas, e 44,4\% possuíam alguma alteração em parâmetros físicoquímicos. Neste sentido das $88,8 \%$ das amostras se apresentam impróprias para o consumo humano no que se referia a aspectos físico-químicos ou microbiológicos.

Discussão: Segundo observado nesse estudo na maioria das propriedades rurais os poços e fontes não são devidamente cuidados para evitar que as nascentes sejam contaminadas por agentes biológicos ou químicos. Geralmente os poços ou fontes ficam descobertas, próximas de pastagens, perto de lavouras, correndo o risco de recebem defensivos agrícolas ou dejetos de animais ou humanos. Calheiros et al. (2004) explicam que a falta de cuidados adequados com as nascentes, pode durante as estações de chuvas, provocar erosão do solo facilitando a sua contaminação.

Conclusão: Neste trabalho observou-se que não houve contaminação na água por enteroparasitas, mas houve um alto índice de contaminação por agentes microbiológicos e alterações físico-químicos. Portanto, concluiu-se que as amostras de águas das fontes e nascentes estava impróprias para o consumo humano nesses requisitos.

\section{Referências}

BRASIL. Ministério da Saúde. Agência Nacional de Vigilância Sanitária. Resolução n. 518, de 25 de março 2004.

BRASIL. Ministério da Saúde. Portaria ${ }^{\circ}$ 2.914, de 12 de dezembro de 2011. Dispõe sobre os procedimentos de controle e de vigilância da qualidade da água para consumo humano e seu padrão de potabilidade. Brasília, 2011. 
CALHEIROS, R.O. et. al. Preservação e Recuperação de Nascentes (de água e de vida). Piracicaba: Comitê das Bacias Hidrográficas dos rios PCJ CTRN, 2004.

CUNHA, D.G.F. et al. Resolução CONAMA 357/2005: análise espacial e temporal de não conformidades em rios e reservatórios do estado de São Paulo de acordo com seus enquadramentos (2005-2009). Engenharia Sanitária e Ambiental, v. 18, n. 2, p. 159-168, 2013.

FAUST, E. C. et al. Comparative efficiency of various technics for the diagnosis of Protozoa and helminths in feces. J. Parasit., 25:241-62, 1939.

MARQUES, F.P.P. et al. Qualidade microbiológica da água proveniente de poços artesianos em unidades de alimentação e nutrição da cidade de Goiânia (GO): análise de laudos laboratoriais constantes na divisão de saneamento da vigilância sanitária municipal. Higiene Alimentar, v. 22, n. 1, p. 52-55, 2008.

MELGAÇO, C.A.S. et al. Pesquisa de coliformes termotolerantes e bactérias aeróbias mesófilas em uma fonte pública de água do município de Teixeira de Freitas, BA. Higiene Alimentar, v. 22, n. 1, p. 72-80, 2008.

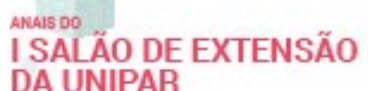

DA UNIPAR

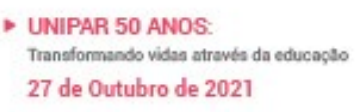

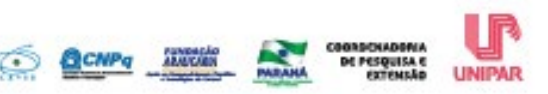




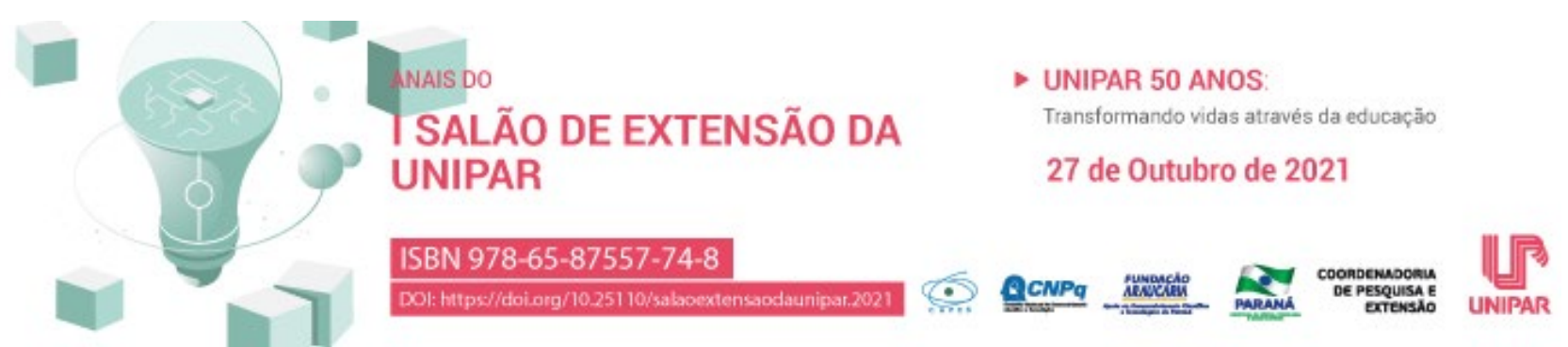

\section{PROGRAMA MOMENTO SAÚDE E BEM-ESTAR}

${ }^{1}$ GABRIELA ANDRADE SIQUEIRA, ${ }^{2}$ IZADORA MAITAN DO NASCIMENTO, ${ }^{3} \mathrm{VINICIUS}$ FREITAS TREVISAN, ${ }^{4}$ NATHALIA REGINA CERANTO DE SOUZA, ${ }^{5}$ NATALIA PIRES DE SOUZA, ${ }^{6}$ LETICIA MARILUCE DE SOUZA ALVES, ${ }^{7}$ LETICIA CASALLI COUTO, ${ }^{8}$ EDUARDA DE OLIVEIRA MACHADO, ${ }^{9}$ MAYCON JORGE BRANDOLIM, ${ }^{10}$ KATHIANE VIEIRA AVELINO, ${ }^{11}$ ELIZABETI DE MATOS MASSAMBANI

${ }^{1}$ Acadêmica do Curso de Estética e Cosmética da UNIPAR - Umuarama

${ }^{2}$ Acadêmica do Curso de Medicina da UNIPAR - Umuarama

${ }^{3}$ Acadêmico do Curso de Medicina da UNIPAR - Umuarama

${ }^{4}$ Acadêmica do Curso de Medicina da UNIPAR - Umuarama

${ }^{5}$ Acadêmica do Curso de Estética e Cosmética da UNIPAR - Umuarama

${ }^{6}$ Acadêmica do Curso de Estética e Cosmética da UNIPAR - Umuarama

${ }^{7}$ Acadêmica do Curso de Medicina da UNIPAR - Umuarama

${ }^{8}$ Acadêmica do Curso de Estética e Cosmética da UNIPAR - Umuarama

${ }^{9}$ Acadêmico do Curso de Medicina da UNIPAR - Umuarama

${ }^{10}$ Acadêmica do Curso de Estética e Cosmética da UNIPAR - Umuarama

${ }^{11}$ Docente da UNIPAR - Umuarama

Introdução: A sociedade dispõe de meios de comunicação importantes para veicular notícias e fatos que possam mostrar aos indivíduos tudo o que se passa ao seu redor. Uma maneira de se veicular informações necessárias à rotina, e que é de fácil acesso ao público, está relacionada com a comunicação através do rádio. $O$ rádio é a união de três grandes tecnologias: a telegrafia, o telefone sem fio e as ondas de transmissão. A história do rádio brasileiro é marcada por momentos de mudanças para incorporar novas tecnologias ou de se adaptar aos novos contextos trazidos pelas inovações tecnológicas, modificando os processos de produção, recepção e interação influenciando a linguagem, o trabalho dos profissionais e a forma de ouvir as emissoras (MAGNONI, 2013). O Brasil tornou-se reconhecido internacionalmente como um dos países que mais produzem conhecimento qualificado sobre a radiodifusão sonora (MIRANDA NETO, 2019). Este projeto Programa Momento Saúde e Bemestar contempla a integração de pesquisas, informações e orientações prestadas por acadêmicos de diferentes cursos pertencentes a Unipar em prol da comunidade de Umuarama e região. São pesquisados e preparados temas a respeito de questões diversas de saúde e melhoria da qualidade de vida, como por exemplo, informações sobre patologias e medidas de prevenção, medicamentos, importância de alimentação adequada, informações da área estética facial, corporal, capilar e complementar/alternativa, enfatizando as novidades em princípios ativos, técnicas, procedimentos e orientações aos ouvintes.

Objetivo: Este projeto visa proporcionar informações e orientações à comunidade sobre temas relacionados à saúde, nutrição, qualidade de vida e estética através do Programa Momento Saúde e Bem-estar na Rádio Universitária Paranaense.

Resultados: Não temos uma metodologia própria para avaliar o número de ouvintes do programa, contudo temos muitas vezes o retorno da população que de maneira informal elogia as temáticas dos programas. Outros resultados positivos são o estímulo contínuo que o acadêmico tem para realizar as pesquisas sobre os temas, adquirir desenvoltura na prestação de informações e comunicação, e permitir a interação destes futuros profissionais com a comunidade para estimular o exercício da cidadania.

Conclusão: A transmissão de informações pelo rádio é uma das mais viáveis devido à facilidade do seu manuseio e o baixo custo para aquisição. É possível estabelecer uma proximidade do ouvinte com assuntos que causem curiosidade e ao mesmo tempo conhecimento como as informações prestadas pelo Programa Momento Saúde e Bem-estar.

\section{Referências}

MAGNONI, Antonio Francisco; RODRIGUES, Kelly De Conti. O rádio e a adaptação à nova era das tecnologias da comunicação e informação: contextos, produção e consumo. UFOP: Encontro Nacional de História da Mídia. 2013. Disponível em:

http://www.ufrgs.br/alcar/encontros-nacio-1/9o-encontro-2013/gt. Acesso em: 12 ago. 2021.

MIRANDA NETO, Marcílio Hubner; GALDIOLI, Marcelo Henrique; BROSSO, Heloísa Bersan. 0 rádio como instrumento da comunicação do conhecimento científico. 2019. Disponível em: http://www.eaex.uem.br/eaex2019/anais/art/36.pdf. Acesso em: 12 ago. 2021. 
- unIPAR 50 anos:

I SALAOO DE EXTENSÃO Transformando vidas atravies da educaģso

DA UNIPAR 


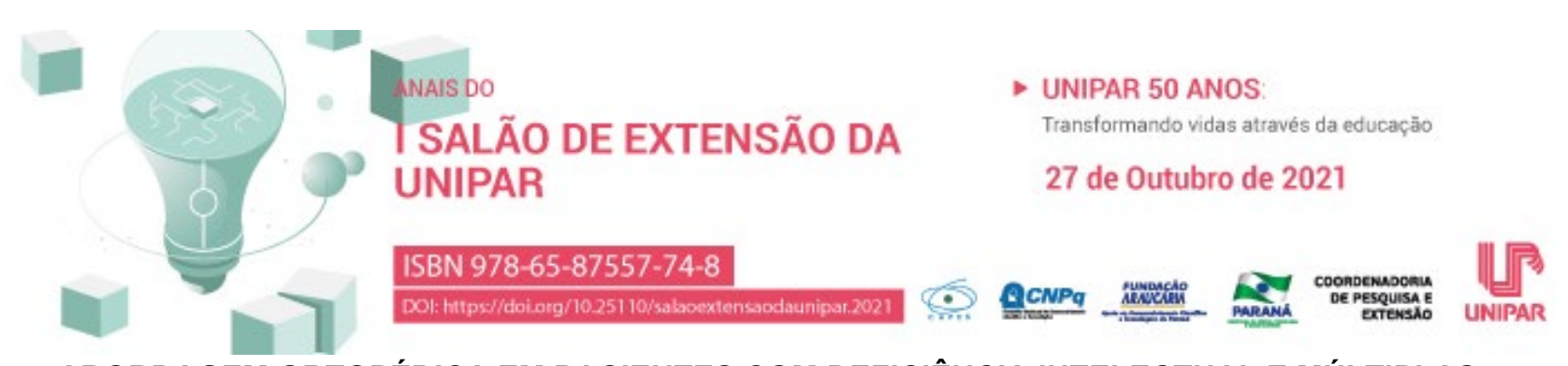

\title{
ABORDAGEM ORTOPÉDICA EM PACIENTES COM DEFICIÊNCIA INTELECTUAL E MÚLTIPLAS
}

\author{
1JOAO PEDRO DOS SANTOS COSSI, 2LUANA PINHEIRO DE FREITAS, ${ }^{3}$ LUIZA MAYUMI CAZELOTO SILVA, ${ }^{4}$ MATHEUS \\ ALEXANDRE VICTORIO, ${ }^{5}$ MATHEUS WALDOW PAREDES, ${ }^{6}$ RAFAELA DIAS DE ARAUJO , ${ }^{7}$ MAXSUEL FIDELIS DE PADUA \\ ALMEIDA
}

${ }^{1}$ Acadêmico do Curso de Medicina da UNIPAR
${ }^{2}$ Acadêmica do Curso de Medicina da UNIPAR
${ }^{3}$ Acadêmica do Curso de Medicina da UNIPAR
${ }^{4}$ Acadêmico do Curso de Medicina da UNIPAR
${ }^{5}$ Acadêmico do Curso de Medicina da UNIPAR
${ }^{6}$ Acadêmica do Curso de Medicina da UNIPAR
${ }^{7}$ Docente da UNIPAR

Introdução: Segundo Almeida (2016), a deficiência intelectual ocorre quando o indivíduo apresenta limitações no seu funcionamento mental e no desempenho de tarefas. Para o Ministério da Saúde (2020), a deficiência múltipla caracteriza-se como o conjunto de duas ou mais deficiências associadas, de ordem física, sensorial, mental, emocional ou de comportamento social. Há alguns fatores de risco para tais deficiências tais como a desnutrição materna, má assistência à gestação, sífilis, rubéola, toxoplasmose, medicamentos teratogênicos, tabagismo, oxigenação cerebral insuficiente, prematuridade, sarampo, meningoencefalites e algumas condições genéticas. De acordo com Sizínio (2017), na realização do exame ortopédico de pacientes com deficiência intelectual e múltiplas são avaliados o quadril, joelho, tornozelo e pés com testes específicos, radiografia da bacia a cada 6 meses, avaliação morfológica e funcional, posição ortostática, exames estáticos avaliando a força muscular e tomografia quando necessário.

Objetivo e Metodologia: Realizar um projeto de extensão local, na APAE de Umuarama-PR na Semana Nacional da Pessoa com DI e Múltiplas, juntamento com os Ligantes Acadêmicos de Ortopedia e Traumatologia, deMedicina da UNIPAR. Realizando uma abordagem ortopédica de extensão em pacientes com deficiência intelectual (DI) e múltiplas e relatar os resultados dessa atividade.

Resultados: Foram avaliados 10 pacientes com disfunção neuromuscular, com orientações para acompanhamento e seguimento ortopédico adequado e para cuidados pessoais, assim como solicitado exames correlacionados com a patologia de cada paciente, ainda foram realizados exames físicos específicos com base na literatura do Falopa. Utilizou-se durante o evento, a classificação da função motora grossa GMFCS (Gross motor function classification system), o qual consiste em uma escala ordinal de cinco níveis utilizada para classificar o nível de comprometimento motor de crianças que são portadoras de PC (paralisia cerebral), sendo o nível 1 o mais brando, apresentando deambulação independente e sem restrições, enquanto o nível 5 representa um grave comprometimento de auto deslocamento, mesmo que cadeirante, para orientar os familiares sobre o prognostico do paciente sobre o desenvolvimento neuromuscular.

Conclusão: A atividade forneceu uma rica experiência aos integrantes da Liga Acadêmica de Ortopedia e Traumatologia, os quais puderam colocar em prática alguns ensinamentos literários. Além disso, a atividade também foi de grande valia para os pacientes, que tiveram a oportunidade de serem avaliados pelo médico ortopedista e seus acadêmicos, recebendo as devidas orientações.

\section{Referências}

ALMEIDA, A. M. C. Humanização da assistência como ferramenta de gestão hospitalar em serviços públicos de saúde [Monografia]. Universidade Estadual da Paraíba, 2016.

HEBERT, Sizínio K. et al. Ortopedia e traumatologia: princípios e prática. 5.ed. ed. Porto Alegre : Artmed, 2017.

MINISTÉRIO DA SAÚDE. Rede de cuidados à pessoa com deficiência no âmbito SUS. 2020. Disponível em: bvsms.saude.gov.br/bvs/saudelegis/gm/2012/prt0793_24_04_2012.html . Acesso em 23, set. 2021.

ORGANIZAÇÃO MUNDIAL DA SAÚDE. Classificação Internacional de Funcionalidade. Organização Mundial da Saúde. Lisboa, 2019. Disponível em: www.inr.pt/uploads/docs/cif/CIF_port_\%202004.pdf. Acesso em: 23, set. 2021. 


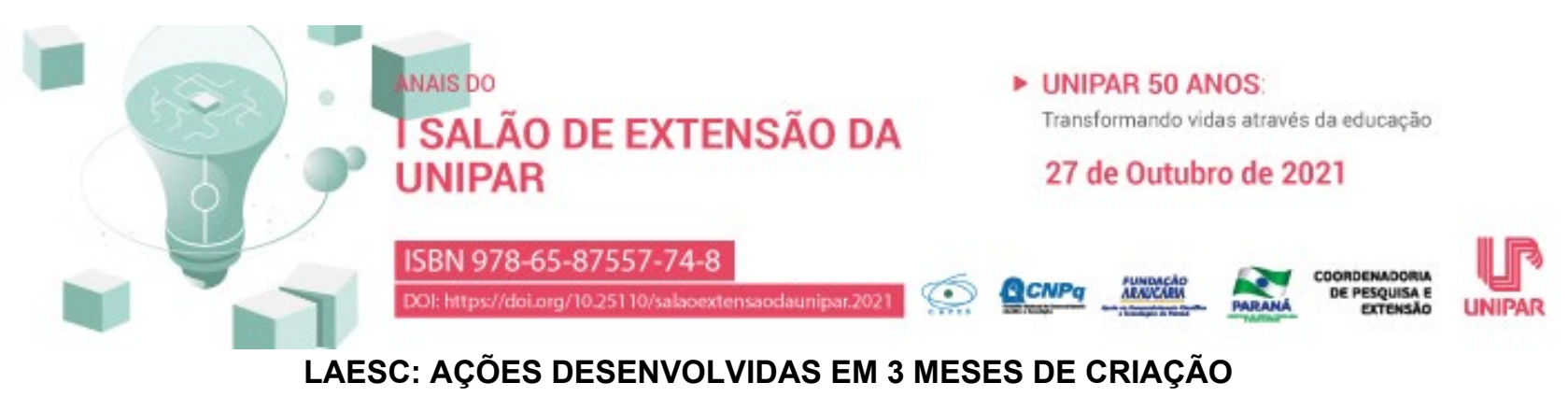

${ }^{1}$ ISABELA SILVA TRODORFE, ${ }^{2}$ CAMILA LOPES DIAS ARROYO, ${ }^{3}$ INGRIDY RHAIANY PARREIRA MENEGASSI, ${ }^{4}$ SABRINA SUEMY KATO TANAKA, ${ }^{5}$ JOAO THOMAZ TERRA PRADO BORGES, ${ }^{6}$ VICTOR HUGO DRANKA MORI, ${ }^{7}$ GABRIELE JUSSIANI CAETANO, ${ }^{8}$ EULLER CONDE FERNANDES, ${ }^{9}$ CRISTIANO JOSE DA SILVA, ${ }^{10}$ KEROLAINE MANTOVI COSTA, ${ }^{11}$ LAIS TEODORO LOPES, ${ }^{12}$ EDSON MEDINE SEREJO NETO, ${ }^{13}$ NATALIA COLCETTA, ${ }^{14}$ DEBORA KUCMANSKI, ${ }^{15}$ MARINA GIMENES

\footnotetext{
${ }^{1}$ Acadêmico do Curso de Medicina da UNIPAR

${ }^{2}$ Acadêmica do Curso de Medicina da UNIPAR

${ }^{3}$ Acadêmica do Curso de Medicina da UNIPAR

${ }^{4}$ Acadêmica do Curso de Medicina da UNIPAR

${ }^{5}$ Acadêmico do Curso de Medicina da UNIPAR

${ }^{6}$ Acadêmico do Curso de Medicina da UNIPAR

${ }^{7}$ Acadêmica do Curso de Medicina da UNIPAR

${ }^{8}$ Acadêmico do Curso de Medicina da UNIPAR

${ }^{9}$ Acadêmico do Curso de Medicina da UNIPAR

${ }^{10}$ Acadêmica do Curso de Medicina da UNIPAR

${ }^{11}$ Acadêmica do Curso de Medicina da UNIPAR

${ }^{12}$ Acadêmico do Curso de Medicina da UNIPAR

${ }^{13}$ Acadêmica do Curso de Medicina da UNIPAR

${ }^{14}$ Acadêmica do Curso de Medicina da UNIPAR

${ }^{15}$ Docente da UNIPAR
}

Introdução: A primeira liga brasileira foi fundada na Faculdade de Medicina e Cirurgia de São Paulo, para o combate a sífilis Liga de Combate à Sífilisl", em 29 de agosto de 1920, pois os números da doença eram assustadores. Após 20 anos da Liga, o trabalho realizado nos ambulatórios mostrava atendimento de 24.398 doentes (DENEM, 2014). As Ligas Acadêmicas são potentes vias de interlocução de acadêmicos e sociedade, com acompanhamento docente desencadeando estratégias na formação em saúde, que integram atividades de ensino, pesquisa e extensão, bem como antecipam a inserção de seus ligantes nos campos de atuação preenchendo as lacunas encontradas na graduação por meio do protagonismo e da autonomia discentes, além de proporcionar a integração ensino-serviço-comunidade (CAVALCANTE et al., 2018). Na UNIPAR, a Liga Acadêmica é definida como uma entidade estudantil autônoma, apolítica e sem fins lucrativos, com o objetivo de aprofundar o trinômio Ensino, Pesquisa e Extensão em uma área específica do campo científico, complementando a formação acadêmica, de acordo com o regulamento (UNIPAR, 2021). A Liga de Epidemiologia e Saúde Coletiva da UNIPAR (LAESC) foi criada em, em julho de 2021, e se propõem a somar forças junto aos estabelecimentos parceiros, através de grupos de estudo, discussões, pesquisas e atividades norteadoras da situação de saúde do Município e daRegional de Saúde.

Objetivo: Descrever os resultados atingidos pela LAESC de julho a setembro de 2021.

Resultados: Foram realizadas 4 palestras, sendo: a. Inauguração da Liga, Dra Déborah Kantor, Ficha Notificação Compulsória; b.Introdução sobre Epidemiologia, Prof. ${ }^{a}$ Marina Gimenes; c. Sífilis com o Dr. Paulo Caetano; d. Epidemiologia da infecção pelo HIV com o Dr. Ricardo Perci; Aula sobre Tuberculose com as ligantes Débora Kucmanski e Kerolaine Mantovi Costa; Prova para ingressantes; Campanha de ISTs em parceria com o Ambulatório de Doenças Infecciosas (ADI), para acadêmicos - 180 atendimentos; Contato e aceite para Estágios no ADI; submissão de 2 resumos para o V CICTI e XX EAIC e 2 resumos para o Salão de Extensão e Campanha de alimentos - Lar São Vicente de Paulo em andamento.

Conclusão: Os três primeiros meses da LAESC mostram que as atividades estão sendo cumpridas em consonância com os objetivos pretendidos, e essas conquistas só foram possíveis pelos esforços dos seus integrantes e parcerias com as instituições envolvidas, permitindo aos acadêmicos conhecer, estabelecer contatos e aprender fazendo.

\section{Referências}

DIREÇÃO EXECUTIVA NACIONAL DOS ESTUDANTES DE MEDICINA (DENEM) . Ligas acadêmicas. Julho 2014 . Disponível 
em: https://bit.ly/38IOPXV. Acesso em 02 set. 2021.

CAVALCANTE, Ana Suelen Pedroza et al. As ligas acadêmicas na área da saúde: lacunas do conhecimento na produção científica brasileira. Revista Brasileira de educação médica, v. 42, n. 1, p. 199-206, 2018.Disponível em: https://bit.ly/3h7dUyM. Acesso em 02 set. 2021.

UNIVERSIDADE PARANAENSE. Regulamento Geral das Ligas Acadêmicas. Umuarama, 07 abr. 2021. Disponível em:https://bit.ly/3jQpkc5. Acesso em 02 set. 2021.

$\begin{array}{ll}\text { Anuis do } & \text { UNIPAR } 50 \text { ANOS: } \\ \text { I SALÄO DE EXTENSÃO } & \text { Transformando vidas atravis da educagto } \\ \text { DA UNIPAR } & 27 \text { de Outubro de } 2021\end{array}$



SOLIAL E DA SAÚDE MENTAL. PREVENÇÃO DE RISCOS CARDÍACOS, LESÕES E INFECÇÃO PELO CORONAVÍRUS

\author{
${ }^{1}$ GUSTAVO SUZUKI RUZZON, ${ }^{2}$ FATIMA HASSAN SAFIEDDINE, ${ }^{3}$ LEONARDO DELAZARI CARVALHO, ${ }^{4}$ FELIPE AUGUSTO \\ SPANHOLI, ${ }^{5}$ LUIS FERNANDO DELAZARI VALERIO, ${ }^{6}$ MATHEUS WALDOW PAREDES, ${ }^{7}$ MARIANA SAUSEN BASSO, \\ ${ }^{8}$ MICHELLE BONATTO SAMPAIO, ${ }^{9}$ LuCAS REZENDE, ${ }^{10}$ GUSTAVO PEDRO ALVES, ${ }^{11}$ KARLA MACHADO QUINTAS, \\ ${ }^{12}$ HIGOR DIAS DO PRADO, ${ }^{13}$ MAXSUEL FIDELIS DE PADUA ALMEIDA
}

\footnotetext{
${ }^{1}$ Acadêmico do Curso de Medicina da UNIPAR

${ }^{2}$ Acadêmica do Curso de Medicina da UNIPAR

${ }^{3}$ Acadêmico do Curso de Medicina da UNIPAR

${ }^{4}$ Acadêmico do Curso de Medicina da UNIPAR

${ }^{5}$ Acadêmico do Curso de Medicina da UNIPAR

${ }^{6}$ Acadêmico do Curso de Medicina da UNIPAR

${ }^{7}$ Acadêmica do Curso de Medicina da UNIPAR

${ }^{8}$ Acadêmica do Curso de Medicina da UNIPAR

${ }^{9}$ Acadêmico do Curso de Medicina da UNIPAR

${ }^{10}$ Acadêmico do Curso de Medicina da UNIPAR

${ }^{11}$ Acadêmica do Curso de Medicina da UNIPAR

${ }^{12}$ Acadêmico do Curso de Medicina da UNIPAR

${ }^{13}$ Docente da UNIPAR
}

Introdução: Desde o início da pandemia a atividade física foi enfatizada, com base em evidências sobre os diversos benefícios proporcionados à saúde e as questões biopsicossociais. Nesse aspecto, é de demasiada importância a necessidade de manterse ativo mesmo durante a pandemia do novo coronavírus (PITANGA, 2021). Tendo em vista os diversos cuidados para evitar os riscos cardíacos e de lesões já que muitos demonstram dificuldade em realizar essas atividades em casa.

Objetivo: Discussão por meio de uma mesa redonda sobre a importância da atividade física, no que diz respeito a diminuição do sedentarismo e a prevenção de riscos cardíacos e lesões gerados pelo Coronavírus, englobando também toda a questão biopsicossocial.

Resultados: Realizamos juntamente com a atlética de medicina e com a atlética de psicologia, uma mesa redonda com quatro profissionais da saúde: o médico cardiologista $\mathrm{Dr}$ Jeanderson Oliveira, o medico ortopedista $\mathrm{Dr}$ Maxsuel F. de Paula, o fisioterapeuta da seleção brasileira de futsal Kleber Barbão e a Coordenadora multicampi do Piai Giuliana de Oliveira Marzon Teixeira. Este evento ocorreu de modo online voltado para todos os alunos da Unipar e teve como objetivo a discussão de uma temática de extrema importância para a qualidade de vida de muitos que ficaram à mercê do isolamento social e que agora retornam aos poucos as atividades. Nesse sentido, realizamos a seguinte pergunta norteadora: Na opinião de cada um de vocês, e no contexto da pandemia, como manter-se ativo e saudável visando o bem estar biopsicossocial . Dessa forma, englobamos a opinião de diferentes profissionais da saúde e conseguimos um alcance de quase 200 alunos. O evento aconteceu dentro das dependências da universidade Unipar em uma sala de tutorial, no dia primeiro de setembro de 2021, tendo uma duração de uma hora e quarenta e cinco minutos, onde cada convidado pode discorrer livremente sobre o tema proposto por um período de quinze minutos cada. Ao término desta etapa, cada profissional pode fazer sua réplica, e pudemos responder algumas perguntas vindas dos próprios convidados e perguntas feitas pelos ouvintes que participaram da chamada on-line.

Considerações Finais: Os impactos positivos que a atividade física propõe são muito importantes, sendo um fator de proteção à saúde mental durante a infância e a idade adulta (DA SILVA, 2017). Infelizmente o sofrimento psíquico afeta qualquer indivíduo, independente de idade e gênero, aumentando a frequência muito mais em época de pandemia, por conta do isolamento social, incertezas e medo do desconhecido. Dessa forma, faz-se necessário cuidados que promovam o benefício de ambos, ou seja, saúde mental e física.

Conclusão: Sendo assim, a conscientização acerca da atividade física mostra-se um poderoso aliado, especialmente em tempos delicados de pandemia, nos quais as pessoas necessitam realizar o distanciamento social, abrindo mão de diversas atividades corriqueiras e de esportes coletivos a fim de evitar possíveis aglomerações, tornando-se, assim, mais conscientes acercas dos 
diversos benefícios que a prática esportiva pode lhes proporcionar tanto física quanto mentalmente. Desse modo, a LAMEFT, por meio de atividades como a Mesa Redonda buscou conscientizar a população acadêmica e geral da cidade acerca da necessidade intrínseca de realizar alguma atividade física mesmo em épocas de COVID-19.

\section{Referências}

DE LIMA, G. O., Mendes, B. M., Klein, S. K., Formentin, C. M., \& Garlipp, D. C. Nível de atividade física e risco de desenvolvimento de doenças cardiovasculares em acadêmicos do Curso de Educação Física. RBPFEX - Revista Brasileira De Prescrição E Fisiologia Do Exercício, 2017.

DA SILVA, Gabrielle Cerqueira, SILVA, Rodrigo Alves dos Santos, NETO, Jorge Lopes CAVALCANTE. Saúde mental e níveis de atividade física em crianças: uma revisão sistemática. Cad. Bras. Ter. Ocup., São Carlos, v. 25, n. 3, p. 607-615, 2017.

PITANGA, Francisco José Gondim, Beck, Carmem Cristina e Pitanga, Cristiano Penas Seara. Atividade Física e Redução do Comportamento Sedentário durante a Pandemia do Coronavírus. Arquivos Brasileiros de Cardiologia, 2020. 


\section{(1) \\ - UNIPAR 50 ANOS: \\ Transformando vidas através da educação \\ 27 de Outubro de 2021 \\ ISBN 978-65-87557-74-8

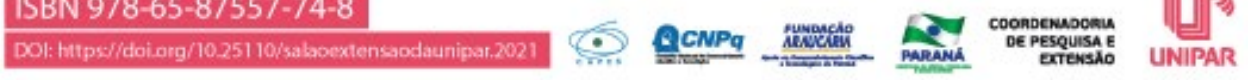 \\ CAMPANHA CONTRA A POBREZA MENSTRUAL - ARRECADAÇÃO DE ABSORVENTES PARA POPULAÇÃO CARENTE NO MUNICÍPIO DE UMUARAMA-PR}

1BARBARA HELENA SIOLARI DE MICO ROBERTO, ${ }^{2}$ AMANDA BROSDA PACKER, ${ }^{3}$ CAROLINE SPESSATTO TEIXEIRA ARAUJO, ${ }^{4}$ ERIC ALVES CORREIA, ${ }^{5}$ GABRIELA GUERINI CARDOSO, ${ }^{6}$ GUILHERME DE ALMEIDA FAHEL CHUEIRI, ${ }^{7}$ LUIZ FELIPE MANTOVANI RODRIGUES, ${ }^{8}$ MATHEUS MENNA, ${ }^{9}$ MARCIA ELIZA BAVARESCO TOZONI, ${ }^{10}$ MARCOS VINICIUS SILVA ANGELO, ${ }^{11}$ RANIEL RAMIRO PAZ DE ARAUJO, ${ }^{12}$ SILVANO FARIAS DIAS JUNIOR, ${ }^{13}$ KARINA FARAH SAKUMOTO

\footnotetext{
${ }^{1}$ Acadêmica do Curso de Medicina/UNIPAR

${ }^{2}$ Acadêmica do Curso de Medicina da UNIPAR

${ }^{3}$ Acadêmica do Curso de Medicina da UNIPAR

${ }^{4}$ Acadêmico do Curso de Medicina da UNIPAR

${ }^{5}$ Acadêmica do Curso de Medicina da UNIPAR

${ }^{6}$ Acadêmico do Curso de Medicina da UNIPAR

${ }^{7}$ Acadêmico do Curso de Medicina da UNIPAR

${ }^{8}$ Acadêmico do Curso de Medicina da UNIPAR

${ }^{9}$ Acadêmica do Curso de Medicina da UNIPAR

${ }^{10}$ Acadêmico do Curso de Medicina da UNIPAR

${ }^{11}$ Acadêmico do Curso de Medicina da UNIPAR

${ }^{12}$ Acadêmico do Curso de Medicina da UNIPAR

${ }^{13}$ Docente da UNIPAR
}

Introdução: Desde 2014, a Organização das Nações Unidas (ONU) considera o acesso à higiene menstrual um direito que precisa ser tratado como uma questão de saúde pública e de direitos humanos (BRASIL, 2021). É denominada pobreza menstrual "a situação de precariedade e vulnerabilidade econômica e social à qual bilhões de pessoas menstruantes ao redor do mundo estão submetidas por não terem acesso adequado à saneamento básico, banheiros e itens de higiene pessoal, incluindo protetores menstruais (ASSAD, 2021). Haja vista as necessidades biológicas específicas, as mulheres tendem a ser mais afetadas pela falta de saneamento básico e de acesso à água tratada, explica-se devido ao fato do órgão genital feminino possuir uma microbiota em constante equilíbrio e, assim, demanda uma higiene correta para a prevenção de infecções, intensificando a mesma nos períodos de menstruação. Uma pessoa que menstrue precisa, por exemplo, trocar de absorvente descartável (se for o método) algumas vezes ao dia para conter o fluxo e evitar doenças (ASSAD, 2021). Como se não bastasse a omissão e negligência do Estado no que tange o combate à pobreza menstrual, o Brasil possui uma das mais elevadas taxações sobre absorventes no mundo. Em média, esse valor equivale a $25 \%$ do preço do produto, variando de acordo com o Estado da Federação (ASSAD, 2021).

Objetivo: Promover e coordenar a arrecadação de absorventes para destinar à população carente do município de UmuaramaPR.

Resultados: A atividade Campanha para Doação de Absorventes 2021 foi idealizada pela Liga Acadêmica de Semiologia Médica (LASEM). A atividade foi desenvolvida no período de 27/08 a 09/09 e contou com 2 pontos de arrecadação nas dependências da Universidade Paranaense de Umuarama. Foi arrecadado um total de 50 pacotes de absorventes. Os itens arrecadados foram distribuídos para adolescentes menstruantes em situação de carência.

Conclusão: Assim sendo, fica claro que uma campanha que vise minimizar a pobreza menstrual se faz extremamente necessária, tendo em vista o negligenciamento das pessoas menstruantes, desconhecimento e a perpetuação de tabus acerca da questão.

\section{Referências}

ASSAD, Beatriz Flügel. POLítICAS PÚBLICAS ACERCA DA POBREZA MENSTRUAL E SUA CONTRIBUIÇÃO PARA O COMBATE À DESIGUALDADE DE GÊNERO. Revista Antinomias, v. 2, n. 1, p. 140-160, 2021. Disponível em: . Acesso em: 07 set. 2021.

O que é pobreza menstrual e por que ela afasta estudantes das escolas: Agência Senado, Jornal do Senado. Brasília: 
Senado Federal, 2021. Disponível em: . Acesso em: 08 set. 2021.

AMAISDO " UNIPAR 50 ANOS:

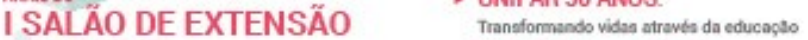

DA UNIPAR

27 de Outubro de 2021

\&.S ACNPQ 


\title{
(1) $\begin{aligned} & \text { NaIs Do } \\ & \text { SALÃO DE EXTENSÃO DA } \\ & \text { UNIPAR }\end{aligned}$ \\ - UNIPAR 50 ANOS: \\ Transformando vidas através da educação \\ 27 de Outubro de 2021 \\ ISBN 978-65-87557-74-8

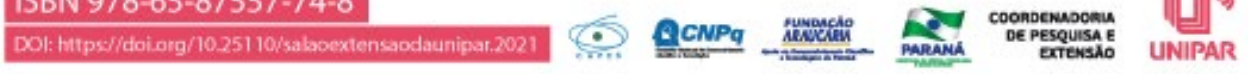 \\ INFLUÊNCIA DOS HORÁRIOS DE CORREÇÃO DA CAIXA DE SOLUÇÃO NUTRITIVA NA CULTURA DO ALFACE (Lactuca sativa) EM SISTEMA HIDROPÔNICO
}

\author{
${ }^{1}$ MARIA CAROLINA OLIVEIRA TONA, ${ }^{2}$ ESTEVAO AUGUSTO LOMBERTI MELHORANCA, ${ }^{3}$ RENAN RIZZATO ESPESSATO
}

\author{
${ }^{1}$ Acadêmico do PEX/UNIPAR \\ ${ }^{2}$ Responsável técnico do curso de engenharia agronômica da UNIPAR \\ ${ }^{3}$ Docente da UNIPAR
}

Introdução: O sistema de hidroponia se define como o cultivo de plantas sem a utilização de solo, onde as raízes recebem uma solução nutritiva balanceada que contém água e todos os nutrientes essenciais ao desenvolvimento da planta (BEZERRA NETO; 2017). A alface é a folhosa mais cultivada e que possui maior adaptabilidade para hidroponia, principalmente através da técnica do NFT (Nutrient Film Technique) ou fluxo laminar de nutrientes (GALON et al.; 2011). Uma das maiores dificuldades encontradas para a produção hidropônica em sistema NFT de hortaliças é o aumento da temperatura da solução nutritiva (BREMENKAMP et al.; 2012).

Objetivo: O presente trabalho teve por objetivo caracterizar a interferência e influência em relação ao horário de correção da solução nutritiva no que se refere ao desenvolvimento da cultura do alface hidropônico.

Resultados: O trabalho foi conduzido no centro de difusão de tecnologia em cultivo hidropônico localizada no Campus III da Universidade Paranaense (UNIPAR) no município de Umuarama PR. O experimento foi conduzido em delineamento inteiramente casualizados (DIC), com 4 quatro tratamentos, onde cada tratamento pertencia a um horário diferente de correção da solução nutritiva, ( $T 1=$ correção às $8 \mathrm{~h}, T 2=$ correção às $11 \mathrm{~h}, T 3=$ correção às $14 \mathrm{~h}$ e $T 4$ correção às $17 \mathrm{~h})$, em todos os horários verificou-se os dados de pH e Ec de todas as caixas, porém apenas em seus respectivos horários era corrigido cada caixa. Os resultados não apresentaram diferença significativa para as variáveis de matéria fresca parte raiz, matéria fresca parte total, número de folhas, diâmetro do coração, volume da raiz, matéria seca parte raiz e matéria seca parte total. Para as avaliações relacionadas ao crescimento da altura do coração da alface, nas duas primeiras semanas as plantas não apresentaram diferenças significativas, porém aos 21 DAT as correções da solução nutritiva realizadas as 11 e 14 horas apresentaram menor taxa de crescimento quando comparadas as correções realizadas as 8 e 17 horas.

Conclusão: Podemos concluir que se o produtor realizar a aferição da solução nutritiva em horários de temperaturas elevadas como o das 11:00 e 14:00 irá influenciar de forma negativa o desenvolvimento das plantas afetando assim a sua produtividade.

\section{Referências}

BEZERRA NETO, Egídio. O cultivo hidropônico. In: BEZERRA NETO, E. Hidroponia, Pernambuco, n. 6, p.15-30, 2017.

BREMENKAMP, Diene Maria.; GALON, Karla.; HELL, Leonardo Raasch.; PASSOS, Gabriel.; CAZAROTI, Eline Paula Figueira.; COMETTI, Nilton Nélio. Efeito da temperatura da solução nutritiva no crescimento da alface (Lactuca sativa L.) em hidroponia. Horticultura Brasileira, Espirito Santo, v. 30, p. 596-604, jul. 2012.

GALON, Karla.; BREMENKAMP, Diene Maria.; BREMENKAMP, Cintia Aparecida.; ALMEIDA, Joyce de.; PASSOS, Gabriel.; COMETTI, Nilton Nélio. Desempenho de quatro cultivares de alface (Lactuca sativa L.) em cultivo hidropônico em ambiente tropical. In: CONGRESSO BRASILEIRO DE OLERICULTURA, 51. 2011. Anais... Viçosa: ABH. p.126-131, jul. 2011.

I SALÁO DE EXTENSÃO DA UNIPAR

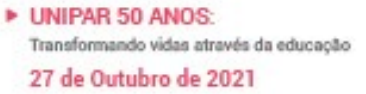

Transformando vides atravis

27 de Outubro de 2021

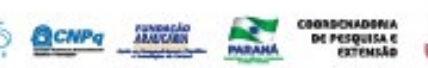




\title{
( (2) ISALÃO DE EXTENSÃO DA UNIPAR \\ PLANTÃO DE ATENDIMENTO PSICOLÓGICO - PAP : UMA PROPOSTA DE INTERVENÇÃO NAS EMERGÊNCIAS PSICOLÓGICAS EM UM SERVIÇO ESCOLA
}

\author{
${ }^{1}$ DANIELA GOLTZ, ${ }^{2}$ AMANDA CRISTINA FAVARETTO, ${ }^{3}$ ISADORA GAGLIOTTO GALVAN, ${ }^{4}$ LARISSA IEZ WESSLING, \\ ${ }^{5}$ VIVIANE SAGIN, ${ }^{6}$ DIELLI CAROLINE CAPELLI, ${ }^{7}$ TAISE SIGNORINI
}

\author{
${ }^{1}$ Acadêmica do Curso de Psicologia da UNIPAR \\ ${ }^{2}$ Acadêmica do Curso de Psicologia da UNIPAR \\ ${ }^{3}$ Acadêmica do Curso de Psicologia da UNIPAR \\ ${ }^{4}$ Acadêmica do Curso de Psicologia da UNIPAR \\ ${ }^{5}$ Acadêmica do Curso de Psicologia da UNIPAR \\ ${ }^{6}$ Docente da UNIPAR \\ ${ }^{7}$ Docente da UNIPAR
}

Introdução: Conforme consolidado nas práticas de saúde, os atendimentos de plantões visam o acolhimento emergencial de diversas demandas, sem o agendamento prévio, em consonância com as necessidades e desejos do atendido (FURIGO et al, 2008). No que tange à Psicologia, a prática de Plantão Psicológico é reconhecida por romper com os modelos tradicionais de psicoterapias contínuas, por possuir um caráter não diretivo e com foco nas emergências trazidas pelo sujeito, por meio do acolhimento em situações de crise. Desta forma, esta modalidade de atendimento, apresenta caracterizações específicas, tais como flexibilidade, pois pode estar inserido em diversos contextos e diferentes locais, organização, podendo ser realizado em um único ou mais encontros, e as intervenções sem planejamentos prévios, uma vez que o plantão se propõe ao inesperado. (SOUZA; FARIAS, 2015). Nesta perspectiva, o Plantão de Atendimento Psicológico (PAP), enquanto Projeto de Extensão Universitário previsto no Centro de Psicologia Aplicada (CPA), pretende satisfazer as necessidades da formação acadêmica, e as demandas emergentes da comunidade.

Objetivo: O PAP tem como principal escopo contribuir para a formação teórico-prática dos acadêmicos, visando ampliar os cuidados em saúde mental, através do acolhimento emergencial em situações de crise, vivenciadas por pessoas da comunidade interna e externa da universidade.

Resultados: Até o presente momento, apenas foram realizados estudos teóricos, revisões bibliográficas e discussão de casos clínicos (fictícios). Segundo Daher et al (2017) estes fundamentos subsidiam as intervenções práticas, constituindo-se como ferramentas e estratégias no acolhimento e nas intervenções destinadas às pessoas em situações de crise e de emergências psicológicas, com vistas a minimizar tais sofrimento, e favorecer a prevenção e promoção da saúde mental (GOMES, 2008).

Conclusão: A partir da revisão da literatura, constatou-se que os atendimentos de urgência em psicologia são de grande importância, pois auxiliam no enfrentamento de situações geradoras de sofrimento, possibilitando maior acessibilidade e adesão ao atendimento, tendo em vista que ocorre no exato momento em que emerge uma necessidade. Ademais, colabora com a construção de encaminhamentos mais assertivos e apontam possibilidades na busca pela minimização do sofrimento humano.

\section{Referências}

DAHER, Ana Claudia Broza. et al. Plantão psicológico a partir de uma escuta psicanalítica. Semina: Ciências Sociais e Humanas, Londrina, vol. 38, n.2, p.147-158, jul./dez. 2017. Disponível em .

FURIGO, Regina Célia Paganini. et al. Plantão Psicológico: uma prática que se consolida. Revista Boletim de Psicologia, vol. 58, n. 129, p. 185-192, 2008. Disponível em: http://pepsic.bvsalud.org/pdf/bolpsi/v58n129/v58n129a06.pdf. Acesso em: 25 Ago. 2021.

GOMES, Fernanda Maria Donato. Plantão psicológico: novas possibilidades em saúde mental. Revista SPAGESP, Ribeirão Preto, v. 9, n. 1, p. 39-44, jun. 2008. Disponível em: Acessos em: 30 ago. 2021.

SOUZA, Sandra; FARIAS, Arethusa Eire Moreira. Plantão psicológico: a urgência da acolhida. In: SOUZA, Sandra; SILVA FILHO, Francisco Bento da; MONTENEGRO, Liana Aparecida de Andrade (ORG). Plantão Psicológico: ressignificando o humano na experiência da escuta e acolhimento. 1. Ed. Curitiba, PR: CRV, 2015. p. 15-32.

\section{SALÃO DE EXTENSÃO DA UNIPAR}

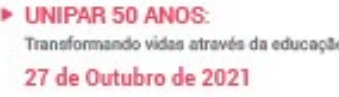

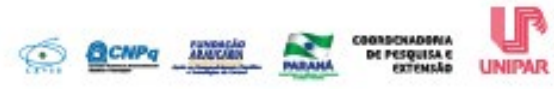




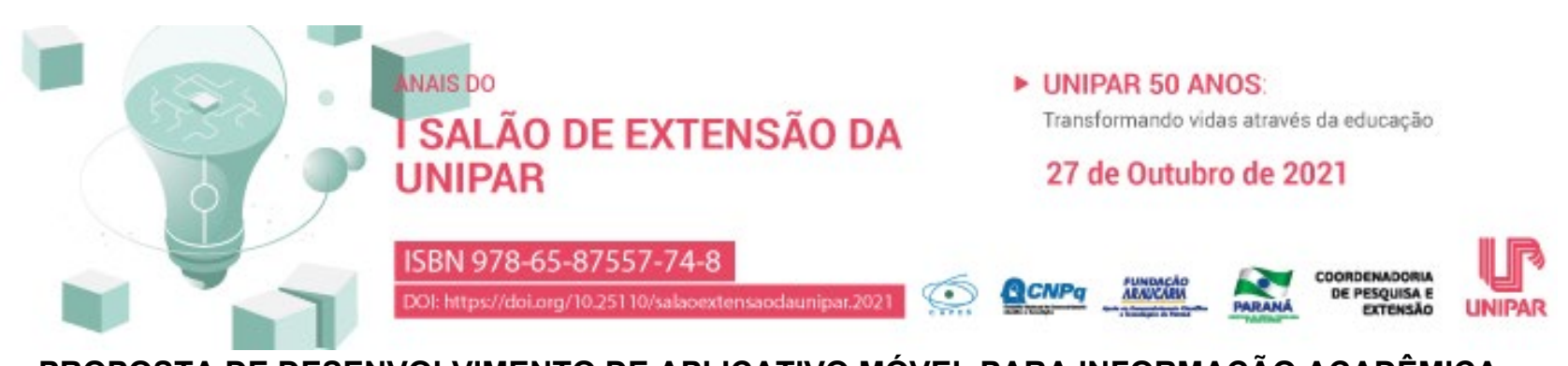

PROPOSTA DE DESENVOLVIMENTO DE APLICATIVO MÓVEL PARA INFORMAÇÃO ACADÊMICA

\author{
${ }^{1}$ GUILHERME MORETTO DE ARAUJO, ${ }^{2}$ LEANDRO CLEMENTINO DE LIMA
}

${ }^{1}$ Acadêmico do $3^{\circ}$ ano de Sistemas de Informação da Unipar

${ }^{2}$ Docente da UNIPAR

Introdução: Após a transição para o meio digital decorrente da pandemia do Covid-19, as metodologias de ensino não retornarão a ser como eram. As novas formas de ensinar e aprender mostram que é necessário adaptar-se ao ambiente digital (CORDEIRO, 2020). Sendo assim, se faz necessária a atualização ou diponibilização de ferramentas adequadas para gerenciar a informação acadêmica produzida no meio educacional.

Objetivo: Este projeto tem como objetivo propor o desenvolvimento de uma aplicação móvel a ser utilizada por acadêmicos, para consulta de informações como notas, horários e frequência.

Resultados: Após estudar as tecnologias disponíveis, foi escolhido o framework Flutter para a construção da aplicação. $O$ principal motivo desta escolha é a sua capacidade multiplataforma, permitindo que, com o mesmo código, seja possível desenvolver uma aplicação para os sistemas Android e IOS (CORAZA, 2018). Outra vantagem da utilização do Flutter é a sua característica de código aberto, o que permite que outros desenvolvedores disponibilizam componentes que facilitam a criação de funcionalidades (OLIVEIRA; OLIVEIRA, 2019). Para poder construir uma aplicação que atenda às necessidades de seus usuários, será feito um levantamento de requisitos seguindo os processos de engenharia de software indicados por Sommerville (2007).

Conclusão: Tendo em vista o cenário da educação atual e as perspectivas para o futuro, conclui-se que o aplicativo proposto deve atender às necessidades dos alunos que o utilizarão, garantindo o acesso e consumo das informações digitais disponibilizadas pela sua instituição de ensino ao maior número de acadêmicos possível.

\title{
Referências
}

CORAZZA, Paulo Victor. Um aplicativo multiplataforma desenvolvido com Flutter e NoSQL para o cálculo da probabilidade de apendicite. 2018. Disponível em: http://hdl.handle.net/10183/190147. Acesso em: set/2021.

CORDEIRO, Karolina Maria de Araújo. O Impacto da Pandemia na Educação: A Utilização da Tecnologia como Ferramenta de Ensino. 2020. Disponível em: http://repositorio.idaam.edu.br/jspui/handle/prefix/1157. Acesso em: set/2021.

OLIVEIRA, Filipe; OLIVEIRA, Elthon. Aprendizado de máquina aplicado a dados agrometeorológicos. 2019. Disponível em: https://sol.sbc.org.br/index.php/erbase/article/view/8962/8863. Acesso em: set/2021.

SOMMERVILLE, lan. Engenharia de Software. 8. ed. [S. I.]: Editora Pearson, 2007.

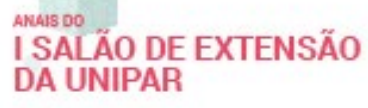

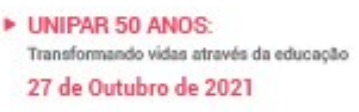

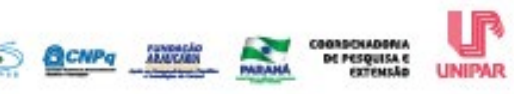




\title{
(1) \\ - UNIPAR 50 ANOS: \\ Transformando vidas através da educaçào \\ 27 de Outubro de 2021 \\ ISBN 978-65-87557-74-8

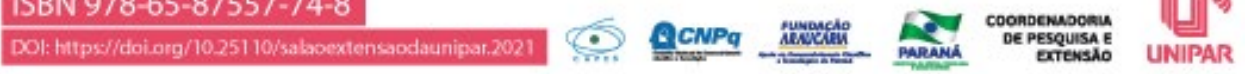 \\ DESENVOLVENDO HABILIDADES PARA VIDA NO CONTEXTO ESCOLAR: UMA PROPOSTA DE INTERVENÇÃO PSICOLÓGICA EM RODAS DE CONVERSA ON-LINE
}

\author{
${ }^{1}$ BRUNA PASSAURA, ${ }^{2}$ LARISSA VIAPIANA, ${ }^{3}$ THAIS CRISTINA GUTSTEIN NAZAR
}

\author{
${ }^{1}$ Discente do curso de Psicologia da Universidade Paranaense UNIPAR, campus de Fco Beltrão/PR \\ ${ }^{2}$ Discente do curso de Especialização em Psicoterapia Analítico-Comportamental da Universidade Paranaense UNIPAR, \\ campus de Fco Beltrão \\ ${ }^{3}$ Docente do curso de Psicologia da Universidade Paranaense UNIPAR, campus de Fco Beltrão/PR
}

Introdução: A pandemia de Covid-19 afetou a vida de adolescentes, que passaram a ficar mais tempo em casa - também devido à adaptação das aulas para a modalidade remota, o que pode ter trazido impactos em seus aspectos emocionais e comportamentais (MALTA et al, 2021).

Objetivo: Proporcionar a adolescentes estudantes do Ensino Médio intervenção psicológica do tipo roda de conversa a fim de fomentar habilidades para a vida.

Material e métodos: A partir da demanda apresentada por uma instituição privada de ensino em Francisco Beltrão-PR, foram propostas intervenções psicológicas grupais visando o desenvolvimento de habilidades para a vida. Participaram dos encontros cinco alunas, de $1^{\circ}$ e $2^{\circ}$ anos do Ensino Médio, com idades entre 15 e 17 anos. Foram realizados seis encontros semanais, com duração entre $1 \mathrm{~h} 30$ a $2 \mathrm{~h}$ cada, de forma on-line, utilizando-se da ferramenta Google Meet. As temáticas abordadas, sugeridas pelas participantes, foram: ansiedade, rede de apoio, autoestima e escolha profissional. Foram utilizadas técnicas de Terapia da Aceitação e Compromisso - ACT (SABAN, 2015), de interação, de relaxamento, metáforas e psicoeducação.

Resultados: Ao longo dos encontros, foi possível criar gradualmente vínculo entre o grupo e participação efetiva. $O$ tema mais recorrente foi o da ansiedade, agravada devido à pandemia de covid-19, uma vez que o sistema de aulas remotas impossibilitou maior interação entre os pares. Em relação ao tema autoestima, percebeu-se uma relação intrínseca à aparência física. Quanto à escolha profissional houveram divergências, estando algumas participantes decididas e outras indecisas. Por isso, foi abordado o processo de tomada de decisão (MOURA, 2004).

Discussão: Com a intenção de transformar a terapia numa situação mais próxima ao ambiente natural, facilitando a aprendizagem de comportamentos (DELITTI, 2008, p. 18) foi proposta a metodologia de roda de conversa. Algumas dificuldades oriundas do contexto remoto foram identificadas, como a interação apenas por áudio na maioria dos encontros. Contudo, mesmo assim foi possível identificar resultados relevantes, como a possibilidade de um momento terapêutico - ao qual nem todas as participantes ainda haviam tido acesso -, a relação de confiança estabelecida, a criação de um espaço de fala e escuta, além do desenvolvimento de habilidades para a vida.

Conclusão: A intervenção do tipo roda de conversa se mostrou útil para a promoção das habilidades para a vida entre adolescentes estudantes do Ensino Médio. Sugerem-se que intervenções futuras sejam realizadas presencialmente e que as intervenções possam ser acessíveis a outros contextos escolares.

\section{Referências}

DELITTI, Maly; DERDYK, Priscila. (Orgs.). Terapia analítico-comportamental em grupo. Santo André-SP: ESETs, 2008. MALTA, Deborah Carvalho, et al. A pandemia de COVID-19 e mudanças nos estilos de vida dos adolescentes brasileiros. Rev. Bras. Epidemiol., v. 24, art. E210112, 2021. Disponível em: . Acesso: 06 set. 2021.

MOURA, Cyntia Borges de. Orientação profissional: sob enfoque da análise do comportamento. Campinas-SP: Alínea, 2004. SABAN, Michele Terena. Introdução a teoria de aceitação e compromisso. 2. ed. Belo Horizonte-MG: Artesã, 2015.

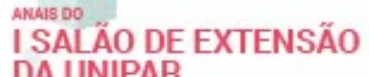

DA UNIPAR

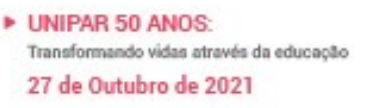

- UNIPAR 50 ANOS:

Transformando vides atravta da educaģso 27 de Outubro de 2021

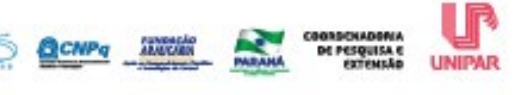




\section{- (2) SALÃO DE EXTENSÃO DA UNIPAR UMUARAMA-PR}

${ }^{1}$ MICHELE AYUMI CHAVES, ${ }^{2}$ SUELEN STEFANONI BRANDAO, ${ }^{3}$ AMANDA PINHEIRO PRADO, ${ }^{4}$ VANESSA MARCONDES BRASILEIRO FREDERICO, ${ }^{5}$ MARIO MARQUES PEREIRA FILHO, ${ }^{6}$ BRUNA MONTEIRO SANCHES, ${ }^{7}$ VINICIUS PAIE MARQUES DOS REIS, ${ }^{8}$ MIGUEL FRANCISCO FERREIRA BATISTA, ${ }^{9}$ LUCAS ALEXANDRE GUBERT SCHIER, ${ }^{10}$ GABRIELA ALVES DE OLIVEIRA, ${ }^{11}$ PATRICIA RODRIGUES HAUCK PRANTE

\footnotetext{
${ }^{1}$ Acadêmica do Curso de Medicina da UNIPAR

${ }^{2}$ Acadêmica do Curso de Medicina da UNIPAR

${ }^{3}$ Acadêmica do Curso de Medicina da UNIPAR

${ }^{4}$ Acadêmica do Curso de Medicina da UNIPAR

${ }^{5}$ Acadêmico do Curso de Medicina da UNIPAR

${ }^{6}$ Acadêmica do Curso de Medicina da UNIPAR

${ }^{7}$ Acadêmico do Curso de Medicina da UNIPAR

${ }^{8}$ Acadêmico do Curso de Medicina da UNIPAR

${ }^{9}$ Acadêmico do Curso de Medicina da UNIPAR

${ }^{10}$ Acadêmica do Curso de Medicina da UNIPAR

${ }^{11}$ Docente da UNIPAR
}

Introdução: A obesidade é uma doença crônica caracterizada pelo excesso de gordura corporal em relação a massa magra. Está relacionada com múltiplas complicações, que dependem de fatores genéticos, mas também de fatores externos, como aspectos sociais, psicológicos associados à quantidade e qualidade da alimentação (MARTINS, 2009). A patologia predispõe o surgimento de uma variedade de doenças crônicas, incluindo doenças cardiovasculares; distúrbios metabólicos, digestivos, respiratórios e gonadais; alguns tipos de cânceres e uma ampla gama de condições osteomusculares (VILAR, 2021). De acordo com as Diretrizes Brasileiras de Obesidade, 2016, convenciona-se chamar de sobrepeso o IMC de 25 a $29,9 \mathrm{~kg} / \mathrm{m} 2$ e obesidade o IMC maior ou igual a $30 \mathrm{~kg} / \mathrm{m} 2$. Existem medicações aprovadas no Brasil, mas nenhum tratamento medicamentoso exclui a necessidade de mudança no estilo de vida. O tratamento cirúrgico é indicado apenas para pacientes com IMC muito elevado e/ou IMC elevado mais comorbidades associadas (MARTINS, 2009.)

Objetivo: Analisar o IMC dos pacientes atendidos na unidade Centro de Saúde Escola - Unipar, explicar o resultado obtido e dar as informações cabíveis e necessárias diante do que foi encontrado.

Desenvolvimento: No período de 26/08 a 06/09 os discentes da liga acadêmica de Endocrinologia e Metabologia se dividiram em duplas e acompanharam na UBS Centro Saúde Escola os pacientes que por lá passaram para eventuais consultas. Na abordagem foram verificados peso e altura e realizado o cálculo do IMC; em seguida o mesmo era informado em qual situação se encaixava de acordo com a classificação internacional de obesidade e, para aqueles pacientes que estavam com IMC maior ou igual a $25 \mathrm{~kg} / \mathrm{m} 2$ eram feitas ações de prevenção sobre os riscos relacionados ao sobrepeso e obesidade; os mesmos também eram conscientizados a procurar a nutricionista da UBS para possível reeducação alimentar.

Conclusão: A obesidade é a enfermidade de maior impacto global das últimas décadas. Sua abrangência cria um novo potencial devastador para a economia global, especialmente, para países em desenvolvimento. A ingestão excessiva de carboidratos e gorduras saturadas, bem como o aumento no consumo de bebidas alcoólicas e o sedentarismo tem sido primordial para o desenvolvimento da mesma. Sugere-se mudanças de hábitos em relação à alimentação e práticas de exercícios físicos e maior fomento por parte das políticas públicas de saúde no combate à obesidade.

\section{Referências}

Diretrizes brasileiras de obesidade, 4 ed. São Paulo, 2016. Disponivel em: http://abeso.org.br

MARTINS, Mílton de Arruda; CARRILHO, Flair Jose; ALVES, Venancio Avancini Ferreira; CASTILHO, Euclides Ayres; CERRI, Giovanni Guido; WEN, Chao Lung. Clínica Médica, doenças endócrinas e metabólicas, doenças ósseas e reumatológicas, vol. 5, Barueri-São Paulo, Editora Manole, 2009.

VILLAR, Lucio. Endocrinologia Clínica. 7. ed. Rio de Janeiro: Guanabara Koogan, 2021. 
- unIPAR 50 anos:

I SALAOO DE EXTENSÃO Transformando vidas atravies da educaģso

DA UNIPAR 


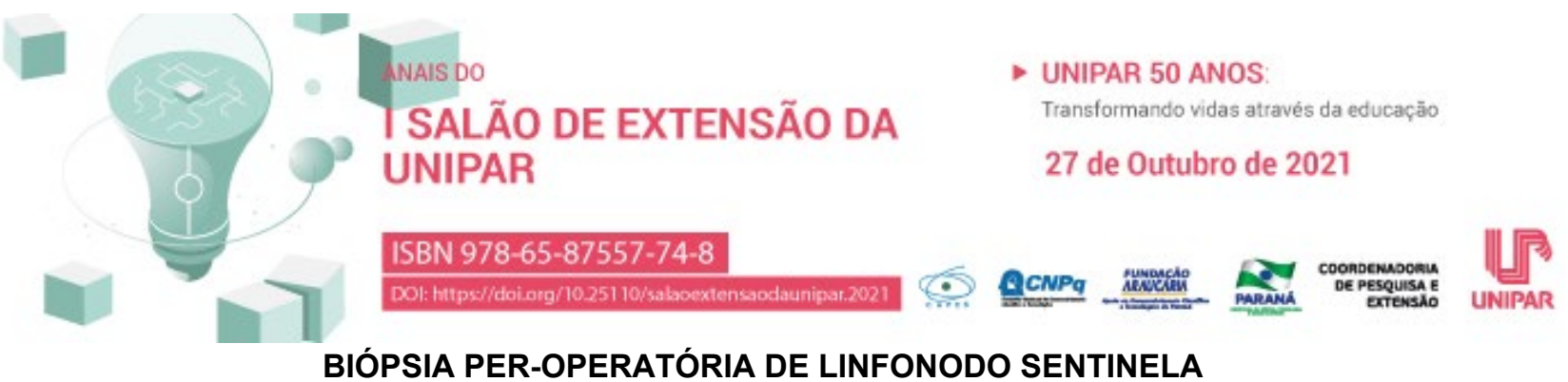

\author{
${ }^{1}$ MARINA BOITO DE OLIVEIRA, ${ }^{2}$ KEROLLIN WALTRICK DA SILVA, ${ }^{3}$ IZABEL PUZISKI ROSSATO, ${ }^{4}$ BRUNA FAVRETTO DA \\ SILVA, ${ }^{5}$ CRISTIANE EDNA DA ROCHA, ${ }^{6}$ AMANDA SIHNEL CORTEZ DA SILVA, ${ }^{7}$ ANA BEATRIZ SILVESTRI RIBEIRO, \\ ${ }^{8}$ ISABELLA MORAIS TAVARES, ${ }^{9}$ LETICIA AITA, ${ }^{10}$ RICARDO MARCELO ABRAO
}

${ }^{1}$ Acadêmico do Curso de Medicina da UNIPAR

${ }^{2}$ Acadêmica do Curso de Medicina da UNIPAR

${ }^{3}$ Acadêmica do Curso de Medicina da UNIPAR

${ }^{4}$ Acadêmica do Curso de Medicina da UNIPAR

${ }^{5}$ Acadêmica do Curso de Medicina da UNIPAR

${ }^{6}$ Acadêmica do Curso de Medicina da UNIPAR

${ }^{7}$ Acadêmica do Curso de Medicina da UNIPAR

${ }^{8}$ Professora Adjunta do Curso de Medicina da UNIPAR

${ }^{9}$ Professora Assistente do Curso de Medicina da UNIPAR

${ }^{10}$ Professor Titular do Curso de Medicina da UNIPAR

Introdução: $O$ exame histopatológico per-operatório é aquele realizado durante o ato cirúrgico com o objetivo de analisar o material biológico em questão (SILVA et al., 2011). Esse exame é importante porque concede um diagnóstico precoce que auxilia o cirurgião a definir qual melhor abordagem ou procedimento mais adequado em cada caso, ou seja, o exame intra-operatório realizado pelo médico patologista guia o cirurgião em qual estratégia ele deve seguir (CMAÉLIA; DIACONU, 2009). No caso de cirurgias oncológicas, a biópsia per-operatória do linfonodo sentinela permite uma rápida diferenciação entre neoplasias benignas e malignas, especialmente com relação à possibilidade de metástase (ZAHOOR et al., 2017).

Objetivo: Conhecer a técnica utilizada pelos médicos patologistas no diagnóstico de metástase em linfonodos sentinelas e acompanhar o exame per-operatório.

Resultados: Na preparação para a cirurgia de mastectomia total, ao entrar no centro cirúrgico foi trajada a vestimenta adequada (pijama cirúrgico, propé, gorro e máscara) (PARANÁ, 2016). No bloco cirúrgico, os enfermeiros estavam preparando a paciente para esse procedimento, que ocorreria em decorrência de câncer de mama. Quando a paciente estava pronta, o cirurgião oncológico responsável pelo procedimento, retirou o linfonodo sentinela e entregou à médica patologista. Ela, por sua vez, dirigiuse à sala de patologia, preparou o raspado da amostra utilizando a coloração panótico rápido (UEMURA, 2018) e analisou ao microscópio. A patologista procurou evidências de metástase, uma vez que esses achados indicam mau prognóstico da doença (ZAHOOR et al., 2017). No caso acompanhado, não houve sinal de disseminação sistêmica. Ao final do exame, a médica patologista retornou ao bloco cirúrgico com a amostra biológica e relatou ao médico responsável o laudo preliminar de que a paciente não apresentava sinais de metástase. Por conta disso, o cirurgião não precisou fazer a retirada dos demais linfonodos.

Conclusão: Acompanhar a realização da biópsia intra-operatória, oportunizada pelo projeto de extensão, proporcionou um conhecimento mais aprofundado sobre uma das áreas de atuação do médico patologista e suas relações com as demais áreas médicas, bem como sobre a técnica utilizada na análise de amostras biológicas. Participar dessa experiência extracurricular foi de grande valia na formação acadêmica, pois possibilitou um contato maior com essa área da medicina.

\author{
Referências \\ CMAÉLIA, Chifu; DIACONU, C. Frozen section exam value in breast cancer. Revista medico-chirurgicala a Societatii de \\ Medici si Naturalist Din lasi, vol. 113, n. 3, jul-set, 2009. Disponível em: https://pubmed.ncbi.nlm.nih.gov/20191831/. Acesso: 8 de \\ set. de 21. \\ UEMURA, Elisa H. Coloração Panótico Rápido. Laborclin Produtos para Laboratórios Ltda, rev. 08 12/2018. Disponivel em: \\ https://www.laborclin.com.br/wp- \\ content/uploads/2019/06/Coloracao_panotico_rapido_620259_620100_620105_620106_620107.pdf. Acesso em: 8 de set. de 21 \\ PARANÁ. Resolução SESA $n^{\circ}$ 165/2016, 05 de maio de 2016. Estabelece norma técnica para o funcionamento de \\ estabelecimentos hospitalares. Disponível em: https://www.saude.pr.gov.br/sites/default/arquivos_restritos/files/documento/2020- \\ 05/165.pdf. Acesso em: 8 de set. de 21
}

SILVA, Rafael D. P. et al. Precisão diagnóstica das doenças cirúrgicas nos exames por congelação. Scielo Brasil

Revista 
do Colégio Brasileiro de Cirurgiões, v. 38, n. 3, jun - $2011 . \quad$ Disponível em: https://www.scielo.br/j/rcbc/a/K9YRdxdHcD9f7Tf3NCYLmTN/?lang=pt. Acesso em 8 de set. de 21.

ZAHOOR, Sheikh et al. Sentinel lymph node biopsy in breast cancer: a clinical review and update. Jornal of Breast Cancer, vol. 30, n. 3, pg. 217-227, setembro - 2017. Disponível em: https://www.ncbi.nlm.nih.gov/pmc/articles/PMC5620435/ Acesso em: 8 de set. de 21

$\begin{array}{ll}\text { Anuals Do } \\ \text { I SALĂO DE EXTENSÃO } & \text { UNIPAR } 50 \text { ANOS: } \\ \text { DA UNIPAR } & 27 \text { de Outubro de } 2021\end{array}$




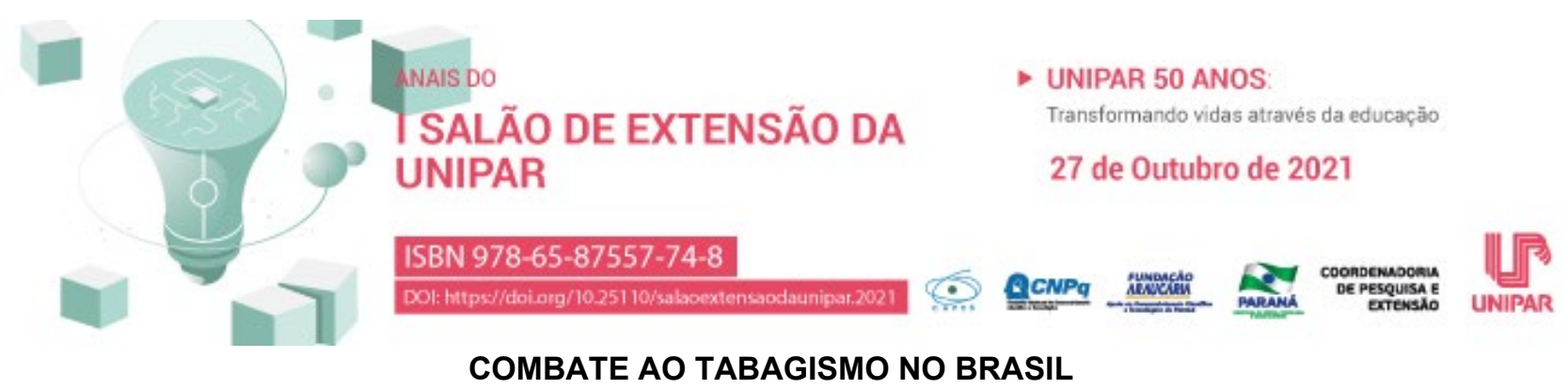

${ }^{1}$ ELIEZER FERREIRA DA SILVA, ${ }^{2}$ FABIANE ANGELICA DE PAIVA PAULA, ${ }^{3}$ JESSICA XAVIER SANTINI, ${ }^{4}$ THALYA VITORIA BECHER, ${ }^{5}$ SUELEN STEFANONI BRANDAO, ${ }^{6}$ CLEIDI BOING VOLTOLINI, ${ }^{7}$ ISABELLLA ARANTES TOBBIN, 8 JULIA MUNARETTO ZONIN, ${ }^{9}$ LUIZ GUSTAVO PIRES SILVA, ${ }^{10}$ LUIZA MENDES MONTRAY RODRIGUES, ${ }^{11}$ MONICA MICHELI ALEXANDRE, ${ }^{12}$ RAFAELA DE FREITAS DA SILVA, ${ }^{13}$ THAMIRYS SIQUEIRA CARPEJANI, ${ }^{14}$ GIULIANA ZARDETO SABEC, 15PAULO HENRIQUE KINOSHITA CANDIDO

${ }^{1}$ Acadêmico do Curso de Medicina da UNIPAR
${ }^{2}$ Acadêmica do Curso de Medicina da UNIPAR
${ }^{3}$ Acadêmica do Curso de Medicina da UNIPAR
${ }^{4}$ Acadêmica do Curso de Morfofisiologia Humana I da UNIPAR
${ }^{5}$ Acadêmica do Curso de Medicina da UNIPAR
${ }^{6}$ Acadêmica do Curso de Medicina da UNIPAR
${ }^{7}$ Acadêmica do Curso de Medicina da UNIPAR
${ }^{8}$ Acadêmica do Curso de Medicina da UNIPAR
${ }^{9}$ Acadêmico do Curso de Medicina da UNIPAR
${ }^{10}$ Acadêmica do Curso de Medicina da UNIPAR
${ }^{11}$ Acadêmica do Curso de Medicina da UNIPAR
${ }^{12}$ Acadêmica do Curso de Medicina da UNIPAR
${ }^{13}$ Acadêmica do Curso de Medicina da UNIPAR
${ }^{14}$ Docente da UNIPAR
${ }^{15}$ Docente da Disciplina de Anatomia Topográfica e Descritiva do Curso de Medicina da UNIPAR

Introdução: No mundo há 1,1 bilhão de pessoas tabagistas e destes um terço dos adultos e metade dos jovens são expostos com regularidade à fumaça do tabaco (PORTES et al., 2021). Este hábito está relacionado a diversas patologias como o câncer $\mathrm{e}$ doenças respiratórias crônicas, além de ser considerado responsável por milhões de óbitos por ano (MALTA et al., 2015). É importante mencionar que a partir dos anos 2000 , foi constatada a expansão de políticas públicas que almejam a redução do impacto negativo do tabagismo em diversos países, sendo o Brasil considerado uma referência internacional no controle do tabaco (PORTES et al., 2021). Dentre os fatores responsáveis pela redução da prevalência de fumantes no país encontram-se a regulamentação de produtos do tabaco, a restrição da disponibilidade, ações educativas nas escolas, atendimento na atenção primária à saúde, entre outros (SILVA et al., 2014). No entanto, apesar das medidas atuantes no combate ao tabagismo, este ainda representa um problema de saúde pública, sendo necessário priorizar o tema no setor da saúde, além de expandir medidas legislativas, econômicas, regulatórias e educativas. (PORTES et al., 2021).

Objetivo: Descrever ação de extensão realizada pela Liga Acadêmica de Anatomia Clínica da Unipar (LAAC) a qual consistiu na elaboração e entrega de panfletos com o tema combate ao tabagismo.

Resultados: No dia 28 de agosto de 2021 foi realizada pela LAAC uma atividade de extensão, em comemoração ao Dia Nacional de Combate ao Fumo. Os integrantes da liga foram divididos em dois grupos, sendo um responsável pela elaboração e confecção dos panfletos e outro responsável pela entrega. Foram confeccionados um total de 100 panfletos, dos quais 50 foram destinados para distribuição na Unipar Campus Sede e 50 para distribuição na Praça Mascarenha de Moraes e arredores. A campanha contribuiu para o aprendizado e sensibilização da população frente ao tabagismo e evidenciou a importância do controle deste, buscando promoção e prevenção da saúde.

Conclusão: A ação desenvolvida pela LAAC atingiu um número considerável de pessoas, alcançando o objetivo de orientar, mobilizar e sensibilizar a população sobre os danos causados pelo tabaco. Levando em consideração que o tabagismo é um problema de saúde pública, faz-se necessário reforçar cada vez mais a importância de ações que visem a conscientização da população e que também ofereçam o suporte adequado para os fumantes buscarem e aderirem ao tratamento.

\section{Referências}

MALTA, Deborah Carvalho et al. Uso e exposição à fumaça do tabaco no Brasil: resultados da Pesquisa Nacional de Saúde 
2013. Epidemiologia e Serviços de Saúde, v. 24, p. 239-248, 2015. Disponível em: https://www.scielosp.org/article/ress/2015.v24n2/239-248/. Acesso em: 31 ago, 2021.

PORTES, Leonardo Henriques et al. A Política de Controle do Tabaco no Brasil: um balanço de 30 anos. Ciência \& Saúde Coletiva, v. 23, p. 1837-1848, 2018. Disponível em: https://www.scielosp.org/article/csc/2018.v23n6/1837-1848/\#. Acesso em: 31 ago, 2021.

SILVA, Sandra Tavares da et al. Combate ao Tabagismo no Brasil: a importância estratégica das ações governamentais. Ciência \& Saúde Coletiva, v. 19, p. 539-552, 2014. Disponível em: https://www.scielo.br/j/csc/a/Wq3hFwwN8m8JBfZ3sd4nCvF/? lang=pt\&format=html. Acesso em: 31 ago, 2021.

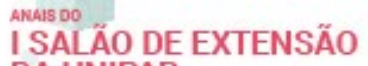

DA UNIPAR
D UNIPAR 50 ANOS:

Traneformando vides atraven da educagto

27 de Outubro de 2021

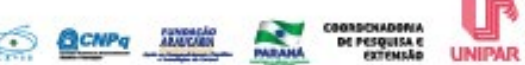




\section{- \\ E \\ SALÃO DE EXTENSÃO DA UNIPAR}

ISBN 978-65-87557-74-8

年

ARRECADAÇÃO DE PRODUTOS DE HIGIENE PESSOAL PARA POPULAÇÃO CARENTE NO MUNICÍPIO DE UMUARAMAPR

${ }^{1}$ GABRIEL HENRIQUE DO PRADO GONCALVES, ${ }^{2}$ LUIZA LOPES DA ROSA, ${ }^{3}$ ANA BEATRIZ BARBOSA LOPES, ${ }^{4}$ ANA CAROLINA DE MELLO LEONI, ${ }^{5}$ ANDRIELLE MORESCHI VIANA, ${ }^{6}$ JESSICA XAVIER SANTINI, ${ }^{7}$ ELIS MARIA MACENTE, ${ }^{8}$ THALITA ETIENE WILLEMANN DE CASTRO, ${ }^{9}$ GIULIA ROBERTA PEREIRA, ${ }^{10}$ GABRIELLA PRADO BATISTA, ${ }^{11}$ ALANA CAROLINE OSTETTI BORGES, ${ }^{12}$ VALENTINA DE PAULA GARCIA, ${ }^{13}$ KARINA FARAH SAKUMOTO

${ }^{1}$ Discente do Curso de Medicina/UNIPAR

${ }^{2}$ Discente do Curso de Medicina/UNIPAR

${ }^{3}$ Discente do Curso de Medicina/UNIPAR

${ }^{4}$ Discente do Curso de Medicina/UNIPAR

${ }^{5}$ Discente do Curso de Medicina/UNIPAR

${ }^{6}$ Discente do Curso de Medicina/UNIPAR

${ }^{7}$ Discente do Curso de Medicina/UNIPAR

${ }^{8}$ Discente do Curso de Medicina/UNIPAR

${ }^{9}$ Discente do Curso de Medicina/UNIPAR

${ }^{10}$ Discente do Curso de Medicina/UNIPAR

${ }^{11}$ Discente do Curso de Medicina/UNIPAR

${ }^{12}$ Discente do Curso de Medicina/UNIPAR

${ }^{13}$ Docente do Curso de Medicina/UNIPAR

Introdução: A mudança de hábitos de higiene estão correlacionadas diretamente com a prevenção de doenças, como doenças diarreicas e infecções respiratórias agudas (JAIR; NARA, 2021), que causam a morte de milhões de crianças menores de 5 anos no mundo, sendo a maioria destas possíveis de serem evitadas através de uma boa lavagem das mãos (QUINTA; HELUY; SANTOS, 2015).

Objetivo: A ação desenvolvida consistiu na arrecadação de produtos de higiene pessoal destinados para a população carente no município de Umuarama-PR, tendo como compromisso e principal objetivo proporcionar o acesso da população carente a recursos, de forma a promover mudanças na sociedade, tais como melhorar a qualidade de vida deste grupo e prevenir determinadas doenças. Para tanto, o projeto foi realizado entre os dias 27/08 a 09/09 de 2021.

Resultados: O projeto realizado com o intuito de arrecadar produtos de higiene pessoal para população carente no município de Umuarama-PR foi realizado pela Liga Acadêmica de Semiologia Médica (LASEM), no período de 27/08 a 09/09 do ano de 2021. A divulgação das arrecadações foi feita através de mídias sociais e na própria universidade; com isso, foi possível realizar a arrecadação por meio dos membros da LASEM durante o período anteriormente citado. A atividade contou com a ajuda de doações de acadêmicos e até mesmo de indivíduos da comunidade, totalizando uma arrecadação de 75 produtos. Os itens foram distribuídos para a população, de modo a proporcionar uma melhora nas condições de vida desses indivíduos.

Conclusão: À luz do exposto, é evidente a carência de grande parte da população ao acesso a produtos de higiene pessoal básica, por esse motivo campanhas de arrecadação relacionadas ao tema fornecem relevantes impactos sociais e na vida de quem recebe a doação, uma vez que a correta manutenção da higiene pessoal tem como consequência uma melhor qualidade de vida e saúde.

\section{Referências}

QUINTA, Andressa Rodrigues Martins da; HELUY, Tárik Reis; SANTOS, Lucinéia dos. Mudanças de hábitos de higiene à prevenção de doenças. In: Congresso de extensão universitária da UNESP. Universidade Estadual Paulista (UNESP), p. 1-5, 2015.

JAIR, Murillo Le Luciano; NARA, Lígia Martins Almeida. Doenças parasitárias e a relação com o panorama sanitário, socioeconômico e a educação em saúde no brasil: uma revisão narrativa da literatura. Revista Multidisciplinar em Saúde, v. 2, n. 1, p. 53-53, 2021. 
- unIPAR 50 anos:

I SALAOO DE EXTENSÃO Transformando vidas atravies da educaģso

DA UNIPAR 


\section{9}

LANNC: AULA SOBRE ACIDENTE VASCULAR CEREBRAL COMO FORMA DE AUXILIAR A POPULAÇÃO

${ }^{1}$ THAYNARA KNOPIK DECHECHI, ${ }^{2}$ RAYANE BIOLCHI, ${ }^{3}$ IGOR KEIDI OKAMOTO OISHI, ${ }^{4}$ MARINA CHAVES ORBEN, ${ }^{5}$ ANA CLARA BARRADAS BASSI, ${ }^{6}$ GIOVANA TOLOTTI, ${ }^{7}$ GLESIE BERTULUCI MARTINS, ${ }^{8}$ TAZIANE MARA DA SILVA, ${ }^{9}$ VIDA PASCHOAL, ${ }^{10}$ MILENA DE SOUZA MELO, ${ }^{11} \mathrm{HIGOR}$ DIAS DO PRADO, ${ }^{12}$ LUIZ GUSTAVO PIRES SILVA, ${ }^{13} \mathrm{FELIPE} \mathrm{MARCHI,}$ ${ }^{14}$ VICTOR HUGO ONO SAKUMA DOLCI DOS SANTOS, ${ }^{15}$ DANILO MAGNANI BERNARDI

${ }^{1}$ Discente do curso de Medicina da Universidade Paranaense

${ }^{2}$ Discente do curso de Medicina da Universidade Paranaense

${ }^{3}$ Discente do curso de Medicina da Universidade Paranaense

${ }^{4}$ Discente do curso de Medicina da Universidade Paranaense

${ }^{5}$ Discente do curso de Medicina da Universidade Paranaense

${ }^{6}$ Discente do curso de Medicina da Universidade Paranaense

${ }^{7}$ Discente do curso de Medicina da Universidade Paranaense

${ }^{8}$ Discente do curso de Medicina da Universidade Paranaense

${ }^{9}$ Discente do curso de Medicina da Universidade Paranaense

${ }^{10}$ Discente do curso de Medicina da Universidade Paranaense

${ }^{11}$ Discente do curso de Medicina da Universidade Paranaense

${ }^{12}$ Discente do curso de Medicina da Universidade Paranaense

${ }^{13}$ Discente do curso de Medicina da Universidade Paranaense

${ }^{14}$ Discente do curso de Medicina da Universidade Paranaense

${ }^{15}$ Docente do curso de Medicina da Universidade Paranaense

Introdução: Este trabalho mostra um Projeto de Expansão da Universidade Paranaense (UNIPAR), da Liga Acadêmica de Neurologia e Neurocirurgia (LANNc), que realizou uma aula expositiva com a intenção de auxiliar a população com informações sobre Acidente Vascular Cerebral (AVC). Essa ação social demonstra grande importância, uma vez que, conforme aponta Bule (2014), o conhecimento populacional somado à atuação dirigida ao correto encaminhamento são importantes no acesso ao tratamento precoce do AVC e na prevenção de complicações advindas da patologia.

Objetivo: O objetivo deste estudo é mostrar como a UNIPAR, por meio de seus professores e acadêmicos de Medicina, difunde informações sobre saúde, no sentido de auxiliar a população a respeito do reconhecimento de quadros sugestivos de AVC. Outro objetivo adotado pelo projeto consistiu em arrecadar alimentos por intermédio de doação dos participantes da aula expositiva, para que estes fossem direcionados a Instituição Tia Lili na cidade de Umuarama-PR.

Resultados: O AVC é a segunda principal causa de mortalidade e um dos principais motivos de internação hospitalar. O controle desta patologia pode ser realizado através da prevenção primária e qualidade especializada dos cuidados hospitalares. Além disso, alertar as pessoas sobre o controle de fatores de risco para o desenvolvimento do AVC é essencial (ALMEIDA, 2012). De acordo com o Ministério da Saúde (2013), o AVC pode ser classificado como hemorrágico ou isquêmico e essa classificação é de extrema importância para nortear o tratamento adequado. É importante que a sociedade saiba reconhecer um quadro sugestivo de AVC e para isso utiliza-se muito a escala de Cincinnati. Na aula expositiva proporcionada pelos doutores Danilo Magnani Bernardi e Julys Souza Barbosa, foram explicados os princípios do AVC, bem como suas classificações, escalas de detecção, formas de atendimento inicial, tratamento específico e prevenções primária e secundária, com isso conseguimos arrecadar $50 \mathrm{~kg}$ de alimentos não perecíveis que foram destinados ao Abrigo Tia Lili.

Conclusão: O AVC se apresenta como uma patologia de grande gravidade, gerando muitas vezes, complicações que podem impactar significativamente na vida dos acometidos, influenciando diretamente na qualidade de vida. A LANNc desenvolveu esse projeto com o objetivo de orientar a população sobre os sinais e sintomas da patologia e por meio desta ação promover a arrecadação e doação de alimentos a Entidade da cidade.

\section{Referências}

ALMEIDA, S. R. M.. Análise epidemiológica do Acidente Vascular Cerebral no Brasil. Revista Neurociências, v. 20, n. 4, p. $481482,2012$. 
BULE, Maria José, et al. Reconhecer o AVC pela Cincinnati PreHospital Stroke Scale-CPSS. Póster apresentado no Encontro Internacional de Enfermagem de Reabilitação, Caldas da Rainha, 2014.

MINISTÉRIO DA SAÚDE. Secretaria de Atenção à Saúde. Departamento de Atenção Especializada. Manual de rotinas para atenção ao AVC. Brasília: Ministério da Saúde, 2013.

Ancus do

I SALÃO DE EXTENSÃO

DA UNIPAR
- UNIPAR 50 ANOS:

Transformando videa atreven da educagts

27 de Outubro de 2021
9CNPG 


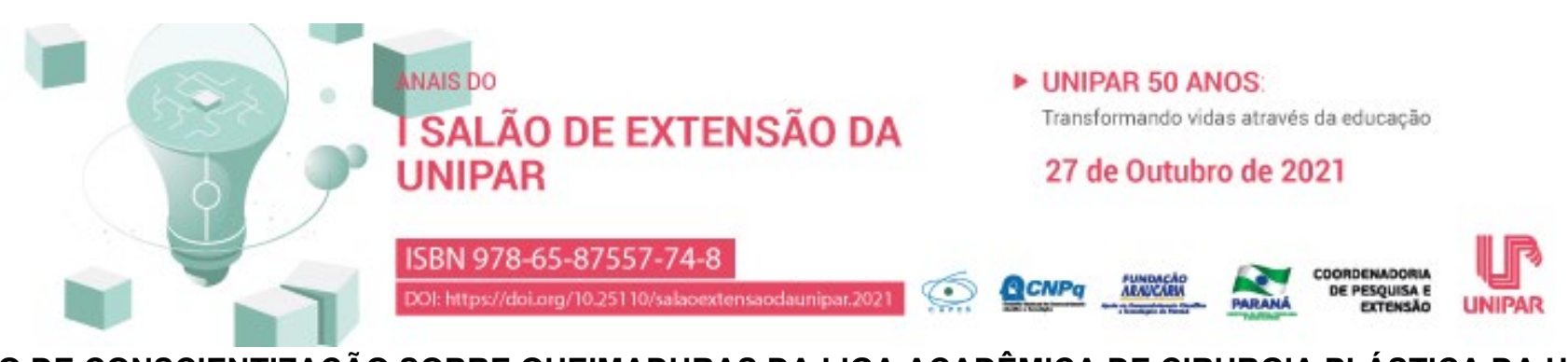

PROJETO DE CONSCIENTIZAÇÃO SOBRE QUEIMADURAS DA LIGA ACADÊMICA DE CIRURGIA PLÁSTICA DA UNIPAR

\author{
${ }^{1}$ VINICIUS PAIE MARQUES DOS REIS, ${ }^{2}$ ISABELA TONON LAINO, ${ }^{3}$ JOAO GABRIEL PUTON MOREIRA, ${ }^{4}$ JOATA CAMPETTI \\ MEDINA, ${ }^{5}$ LARA MARIA SOUZA MARCONDES COLOGNESI, ${ }^{6}$ LUCAS COSTA DE OLIVEIRA, ${ }^{7}$ LUMA MAZIERI, ${ }^{8}$ MARIANA \\ SAUSEN BASSO, ${ }^{9}$ FERNANDA ANDRADE FORMIGHIERI, ${ }^{10}$ THIAGO AUGUSTO RIBEIRO IRIA
}

${ }^{1}$ Acadêmico do Curso de Medicina da UNIPAR

${ }^{2}$ Acadêmica do Curso de Medicina da UNIPAR

${ }^{3}$ Acadêmico do Curso de Medicina da UNIPAR

${ }^{4}$ Acadêmico do Curso de Medicina da UNIPAR

${ }^{5}$ Acadêmica do Curso de Medicina da UNIPAR

${ }^{6}$ Acadêmico do Curso de Medicina da UNIPAR

${ }^{7}$ Acadêmica do Curso de Medicina da UNIPAR

${ }^{8}$ Acadêmica do Curso de Medicina da UNIPAR

${ }^{9}$ Acadêmica do Curso de Medicina da UNIPAR

${ }^{10}$ Docente da UNIPAR

Introdução: A queimadura se constitui em uma das mais graves e frequentes agressões a que o ser humano pode ser exposto, conforme descrito por Pereima, et al. (2001). Desse modo, um dos fatores mais importantes no tratamento de queimados é o primeiro atendimento ao paciente, sendo necessário ocorrer o mais rápido possível. De acordo com Carlucci et al. (2007), toda agressão térmica causa danos físicos e psicológicos ao indivíduo, principalmente quando há necessidade de hospitalização. Além disso, os acidentes que resultam em queimaduras estão entre as principais causas de afastamento do trabalho, evidenciando o prejuízo econômico. Assim, torna-se necessário o esclarecimento da população na tentativa de garantir um atendimento mais rápido e efetivo dos pacientes queimados, possibilitando um manejo adequado e melhor prognóstico.

Objetivo: O presente projeto objetiva prestar informações a fim de conscientizar a população sobre a correta classificação e a como tomar decisões corretas na ocorrência de queimaduras.

Resultados: foram realizadas postagens informativas sobre queimaduras, com os seguintes temas: classificação de queimaduras; o que fazer na queimadura de primeiro, segundo e terceiro grau e, por último, os mitos e verdades sobre queimaduras. Com isso, foram esclarecidas as principais condutas que os pacientes precisam ter em cada tipo de queimadura, além do que não se deve fazer e quando deve ser procurado um serviço hospitalar com urgência. As informações foram publicadas nas redes sociais da Liga Acadêmica de Cirurgia Plástica da Unipar, alcançando um total de 608 pessoas.

Conclusão: Apesar da população se mostrar informada, é notável a necessidade de haver mais campanhas informativas, a fim de diminuírem os fatores de risco e de se quebrarem os costumes ineficazes em relação à conduta popular das queimaduras, como a utilização de preparações caseiras que são ineficazes e pioram o quadro aumentando o processo inflamatório e elevando o risco de infecção. Estudos com amostras maiores devem ser feitos, a fim de se ter resultados mais representativos e, assim, medidas mais eficazes nos pontos deficitários encontrados.

\title{
Referências
}

CARLUCCI, Viviane Dias da Silva et al. A experiência da queimadura na perspectiva do paciente. Revista da Escola de Enfermagem da USP, v. 41, p. 21-28, 2007.

MALTA, Deborah Carvalho et al. Perfil dos casos de queimadura atendidos em serviços hospitalares de urgência e emergência nas capitais brasileiras em 2017. Revista Brasileira de Epidemiologia, v. 23, 2020.

PEREIMA, Maurício José Lopes et al. Importância do primeiro atendimento em queimaduras. ACM arq. catarin. med, p. 20-26, 2001.

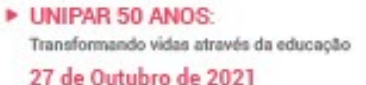

27 de Outubro de 2021

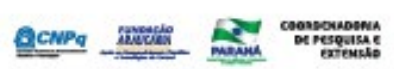

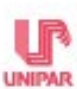




\title{
(1) \\ - UNIPAR 50 ANOS: \\ Transformando vidas através da educação \\ 27 de Outubro de 2021 \\ ISBN 978-65-87557-74-8 \\ DOl: hatps//doiorg/10.251 10/saboextensadaunipar:2021

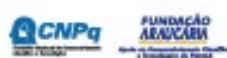

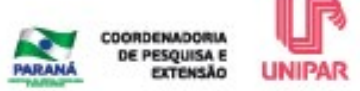 \\ IMPORTÂNCIA DA ORIENTAÇÃO AO PACIENTE ANTES NA REALIZAÇÃO DE EXAMES LABORATORIAIS
}

\begin{abstract}
${ }^{1}$ RAQUEL BIRCK, ${ }^{2}$ ERICA HELENA DE RAMOS, ${ }^{3}$ JULIA COMACHIO FAVRETTO, ${ }^{4}$ ERICA HELENA DE RAMOS, ${ }^{5}$ ALICE MAZZON, ${ }^{6}$ ELOISE GABRIELE MUCKLER, ${ }^{7}$ VANESSA MACHADO PACHTMANN, ${ }^{8}$ JULIA GABRIELA SAUSEN, ${ }^{9} \mathrm{JULIA}$ VITORIA CALGAROTTO, ${ }^{10}$ NATIELE CHAVES DA SILVA, ${ }^{11}$ PATRICIA AMARAL GURGEL VELASQUEZ
\end{abstract}

\footnotetext{
${ }^{1}$ Acadêmica PIBEX do Curso de Farmácia da UNIPAR de Francisco Beltrão

${ }^{2}$ Acadêmica PEX do curso de Farmácia da UNIPAR de Francisco Beltrão

${ }^{3}$ Acadêmica PEX do curso de Farmácia da UNIPAR de Francisco Beltrão

${ }^{4}$ Acadêmica PEX do curso de Farmácia da UNIPAR de Francisco Beltrão

${ }^{5}$ Acadêmica PEX do curso de Farmácia da UNIPAR de Francisco Beltrão

${ }^{6}$ Acadêmica PEX do curso de Farmácia da UNIPAR de Francisco Beltrão

${ }^{7}$ Acadêmica PEX do curso de Farmácia da UNIPAR de Francisco Beltrão

${ }^{8}$ Acadêmica PEX do curso de Farmácia da UNIPAR de Francisco Beltrão

${ }^{9}$ Acadêmica PEX do curso de Farmácia da UNIPAR de Francisco Beltrão

${ }^{10}$ Acadêmica PEX do curso de Farmácia da UNIPAR de Francisco Beltrão

${ }^{11}$ Docente do Curso de Farmácia da UNIPAR
}

Introdução: Estudos indicam que os erros na fase pré-analítica laboratorial podem chegar a $70 \%$ do total. Nesta fase encontramse as orientações ao paciente antes da coleta, em relação ao tipo de exame que será realizado, qual amostra biológica será coletada, entre outras (CODAGNONE et al, 2014).

Objetivos: Este trabalho buscou analisar a importância da orientação aos pacientes antes dos exames laboratoriais.

Desenvolvimento: O preparo para a realização de exames laboratoriais é de extrema importância e deve ser feito com muita cautela, porém os erros durante a realização dos exames são frequentes, tornando- se uma ameaça aos pacientes, por isso, é necessário seguir um rigor técnico para garantir a liberação de resultados exatos. Por exemplo, no PSA (Prostate Specific Antigen), uma preparação inadequada pode indicar o falso diagnóstico de câncer. Portanto, é necessário que o profissional da saúde, que atua em laboratórios de análises clínicas saiba orientar os pacientes e tenha consciência desses procedimentos para evitar ao máximo os possíveis erros e não influenciar diretamente no diagnóstico por meio de resultados falso-positivos e/ou falso-negativos (COSTA; MORELLI, 2012). Uma fonte importante de erros nos exames laboratoriais é o uso de medicamentos pelo paciente. As interferências podem ser analíticas ou biológicas e é de suma importância que os profissionais saibam reconhecer essas alterações para que não haja prejuízo para o paciente (SILVA et al, 2021). O exame qualitativo de urina é um dos exames mais solicitados aos laboratórios de análises clínicas, e pelo fato de ser colhido pelo próprio paciente na maioria das vezes, pode sofrer inúmeras interferências. Assim, é necessário que o laboratório forneça orientações claras ao paciente sobre a forma correta de coleta e armazenamento da amostra, evitando a inserção de contaminantes na amostra quando por exemplo não se coleta o jato médio de forma adequada, ou a deterioração dos componentes urinários por demora na entrega do material no laboratório (PERUCCl et al, 2016).

Considerações Finais: Informações passadas de modo claro e adequado para o paciente e uma equipe técnica treinada em relação aos procedimentos pré-analíticos podem evitar contratempos, como o inconveniente de coletar nova amostra biológica e custos adicionais ao laboratório pela repetição dos exames.

\section{Referências}

CODAGNONE, Fábio Triachini et al. The use of indicators in the pre-analytical phase as a laboratory management tool. J Bras Patol Med Lab. v. 50, n.2, p. 100-104, 2014.

COSTA, Vivaldo Gomes, MORELI, Marcos Lázaro. Principais parâmetros biológicos avaliado sem erros na fase pré-analítica de laboratórios clínicos: revisão sistemática. J Bras Patol Med Lab. v. 48, n.3, p.163-168, 2012.

PERUCCI, Luiza Oliveira, MAGALHÃES, Henrique Pimenta Barroso, BORGES, Karina Braga Gomes. Interferências préanalíticas da urinálise. Analisando - Informe Técnico. n.18 - Ano 5 Fev/Abr 2016.

SILVA, Raquel et al. Interference of medicines in laboratory exams. J Bras Patol Med Lab. v.57, n.1, p.1-15, 2021. 
- unIPAR 50 anos:

I SALAOO DE EXTENSÃO Transformando vidas atravies da educaģso

DA UNIPAR 


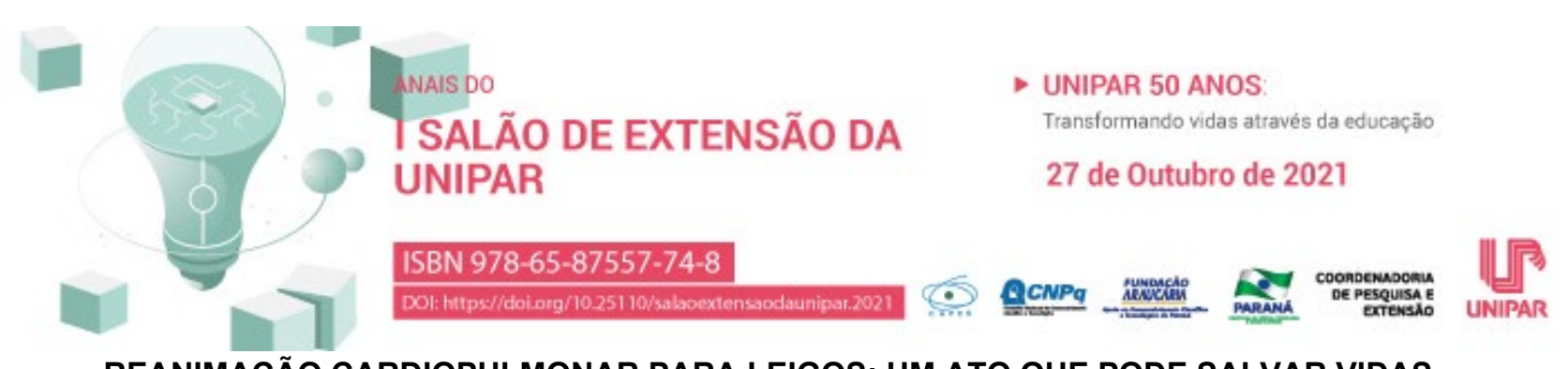

\title{
REANIMAÇÃO CARDIOPULMONAR PARA LEIGOS: UM ATO QUE PODE SALVAR VIDAS
}

${ }^{1}$ SUELEN STEFANONI BRANDAO, ${ }^{2}$ ELIEZER FERREIRA DA SILVA, ${ }^{3}$ CLEIDI BOING VOLTOLINI, ${ }^{4}$ MONICA MICHELI ALEXANDRE , ${ }^{5}$ RAFAELA DE FREITAS DA SILVA, ${ }^{6}$ THALYA VITORIA BECHER, ${ }^{7}$ LUIZ GUSTAVO PIRES SILVA, ${ }^{8}$ THAMIRYS SIQUEIRA CARPEJANI, ${ }^{9}$ GIULIANA ZARDETO SABEC, ${ }^{10}$ FABIANE ANGELICA DE PAIVA PAULA, ${ }^{11}$ ISABELLA ARANTES TOBBIN, ${ }^{12} \mathrm{JESSICA}$ XAVIER SANTINI, ${ }^{13}$ JULIA MUNARETTO ZONIN, ${ }^{14}$ LUIZA MENDES MONTRAY RODRIGUES, ${ }^{15}$ PAULO HENRIQUE KINOSHITA CANDIDO

\author{
${ }^{1}$ Acadêmica bolsista PIBIC/UNIPAR \\ ${ }^{2}$ Acadêmico do Curso de Medicina da UNIPAR \\ ${ }^{3}$ Acadêmica do Curso de Medicina da UNIPAR \\ ${ }^{4}$ Acadêmica do Curso de Medicina da UNIPAR \\ ${ }^{5}$ Acadêmica do Curso de Medicina da UNIPAR \\ ${ }^{6}$ Acadêmica do Curso de Morfofisiologia Humana I da UNIPAR \\ ${ }^{7}$ Acadêmico do Curso de Medicina da UNIPAR \\ ${ }^{8}$ Acadêmica do Curso de Medicina da UNIPAR \\ ${ }^{9}$ Docente da UNIPAR \\ ${ }^{10}$ Acadêmica do Curso de Medicina da UNIPAR \\ ${ }^{11}$ Acadêmica do Curso de Medicina da UNIPAR \\ ${ }^{12}$ Acadêmica do Curso de Medicina da UNIPAR \\ ${ }^{13}$ Acadêmica do Curso de Medicina da UNIPAR \\ ${ }^{14}$ Acadêmica do Curso de Medicina da UNIPAR \\ ${ }^{15}$ Docente da Disciplina de Anatomia Topográfica e Descritiva do Curso de Medicina da UNIPAR
}

Introdução: A falta de conhecimento da população em geral, em situações emergenciais, pode ocasionar inúmeros problemas. Condutas incorretas com a vítima, entre outras situações, podem agravar ainda mais o caso (NARDINO et al., 2012). É fundamental reconhecer os sinais e sintomas de uma Parada Cardiorrespiratória (PCR), os mais comuns são: a perda da consciência acometida pela diminuição da circulação, pulsos fracos ou ausentes, parada de movimentos respiratórios. Estes sinais são essenciais para identificação correta de uma PCR, e sendo realizada de forma imediata, é crucial para a Reanimação cardiopulmonar (RCP) de qualidade, sobrevida e prognóstico do paciente (MAIA et al., 2020). O SBV compreende etapas que podem ser iniciadas fora do ambiente hospitalar (PERGOLA e ARAUJO, 2009). O treinamento de indivíduos leigos pode elevar a probabilidade de um não profissional da área da saúde realizar a RCP e aumentar a sobrevida de uma vítima que sofreu parada cardíaca (ROCHA e ALCANTARA, 2011).

Objetivo: Repassar para o público leigo, jovens da faixa etária de 17 até 25 anos, técnicas sobre o reconhecimento de uma Parada Cardiopulmonar e realização de uma Reanimação Cardiopulmonar, incluindo manobra de Heimlich e, enfatizar que a simples atuação de uma pessoa não envolvida na área da saúde pode prevenir a deterioração miocárdica e cerebral.

Resultados: No dia 21 de agosto do ano de 2021, período matutino, no Município de Umuarama os discentes da liga acadêmica de anatomia clínica, com o auxílio do Doutor Eder Voltolini, realizaram um treinamento voltado para o público já referido. A ação se dividiu em duas partes: sendo a primeira delas uma aula teórica sobre parada cardiorrespiratória, reconhecimento dos sinais clínicos, sequência correta da cadeia de sobrevivência e manobra de Heimlich, logo após, prática com o auxílio de bonecos e Desfibrilador Externo Automático (DEA). Sob supervisão do Doutor Eder, os jovens envolvidos na ação, com o auxílio dos bonecos, puderam aprender a sequência correta das ações necessárias para se realizar uma RCP de qualidade e, a técnica correta para manobra de Heimlich.

Conclusão: Conclui-se que a ação realizada contribuiu para a formação de cidadãos mais conscientes e responsáveis, deve-se levar em consideração que grande parte dos acidentes acontecem em ambiente extra-hospitalar, e que diante de situações de agravos à saúde os mesmos possam agir prestando atendimento de primeiros socorros, disseminando esta importante prática, que pode evitar sequelas e salvar vidas.

\section{Referências}


MAIA, Samuel Ramalho; LEMOS, Aline Mesquita; FRUTUOSO, Mercia Sindeaux; JUNIOR, Cristiano Walter Moraes Rola. Conhecimento dos leigos acerca da ressuscitação cardiopulmonar em pacientes adultos no Brasil. Brazilian Journal Development, Curitiba, v. 6, n.5, p.28933-28948 maio. 2020.

NARDINO, Janaine Nardino; BADKE, Marcio Rossato; BISOGNO, Silvana Bastos Cogo; GUTH, Emerson José. Atividades educativas em saúde. Revista contexto \& saúde ljuí. Editora Unijuí. v.12 n. 23 p. $88-92$

PERGOLA, Aline Maino; ARAUJO, Izilda E. M. O leigo e o suporte básico de vida. Revista da Escola de Enfermagem da USP, v. 43, n. 2, p. 335-34, julho./Dezembro. 2012

ROCHA, Marta. P. S; ALCÂNTARA, Carlos. Suporte Básico de Vida e Socorros de Emergência. AVM Instituto Brasília-DF, 2011.

ANats Do

I SALÃO DE EXTENSÃO

DA UNIPAR
- UNIPAR 50 ANOS:

Transformando videa atraves da educaço

27 de Outubro de 2021

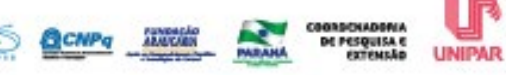




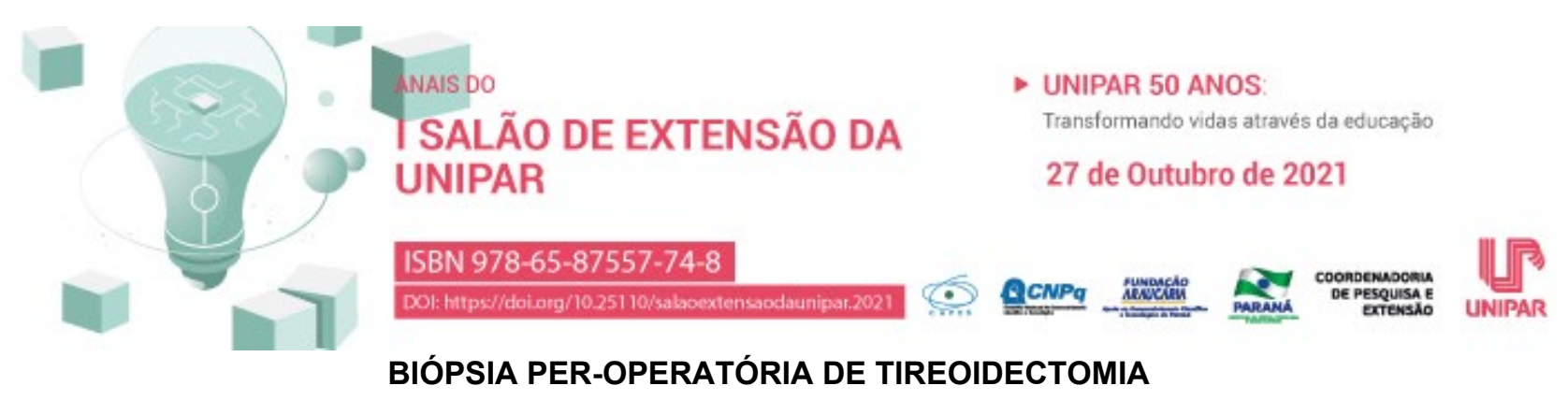

\begin{abstract}
${ }^{1}$ BRUNA FAVRETTO DA SILVA, ${ }^{2}$ LAIS TEODORO LOPES, ${ }^{3}$ MARINA BOITO DE OLIVEIRA, ${ }^{4}$ CRISTIANE EDNA DA ROCHA, ${ }^{5}$ AMANDA SIHNEL CORTEZ DA SILVA, ${ }^{6}$ ANA BEATRIZ SILVESTRI RIBEIRO, ${ }^{7}$ HYGOR RAKOSKI GONCALVES, ${ }^{8}$ ISABELLA MORAIS TAVARES, ${ }^{9}$ LETICIA AITA, ${ }^{10}$ RICARDO MARCELO ABRAO
\end{abstract}

\footnotetext{
${ }^{1}$ Acadêmica do Curso de Medicina da UNIPAR

${ }^{2}$ Acadêmica do Curso de Medicina da UNIPAR

${ }^{3}$ Acadêmica do Curso de Medicina da UNIPAR

${ }^{4}$ Acadêmica do Curso de Medicina da UNIPAR

${ }^{5}$ Acadêmica do curso de Medicina da UNIPAR

${ }^{6}$ Acadêmica do Curso de Medicina da UNIPAR

${ }^{7}$ Acadêmico do Curso de Medicina da UNIPAR

${ }^{8}$ Professor Adjunto do curso de Medicina da UNIPAR

${ }^{9}$ Professor Assistente do curso de Medicina da UNIPAR

${ }^{10}$ Professor Titular do curso de Medicina da UNIPAR
}

Introdução: Durante uma cirurgia oncológica, a tomada de decisão para diversas condutas está intimamente relacionada ao exame histopatológico per-operatório (SILVA et al., 2011). Esse exame proporciona um diagnóstico histopatológico imediato, em que seu resultado auxilia o cirurgião a escolher a melhor alternativa cirúrgica (TOBÓN; GARCIA; ARIAS, 2012). Para o diagnóstico do câncer de tireoide é realizado com uma biópsia, na qual as células da área suspeita são removidas e examinadas em laboratório (FONSECA et al., 2019).

Objetivo: Conhecer o trabalho do médico patologista dentro do ambiente cirúrgico e as técnicas usadas para avaliação de nódulos na tireóide.

Resultados: Com projeto de extensão foi possibilitada a visita até o Hospital de Câncer de Umuarama-Pr para acompanhar a médica patologista em uma tireoidectomia parcial do lado direito. Ao chegarmos no hospital, nos direcionamos até o vestiário, onde nos equipamos com as vestimentas necessárias para adentrar ao centro cirúrgico (pro-pé, touca, pijama cirúrgico e máscara). Adiante, seguimos para a sala de operações, onde o cirurgião oncológico responsável já estava realizando o procedimento. Logo após isso, o cirurgião entregou o lobo direito da tireóide para a patologista, a qual iria analisá-lo. Nos direcionamos para o laboratório de análises patológicas, em que foi preparado as lâminas para análise no microscópio a partir da peça obtida. A patologista corou o nódulo com panótico rápido e observou que não existiam alterações histológicas que indicavam caráter maligno, assim, preservando a tireóide do paciente.

Conclusão: Com essa experiência, conseguimos entender e observar na prática o trabalho e a importância do médico patologista associada com as outras áreas médicas, acrescentando positivamente com os nossos estudos. Bem como entender a importância da biopsia de congelamento, a qual possui precisão em seus diagnósticos superior a 90\% (TOBÓN; GARCIA; ARIAS, 2012).

\title{
Referências
}

TOBÓN, G.; GARCIA, V.; ARIAS, L. Biópsia por congelação. Revista Lab Med, v. 18, p. 161-172. 2012.

SILVA, Rafael D. P. et al. Precisão diagnóstica das doenças cirúrgicas nos exames por congelação. Scielo Brasil Revista do Colégio Brasileiro de Cirurgiões, 2011. Disponível em: https://www.scielo.br/j/rcbc/a/K9YRdxdHcD9f7Tf3NCYLmTN/?lang=pt. Acesso em: 8 set. 2021.

FONSECA, L. W. et al. Punção aspirativa por agulha fina em nódulos tireoidianos e seu valor diagnóstico para o câncer. Revista Educação em Saúde, v. 7, suplemento 3. 2019. 


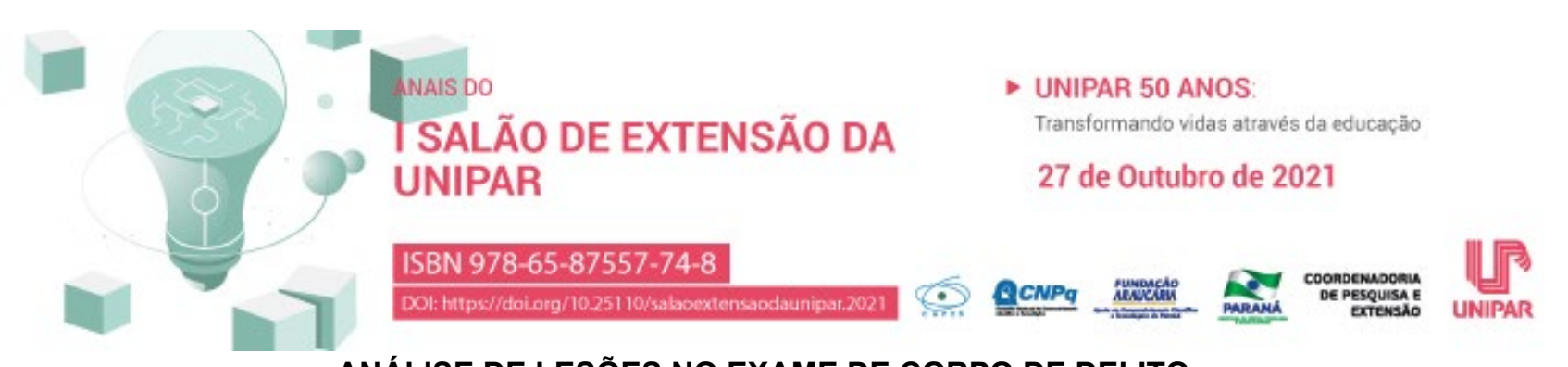

ANÁLISE DE LESÕES NO EXAME DE CORPO DE DELITO

${ }^{1}$ CRISTIANE EDNA DA ROCHA, ${ }^{2}$ AMANDA SIHNEL CORTEZ DA SILVA, ${ }^{3}$ ANA BEATRIZ SILVESTRI RIBEIRO, ${ }^{4}$ MARINA BOITO DE OLIVEIRA, ${ }^{5}$ BRUNA FAVRETTO DA SILVA, ${ }^{6}$ THAMIRYS SIQUEIRA CARPEJANI, ${ }^{7}$ ISADORA VAROTTO FELTRIN, ${ }^{8}$ MARCELO FLAGMIR BARCARO, ${ }^{9}$ RICARDO MARCELO ABRAO

${ }^{1}$ Acadêmica do Curso de Medicina da UNIPAR

${ }^{2}$ Acadêmica do Curso de Medicina da UNIPAR

${ }^{3}$ Acadêmica do Curso de Medicina da UNIPAR

${ }^{4}$ Acadêmica do Curso de Medicina da UNIPAR

${ }^{5}$ Acadêmica do Curso de Medicina da UNIPAR

${ }^{6}$ Acadêmica do Curso de Medicina da UNIPAR

${ }^{7}$ Acadêmica do Curso de Medicina da UNIPAR

${ }^{8}$ Professor Assistente do Curso de Medicina da UNIPAR

${ }^{9}$ Professor Titular do Curso de Medicina da UNIPAR

Introdução: Cada vez mais é observado no ramo judicial a busca pela tentativa de elucidação de crimes, usando a ciência para esse meio, o que faz da traumatologia forense condicionante para práticas justas baseadas em provas técnicas (KUSS et al., 2017). A Traumatologia forense, capítulo da Medicina Legal, busca estudar os aspectos médico-jurídicos de lesões causadas por agentes com potencial capacidade de lesão (COELHO, 2010).

Objetivos: Experienciar as maneiras pelas quais são realizadas as análises de lesões corporais no Instituo Médico Legal, bem como a prática médica em situações atípicas, como lesões criminais.

Resultados: De início, no Instituto Médico Legal de Umuarama, a vítima foi convocada para entrar na sala e iniciar os exames das queixas prestadas. A vítima referiu ter participado de uma discussão calorosa que progrediu para agressão física, mas que apenas dias depois realizou boletim de ocorrência e ainda com o passar do tempo tomou a iniciativa de realizar o exame de corpo de delito. Desse modo, o médico já ressaltava que os hematomas seguem um padrão de evolução, o que facilita a comprovação indicativa da possível data do episódio referido pela vítima de violência, sendo corroborada pela cor, inchaço e cicatrizes, de acordo com a Traumatologia Forense. Esses mecanismos são fundamentais para compreender como se deu a lesão e se foi por materiais perfurantes, cortantes ou contundentes (SABES; GIRARDI; VASCONCELOS, 2016). Portanto, o médico legista constatou lesões mistas, ou seja, por ação contundente, sendo os hematomas com caracterização atual condizentes com a data de origem, tendo o tempo devido de transformação da lesão e diminuição do edema facial. Ainda também apresentava discreta lesão por material perfuro-cortante com indícios de cicatrização, outro fator que afirmava a data da lesão indicada pela vítima. Foi ressaltado pelo médico legista que por meio das lesões averiguadas foi feita a relação com ramos do judical, realizando o desdobramento das feridas apresentadas e a queixa prestada, com o fito de servir como prova objetiva e técnica sendo base para o cumprimento da justiça (FLORENTINO; SILVA, 2019).

Conclusão: $O$ projeto de extensão proporcionou experiências além do meio acadêmico, solidificando o aperfeiçoamento estudantil. Participar da rotina do médico legista foi observada a relação entre as diversas disciplinas da área médica, como, anatomia, patologia, semiologia, ou seja, uma relação multidisciplinar eficaz e extremamente gratificante.

\section{Referências}

COÊLHO, Bruna Fernandes. Histórico da medicina legal. Revista da Faculdade de Direito, Universidade de São Paulo, v. 105, p. 355-362, 2010.

FLORENTINO, Anderson Hélcio; DA SILVA, Diogo Severino Ramos. Traumatologia forense. Derecho y Cambio Social, n. 56, p. 333-345, 2019.

KUSS, Jean Carlos et al. A IMPORTÂNCIA DA TRAUMATOLOGIA NA ELUCIDAÇÃO DO CRIME. Extensão em Foco (ISSN: 2317-9791), v. 5, n. 1, 2017.

SABES, Amanda Festa; GIRARDI, Annita Morais; VASCONCELOS, Rosemeri O. Traumatologia forense revisão de literatura. Nucleus Animalium, v. 8, n. 2, p. 2, 2016. 
- unIPAR 50 anos:

I SALAOO DE EXTENSÃO Transformando vidas atravies da educaģso

DA UNIPAR 


\title{
ACESSO À JUSTIÇA POR MEIO DA GRATUIDADE E A EFETIVA ATUAÇÃO DA ASSISTÊNCIA JUDICIÁRIA NA VARA DA FAMÍLIA
}

${ }^{1}$ IZABELA MARTIGNAGO DE LIMA, ${ }^{2}$ MARICELES CRISTHINA FECHIO

\author{
${ }^{1}$ Acadêmica Bolsista do PIBEX \\ ${ }^{2}$ Docente da UNIPAR
}

Introdução: O direito à assistência judiciária gratuita tem assento na Constituição e decorre do princípio do acesso à justiça (art. $\left.5^{\circ}, \mathrm{XXV}, \mathrm{CR}\right)$, e modernizado infra constitucionalmente por meio do Novo Código de Processo Civil Brasileiro, que trouxe em seu bojo legal a previsão expressa da Gratuidade da Justiça.

Objetivo: Discorrer sobre o Acesso à Justiça como garantia fundamental previsto no ordenamento jurídico, demonstrando sua efetivação por meio do mecanismo da Gratuidade da Justiça, trazido pela Lei ${ }^{\circ}$ 1.060/50 com previsão expressa.

Resultados: O ponto inicial do Acesso à Justiça encontra-se na possibilidade de ingresso ao judiciário, no entanto, o elevado custo processual acarreta às partes dificuldades para a propositura da ação e para o desenvolvimento do processo até sua sentença final, ou mesmo até sua execução. Dessa forma, o Acesso à Justiça não tem como função apenas dizer que um cidadão tem direito de buscar o Judiciário para a resolução de seu problema, mas busca a real apreciação da lide a fim de que o problema seja realmente resolvido e que o mesmo tenha um tratamento igualitário com relação aos demais utilizadores do sistema. Importante destacar a distinção entre Assistência Judiciária e Justiça Gratuita. Ambas as expressões fazem parte da Assistência Jurídica, sendo a primeira, a gratuidade no serviço de um advogado para a causa, oferecido ou não pelo Poder Público. Já a segunda expressão se refere à gratuidade das custas processuais concedida pelo Poder Público. O CPC passou a estabelecer em seu art. 98 a legitimidade para requerer o benefício, sendo tal legitimidade cabível a qualquer pessoa que não possuir recursos suficientes para arcar com as custas processuais de uma ação, assim como os honorários advocatícios. 0 direito à assistência judiciária gratuita, como disse, tem assento na Constituição e decorre do princípio do acesso à justiça (art. $5^{\circ}$, XXV, CR), logo, a partir desse princípio, se ampara o órgão da UNIPAR denominado Assistência Judiciária Gratuita SAJUG, vinculando ao hipossuficiente a oportunidade de ingressar no Poder Judiciário para que o mesmo aprecie uma controvérsia, oferecendo acesso amplo ao judiciário com assistência jurídica integral e gratuita, além de garantir razoável duração do Processo em questão. O Acesso à Justiça oferecido por esse órgão oportuniza a resolução de causas que dificilmente abrangeria tal benifício no particular, vez que os clientes que ingressam nesse órgão não são apenas hipossuficientes, como também leigos, de tal forma que se veem sem preparação alguma ou ajuda para saber como solucionar suas causas. O âmbito familiar é permeado de causas a serem solucionadas todos os dias, seja na dissolução da família ou no amparo para o filho menor necessitado de alimentos. Ademais, a Assistência Judiciária da UNIPAR oferece amplo acesso aos estagiários, dando-os a oportunidade de vivenciarem os atendimentos na prática e os preparando para a vida profissional, em virtude de que os processos, desde o atendimento ao cliente até a preparação da inicial, são realizados pelos alunos de direito, vistoriados e corrigidos pelos professores competentes.

Conclusão: Conclui-se que o tema da Gratuidade da Justiça se mostra de forma relevante e atual para a sociedade, uma vez que se encontra como o meio inicial para a efetivação do Acesso à Justiça, já que o mesmo se caracteriza com a observância de inúmeras garantias na demanda judicial.

\section{Referências}

ALVES, Cleber Francisco. Justiça para todos! Assistência Jurídica Gratuita nos Estados Unidos, França e no Brasil. Rio de Janeiro. Ed. Lúmen Júris. 2006.

Lei 13.105, de 16 de março de 2015. Institui o Código de Processo Civil. Diário Oficial da União, Brasília, 16 mar. 2015.

BRASIL. Constituição da República Federativa do Brasil de 1988. Brasília: Senado Federal. $X$

COSTA NETO, José Wellington Bezerra da. Assistência Judiciária Gratuita: Acesso À Justiça e Carência Econômica. São Paulo: Gazeta Jurídica, 2013.

- UNIPAR 50 ANOS:

Transformando vides atrewta da educageso

27 de Outubro de 2021

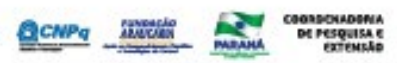

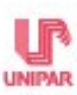




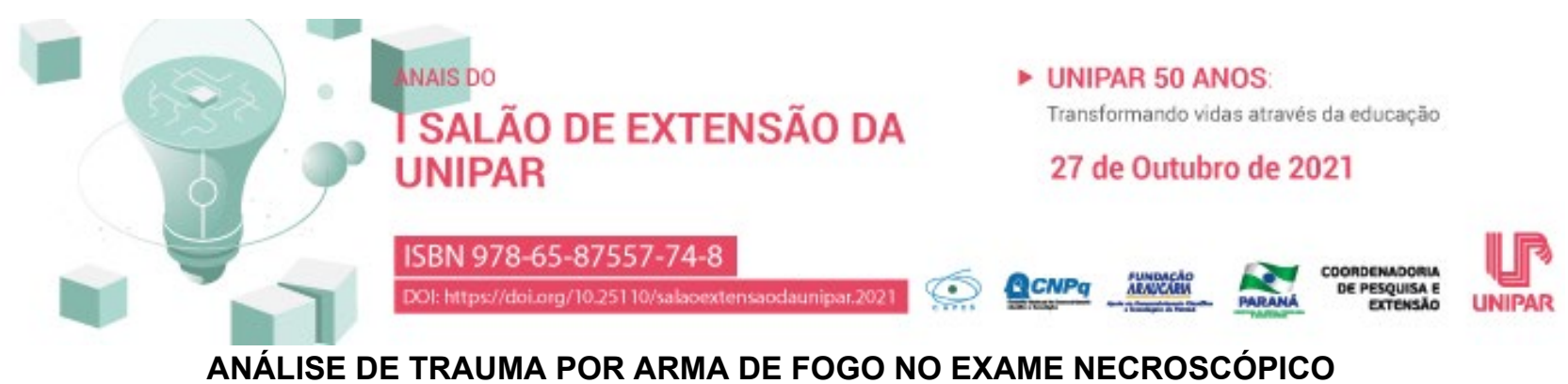

\begin{abstract}
${ }^{1}$ ANA BEATRIZ SILVESTRI RIBEIRO, ${ }^{2}$ BRUNA FAVRETTO DA SILVA, ${ }^{3}$ LAIS TEODORO LOPES, ${ }^{4}$ THALYTA CUSTODIO, ${ }^{5}$ MARIA LUIZA MARCHI SILVA, ${ }^{6}$ AMANDA SIHNEL CORTEZ DA SILVA, ${ }^{7}$ MARINA BOITO DE OLIVEIRA, ${ }^{8}$ CRISTIANE EDNA DA ROCHA, ${ }^{9}$ MARCELO FLAGMIR BARCARO, ${ }^{10}$ RICARDO MARCELO ABRAO
\end{abstract}

${ }^{1}$ Acadêmica do Curso de Medicina da UNIPAR

${ }^{2}$ Acadêmica do Curso de Medicina da UNIPAR

${ }^{3}$ Acadêmica do Curso de Medicina da UNIPAR

${ }^{4}$ Acadêmica do Curso de Medicina da UNIPAR

${ }^{5}$ Acadêmica do Curso de Medicina da UNIPAR

${ }^{6}$ Acadêmica do Curso de Medicina da UNIPAR

${ }^{7}$ Acadêmica do Curso de Medicina da UNIPAR

${ }^{8}$ Acadêmica do Curso de Medicina da UNIPAR

${ }^{9}$ Professor Assistente do curso de Medicina da UNIPAR

${ }^{10}$ Professor Titular do curso de Medicina da UNIPAR

Introdução: A necropsia médico-legal é solicitada nos casos de morte comprovada ou supostamente violenta (ROCHA, 2014). Quando o caso é de ferimentos mortais por arma de fogo cabe a atuação do médico-legista responder os quesitos como, identificar o cadáver, estabelecer o mecanismo e a causa da morte, o diagnóstico diferencial médico-legal, partindo de informações sobre as circunstâncias da morte, do exame do local, do exame necrópsico, dos exames complementares, e especificações se o tipo do trauma foi acidente, homicídio ou suicídio (FRANÇA, 2015; COSTA, 2011).

Objetivo: Acompanhar o procedimento da necropsia médico-legal e compreender suas diversas aplicações.

Resultado: Com projeto de extensão foi possibilitada a visita ao Instituto Médico-legal (IML) da cidade de Umuarama/PR e o acompanhamento dos procedimentos do médico legista no caso de uma morte causada por arma de fogo. Tratava-se de um adolescente do sexo masculino, 19 anos de idade, o qual foi ferido com um projétil na região lombar esquerda, decorrido de uma troca de tiros com os policiais locais. O mesmo não veio à óbito no local, sendo levado até o hospital onde foi realizada uma laparoscopia exploratória, porém, ele não resistiu. No primeiro momento, na sala de necropsia, encontramos o corpo deitado sobre a mesa de análise, ainda com a roupa do centro cirúrgico, onde o médico legista colocou sobre o corpo o número de identificação e fotografou. Após isso, o médico legista juntamente com a auxiliar de necropsia analisou o corpo, arcada dentária possuindo aparelho ortodôntico, olhos, cor, corte de cabelo e tatuagens, anotando na ficha de identificação que não havia nenhuma alteração considerável. Adiante, foi localizado o local de entrada do projétil e suturas da cirurgia realizada no dia anterior. Além disso, foi retirado uma amostra de sangue para preservação do DNA para o banco de dados. A amostra de sangue foi devidamente lacrada, identificada e encaminhada para o laboratório de Curitiba/PR. Terminado os procedimentos e exames, o corpo ficou disponível para ser entregue aos familiares e/ou responsável.

Conclusão: A visita ao IML, proporcionada através do projeto de extensão, foi muito enriquecedora de conhecimento e edificadora na nossa carreira profissional, pois foi possível conhecer melhor a atuação do médico legista, bem como ter maior contato com essa especialidade médica. Foi possível também conhecer os procedimentos realizados na necropsia e em como deve ser preenchida a ficha de identificação e atestado de óbito.

\title{
Referências
}

ROCHA, Luiz Otávio Savassi. Necrópsia e educação médica. Revista Médica Minas Gerais, v. 24, n. 1, p. 106-13, 2014.

COSTA, Nelylena Batista da. Atitude médica perante uma vítima de ferimentos por arma de fogo: Como proceder. Orientador: Agostinho José Carvalho Santos. 2010. Mestrado Integrado em Medicina. Faculdade de Medicina Universidade do Porto, Porto, 2010.

FRANÇA, Genival Veloso de. Medicina Legal. 10. ed. Rio de Janeiro: Guanabara Koogan, 2015.

\section{AnGas Do}

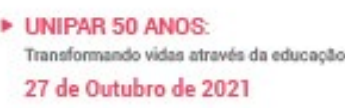

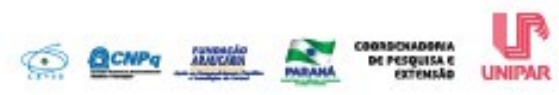




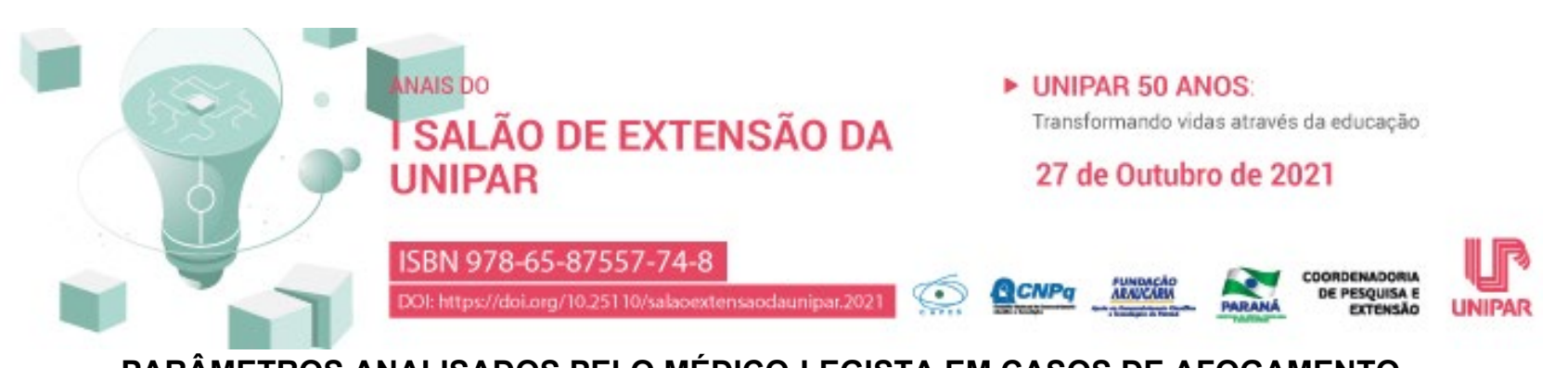

PARÂMETROS ANALISADOS PELO MÉDICO-LEGISTA EM CASOS DE AFOGAMENTO

\begin{abstract}
${ }^{1}$ AMANDA SIHNEL CORTEZ DA SILVA, ${ }^{2}$ CRISTIANE EDNA DA ROCHA, ${ }^{3}$ ANA BEATRIZ SILVESTRI RIBEIRO, ${ }^{4}$ MARINA BOITO DE OLIVEIRA, ${ }^{5}$ BRUNA FAVRETTO DA SILVA, ${ }^{6}$ EULLER CONDE FERNANDES,${ }^{7}$ FABIOLA COSTA TAKAKUA , ${ }^{8}$ MARCELO FLAGMIR BARCARO, ${ }^{9}$ RICARDO MARCELO ABRAO
\end{abstract}

${ }^{1}$ Acadêmica do Curso de Medicina da UNIPAR

${ }^{2}$ Acadêmica do Curso de Medicina da UNIPAR

${ }^{3}$ Acadêmica do Curso de Medicina da UNIPAR

${ }^{4}$ Acadêmica do Curso de Medicina da UNIPAR

${ }^{5}$ Acadêmica do Curso de Medicina da UNIPAR

${ }^{6}$ Acadêmico do Curso de Medicina da UNIPAR

${ }^{7}$ Acadêmica do Curso de Medicina da UNIPAR

${ }^{8}$ Professor Assistente do curso de Medicina da UNIPAR

${ }^{9}$ Professor Titular do curso de Medicina da UNIPAR

Introdução: Conforme preconiza França (2015), o afogamento concerne a uma asfixia mecânica, consequência de uma infiltração líquida ou semilíquida no sistema respiratório, obstruindo a passagem do ar até os pulmões. De acordo com a Sociedade Brasileira de Salvamento Aquático (SOBRASA, 2019), o afogamento é a segunda maior causa de óbito em crianças de 1 a 4 anos. Destarte, a instituição reforça veementemente a importância do estudo desse incidente, tido a possibilidade de prevenção. Em concomitância, a Medicina-Legal reserva sua atuação a resolver obscuridades associadas ao evento, identificando a vítima e o desdobramento dos fatos.

Objetivo: O estudo tem por escopo projetar os parâmetros analisados pelo médico-legista quando do afogamento.

Resultados: França (2015) assevera que as etiologias de afogamento derivam de acidente, suicídio ou homicídio. Ademais, quando do caso ora em tela, assinala algumas pontuações imprescindíveis, tais quais: a identificação da vítima; se o afogamento foi a causa mortis; se estava viva previamente adentrar a água; se a morte foi violenta; se houve alguma motivação que dificultou a saída do local; período de permanência submerso, entre outros. Através do Projeto de Extensão Patologias e Mortes foi possibilitada a visita ao Instituto Médico-Legal de Umuarama. No cenário, observou-se a chegada de um cadáver pediátrico, permeando a idade de dois anos, vítima de afogamento acidental em tanque de peixe particular de zona rural. Dentre os sinais de afogamento esperados (HIGA, 2021), foi detectado pelo médico-legista o fenômeno do cogumelo de espuma quando tórax pressionado, hipóstase, embebição cadavérica e potenciais lesões post mortem produzidas por animais aquáticos. Nesse prisma, é oportuno mencionar as explanações de Araújo (2007), ao versar que, em baixas faixas etárias, o afogamento é vinculado a $27 \%$ dos óbitos de causas externas não premeditadas. Corroborando com esse entendimento, Bordoni, et al. (2019) revisam que as crianças menores de 5 anos são as mais afligidas por essas fatalidades.

Conclusão: Perante o exposto, resta concluir a importância dos conhecimentos atinentes ao afogamento no âmbito da MedicinaLegal, tido que esta desobstrui obscuridades do caso, podendo trazer elucidações para a família, mormente em casos pediátricos. Nessa direção, sobreleva-se a relevância do acompanhamento dos estudantes de Medicina junto ao médico-legista, por intermédio do Projeto de Extensão da UNIPAR.

\title{
Referências
}

ARAÚJO, Rodrigo Tadeu de. Aspectos Médicos Legais e Preventivos dos Casos de Afogamentos na Região de Ribeirão Preto. Orientador: Prof. Dr. Marco Aurelio Guimarães. 2007. 59 f. Dissertação (Mestrado) - Departamento de Patologia da Faculdade de Medicina de Ribeirão Preto da Universidade de São Paulo, São Paulo, 2007. Disponível em: http://www.sobrasa.org/biblioteca/monografia_rodrigo.pdf. Acesso em: 09 ago. 2021.

BORDONI, Leonardo Santos; et al. Análise Médico-Legal de 553 Casos Suspeitos de Afogamento. Revista Médica de Minas Gerais, v. 29, n. 8, p. $10 \quad 18,2019$.

FRANÇA, Genival Veloso de. Medicina Legal. 10. ed. Rio de Janeiro: Guanabara Koogan, 2015.

HIGA, Rita de Cássia Bonfim Leitão. Da Pergunta ao Aprendizado em Medicina Legal. Presidente Prudente: Unoeste Universidade do Oeste Paulista, 2021.

SOCIEDADE BRASILEIRA DE SALVAMENTO AQUÁTICO. Afogamentos - O que está acontecendo? Boletim Brasil - 2019.

$\begin{array}{llllll}\text { Barra da } & \text { Tijuca, } & \text { ago. } & 2019 . & \text { Disponível } & \text { em: }\end{array}$


http://www.sobrasa.org/new_sobrasa/arquivos/baixar/AFOGAMENTOS_Boletim_Brasil_2019.pdf. Acesso em: 09 ago. 2021.

ANALS DO " UNIPAR 50 ANOS:

I SALÃO DE EXTENSÃO Transformando vides atrevents da educages

DA UNIPAR

27 de Outubro de 2021

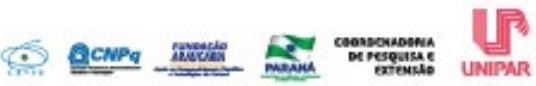




\title{
a DaIS DO UNIPAR 50 ANOS \\ SALÃO DE EXTENSÃO DA Transtormando vidas attravés da educaçăo UNIPAR DOMÉSTICAS
}

\author{
${ }^{1}$ PAULA MOSCOVITS QUEIROZ, ${ }^{2}$ TAZIANE MARA DA SILVA, ${ }^{3}$ LEONARDO LUIZ CASTELLI JUNIOR, ${ }^{4}$ BEATRIZ MANCHINI \\ MARUJO, ${ }^{5}$ FERNANDA KAYUMI YOSHIMURA, ${ }^{6}$ CAMILA MORENO GIAROLA, ${ }^{7}$ KAMUNI AKKACHE COUTINHO, ${ }^{8}$ DAISI DE \\ LIMA GEREVINI, ${ }^{9}$ BRUNA LUANA CHAPLA, ${ }^{10}$ THIAGO AUGUSTO RIBEIRO IRIA
}

\author{
${ }^{1}$ Acadêmica bolsista do PIBIC/UNIPAR \\ ${ }^{2}$ Acadêmica do Curso de Morfofisiologia Humana I da UNIPAR \\ ${ }^{3}$ Acadêmico do Curso de Morfofisiologia Humana I da UNIPAR \\ ${ }^{4}$ Acadêmica do Curso de Medicina da UNIPAR \\ ${ }^{5}$ Acadêmica do Curso de Medicina da UNIPAR \\ ${ }^{6}$ Acadêmica do Curso de Morfofisiologia Humana I da UNIPAR \\ ${ }^{7}$ Acadêmica do Curso de Morfofisiologia Humana I da UNIPAR \\ ${ }^{8}$ Acadêmica do Curso de Medicina da UNIPAR \\ ${ }^{9}$ Acadêmica do Curso de Medicina da UNIPAR \\ ${ }^{10}$ Docente da UNIPAR
}

Introdução: O presente trabalho busca demonstrar um Projeto de Extensão da Universidade Paranaense (UNIPAR), realizado pela Liga Acadêmica de Cirurgia Plástica (LACP), que utilizou a Rádio Universitária Paranaense para promover um maior conhecimento da população sobre meios de prevenção de queimaduras em ambientes domésticos. Este assunto, adquire grande relevância especialmente pelo seu aspecto epidemiológico, uma vez que, conforme aponta Souza et al. (2021), todos os anos, tem-se aproximadamente 1 milhão de ocorrências por queimaduras, principalmente por acidentes domésticos, com maior acometimento da população de 0 a 4 anos.

Objetivo: Este estudo tem como objetivo demonstrar a importância da disseminação de conhecimento sobre prevenção de queimaduras por meio de recurso midiático de fácil acesso a população, a Rádio, a fim de que os acidentes de queimaduras domésticos possam ser evitados.

Resultados: A audiência radiofônica tem contribuído para a disseminação de informações por parte de cientistas e profissionais da saúde, em especial no último ano, o qual evidenciou aumento da frequência de ouvintes, fato relatado por De Loudes Fraga (2021) em pesquisas comparando o antes e depois da pandemia. Concomitantemente ao número de acidentes por queimaduras que ocorrem todos os anos, fez-se de suma relevância o projeto. Para tal, através da Rádio Universitária Paranaense foi exposto o tema, no qual englobou os conceitos principais de queimaduras e seus tipos, elucidando que tal acidente pode ser grave e por isso sua importância; citou-se os principais modos de prevenir este acidente, como por exemplo o cuidado com cabos de panelas e a checagem da temperatura da água antes dos banhos em crianças; e discutiu-se as medidas a serem tomadas caso ocorra uma queimadura em casa, frisando a necessidade de procurar o serviço de saúde mais próximo. A Rádio tem uma audiência de 200.000 ouvintes pois atinge um raio de $150 \mathrm{~km}$, chegando assim, a informação para Umuarama - PR e diversos municípios vizinhos.

Conclusão: Diante do exposto, observa-se que informações pertinentes sobre prevenção de queimaduras precisam ser disseminadas em meios de alcance maciço a população, para que as pessoas possam entender a importância do assunto e estabelecer formas de cuidado em suas rotinas diárias para evitar acidentes domésticos com queimaduras, especialmente intercorrências com crianças pequenas, que é o público mais acometido.

\section{Referências}

SOUZA, Laryssa Ramos Pino. O tratamento de queimaduras: uma revisão bibliográfica. Brazilian Journal of Development, Curitiba, v.7, n.4, p. 37061-37074, Abril, 2021. Disponível em: https://www.google.com/search? $\mathrm{q}=$ queimaduras+scholar\&oq=queimaduras+scholar\&aqs=chrome..69i57.5006j0j7\&sourceid=chrome\&ie=UTF-

8\#: :text=O\%20tratamento\%20de,brazilianjournals.com\%20\%E2\%80\%BA\%20download. Acesso em 11 set. 2021.

DE LOURDES FRAGA, Kátia. Rádio local e comunidades afetivas em tempos de pandemia: estudo de caso de emissoras em Viçosa, Minas Gerais. Radiofonias Revista de Estudos em Mídia Sonora, v. 12, n. 1, 2021. 
- unIPAR 50 anos:

I SALAOO DE EXTENSÃO Transformando vidas atravies da educaģso

DA UNIPAR 


\section{(1) \\ ISBN 978-65-87557-74-8 \\ .

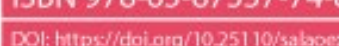 \\ BONS HÁBITOS PARA SE LEVAR PÓS PANDEMIA: PROJETO PRODUZIDO PELA LIGA ACADÊMICA DE CIRURGIA GERAL DA UNIPAR (LACG)}

${ }^{1}$ BEATRIZ CORREA CERNKOVIC, ${ }^{2}$ ARTHUR LORHAN CALDEIRA, ${ }^{3}$ DANILLO PRECHLAK DE SOUZA, ${ }^{4}$ LARISSA LOYOLA BARBOSA, ${ }^{5}$ RAFAEL BEZERRA MARIM, ${ }^{6}$ GABRIELA CAROLINA CREMONESE VON BORSTEL, ${ }^{7}$ MARIA EDUARDA MADALOZZO, ${ }^{8}$ MICHELLE BONATTO SAMPAIO, ${ }^{9}$ NATHALIA POSSAGNOLO PAGANINI, ${ }^{10} \mathrm{KENGO} \mathrm{MATSUGUMA} \mathrm{JUNIOR,}$ ${ }^{11}$ IARA HENRIQUE ROCHA, ${ }^{12}$ MARIA JULIA DACAS DACHEUX DO NASCIMENTO, ${ }^{13}$ ANTONIO HENRIQUE RUZZON MARTINS, ${ }^{14}$ KAROLAYNE SKIBA LAZZARI, ${ }^{15} \mathrm{FELIPE} \mathrm{MARCHI,}{ }^{16} \mathrm{FERNANDO} \mathrm{EDUARDO} \mathrm{PAULATTI} \mathrm{FREDERICO}$

${ }^{1}$ Acadêmica do Curso de Medicina da UNIPAR

${ }^{2}$ Acadêmico do Curso de Medicina da UNIPAR

${ }^{3}$ Acadêmico do Curso de Medicina da UNIPAR

${ }^{4}$ Acadêmica do Curso de Medicina da UNIPAR

${ }^{5}$ Acadêmico do Curso de Medicina da UNIPAR

${ }^{6}$ Acadêmica do Curso de Medicina da UNIPAR

${ }^{7}$ Acadêmica do Curso de Medicina da UNIPAR

${ }^{8}$ Acadêmica do Curso de Medicina da UNIPAR

${ }^{9}$ Acadêmica do Curso de Medicina da UNIPAR

${ }^{10}$ Acadêmico do Curso de Medicina da UNIPAR

${ }^{11}$ Acadêmica do Curso de Medicina da UNIPAR

${ }^{12}$ Acadêmica do Curso de Medicina da UNIPAR

${ }^{13}$ Acadêmico do Curso de Medicina da UNIPAR

${ }^{14}$ Acadêmica do Curso de Medicina da UNIPAR

${ }^{15}$ Acadêmico do Curso de Medicina da UNIPAR

${ }^{16}$ Docente da UNIPAR

Introdução: De acordo com Guenther (2020), a pandemia transformou o planeta em pouco tempo, assim o ser humano criou novas formas de se comunicar, trabalhar e se relacionar diante do isolamento social. A forma como o ser humano tem vivido atualmente diante da pandemia da COVID-19 é reflexo direto da relação que possui com o meio ambiente. Com isso cabe a todos pensarem quais atitudes serão tomadas diante de tudo o que tem acontecido. Mudar os hábitos e costumes ou observar a humanidade findar?

A atual situação fez o ser humano repensar em suas prioridades, seus hábitos em relação à saúde, fez com que buscassem melhorar a alimentação na tentativa de combater a doença em busca de uma luz em meio ao caos. Passaram a cuidar mais do ambiente ao redor ainda que se resuma às quatro paredes que os cercam durante o isolamento. Aumentaram o cuidado com a limpeza das casas por medo de se contaminarem ou até mesmo porque não têm nada para se fazer (GUENTHER, 2020).

Os bons hábitos para se levar pós pandemia foram ofertados para a população em geral, por meio, de panfletos, distribuídos por alunos da LACG, com o intuito de proporcionar informações para promover o cuidado com a higiene de modo amplo, como também, evitar surgimentos de novas epidemias relacionadas a preservação da saúde mental e física. Dessa forma, a utilização de panfletos é muito utilizada, sendo de suma importância para a população sem acesso a informações verbais e digitais, atuando como um complemento positivo na vida dos mesmos (NASCIMENTO et al., 2015).

Objetivo: Conscientizar a população sobre os bons hábitos para se levar pós pandemia do Covid-19, como forma de autocuidado e prevenção, por meio de um projeto visual e panfletário realizado por alunos da LACG.

Resultados: A Liga Acadêmica de Cirurgia Geral (LACG), teve a ideia de realizar um projeto panfletário, com um único objetivo: propagar a melhora dos bons hábitos, favorecendo uma alimentação saudável seguida de uma rotina de exercícios físicos, auxiliando no sono com qualidade. Assim como, continuar valorizando momentos especiais que favorecem o bem estar da saúde mental. Dessa forma, essa proposta panfletária foi realizada de maneira digital por integrantes da LACG, e entregue à população no dia 28/08/2021 no período da manhã, na praça Miguel Rossafa juntamente com membros da Liga de Anestesiologia e Dor da Unipar. Ao todo foram 12 acadêmicos envolvidos na execução deste trabalho. Assim, projetos realizados com panfletos, como 
neste caso, não possuem um direcionamento específico, mas contribuem para o acesso à informação, a qual é adquirida muitas vezes por fake news, desta forma cooperando para a prevenção e promoção da saúde (BASSO; SILVA; TERENCIO, 2018). Por conseguinte, notou-se uma elevada participação de acadêmicos colaborando para um crescimento profissional mediante a área da saúde e conciliador com a sociedade.

Conclusão: Conclui-se que a integração de informações por meio de projetos panfletários são de extrema importância para a conscientização do indivíduo referente a temas trabalhados. Além disso, participa como instrumento de aprendizagem para o profissional que realizou a execução do mesmo. Sem embargo, a pandemia do covid-19 teve e ainda tem uma repercussão no mundo, e propostas como essa onde se desfruta o intuito, de propagar conhecimento são muito válidas para a queda do número de casos, como também em um período pós pandêmico, o evitar de novas epidemias e a contribuição para o bem estar da população no geral.

\section{Referências}

BASSO, C; SILVA, E; TERENCIO, M. Educação em Saúde: a utilização de panfletos informativos e educativos como estratégia de prevenção às patologias mais prevalentes da população no contexto da atenção básica. SIEPE SAÚDE, 2018.

GUENTHER, Mariana. Como será o amanhã? O mundo pós-pandemia. Revista Brasileira De Educação Ambiental (RevBEA), v. 15 , n. 4 , p. $31-44,2020$.

NASCIMENTO, Évelyn Aparecida et al. Folhetos educativos em saúde: estudo de recepção. Revista da Escola de Enfermagem da USP, v. 49, p. 432-439, 2015.

\section{SALÁ̃O DE EXTENSÃO} DA UNIPAR
- UNIPAR 50 ANOS:

Tranoformando vidoa atrave da educaces

27 de Outubro de 2021

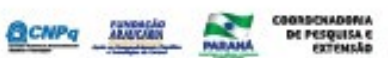




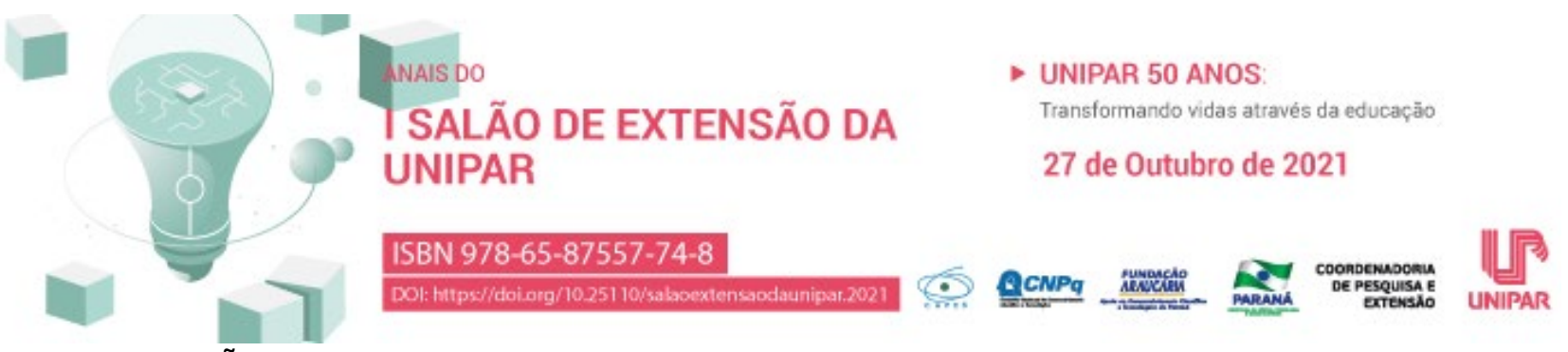 \\ AÇÕES EXTRA MUROS :DAS PAREDES DA UNIVERSIDADE PARA O MUNDO
}

\author{
${ }^{1}$ LUANA CAROLINA ALVES DE OLIVEIRA, ${ }^{2}$ VIVIANE SAGIN, ${ }^{3}$ MANOELLA MENSOR MARTINHAGO, ${ }^{4}$ THAYNA MORETTI , \\ ${ }^{5}$ JAQUELINE TEREZINHA DALSASSO FILIPPIM, ${ }^{6}$ TAINARA OLIVEIRA VALDAMERI, ${ }^{7}$ TAISE SIGNORINI
}

\begin{abstract}
${ }^{1}$ Acadêmico do curso de psicologia da UNIPAR
${ }^{2}$ Acadêmica do Curso de Psicologia da UNIPAR

${ }^{3}$ Acadêmica do Curso de Psicologia da UNIPAR

${ }^{4}$ Acadêmica do Curso de Psicologia da UNIPAR

${ }^{5}$ Acadêmica do Curso de Psicologia da UNIPAR

${ }^{6}$ Docente da UNIPAR

${ }^{7}$ Docente da UNIPAR
\end{abstract}

Introdução: Considerando o contexto atual de globalização e a conjuntura pandêmica, as redes sociais tornaram-se um meio rápido e prático para difundir informações com diferentes objetivos. Nesse sentido, ao interagirmos em redes sociais veiculando informações de caráter científico, estamos intervindo de acordo com que prevê o Código de Ética Profissional do Psicólogo (2005) em seu V princípio fundamental: O psicólogo contribuirá para promover a universalização do acesso da população às informações, ao conhecimento da ciência psicológica, aos serviços e aos padrões éticos da profissão . E ainda, de acordo com Araújo e Magalhães (2015, p.61) Compartilhar ideias é um fenômeno histórico, inserido no processo cultural e social das civilizações humanas . Sendo assim, ao elaborar materiais informativos o profissional da psicologia contribui com a comunidade proporcionando conhecimento, conscientização, prevenção e promoção de saúde e bem-estar.

Objetivo: Desenvolver e transmitir através de redes sociais conteúdos informativos de temáticas relacionadas à Psicologia. Tendo como público-alvo a população em geral, os conteúdos serão transmitidos através de campanhas interativas que envolvam diferentes áreas. Abrindo espaço para o compartilhamento de saberes, diálogos, reflexões e intervenções junto à comunidade.

Resultados: Até o presente momento, foram desenvolvidas duas campanhas interativas por meio de postagens nas redes sociais do curso. No mês de agosto, em comemoração ao dia do psicólogo, falamos sobre: a atuação em Psicologia, as áreas de atuação e algumas estratégias de intervenção do psicólogo. Já no mês de setembro, em alusão a campanha nacional I"Setembro Amarelol" de prevenção ao suícidio, abordamos: a importância da campanha, os mitos e verdades sobre o suícidio e como buscar ajuda. Apesar das ações terem iniciado recentemente, é notória a sua efetividade, tendo em vista que recebemos interações diversas, por meio de compartilhamentos, comentários e curtidas, nas publicações produzidas. As quais corroboram com o objetivo do projeto, ressaltando a importância das campanhas.

Conclusão: Nota-se a importância da Psicologia no campo da comunicação, contribuindo para a possibilidade de ampliar a compreensão da sociedade, na conscientização, promoção e prevenção da saúde. Partilhando principalmente através de redes sociais conhecimentos de uma forma dinâmica e interativa.

\section{Referências}

ARAÚJO, Késia; MAGALHÃES, Pablo Michel. As mídias digitais e os seus reflexos em campanhas de conscientização em tempos de compartilhamento. Revista Expansão Acadêmica, Ano 1, n. 1, p. 55-65, jul./dez. 2015.

CONSELHO FEDERAL DE PSICOLOGIA. Resolução nº 010/2005. Aprova o Código de Ética Profissional do Psicólogo. Código de Ética Profissional do Psicólogo, XIII Plenário. Brasília, DF: CFP, ago. 2005.

I SALÃO DE EXTENSÃO DA UNIPAR

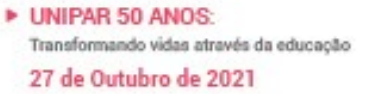

27 de Outubro de 2021

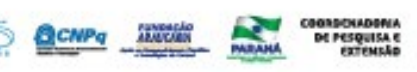

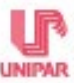




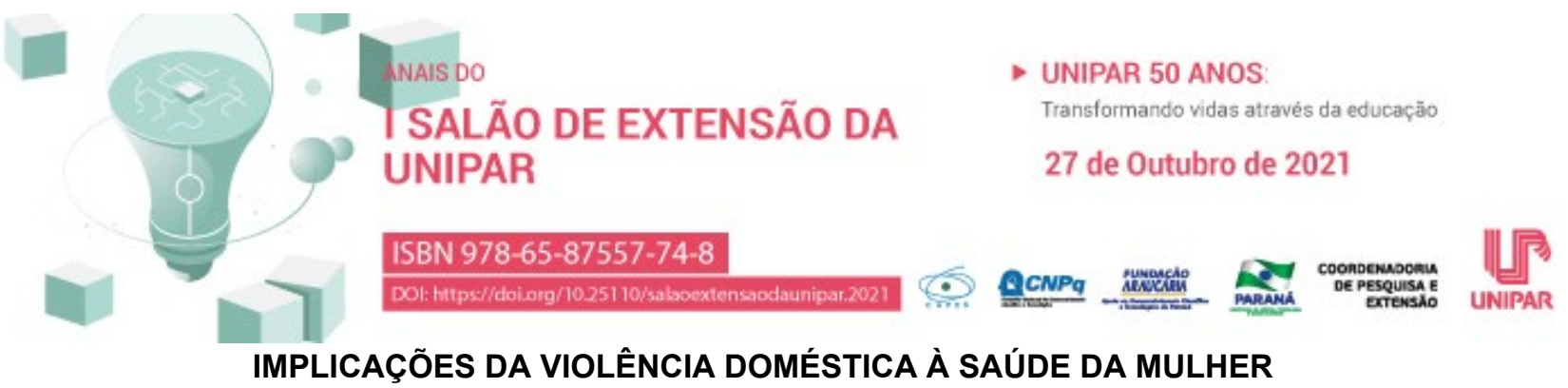

\author{
${ }^{1}$ SAMILLY LORENZATTO DA SILVA, ${ }^{2}$ ANNA CAROLINE DOS SANTOS BLASIUS, ${ }^{3}$ TATIANE PELISSARI, ${ }^{4}$ LETICIA THAMARA \\ CARDOZO MENDONCA, ${ }^{5}$ ANA MARIA CANZI, ${ }^{6}$ DYENIFFER JESSICA BEZERRA PARISOTO
}

\begin{abstract}
${ }^{1}$ Acadêmica do Curso de Psicologia do PEX/UNIPAR- Cascavel
${ }^{2}$ Acadêmica do Curso de Psicologia do PEX/UNIPAR- Cascavel

${ }^{3}$ Acadêmica do Curso de Psicologia do PEX/UNIPAR- Cascavel

${ }^{4}$ Acadêmica do Curso de Psicologia do PEX/UNIPAR- Cascavel

${ }^{5}$ Acadêmica do Curso de Psicologia do PEX/UNIPAR- Cascavel

${ }^{6}$ Orientadora do Projeto de Extensão Saúde da Mulher e Responsável Técnica do Centro de Psicologia Aplicada da UNIPARCascavel
\end{abstract}

Introdução: Este trabalho é resultante do Projeto de Extensão Universitária denominado Saúde da Mulher da Universidade Paranaense - UNIPAR, campus Cascavel-PR., que contempla acadêmicas(os) do curso de Psicologia visando integrar os conhecimentos teóricos e práticos sobre a saúde da mulher. Na sociedade atual, de acordo com Saffioti (2004) além da desigualdade de classe e raça, também faz parte da estrutura social a desigualdade de gênero. As mulheres têm uma sobrecarga de trabalho, desigualdade salarial, assim como, em pesquisa realizada pelo Fórum Brasileiro de Segurança Pública e DataFolha (2021), aponta que, 1 em cada 4 brasileiras sofreu algum tipo de violência no último ano, 8 mulheres são agredidas fisicamente por minuto no Brasil. Dessa forma, o conceito de violência contra as mulheres está apoiado na questão de gênero e, remete a uma conjectura multifacetada, ligada a questões históricas, culturais e sociais que afeta e implica na saúde mental de cada mulher.

Objetivos: Integrar conhecimentos teóricos e práticos sobre à saúde mental das mulheres, e oferecer atendimento psicológico prioritariamente às demandas de mulheres que estiveram ou estão em situações de violência que são encaminhadas ao Centro de Psicologia Aplicada.

Resultados: Os resultados obtidos com o levantamento teórico de artigos e dissertações, consistem na base teórica dos acompanhamentos psicoterápicos das usuárias em situação de violência. Após estudo da construção da categoria de gênero e da violência, em conjunto com os elementos da singularidade de cada mulher e o contexto histórico e social em que ela se encontra, intenciona-se construir junto às usuárias novos sentidos, num processo de fortalecimento da autonomia, visando à participação ativa da mulher no desenvolvimento das condições de superação da situação de violação de direitos (CFP, p. 92, 2012).

Conclusão: Desta forma, com base na emergência dos casos de violências contra as mulheres que afetam e constroem a vida e história de cada mulher, gerando diversos sofrimentos psicológicos, como ressalta o CFP (2012), é de suma importância que tanto essas mulheres tenham atendimentos psicológicos, como que os(as) profissionais de Psicologia estejam preparados para atender as demandas que envolvem a saúde mental das mulheres.

\section{Referências}

CONSELHO FEDERAL DE PSICOLOGIA. Referências técnicas para atuação de psicólogas(os) em Programas de Atenção à Mulher em situação de Violência. Brasília, CFP, 2012. Disponível em: . Acesso em 20 de Ago. de 2021.

FÓRUM BRASILEIRO DE SEGURANÇA PÚBLICA E DATAFOLHA INSTITUTO DE PESQUISA. Visível e Invisível: A Vitimização de Mulheres no Brasil. Fórum Brasileiro de Segurança Pública, DataFolha Instituto de Pesquisas e Uber. $3^{\mathrm{a}}$ ed. 2021. Disponível em: . Acesso em 25 de Ago. de 2021.

SAFFIOTI, Heleieth lara Bongiovani. Gênero, patriarcado, violência. São Paulo: Editora Fundação Perseu Abramo, 2004.

I SALÃO DE EXTENSÃO

DA UNIPAR

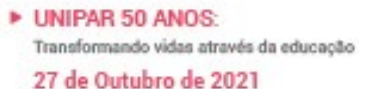

27 de Outubro de 2021

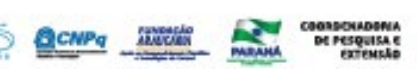

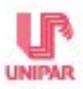




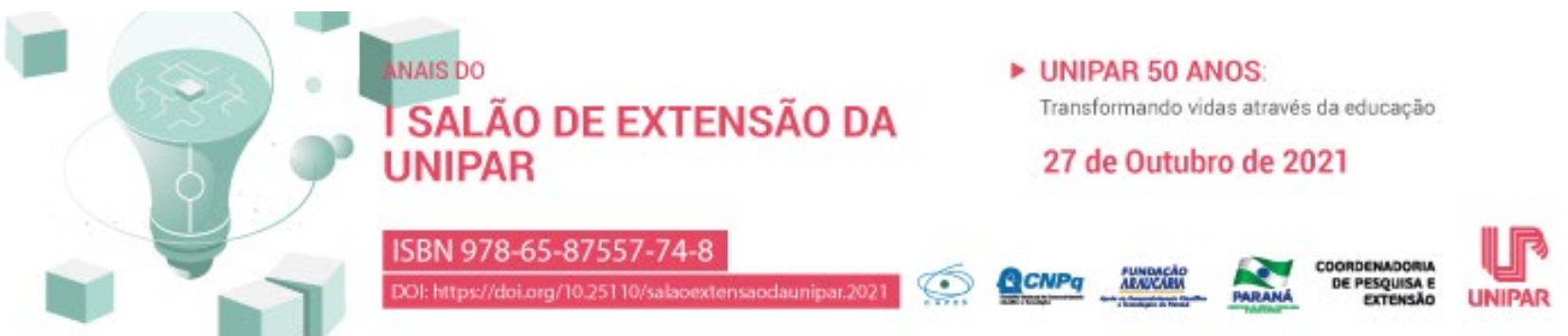

ALTERNATIVAS PARA CONTROLE DO Aedes aegypti

${ }^{1}$ LUCAS MATHEUS SILVA DA ROCHA, ${ }^{2}$ GABRIELLE CAROLINE BRUGIM RAMOS, ${ }^{3}$ RAISA LENHANI, ${ }^{4}$ LETHICIA SANTOS ALVES, ${ }^{5}$ LORENA DE FATIMA MORETTO, ${ }^{6}$ ISABELLA ARANTES TOBBIN, ${ }^{7}$ ANTHONY FELIPE MORANDO BORGES, ${ }^{8}$ PEDRO KROMINSKI BICUDO, ${ }^{9}$ VICTOR HUGO DRANKA MORI, ${ }^{10}$ REBECA HELOISE PINHEIRO MEIER, ${ }^{11}$ THIAGO RIOS FERREIRA, ${ }^{12}$ GABRIEL MONFE FAVARO, ${ }^{13}$ VANDA ZAGO LUPEPSA, ${ }^{14}$ CRISTIANE CLAUDIA MEINERZ, ${ }^{15}$ DENISE ALVES LOPES, ${ }^{16}$ ROSILEY BERTON PACHECO

\footnotetext{
${ }^{1}$ Acadêmica do Curso de Medicina da UNIPAR

${ }^{2}$ Acadêmica do Curso de Medicina da UNIPAR

${ }^{3}$ Acadêmica do Curso de Medicina da UNIPAR

${ }^{4}$ Acadêmica do Curso de Medicina da UNIPAR

${ }^{5}$ Acadêmica do Curso de Medicina da UNIPAR

${ }^{6}$ Acadêmica do Curso de Medicina da UNIPAR

${ }^{7}$ Acadêmico do Curso de Medicina da UNIPAR

${ }^{8}$ Acadêmico do Curso de Medicina da UNIPAR

${ }^{9}$ Acadêmico do Curso de Medicina da UNIPAR

${ }^{10}$ Acadêmica do Curso de Medicina da UNIPAR

${ }^{11}$ Acadêmico do Curso de Medicina da UNIPAR

${ }^{12}$ Acadêmico do Curso de Medicina da UNIPAR

${ }^{13}$ Docente da UNIPAR

${ }^{14}$ Docente da UNIPAR

${ }^{15}$ Docente da UNIPAR

${ }^{16}$ Docente da UNIPAR
}

Introdução: A dengue é uma enfermidade causada por um vírus pertencente ao gênero flavivírus, da família flaviridae, sendo caracterizado como uma doença febril de início abrupto, com duração de 5 a 7 dias. $O$ vírus da dengue apresenta quatro sorotipos: DEN-1, DEN-2, DEN-3 e DEN-4 (CASALI, et al, 2004). Sua transmissão se dá a partir da picada do mosquito Aedes aegypti contaminado, ou seja, a fêmea do mosquito Aedes entra em contato com o sangue de um indivíduo contaminado através da picada, e assim, torna-se transmissor do vírus; pode ainda ocorrer transmissão vertical, fato esse raro (SINGHI; KISSOON; BANSAL, 2007). O vírus da dengue está presente em regiões tropicais e subtropicais e estima-se que aproximadamente três bilhões de pessoas estão susceptíveis a infecção pelo vírus da dengue (DALBEM, et al, 2014). De acordo com a classificação clínica da dengue, ela pode ser definida como doença febril não-diferenciada ou síndrome viral; dengue e dengue hemorrágico (DH) podendo esta ser $\mathrm{DH}$ sem choque ou podendo evoluir para síndrome do choque associada ao dengue (SCD) (SINGHI; KISSOON; BANSAL, 2007). Salienta-se que a dengue, embora esteja entre as doenças emergentes, ainda encontra-se dentre as doenças negligenciadas pelas economias dominantes e seu aparato técnico-científico. Apesar de seu agravante impacto sobre a humanidade, ela parecer ter sido reiteradamente marginalizada, tanto pelo setor público quanto privado, pois seu recrudescimento não tem sido acompanhado por investimentos capazes de gerar seu controle. Sem dúvida todas as ações relacionadas ao vírus da dengue no Brasil e as medidas de prevenção e de vigilância para seu controle e erradicação devem ser desenvolvidas em articulação com os Governos Federal, Estaduais e Municipais que fortalecerá ainda mais as atividades de vigilância epidemiológica. A notificação oportuna dos casos é medida essencial para que a vigilância seja capaz de acompanhar o padrão de transmissão da doença na área e na curva endêmica (MINISTÉRIO DA SAÚDE, 2002, p. 39).

Objetivo: Demonstrar medidas alternativas de controle do Aedes aegypti.

Resultados: Em Umuarama, cidade no estado do Paraná, cidade de 109.955 mil habitantes, a situação epidemiológica da doença de dengue é preocupante devido ao grande número de localidades onde contam com notificações de casos suspeitos. Realizaram visitas residências e comércios para arrastões, informações sobre as medidas de redução e combate do mosquito e panfletagem O projeto foi desenvolvido durante o ano de 2019, 2020 e 2021 na cidade de Umuarama. Acadêmicos da Unipar, dos cursos de Pedagogia, Enfermagem, Estética e principalmente da Medicina juntamente com a Vigilância Sanitária 4 arrastões 
no mês de fevereiro de março de 2020 em bairros onde o índice de casos de dengue eram mais elevados no município. Ainda nas escolas Estaduais do Município de Umuarama, foram ministradas palestras e atividades para que pudessem compreender a importância de se tomar medidas de prevenção para combater o mosquito da dengue, Aedes aegypti.

Considerações Finais: O projeto tem como o objetivo geral demonstrar medidas alternativas de controle do Aedes aegypti. Os alunos avaliaram as condições dos serviços básicos de saneamento e sua relação com os casos de dengue. Na sequência apresentaram à comunidade as medidas de prevenção segundo os protocolos da Vigilância Sanitária. Planejaram juntamente com a Vigilância Sanitária, ações para combater o mosquito transmissor da doença. Divulgaram as atividades realizadas pelas equipes de endemias no combate à dengue para fortalecer as ações. Conscientizaram a comunidade através de palestras em escolas, repartições públicas e privadas, enfatizando a importância do controle da dengue com medidas alternativas e alta eficácia.

\section{Referências}

BRASIL. Ministério da Saúde. Fundação Nacional de Saúde. Dengue: aspectos epidemiológicos, diagnóstico e tratamento. Ministério da Saúde, Fundação Nacional de Saúde. Brasília: Fundação Nacional de Saúde, 2002. 20 p.

CASALI, Clarisse Guimarães; et al. A epidemia de dengue/dengue hemorrágico no município do Rio de Janeiro, 2001/2002. Revista da Sociedade Brasileira de Medicina. Tropical, v. 37, n. 4, p. 296-299, jul-ago, 2004.

DALBEM, A. G; et al. Dengue clássica e febre hemorrágica da dengue: etiologia, fisiologia, epidemiologia e fatores de risco. Revista Ciência e Estudos Acadêmicos de Medicina. Universidade do Estado de Mato Grosso - UNEMAT (Cáceres). n. 1, p.18-36, 2014.

SINGHI, Sunit; KISSOON, Niranjan; BANSAL, Arun . Dengue e dengue hemorrágico: aspectos do manejo na unidade de terapia intensiva. Artigos de Revisão, Jornal Pediátrico. Rio Janeiro, v. 83, 2 suppl. Maio, 2007. https://doi.org/10.1590/S002175572007000300004. Acesso em: 08/09/2021.

I SALĂO DE EXTENSÃO

DA UNIPAR
- UNIPAR 50 ANOS:

Transformanso vides atreves da educasto

27 de Outubro de 2021

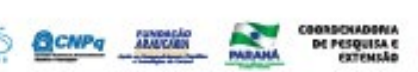




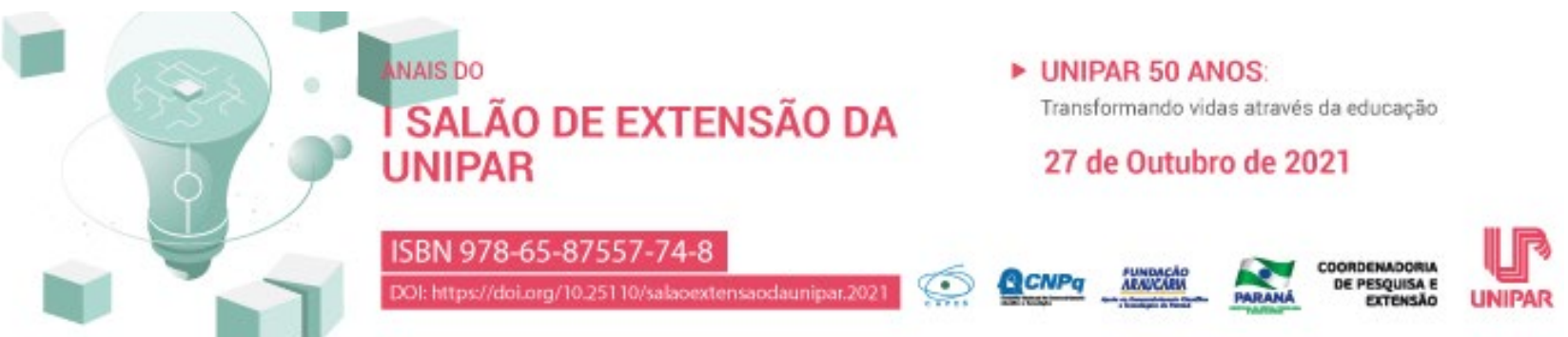 Rosmarinus officinalis CLASSIFICAÇÃO BOTÂNICA E USO MEDICINAL}

\section{${ }^{1}$ MAISA STEFFANI ADAMCZUK, ${ }^{2}$ JAQUELINE HOSCHEID}

${ }^{1}$ Discente do curso de Farmácia da Universidade Paranaense UNIPAR

${ }^{2}$ Docente do curso de Farmácia da Universidade Paranaense - UNIPAR

Introdução: O Rosmarinus officinalis, conhecido popularmente como alecrim, é uma espécie nativa da região do Mediterrâneo e de clima temperado. Esta planta foi uma das primeiras ervas com utilização medicinal pela humanidade e em algumas culturas ela é considerada como sagrada e usada para proteção.

Objetivo: Expressar de forma clara e simplificada a classificação botânica, o uso medicinal e as propriedades botânicas do Rosmarinus officinalis.

Desenvolvimento: Sua classificação botânica segue: Reino: Plantae; Filo: Magnoliophyta; Classe: Magnoliopsida; Ordem: Lamiales; Família: Lamiaceae; Gênero: Rosmarinus; Espécie: officinalis; Sinonímia botânica: Rosmarinus latifolius Mill; Nomes populares: alecrim-de-jardim; alecrim; rosmarino; labinotis; alecrinzeiro; alecrim comum; alecrim-decheiro; alecrim-de-horta; ervacoada; flor-do-olimpo; rosa-marinha; rosmarinho (LORENZI; MATOS, 2006). As partes utilizadas na medicina popular são as folhas e as flores, para o preparo de xaropes, infusões e os óleos essenciais. O alecrim é considerado um estimulante digestivo, utilizado para a abrir apetite, contra azia, digestão lenta, e flatulências (BOORHEM et al., 1999). Esta planta possui propriedades antissépticas, diuréticas, antiespasmódico, cicatrizantes (externo), protetor hepático, antitumoral, antidepressivo natural, calmantes, vasodilatadoras (BOORHEM et al., 1999), antioxidante e antimicrobiana, graças a estas propriedades o alecrim é usado na indústria alimentícia como conservante (RA KOVIĆ et al., 2014), também é utilizada em perfumes, em pomadas, nos shampoos e nos sabonetes (BEGUM et al., 2013). Ademais, há estudos relatando o potencial de $R$. officinalis no estímulo ao crescimento capilar em ratos (MURATA et al., 2013), o efeito estimulante e antiestresse do uso óleo essencial puro de alecrim, por via inalatória, em humanos (VILLAREAL et al., 2017) e a melhora da função cognitiva na demência do tipo Alzheimer em ratos (SATOU et al., 2018).

Conclusão: Revisões de literatura sobre o uso de plantas medicinais, e a realização de estudos clínicos são de extrema relevância a fim de observar os reais efeitos do uso de plantas medicinais e condimenteres, como o alecrim, em humanos nas diferentes condições clínicas.

\section{Referências}

BEGUM, A.; SANDHYA, S.; SHAFFATH, A. S. et al. An in-depth review on the medicinal flora Rosmarinus officinalis (Lamiaceae). Acta Scientiarum Polonorum Technologia Alimentaria, v.12, n.1, p.61-73, 2013.

BOORHEM, R. L. et al. Segredos e Virtudes das Plantas Medicinais. Editora Reader's Digest Brasil Ltda, Rio de Janeiro, 416 pp., 1999.

LORENZI, H.; MATOS, F. J. Plantas Medicinais no Brasil: Nativas e Exóticas Cultivadas/ Francisco José de Abreu Matos/ Primeira Edição/ Instituto Plantarum/ Nova Odessa/ 512 pp. 2006.

MURATA, K. et al. Promotion of hair growth by Rosmarinus of icinalis leaf extract. Phytotherapy research, v. 27, n. 2, p. $212-$ 217, 2013.

RA KOVIĆ, A.; MILANOVIĆ, I.; PAVLOVIĆ, N.; et al. Antioxidant Activity of Rosemary (Rosmarinus officinalis L.) Essential Oil and its Hepatoprotective Potential. BMC Complementary and Alternative Medicine, v. 14, p. 225, 2014.

SATOU, T. et al. The effect of inhalation of essential oil from Rosmarinus of icinalis on scopolamine-induced Alzheimer's type dementia model mice. Flavour and Fragrance Journal, v. 33, n. 3, p. 230-234, 2018.

VILLAREAL, M. O., IKEYA A., SASAKY, K., BEN ARFA, A., NEFFATI, M., \& ISOLDA, H. (2017). Antistress and neuronal cell differentiation induction effects of Rosmarinus officinalis L. essential oil. BMC Complementary and Alternative Medicine, 17. doi: 10.1186/s12906-017-2060-1

\section{SALĀO DE EXTENSÃO} DA UNIPAR

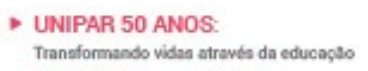

27 de Outubro de 2021

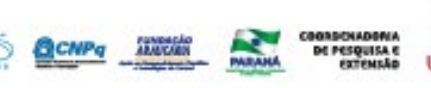

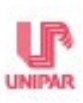




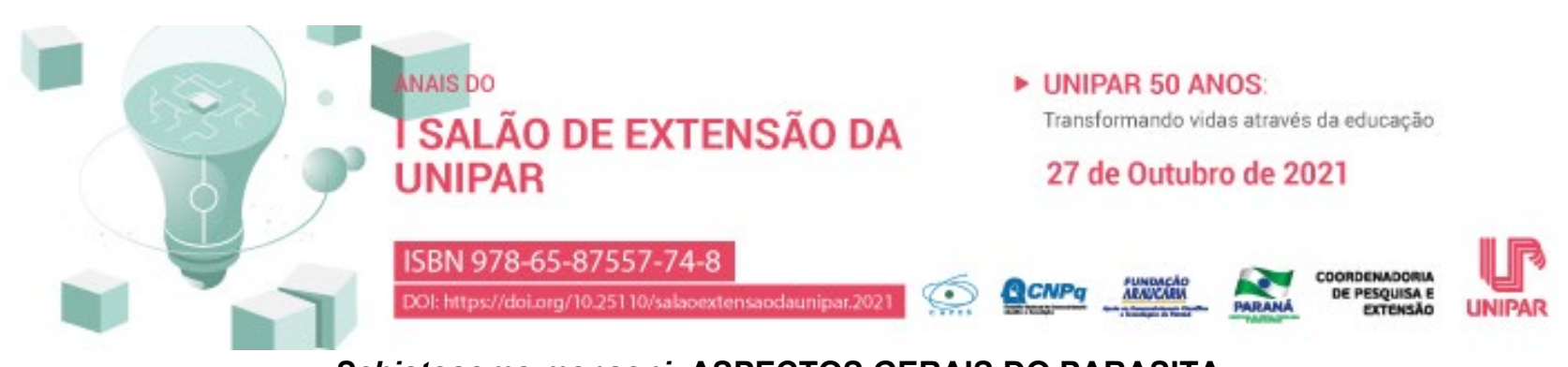

\title{
Schistosoma mansoni: ASPECTOS GERAIS DO PARASITA
}

\begin{abstract}
${ }^{1}$ MAISA STEFFANI ADAMCZUK, ${ }^{2}$ THAIS EDUARDA ADAMCZUK, ${ }^{3}$ JULIA VALER GUERRA, ${ }^{4}$ LAURA RICARDA EBELING LAUTERT , ${ }^{5}$ THAINARA LOURENCO DE VASCONCELLOS,${ }^{6}$ ALLEX VITAL PEREIRA, ${ }^{7}$ ERIKA DE GOIS FREIRE LOPES, ${ }^{8}$ GIULIANA ZARDETO SABEC
\end{abstract}

${ }^{1}$ Acadêmica do Curso de Farmácia e do PEX/UNIPAR

${ }^{2}$ Acadêmica do Curso de Farmácia da UNIPAR

${ }^{3}$ Acadêmica do Curso de Farmácia da UNIPAR

${ }^{4}$ Acadêmica do Curso de Farmácia da UNIPAR

${ }^{5}$ Acadêmica do Curso de Farmácia da UNIPAR

${ }^{6}$ Acadêmico do Curso de Farmácia da UNIPAR

${ }^{7}$ Acadêmica do Curso de Farmácia da UNIPAR

${ }^{8}$ Docente da UNIPAR

Introdução: A esquistossomose mansônica (EM) classificada como uma doença tropical negligenciada (DTNs), ela afeta a maioria das pessoas que vivem em condições precárias de higiene e a magnitude de sua prevalência, associada à severidade das formas clínicas e a sua evolução, conferem a essa enfermidade uma grande relevância enquanto problema de saúde pública. Este parasita é conhecido por causar a esquistossomose também conhecida como barriga d'água (SILVA-MORAES et al., 2019). Ele é um platelminto, trematódeo, dióico que possuem diferentes estágios de desenvolvimento (verme adulto (macho e fêmea), ovo, miracídio, esporocistos, cercária e esquistossômulo) (SOUZA et al., 2011). Acredita-se que que agente etiológico da esquistossomose, o Schistosoma mansoni, tenha sido introduzido no Brasil juntamente com o tráfico negreiro, e aqui em território brasileiro achou um habitat perfeito para se proliferar, com dois principais hospedeiros, sendo um intermediário moluscos do gênero Biomphalaria e o outro definitivo o Homo sapiens sapiens (SOUZA et al., 2011).

Objetivo: Expressar de forma clara e simplificada, uma visão geral sobre o ciclo de vida do parasita Schistosoma mansoni. E a breve história natural da doença causada por este parasita, a esquistossomose.

Resultados e discussões: Neste trabalho realizou-se um levantamento bibliográfico, por meio da base de dados Google acadêmico, entre os anos de 2011 à 2021, buscando ressaltar as principais características da esquistossomose mansônica. A esquistossomose em fase crônica se apresenta de maneira polimórfica, ou seja, é bem variada de sintomas, já a esquistossomose aguda é representada por manifestações pruriginosas na pele (SOUZA et al., 2011). Em seu ciclo evolutivo, o helminto alterna fases assexuadas e sexuadas de reprodução, sendo heteroxênico (necessidade de mais de um hospedeiro para que a evolução se processe) (SILVA-MORAES et al., 2019). Suspeita-se da doença quando aparecem sintomas dispépticos, tais como: eructações, sensação de plenitude gástrica, náuseas, vômitos, pirose, flatulência e anorexia, diarreia, entre outros. Ao exame físico são escassos os achados, exceto o emagrecimento, presente em alguns doentes, e a hepatomegalia. O diagnóstico é laboratorial, isto é, através do exame parasitológico de fezes, quando o analista clínico encontra presença de ovos viáveis de $S$. mansoni em um exame de fezes rotineiro (SOUZA et al., 2011). Cerca de 25 milhões de pessoas estão expostas ao risco de contrair a esquistossomose, estimando-se que já existam seis milhões de casos de indivíduos infectados. Sendo assim, os altos índices de prevalência anual são agravados pela situação social e econômica da sociedade que conjugados aos fatores ecológicos promovem uma maior dispersão da doença (SILVA-MORAES et al., 2019).

Conclusão: Concluiu-se que essa doença ainda se encontra com números alarmantes, fortalecendo a falta de saneamento e educação continuada para comunidade. Neste sentido, mais informações e estudos afim da erradicação são necessários, assim como, o alerta à população do diagnóstico precoce, através do exame parasitológico de fezes.

\section{Referências}

SILVA-MORAES, V.; SHO SHOLLENBERGER, L. M.; SIQUEIRA, L. M.; BORGES, W. C.; HARN, D. A.; GRENFELL, R. F. Q.; RABELLO, A. L. T.; COELHO, P. M. Z. Diagnosis of Schistosoma mansoni infections: what are the choices in Brazilian lowendemic areas?. Memórias do Instituto Oswaldo Cruz, v. 114, 2019.

GRENFELL, R. F. Q.; MARTINS, W.; ENK, M.; ALMEIDA, A.; SIQUEIRA, L.; SILVA-MORAES, V. Schistosoma mansoni in a lowprevalence area in Brazil: the importance of additional methods for the diagnosis of hard-to-detect individual carriers by low-cost immunological assays - Memórias do Instituto Oswaldo Cruz, v. 114, Rio de Janeiro, Fevereiro de 2019.

SOUZA, F. P. C.; VITORINO, R. R.; COSTA, A. P.; FARIA, J.; CORREAA, F. ; SANTANA, L. A.; GOMES, A. P. Schistosomiasis 
mansoni: general aspects, immunology, pathogenesis and natural history. Revista da Sociedade Brasileira de Clínica Médica, v. 9, n. 1, p. 300-307,São Paulo, Agosto de 2011.
ISALÃOO DE EXTENSÃO
- UNIPAR 50 ANOS:
DA UNIPAR

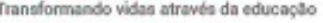
27 de Outubro de 2021
8 ACNPG 


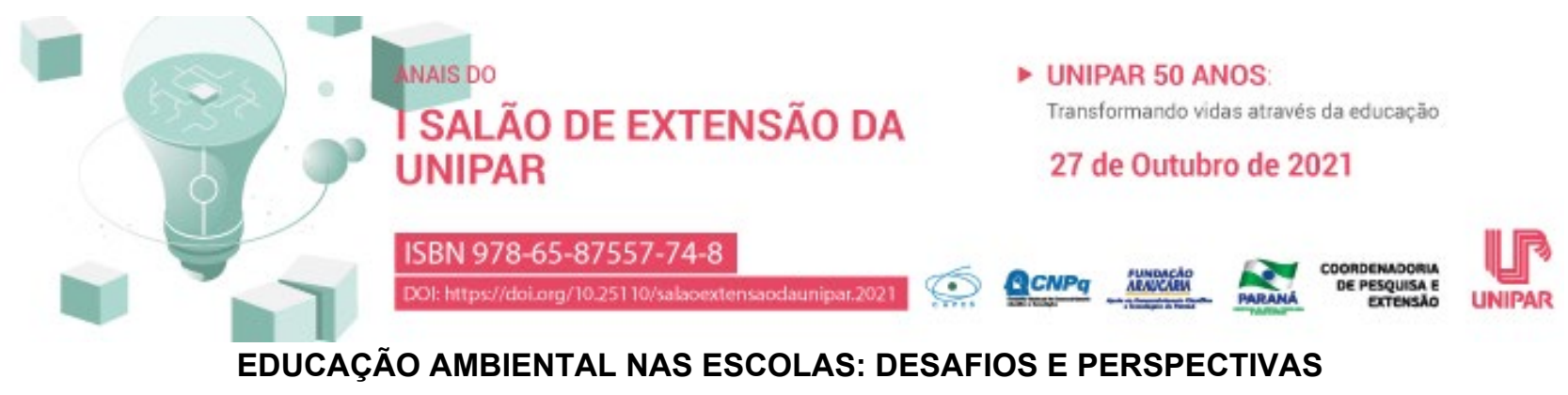

\author{
1'LEILA ISABEL DA SILVA, ${ }^{2}$ FRANCISLAINE APARECIDA DOS REIS LIVERO
}

${ }^{1}$ Doutoranda do Programa de Pós-graduação em Biotecnologia Aplicada a Agricultura Unipar, Umuarama-PR

${ }^{2}$ Docente Orientadora do Programa de Pós-graduação em Biotecnologia Aplicada a Agricultura Unipar, Umuarama-PR

Introdução: Professores que possuem forte conhecimento para alfabetização ambiental, têm apoio de suas escolas, sensibilidade e atitudes ambientais positivas, tornando-se assim pessoas influentes na educação de crianças e adolescentes para se tornarem futuros líderes na defesa do meio ambiente (ERNST, 2007). Conhecimento e habilidades na escolha de métodos de ensino e auxiliares influenciam significativamente a qualidade da aprendizagem (MIKEROVA et al., 2018). Assim, é fundamental que o professor promova um aprendizado centrado no aluno, planejando lições contínuas e utilizando técnicas colaborativas de ensino experiencial (MUSTAM; DANIEL, 2016).

Objetivo: Realizar um levantamento bibliográfico sobre os desafios e perspectivas encontrados na educação ambiental.

Desenvolvimento: As ações e atitudes do professor em relação ao meio ambiente são muito importantes, pois serão os modelos seguidos por seus alunos no futuro, uma vez que o comportamento do aluno é influenciado pelo comportamento do professor (UÇAR; CANPOLAT, 2019). Além disso, os professores podem ser líderes em educação ambiental, podendo influenciar colegas, diretores e outros membros da comunidade escolar para melhorar as práticas de ensino com o objetivo de melhorar a aprendizagem e o desempenho dos alunos (YORK-BARR; DUKE, 2004). Para acessar este novo cenário educacional, o professor além de ser orientador, mediador, cooperador e organizador da aprendizagem do aluno, deve ser um aprendiz permanente (GADOTTI, 2000). Entretanto, apesar da importância do professor na condução da construção do conhecimento do aluno, poucos são os que realizam cursos ou especializações voltadas para a área de educação ambiental nas escolas e em espaços educadores sustentáveis (DIAS, 2004). Dentre os motivos que levam às limitações da educação ambiental, destacam-se obstáculos importantes, como 1) barreiras conceituais, como a falta de percepção dos professores sobre a definição de educação ambiental, bem como sua localização no currículo; 2) barreiras logísticas, como falta de tempo, falta de material didático e falta de financiamento; 3) barreiras educacionais, como a preparação e treinamento dos professores para conduzir atividades; e 4) barreiras de atitude, como o entendimento dos professores sobre a importância da educação ambiental em relação a outras partes do currículo (VALDERRAMA-HERNÁNDEZ; ALCÁNTARA; LIMÓN, 2017).

Conclusão: A escola é o ambiente propício para a inclusão de práticas educacionais relacionadas ao meio ambiente devido à sua capacidade de exercer influência e promover transformação na comunidade onde está inserida. Entretanto, algumas dificuldades, como a passividade dos alunos e a falta de qualificação dos professores, tem limitado a promoção da educação ambiental.

\title{
Referências
}

DIAS, Genebaldo Freire. Ecopercepção: um resultado didático dos desafios socioambientais. São Paulo: Gaia, 2004.

ERNEST, Julie. Factors associated with k 12 teachers' use of environment-based education. Journal Environmental Education, v. 38, p. 15-31, 2007.

GADOTTI, Moacir. Perspectivas atuais na educação. São Paulo em Perspectiva, v. 14, p. 1-9, 2000.

MIKEROVA, Galina; SERGEEVA, Bella; MARDIROSOVA, Galina; KAZANTSEVA, Victoria; KARPENKO, Angelica. Learning environment affecting primary school student's mental development and interest. International Electronic Journal Element Education, v. 10, p. 407 412, 2018.

MUSTAM, Baniah; DANIEL, Esther Sarojini. Informal and formal environmental education infusion : actions of malaysian teachers and parents among students in a polluted area. Malaysian Online Journal Education Science, v. 4, p. 9 20, 2016.

UÇAR, Murat Bear; CANPOLAT, Erdal. Modelling preservice science teachers environment -friendly behaviours. Australian Journal Teacher Education, v. 44, p. 1 14, 2019.

YORK-BARR, Jennifer; DUKE, Karen. What do we know about teacher leadership? Findings from two decades of scholarship. Review Educational Research, v. 74, p. 255 316, 2004.

VALDERRAMA-HERNÁNDEZ, Rocío; ALCÁNTARA, Lucía; LIMÓN, Dolores. The complexity of environmental education: teaching ideas and strategies from teachers. Proceed-Social and Behavioral Sciences, v. 237, p. 968-974, 2017. 


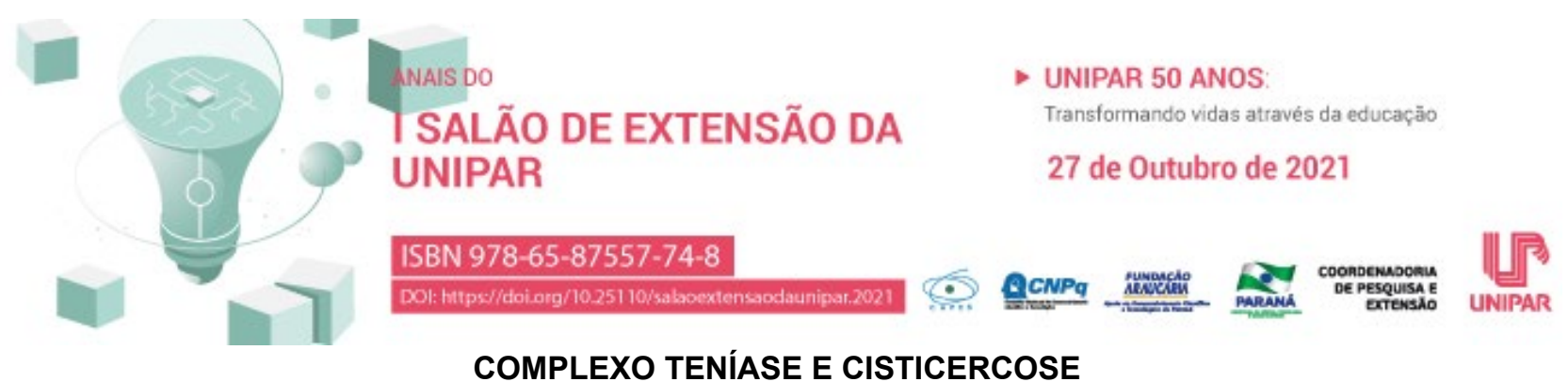

\begin{abstract}
${ }^{1}$ ERIKA DE GOIS FREIRE LOPES, ${ }^{2}$ THAINARA LOURENCO DE VASCONCELLOS, ${ }^{3}$ JULIA VALER GUERRA, ${ }^{4}$ THAIS EDUARDA ADAMCZUK, ${ }^{5}$ LAURA RICARDA EBELING LAUTERT,${ }^{6}$ MAISA STEFFANI ADAMCZUK, ${ }^{7}$ ALLEX VITAL PEREIRA, ${ }^{8}$ EDSON GERONIMO , ${ }^{9}$ GIULIANA ZARDETO SABEC
\end{abstract}

${ }^{1}$ Acadêmica do Curso de Farmácia da UNIPAR

${ }^{2}$ Acadêmica do Curso de Farmácia da UNIPAR

${ }^{3}$ Acadêmica do Curso de Farmácia da UNIPAR

${ }^{4}$ Acadêmica do Curso de Farmácia da UNIPAR

${ }^{5}$ Acadêmica do Curso de Farmácia da UNIPAR

${ }^{6}$ Acadêmico do Curso de Farmácia da UNIPAR

${ }^{7}$ Acadêmico do Curso de Farmácia da UNIPAR

${ }^{8}$ Acadêmico do Curso de Farmácia e do Doutorado Em Ciência Animal Com Ênfase Em Produtos Bioativos da UNIPAR

${ }^{9}$ Docente da UNIPAR

Introdução: As verminoses são doenças frequentes causadas por diferentes tipos de vermes e é considerada um problema de saúde pública. A Taenia solium e a Taenia saginata pertencem à classe Cestoidea, ordem Cyclophillidea, família Taenidae e gênero Taenia. Na forma larvária (Cysticercus cellulosae da T. solium e Cysticercus bovis da $T$. saginata) causam a teníase. Na forma de ovo, a $T$. saginata desenvolve a cisticercose no bovino e a $T$. solium, no suíno ou no homem (MEDEIROS et al., 2008).

Objetivo: O objetivo do presente estudo foi de conscientizar a população sobre as verminoses causadoras da teníase, sua forma de diagnóstico e controle higiênico sanitário.

Resultados e discussões: Neste trabalho realizou-se um levantamento bibliográfico, por meio da base de dados Google acadêmico, entre os anos de 2008 à 2021, buscando ressaltar as principais características destas verminoses, sua epidemiologia, forma de diagnóstico e controle realizado pela indústria de alimentos para segurança dos consumidores. Em humanos a teníase, é também conhecida como solitária, é provocada pela presença da forma adulta da $T$. saginata ou da $T$. solium, que se localizam no seu intestino delgado (MEDEIROS et al., 2008). As verminoses podem ser transmitidas através de alimentos contaminados, frutas e verduras mal lavadas, água contaminada, mãos sujas, objetos contaminados, portanto, um maior cuidado básico de higiene pode evitar a disseminação dessas parasitoses (TOLEDO et al., 2018). A teníase pode causar uma infecção menos grave, havendo sintomas como tonturas, náuseas, astenia, dor abdominal, apetite excessivo e vômito. A cisticercose humana é uma doença mais grave, onde o cisticerco se aloja na região com mais frequência o Sistema Nervoso Central (SNC), podendo alojar-se em várias outras regiões do organismo (MEDEIROS et al., 2008). Estima-se que mais de 70 milhões de pessoas estejam infectadas por $T$. saginata e que até 2,5 milhões possam estar infectadas por $T$. solium no mundo. No Brasil, a cisticercose bovina está presente em todos os estados (FERREIRA; FERREIRA, 2017). Ao suspeitar de teníase, é preciso pesquisar proglotes nas fezes, através da realização do exame laboratorial para posterior tratamento farmacológico (FERREIRA; FERREIRA, 2017), neste sentido, o exame parasitológico de fezes é fundamental para a identificação dos possíveis parasitos intestinais. A inspeção do animal é realizada através da avaliação visual macroscópica de cisticercos nos tecidos e órgãos da carcaça (TOLEDO et al., 2018). A profilaxia do complexo teníase-cisticercose depende de inúmeros fatores combinados, como: a educação sanitária do homem; a detecção e tratamento do indivíduo parasitado; o uso de instalações sanitárias com fossas ou redes de esgoto; ingestão de carnes ou produtos derivados bem cozidos ou assados (FERREIRA; FERREIRA, 2017).

Conclusão: Conclui-se que as medidas de prevenção são de grande importância para interromper a cadeia epidemiológica do complexo teníase-cisticercose. Sendo assim, mais estudos e medidas protetivas devem ser tomadas a fim de alcançarmos a erradicação desta zoonose.

\title{
Referências
}

FERREIRA, Daniela; FERREIRA, Fernanda Lúcia Alves. Teníase e Cisticercose. PUBVET, v. 11, p. 103-206, 2016. MEDEIROS, Fabrícia et al. Complexo teníase-cisticercose. Revista Científica Eletrônica de Medicina Veterinária, v. 11, p. 1679-7353, 2008.

TOLEDO, Rômulo César Clemente et al. complexo teníase/cisticercose: uma revisão. Higiene Alimentar, v. 32, n. 282/283, p. 31-34, 2018. 
- unIPAR 50 anos:

I SALAOO DE EXTENSÃO Transformando vidas atravies da educaģso

DA UNIPAR 


\title{
DE \\ SALÃO DE EXTENSÃO DA Transformando vidas através da educaçăo \\ UNIPAR 27 de Outubro de 2021

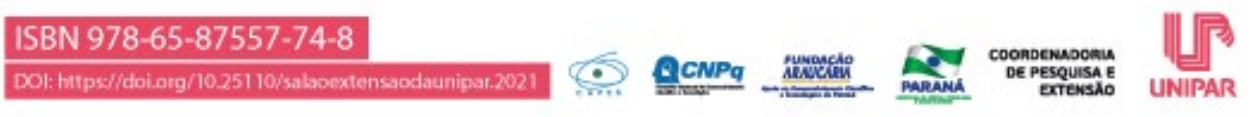 \\ ALTERAÇÕES FÍSICO-QUÍMICAS EM AMOSTRAS DE ÁGUA DE POÇOS E FONTES DE PROPRIEDADES RURAIS DE UM MUNICÍPIO DO SUDOESTE DO PARANÁ
}

\author{
${ }^{1}$ NATIELE CHAVES DA SILVA, ${ }^{2}$ JULIA COMACHIO FAVRETTO, ${ }^{3}$ PRISCILA YANO RUTES, ${ }^{4}$ CASSIANE PARIZOTTO, \\ ${ }^{5}$ VANEZA PAULA POPLAWSKI CARNEIRO, ${ }^{6}$ VOLMIR PITT BENEDETTI
}

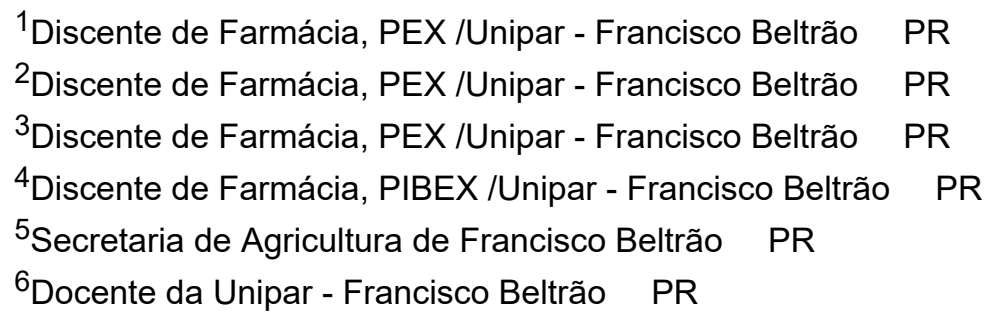

Introdução: O consumo de água é indispensável para que todos os seres vivos tenham uma saúde de qualidade, a ingestão de água de baixa qualidade pode ocasionar diversos malefícios, podendo carregar uma quantidade alta de contaminantes físicoquímicos, acarretando em distúrbios do bem-estar (LEITE et al., 2003). Desta forma é de extrema importância o conhecimento que esta água está devidamente tratada e própria para o consumo humano (SOUZA et al., 2014).

Objetivo: Analisar a qualidade físico-química em amostras de água de poços e fontes de propriedades rurais de um município do sudoeste do Paraná. Para isso foram realizadas análises de 8 (oito) amostras de água de fonte ou poços que eram utilizadas para consumo humano em propriedades rurais do município de Francisco Beltrão PR Foram analisados parâmetros físicoquímico, microbiológico e parasitológico, seguindo as exigências de potabilidade segundo a PORTARIA No 2.914, 12/12/2011 (BRASIL, 2011). Paralelamente, foi aplicado um checklist para avaliar os fatores de risco para a contaminação das águas por agentes químicos ou biológicos.

Resultados: Neste projeto foi observado que das amostras de água analisadas, 100\% estavam em conformidade para os analitos de Amônia (NH3), Ferro (Fe), Manganês (Mn), Sódio (Na), Sulfato (SO4), Zinco (Zn), Cloretos (Cl-), Sulfeto (S2-), Dureza, Sólidos Totais Dissolvidos (STD) e Substâncias Tensoativas que reagem com o Azul de Metileno - Surfactantes. Contudo, constatou-se que $11,1 \%$ das amostras analisadas estavam com os valores de Alumínio (Al), cor e turbidez acima do padronizado e $22,2 \%$ apresentaram alterações de $\mathrm{pH}$. Observou-se neste estudo que alguns analítos estavam levemente alterados como Alumínio (Al), cor, turbidez e pH. O potencial hidrogeniônico $(\mathrm{pH})$ é uma medida que estabelece a condição ácida ou alcalina de uma determinada amostra. É um parâmetro de caráter operacional que deve ser acompanhado para processos de tratamento, não tem risco sanitário associado diretamente à sua medida.

Conclusão: Neste estudo foi observado que para a maior parte dos parâmetros analisados, as amostras estavam em conformidade com os valores de referência segundo estipulados pelos órgãos governamentais. Contudo os analítos que se apresentaram alterados não oferecem riscos ao bem estar da população, portanto, para os quesitos físico-químicos analisados, estas amostras de água estão próprias para o consumo humano.

\section{Referências}

BRASIL. Portaria n. ${ }^{\circ} 2914$, de 12 de dezembro de 2011. Estabelece os procedimentos e responsabilidades relativos ao controle e vigilância da qualidade da água para consumo humano e seu padrão de potabilidade, e dá outras providências. Diário Oficial da União, Brasília, 12 dez., 2011.

LEITE, M. O.; et.al. Controle de qualidade da água em indústrias de alimentos. Leite \& Derivados, v. 69, p.38-45, 2003.

SOUZA. J. R. et.al. A Importância da Qualidade da Água e os seus Múltiplos Usos: Caso Rio Almada, Sul da Bahia, Brasil. REDE - Revista Eletrônica do Prodema. v.8, n.1, p. 26-45, 2014.

I SALÄO DE EXTENSÃO DA UNIPAR

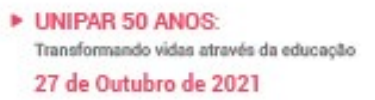

27 de Outubro de 2021
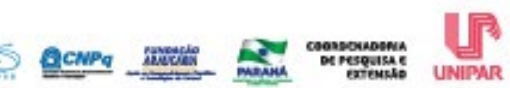


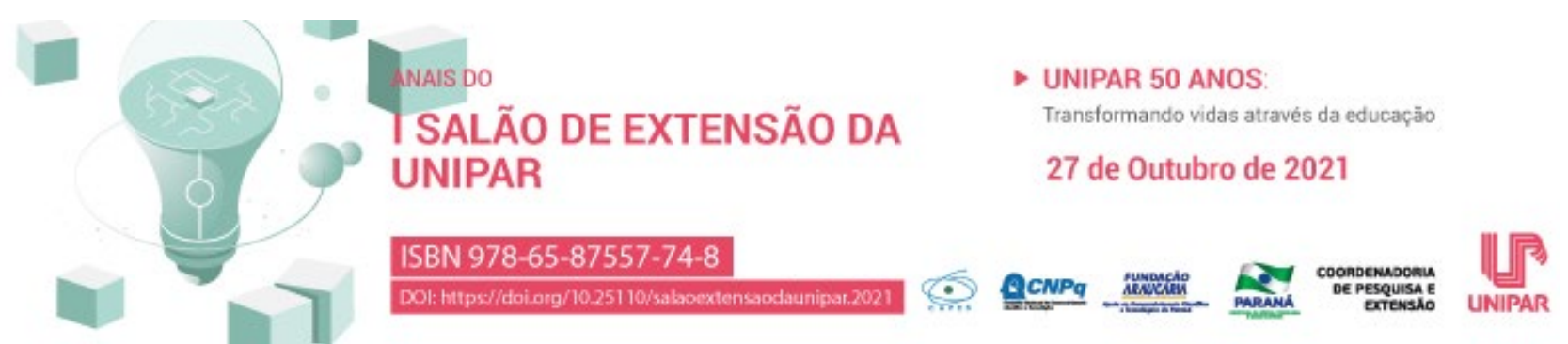

PROJETO DE EXTENSÃO: "FUTSAL NO CAMPUS"

${ }^{1}$ PAULA KAMILA SILVA CIRILO , ${ }^{2}$ ANGELICA SAVIOLI DE FREITAS, ${ }^{3}$ THAIS KAROLYNE VIEIRA CANUTO, ${ }^{4}$ TAISE BRUN FEITOSA, ${ }^{5}$ LARISSA PEREIRA DA CRUZ, ${ }^{6}$ DRIELY URBANO MACKERT, ${ }^{7}$ GABRIEL FAVORETO FRASSON, ${ }^{8}$ GABRIEL FAVORETO FRASSON, ${ }^{9}$ MARCELO FIGUEIRO BALDI

${ }^{1}$ Acadêmica do PEX/UNIPAR

${ }^{2}$ Acadêmica do Curso de EducaÃßÃ£o FÃsica da UNIPAR

${ }^{3}$ Acadêmica do Curso de EducaÃß̃̃̃o FÃsica da UNIPAR

${ }^{4}$ Acadêmica do Curso de EducaÃß̃̃£o FÃsica da UNIPAR

${ }^{5}$ Acadêmica do Curso de EducaÃß̃̃̃o FÃsica da UNIPAR

${ }^{6}$ Acadêmica do Curso de EducaÃßÃ£o FÃsica da UNIPAR

${ }^{7}$ Acadêmico do Curso de EducaÃß̃̃̃o FÃsica da UNIPAR

${ }^{8}$ Acadêmico do Curso de EducaÃß̃̃̃o FÃsica da UNIPAR

${ }^{9}$ Docente da UNIPAR

Introdução: As mudanças sociais e tecnológicas tem promovido diversas transformações que impactam positiva e negativamente a vida de crianças e adolescentes. Entre os aspectos negativos destacam-se, por exemplo, o crescimento dos atrativos tecnológicos tais como celulares, notebooks e laptops os quais tem seduzido crianças e adolescentes transformando as suas brincadeiras, outrora ativas, em momentos, cada vez mais, passivos, implicando na adoção de um estilo de vida sedentário acompanhado de um pobre repertório motor. Paralelamente, observa-se o consumo excessivo de alimentos ultra processados, hipercalóricos e refinados que contribuem para o aumentando da incidência e prevalência de sobrepeso e obesidade nesta fase da vida. Tudo isto tem produzido meninos e meninas com problemas de aceitação, baixa autoestima, isolamento social, baixo limiar de frustração, aumento da provocação no âmbito escolar (bullying) e da intolerância entre os jovens. Neste sentido, o futebol e futsal tornam-se opções para contribuirem no desenvolvimento bio-psico-social de crianças e adolescentes (BALDI, 2014). Uma vez que tratam-se de modalidades ricas do ponto de vista do estimulo fisiológico e motor. Além disso, através da sua prática o professor pode trabalhar, além dos aspectos motores, questões fundamentais do desenvolvimento da criança tais como a autoestima, as amizades, o trabalho em equipe, a cooperação, a união, o respeito, a disciplina e a tolerância, fomentando assim uma experiência esportiva positiva (MARTENS, 2004).

Objetivo: Apresentar o projeto de extensão Futsal no Campus do curso de Educação Física da Universidade Paranaense de Umuarama.

Desenvolvimento: $O$ projeto de extensão Futsal no Campus é na realidade uma escola de futebol e futsal para meninos e meninas com idades entre 8 e 11 anos. As atividades acontecem todas as quartas e sextas feiras das 15:30hs as 16:30hs no ginásio de futsal e no campo de futebol do campus 3 da Unipar de Umuarama. O projeto é coordenado pelo professor mestre Marcelo Figueiró Baldi e conduzido pelos acadêmicos do curso de Educação Física. As atividades propostas alternam entre treinos no Futsal (as quartas feiras) e treinos no futebol de campo (as sextas feiras). Esta alternância entre as modalidades tem como objetivo enriquecem o acervo motor e de experiências tanto dos praticantes quanto dos acadêmicos futuros treinadores de futebol e/ou futsal. O projeto é inteiramente gratuito e atende principalmente crianças da comunidade. Neste sentido, a escola tem como missão contribuir no desenvolvimento bio-psico-social de crianças e adolescentes a partir de uma prática esportiva ética e ajustada aos seus interesses. Por sua vez, tem como visão ser a escola de futebol e futsal referência em Umuarama e região pela excelência do processo de ensino, aprendizagem e treinamento, reconhecida como a melhor opção pelas crianças, famílias e comunidade. Ainda, o projeto tem como princípios norteadores: a ética, a honestidade, o comprometimento, a disciplina, o respeito, a amizade e a união. Por fim, a filosofia de ensino, aprendizagem e treinamento da escola de futebol e futsal da Unipar pauta-se predominantemente em atividades-jogo motivantes e prazerosas que atendam as características e interesses das crianças (GRAÇA, 1998).

Conclusão: $O$ projeto de extensão Futsal no Campus caracteriza-se por ser um espaço de vanguarda aproximando o ensino, a pesquisa e a extensão criando um ambiente positivo de desenvolvimento integral que beneficia tanto as crianças, as famílias, a comunidade, os acadêmicos bem como a instituição.

\section{Referências}

BALDI, M. F. Treinamento tático no futebol: efeito das modificações de jogos reduzidos. 2014. 93 f. Dissertação (Mestrado em 
Educação Física) Universidade Federal de Santa Catarina, 2014.

GRAÇA, A. Os comos e os quandos no ensino dos jogos. In: GRAÇA, A.; OLIVEIRA, J. O ensino dos jogos desportivos. Porto: Rainho \& Neves, 1998, p. 27-34.

MARTENS, R. Successful coaching. $3^{a}$ ed. Estados Unidos da America: Human Kinetics, 2004.

$\begin{array}{ll}\text { Anuis do } & \text { UNIPAR } 50 \text { ANOS: } \\ \text { I SALÄO DE EXTENSÄO } & \text { Tranofonnando vidas atravia da educagto } \\ \text { DA UNIPAR } & 27 \text { de Outubro de } 2021\end{array}$




\title{
LOGÍSTICA REVERSA DE MEDICAMENTOS EM ESTABELECIMENTOS FARMACÊUTICOS COMO PARTE DA EDUCAÇÃO AMBIENTAL
}

\author{
${ }^{1}$ KAUAN APARECIDO DE CARVALHO, ${ }^{2}$ MARCIA MARCONDES VELOSO VENITES, ${ }^{3}$ DEJANIRA ALVES RAPOSO DINELLY, \\ ${ }^{4}$ WELLINGTON FRANCISCO BESCOROVAINE
}

\author{
${ }^{1}$ Acadêmico do curso de farmácia UNIPAR \\ ${ }^{2}$ Acadêmica do Curso de FarmÃ $i c i a$ da UNIPAR

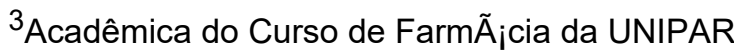 \\ ${ }^{4}$ Docente da UNIPAR
}

Introdução: A prática de disposição de resíduos em locais inadequados tem gerado sérios problemas ambientais. Alvarenga e Nicoletti (2010) relatam que, nesse panorama, também está o descarte de medicamentos, que pode abalar diretamente o ecossistema, ocasionando riscos à saúde, contaminação do ambiente e até mesmo alteração do aquecimento global (CALISTO; SILVA, 2016). Nessa problemática, está a logística reversa, a qual caracteriza-se pelo retorno de bens após a venda ou consumo ao ciclo de negócios ou de produção, por meio dos canais de distribuição reversos. Em uma definição mais atualizada, essa prática envolve também redução na fonte, reciclagem, reuso e substituição de materiais, entre outros aspectos (LEITE, 2002).

Objetivo: Diante do exposto, o objetivo do presente trabalho é analisar a relação entre a logística reversa de fármacos e a conscientização ambiental.

Desenvolvimento: Artigo de revisão bibliográfica, desenvolvido durante segundo bimestre na Universidade Paranaense UNIPAR campus Toledo, no decorrer das aulas da disciplina Responsabilidade Social e Sustentabilidade ministrada pelo professor Wellington Francisco Bescorovaine. Estudos recentes, como o de Falqueto e Kligerman (2012), apontam para um descarte de aproximadamente $20 \%$ dos medicamentos em locais impróprios, tais como lixo comum e redes de esgoto sanitário. Entre eles estão os antibióticos, drogas que são apenas parcialmente removidas nos processos de tratamento de esgoto, quando existentes. Outras pesquisas, como Ternesa et al. (1999) e Harris, Cormican e Cummins (2012), indicam a presença de resíduos de fármacos como estrogênio, estradiol e ciprofloxacina nos esgotos domésticos brasileiros e seus efluentes. Diante do exposto, fica clara a necessidade e importância de se promover a educação ambiental quanto à correta disposição final desses produtos (PINHEIRO et al., 2018). Ademais, a logística reversa exerce importante papel no futuro da indústria e do comércio mundial, uma vez que é esperado uma crescente maior adesão das empresas a essa prática. As farmácias devem criar regras específicas de devolução de produtos farmacêuticos por parte dos clientes e proporcionar a destinação adequada aos mesmos (FIALHO; QUENTAL; GADELHA, 2001). Silva et al. (2014) analisou a prática ou não da logística reversa em 50 farmácias e drogarias do estado do Rio Grande do Sul e obteve o resultado de que quase metade dos locais (48\%) não realizava a coleta dos resíduos dos consumidores, somente destinava os resíduos produzidos no próprio estabelecimento. Ademais, $80 \%$ das farmácias entrevistadas desconheciam o tratamento e destinação dados aos fármacos após o recolhimento pela empresa responsável. Após a Lei n. 9.974/2000, a qual estabelece sanções administrativas, penais e civis ao produtor, comerciante e profissional que não realizar a logística reversa de maneira adequada, diversos setores aprenderam a explorar as potencialidades e a aproveitar os benefícios dessa ferramenta (HEMPE; HEMPE, 2015).

Conclusão: Foi possível observar em algumas situações relatadas na pesquisa bibliográfica que a logística reversa, quando realizada nos estabelecimentos, gera conscientização ambiental, uma vez que uma parte das pessoas envolvidas entendem a importância da sua realização, mas ainda não proporciona profundos conhecimentos dos processos e atividades desenvolvidas (como a destinação final dos resíduos após serem encaminhados às empresas responsáveis).

\section{Referências}

ALVARENGA, L. S. V.; NICOLETTI, M. A. Descarte doméstico de medicamnetos e algumas considerações sobre o impacto ambiental decorrente. Revista Saúde, São Paulo, p. 34-39, 2010.

CALISTO, L. B.; SILVA, J. H. A disposição final dos resíduos de medicamentos: Um estudo na empresa Ecobar Meio Ambiente. Qualia: a ciência em movimento, v. 2, n.2, p.77-93, 2016.

FALQUETO, E.; KLIGERMAN, D. C. Análise normativa para descarte de resíduos de medicamentos: estudo de caso da região sudeste do Brasil. Revista de Direito Sanitário, São Paulo, v. 13, n. 2, p. 10-23, 2012.

FIALHO, B. C.; QUENTAL, C.; GADELHA, C. A. G. Public Roles in the Pharmaceutical Sector. Fundação Oswaldo Cruz, Rio de Janeiro, 2001. 
HARRIS, S. J.; CORMICAN, M.; CUMMINS, E. Antimicrobial Residues and Antimicrobial-Resistant Bacteria: Impact on the Microbial Environment and Risk to Human Health. A Review, Human and Ecological Risk Assessment, v. 18, n. 4, p. 767-809, 2012.

HEMPE, L. J.; HEMPE, C. A Logística Reversa à Serviço do Desenvolvimento Sustentável e o Papel da Escola com Relação à Educação Ambiental. Revista Monografias Ambientais, v. 14, p. 17-25, 2015.

LEITE, P. R. Logística reversa: nova área da logística empresarial. Revista Tecnologística, São Paulo, v. 78, p. 102-109, 2002.

PINHEIRO, V. M. F.; LAMEIRA, J.; SOUZA, G. R. L. C.; MACEDO, J. C. Logística reversa de medicamentos: uma proposta ambiental e políticas públicas. In: 15o Congresso Nacional de Meio Ambiente, Poços de Caldas, Instituto Federal de Educação, Ciência e Tecnologia IFMG, 2018. Anais do evento.

SILVA, A. L. E.; MORAES, J. A. R.; REHBEIN, A.; BENCKE, D.; GERHARD, G. Posicionamento das farmácias e a logística reversa no controle dos medicamentos em desuso. Revista Eletrônica em Gestão, Educação e Tecnologia Ambiental, v. 18, n. 1, p. 57-65, 2014.

TERNESA, T.A.; STUMPFA, U.M.; MUELLERA, J. et al. ,Behavior and occurrence of estrogens in municipal sewage treatment plants: Investigations in Germany, Canada and Brazil. The Science of the Total Environment, 225 v., p. 81-90, 1999.

ANA1s00

I SALĀO DE EXTENSÃO

DA UNIPAR
- UNIPAR 50 ANOS:

Traneformando vides atrewés da educaçso

27 de Outubro de 2021

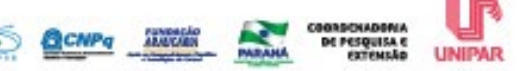




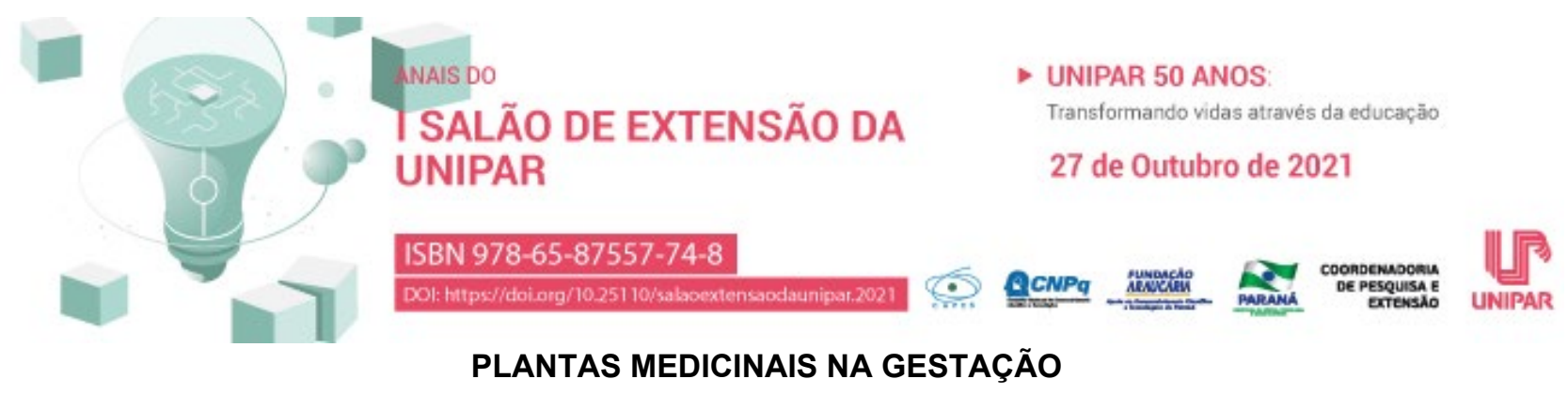

${ }^{1}$ CAMILA GONCALVES DE BARROS, ${ }^{2}$ MARIANA RAFAELLY PIGOZZO RAMOS, ${ }^{3}$ JULIANA PELISSARI MARCHI, ${ }^{4}$ LUANA PILAR GRONDONA, ${ }^{5}$ ALESSANDRA TOBIAS DOS SANTOS, ${ }^{6}$ SIMONE CASTAGNA ANGELIM COSTA, ${ }^{7}$ ROMIR RODRIGUES, ${ }^{8}$ PAULO HENRIQUE DA SILVA PEREIRA, ${ }^{9}$ SAMANTHA WIETZIKOSKI SATO, ${ }^{10}$ RAQUEL COSTA MACHADO

${ }^{1}$ Acadêmica do Curso de Estética e Cosmética - PEX - UNIPAR

${ }^{2}$ Acadêmica do Curso de Estetica e Cosmetica - PEX - UNIPAR

${ }^{3}$ Docente da UNIPAR

${ }^{4}$ Acadêmica do Curso de Estetica e Cosmetica - PEX UNIPAR

${ }^{5}$ Acadêmica do Curso de Estetica e Cosmetica - PEX UNIPAR

${ }^{6}$ Docente da UNIPAR

${ }^{7}$ Docente da UNIPAR

${ }^{8}$ Docente da UNIPAR

${ }^{9}$ Docente da UNIPAR

${ }^{10}$ Docente da UNIPAR

Introdução: As plantas medicinais são definidas como espécies vegetais que apresentam potencial de cura e/ou alívio de sintomas quando utilizadas (MACHADO; DÓRIA, 2017). No Brasil, as plantas medicinais têm sido utilizadas, para fins terapêuticos como uma terapia alternativa, de acordo com os conhecimentos populares, passados de geração a geração, por muitos anos (CAVAGLIER; MESSEDER, 2014). Por muito tempo, por serem naturais, as plantas foram classificadas sem efeitos colaterais ou com toxicidade. No entanto, considerando a diversidade das espécies e avanços em pesquisas, sabe-se que a utilização das espécies vegetais consideradas medicinais deve ser utilizada com cautela, principalmente por gestantes, pois muitas destas espécies possuem agente teratogênico e abortivo quando utilizadas no período gestacional (OLIVEIRA et al, 2013).

Objetivo: Relatar o resultado de uma das atividades realizadas no Programa de Extensão Plantas Medicinais e Aromáticas, sua importância e benefícios para saúde, bem como proporcionar conhecimento das plantas medicinais e seu uso por gestantes.

Conclusão: Diante do exposto, foi possível observar que de acordo com a literatura cientifica, ainda existe certo desconhecimento, por grande parte da população, sobre os riscos que o uso das plantas medicinais pode proporcionar durante a gestação e lactação. Desta forma, conclui-se que ações de cunho educativo, devem ser realizadas com mais frequência, esclarecendo a população sobre o uso seguro de plantas medicinais no período gestacional e de lactação.Resultados: Através do levantamento realizado, observamos que as gestantes fazem uso frequente das plantas medicinais para aliviar desconfortos e sintomas que surgem no período gestacional, como: enjoo, náuseas, flatulências, constipação, cólica, pirose e edema (SILVA, 2014). Porém, muitos desconhecem, mas existem estudos que revelam que algumas substâncias e compostos de origem vegetal são embriotóxicos e teratogênicos (ANHESI et al., 2016). As plantas possuem alguns compostos, que quando ingeridos em grandes quantidades, podem atravessar a placenta e causar danos ao feto, à gestante, como aborto, má formação e toxicidade materna, sendo os efeitos teratogênicos, maior no início da gestação, correspondente ao período da embriogênese, considerado de maior risco a gestante e seu concepto, pois estará ocorrendo a diferenciação dos tecidos e a organogênese (RODRIGUES et al., 2011). Conforme levantamento realizado por Anhesi et al. (2016), as plantas mais utilizadas por gestantes são: camomila, contraindicada por possui ação abortiva e relaxante uterina; hortelã, também com ação abortiva; melissa; boldo, apresenta ação abortiva e pode acarretar redução do peso fetal; sene, também apresenta ação abortiva e diarreia na lactante; guaco; carqueja e alcachofra também são contraindicadas, no período gestacional (BERGSTEN-MENDES, 2002).

\section{Referências}

ANHESI, N.; ROSA, L. G. da; PEREIRA, A. C.; MELO, A. Uso de plantas medicinais na gestação. RETEC, Ourinhos, v. 9, n. 2, p. 101-109, jul./dez., 2016.

BERGSTEN-MENDES, G. Prevalência do uso de medicamentos na gravidez: uma abordagem farmacoepidemiológica. Rev Saúde Pública 36(2):205-212, 2002.

CAVAGLIER, M. C. dos S.; MESSEDER, J. C. Plantas Medicinais no Ensino de Química e Biologia: Propostas Interdisciplinares na Educação de Jovens e Adultos. Revista Brasileira de Pesquisa em Educação em Ciências, vol.14, n.1, 2014. 
MACHADO, T. T.; DÓRIA, K. M. A. B.V. S. Principais ervas medicinais utilizadas nos Quilombos do Camburi e da Caçandoca, Ubatuba SP. Unisanta Revista Bioscience, v. 6, n. 2, p. 145-152, 2017.

OLIVEIRA, E. P.; BARBOSA, I. T. S.; OlIVEIRA, M.; PEREIRA, M. M.; SILVA, B. A.; CAVALCANTE, F. A. Uso racional de plantas medicinais na gravidez por moradoras do Bairro Cristo João Pessoa PB. In: ENCONTRO DE EXTENSÃO (ENEX), 14., ENCONTRO DE INICIAÇÃO À DOCÊNCIA, 15., A construção do conhecimento no cotidiano acadêmico: práticas e reflexões. Universidade Federal da Paraíba, 2013.

RODRIGUES, H. G.; MEIRELES, C. G.; LIMA, J. T. S.; TOLEDO, G. P.; CARDOSO, J. L.; GOMES, S. L. Efeito embriotóxico, teratogênico e abortivo de plantas medicinais. Revista Brasileira de Plantas Medicinais, Botucatu, v. 13, n. 3, p. 359-366, 2011. SILVA, L. S. Utilização de plantas medicinais e seus riscos na gestação: orientação do enfermeiro quanto o uso indiscriminado. 2014. 26 p. Trabalho (Conclusão de Curso de Graduação em Enfermagem) Universidade Estadual da Paraíba, Campina Grande, PB, 2014.

I SALÃOO DE EXTENSÃO

DA UNIPAR
- UNIPAR 50 anOS:

Transformando vides atraves da educagsto

27 de Outubro de 2021
(5) AcNPG

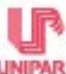




\title{
FATORES DE RISCOS RELACIONADOS A CONTAMINAÇÃO DA ÁGUA NO MEIO RURAL DO MUNICÍPIO DE FRANCISCO BELTRÃO PR
}

\author{
${ }^{1}$ PRISCILA YANO RUTES, ${ }^{2}$ CASSIANE PARIZOTTO, ${ }^{3}$ JULIA COMACHIO FAVRETTO, ${ }^{4}$ NATIELE CHAVES DA SILVA, \\ ${ }^{5}$ ARNALDO RAFAEL DONATTI, ${ }^{6}$ VOLMIR PITT BENEDETTI
}

${ }^{1}$ Discente de Farmácia, PEX /Unipar - Francisco Beltrão PR

${ }^{2}$ Discente de Farmácia, PIBEX /Unipar - Francisco Beltrão PR

${ }^{3}$ Discente de Farmácia, PEX /Unipar - Francisco Beltrão PR

${ }^{4}$ Discente de Farmácia, PEX/Unipar - Francisco Beltrão PR

${ }^{5}$ Departamento de Vigilância em Saúde Secretaria municipal de Saúde - Francisco Beltrão PR

${ }^{6}$ Docente da Unipar - Francisco Beltrão PR

Introdução: A água de consumo humano é indispensável na manutenção da vida (DAHI, 1992), sendo primordial a avaliação das possibilidades de contaminação na inadequação do armazenamento ou conservação da água (STUKEL et al, 1990). A inexistência dos fatores de proteção que são de grande importância para a preservação da qualidade de água no meio rural evidencia uma preocupação no risco de contaminação nessa água (KRAVITZ et al, 1999). Dados indicam que 748 milhões de pessoas carecem de uma fonte segura e sustentável de água potável e 2,5 bilhões não possuem acesso às instalações sanitárias adequadas (OMS/UNICEF, 2014). As principais fontes de abastecimento de água nos meios rurais normalmente são poços rasos e nascentes, que são fontes suscetíveis a contaminação por agentes microbiológicos e parasitológicos, podendo causar surtos de doenças de veiculação hídrica (FEWTRELL et al, 1998).

Objetivo: Avaliar e identificar os principais fatores de riscos que podem levar a uma possível contaminação das águas das zonas rurais da cidade de Francisco Beltrão.

Metodologia: Para isso foram realizadas análises de 8 (oito) amostras de água de fonte ou poços que eram utilizadas para consumo humano em propriedades rurais do município de Francisco Beltrão PR. Foram analisados parâmetros físico-químico, microbiológico e parasitológico, seguindo as exigências de potabilidade segundo a portaria № 2.914, 12/12/2011 do Ministério da Saúde (BRASIL, 2011). Paralelamente, foi aplicado um checklist para avaliar os fatores de risco para a contaminação das águas por agentes químicos ou biológicos. Para a determinação dos parâmetros microbiológicos foi utilizada a metodologia do meio de cultura Colilert@. Os parâmetros físico-químicos foram realizados segundo o que está descrito na portaria, e para as análises parasitológicas será empregado a metodologia preconizada por Faust e colaboradores.

Resultados: Foram analisados como possíveis fatores de risco: focos de contaminação no entorno de 15 metros, tipo de proteção do poço, área de alagamento próxima ao poço, nível de lençol de água abaixo de três metros da boca do poço, necessidade de manutenção da estrutura de extração, informações sobre a qualidade e controle da qualidade da água. Outro fator de risco avaliado foram as condições de higiene e conservação dos reservatórios de água dos moradores do meio rural. No período foram avaliados um total de 8 poços ou nascentes, dentre elas $4(50 \%)$ possuíam área de alagamento próxima, 8 (100\%) com profundidade de menos de 3 metros escavados, $6(75 \%)$ não realizavam tratamento e análise da água, $5(62,5 \%)$ com ausência de conservação e higienização e $5(62,5 \%)$ com falta de manutenção da estrutura.

Discussão: Os fatores de risco avaliados nesta pesquisa seguem o roteiro de inspeção da Secretaria de Vigilância em SaúdeSVS, do Ministério da Saúde (BRASIL, 2005), mediante a este protocolo, foi possível evidenciar quanto a identificação dos fatores de risco de contaminação da água o resultado de $100 \%$ das fontes ou poços não possuírem mais de 3 metros escavados. Há de destacar também, quanto a falta de manutenção da estrutura, e a não realização do tratamento e análise de água, coincidindo com os achados do programa de saneamento da água de poços rasos de escolas públicas rurais do município de Ibiúna-SP, que relatou que $92 \%$ dos poços estavam em condições insatisfatórias de higiene e conservação e $100 \%$ dos poços não possuíam manutenção e controle da qualidade da água. Estes resultados mostram o quanto ainda existe de carência em informações e ações para a resolução dos principais fatores de risco de contaminação da água.

Conclusão: Diante dos dados observados, pode-se concluir que os poços e fontes de onde ocorre extração de água para consumo humano, precisam de melhorias, pois na maioria das amostras analisadas observou-se a presença de algum fator que pode representar um risco para a contaminação destas águas. Neste sentido medidas preventivas, visando a preservação e o tratamento da água utilizada, são necessários, para diminuir o risco da ocorrência de enfermidades de veiculação hídrica. 
vigilância da qualidade da água para consumo humano e seu padrão de potabilidade, e dá outras providências. Diário Oficial da União, Brasília, 12 dez., 2011.

DAHI, E. Water Supply in Developing Countries: Problems and Solutions. Lyngby: Eds. Technical, University of Denmark, 1992.

FEWTRELL L, KAY D, GODFREE A. The microbiological qualite of private water supplies. J Ciwen. p:98-100. 1998:

KRAVITZ JD, NYAPHUSI M, MANDEL R, PETERSEN E. Quantitative bacterial examination of domestic water supplies in Lesotho Highlands: water quality, sanitation and vilage health. Bul World Health Organ. v.77, p:829-36, 1999.

OMS/UNICEF. Progress on sanitation and drinking-water: 2014 Update. Geneva/New York: World Health Organization/United Nations Children's Fund. 2014. 76p.

STUKEL TA, et al. A longitudinal study of rainfall and coliform contamination in small community drinking water supplies. Environ Sci Technol. v. 24, p:571-5, 1990.

\section{SALĂO DE EXTENSÃO \\ DA UNIPAR}

- UNIPAR 50 anOS:

Traneformando vidas atraves da educaģ⿻

27 de Outubro de 2021

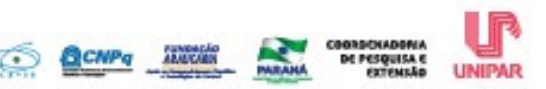




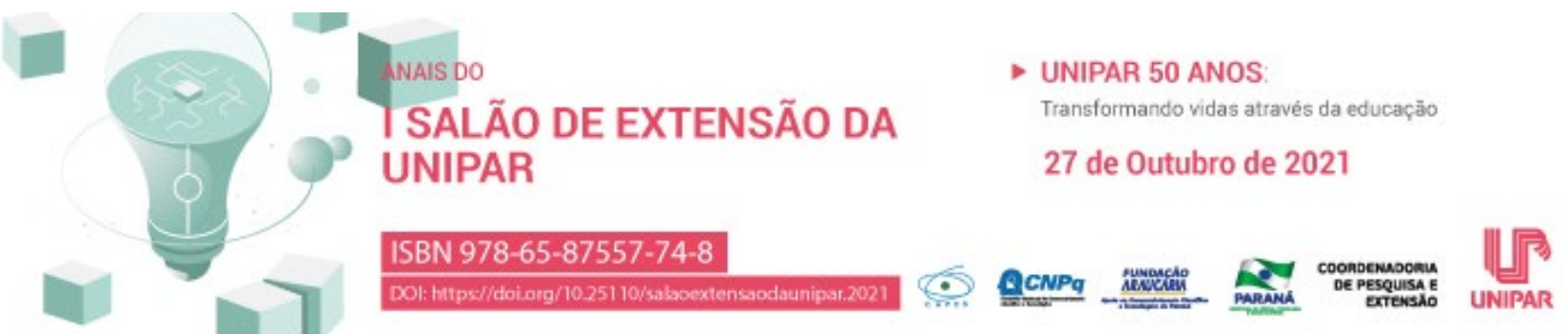 \\ VACINAÇÃO: ESTRATÉGIAS DE PROMOÇÃO DA COBERTURA VACINAL
}

\section{${ }^{1}$ ANDERSON CLAYTON DE AGUIAR, ${ }^{2}$ KATIA BIAGIO FONTES}

\author{
${ }^{1_{1}}$ Acadêmico do Curso de Enfermagem da UNIPAR \\ ${ }^{2}$ Docente da UNIPAR
}

Introdução: Em meados do século XX, o Brasil ainda lutava com a falta de saneamento básico e das epidemias em virtude das péssimas condições de higiene das cidades. Isso resultou num alarmante crescimento de doenças como: febre amarela, varíola e peste. Contudo, o médico sanitarista Oswaldo Cruz, trouxe medidas para a estruturação de um sistema de saúde que traria benefícios aos usuários e um controle sobre as epidemias, entre elas a vacinação (PORTO, 2021). Observada pelos programas nacionais, houve uma melhoria na cobertura nacional de vacinações no decorrer dos anos, porém, vários fatores contribuíram para a não adesão da população e desconfiança da eficácia de várias vacinas, entre eles: baixa renda, residências rurais, baixa ou falta de escolaridade, desconhecimento sobre as doenças, má informação acerca das vacinas, entre outros (SILVA et al., 1999). Neste sentido, a atuação dos profissionais da atenção primária em saúde, tem contribuído com um papel fundamental para a promoção, controle e cobertura vacinal (RAMOS et al., 2010).

Objetivo: Identificar na literatura científica as principais estratégias de promoção da cobertura vacinal pelos profissionais de saúde.

Resultados: O acesso à informação baseadas em evidências, apresentar a população os benefícios da vacinação, utilização de mídias eletrônicas aumentando a visibilidade das campanhas, busca ativa da população alvo, ampliação dos horários de atendimentos nas unidades básicas, além de treinamentos e capacitações para a equipe de profissionais de saúde, tem sido apresentado como estratégias de promoção a cobertura vacinal DOMINGUES et al., 2019). Estratégias essas que visam reeducar a população, fazendo com que aumente a adesão da população à vacinação (LEMES, 2014).

Conclusão: Pode-se concluir que as principais estratégias identificadas na literatura de promoção a cobertura vacinal pelos profissionais de saúde foram o acesso à informação, utilização de mídias eletrônicas nas campanhas, busca ativa, ampliação dos horários de atendimentos, treinamentos e capacitações dos profissionais de saúde.

\section{Referências}

PORTO, Mayla Yara. Uma revolta popular contra a vacinação. Universidade Estadual de Campinas, v. 55, p. 53-54, 2003. Disponível em: http://cienciaecultura.bvs.br/scielo.php?pid=S0009-67252003000100032\&script=sci_arttext\&tlng=pt. Acesso em: 05 set. 2021.

SILVA, Antônio Augusto Moura da Silva et al. Cobertura vacinal e fatores de risco associados à não-vacinação em localidade urbana do nordeste brasileiro. Revista de Saúde Pública, v. 33. n. 2 p. 3-5, 1999. Disponível em: https://www.scielo.br/j/rsp/a/jVGX5Y7HQyWbtw8CNWYzYYC/abstract/?lang=pt\&format=html . Acesso em: 04 set. 2021.

RAMOS, Camilo Ferreira et al. Cumprimento do calendário vacinal infantil na unidade de saúde da família. Revista PanAmericana de Saúde, v. 1. n. 2. p. 55-60, 2010. Disponível em: http://scielo.iec.gov.br/scielo.php?pid=S2176$62232010000200006 \&$ script=sci_arttext\&tIng=es. Acesso em: 06 set. 2021.

DOMINGUES, Carla Magda Allan Santos et al. Vacina Brasil e estratégias de formação e desenvolvimento em imunizações. Epidemol. Serv. Saúde., v. 2. p. 2, 2019. Disponível em: https://www.scielosp.org/pdf/ress/2019.v28n2/e20190223/pt. Acesso em: 09 set. 2021.

LEMES, Paola Fernanda. Propostas de ações a serem realizadas pela equipe de enfermagem para o cumprimento do calendário vacinal pediátrico. Orientador: Virgínia Resende Silva Weffort. 2014. 28 f. Trabalho de Conclusão de Curso. (Especialização em Estratégia Saúde da Família). Universidade Federal do Triângulo Mineiro, Minas Gerais, Uberaba, 2014.

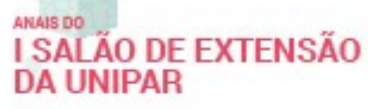

I SALÃO DE EXTENSÃO DA UNIPAR

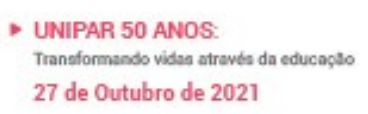

Transformando vidas atrevéa da educagto

27 de Outubro de 202

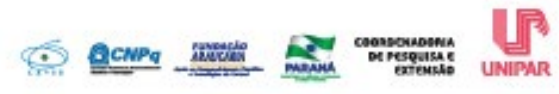




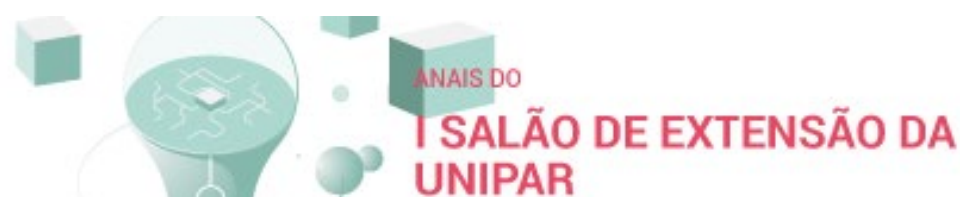 \\ - UNIPAR 50 ANOS: \\ Transformando vidas através da educação \\ 27 de Outubro de 2021 \\ ISBN 978-65-87557-74-8 \\ DOl: hitps//doiong/10.25110/saboextensadaunipar.2021

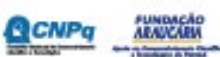

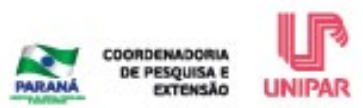 \\ EDUCAÇÃO NO TRÂNSITO: COMPROMISSO SOCIAL COM O OBJETIVO DE PREVINIR ACIDENTES E PROMOVER A CIDADANIA
}

\author{
${ }^{1}$ DANIELA ARAUJO BARRETO, ${ }^{2}$ MARIA ADELAIDE PESSINI
}

${ }^{1}$ Acadêmica do curso de Psicologia Unipar

${ }^{2}$ Docente da UNIPAR

Introdução: A atividade apresenta de forma sucinta o projeto de extensão universitária intitulado: Educação e saúde no trânsito promovendo cidadania e qualidade de vida. O projeto se justifica, pois o trânsito é formado por sub sistemas: homem, via e veículo e o acidente de trânsito é resultado de um processo no qual se encadeiam diversos eventos, condições e condutas. Segundo Ordoñez, (2005), no mundo atual, a adaptação às novas exigências é uma das características mais relevantes para a vida em sociedade. Cada vez mais a escola tem assumido um papel social que busca formar cidadãos aptos a viver em comunidade. A educação para o trânsito é, em seu conjunto, uma tarefa de todos, posto que a criança está imersa numa família desde que nasce. Seu principal modelo são seus pais, passando posteriormente a um sistema educativo, no qual a unidade mínima é a sala de aula, sendo o professor seu principal modelo de comportamento, e logo seus pares, colegas e demais professores (HOFFMANN; CRUZ; ALCHIERI, 2003). São beneficiários, alunos, pais e professores das escolas da rede pública e/ou privada da cidade de Umuarama/Pr e região, matriculados no ensino fundamental, preferencialmente nas séries iniciais.

Objetivo: Desenvolver ações integradas no contexto da educação, com os diversos segmentos, visando a aprendizagem, a informação e a conscientização de alunos, pais e professores para que diminua os acidentes de trânsito.

Resultados: Até o momento, realizou-se revisões teóricas sobre a temática, pesquisas no Google sobre ações desta natureza aos nossos beneficiários, e o conhecimento dos resultados destas ações. Está sendo criado recursos para a divulgação das ações aos beneficiários e a as intervenções, utilizando-se das ferramentas do Google. Pretende-se intervir por meio cartilhas, áudios/podcasts, atividades escolares aos alunos, tudo de forma online.

Conclusão: Considera-se fundamental, propiciar aos acadêmicos envolvidos, maior conhecimento teórico e prático no campo da psicologia do trânsito, e o reconhecimento do trabalho multi e interprofissional. E aos beneficiários, a ampliação do repertório comportamental seguro no trânsito, maior consciência de que o trânsito é um espaço de convivência social. A educação para o trânsito, trabalhando de forma multidisciplinar, permite uma maior e mais profunda reflexão de toda a comunidade escolar (alunos, pais e professores), acerca das imprudências cometidas no trânsito por motoristas e pedestres.

\section{Referências}

ORDOÑEZ, V. M. A educação fundamental no século XXI, In: DELORS, J. Educação para o século XXI. Porto Alegre: Artmed, 2005. p. 155-159.

HOFFMANN, M. H.; CRUZ, R. M.; ALCHIERI, J. C. Comportamento humano no trânsito. São Paulo: Casa do Psicólogo, 2003.

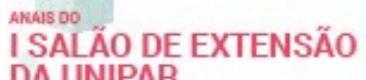

DA UNIPAR

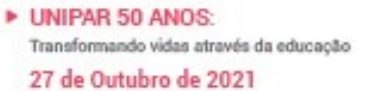

Transformando vides atraves da educagto

27 de Outubro de 2021

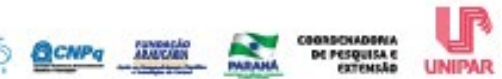




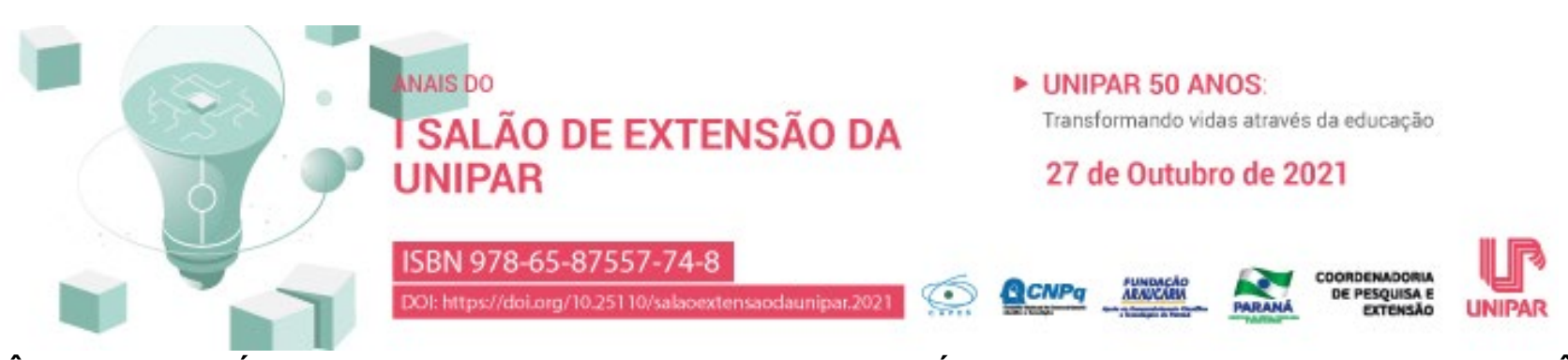

\title{
IMPORTÂNCIA DO ESTÁGIO SUPERVISIONADO NO CENTRO DE ESTÉTICA ESCOLA: UM RELATO DE EXPERIÊNCIA
}

\author{
${ }^{1}$ AIANE DE SOUZA DE OLIVEIRA, ${ }^{2}$ GIOVANA MIOTO DE MOURA, ${ }^{3}$ MARIANA BARBOSA REIS, ${ }^{4}$ PAMELA BEATRIZ BORGES \\ FERREIRA RIBEIRO, ${ }^{5}$ JULIANA PELISSARI MARCHI, ${ }^{6}$ EDINEIA SOARES LANGE, ${ }^{7}$ DIESSICA GUIMARAES DA CUNHA, \\ ${ }^{8}$ SIMONE CASTAGNA ANGELIM COSTA, ${ }^{9}$ NAYARA PATRICIA PEREIRA DE LIMA, ${ }^{10}$ CRISTIANE MOSER, ${ }^{11}$ RAQUEL \\ COSTA MACHADO
}

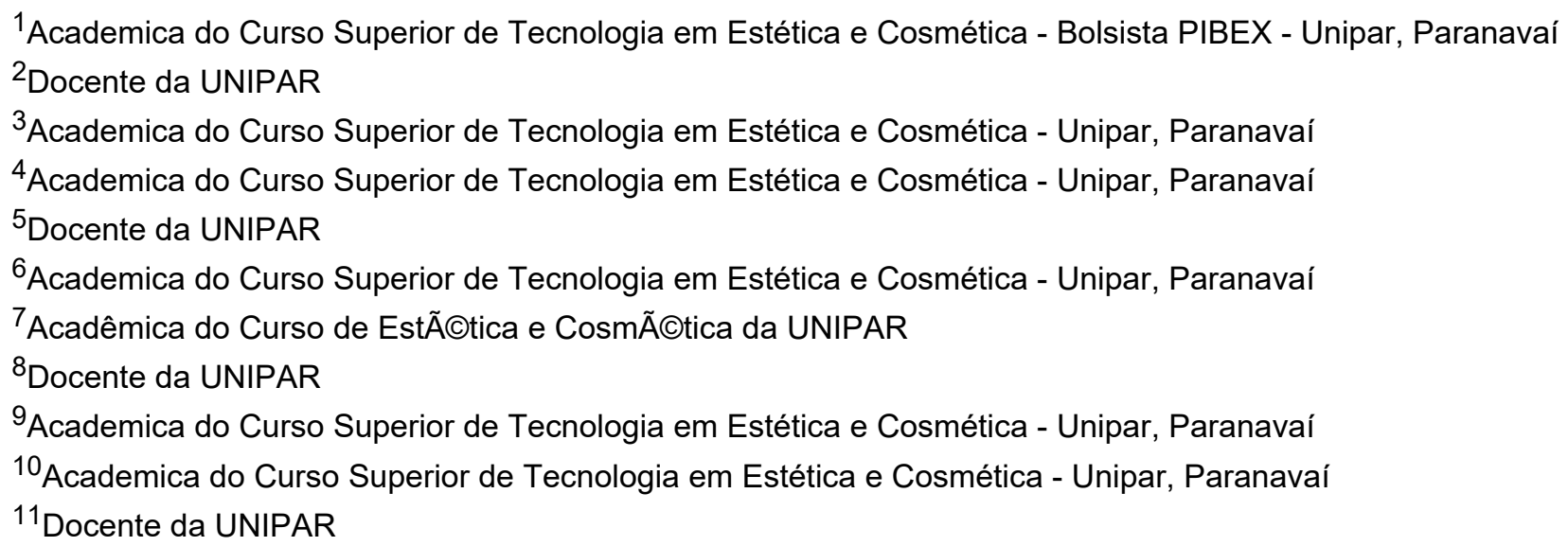

Introdução: O estágio supervisionado curricular oportuniza ao acadêmico a experiência em compreender a teoria e a prática ensinada em sala de aula, e fazer uma relação entre essa teoria e a prática (desenvolvendo as habilidades inerentes da profissão), conhecer a realidade de sua profissão, vivenciando momentos reais do cotidiano do seu trabalho (MAFUANI, 2011). Bianchi et al. (2005) vão além e relatam que esta etapa da formação acadêmica, é uma experiência do qual o acadêmico também mostra sua criatividade, independência e caráter. Diante do contexto apresentado, o Centro de Estética Escola da Universidade Paranaense UNIPAR é um ambiente especializado que proporciona aos acadêmicos do Curso Superior de Tecnologia em Estética e Cosmética, a vivência prática do profissional da área, em todas as suas especificidades que o mercado de trabalho exige para sua atuação profissional.

Objetivo: Relatar a experiência do estágio desenvolvido, no Centro de Estética e Cosmética Escola da UNIPAR e demonstrar sua importância na formação acadêmica.

Resultados: O contato com a comunidade, através do Programa Institucional Centro de Estética Escola, permite que os acadêmicos realizem o Estágio Supervisionado, oportunizando o crescimento pessoal e profissional, sendo um importante elo de integração entre universidade, escola e comunidade (FILHO, 2010). O objetivo do Estágio Supervisionado é proporcionar ao aluno a oportunidade de aplicar seus conhecimentos acadêmicos em situações da prática profissional, criando a possibilidade do exercício de suas habilidades. Espera-se que, com isso, que o aluno tenha a opção de incorporar atitudes práticas e adquirir uma visão crítica de sua área de atuação profissional (OLIVEIRA; CUNHA, 2006). O estágio, obrigatório ou não, em um ambiente especializado, é uma oportunidade de suma importância para acadêmicos de qualquer segmento educacional (AUER, 2019). De acordo com o relato dos acadêmicos participantes deste Programa Institucional, o estágio serviu como incentivo e ajudou a compreender melhor o curso, colaborou para ter mais responsabilidade com as atividades da profissão, além de despertar maior interesse em áreas especificas da estética. Com a orientação e auxilio do professor supervisor e coordenador do programa, tem facilitado o aprendizado, realizado de forma dinâmica, aprendemos de forma clara e objetiva a colocar os ensinamentos da sala de aula e laboratórios em prática propriamente dita.

Conclusão: Conclui-se que as atividades desenvolvidas no Programa Institucional Centro de Estética Escola, são de suma importância para o desenvolvimento acadêmico, profissional e pessoal. Proporciona uma vivência impar que deveria ser mais explorada, pois o ambiente propicia realização de outros estudos e pesquisas importantes para a carreira profissional do Tecnólogo em Estética.

\section{Referências}

AUER, E. Q. A importância da realização do estágio supervisionado no curso técnico em mecânica. Revista Ifes Ciência Instituto Federal do Espirito Santo, vol.5, n. 2, p. 163-174, 2019.

BIANCHI, A. C. M., et al. Orientações para o Estágio em Licenciatura. São Paulo: Pioneira Thomson Learning, 2005. 
FILHO, A. P. O. Estágio Supervisionado e sua importância na formação docente. Revista P@rtes. 2010. Disponível em: http://www.partes.com.br/educacao/estagiosupervisionado.asp. Acesso em: 07/09/2021.

MAFUANI, F. Estágio e sua importância para a formação do universitário. Instituto de ensino superior de Bauru, 2011. Disponível em http://www.iesbpreve.com.br/base.asp?pag=noticiaintegra.asp\&IDNoticia=1259. Acesso em: 05/09/2021.

OLIVEIRA, E.S.G.; CUNHA, V.L. O estágio Supervisionado na formação continuada docente à distância: desafios a vencer e construção de novas subjetividades. Revista de Educación a Distancia. ano V, n. 14, 2006. Disponível em http://www.um.es/ead/red/14/. Acesso em: 05/09/2021.

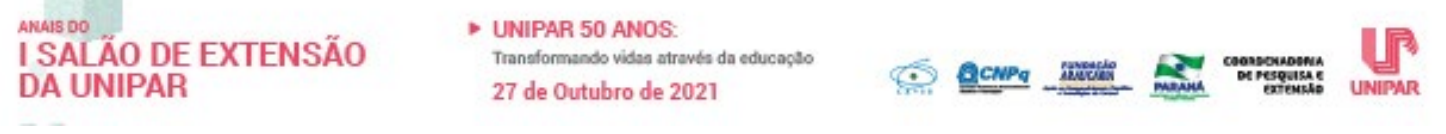




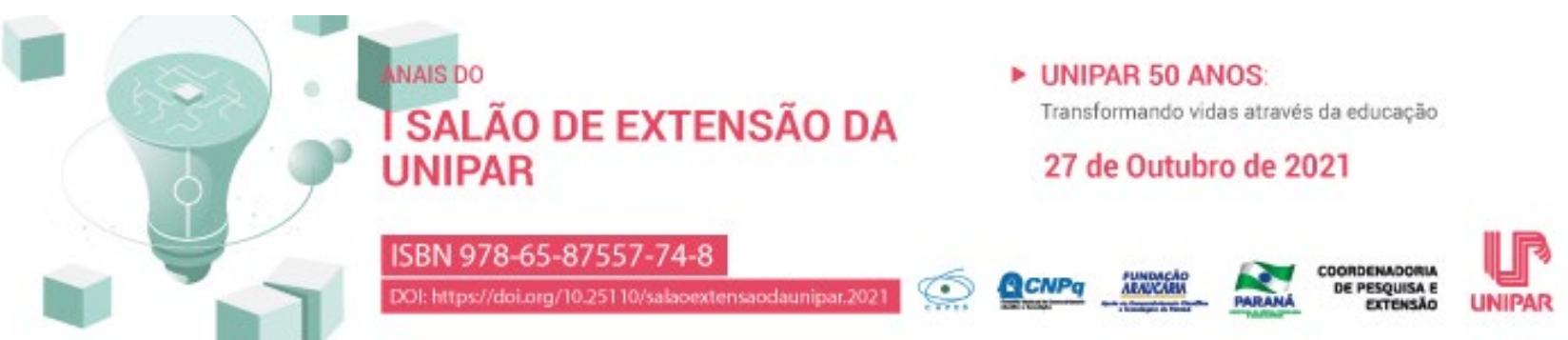 \\ UNIPAR NA PRAÇA: VITALIDADE URBANA POR MEIO DA AÇÃO SOCIAL
}

\author{
${ }^{1}$ FERNANDO MARTINS PIERIM, ${ }^{2}$ JHENIFER DE ALMEIDA DOS SANTOS, ${ }^{3}$ ELLEN ROSANE RODELA ALONSO BONFIM, \\ ${ }^{4}$ JULIANE THAIS AMBROSIO, ${ }^{5}$ PAULA ANDRÉIA GOMES DA CRUZ, ${ }^{6}$ GUILHERME SERAFIM
}

\author{
${ }^{1}$ Acadêmico do Curso de Arquitetura e Urbanismo da UNIPAR \\ ${ }^{2}$ Acadêmica do Curso de Arquitetura e Urbanismo da UNIPAR \\ ${ }^{3}$ Acadêmica do Curso de Design de Interiores da UNIPAR \\ ${ }^{4}$ Acadêmica do Curso de Arquitetura e Urbanismo da UNIPAR \\ ${ }^{5}$ Docente da UNIPAR \\ ${ }^{6}$ Responsável técnico da UNIPAR
}

Introdução: Vitalidade urbana refere-se à vida nas ruas, praças, passeios e demais espaços públicos abertos. Está diretamente relacionada à utilização dos espaços pelas pessoas para diversas atividades, como encontros, caminhadas, trocas comerciais, contemplação, manifestações artísticas, entre outras. A vitalidade urbana pode ser entendida como a alta intensidade, frequência e riqueza de apropriação do espaço público, bem como à interação deste com as atividades que acontecem dentro das edificações (SABOYA, 2016).

Objetivo: Apresentar reflexões sobre a importância da apropriação dos espaços públicos abertos para a vitalidade urbana, com foco no evento Unipar na Praça, projeto institucional da Universidade Paranaense.

Resultados: A praça é uma construção espacial para manutenção ambiental com diversos modos de uso e apropriação do seu espaço. De acordo com Santos (1997), o espaço é formado por um conjunto indissociável, solidário e contraditório, de sistemas de objetos e sistemas de ações, não considerados isoladamente, mas como o quadro único no qual a história se dá. Nesse contexto, o Unipar na Praça é uma ação social da Universidade Paranaense que oferece aos visitantes esclarecimentos sobre as diversas áreas de atuação dos cursos de graduação. Instalados em praças públicas, professores e acadêmicos sanam dúvidas e prestam inúmeros serviços à comunidade. Entre estes serviços destacam-se: recreação infantil, educação financeira familiar, doação de hortaliças, dicas de alimentação saudável, aferição de pressão arterial, testes de glicemia, entre outros (UNIPAR, 2019). Na cidade de Umuarama, o evento acontece na Praça Arthur Thomas, que consiste num referencial de centralidade. Segundo Held (2013), a praça foi projetada pela Companhia Melhoramentos do Norte do Paraná, junto ao traçado original da cidade e representa o Marco Zero de colonização. Desde a década de 1960, já configurava como centro comercial regional, lugar de intenso fluxo, troca cultural e festividade, antes mesmo de receber um desenho de praça ou qualquer tratamento estético apropriado para esse uso. Assim, é possível constatar a importância histórica e cultural da praça Arthur Thomas para a cidade de Umuarama.

Conclusão: O evento Unipar na Praça contribui para o fortalecimento da identidade da Praça Arthur Thomas e promove a apropriação desta ao induzir o fluxo e permanência de pessoas por meio da ação social, corroborando com a vitalidade urbana.

\section{Referências}

HELD, Regina. A narrativa preservacionista da paisagem humana na praça Arthur Thomas na cidade de Umuarama Paraná. 248 f. Tese (Doutorado em Geografia). Universidade Estadual de Maringá, Maringá, 2013.

SABOYA, Renato. Fatores morfológicos da vitalidade urbana Parte 1: Densidade de usos e pessoas. ArchDaily Brasil, 16 nov. 2016 . Disponível em: . Acesso em: 27 ago. 2021.

SANTOS, Milton. A natureza do espaço: Técnica e tempo, razão e emoção. 2 ed. São Paulo: Hucittec, 1997.

UNIVERSIDADE PARANAENSE. Unipar na Praça: Projeto socializa conhecimento na Arthur Thomas. Unipar, Umuarama, 14 jun. 2019. Disponível em: . Acesso em: 03 set. 2021.

I SALÃO DE EXTENSÃO

DA UNIPAR

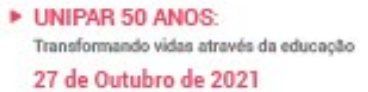

50 ANOS:

27 de Outubro de 2021
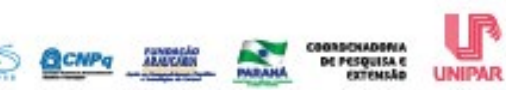


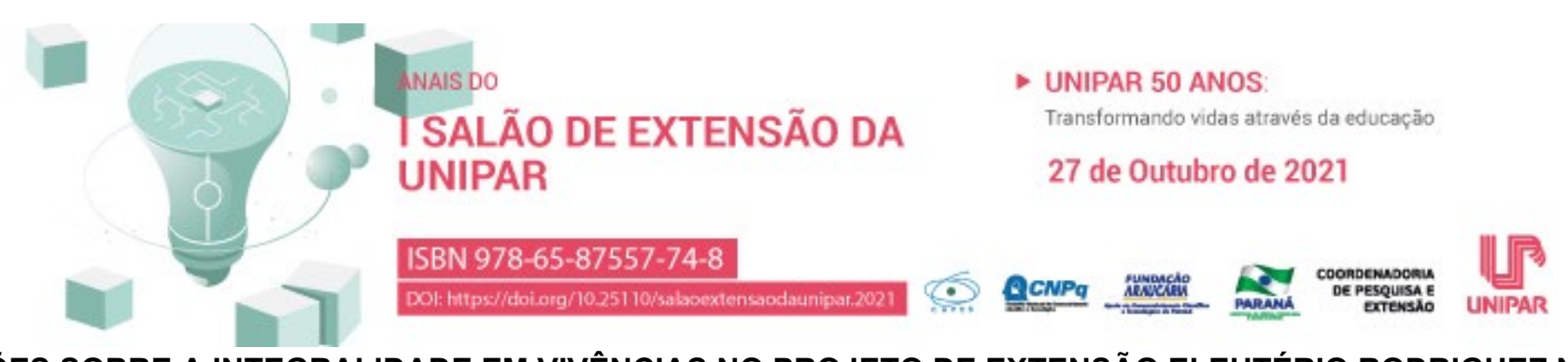

\title{
ALUSÕES SOBRE A INTEGRALIDADE EM VIVÊNCIAS NO PROJETO DE EXTENSÃO ELEUTÉRIO RODRIGUEZ NETO
}

\author{
${ }^{1}$ MARIANGELA DE ABREU ANTONELO, ${ }^{2}$ LUCIANA PELLIZZARO, ${ }^{3}$ BRUNO HENRIQUE NESI, ${ }^{4}$ GRASIELE SCHMATZ DE \\ MORAES, ${ }^{5}$ NATIELI RAUBER NICOLAU, ${ }^{6}$ ARIELI KOZERSKI, ${ }^{7}$ ANNA VITORIA PINTO DE OLIVEIRA FERREIRA, ${ }^{8}$ GISELE \\ LOTICI, ${ }^{9}$ MARLI DE OLIVEIRA DE PAULA, ${ }^{10} \mathrm{KESSIA} \mathrm{HELEN} \mathrm{DALMUTH,}{ }^{11}$ ALESSANDRO RODRIGUES PERONDI
}

${ }^{1}$ Discente do Programa de Iniciação a Extensão da Universidade Paranaense UNIPAR/Francisco Beltrão-PR.

${ }^{2}$ Docente da UNIPAR

${ }^{3}$ Acadêmico do Curso de Enfermagem da UNIPAR

${ }^{4}$ Acadêmica do Curso de Enfermagem da UNIPAR

${ }^{5}$ Acadêmica do Curso de Enfermagem da UNIPAR

${ }^{6}$ Acadêmica do Curso de Enfermagem da UNIPAR

${ }^{7}$ Acadêmica do Curso de Enfermagem da UNIPAR

${ }^{8}$ Acadêmica do Curso de Enfermagem da UNIPAR

${ }^{9}$ Acadêmica do Curso de Enfermagem da UNIPAR

${ }^{10}$ Acadêmica do Curso de Enfermagem da UNIPAR

${ }^{11}$ Docente da UNIPAR

Introdução: A integralidade pode ser considerada um dos temas mais recorrentes nas discussões acerca da formação profissional em saúde. Apresenta muitos sentidos possíveis, e é justamente essa gama de sentidos que a fortalece como princípio, imagem-objetivo, bandeira de luta e práticas (OLIVEIRA; CUTOLO, 2018). A integralidade se apresenta como eixo norteador da formação profissional, na tentativa de romper com o modelo tradicional de formação, tendo como foco o ensino em saúde próximo das necessidades sócio-históricas da população (NUNES et al., 2019).

Objetivo: O presente trabalho objetivou aludir a integralidade em vivencias no Projeto de Extensão Eleutério Rodrigues Neto.

Desenvolvimento: A prática profissional é resultado da forma como os conhecimentos são organizados no âmbito acadêmico. Uma formação biomédica tem como produto final um profissional cuja prática valoriza apenas o biológico e se torna impessoal, desconsiderando a singularidade das pessoas. No Projeto, nas diversas atividades executadas, além da preocupação com a questão sanitária das pessoas, o objetivo é a superação da lógica queixa-conduta. O foco volta-se para as dimensões socioambientais, psicológicas, biológicas e culturais do ser humano, no sentido do conceito ampliado de saúde, relacionando, portanto, as condições de vida com o processo de saúde e adoecimento. Acredito que a maior contribuição do projeto foi ensinar a importância de olharmos para o paciente como um todo, iniciando pelo ambiente em que ele vive, as relações que ele tem com a família, amigos e comunidade... (Acadêmico 1). Apesar de haver no currículo formal a discussão de uma abordagem ampliada, parece haver um distanciamento de uma vivência mais prática nas atividades regulares. $O$ que parece de fato contribuir para que o acadêmico perceba a importância da escuta e do entendimento do contexto é a experiência prática. No projeto, a necessidade de dar respostas positivas aos problemas de saúde, sem apoio imediato de tecnologias duras, faz com que a escuta seja valorizada, pois em algumas situações ela é a única tecnologia disponível. A satisfação das pessoas e a confirmação de que as tecnologias leves são importantes para a resolução dos problemas sensibilizam e legitimam para uma nova prática em saúde.

Conclusão: Portando, devemos considerar a integralidade como superação de dicotomias clássicas no âmbito da saúde, ou seja, na perspectiva da integralidade, pensasse a saúde como o resultado de aspectos múltiplos da vida de um indivíduo, que não podem ser reduzidos a meras díades conceituais.

\section{Referências}

OLIVEIRA, Inajara Carla; CUTOLO, Luiz Roberto Agea. Integralidade: algumas reflexões. Revista Brasileira de Educação Médica, v. 42, p. 146-152, 2018.

NUNES, Maria Julia de Siqueira et al. Integralidade na saúde: guia para estudantes e profissionais de saúde. 2019. 



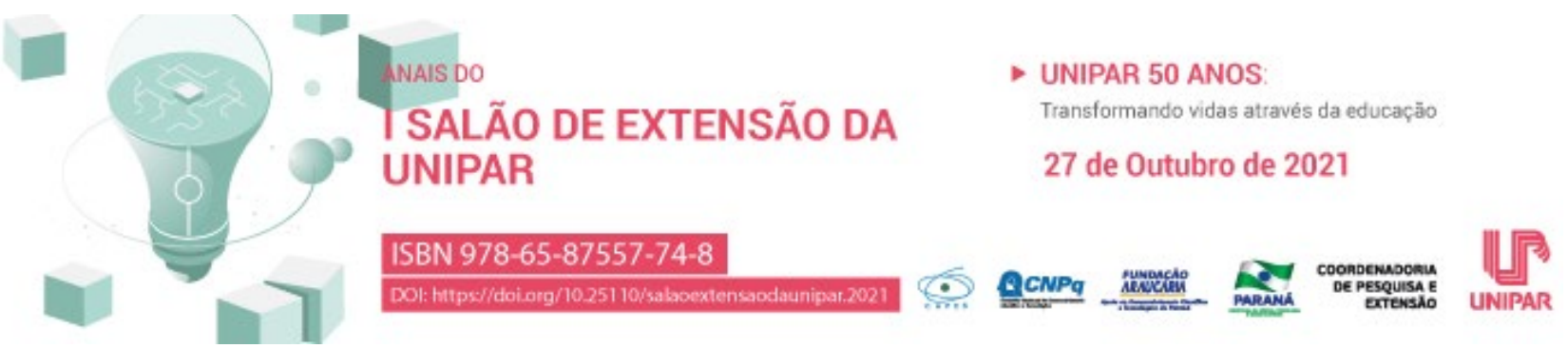 \\ PROJETO ARQUITETÔNICO: O IMPACTO DA SUA ELABORAÇÃO - ESTUDO DE REVISÃO
}

\author{
${ }^{1}$ GABRIEL AUGUSTO BATISTA RAMOS, ${ }^{2}$ IGO HENRIQUE SILVA NUNES, 3 JOAO VICTOR POSSOBOM RIGOBELLO, \\ ${ }^{4}$ LORENA MARCIELE VIANA ACOSTA, ${ }^{5}$ VANDA ZAGO LUPEPSA
}

\author{
${ }^{1}$ Acadêmico do Curso de Engenharia Civil/UNIPAR \\ 2Docente da UNIPAR \\ ${ }^{3}$ Responsável Técnico do Escritório Modelo da UNIPAR \\ ${ }^{4}$ Acadêmica do Curso de Engenharia Civil da UNIPAR \\ ${ }^{5}$ Docente da UNIPAR
}

Introdução: Para a economia do país, Silva (2021) afirma que a construção civil possui enorme importância ao ser responsável por grande parte da geração de renda devido a variedade de serviços ofertados no setor. Segundo Corredato et al. (2021), os projetos de engenharia e arquitetura tem por finalidade o bem-estar para os usuários da edificação, buscando proporcionar o maior conforto possível. Giesta et al. (2019) aponta que o projeto arquitetônico advém de uma solicitação, caminha pela elaboração de uma proposta satisfatória, até que tenha seu objetivo alcançado, e, por tratar-se de uma estrutura complexa de elaboração, desde o planejamento até sua realização, etapas são seguidas durante a execução dos procedimentos. Souza (2020), ressalta a relação de projetos de arquitetura à combinação de requisitos complexos como sustentabilidade, flexibilidade e qualidade, ao abranger, por exemplo, a utilização consciente dos recursos naturais, a diversificação das edificações e a própria percepção dos usuários com as construções ao seu entorno, necessidades que despertam no profissional da área a busca por medidas criativas na hora de projetar.

Objetivo: Realizar um estudo sobre a importância dos projetos arquitetônicos e de engenharia, e o impacto da qualidade dos mesmos na vida dos usuários.

Resultados: Segundo Ferreira, Corcini e Aleixo (2019), há significativas mudanças ocorrendo no setor de projetos devido a exigência cada vez maior do mercado por mais qualidade e menor prazo de entrega. Para que um projeto arquitetônico seja executado com sucesso, todos os detalhes devem ser observados, tal como, a escolha do terreno, materiais a serem utilizados, até a escolha da construtora, tudo pode influenciar no resultado (AMPLUS, 2019).

Conclusão: Conclui-se que a elaboração de projetos contribui para a economia do país ao movimentar o setor da construção civil, e, em uma visão mais minimalista, impacta diretamente a vida dos usuários das edificações projetadas, ao proporcionar, por exemplo, maior conforto. Tudo isso através da perspectiva do profissional da área, sua criatividade e capacidade de trabalhar no meio a sua volta de modo a satisfazer a necessidade dos que o procuram.

\section{Referências}

AMPLUS CONSTRUTORA. Entenda o que é a compatibilização de projetos e porque ela é tão importante. Disponível em: CORREDATO, Aryon Pugsley. et al. Avaliação da iluminação natural em edificação de uso coletivo em Cascavel. Latin American Journal of Energy Research, v. 8, n. 1, p. 36-45, 2021. Disponível em: Acesso em 23 de setembro de 2021. GIESTA, Josyanne Pinto. et al. Proposta de inserção do BIM no processo de projeto arquitetônico. In: Conference On Automation Innovation In Construction, Leiria, Portugal. 2019. Disponível em: . Acesso em 22 de setembro de 2021. FERREIRA, Juscelina Rosiane; CORCINI, Matheus Philippe; ALEIXO, Hugo Penna. O ensino de bim na disciplina projeto arquitetônico. Revista de Ensino de Engenharia, v. 38, n. 2, 2019. Disponível em: . Acesso em 23 de setembro de 2021.

SILVA, Rosimaria Gomes Da. A importância do projeto elétrico residencial. Trabalho de conclusão de curso (Bacharelado em Engenharia Civil). Centro Universitário UNIAGES , Paripiranga, 2021. Disponível em: . Acesso em 21 de setembro de 2021. SOUZA, Natalya Cristina de Lima. A criatividade no projeto arquitetônico: um estudo exploratório em trabalhos finais de graduação do CAU-UFRN. 2020. Dissertação de Mestrado. Universidade Federal do Rio Grande do Norte. Disponível em: . Acesso em 21 de setembro de 2021.

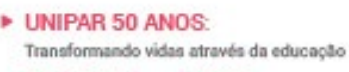

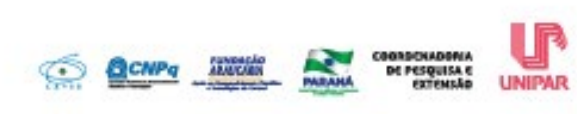




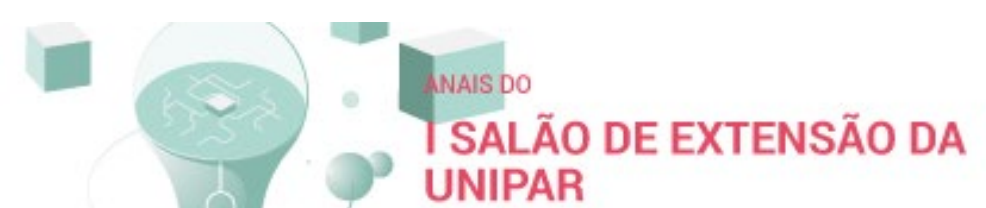

ISBN 978-65-87557-74-8
- UNIPAR 50 ANOS:

Transformando vidas através da educação

27 de Outubro de 2021

Dol: hitps//doiorg/10251 10/saboextonsas

\title{
ATIVIDADE SOBRE A SEMANA NACIONAL DA PESSOA COM DEFICIÊNCIA INTELECTUAL E MÚLTIPLA NA UNIDADE APAE DE UMUARAMA
}

\author{
${ }^{1}$ FATIMA HASSAN SAFIEDDINE, ${ }^{2}$ ISADORA MARIAH MENOIA, ${ }^{3}$ LUDIMILA IZABELI PEREIRA DA SILVA, ${ }^{4}$ MARCIA ELIZA \\ BAVARESCO TOZONI, ${ }^{5}$ EGUIMAR ROBERTO MARTINS
}

\author{
${ }^{1}$ Acadêmico do Curso de Medicina da UNIPAR \\ ${ }^{2}$ Acadêmica do Curso de Medicina da UNIPAR \\ ${ }^{3}$ Acadêmica do Curso de Medicina da UNIPAR \\ ${ }^{4}$ Acadêmica do Curso de Medicina da UNIPAR \\ ${ }^{5}$ Docente da UNIPAR
}

Introdução: Crianças com Necessidades Especiais de Saúde (CRIANESs) precisam de um acompanhamento em saúde, que compreende um conjunto de serviços que vai além daqueles médicos e de enfermagem, estendendo-se a atendimentos na área de reabilitação, apoio educacional, social e familiar (SILVEIRA, 2013). Independente da demanda de cuidados médicos, faz-se necessário o apoio estrutural no que diz respeito aos cuidados básicos e importantes para a sua qualidade de vida como os que foram abordados nesse evento, ou seja, os cuidados de higiene, prevenção de úlceras de decúbito e prevenção de acidentes de mobilidade.

Objetivo: Esclarecer aos pais de Crianças com Necessidades Especiais de Saúde (CRIANESs) e familiares próximos sobre os cuidados básicos que evitam futuros prejuízos à saúde e incentivar a qualidade de vida, visto a natureza complexa e contínua dos desafios inerentes no domicílio.

Resultados: Por meio dessa atividade conseguimos difundir as informações mais importantes no que diz respeito às particularidade das demandas de cuidado domiciliar, como as informações sobre os cuidados de higiene dentre elas incentivar quando possível escovarem os dentes sozinhos e na hora do banho ajustar a temperatura e incentivá-los a tomarem banho sozinhos. Também abordamos os cuidados e prevenção das úlceras de decúbito em pacientes acamados, explicitando medidas simples, porém que podem interferir na sua qualidade de vida e por fim abordamos sobre a prevenção de acidentes de mobilidade para que assim possamos evitar e alertá-los sobre acidentes comuns como quedas que podem trazer diversos problemas futuros.

Conclusão: As campanhas de cuidado domiciliar são de suma importância para a criança em sua individualidade e para o núcleo familiar, na tentativa de reduzir acidentes que podem ser evitados com medidas simples e impulsionar medidas que muitas vezes geram pequenas independências para aqueles que necessitam de cuidados.

\section{Referências}

SILVEIRA, Andressa da, Neves, Eliane Tatsch e Paula, Cristiane Cardoso de Cuidado familiar das crianças com necessidades especiais de saúde: um processo (sobre)natural e de (super)proteção. Texto \& Contexto - Enfermagem [online]. 2013, v. 22, n. 4

\section{SALÃO DE EXTENSÃo DA UNIPAR}

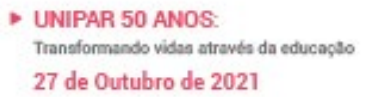

Transformando vides atreves da educagto
27 de Outubro de 2021

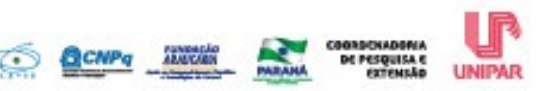




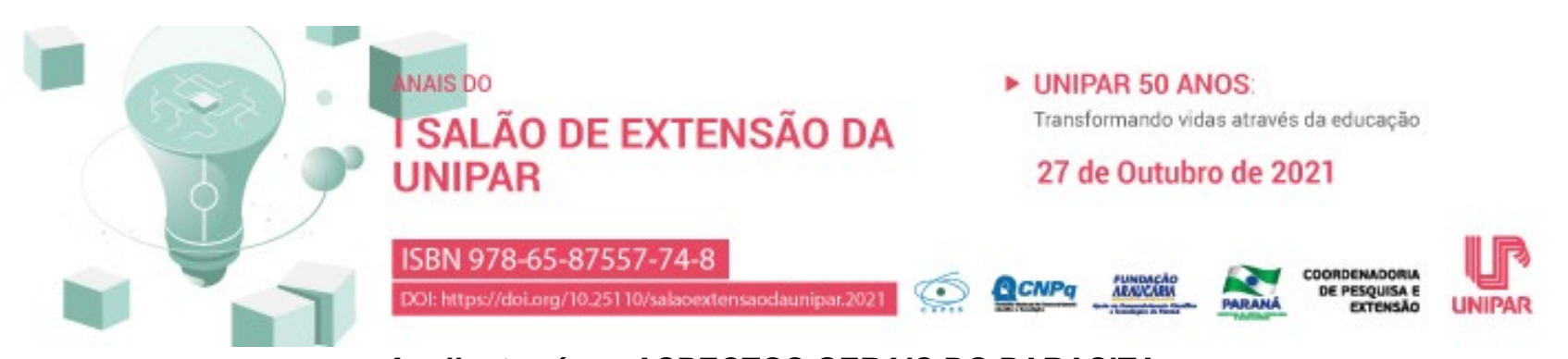

Ancilostomíase: ASPECTOS GERAIS DO PARASITA

\begin{abstract}
${ }^{1}$ LAURA RICARDA EBELING LAUTERT, ${ }^{2}$ THAINARA LOURENCO DE VASCONCELLOS, ${ }^{3}$ JULIA VALER GUERRA, ${ }^{4}$ THAIS EDUARDA ADAMCZUK, , ${ }^{5}$ MAISA STEFFANI ADAMCZUK, ${ }^{6}$ ALLEX VITAL PEREIRA, ${ }^{7}$ EDSON GERONIMO , ${ }^{8}$ ERIKA DE GOIS FREIRE LOPES, ${ }^{9}$ GIULIANA ZARDETO SABEC
\end{abstract}

\author{
${ }^{1}$ Acadêmica do Curso de Farmácia da UNIPAR \\ ${ }^{2}$ Acadêmica do Curso de Farmácia da UNIPAR \\ ${ }^{3}$ Acadêmica do Curso de Farmácia da UNIPAR \\ ${ }^{4}$ Acadêmica do Curso de Farmácia da UNIPAR \\ ${ }^{5}$ Acadêmico do Curso de Farmácia da UNIPAR \\ ${ }^{6}$ Acadêmico do Curso de Farmácia da UNIPAR \\ ${ }^{7}$ Acadêmico do Curso de Farmácia e do Doutorado Em Ciência Animal Com Ênfase Em Produtos Bioativos da UNIPAR \\ ${ }^{8}$ Acadêmica do Curso de Farmácia da UNIPAR \\ ${ }^{9}$ Docente da UNIPAR
}

Introdução: As parasitoses intestinais apresentam diferentes formas de transmissão, os quais estão diretamente associados às condições inadequadas de higiene, entre elas, o hábito de levar às mãos sujas a boca (NUNES; MATOS-ROCHA, 2019). Neste sentido, a Ancilostomíase é causada por parasitas nematoides das espécies Necator americanus e Ancylostoma duodenale. É uma das formas de infecção crônica mais comum em humanos com estimativa de 740 milhões de casos especialmente em áreas rurais pobres dos trópicos e subtrópicos segundo a Organização Mundial de Saúde (OMS). As principais manifestações clínicas da doença resultam da perda crônica de sangue intestinal causada pela fixação dos vermes adultos à mucosa e submucosa dos intestinos (VALENTE, 2013). Quando a perda de sangue excede as reservas nutricionais, há deficiência de ferro e desenvolvimento de anemia, relacionada ao baixo rendimento escolar em crianças, apatia e queda da produtividade em adultos (NUNES; MATOS-ROCHA, 2019).

Objetivo: Expressar de uma forma clara e objetiva o ciclo de vida do parasita Ancilostomíase, bem como as características da parasitose.

Desenvolvimento: Neste trabalho realizou-se um levantamento bibliográfico, por meio da base de dados Google acadêmico, entre os anos de 2013 à 2021, buscando ressaltar as principais características da Ancilostomíase. A anemia e suas consequências são as principais manifestações clínicas da ancilostomíase, por isso ela também recebe comumente a denominação de amarelão (DE MENEZES; COSTA; VANDESMET, 2017). A falta de conhecimento e higiene pessoal e os cuidados com a preparação de alimentos aumentam o risco de doenças, principalmente as parasitoses. Mesmo que as parasitoses sejam uma das infecções mais comuns, ainda há uma dificuldade na realização de exames coproparasitológicos (NUNES; MATOS-ROCHA, 2019). Seu diagnóstico baseia-se na identificação de ovos no exame parasitológico de fezes em conjunto com anamnese e exame clínico. Hábitos de higiene, o uso de calçados e saneamento básico são as medidas profiláticas mais adequadas para reduzir os índices dessa parasitose (DE MENEZES; COSTA; VANDESMET, 2017).

Conclusão: Fica evidente que, por falta de saneamento básico, higiene, atendimento médico hospitalar, ou qualquer outro motivo que leve a falta de condições decentes de sobrevivência, os agentes parasitas continuam causando problemas seríssimos para os povos de todo o mundo. São necessários maiores investimentos na saúde e condições mínimas de sobrevivência para a população, acompanhada de seriedade política, pois se sabe que população doente e mal tratada reflete no crescimento de uma população.

\footnotetext{
Referências

DE MENEZES, Saulo Almeida; COSTA, Yasmim Arruda; VANDESMET, Lilian Cortez Sombra. Ancilostomíase: aspectosclínicos, diagnóstico e medidas preventivas. Mostra Científica em Biomedicina, v. 2, n. 1, 2017.

NUNES, Marcela Oliveira; ROCHA, Thiago José Matos. Fatores condicionantes para a ocorrência de parasitoses entéricas de adolescentes. Journal of Health \& Biological Sciences, v. 7, n. 3 (Jul-Set), p. 265-270, 2019.

VALENTE, Vanderson Firmiano. Dinâmica da infecção e reinfecção por ancilostomídeos seguido ao tratamento antihelmíntico em crianças residentes em seis comunidades dos municípios de Novo Oriente de Minas e Caraí na região nordeste de Minas Gerais, Brasil. 2013. Tese de Doutorado. Fundação Oswaldo Cruz. p 16-58, 2013.
} 
- unIPAR 50 anos:

I SALAOO DE EXTENSÃO Transformando vidas atravies da educaģso

DA UNIPAR 


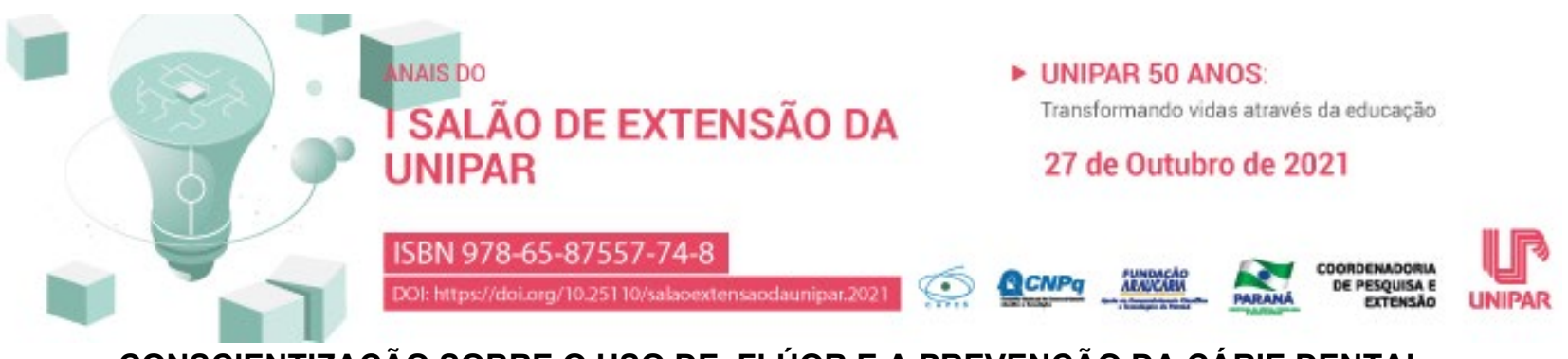 \\ CONSCIENTIZAÇÃO SOBRE O USO DE FLÚOR E A PREVENÇÃO DA CÁRIE DENTAL}

${ }^{1}$ GEOVANA PAULINO DA SILVA, ${ }^{2}$ EMANUELLE RAYANE SALAMON, ${ }^{3}$ MATHEUS DIAS FERREIRA, ${ }^{4}$ NUBYA JACOMINI, ${ }^{5}$ TAYNA CORREA OKADA,${ }^{6}$ HENRIQUE SARTORI ANDRE, ${ }^{7}$ IZADORA BRAGA DE MELLO BRUDER, ${ }^{8}$ RICARDO MARQUES BARROSO, ${ }^{9}$ ITALO MATEUS DE ALMEIDA COVALI, ${ }^{10} \mathrm{KAYLAINE}$ BRASIL DE ALMEIDA, ${ }^{11}$ GEOVANA PAULINO DA SILVA, ${ }^{12}$ VIVIANE MARTINS DE OLIVEIRA, ${ }^{13}$ DAIANE FALASQUI DA SILVA,${ }^{14}$ PEDRO SELA DE OLIVEIRA,${ }^{15}$ GRACIELI LEITE DA COSTA, ${ }^{16}$ ANA CAROLINA SOARES FRAGA ZAZE

${ }^{1}$ Acadêmico do Curso de Odontologia UNIPAR

${ }^{2}$ Acadêmica do Curso de Odontologia da UNIPAR

${ }^{3}$ Acadêmico do Curso de Odontologia da UNIPAR

${ }^{4}$ Acadêmica do Curso de Odontologia da UNIPAR

${ }^{5}$ Acadêmica do Curso de Odontologia da UNIPAR

${ }^{6}$ Acadêmico do Curso de Odontologia da UNIPAR

${ }^{7}$ Acadêmica do Curso de Odontologia da UNIPAR

${ }^{8}$ Acadêmico do Curso de Odontologia da UNIPAR

${ }^{9}$ Acadêmico do Curso de Odontologia da UNIPAR

${ }^{10}$ Acadêmica do Curso de Odontologia da UNIPAR

${ }^{11}$ Acadêmica do Curso de Odontologia da UNIPAR

${ }^{12}$ Acadêmica do Curso de Odontologia da UNIPAR

${ }^{13}$ Acadêmica do Curso de Odontologia da UNIPAR

${ }^{14}$ Acadêmico do Curso de Odontologia da UNIPAR

${ }^{15}$ Acadêmica do Curso de Odontologia da UNIPAR

${ }^{16}$ Docente da UNIPAR

Introdução: A cárie é a principal doença que acomete a boca e quando seu tratamento é negligenciado, leva à perda do órgão dental. Sua prevenção é baseada no controle dos fatores etiológicos e no aumento da resistência dos tecidos dentais, por meio da utilização de fluoretos, principalmente. Alguns produtos foram desenvolvidos e apresentam indicações específicas, considerando a necessidade individual em relação ao risco de desenvolvimento ou atividade da doença. Produtos com alta concentração de flúor são de uso exclusivo dos profissionais e devem ser utilizados em ambiente odontológico, entretanto, produtos de baixa concentração são indicados para uso caseiro. Além dos produtos desenvolvidos para uso tópico, deve ser considerado também o uso sistêmico, que acontece por meio da ingestão de flúor. O método de abrangência populacional instituído em nosso país para o uso sistêmico se dá pela fluoretação da água, que mostra resultados significativos na redução da prevalência de cárie.

Objetivo: Conhecer a influência da utilização de fluoretos para o controle e a prevenção da cárie, bem como as diferentes fontes de flúor que a população tem acesso, considerando suas principais características e indicações.

Resultados: Os acadêmicos participantes do projeto de extensão |"Educação direcionada à saúde bucall" foram instruídos a pesquisar sobre o tema, para que pudessem desenvolver uma proposta voltada à crianças de 5 a 10 anos de idade. Idealizaram histórias para serem apresentadas na forma de teatro, de forma presencial, ou vídeo, para serem divulgados nas redes sociais. Abordaram a importância da utilização de produtos fluoretados de uso caseiro para deixar os dentes mais resistentes ao processo da desmineralização dos tecidos dentários, causada pela liberação de ácidos oriundos de bactérias cariogênicas. Apresentaram produtos que contém flúor, como dentifrícios e enxaguantes bucais e alertaram sobre o risco de ingestão desses produtos, que podem levar à quadros de intoxicação, principalmente crônica causando a fluorose em algumas situações. Enalteceram que o consumo de água fluoretada é seguro e importante para a saúde bucal, bem como as visitas regulares ao dentista.

Conclusão: Os acadêmicos aprenderam sobre a utilização de fluoretos para o controle e prevenção da cárie, bem como desenvolveram materiais lúdicos para realizar a educação direcionada à saúde bucal, visando a promoção de saúde. 


\section{Referências}

CUNHA, Lia Alves da. Ação do flúor na microdureza do esmalte humano submetido a dois tipos de agentes clareadores. 2005. $131 \mathrm{f}$. Dissertação (mestrado) - Universidade Estadual Paulista, Faculdade de Odontologia de São José dos Campos, 2005. Disponível em: . Acesso em 09 set. 2021.

SANTOS, Helen Evelyn da Silva; MIRANDA, José Lucas Figueiredo; CARVALHO, Mikaila Romão de; LORENA SOBRINHO, José Eudes de. Flúor uso terapêutico e cárie dentária. 2018. $24 \mathrm{f}$. Monografia (Trabalho de conclusão de curso) - Centro Universitário Tabosa de Almeida, Caruaru, 2018. Disponível em: http://repositorio.asces.edu.br/handle/123456789/1804. Acesso em 09 set. 2021.
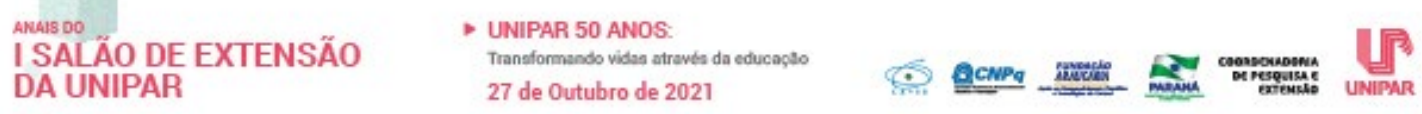


\title{
(1) D UNIPAR 50 ANOS \\ SALÃO DE EXTENSÃO DA Transformando vidas através da educą̧̧̄o UNIPAR \\ CARIMBO DE PLACENTA: UMA INTRODUÇÃO À PLACENTA E A CRIAÇÃO DO CARIMBO NAS GESTANTES DE PARTO NORMAL EM MATERNIDADE
}

\author{
${ }^{1}$ ANDERSON CLAYTON DE AGUIAR, ${ }^{2}$ LAIS ARAUJO LOCATELI, ${ }^{3}$ TAILA ATILA DA LUZ FERREIRA, ${ }^{4}$ EMANUELY SANTANA \\ SANTOS, ${ }^{5}$ KELLY CRISTINA DE SOUZA LIMA RODRIGUES, ${ }^{6}$ AMANDA NASCIMENTO VASQUES DE SOUZA, ${ }^{7} \mathrm{NANCI}$ \\ VERGINIA KUSTER DE PAULA
}

\footnotetext{
${ }^{1}{ }^{1}$ Acadêmico do Curso de Enfermagem da UNIPAR

${ }^{2}$ Acadêmica do Curso de Enfermagem da UNIPAR

${ }^{3}$ Acadêmica do Curso de Enfermagem da UNIPAR

${ }^{4}$ Acadêmica do Curso de Enfermagem da UNIPAR

${ }^{5}$ Acadêmica do Curso de Enfermagem da UNIPAR

${ }^{6}$ Docente da UNIPAR

${ }^{7}$ Docente da UNIPAR
}

Introdução: O corpo humano é uma ferramenta fascinante, sua forma anatômica e suas diversas funções fazem parte de um esquema essencial para o desenvolvimento da vida (SANTOS; SILVA, 2019). Desde o nascimento, o corpo humano passa por inúmeros processos de transformação e durante a gestação temos um processo de formação da placenta, que tem um papel fundamental para essa nova vida que surge no ventre de uma mulher, considerado um órgão fetomaterno, que se desenvolve durante a gestação, ocorrendo um trabalho conjunto entre a mãe e o bebê, sendo responsável por levar os nutrientes e oxigênio necessários para o crescimento saudável do bebê (MOTA et al, 2019).

Objetivo: $O$ objetivo central deste trabalho é divulgar a ação do projeto de extensão realizado pelo curso de Enfermagem na Maternidade Norospar, bem como despertar nas famílias o conhecimento da a funcionalidade da placenta e a lembrança do órgão que nutre o bebê.

Resultados: trata-se do Projeto de Extensão Enfermagem nos Diferentes Ciclos da Vida realizada por vinte por acadêmicos do Curso de Enfermagem da UNIPAR, no primeiro semestre de 2021, na Maternidade Norospar, no município de Umuarama-Pr. Para atingir os objetivos propostos os acadêmicos participaram de uma oficina sobre confecção de carimbo de placenta, realizada pela Enfermeira Obstetra da Instituição. Para realização dos carimbos foram utilizadas placentas dequitadas da própria mãe, folhas A3, tinta de tecido, lápis de cor. Durante o período do projeto foram confeccionadas e entregues as mães em média 70 carimbos. Utilizamos a dinâmica da placenta como carimbo, primeiramente explicando sobre a importância da placenta as mães e oferecendo a oportunidade delas receberem essa lembrança, dando um novo sentido a esse órgão tão fascinante e de ligação entre mãe e filho. O órgão materno após o parto é descartada, ao utilizarmos e sua forma anatômica remete a imagem de uma árvore, o cordão umbilical representa o caule, os vasos sanguíneos remetem os galhos e o tecido placentário são as folhas. Essa é a casinha que o bebe foi gerado durante a gestação, como fonte de lembrança, é decorado com as características do nascimento do recém-nascido, como: data do parto, horário do nascimento, peso do bebê, profissionais envolvidos no parto, entre médicos, enfermeiros, técnicos de enfermagem, etc. Cada mãe ao receber o carimbo do órgão que nutriu seu bebê,

Conclusão: $O$ projeto vem proporcionando vem aproximação entre os acadêmicos e as mães, onde a academia propõe expandir o conhecimento sobre a funcionalidade e divulgação sobre a placenta despertando o desejo e interesse das mães em eternizar ainda mais esse momento tão mágico que é o nascimento de um bebê.

\section{Referências}

COSTA, Victor Ribeiro de Oliveira et al. A inserção de novos métodos no ensino da anatomia humana: revisão integrativa. Atena editora, v. 3, p. 2,3-226, 2019. DOI: 10.22533/at.ed.4301925091. Disponível em: https://www.atenaeditora.com.br/wpcontent/uploads/2019/09/E-BOOK-O-Estudo-de-Anatomia-Simples-e-Dinamico-3-.pdf. Acesso em: 04 set. 2021.

MOTA, Rafaela de Oliveira et al. Carimbo de placenta: uma memória em forma de arte. Universidade Estadual do Ceará, p. 4, 2019. Disponível em: http://uece.br/eventos/enfermaio/anais/resumos/18930.html. Acesso em: 04 set. 2021.

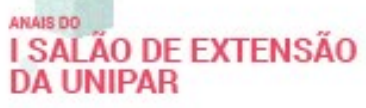

DA UNIPAR

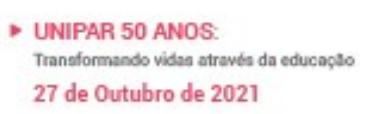

Transformando vidas atravis da educagto
27 de Outubro de 2021

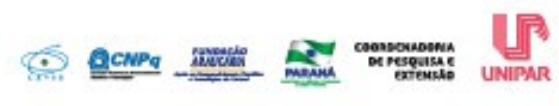




\title{
DNAIS DO UNIPAR 50 ANOS \\ SALÃO DE EXTENSÃO DA Transformando vidas através da educaçäo UNIPAR \\ ASSISTÊNCIA À CRIANÇA E ADOLESCENTE EM SITUAÇÃO DE VIOLÊNCIA DOMÉSTICA E FAMILIAR: MUDANÇA DE GUARDA COM PEDIDO LIMINAR DE GUARDA PROVISÓRIA
}

\author{
${ }^{1}$ GABRIEL TRENTINI PAGNUSSAT, ${ }^{2}$ GABRIELA BEATRIZ ANGELOTTI, ${ }^{3}$ ELAINE CRISTINA BESSAO NAKAMURA, ${ }^{4}$ LUIS \\ IRAJA NOGUEIRA DE SA JUNIOR
}

\author{
${ }^{1}$ Acadêmico participante do Programa de Iniciação à Extensão - PEX/Unipar. \\ ${ }^{2}$ Acadêmico participante do Programa de Iniciação à Extensão - PEX/Unipar. \\ ${ }^{3}$ Docente da UNIPAR \\ ${ }^{4}$ Docente da UNIPAR
}

Introdução: A violência sofrida por crianças e adolescentes no seio familiar é mais comum do que possa parecer. Trata-se de um estudo de caso onde após o divórcio, a cônjuge virago constituiu novo casamento e passou a residir sobre o mesmo teto com a filha do primeiro casamento e o atual marido. Após um curto período de convivência o padrasto passou a agredir verbal e fisicamente a criança, com a conivência e participação da mãe. A situação de extrema vulnerabilidade da criança exige do Poder Judiciário medida urgente para proteção integral da menor.

Objetivo: Analisar as medidas de assistência à criança e adolescente em situação de violência doméstica previstas na Lei 8.069/1990 (ECA), tendo como foco a sua atuação na busca da proteção integral do menor.

Resultados: A ação de mudança de guarda com pedido liminar prevista no artigo 300 do Código de Processo Civil (BRASIL, 2021) é instrumento hábil a impedir a prática reiterada de violência contra criança e adolescente em situação de vulnerabilidade. Nesse contexto, a Lei 8.069/90 foi criada com a mister de assegurar proteção integral aos menores em situação de risco e, é precisa para embasar (art. $33, \S 2^{\circ}$ ) a concessão de liminar em decisão judicial. No caso em tela, o atendimento ao pedido de socorro feito pelo genitor da criança aos advogados e estagiários do Sajug foi prontamente atendido. Sustentado em provas préconstituídas (parecer do conselheiro tutelar, gravações de áudios de conversas entre a mãe e a filha e entre o pai e a filha, boletim de ocorrência de agressões, etc.) foi ajuizada a ação e o pedido liminar de guarda provisória foi deferido imediatamente pelo magistrado. Marinoni (2.017) ensina que para ser deferida medida liminar pelo Juiz é necessário a observação de dois requisitos: o 'fumus boni iuris', que significa que há indícios de que a parte tem direito ao objeto da liminar, e o 'periculum in mora' que é o receio de dano irreparável ou de difícil reparação a tal direito discutido. Vale lembrar que é costume a guarda das crianças ficar com a mãe e, nesse caso, temos uma decisão liminar, invertendo a guarda da criança fundada em maus tratos perpetrados pela mãe e o padrasto em favor do genitor da criança.

Conclusão: Diante do exposto e com vistas à efetiva assistência à criança e adolescente vítima de violência doméstica, é possível afirmar que a medida liminar é instrumento hábil a impedir violação de direitos fundamentais, bem como, evitar a ocorrência de dano irreparável à vítima. Onde, neste caso estudado, operou-se uma justiça célere e eficaz por meio das medidas elencadas.

\section{Referências}

BRASIL. Lei n 13.105, de 16 de março de 2.015. Código de Processo Civil. Diário Oficial da União, Brasília, Seção 1, p. 1 e 51, 17 mar. 2015.

BRASIL. Lei n 8.069, de 13 de julho de 1.990. Estatuto da Criança e Adolescente. Diário Oficial da União, Brasília, Seção 1, p. 178 e 210,14 jul. 1.990.

MARINONI; Luiz Guilherme. Tutela de Urgência e Tutela de Evidência. Revista dos Tribunais. São Paulo: 2017.

Não consta nas resferências o caso concreto utilizado e citado no texto do resumo: Caro revisor, não poderei referenciar a ação judicial referida, pois ela tramita em segredo de justiça uma vez que se trata de violência em face de menor, assim, nem ao menos o número do processo pode ser divulgado, sob pena de responsabilização.

\section{SALÄO DE EXTENSÃO DA UNIPAR}

> UNIPAR 50 ANOS: Transformando vidas atrevta da educapto 27 de Outubro de 2021

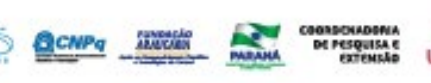




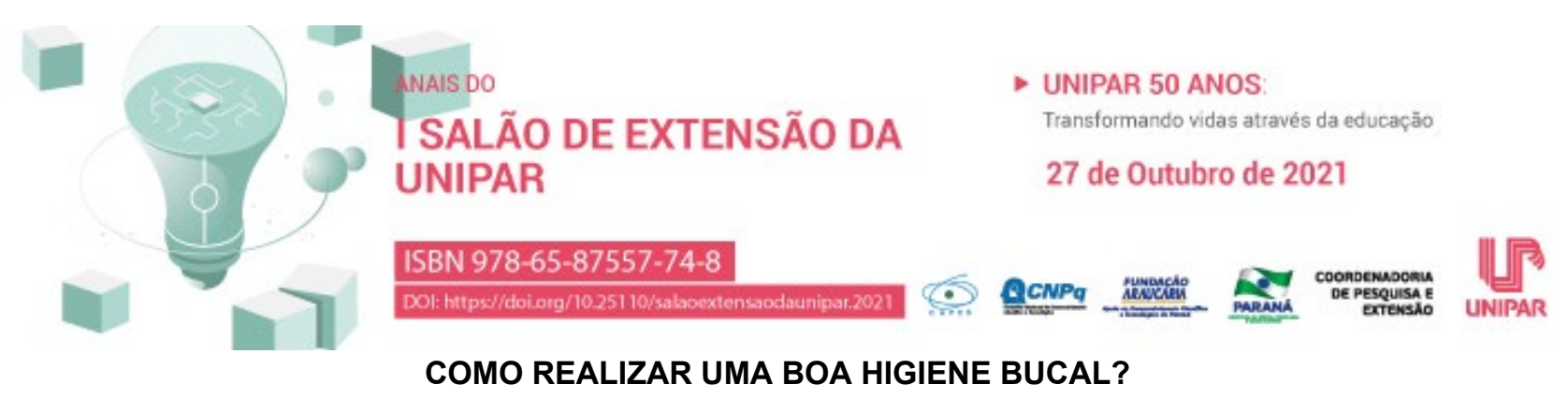

${ }^{1}$ KAMILA SALOMAO GALDINO, ${ }^{2}$ THIAGO MATHEUS LEITE SILVA, ${ }^{3}$ DEBORAH PEREIRA CARDOSO, ${ }^{4}$ HELOISA MARIA FERREIRA DA SILVA, 5 LAVINIA PRADO HERNANDES, ${ }^{6}$ CAMILLY FONTES SODRE DA SILVA, ${ }^{7}$ LAURA DA SILVA MARTINS, ${ }^{8}$ SARAH CRISTINA DA SILVEIRA, ${ }^{9}$ RAFAELA RITI ZAMBON, ${ }^{10}$ AYANY KAMILLI SILVA SOUZA, ${ }^{11}$ HELOISA SANTOS FERNANDO, ${ }^{12}$ DIEISE PALOMA SALOME, ${ }^{13}$ ANA CAROLINA SOARES FRAGA ZAZE

\footnotetext{
${ }^{1}$ Acadêmica do COPEX/UNIPAR

${ }^{2}$ Acadêmico do Curso de Odontologia da UNIPAR

${ }^{3}$ Acadêmica do Curso de Odontologia da UNIPAR

${ }^{4}$ Acadêmica do Curso de Odontologia da UNIPAR

${ }^{5}$ Acadêmica do Curso de Odontologia da UNIPAR/ PIC

${ }^{6}$ Acadêmica do Curso de Odontologia da UNIPAR

${ }^{7}$ Acadêmica do Curso de Odontologia da UNIPAR

${ }^{8}$ Acadêmica do Curso de Odontologia da UNIPAR

${ }^{9}$ Acadêmica do Curso de Odontologia da UNIPAR

${ }^{10}$ Acadêmica do Curso de Odontologia da UNIPAR

${ }^{11}$ Acadêmica do Curso de Odontologia da UNIPAR

${ }^{12}$ Acadêmica do Curso de Odontologia da UNIPAR

${ }^{13}$ Docente do curso de Odontologia da UNIPAR
}

Introdução: As principais doenças que se manifestam na cavidade bucal estão relacionadas ao acúmulo de biofilme, que contém microrganismos patogênicos, além de outros componentes. Portanto, manter um bom padrão de higiene bucal é primordial para ter uma boa saúde bucal e consequentemente, uma boa saúde geral.

Objetivo: Versar sobre os requisitos necessários para realizar uma boa higiene bucal, considerando técnicas e dispositivos indicados para o controle do biofilme dental, com o intuito de realizar atividades de educação em saúde, na comunidade.

Resultados: Para evitar a organização de microrganismos patogênicos no biofilme bucal, é necessário considerar que a boca apresenta superfícies rígidas (dentes) e descamativas (mucosa, língua e gengiva), bem como regiões de difícil acesso, principalmente dos dentes. Nas superfícies rígidas, formam-se colônias de microrganismos cariogênicos e/ou periodontopatogênicos, que possuem capacidade de adesão sobre as superfícies dos dentes. Para promover uma boa higiene bucal, é importante considerar que diversos dispositivos são necessários para desorganizar o biofilme que tende a se formar constantemente, de acordo com características anatômicas e superfícies de contatos existentes entre os dentes. $O$ uso da escova dental manual é extremamente difundido e bem aceito, entretanto, se uma técnica de escovação não for seguida, existe a tendência do biofilme não ser removido eficazmente ou da ocorrência de danos aos tecidos moles, principalmente da gengiva. Considerando o exposto, os acadêmicos participantes do projeto de extensão I"Educação direcionada à saúde bucall" foram instruídos a pesquisar sobre o tema, para que pudessem desenvolver uma proposta voltada à educação em saúde, para crianças de 5 a 10 anos de idade. Foi apresentada a ideia da confecção de um macromodelo utilizando garrafas pet, onde diferentes técnicas de escovação e do uso do fio dental podem ser demonstradas, facilitando a compreensão da explicação e melhorando a qualidade do controle do biofilme, realizado pelas crianças.

Conclusão: Os acadêmicos aprenderam sobre técnicas de escovação e dispositivos de controle do biofilme dental, bem como desenvolveram habilidades e materiais lúdicos para realizar a educação direcionada à saúde bucal na comunidade, visando a promoção de saúde.

\section{Referências}

AZEVEDO, Marina Sousa; HARTWIG, Andreia Drawanz; JUNIOR, Ivam Freira da Silva; SCHARDOSIM, Lisandrea Rocha; STUERMER, Vanessa Muller. Recursos e técnicas para a higiene bucal de pacientes com necessidades especiais. Revista da ACBO, v. 4, n. 3, 2015.Disponível em: http://www.rvacbo.com.br/ojs/index.php/ojs/article/view/272. Acesso em: 09 set. 2021.

BARROS, Olavo Bergamaschi; PERNAMBUCO, Renata de Almeida; SALGADO, Miguel Angel Castillo; TOMIT, Nilce Emy. Escovas Dentais. PGR-Pós-Grad Rev Fac Odontol São José dos Campos, v. 4, n. 1, jan./abr., 2001. Disponível 
em: https://ojs.ict.unesp.br/index.php/cob/article/view/104. Acesso em: 09 set. 2021.

BRITO, Filipe Oliveira de; MORAIS, Emanuel Rodrigues; SAMPAIO, Helena Alves de Carvalho; VERGARA, Clarice Maria Araújo Chagas.Serious games para educação em higiene bucal infantil: uma revisão integrativa e a busca de aplicativos. Ciênc. sáude coletiva, v. 25, n.8, ago., 2020. Disponível em: https://doi.org/10.1590/1413-81232020258.11782018. Acesso em: 09 set. 2021.

ANGals DO

I SALAO DE EXTENSÁOO Transformando videa atrewen da educagato

DA UNIPAR

27 de Outubro de 2021

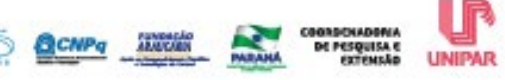




\title{
CARACTERIZAÇÃO DO SISTEMA DE PROTEÇÃO DE FONTES DE ÁGUAS DESTINADAS AO CONSUMO HUMANO DE PROPRIEDADES RURAIS DE UM MUNICÍPIO DO SUDOESTE DO PARANÁ
}

\author{
${ }^{1}$ JULIA COMACHIO FAVRETTO, ${ }^{2}$ NATIELE CHAVES DA SILVA, ${ }^{3}$ PRISCILA YANO RUTES, ${ }^{4}$ CASSIANE PARIZOTTO, \\ ${ }^{5}$ VANEZA PAULA POPLAWSKI CARNEIRO, ${ }^{6}$ VOLMIR PITT BENEDETTI
}

${ }^{1}$ Discente de Farmácia, PEX /Unipar - Francisco Beltrão PR

${ }^{2}$ Discente de Farmácia, PEX /Unipar - Francisco Beltrão PR

${ }^{3}$ Discente de Farmácia, PEX/Unipar - Francisco Beltrão PR

${ }^{4}$ Discente de Farmácia, PIBEX /Unipar - Francisco Beltrão PR

${ }^{5}$ Secretaria de Agricultura de Francisco Beltrão PR

${ }^{6}$ Docente da Unipar - Francisco Beltrão PR

Introdução: Com a crescente modificação do uso da terra, o crescimento populacional e a aceleração do desenvolvimento industrial nas últimas décadas, tornou-se notória a importância de proteger as fontes de águas naturais ou poços profundos em função da necessidade de possuir uma água com qualidade, destinada principalmente para o consumo humano. Através das atividades exercidas pela produção agrícola e a interferência humana cada vez maior no ciclo da água, é fundamental à promoção a qualidade de vida e a proteção de ambientes hídricos, que, frequentemente, possuem algum grau de contaminação. (FOSTER, 2006)

Objetivo: Este projeto possui como objetivo avaliar o sistema de proteção de fontes de águas destinadas ao consumo humano de propriedades rurais de um município do sudoeste do Paraná. Para isso foram realizadas análises de 8 (oito) amostras de água de fonte ou poços que eram utilizadas para consumo humano em propriedades rurais do município de Francisco Beltrão PR Foram analisados parâmetros físico-químico, microbiológico e parasitológico, seguindo as exigências de potabilidade segundo a PORTARIA N ${ }^{\circ} 2.914,12 / 12 / 2011$ (BRASIL, 2011). Paralelamente, foi aplicado um checklist para avaliar os fatores de risco para a contaminação das águas por agentes químicos ou biológicos.

Resultados: Analisando os resultados referentes aos fatores de risco para contaminação de águas destinadas a consumo humano, verificou-se que $25 \%$ das fontes eram classificadas como poços rasos, e $75 \%$ como minas ou nascentes. No quesito que avaliou o tipo de proteção física, encontrou-se que $50 \%$ das fontes possuíam proteção física parcial, $25 \%$ proteção integral e $25 \%$ sem proteção física. No item que analisava a proteção ciliar, verificou-se que apenas $50 \%$ possuíam mata ciliar constituída no entorno da fonte. Analisou-se também aspectos relacionado à proteção da fonte contra acesso de animais, constatou que somente $37,5 \%$ possuíam este tipo de proteção. No que se refere aos riscos de contaminação com dejetos humanos, percebeuse que $87,5 \%$ corriam o risco de contaminação com produtos químicos, $50 \%$ risco de contaminação com detritos animais e 12,5 apresentavam possibilidade de contaminação com matéria orgânica de origem humana. Finalmente, analisou-se a presença de contaminantes macroscópicos nas fontes de águas, nas quais 37,5 apresentavam algum tipo de contaminante macroscópico, sendo eles insetos, anfíbios ou algas. Observou-se no estudo que na maioria das fontes das propriedades rurais não havia um sistema de proteção completamente constituído. Sendo as mesmas de extrema importância para evitar que a água destinada a consumo humano seja contaminada.

Conclusão: Neste sentido observou-se que a ausência de um sistema de proteção de fontes bem instituído, pode representar um grave risco para as pessoas que consomem esta água. Pois como foi comentado, a criação de barreiras físicas juntamente com a preservação da mata ciliar em torno das fontes, este intimamente ligado a qualidade da água que se consome nas propriedades rurais deste município.

\section{Referências}

BRASIL. Portaria n. ${ }^{\circ} 2914$, de 12 de dezembro de 2011. Estabelece os procedimentos e responsabilidades relativos ao controle e vigilância da qualidade da água para consumo humano e seu padrão de potabilidade, e dá outras providências. Diário Oficial da União, Brasília, 12 dez., 2011.

FOSTER, S. et al. Proteção da qualidade de águas subterrâneas Guia para empresas de água, autoridades municipais e agências ambientais. 2006. Banco Mundial, Washington/EUA. 
- unIPAR 50 anos:

I SALAOO DE EXTENSÃO Transformando vidas atravies da educaģso

DA UNIPAR 


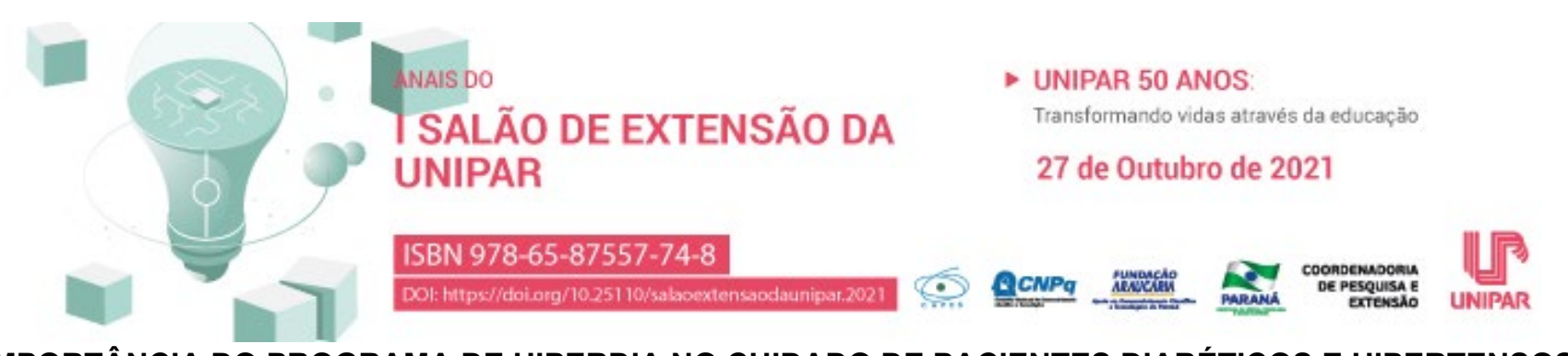

A IMPORTÂNCIA DO PROGRAMA DE HIPERDIA NO CUIDADO DE PACIENTES DIABÉTICOS E HIPERTENSOS

\author{
${ }^{1}$ LIVIA RIEDI, ${ }^{2}$ DANIELE GARCIA DE ALMEIDA SILVA
}

${ }^{1}$ Acadêmica Bolsista PIBEX/Unipar

${ }^{2}$ Docente da UNIPAR

Introdução: O Programa Hiperdia foi criado pelo Ministério da Saúde em 2002, no plano de reorganização da atenção básica a hipertensão arterial sistêmica e diabetes mellitus, afim de estabelecer muitas metas e diretrizes para a prevenção, diagnóstico, tratamento e o controle da comorbidade (BRASIL, 2001).

Objetivo: Destacar as ações do Programa de Hiperdia como uma importante estratégia de saúde pública no atendimento dos pacientes diabéticos e hipertenos.

Desenvolvimento: O Programa de Hiperdia tem o objetivo de cadastrar e acompanhar todos os pacientes hipertensos e diabéticos através do cuidado especial, para que consiga fazer um controle das doenças e assim garantir uma qualidade de vida aos pacientes (PEREIRA, 2013). Os melhores benefícios da hiperdia se destacam a orientação aos gestores públicos na adoção de estratégias de intervenção, para melhor conhecer o perfil epidemiológico da hipertensão arterial e da diabetes mellitus na população (SANTOS, 2018). A classificação dos medicamentos para o tratamento dessas doenças, que são destribuidos pelo SUS, sendos eles: Captopril 25mg, Hidroclorotiazida 25mg e Cloridrato de Propanolol 40mg (anti-hipertensivos); Insulina NPH100, Glibenclamida 5mg, e Metformina 850mg (hipoglicemiantes) (PAULA, 2011). O Hiperdia forma-se um mecanismo de acompanhamento dos usuários hipertensos e diabéticos com as funções de vincular o paciente a equipe saúde da família de sua escolha, para a realização de uma assistência continua e de qualidade a fornecer os medicamentos de forma regular (SOUZA, 2015). A execução do sistema padronizado de acompanhamento dos pacientes buscar intervir aos fatores de risco e manter o controle mais efetivo da HAS e DM. Tais morbidades apresentam diversos fatores que alteram o controle e as descompensam, desta maneira é esperado também, que a equipe possa dar a continuidade, complementando cada vez mais esforços na abordagem multidisciplinar que estas morbidades requisitas.

Considerações Finais: Após o estudo realizado sobre os benefícios do programa que pode atuar na prevenção e controle das patologias e eventualmente reduzir os possiveis agravos dos pacientes portadores de Diabetes e Hipertensão. Sendo assim é de extrema importância o acompanhamento mensal a esses usuários para conscientizar sobre as mudanças dos hábitos de vida, para prevenir estas doenças patológicas é de suma importância para que possuam uma qualidade de vida melhor e evitem novas complicações. Podemos perceber que a melhor forma para conscientizar todos é através de palestras educativas ou até mesmo orientações individuais, para explicar a população a importância da prevenção do controle. O estudo demonstrou a importância do Programa Hiperdia para ajudar os pacientes que são portadores a enfrentarem e aderir ao tratamento. Desde que seja desenvolvido por uma equipe multidisciplinar.

\title{
Referências
}

BRASIL. MINISTÉRIO DA SAÚDE. Departamento de Atenção Básica. Área Técnica de Diabetes e Hipertensão Arterial. Hipertensão arterial sistêmica (HAS) e Diabetes mellitus (DM): protocolo / Ministério da Saúde, Departamento de Atenção Básica. Área Técnica de Diabetes e Hipertensão Arterial. Brasília: Ministério da Saúde, 2001.

PAULA, PAB. et al. O uso do medicamento na percepção do usuário do Programa Hiperdia. Revista Ciência \& Saúde Coletiva, 16(5):2623-2633, Rio de Janeiro, 2011.

PEREIRA, Tiago Spizziri. Contribuições do hiperdia no controle dos pacientes hipertensos. Universidade Federal de Minas Gerais. Faculdade de Medicina. Núcleo de Educação em Saúde Coletiva . Belo Horizonte, 2013. 47f.Monografia (Especialização em Atenção Básica em Saúde da Família).

SANTOS, Aliny de Lima, SILVA, Elza Monteiro, MARCON, Sonia Silva. Assistência as pessoas com diabetes no hiperdia: potencialidades e limites a perspectiva de enfermeiro. Disponível. em: https://www.scielo.br/j/tce/a/gT4mFsZGMcPNTSvywD7rNBq/?format=pdf\&lang=pt 2018; 27(1):e2630014

SOUZA, Claudianara, Osana, PISSAIA, Ediane. SILVA, Diuslene, Rodrigues, O programa hiperdia como tratamento para pacientes portadores de hipertensão arterial e diabetes mellitus. 2015. Disponível em: http://tcconline.fag.edu.br:8080/app/webroot/files/trabalhos/20181209-225608.pdf.

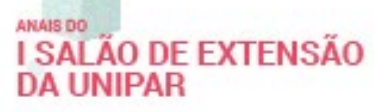

I SALĀO DE EXTENSÃO
DA UNIPAR

(2) DA UNIPAR
UNIPAR 50 ANOS:
Transformando vidas atrawis da educagato
27 de Outubro de 2021

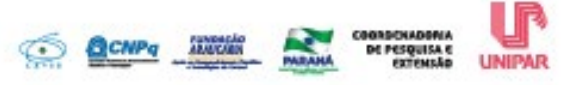




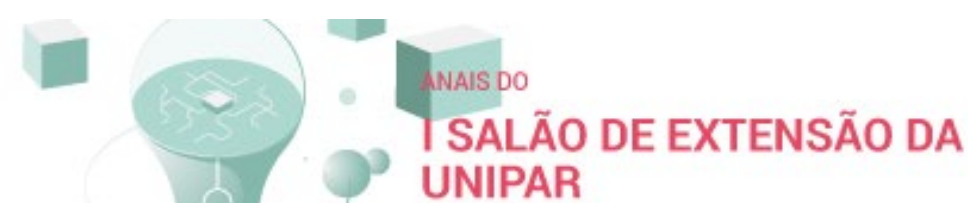 \\ - UNIPAR 50 ANOS: \\ Transformando vidas através da educação \\ 27 de Outubro de 2021 \\ ISBN 978-65-87557-74-8 \\ DOl: hitps//doiorg/10.251 10/saboextensadaunipar.2021 \\ QCNPq Awoctin

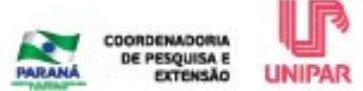 \\ APRESENTAÇÃO DA MANOBRA DE HEIMLICH EM RECÉM NASCIDOS PARA PUÉRPERAS NA MATERNIDADE NOROSPAR
}

\author{
${ }^{1}$ LUANA GABRIELY BATISTA DA SILVA, ${ }^{2}$ MATEUS DA SILVA CAMOSSATO, ${ }^{3}$ JESSICA AYUMI OKADA, ${ }^{4}$ LEONARDO DE \\ OLIVEIRA SILVA, ${ }^{5}$ AMANDA NASCIMENTO VASQUES DE SOUZA, ${ }^{6}$ NANCI VERGINIA KUSTER DE PAULA
}

\author{
${ }^{1}$ Acadêmico do Curso de Enfermagem da UNIPAR \\ ${ }^{2}$ Acadêmico do Curso de Enfermagem da UNIPAR \\ ${ }^{3}$ Acadêmica do Curso de Enfermagem da UNIPAR \\ ${ }^{4}$ Acadêmico do Curso de Enfermagem da UNIPAR \\ ${ }^{5}$ Docente da UNIPAR \\ ${ }^{6}$ Docente da UNIPAR
}

Introdução: Observando o cenário atual, a obstrução das vias aéreas em recém nascidos pode ser fatal, além disso, $44 \%$ das gestantes relatam desconhecimento da manobra de Heimlich (SANTOS; PAES, 2020). Evidentemente $90 \%$ dos acidentes fatais ocorrem por objetos estranhos em crianças menores que 5 anos, ademais, a ausência de respiração em recém nascidos apresenta-se nomeadamente por cianose que, se caracteriza por roxidão na face e veias do pescoço aparentes, falta de choro $\mathrm{e}$ ausência de resposta (DA SILVA; et al., 2017)

Objetivo: Descrever as atividades desenvolvidas para o ensino da manobra Heimlich em recem nascidos para puérperas da maternidade do hospital Norospar.

Resultados: A atividade foi realizada pelos acadêmicos de enfermagem do projeto de extensão Enfermagem nos diferentes ciclos da vida no hospital Norospar de Umuarama, com 23 puérperas e acompanhantes, das quais 13 pessoas ouviram falar sobre a manobra de Heimlich, mas nunca realizaram, apenas 1 pessoa já havia realizado, e 9 participantes nunca tiveram contato com o assunto. Após explicar os procedimentos em caso de falta de ar e engasgo, as puérperas relataram ter entendido a necessidade da manobra. Foi apresentada a técnica correta da manobra, bem como, identificar quando o recém nascido não estiver respirando e verificar se teve o desengasgo. Para atingir os objetivos propostos foram utilizados bonecos na demonstração das manobras, onde foram destacados 8 passos seguindo orientações da American Heart Association (AHA), que descreve a técnica de desengasgo em lactente, destacando a posição que bebê deve ficar, como devem ser aplicadas as pancadas nas costas e se necessário a aplicação de compressões torácicas.

Conclusão: $O$ conhecimento dessa manobra possibilita a chance de sobrevida até a chegada de um suporte avançado para salvar a vida do recém nascido e educar as puérperas aumenta a segurança no cuidado com o recém-nato.

\section{Referências}

DA SILVA, Tatiane Lima et al., SABERES DA COMUNIDADE ACERCA DA APLICAÇÃO DA MANOBRA DE HEIMLICH: ação de uma liga acadêmica em saúde. In: $\mathbf{1 3}^{\circ}$ Congresso Internacional Rede Unida. 2017.

SANTOS, Victória; PAES, Luciana Braz de Oliveira. Avaliação do conhecimento materno sobre manobra de heimlich: construção de cartilha educativa. CuidArte, Enferm, p. 219-225, 2020.

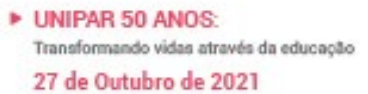

Transformando vides atrave

27 de Outubro de 202
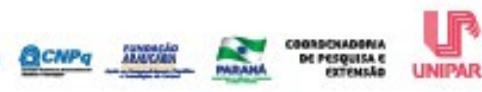


\section{(1) DUNIPAR 50 ANOS \\ SALÃO DE EXTENSÃO DA Transformando vidas através da educą̧̧̄o UNIPAR \\ PERCEPÇÃO DOS ACADÊMICOS DO CURSO DE ODONTOLOGIA DA UNIPAR- CASCAVEL SOBRE TRAUMA DENTO ALVEOLAR}

${ }^{1}$ LUCAS GARCIA VIEIRA SOUZA, ${ }^{2}$ PEDRO HENRIQUE ROLDE, ${ }^{3}$ ADRIELLY SANTOS MEDEIROS, ${ }^{4}$ ANDRESSA MARTINS DE CARVALHO, ${ }^{5}$ BRUNA MIRELLA FELICIANO DA SILVA, ${ }^{6}$ CAMILA MARTIN, ${ }^{7}$ CAROLINA MACHADO DE CRISTO, ${ }^{8}$ FELIPE PEIXOTO BURMANN, ${ }^{9}$ GABRIELA CORDEIRO GELINSKI, ${ }^{10}$ GUILHERME FERRABOLI, ${ }^{11}$ GUSTAVO BONNER CARRASCO OLIVEIRA, ${ }^{12}$ JULIANA GARCIA MUGNAI VIEIRA SOUZA

\footnotetext{
${ }^{1}$ Discente do Curso de Odontologia UNIPAR - Cascavel PR

${ }^{2}$ Discente do curso de Odontologia da UNIPAR- Cascavel PR

${ }^{3}$ Discente do curso de Odontologia da UNIPAR- Cascavel PR

${ }^{4}$ Discente do Curso de Odontologia da UNIPAR- Cascavel PR ${ }^{5}$ Discente do curso de Odontologia da UNIPAR- Cascavel PR ${ }^{6}$ Discente do Curso de Odontologia da UNIPAR- Cascavel PR ${ }^{7}$ Discente do Curso de Odontologia da UNIPAR- Cascavel PR ${ }^{8}$ Discente do Curso de Odontologia da UNIPAR- Cascavel PR ${ }^{9}$ Discente do Curso de Odontologia da UNIPAR- Cascavel PR ${ }^{10}$ Discente do curso de Odontologia da UNIPAR- Cascavel PR ${ }^{11}$ Discente do curso de Odontologia da UNIPAR- Cascavel PR ${ }^{12}$ Docente da UNIPAR-Campus Cascavel
}

Introdução: $O$ traumatismo alvéolo-dentário (TAD) é um dos principais agravos de saúde bucal em todo o mundo, juntamente com a doença cárie e o câncer bucal (PETERSEN et al., 2005). É um problema comum na Odontologia que influencia negativamente na qualidade de vida das pessoas (SOUZA et al.; 2018). O alto índice de violência, de acidentes automobilísticos e grande participação de crianças e adolescentes em esportes violentos tem contribuído para a transformação do traumatismo dentário em problema crescente de saúde pública. Os traumas dentários podem acarretar danos de vários tipos, que envolvem desde a fratura do esmalte até a fratura óssea (SOARES; SOARES, 1998; TRAEBERT; MARCON; LACERDA, 2010).

Objetivo: O objetivo deste trabalho foi avaliar o conhecimento dos acadêmicos de odontologia da UNIPAR, campus Cascavel, frente a um trauma dento alveolar.

Metodologia: A amostra do estudo foi composta por 63 acadêmicos do $2^{\circ}, 3^{\circ}$ e $4^{\circ}$ ano de odontologia da UNIPAR campus Cascavel no ano de 2020, os quais responderam o questionário antes de participarem do projeto de extensão Prevenção do traumatismo dental .

Resultados: Sendo $71,4 \%(n=45)$ indivíduos do sexo feminino e $28,6 \%(n=18)$ do sexo masculino. A faixa de idade foi de 18 a 52 anos. Quando questionados se já receberam algum tipo de informação sobre traumatismo dento alveolar antes da pesquisa, $79,4 \%(n=50)$ dos acadêmicos de odontologia afirmaram que sim e $20,6 \%(n=13)$ dos alunos de odontologia afirmaram que nunca receberam informações sobre o assunto. A maioria $(66,7 \%)(n=42)$ nunca sofreu ou presenciou uma situação de trauma dental e $33,3 \%(n=21)$ já sofreu ou presenciou. Sobre o conhecimento de avulsão dentária, $88,9 \%(n=56)$ dos acadêmicos de odontologia sabiam que avulsão é o deslocamento completo do dente, $1,6 \%(n=1)$ disseram que é deslocamento parcial do dente e $1,6 \%(n=1)$ disseram que é deslocamento do dente para dentro, os outros $7,9 \%(n=5)$ não souberam responder (tabela 2).

Conclusão: Conclui-se que o cirurgião-dentista deve ter conhecimentos científico e clínico suficientes para avaliar, diagnosticar e realizar a conduta adequada, tendo em vista que os tipos de traumatismos dentoalveolares são variados e podem comprometer a saúde do paciente.

\section{Referências}

PETERSEN, Poul Erik. et al. The global burden of oral diseases and risks to oral health. World Health Organ, v. 83, p. 661-669, 2005.

SOARES, Iara Maria Lohmann; SOARES, Ilson José. Técnica do reimplante dental: tratamento dos dentes traumatizados e conduta clínica para reimplantação. RGO, v. 36, n. 5, p. 331-336, 1998.

SOUZA, Juliana Garcia Mugnai Vieira; LAZZARIN, Helen Cristina; ZENI, Bruna Cristina; FILIPIN, Carla Letícia; BERF, Cínthia 
Laís; ZILIO, Thainara Hellen. Conhecimento dos responsáveis das crianças atendidas na clínica odontológica da unipar campus cascavel - Pr sobre traumatismo alvéolo dentário. Odontol. Clín.-Cient., Recife, v. 17, n. 1, p. 33 - 38, jan./mar. 2018.

TRAEBERT, Jefferson; MARCON, Karine Boneti; LACERDA, Josimari Telino. Prevalência de traumatismo dentário e fatores associados em escolares do município de Palhoça (SC). Ciên Saúde coletiva, v. 15, supl 1, 2010.

I SALĂOO DE EXTENSÃO

DA UNIPAR
- unIPAR 50 anos.

Transformando vidas atravta da educaģto

27 de Outubro de 2021

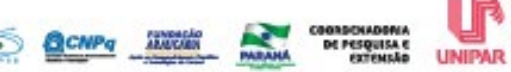




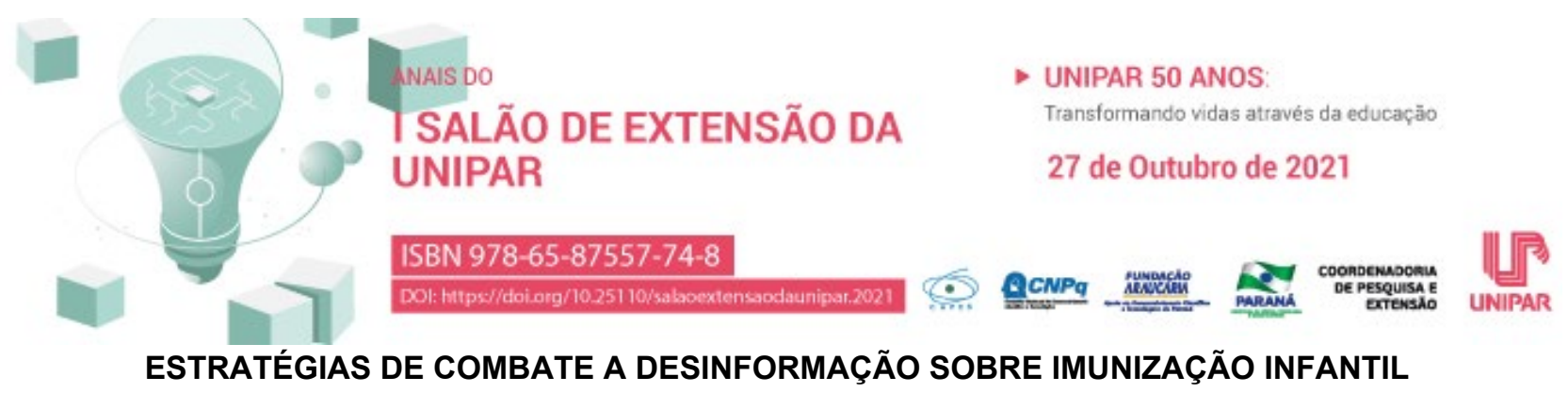

\title{
${ }^{1}$ GABRIEL RIBEIRO DA SILVA, ${ }^{2}$ NEUSA VIANA LOPES, ${ }^{3}$ KATIA BIAGIO FONTES
}

\author{
${ }^{1}$ Acadêmico do Curso de Enfermagem da UNIPAR \\ ${ }^{2}$ Enfermeira Responsável pelo Pronto Atendimento Ambulatorial de Enfermagem da Unipar \\ ${ }^{3}$ Docente da UNIPAR
}

Introdução: É comprovado que a vacinação infantil é de grande relevância na proteção à saúde e na prevenção de doenças imunopreveníveis, além de evitar a ocorrência de surtos epidêmicos. Porém, a saúde é um bom meio de cultura para boatos e rápida circulação de notícias. Isso acontece, em parte, porque a maior parte da população tem pouco conhecimento sobre a área e, em parte, pela ansiedade que causam as notícias sobre doenças e epidemias. As informações contraditórias sobre vacinas na mídia e nas redes sociais podem ser um mecanismo que gera e perpetua uma cultura de hesitação vacinal. Fatores esses que podem, portanto, comprometer a ampliação da cobertura vacinal. Quanto maior o percentual de crianças vacinadas, maior será o controle de qualquer doença.

Objetivo: Identificar na literatura científica sobre estratégias de enfrentamento para o combate a desinformação sobre a imunização, visando a ampliação da cobertura vacinal.

Resultados: Uma das principais estratégias do Sistema Único de Saúde (SUS) são as unidades de saúde, é lá que as equipes conseguem ter maior proximidade com os responsáveis, visto que as atitudes e crenças dos pais envolvem o processo de tomada de decisão na imunização de seus filhos, a proposta é a realização de uma campanha de combate à desinformação, por meio da educação dos pais a fim de compreenderem a importância da vacinação. Sendo assim um campo propício para promoção de ações educativas e esclarecimento de dúvidas da população local. Informações adequadas sobre os benefícios das vacinas, bem como sobre esquema vacinal, o número de doses necessárias para completar o calendário vacinal, elucidação de possíveis mitos sobre a imunização, divulgação de informes são algumas das ações que contribuem para maior adesão, menor taxa de abandono e promoção da saúde.

Conclusão: Pode-se concluir que as estratégias de enfrentamento apontadas na literatura sugerem que sejam desenvolvidas ações educativas com os pais ou responsáveis com a finalidade de informar sobre a importância da imunização,entre elas: elucidação de dúvidas e mitos, informações sobre doenças imunopreveníveis, benefícios das vacinas, esquema vacinal, doses necessárias e confecção de informes.

\section{Referências}

SOUSA, Caio Cesar Fernandes de et al. O conhecimento sobre o calendário infantil até 15 meses de idade entre seus acompanhantes e os profissionais de saúde. 2018. $41 \mathrm{f}$. Trabalho de Conclusão de Curso (Bacharel em Medicina). Orientador: Prof. Dr Marcelo Cecílio Daher. 2018- Centro Universitário de Anápolis - UniEVANGÉLICA, Goiás, 2018. Disponível em: http://repositorio.aee.edu.br/bitstream/aee/845/1/1.pdf Acesso em: 10 ago. 2021.

HENRIQUES, Cláudio Maierovitch Pessanha. A dupla epidemia: febre amarela e desinformação. Reciss: Revista Eletrônica de Comunicação, Informação e Inovação em Saúde, v.12, n.1, jan./mar., $2018 . \quad$ Disponível em:https://doi.org/10.29397/reciis.v12i1.1513. Acesso em: 10 ago. 2021.

FERNANDES, Jorge Luiz Marques et al. A influência da desinformação e propagação de notícias falsas (fake news) para a baixa cobertura vacinal no município de Campinas. Revista Qualidade HC,2020.Disponível em:https://www.hcrp.usp.br/revistaqualidade/uploads/Artigos/364/364.pdf. Acesso em 09 ago. 2021.

SANTOS, Mariana Quinta de Sousa et al. O conhecimento sobre o calendário vacinal infantil até 15 meses de idade entre seus acompanhantes e os profissionais de saúde. Brazilian Journal of Development, v. 6, n.4, p. 18262-18276, 2020. Disponível em: https://webcache.googleusercontent.com/search?

q=cache:fiTqkaiC8fEJ:https://www.brazilianjournals.com/index.php/BRJD/article/download/8600/7391+\&cd=2\&hl=pt-

BR\&ct=clnk\&gl=br. Acesso em: 09 ago. 2021.

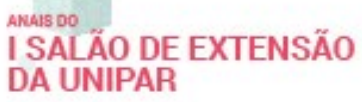

DA UNIPAR

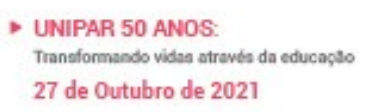

27 de Outubro de 2021

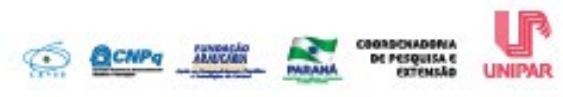




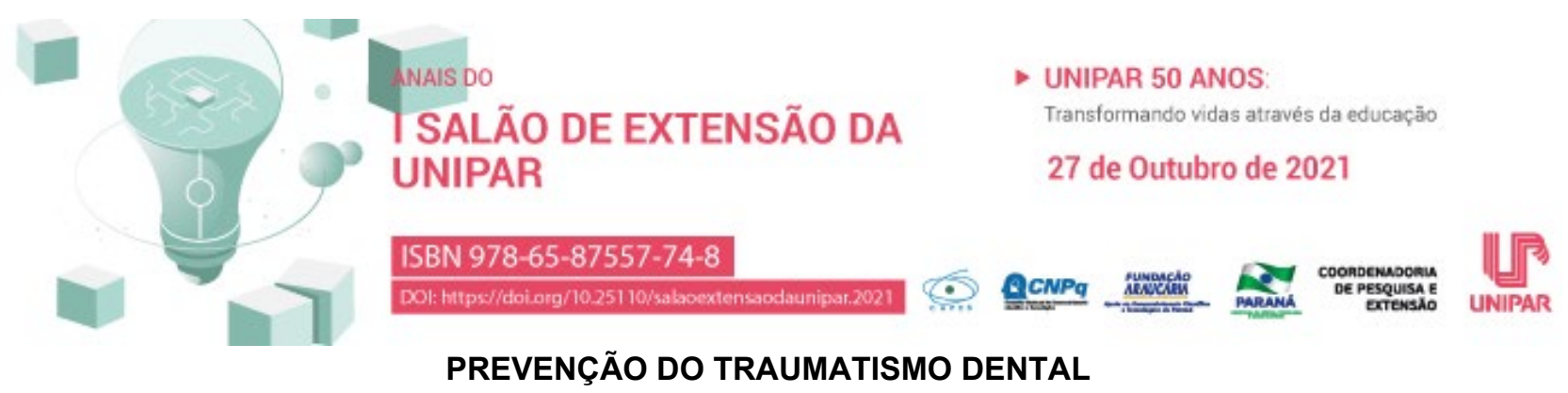

${ }^{1}$ PEDRO HENRIQUE ROLDE, ${ }^{2}$ LUCAS GARCIA VIEIRA SOUZA, ${ }^{3}$ HENRIQUE HUBNER DE OLIVEIRA, ${ }^{4}$ IZADORA FRANCESCHET FARIAS, ${ }^{5}$ JENNIFER LORENSINI DOS SANTOS, ${ }^{6} \mathrm{JESSILY} \mathrm{VITORIA} \mathrm{NUNES} \mathrm{SERRA} \mathrm{CARMO,}{ }^{7}$ KAMYLA RAFAELLY BIAZI DE OLIVEIRA, ${ }^{8}$ KARINA FIDELI KASSAB, ${ }^{9}$ KATLHEEN MAYARA DE SOUZA, ${ }^{10}$ LEONARDO CASAGRANDE DE ARAUJO, ${ }^{11}$ MARIA EDUARDA SCHREINER, ${ }^{12}$ RAFAELLY BARCELOS ESTEVAO DA SILVA, ${ }^{13}$ RICARDO RIGO PIGNATARO, ${ }^{14}$ VICTOR HUGO FERREIRA GNOATTO, ${ }^{15}$ JULIANA GARCIA MUGNAI VIEIRA SOUZA

${ }^{1}$ Discente do curso de Odontologia da UNIPAR- Cascavel PR

${ }^{2}$ Discente do Curso de Odontologia da UNIPAR- Cascavel PR ${ }^{3}$ Discente do curso de Odontologia da UNIPAR- Cascavel PR ${ }^{4}$ Discente do curso de Odontologia da UNIPAR- Cascavel PR ${ }^{5}$ Discente do curso de Odontologia da UNIPAR- Cascavel PR ${ }^{6}$ Discente do curso de Odontologia da UNIPAR- Cascavel PR ${ }^{7}$ Discente do curso de Odontologia da UNIPAR- Cascavel PR ${ }^{8}$ Discente do curso de Odontologia da UNIPAR- Cascavel PR ${ }^{9}$ Discente do Curso de Odontologia da UNIPAR- Cascavel PR ${ }^{10}$ Discente do curso de Odontologia da UNIPAR- Cascavel PR ${ }^{11}$ Discente do curso de Odontologia da UNIPAR- Cascavel PR ${ }^{12}$ Discente do curso de Odontologia da UNIPAR- Cascavel PR ${ }^{13}$ Discente do curso de Odontologia da UNIPAR- Cascavel PR ${ }^{14}$ Discente do curso de Odontologia da UNIPAR- Cascavel PR ${ }^{15}$ Docente da UNIPAR-Campus Cascavel

Introdução:O traumatismo dental é uma situação que requer atendimento imediato e cauteloso, exigindo do paciente agilidade e manejo correto diante dessa situação. Porém, muitos pacientes e responsáveis por crianças e adolescentes geralmente não tem conhecimento das orientações corretas sobre como atuar diante de tal situação levando à inviabilização de muitos procedimentos que poderiam ser executados imediatamente pelo cirurgião-dentista (PETERSEN et al., 2005; TRAEBERT; MARCON; LACERDA, 2010).). Este profissional deve apresentar competência e domínio da situação, pois, além do conhecimento necessário para o atendimento em caráter de urgência, os responsáveis e o próprio acidentado chegam muitas vezes assustados, necessitando que o profissional os tranquilize (PETERSEN et al., 2005). O traumatismo alvéolo dentário é um problema que influencia negativamente na qualidade de vida das pessoas. As consequências do trauma podem variar desde uma simples fratura até avulsão, sendo este um dos eventos que provocam maior apreensão aos pais e aos acidentados (SOUZA, 2018). O trauma dento-alveolar tem se tornado muito prevalente, uma vez que se tem feito a inclusão mais precoce de crianças e adolescentes em atividades desportivas, academias de luta e musculação, além do consequente aumento da violência e imprudências no trânsito, podendo atingir pessoas de todas as faixas etárias, bem como qualquer uma das dentições, a decídua ou a permanente.

Objetivo: é realizar ações educativas e preventivas sobre traumatismos dento-alveolares para escolares.

Metodologia: Devido à pandemia não está sendo possível a realização do projeto presencialmente, mas os acadêmicos dos $2^{\circ}$, $3^{\circ}$ e $4^{\circ}$ ano confeccionam panfletos educativos para os escolares sobre a prevenção ao traumatismo dental, e enviado as escolas de Cascavel- PR. A educação e divulgação de prevenção do trauma dentário, bem como dos procedimentos pós -trauma são essenciais para que, mesmo frente a esta situação adversa, sejam diminuídos os riscos e consequências ao paciente.

Conclusão: A maioria dos escolares e professores nunca receberam informações sobre trauma dental nas escolas. Cabe aos futuros cirurgiões dentistas e cirurgiões dentistas desenvolverem ações educativas para entendimento dessa população frente ao trauma dental.

\section{Referências}

PETERSEN, Poul Erik. et al. The global burden of oral diseases and risks to oral health. World Health Organ, v. 83, p. 661-669, 2005. 
SOUZA, Juliana Garcia Mugnai Vieira ; LAZZARIN, Helen Cristina ; ZENI, Bruna Cristina ; FILIPIN, Carla Letícia ; BERF,Cínthia Laís ; ZILIO, Thainara Hellen. Conhecimento dos responsáveis das crianças atendidas na clínica odontológica da unipar campus cascavel - Pr sobre traumatismo alvéolo dentário. Odontol. Clín.-Cient., Recife, v. 17, n. 1, p. 33 - 38, jan./mar., 2018.

TRAEBERT, Jefferson ; MARCON, Karine Boneti; LACERDA, Josimari Telino. Prevalência de traumatismo dentário e fatores associados em escolares do município de Palhoça (SC). Ciên Saúde coletiva, v. 15, supl 1, 2010.
I SALÄO DE EXTENSÃO
- UNIPAR 50 anos:
DA UNIPAR
Tranefformando vides atrewta da educaglo
27 de Outubro de 2021

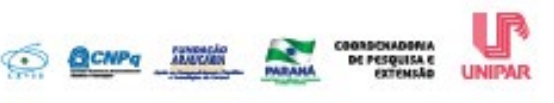




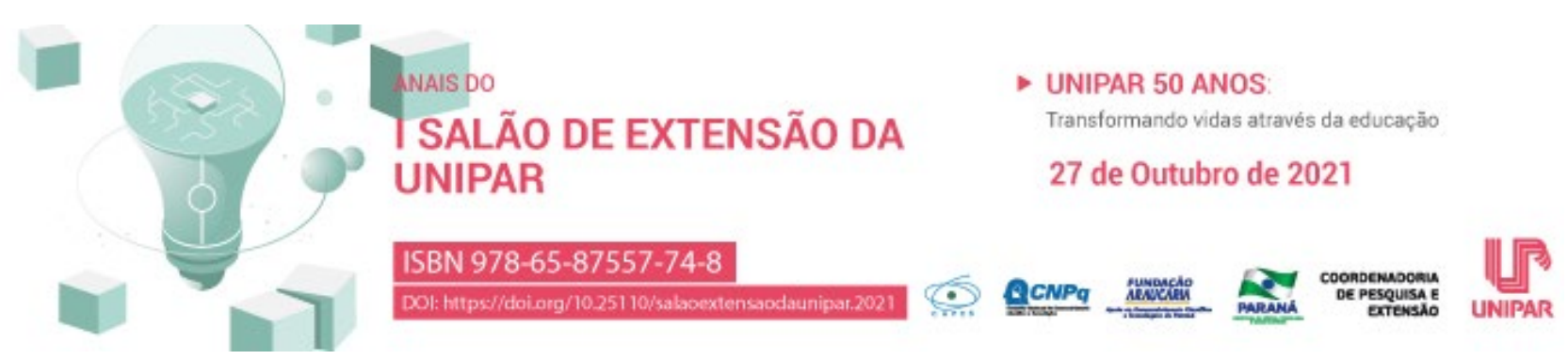

LIGA ACADEMICA EM CIRURGIA E TRAUMATOLOGIA BUCO-MAXILO-FACIAL

${ }^{1}$ GABRIEL MACIEL DA SILVA, ${ }^{2}$ BEATRIZ AYUMI SHIOTANI, ${ }^{3} \mathrm{HELOISA} \mathrm{GARCIA} \mathrm{FRANCOZO,}{ }^{4}$ GABRIELA ZANUTO DE LIMA, ${ }^{5}$ JOAO MURILO GONCALVES GAZOLA, ${ }^{6}$ GUSTAVO BARBOSA CORREA DE MORAIS, ${ }^{7}$ EMANUELLY CRISTINA MIRANDA SARMENTO, ${ }^{8}$ ISABELLA CARDOSO MARTINS, ${ }^{9}$ ELOISA PIANTONI BONONI, ${ }^{10}$ JOAO PEDRO SILVA, ${ }^{11}$ LETICIA SENGER DE PAULA, ${ }^{12}$ ANDRESSA VENTRAMELI DE ANDRADE, ${ }^{13}$ LEISLE VERONICA PRESTES, ${ }^{14}$ ANA CAROLINE DOS SANTOS GRUNOW, ${ }^{15}$ MATHEUS CAZARIN MALDONADO GARCIA, ${ }^{16}$ GIORDANO BRUNO DE OLIVEIRA MARSON

\footnotetext{
${ }^{1}$ Acadêmico PIBIC/UNIPAR

${ }^{2}$ Acadêmica do Curso de Odontologia da UNIPAR

${ }^{3}$ Acadêmica do Curso de Odontologia da UNIPAR

${ }^{4}$ Acadêmica do Curso de Odontologia da UNIPAR

${ }^{5}$ Acadêmico do Curso de Odontologia da UNIPAR

${ }^{6}$ Acadêmico do Curso de Odontologia da UNIPAR

${ }^{7}$ Acadêmica do Curso de Odontologia da UNIPAR

${ }^{8}$ Acadêmica do Curso de Odontologia da UNIPAR

${ }^{9}$ Acadêmica do Curso de Odontologia da UNIPAR

${ }^{10}$ Acadêmico do Curso de Odontologia da UNIPAR

${ }^{11}$ Acadêmica do Curso de Odontologia da UNIPAR

${ }^{12}$ Acadêmica do Curso de Odontologia da UNIPAR

${ }^{13}$ Acadêmica do Curso de Odontologia da UNIPAR

${ }^{14}$ Acadêmica do Curso de Odontologia da UNIPAR

${ }^{15}$ Acadêmico do Curso de Odontologia da UNIPAR

${ }^{16}$ Docente da UNIPAR
}

Introdução: A Liga Acadêmica em Cirurgia e Traumatologia Buco-Maxilo-Facial - LACTBMF- foi criada para estimular a troca de vivências e informações técnico-científicas em Cirurgia e Traumatologia Buco-Maxilo-Facial (CTBMF), entre alunos de graduação em Odontologia. Este é um relato do processo de criação e organização da primeira Liga Acadêmica do curso de graduação em Odontologia da Universidade Paranaense. Atualmente, as LA estão em processo de expansão no cenário do ensino contemporâneo, coincidindo com as reformas curriculares que foram realizadas nos mais variados cursos (CAVALCANTE et al, 2018).

Objetivo: Relatar o processo de criação da Liga Acadêmica em Cirurgia e Traumatologia Buco-Maxilo-Facial da Unipar e seus resultados iniciais.

Metodologia: Para dar início ao processo de criação da Liga, 3 alunos do curso de graduação em Odontologia se uniram e convidaram 1 professor para ser coordenador e todos juntos definiram a organização da liga. O projeto foi criado em 2019 para realizar encontros quinzenais, de cerca de 1 hora, os quais há discussão sobre temas da área baseados em casos clínicos e artigos científicos pelos ligantes. Também, objetiva promover e organizar eventos abertos à comunidade acadêmica com especialistas convidados e compartilhar através das redes sociais informações atuais e relevantes na área de cirurgia.

Resultados: A liga teve início no ano de 2019 e, desde então, manteve seus encontros quinzenais de cerca de 1 hora por meio da plataforma Google Meet entre os ligantes. Foi criada também uma página da liga no Instagram, e com o uso dessa ferramenta, houve também a troca de informações com outras Ligas de CTBMF e divulgação de conteúdo online sobre a especialidade promovidos por outras entidades.

Conclusão: É evidente que a LACTBMF vem aumentando e instigando os alunos da graduação a estudar e saber mais sobre essa área de atuação do Cirurgião Dentista.

\section{Referências}

CAVALCANTE, Ana Suelen Pedroza et al. As ligas acadêmicas na área da saúde: lacunas do conhecimento na produção científica brasileira. Revista Brasileira de educação médica, v. 42, p. 199-206, 2018. 
- unIPAR 50 anos:

I SALAOO DE EXTENSÃO Transformando vidas atravies da educaģso

DA UNIPAR 


\section{ADEQUAÇÃO DO AMBIENTE DE CRIAÇÃO DE GALINHAS POEDEIRAS CRIADAS A PASTO DE ACORDO COM O PADRÃO DA HUMAN FARM ANIMAL CARE}

${ }^{1}$ GUSTAVO MARCOS FAGIANI, ${ }^{2}$ GUSTAVO POMARO, ${ }^{3}$ ANA LUISA CANO, ${ }^{4}$ ANA KARLA FAVORETTO, ${ }^{5}$ HELOYSA PIRES, ${ }^{6}$ LEILA ALVES DE OLIVEIRA, ${ }^{7}$ VINICIUS AUGUSTO SILVA DIAS, ${ }^{8}$ RAFAELA FLÓES DAVILA, ${ }^{9}$ GEYSIANE MOREIRA GEROTTI, ${ }^{10}$ GIOVANA DANTAS GROSSI, ${ }^{11}$ VICTORIA DOS REIS VOLPATTO, ${ }^{12}$ SARAH LISSONI COBO, ${ }^{13}$ NATIELLI BELOTTI PAIE, ${ }^{14}$ LUCIANA KAZUE OTUTUMI FARIAS

${ }^{1}$ Acadêmico do curso de medicina veterinária da UNIPAR, PEX, UNIPAR

${ }^{2}$ Acadêmico do Curso de Medicina Veterinária da UNIPAR, PEX, UNIPAR

${ }^{3}$ Acadêmica do Curso de Medicina Veterinária da UNIPAR, PEX, UNIPAR

${ }^{4}$ Acadêmica do Curso de Medicina Veterinária, bolsista PIBIC, PEX, UNIPAR

${ }^{5}$ Acadêmica do Curso de Medicina Veterinária da UNIPAR, PEX, UNIPAR

${ }^{6}$ Doutoranda em Ciência Animal com Ênfase em Produtos Bioativos, UNIPAR, taxista PROSUP/CAPES

${ }^{7}$ Acadêmico do Curso de Medicina Veterinária da UNIPAR, PEX, UNIPAR

${ }^{8}$ Acadêmica do Curso de Medicina Veterinária da UNIPAR, PEX, UNIPAR

${ }^{9}$ Mestranda em Ciência Animal com Ênfase em Produtos Bioativos, PEX, UNIPAR

${ }^{10}$ Acadêmica do Curso de Medicina Veterinária da UNIPAR, bolsista PIBIC, PEX, UNIPAR

${ }^{11}$ Acadêmica do Curso de Medicina VeterinÃ ria da UNIPAR

${ }^{12}$ Acadêmica do Curso de Medicina Veterinária da UNIPAR, PEX, UNIPAR

${ }^{13}$ Acadêmica do Curso de Medicina Veterinária da UNIPAR, PEX, UNIPAR

${ }^{14}$ Professora do curso de Medicina Veterinária e do Programa de Pós-graduação em Ciência Animal - UNIPAR

Introdução: A criação de galinhas poedeiras de ovos para consumo vem aumentando ao longo dos anos. Dados da Associação Brasileira de Proteína Animal - ABPA (2021) referente ao ano de 2020 demonstrou que a produção de ovos ultrapassou 53 bilhões de unidades oriundos de 124.317.339 milhões de galinhas alojadas. Além disso, cada vez mais aumenta o interesse pela criação de galinhas poedeiras livre de gaiolas, com acesso ao pasto. A Human Farm Animal Care (HFAC) é uma entidade sem fins lucrativos que tem a missão de melhorar a vida dos animais de produção estabelecendo padrões relacionados ao bem-estar, garantindo ao consumidor acesso a produtos certificados de acordo com o estabelecido no referencial de bem-estar para galinhas poedeiras e que segue as diretrizes da Royal Society for the Prevention of Cruelty to Animals (RSPCA), sendo a base para a certificação pelo programa Certified Humane (HFAC, 2018). Na criação de galinhas a pasto as aves ficam soltas no galpão e devem ter acesso diário a uma área externa (piquetes) por pelo menos seis horas (RUSSO, 2021).

Objetivo: O objetivo do trabalho foi avaliar a adequação do ambiente de criação de galinhas poedeiras criadas a pasto do Colégio Agrícola Estadual de Umuarama de acordo com o padrão estabelecido pelo Human Farm Animal Care (HFAC) de galinhas poedeiras.

Resultados: Foram realizadas visitas no Colégio Agrícola Estadual de Umuarama a fim de avaliar o ambiente de criação de galinhas poedeiras criadas no sistema a pasto. Atualmente no setor estavam alojadas 140 aves. As aves tinham acesso a dois piquetes de aproximadamente 16,5 metros de comprimento por nove metros de largura $\left(148,5 \mathrm{~m}^{2}\right.$ cada), totalizando área de $297 \mathrm{~m}^{2}$. A área coberta, destinada ao fornecimento de água e ração, descanso dos animais no período noturno e local para postura dos ovos, apresentava 5,8 metros de comprimento por seis metros de largura $\left(34,8 \mathrm{~m}^{2}\right)$. Nesse local havia 40 ninhos com cama de capim seco. Os ninhos estavam dispostos em duas laterais e em frente dos ninhos havia espaço de poleiro de 5,6 e 5,8 metros de comprimento. Como o objetivo era avaliar o ambiente de criação para atender o estabelecido pela HFAC de galinhas poedeiras criadas a pasto, verificou-se que o espaço mínimo de poleiros de $15 \mathrm{~cm}$ por galinha em postura recomendado pela HFAC não estava adequado, já que de acordo com o comprimento total do poleiro de 11,4 metros havia espaço para apenas 76 galinhas. A quantidade de ninhos recomendada de um para cada cinco aves foi atendida, já que existiam 40 ninhos, sendo que de acordo com a quantidade de aves alojadas era necessário pelo menos 28 ninhos. O piso da área de descanso estava coberta com capim seco. Segundo as recomendações da HFAC pelo menos $15 \%$ do piso deve ter substrato, atendendo dessa forma, os requisitos. A área interna recomendada de $0,09 \mathrm{~m}^{2}$ por galinha foi atendida, já que o espaço interno necessário para alojamento 
de 140 galinhas é de $12,6 \mathrm{~m}^{2}$ e havia $34,8 \mathrm{~m}^{2}$. Em relação à área de pasto, a recomendação é espaçamento de $10 \mathrm{~m}^{2}$ por ave, o que necessitaria de um espaçamento de $1400 \mathrm{~m}^{2}$. Apesar de alguns itens não terem sido atendidos, pode-se perceber que as aves apresentavam comportamentos de bem-estar (ciscar, eram tranquilas, faziam banhos de areia) e o estado nutricional geral era uniforme. Até o presente momento, não foi avaliado itens relacionados ao armazenamento da cama, registros do período e intensidade de luz, registro de mortalidade e produção de ovos, itens também exigidos para a certificação.

Conclusão: Os requisitos preconizados pela HFAC para galinhas poedeiras criadas a pasto em relação ao ambiente são extremamente rigorosos. Apesar de alguns itens não terem sido atendidos, salienta-se que as aves apresentavam comportamentos de bem-estar.

\section{Referências}

ABPA Associação Brasileira de Proteína Animal. Relatório anual 2021. Disponível em: http://abpa-br.org/abpa-lanca-relatorioanual-2021/ Acesso em: 22 ago. 2021.

HUMAN FARM ANIMAL CARE HFAC. Referencial de HFAC de galinhas poedeiras. Middleburg: HFAC. 2018. 48p.

RUSSO, J. C. Tudo que você precisa saber sobre os sistemas de produção de ovos. 2021. Agroceres multimix. Disponível em: https://www.aviculturaindustrial.com.br/imprensa/tudo-que-voce-g-saber-sobre-os-\%20sistemas-de-producao-de-ovos/20190326113131-t740 Acesso em: 29 ago. 2021.

\section{SALÃO DE EXTENSÃO}

DA UNIPAR
- UNIPAR 50 aNOS:

Transformando vides atravta da educaça

27 de Outubro de 2021

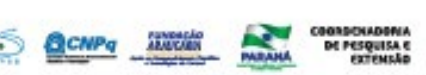




\title{
BIBIS - BRINQUEDOTECA ITINERANTE: BRINCANDO EM SERVIÇO - O BRINCAR E O SOCIAL NA FORMAÇÂO DE ESTUDANTES DE PEDAGOGIA
}

\author{
${ }^{1}$ TAFNES BEDIM DE OLIVEIRA, ${ }^{2}$ JOAO HENRIQUE GARCIA ALMEIDA, ${ }^{3}$ ISABELLI MARIA FAZOLIN, ${ }^{4}$ JAIR RUZZENE \\ JUNIOR, ${ }^{5}$ THALITA AKEMI YNAMURA SOARES, ${ }^{6}$ VITORIA CARDOSO DOS SANTOS, ${ }^{7}$ MARIA DO CARMO DE OLIVEIRA \\ NOGUEIRA
}

${ }^{1}$ Acadêmica do Curso de Pedagogia - PEX/UNIPAR.

${ }^{2}$ Acadêmico do Curso de Pedagogia - PEX/UNIPAR.

${ }^{3}$ Acadêmica do Curso de Pedagogia - PEX/UNIPAR.

${ }^{4}$ Acadêmico do Curso de Pedagogia - PEX/UNIPAR.

${ }^{5}$ Acadêmica do Curso de Pedagogia - PEX/UNIPAR.

${ }^{6}$ Acadêmica do Curso de Pedagogia - PEX/UNIPAR.

${ }^{7}$ Docente da UNIPAR / Curso de Pedagogia - PEX/UNIPAR.

Introdução: No cenário atual brasileiro há a preocupação, cada vez maior com a formação lúdica e social que possa transcender o processo de formação acadêmica teórico-prática e científica, [...] estudantes de Pedagogia precisam ser formados para garantir a educação, com vistas à inclusão plena dos segmentos historicamente excluídos dos direitos sociais, culturais, econômicos e políticos (GRACIANI, 2006, apud PAULA; MACHADO, 2008, p. 7). Tardif e Lessard (2008 apud VIEIRA, 2014, p. 110) nos leva a reflexão que devemos considerar e pensar na complexidade e nas diversidades humanas de nossas crianças no processo educativo, na relação entre a escola, a família e a comunidade. Acrescentamos a isso a importância do brincar, fator preponderante à saúde emocional, física, cultural e educativa para as crianças e seus educadores acarretando maiores vínculos sociais.

Objetivo: Apresentar relatos das ações no projeto BIBS, antes e após a pandemia em relação ao vínculo e as habilidades socioemocionais para a formação acadêmica.

Resultados: O projeto BIBS é ofertado aos acadêmicos de Pedagogia da UNIPAR de Umuarama desde 2014 e tem sido um diferencial na formação. Abarca o propósito de aproximar os estudantes em práticas lúdicas, educativas, artísticas e sociais, das crianças de 3 a 10 anos das comunidades e entidades filantrópicas, promovendo o brincar e o inter-relacionamento saudável, com brinquedos e jogos de estratégias, com pinturas faciais e corporais, e ainda atendendo aos pais, cuidadores e/ou responsáveis com orientações sobre a importância do brincar e sobre como apoiar aos filhos na realização das tarefas e lições escolares. Antes da pandemia, as ações se dava de forma física, nas ONGS e também em espaços abertos - praças - das comunidades. Corroboramos com o que diz Dallabona (2004, p.108) Brincando o sujeito aumenta sua independência, estimula sua sensibilidade visual e auditiva, valoriza sua cultura popular, desenvolve habilidades motoras, exercita sua imaginação, sua criatividade, socializa-se, interage, reequilibra-se, recicla suas emoções, sua necessidade de conhecer e reinventar e, assim, constrói seus conhecimentos . O distanciamento social provocou a mudança no formato de atendimentos e a dificuldade de ações tão prazerosas quanto ao brincar presencialmente fora adaptado pela tecnologia com criação de LIVES sobre como brincar com alguns jogos, o que possibilitou aos estudantes uma nova aprendizagem e a compreensão ainda maior da necessidade do outro, com inter-relacionamento virtual saudável, e, às crianças a possibilidade de uma nova forma de interação e ludicidade.

Conclusão: Com nossas experiências e ações desenvolvidas neste projeto BIBS/UNIPAR, dado ao exposto nos resultados, a prática extensiva e atendimentos às crianças de entidades filantrópicas e aos pais e/ou seus responsáveis, tem prevalecido como elemento muito importante na formação dos acadêmicos de Pedagogia, pois através do brincar presencial e/ou virtual, tem promovido melhora nos vínculos afetivos e socioemocionais saudáveis, integrando e maximizando suas escolhas profissionais.

\section{Referências}

DALLABONA, R.S. MENDES, S.M.S. O lúdico na educação infantil: Jogar, brincar uma forma de educar, p. 1-06. Revista de divulgação técnico-científica do ICPG. Vol. 1 n. 4 - jan.-mar./2004 ISSN 1415-6396. Disponível em: https://conteudopedagogico.files.wordpress.com/2011/02/o-Idico-na-educao-infantil.pdf Acesso em: 02 ago. 2021.

PAULA, Ercília Maria Angeli Teixeira de; MACHADO, Érico Ribas. A Pedagogia Social na Educação: análise de perspectivas de formação e atuação dos educadores sociais no Brasil. In: II CONGRESSO INTERNACIONAL DE PEDAGOGIA SOCIAL, 2., 2008, São Paulo. Proceedings online. Faculdade de Educação da Universidade de São Paulo. Disponível em: 
http://www.proceedings.scielo.br/scielo.php?script=sci_arttext\&pid=MSC0000000092008000100005\&lng=en\&nrm=abn. Acesso em: 03 set. 2021.

VIEIRA, Ana; VIEIRA, Ricardo. Pedagogia social e mediação sociopedagógica como processos de emancipação: Investigação e ação em escolas portuguesas. REALIS, v.4, n. 02, p. 105-125. Jul-Dez. 2014 ISSN 2179-7501, p. 1-06. Disponível em: https://periodicos.ufpe.br/revistas/realis/article/download/8822/8797. Acesso em: 28 ago. 2021.

I SALÄO DE EXTENSÃO

DA UNIPAR
- UNIPAR 50 ANOS:

Transtormando vides atreves da educagto

27 de Outubro de 2021

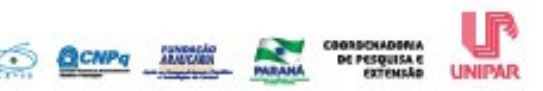




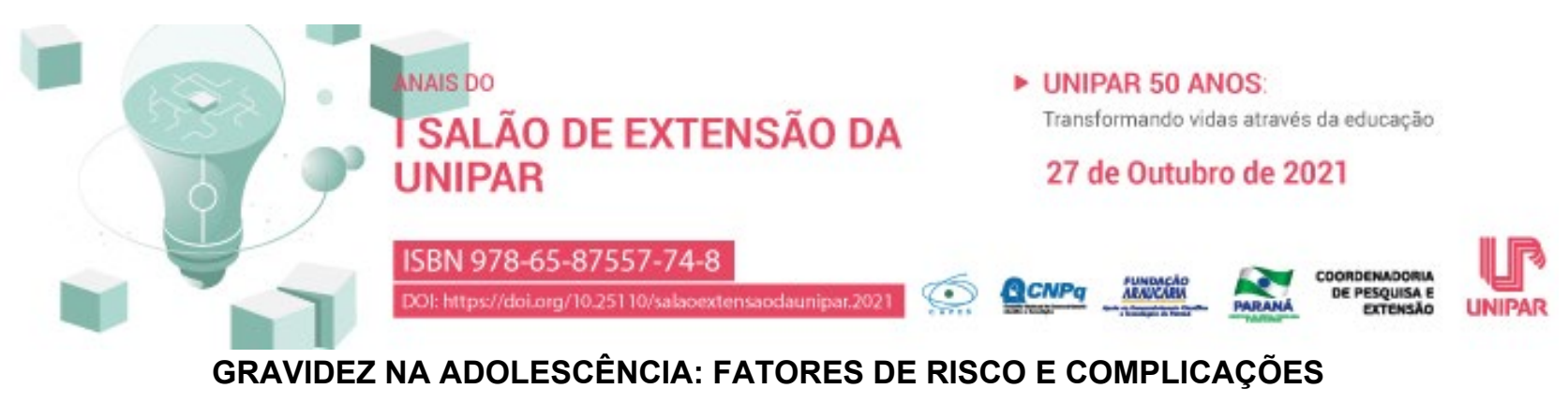

\author{
${ }^{1}$ THALIA CAROLINE LEANDRO PASQUALOTTO, ${ }^{2}$ ANDRIELE KARINE FERNANDES, ${ }^{3}$ ANA BEATRIZ LENTZ, ${ }^{4}$ FRANCIELE \\ DO NASCIMENTO SANTOS ZONTA, ${ }^{5}$ LEDIANA DALLA COSTA
}

\author{
${ }^{1}$ Acadêmica COPEX/enfermagem UNIPAR \\ ${ }^{2}$ Acadêmica do Curso de Enfermagem da UNIPAR \\ ${ }^{3}$ Acadêmica do Curso de Enfermagem da UNIPAR \\ ${ }^{4}$ Docente da UNIPAR \\ ${ }^{5}$ Docente da UNIPAR
}

Introdução: A adolescência é um período de desenvolvimento biopsicossocial e construção da sexualidade, tantas mudanças somadas a uma gravidez não planejada podem acarretar diversos problemas físicos e mentais. Inúmeras situações configuramse como fatores de risco para a gravidez na adolescência, e na maioria das vezes podem ser prevenidas por meio de educação em saúde (LANZA et al, 2017).

Objetivo: Descrever os fatores de risco para a gravidez na adolescência e as complicações relacionadas.

Resultados: No Brasil cerca de 434,5 mil jovens e adolescentes dão à luz todos os anos, registrando uma das maiores taxas, chegando a 68,4 nascidos vivos para cada mil adolescentes e jovens. A gravidez na adolescência está relacionada à desinformação referente à sexualidade, direitos sexuais e reprodutivos, porém, outros fatores devem ser levados em consideração, como menor grau de escolaridade, fatores sociais, culturais e emocionais. (SOUZA et al, 2021). Segundo (Miranda e Souza 2020) em seu estudo desenvolvido em um colégio público de Caturité-PB com alunos de 10 a 19 anos, $47,2 \%$ negam ter ouvido falar em educação sexual, a maioria deles não possui conhecimento satisfatório sobre métodos contraceptivos e as formas de uso. Sabe-se que a gravidez na adolescência impacta em diversas questões biopsicossociais, a falta de apoio gerado a partir dos conflitos no núcleo familiar ocasionados pela gestação não planejada pode resultar em abandono escolar, transtornos mentais em função do sofrimento psíquico gerado pelas mudanças da gestação, acrescidas de sentimento de solidão e de desmotivação por ser necessário adiar ou abdicar de planos, metas e rotina antes estabelecidos (RIBEIRO et al, 2019; SILVA et al, 2018). Ademais, pesquisas demonstram o aumento da mortalidade materno-infantil em gestantes adolescentes, pois nessa fase o risco de complicações gestacionais e puerperais é elevado, uma vez que as condições fisiológicas relacionadas à gestação e parturição não estão totalmente desenvolvidas, assim, o risco de aborto, parto prematuro e complicações no pósparto são frequentes (FERNANDES et al, 2018).

Considerações finais: A falta de conhecimento sobre a saúde sexual é um importante fator de risco para adolescência, a qual se configura como um problema de saúde pública devido às complicações materno-infantil que podem ocorrer desde a gestação, parto até o puerpério.

\title{
Referências
}

LANZA, Leni Boghossiam. Educação em saúde: doenças sexualmente transmissíveis e gravidez na adolescência. Revista da Faculdade de Ciências Médicas de Sorocaba, v. 20, n. 3, p. 138-141, 2018.

SOUSA, Natanael Alenca. Uma proposta de intervenção para o planejamento familiar das adolescentes atendidas em uma unidade básica de saúde do município de Carolina-MA, Acervo da Universidade Federal do Piauí (UFPI), Julho. 2021.

MIRANDA, Larissa Soares Mariz Vilar de; SOUZA, Eliene Maria de. Conhecimento dos Adolescentes Sobre Métodos Contraceptivos e Assistência em Saúde, Revista Interdisciplinar na Faculdade em Saúde, Cajazeiras, v.7, n. 1 pág. 775-791, 2020.

RIBEIRO, Wanderson Alves. A gravidez na adolescência e os métodos contraceptivos: a gestação e o impacto do conhecimento. Nursing (Säo Paulo), 22(253): 2990-2994, jun.2019.

DUARTE, Quezia Albuquerque et al. Gravidez na adolescência: A Percepção de parturientes adolescentes. Revista Ciência \& Saberes-UniFacema, v. 4, n. 3, 1152-1157, setembro. 2018.

FERNANDES, Rita Fernanda Monteiro et al. Intercorrências obstétricas que ocorrem durante a gravidez na adolescência. Ciência, Cuidado e Saúde, v. 17, n. 1, 11 jul. 2018.

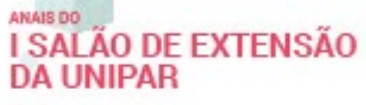

DA UNIPAR

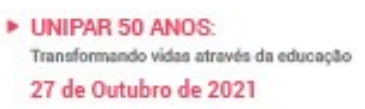

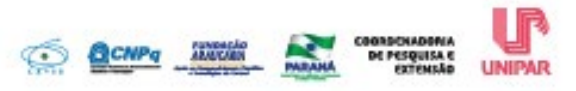




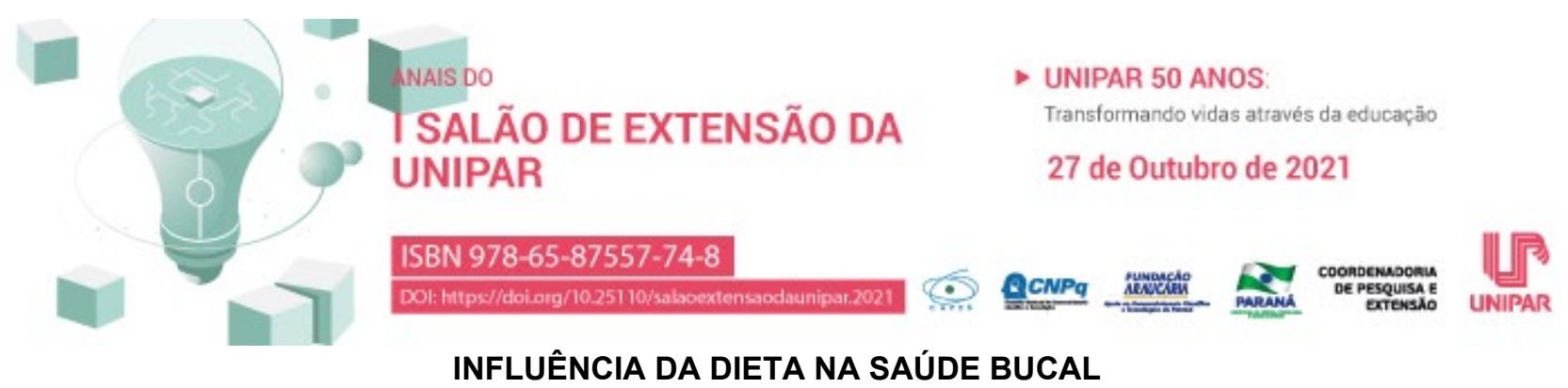

${ }^{1}$ CECILIA DA SILVA RAFAEL, ${ }^{2}$ MARIANA CAROLINA URBANSKI RODRIGUES, ${ }^{3}$ RODRIGO CESAR MANRIQUE CORREA, ${ }^{4}$ LARISSA APARECIDA DA SILVA ROSENI, ${ }^{5}$ LORENNA GABRIELLY DOMENE, ${ }^{6}$ THALITA FABIANA ROMERO, ${ }^{7}$ LARISSA DE SOUZA FERRARESSO, ${ }^{8} \mathrm{CAIO}$ VINNICIUS KARWEL, ${ }^{9}$ FELIPE DE BRITO LEITE, ${ }^{10}$ ANA BEATRIZ MIRANDA LOPES DA SILVA, ${ }^{11}$ CLARICE MOREIRA DUARTE, ${ }^{12}$ DEBORA PEDROSO DE SOUZA, ${ }^{13}$ GIOVANA CAMPOS MADEIRO, ${ }^{14}$ ISABELA MASTRANGELO MARTINUSSI, ${ }^{15}$ ANA CAROLINA SOARES FRAGA ZAZE

${ }^{1}$ Discente do curso de Odontologia Unipar/Umuarama-PR

${ }^{2}$ Acadêmica do Curso de Odontologia da UNIPAR

${ }^{3}$ Acadêmico do Curso de Odontologia da UNIPAR

${ }^{4}$ Acadêmica do Curso de Direito da UNIPAR

${ }^{5}$ Acadêmico do Curso de Odontologia da UNIPAR

${ }^{6}$ Acadêmica do Curso de Odontologia da UNIPAR

${ }^{7}$ Acadêmica do Curso de Odontologia da UNIPAR

${ }^{8}$ Acadêmico do Curso de Odontologia da UNIPAR

${ }^{9}$ Acadêmico do Curso de Odontologia da UNIPAR

${ }^{10}$ Acadêmica do Curso de Odontologia da UNIPAR

${ }^{11}$ Acadêmica do Curso de Odontologia da UNIPAR

${ }^{12}$ Acadêmica do Curso de Odontologia da UNIPAR

${ }^{13}$ Acadêmica do Curso de Odontologia da UNIPAR

${ }^{14}$ Acadêmica do Curso de Odontologia da UNIPAR

${ }^{15}$ Docente da UNIPAR

Introdução: Os alimentos que ingerimos agem de diversas formas em nosso organismo. Ter uma dieta saudável é importante para a saúde geral e bucal. A dieta é um dos fatores etiológicos da cárie, pois fornece substrato para microrganismos que produzem ácidos, influencia na quantidade de biofilme e na qualidade e quantidade de secreção salivar.

Objetivo: Conhecer as características que determinam o potencial cariogênico dos alimentos, com o intuito de realizar atividades de educação em saúde.

Resultados: Os carboidratos, também chamados de glicídios ou açúcares, são a principal fonte de energia dos seres vivos. Dependendo da sua estrutura química podem ser simples (sacarose, lactose, maltose, frutose, entre outros), ou complexos, tais como o amido. Um alimento cariogênico tem o potencial de favorecer o metabolismo de bactérias cariogênicas, que produzem ácido lático, levando à desmineralização das estruturas dentais. Portanto, deve -se considerar a variação no potencial cariogênico dos alimentos, considerando seu tempo de permanência na cavidade bucal (adesão), composição e suas propriedades, tamanho da partícula , textura e sabor. A diversidade e o aumento da oferta de alimentos industrializados podem influenciar os padrões alimentares da população. O consumo inadequado, excessivo e muito frequente desses alimentos pode comprometer a saúde da pessoa desde a infância até a idade adulta. Muitos alimentos industrializados são ricos em gorduras e carboidratos refinados, apresentando elevado valor energético e potencial cariogênico. Além disso, o aumento do consumo de alimentos industrializados pode reduzir o consumo de alimentos in natura. Considerando o exposto, os acadêmicos participantes do projeto de extensão I"Educação direcionada à saúde bucall" foram instruídos a desenvolver uma proposta voltada à crianças de 5 a 10 anos de idade. Apresentaram ideias de confecção de jogos educativos e atividade na forma de gincana, para a classificação dos alimentos cariogênicos e não cariogênicos, enfatizando características importantes de cada grupo alimentar, bem como um teatro abordando o impacto dos alimentos cariogênicos na saúde bucal, facilitando a compreensão do tema pelas crianças.

Conclusão: Os acadêmicos aprenderam sobre a influência da dieta na saúde bucal e as características dos alimentos cariogênicos, bem como desenvolveram habilidades e materiais lúdicos para realizar a educação direcionada à saúde bucal, visando a promoção de saúde.

\section{Referências}


BIRAL, Adriana Manrubia; et al. Cárie dentária e práticas alimentares entre crianças de creches do município de São Paulo. Rev. Nutrição, v. 26, n. 1, p. 37-48, jan/fev., 2013.

DHO, María Silvina. Consumo de alimentos cariogénicos en adultos de la ciudad de Corrientes, Argentina. Hacia Promoc. Salud, v. 20, n. 2, p. 90-101, jul., 2015.

GOMES, Samara Sandrelly Moura; et al. Cárie dentária em adolescentes da cidade de Recife-PE. RFO-UPF, v. 22, n. 1,p. 62-82, ago., 2017.

I SALÃO DE EXTENSÃO

DA UNIPAR
- UNIPAR 50 ANOS:

Transformando videa atravela da educaça

27 de Outubro de 2021

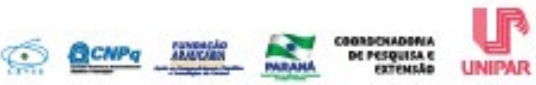




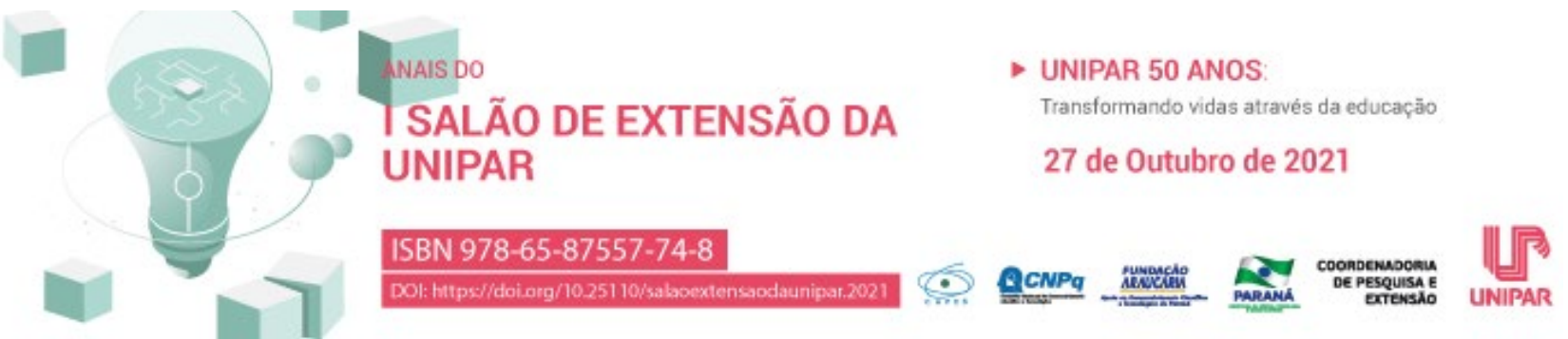 \\ PRÁTICA EDUCATIVA DE INCENTIVO AO ALEITAMENTO MATERNO
}

\author{
${ }^{1}$ MILENA FIAUX POMINI, ${ }^{2}$ AMANDA NASCIMENTO VASQUES DE SOUZA, ${ }^{3}$ NATALIA NAMIE MIZUGUCHI, ${ }^{4} \mathrm{KESSIA}$ TAIANA \\ DE GOUVEIA, ${ }^{5}$ LARISSA DOS SANTOS RODRIGUES , ${ }^{6}$ OLGA APARECIDA BRITO, ${ }^{7}$ AMANDA NASCIMENTO VASQUES DE \\ SOUZA, ${ }^{8}$ NANCI VERGINIA KUSTER DE PAULA
}

${ }^{1}$ Acadêmica do Curso de Enfermagem da UNIPAR
${ }^{2}$ Docente da UNIPAR
${ }^{3}$ Acadêmica do Curso de Enfermagem da UNIPAR
${ }^{4}$ Acadêmica do Curso de Enfermagem da UNIPAR
${ }^{5}$ Acadêmica do Curso de Enfermagem da UNIPAR
${ }^{6}$ Acadêmica do Curso de Enfermagem da UNIPAR
${ }^{7}$ Docente da UNIPAR
${ }^{8}$ Docente da UNIPAR

Introdução: A alimentação tem papel fundamental em todas as etapas da vida, especialmente nos primeiros anos, decisivos para o crescimento e desenvolvimento, para a formação de hábitos e para a manutenção da saúde (BRASIL, 2019a). A amamentação corresponde a uma das etapas mais importantes no processo exterogestacional, sendo um ato que oferece benefícios tanto para mãe quanto para o recém-nascido. O leite materno consegue suprir todas as necessidades nutritivas do recém-nascido, além de reforçar o aumento de anticorpos e ganho de peso. $O$ aleitamento materno proporciona maior vínculo entre mãe e filho, e promove o desenvolvimento das estruturas orais, onde são responsáveis pelo funcionamento adequado da respiração, da sucção, da deglutição, da mastigação e da fala (ROSA; DELGADO, 2017). Além de oferecer diversos benefícios para a mulher e para criança, a amamentação não polui o meio ambiente e não tem custo. É preconizada a amamentação exclusiva até os seis meses de vida, nenhum outro tipo de alimento deve ser oferecido e, que seja complementado até dois anos ou mais (BRASIL, 2021). O leite materno é o alimento adequado para as crianças nos primeiros meses de vida, pois através dele consegue reforçar o aumento de anticorpos, diminuindo assim a Taxa de Mortalidade Infantil (TMI), essa taxa teve importante declínio no Brasil nas últimas sete décadas, passando de 146,6 óbitos a cada mil nascidos vivos, em 1940, para 12,8 em 2017 (BRASIL, 2019). Ainda dos mesmos autores, a redução constante, porém heterogênea, da mortalidade infantil está relacionada a avanços na educação materna, sendo uma delas a Política de Aleitamento Materno, e a TMl é considerada um importante marcador do nível de desenvolvimento social de uma população, tendo em vista sua estreita relação com a disponibilidade e a qualidade dos recursos de saúde.

Objetivo: O objetivo central deste trabalho é informar e auxiliar as mães da maternidade sobre a importância da prática do aleitamento materno.

Resultados: A prática foi levada às mães gestantes e puérperas do Hospital Norospar, em Umuarama, através da realização do projeto de Extensão do curso de Enfermagem Os diferentes ciclos da vida, orientando às mães sobre a prática da amamentação, fazendo da mesma um estilo de vida, através desses métodos, auxílios e técnicas, atingindo em média dez mães por dia. Dentre as atividades desenvolvidas destacamos as práticas educativas sobre manejo do aleitamento materno, apojadura, posições da pega correta do bebê no seio materno e ordenha para aliviar mamas engurgitadas. Foram utilizadas rodas de conversas com troca de experiencias, além de atividades pontuais sobre Agosto Dourado, mês de alusão ao incentivo ao aleitamento materno.

Conclusão: Pode-se então concluir que a atividade de incentivo ao aleitamento materno, pode despertar nas puérperas a conscientização sobre a importância da amamentação, visto que apesar dessa informação estar cada vez mais divulgada, ainda existem muitas dúvidas e mitos a serem difundidos para quem está iniciando o aleitamento materno. Sendo assim, os resultados podem nos guiar para estratégias políticas locais de promoção do aleitamento materno.

\section{Referências}

BRASIL Ministério da saúde. Secretaria de Vigilância em Saúde. Departamento de Análise em Saúde e Vigilância de Doenças não Transmissíveis. Uma análise da situação de saúde com enfoque nas doenças imunopreveníveis e na imunização. 2019. Disponível em: . Acesso em: 07/09/2021.

BRASIL. Ministério da saúde. Secretaria de Atenção Primária à Saúde. Guia alimentar para crianças brasileiras menores de 2 anos. 2019a. Disponível em: . Acesso em: 07/09/2021. 
BRASIL. Ministério da saúde. Secretaria de Atenção Primária à Saúde. Guia alimentar para crianças brasileiras menores de 2 anos. 2021. Disponível em: . Acesso em: 30/08/2021.

ROSA, Juliana de Brito de Souza, DELGADO, Susana Elena. Conhecimento de puérperas sobre amamentação e introdução alimentar. Revista Brasileira em Promoção da Saúde, v. 4, n. 30, p. 1-9, 2017. Disponível em: . Acesso em: 07/09/2021.

I SALALAO DE EXTENSÃO

DA UNIPAR
> UNIPAR 50 ANOS:

Transformando vides atreviba da educagto

27 de Outubro de 2021
S. ACNPG 


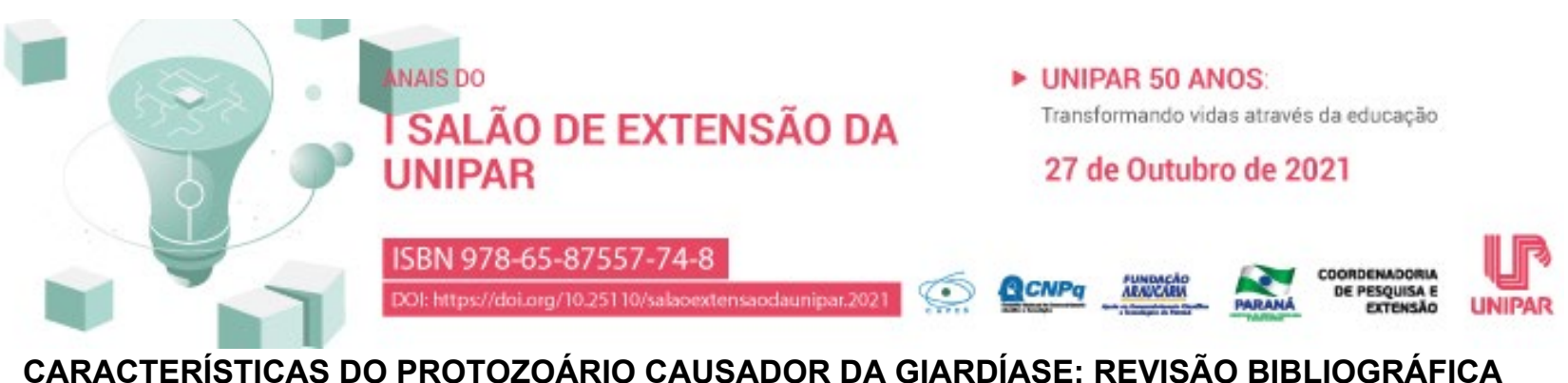

\author{
${ }^{1}$ THAIS EDUARDA ADAMCZUK, ${ }^{2}$ THAINARA LOURENCO DE VASCONCELLOS, ${ }^{3}$ JULIA VALER GUERRA, ${ }^{4}$ LAURA \\ RICARDA EBELING LAUTERT, ${ }^{5}$ MAISA STEFFANI ADAMCZUK, ${ }^{6}$ ERIKA DE GOIS FREIRE LOPES, ${ }^{7}$ EDSON GERONIMO , \\ ${ }^{8}$ GIULIANA ZARDETO SABEC
}

${ }^{1}$ Acadêmica do curso de Farmácia e do PIC da UNIPAR

${ }^{2}$ Acadêmica do curso de Farmácia da UNIPAR

${ }^{3}$ Acadêmica do curso de Farmácia da UNIPAR

${ }^{4}$ Acadêmica do curso de Farmácia da UNIPAR

${ }^{5}$ Acadêmico do curso de Farmácia da UNIPAR

${ }^{6}$ Acadêmica do curso de Farmácia da UNIPAR

${ }^{7}$ Acadêmico do curso de Farmácia e do Doutorado em Ciência animal com ênfase em produtos bioativos da UNIPAR

${ }^{8}$ Docente da UNIPAR

Introdução: A Giardia intestinalis (Giardia duodenalis, Giardia lamblia), é um protozoário da porção superior do intestino delgado e constitui um grave problema de saúde pública. Constitui causa muito frequente de doença diarreica em grande variedade de espécies animais, incluindo o homem. A transmissão da G. intestinalis pode ocorrer após ingestão de cistos infectantes através da água ou de alimentos contaminados, ou por via fecal-oral direta (ALMEIDA, 2019). Os principais sinais clínicos incluem náusea, perda de peso, edema, dor abdominal e diarreia (MUNARETO et al., 2021).

Objetivo: O presente artigo tem como objetivo apresentar todas as características e consequências da Giardia intestinalis.

Resultados e discussões: Foi realizado uma revisão bibliográfica acerca do assunto giardíase nos bancos de dados Google acadêmico e PubMed. Para tal, foram utilizados as paralvras-chaves giardíase, Giardia intestinalis e parasitoses intestinais. Os resutados encontrados demonstraram que a G. intestinalis é um protozoário flagelado, em forma de pera (MUNARETO et al., 2021). Possui ciclo biológico monoxênico (apenas um hospedeiro definitivo). Após a ingestão, os cistos se rompem no duodeno, formando trofozoítos, os quais se multiplicam intensamente. Os cistos são eliminados pelas fezes em grande quantidade (300 milhões a 14 bilhões por dia), ocorrendo períodos de interrupção de eliminação de sete a 10 dias. Os trofozoítos também podem estar presentes nas fezes, mas são os cistos os responsáveis pela transmissão (MUNARETO et al., 2021). A G. lamblia é uma das infecções parasitárias mais comuns do mundo, que atinge tanto homens quanto mulheres, entretanto, sendo encontrado, com mais frequência em faixa etária de 0 a 10 anos, ou seja, a população infantil é uma das mais afetadas por tais parasitoses (ZARDETO-SABEC et al., 2020). Pode ser transmitida por ingestão de cistos que contaminam a água e alimentos (via mais frequente), por contato interpessoal (em enfermos institucionalizados, creches e hospitais (psiquiátricos) (MUNARETO et al., 2021). A pobreza, o analfabetismo, a falta de higiene, clima tropical quente e úmido são alguns dos fatores que estão associados a infecções parasitárias intestinais. As hortaliças consumidas cruas na forma de saladas podem servir como via de transmissão de doenças, uma vez que helmintos, protozoários, bactérias e vírus podem estar presentes nesses vegetais (ZARDETO-SABEC et al., 2020). Para se diagnosticar a presença dos parasitos, o método mais utilizado é HPJ (Hoffmann-Pons e Janer) de sedimentação espontânea. Para realizar o diagnóstico dessas parasitoses, utiliza-se também a microscopia, que tem custo menor, possui alta especificidade e sensibilidade média (ZARDETO-SABEC et al., 2020).

Conclusão: Sendo assim, conclui-se que cabe enfatizar a necessidade de medidas efetivas de saúde pública que controlem ou, minimizem os riscos de infecção ou contaminação por parasitos, como também a informação sobre o uso correto dos medicamentos vermífugos, minimizando os impactos ocasionados por verminoses na população, além de destacar a importância do exame parasitológico de fezes para a população.

\title{
Referências
}

ALMEIDA, Daniela Filipa Correia de. Deteção dos protozoários Giardia lamblia e Cryptosporidium sp. em saladas embaladas prontas a consumir. 2019. Tese de Doutorado. Universidade de Coimbra.

ZARDETO-SABEC, Giuliana et al. Análise dos laudos do exame parasitológico de fezes de um laboratório da cidade de Umuarama-PR no ano de 2018. Brazilian Journal of Surgery and Clinical Research, v. 30, n. 3, p. 07-12, 2020.

MUNARETO, Danilo da Silva et al. Parasitoses em crianças na fase pré-escolar no Brasil: revisão bibliográfica. Research, Society and Development, v. 10, n. 1, p. e1910111195-e1910111195, 2021. 
- unIPAR 50 anos:

I SALAOO DE EXTENSÃO Transformando vidas atravies da educaģso

DA UNIPAR 


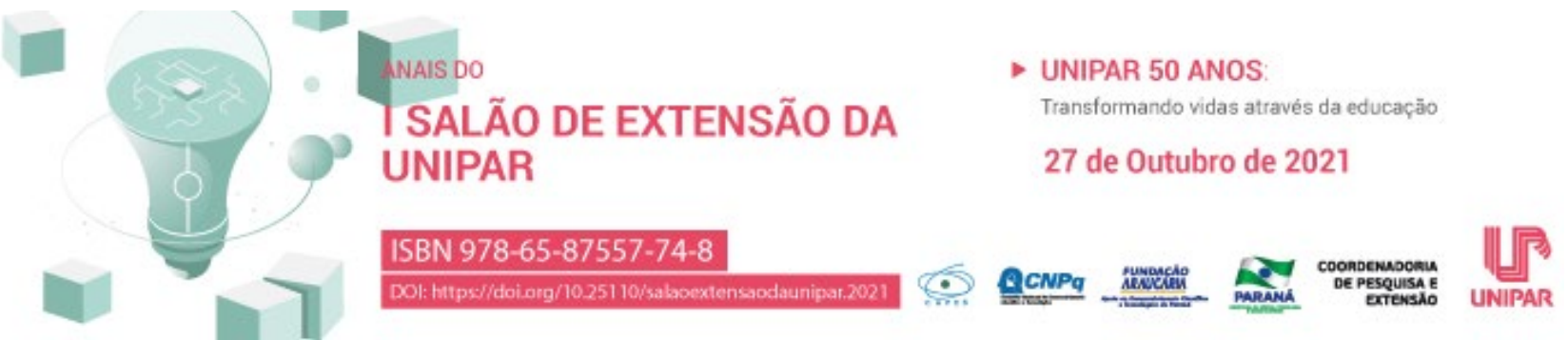 \\ RECICLAGEM E REUTILIZAÇÃO DE MATERIAIS NA PRODUÇÃO DE MOBILIÁRIO
}

\author{
${ }^{1}$ HELOISA REGINA RODRIGUES MENDES, ${ }^{2}$ NICOLE FERREIRA DE SOUZA VIERCINSKI, ${ }^{3}$ TATIANA QUEIROZ BARDI \\ AUGUSTO
}

${ }^{1}$ Acadêmico do Curso de Arquitetura e Urbanismo da UNIPAR

${ }^{2}$ Acadêmica do Curso de Arquitetura e Urbanismo da UNIPAR

${ }^{3}$ Docente da UNIPAR

Introdução: Para Barbalho (2015) et. al. o acúmulo dos resíduos sólidos e os demais acontecimentos de degradação ao meio ambiente são motivos para o aumento da crise ambiental. Para a Associação Brasileira dos Escritórios de Arquitetura (AsBEA) em 2007 foi constatado a transformação efetiva do planeta terra em território urbano, pois mais da metade da população mundial passou a viver nas cidades gerando mais resíduos e descarte de lixos. Portanto, retirar este material da natureza e dar uma outra finalidade se torna primordial para o desenvolvimento social. Viana (2012) afirmar que a produção de mobiliário utilizando materiais recicláveis é uma solução que visa a sustentabilidade, uma vez que aumenta a vida útil de materiais que seriam descartados.

Objetivo: Reaproveitar materiais que são descartados para a produção de mobiliários a fim de proporcionar o aprendizado prático na produção de peças e artefatos e na gestão da consciência ambiental.

Material e Métodos: Para Rodrigues (2012) et. al., o mobiliário sustentável condiz por sua composição ser confeccionada por madeira renovável (reaproveitada) ou outro tipo de material (plástico ou metais descartados na natureza) desde que sua produção respeite obrigatoriamente a todos os aspectos ecológicos, ambientais e sociais. Existe uma carência na consciencialização do reaproveitamento de materiais e, utilizá los na fabricação de mobiliários, faz com que a comunidade acadêmica e sociedade, compreenda e atribua estes conceitos para o seu dia a dia.

Resultados: Reutilizou-se materiais que foram descartados na natureza para a produção de peças proporcionando uma consciencialização ecológica e sustentável. Discussão: A urbanização dos países em desenvolvimento vem intensificando-se mais e mais. A AsBEA (2007), relata que as cidades, com suas atividades, serviços e transportes, consomem $40 \%$ dos recursos naturais extraídos e $50 \%$ da produção de energia, contribuem com aproximadamente $50 \%$ dos resíduos sólidos e são responsáveis por $75 \%$ das emissões de gás carbono. Assim, é necessária uma revisão urgente de atitudes e procedimentos dos setores responsáveis, tanto privados quanto públicos. Estes fatores fazem com que haja uma maior divulgação no quesito de sustentabilidade arquitetônica como também consciencialização ambiental.

Conclusão: Reciclar e reutilizar materiais que seriam descartados em prol de um bem comum é de fundamental importância para do desenvolvimento do ser humano e para uma sociedade mais consciente.

\section{Referências \\ ASSOCIAÇÃO BRASILEIRA DOS ESCRITÓRIOS DE ARQUITETURA. Transformação do Planeta. São Paulo: AsBEA, 2007. ASSOCIAÇÃO BRASILEIRA DE NORMAS TÉCNICAS. NBR 9241-11: Requisitos Ergonômicos para Trabalho de Escritórios com Computadores. Rio de Janeiro: ABNT, 1998. BARBALHO, I. L. P. et. al.. O aproveitamento de materiais recicláveis como fonte de renda. Encontro Internacional sobre Gestão Empresarial e Meio Ambiente. Rio Grande do Norte: ENGEMA, 2015. \\ RODRIGUES, J. A. R. et. al.. Sustentabilidade no Design: A transversalidade das teorias filosóficas e suas articulações na contemporaneidade complexa. Santa Catarina: UDESC, 2012. VIANA, D. F. et. al.. Mobiliário Produzido com Material Reciclável para o Hall do IFSC Campus Criciúma. $1^{\circ}$ Simpósio de Integração Científica e Tecnológica do Sul Catarinense. Santa Catarina: SICT-Sul, 2012}

I SALÃO DE EXTENSÃO DA UNIPAR

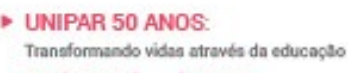

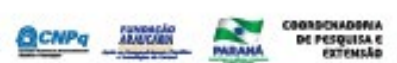

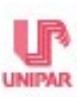




\section{(3) \\ - UNIPAR 50 ANOS: \\ Transformando vidas através da educaçào \\ 27 de Outubro de 2021

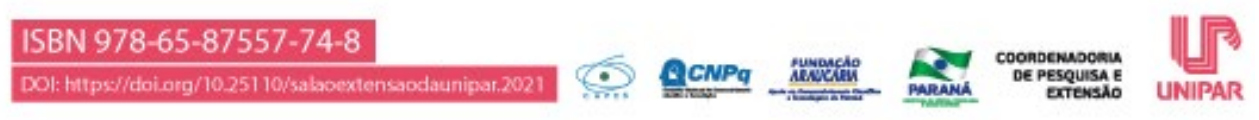 \\ RELATO DE EXPERIÊNCIA: OBESIDADE E RISCO DE DESENVOLVIMENTO DE DOENÇAS CRÔNICAS NÃO TRANSMISSÍVEIS NA ADOLESCÊNCIA}

${ }^{1}$ ALINE MARA STRUB, ${ }^{2}$ DANIELA EMILIO, ${ }^{3}$ SARAH ALESSANDRA PASQUALETTO, ${ }^{4}$ KEILA MARIA MOREIRA, ${ }^{5}$ PRISCILA DA SILVA ROKEMBACH AMARILHO, ${ }^{6}$ EDIANE PISSAIA, ${ }^{7}$ SARAH ALESSANDRA PASQUALETTO, ${ }^{8}$ SARAH ALESSANDRA PASQUALETTO, ${ }^{9}$ INDIOMARA BARATTO

${ }^{1}$ Graduanda do Curso de Nutrição. Universidade Paranaense

UNIPAR

${ }^{2}$ Graduanda do Curso de Nutrição. Universidade Paranaense UNIPAR

${ }^{3}$ Graduanda do Curso de Nutrição. Universidade Paranaense UNIPAR

${ }^{4}$ Graduanda do Curso de Nutrição. Universidade Paranaense UNIPAR

${ }^{5}$ Graduanda do Curso de Nutrição. Universidade Paranaense UNIPAR

${ }^{6}$ Responsável técnica do Curso de Nutrição. Universidade Paranaense UNIPAR

${ }^{7}$ Graduanda do Curso de Nutrição. Universidade Paranaense UNIPAR

${ }^{8}$ Graduanda do Curso de Nutrição. Universidade Paranaense UNIPAR

${ }^{9}$ Docente do Curso de Nutrição. Universidade Paranaense UNIPAR

Introdução: $O$ excesso de peso na infância é considerado principal fator para que a obesidade se desenvolva e estenda até a vida adulta (TAVARES GT et al., 2016). Os impactos deste excesso englobam aumento do risco para o desenvolvimento de morbidades crônicas e surgimento precoce de doença cardiovascular (SOUSA et al., 2020). Recentemente, a pandemia de COVID 19 modificou os hábitos de vida da população, evidenciando a obesidade entre crianças e adolescentes, durante o distanciamento social imposto como estratégia de enfretamento à disseminação do Coronavírus (SBP, 2020). As informações expostas se assemelham ao caso de um paciente de 11 anos, atendido na Clínica Escola de Nutrição da Unipar de Francisco Beltrão, durante desenvolvimento do projeto de extensão. Observou-se que o mesmo procurou a atendimento apresentando obesidade (aumento de peso acentuado na pandemia), alterações de exames laboratoriais (colesterol total, LDL e triglicerídeos acima dos limites desejáveis), má alimentação e baixa ingestão hídrica. Diante disso, a conduta nutricional adotada pelo acadêmico, juntamente com a Responsável Técnica, foi um plano alimentar normocalórico, considerando a fase de crescimento do paciente, hipolipídico, normoglicídico, normoproteico e ingestão hídrica de 1,8 l/dia. Ademais, foi realizado uma intervenção, no Laboratório de Educação Nutricional, objetivando autonomia na elaboração de lanches e escolhas alimentares saudáveis.

Objetivo: O presente trabalho tem como objetivo relatar a atuação do profissional nutricionista na prática clínica associada com a obesidade e risco de desenvolvimento de doenças crônicas não transmissíveis em adolescentes. Bem como, destacar as condutas adotadas na redução de peso, controle de exames laboratoriais e instrução das escolhas alimentares saudáveis. Resultados: O paciente apresentou resultados positivos após um mês e meio do início do acompanhamento. Observou-se perda de $1,3 \mathrm{~kg}$, redução da circunferências de braço e cintura, o mesmo também relatou aumento da ingestão hídrica e a prática na elaboração dos seus lanches. Quanto aos exames laboratoriais, os mesmos serão repetidos após três meses de acompanhamento. Ademais, o paciente relatou ter iniciado treinos de futsal.

Conclusão: Diante disso, observou-se que foi possível atingir parcialmente os resultados propostos ao paciente e seus familiares, reforçando a importância do profissional da área da nutrição na intervenção da educação nutricional.

\section{Referências}

SBP - SOCIEDADE BRASILEIRA DE PEDIATRIA. Obesidade em Crianças e Adolescentes e COVID-19. Nota de Alerta. Grupo de Trabalho em Atividade Física. São Paulo: SBP, 2020.

SOUSA, Graziela Cesar, et al. A pandemia de COVID 19 e suas repercussões na epidemia da obesidade de crianças e adolescentes. Pontifícia Universidade Católica de Minas Gerais (PUC-MG), Betim MG. v. 12, n. 12, dez. 2020. Disponível em: file:///D:/Bibliotecas/Downloads/4743-Artigo-58566-1-10-20201203\%20(2).pdf. Acesso em: 07 set. 2021.

TAVARES MG, et al. Obesidade: fatores de risco para doença cardiovascular na infância. Revista Hospital Universitário Pedro Ernesto, Rio de Janeiro, v. 15, n.2, p. 99 105, jun. 2016. 


\title{
NATAÇÃO PARA PESSOAS COM ATAXIA DE FRIEDREICH: UM RELATO DE EXPERIÊNCIA DO PROJETO AMA - UMUARAMA
}

\author{
${ }^{1}$ BRENDHA DE OLIVEIRA FIAUX, ${ }^{2}$ VITORIA VINCENZI SILVA, ${ }^{3}$ KAUANE PEREIRA DOS SANTOS, ${ }^{4}$ JESSICA CRISTINA \\ PEREIRA, ${ }^{5}$ TAISE BRUN FEITOSA, ${ }^{6}$ PAULO VALERIO SECCO ANTONIO , ${ }^{7}$ MARIA GABRIELLA GIROTO
}

\footnotetext{
${ }^{1}$ Acadêmica do Curso de Educação Física - Alur

${ }^{2}$ Acadêmica do Curso de Educação Física

${ }^{3}$ Acadêmica do Curso de Educação Física

${ }^{4}$ Acadêmica do Curso de Educação Física

${ }^{5}$ Acadêmica do Curso de Educação Física

${ }^{6}$ Acadêmico do Curso de Educação Física

${ }^{7}$ Docente da UNIPAR
}

UNIPAR.

Aluna PEX do Projeto AMA, Universidade Paranaense UNIPAR.

Aluna PEX do Projeto AMA, Universidade Paranaense UNIPAR.

Aluna PIBEX do Projeto AMA, Universidade Paranaense UNIPAR.

Aluna PEX do Projeto AMA, Universidade Paranaense UNIPAR.

Aluno PEX do Projeto AMA, Universidade Paranaense UNIPAR.

Introdução: A Ataxia de Friedreich é uma doença neurodegenerativa progressiva, onde o termo ataxia refere-se a problemas na coordenação dos movimentos. Uma das características é a marcha instável, advinda da degeneração progressiva da região cerebelar e dos tratos espinocerebelares da medula espinal (CASTRO; DUARTE, 2013).

Objetivo: Apresentar a natação como alternativa de prática para indivíduos com Ataxia de Friedreich.

Desenvolvimento: A Ataxia de Friedreich (AF) se manifesta lentamente, podendo levar a incapacidade total (SILVEIRA; GRAVE; PÉRICO, 2012). Os principais sintomas apontados por Silveira, Grave e Périco (2012) são a incoordenação motora e os desequilíbrios, que variam conforme a progressão da doença levando à perdas funcionais importantes como não andar, e dificuldades de interação social. A natação é apresentada como alternativa de exercício físico, por ser realizada em um ambiente que possibilita o desenvolvimento de várias funções debilitadas pela doença, como a coordenação motora e o equilíbrio (VICHIATTO; VINHAS, 2019). Conforme apontam Zonta, Santos e Teive (2018) a água promove desafios e liberdade de movimentos, que, muitas vezes, não são disponíveis no solo, o que facilita o desempenho do exercício. Sendo as atividades que estimulam o fortalecimento muscular, a coordenação motora, o equilíbrio e a resistência são fundamentais para a manutenção de capacidade funcional e independência, e o profissional deve trabalhar para que o indivíduo com Ataxia aprenda a melhorar seus movimentos (ZONTA; SANTOS; TEIVE, 2018). No ano de 2021 o Projeto AMA, na atividade de natação, faz o atendimento à dois jovens, irmãos, portadores de Ataxia de Friedreich com graus variados de comprometimento funcional. O planejamento considera a individualidade dos alunos, as atividades consistem em estimulação motora aquática, com caminhadas, exercícios de perda e retomada de equilíbrio, fortalecimento muscular, de respiração e iniciação aos nados da natação, com o objetivo de desenvolver as capacidades motoras, proporcionar integração social e melhorar a qualidade de vida, através da redução de quedas e melhora do controle motor.

Conclusão: Na experiência específica com estes dois jovens portadores de Ataxia de Friedreich na natação, em três meses de prática observa-se evolução no fortalecimento muscular, resistência, equilíbrio e coordenação de movimentos, mais interação e comunicação com outros participantes.

\section{Referências}

CASTRO, D. S., DUARTE, L. A. Aspectos Neuroanatômicos e Correlações Clínicas da Ataxia de Friedreich. Revista neurociência, p. 302-307, 2013. Disponível em: https://periodicos.unifesp.br/index.php/neurociencias/article/view/8186. Acesso em: 13 jul. 2021.

SILVEIRA, B. T.; GRAVE, M. T. Q.; PÉRICO, E. Avaliação de força muscular e amplitude de movimento em paciente portador de ataxia de friedreich: um estudo de caso. Caderno pedagógico, Lajeado, v. 9, n. 2, p. 49-58, 2012. Disponível em: http://www.meep.univates.br/revistas/index.php/cadped/article/view/856. Acesso em 07 ago. 2021.

VICHIATTO, O. A., VINHAS W. Relato de caso: Benefícios da natação para uma pessoa com paralisia cerebral. Revista Brasileira de Prescrição e Fisiologia do Exercício, v.13. n.88. p.1348-1353, 2019. Disponível em: https://redib.org/Record/oai_articulo2783688-relato-de-caso-benef\%C3\%ADcios-da-nata\%C3\%A7\%C3\%A3o-para-uma-pessoacom-paralisia-cerebral. Acesso em: 07 ago. 2021.

ZONTA, M. B.; SANTOS, L. H. C.; TEIVE, H. A. G. (org.) Reabilitação nas ataxias: orientação multiprofissional aos pacientes, cuidadores e profissionais. Curitiba: Editora UFPR, 2018. Disponível em: https://acervodigital.ufpr.br/handle/1884/63957. Acesso em 14 jul. 2021. 
- unIPAR 50 anos:

I SALAOO DE EXTENSÃO Transformando vidas atravies da educaģso

DA UNIPAR 


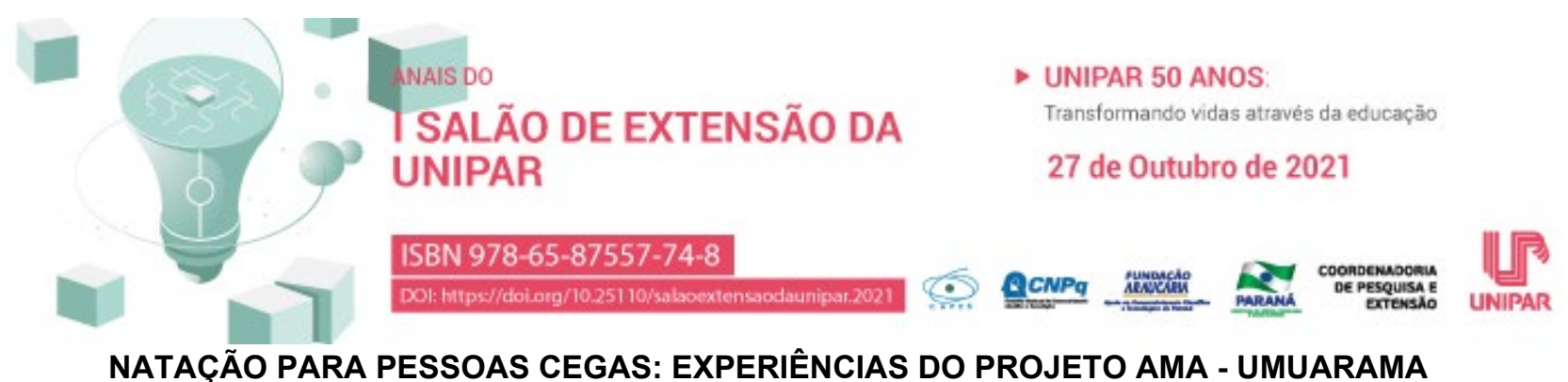

\section{JESSICA CRISTINA PEREIRA, ${ }^{2}$ MARIA GABRIELLA GIROTO}

${ }^{1}$ Acadêmica do Curso de Educação Física Bolsista PIBEX do Projeto AMA, Universidade Paranaense UNIPAR.

${ }^{2}$ Docente da UNIPAR

Introdução: A cegueira é a perda da capacidade funcional de perceber imagens pelos dois olhos, sendo a visão o sentido mais dominante, que desempenha papel fundamental em todas as fases da vida, e sem a mesma, atividades como estudar e trabalhar tornam-se muito mais difíceis (WHO, 2019). Dificuldades também presentes nas práticas motoras, especialmente na natação feita em meio líquido, ambiente não habitual para os indivíduos.

Objetivo: Apresentar a experiência do Projeto AMA no desenvolvimento de aulas de natação para indivíduos cegos.

Desenvolvimento: Segundo Bredariol e de Almeida (2012) a prática da natação por esta população no Brasil ainda é restrita, sendo fundamental a oferta de programas inclusivos, e estratégias de ensino adaptados para suprir as carências no desenvolvimento motor e qualidade de vida de pessoas com deficiência visual. A natação, se bem orientada, é um mecanismo importante para proporcionar independência, desenvolvimento e inclusão social. Entre os benefícios que podem ser alcançados, Moreira (2004) relata a reconstrução da imagem corporal, melhora da mobilidade, autoestima e disposição física. Já Oliveira et al (2013) apontam ganhos na motivação, no condicionamento físico, liberação de energia, diminuição do stress e bom humor. E Soares (2016) indica que a prática organizada da natação, traz ganhos para o autoconhecimento corporal, aguça os sentidos e a auto percepção. Para que os benefícios sejam alcançados deve-se considerar o processo metodológico no trabalho com o aluno cego na natação, neste sentido Bahia (2007) se refere à importância do planejamento das aulas e a didática, verbalizando detalhadamente o movimento, utilizar demonstrações de tato físico, e atividades que envolvem a orientação espacial, noção temporal e coordenação. No Projeto de Extensão AMA, é realizada a estruturação do ambiente, com remoção de obstáculos, feito o mapa mental com o aluno, a descrição verbal de todas as situações, como quem está presente, localização de pessoas e objetos, a descrição verbal e organizada de exercícios, correções e feedback do desempenho à cada atividade. Fatores que consolidam a confiança entre professor e aluno, o processo de aprendizagem e alcance dos benefícios.

Conclusão: Na experiência do Projeto AMA em atender alunos cegos na natação, fatores como adaptação ambiental, mapa mental e descrição verbal de situações, atividades e correções, possibilita a obtenção de melhoras no desenvolvimento motor e psicossocial.

\section{Referências}

BAHIA, Antônio Luiz Ferreira. Aprendizagem da natação por crianças cegas: desafios e possibilidades. 2007. Disponível em: https://repositorio.ufba.br/ri/bitstream/ri/11126/1/Dissertacao_Antonio\%20Bahia1.pdf. Acesso em: 05 ago. 2021.

BREDARIOL, Bruna; DE ALMEIDA, José Júlio Gavião. Acessibilidade de pessoas deficientes visuais à prática da natação uma revisão da literatura. Conexões, v. 10, n. 2, p. 196-213, 2012. Disponível em: https://periodicos.sbu.unicamp.br/ojs/index.php/conexoes/article/view/8637682. Acesso em: 04 ago. 2021.

MOREIRA A. Desporto adaptado, Direito ou oportunidade. Direção de Serviços de Formação e Adaptações Tecnológicas. Revista diversidades. 2004, n2(4) p. 16. Disponível em: http://www02.madeiraedu.pt/Portals/5/documentos/PublicacoesDRE/Revista_Diversidades/dwn_pdf_DesportoAdaptado_DireitoOportunidade_4.pdf. Acesso em: 04 ago. 2021.

OLIVEIRA, G. T. de A. et al. Fatores motivacionais em paratletas com deficiência visual e motora praticantes de natação e atletismo. Conexões, Campinas, SP, v. 11, n. 1, p. $2941, \quad 2013$. Disponível em: https://periodicos.sbu.unicamp.br/ojs/index.php/conexoes/article/view/8637629. Acesso em: 15 ago. 2021.

SOARES, Maria Cecília L. Bonacelli. Natação para deficientes visuais e a corporeidade em Merleau-Ponty. Saúde, Batatais, v. 5 , n. 2, p. 95-103, 2016. Disponível em: file://ID:/Users/Usuario/Downloads/605b71f4b96e769217678048.pdf. Acesso em: 05 de setembro de 2021.

WHO World Health Organization. Relatório Mundial sobre a visão. 2019. Disponível em: https://apps.who.int/iris/bitstream/handle/10665/328717/9789241516570-por.pdf. Acesso em: 06 ago. 2021.

I ARALALÃO DE EXTENSÃO

DA UNIPAR
UNIPAR 50 ANOS:
Transformando vidas atravta da educagto
27 de Outubro de 2021

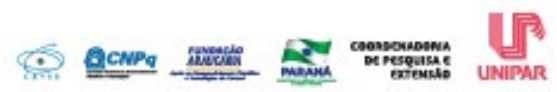




\title{
EXERCÍCIO FÍSICO REMOTO PARA PESSOAS COM DEFICIÊNCIA VISUAL DURANTE A PANDEMIA COVID-19: O USO DA PLATAFORMA GOOGLE MEET PELO PROJETO AMA
}

\author{
${ }^{1}$ JESSICA CRISTINA PEREIRA, ${ }^{2}$ BRENDHA DE OLIVEIRA FIAUX, ${ }^{3}$ PAULO VALERIO SECCO ANTONIO , ${ }^{4}$ THAIS KAROLYNE \\ VIEIRA CANUTO, ${ }^{5}$ MARIA GABRIELLA GIROTO
}

\footnotetext{
${ }^{2}$ Acadêmica do Curso de Educação Física da UNIPAR

${ }^{3}$ Acadêmico do Curso de Educação Física da UNIPAR

${ }^{4}$ Acadêmico do Curso de Educação Física da UNIPAR

${ }^{5}$ Docente da UNIPAR
}

${ }^{1}$ Acadêmica do Curso de Educação Física Bolsista PIBEX do Projeto AMA, Universidade Paranaense UNIPAR.

Introdução: O ano de 2020 marcou o mundo com a pandemia da COVID-19, multiplicando rapidamente o número de casos, sequelas e óbitos, impondo como medida de contenção o distanciamento social. Mudanças de hábitos, e alternativas de práticas de exercício físico orientadas remotamente foram desenvolvidas para a manutenção da saúde e qualidade de vida (MATTOS et al, 2020) (CONFEF, 2020). O distanciamento social obrigatório comprometeu também a qualidade de vida de pessoas com deficiência visual, que apontado pela WHO (2019) tem maior tendência ao isolamento social, devido as dificuldades pela falta da visão.

Objetivo: Apresentar a experiência do Projeto AMA com práticas motoras para pessoas com deficiência visual na Pandemia COVI-19 de forma remota.

Desenvolvimento: A deficiência visual compromete com gravidade a qualidade de vida de adultos, que apresentam taxas mais baixas de desenvolvimento motor e participação no trabalho e na vida social, e maiores taxas de depressão e ansiedade. Sendo o exercício físico componente importante para a manutenção da saúde e qualidade de vida deste público (WHO, 2019). Marmeleira et al (2018) relatam barreiras enfrentadas por estes indivíduos para acesso ás práticas de atividade física como dificuldades ambientais, ações específicas e orientação profissional. Nesta realidade, sabe-se que as atividades físicas contribuem para a melhora do sistema imunológico e para o combate às doenças crônicas, e também para atenuar a ansiedade e tornar o isolamento menos difícil. Para atender a essa nova realidade, profissionais de Educação Física precisaram se readaptar utilizando como ferramentas plataformas eletrônicas (CONFEF, 2020). Ação também desenvolvida pelo Projeto AMA para dar continuidade aos atendimentos para os alunos com deficiência visual, onde através da plataforma Google Meet se manteve os treinos de forma remota. O processo inicial foi de criar o grupo, ensiná-los a acessar o link pelo celular, estruturar o ambiente para a prática em casa, e semanalmente os encontros acontecem, as atividades são todas descritas verbalmente, e através da visualização do aluno em prática, correções e motivação é estabelecida de forma auditiva.

Conclusão: $O$ uso da Plataforma Google Meet permitiu na pandemia que os treinos de exercício físico não parassem no Projeto AMA, dificuldades de acessibilidade eletrônica e compreensão de exercícios foram superadas com a verbalização de todas as ações.

\section{Referências}

CONFEF. Conselho Federal de Educação Física. Atuação profissional em tempos de pandemia. Revista Educação Física. 74/2020. Disponível em: https://www.confef.org.br/extra/revistaef/arquivos/2020/N74_MAR\%C3\%870/06.pdf. Acesso em: 30 jul. 2021.

MARMELEIRA, J. F. F.; FERNANDES, J. M. G. A.; RIBEIRO, N. C.; TEIXEIRA, J. A.; GUTIERRES FILHO, P. J. B. Barreiras para a prática de atividade física em pessoas com deficiência visual. Rer. Bras. Ciênc. Esporte. 2018; 40(2): 197-204. Disponível em: https://www.scielo.br/j/rbce/a/D595fhvkK4c45YxWppsHtbH/?format=pdf\&lang=pt. Acesso em: 30 jul. 2021.

MATTOS, S. M.; PEREIRA , D. S.; MOREIRA , T. M. M. .; CESTARI , V. R. F.; GONZALEZ , R. H. Recomendações de atividade física e exercício físico durante a pandemia Covid-19: revisão de escopo sobre publicações no Brasil. Revista Brasileira de Atividade Física \& Saúde, [S. I.], v. 25, p. 1 12, 2020. Disponível em: https://rbafs.org.br/RBAFS/article/view/14449. Acesso em: 15 ago. 2021.

WHO World Health Organization. Relatório Mundial sobre a visão. 2019. Disponível em: https://apps.who.int/iris/bitstream/handle/10665/328717/9789241516570-por.pdf. Acesso em: 06 ago. 2021. 



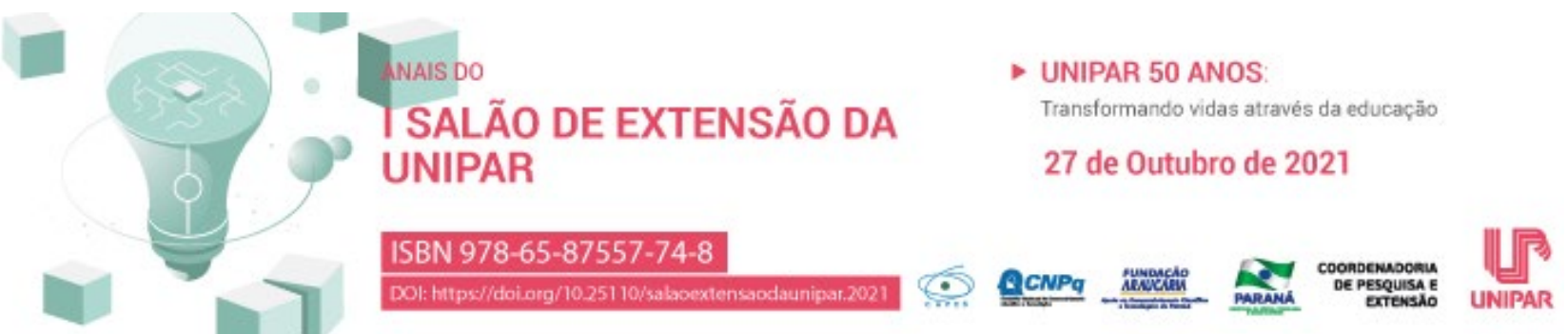 \\ DESIGN DE SOBRANCELHAS COMO PRÁTICA DO AUTOCUIDADO E AUTOESTIMA
}

\author{
${ }^{1}$ THALYTA GARCIA ALBERTO, ${ }^{2}$ ANA CAROLINE ROSALINO DE OLIVEIRA, ${ }^{3}$ KETHLYN SUCHENSKI HANSER, \\ ${ }^{4}$ VANDRESSA APARECIDA BERLANDA, ${ }^{5}$ KELLI KUHNEN, ${ }^{6}$ LUCIANA PELLIZZARO, ${ }^{7}$ JULIANA PELISSARI MARCHI
}

\begin{abstract}
${ }^{1}$ Acadêmica participante do Projeto de Extensão Estética na Comunidade, do C.S.T. em Estética e Cosmética da Universidade Paranaense, UNIPAR.

${ }^{2}$ Acadêmica participante do Projeto de Extensão Estética na Comunidade, do C.S.T. em Estética e Cosmética da Universidade Paranaense, UNIPAR.

${ }^{3}$ Acadêmica participante do Projeto de Extensão Estética na Comunidade, do C.S.T. em Estética e Cosmética da Universidade Paranaense, UNIPAR.

${ }^{4}$ Acadêmica participante do Projeto de Extensão Estética na Comunidade, do C.S.T. em Estética e Cosmética da Universidade Paranaense, UNIPAR.

${ }^{5}$ Responsável Técnica do Centro de Estética Escola do C.S.T. em Estética e Cosmética da Universidade Paranaense, UNIPAR. ${ }^{6}$ Docente do C.S.T. em Estética e Cosmética da Universidade Paranaense, UNIPAR.

${ }^{7}$ Docente do C.S.T. em Estética e Cosmética da Universidade Paranaense, UNIPAR.
\end{abstract}

Introdução: No projeto foram realizados atendimentos diversos à comunidade externa, onde a área de sobrancelha foi a mais requisitada. Segundo Ramthum, Silva e Paganini (2010), o design de sobrancelhas possibilita melhor expressão facial e modelagem ao rosto, que deve ter seu formato respeitado, deixando as sobrancelhas harmônicas e com um aspecto de naturalidade. Com o design é possível tirar as imperfeições da sobrancelha e traçar o perfil de acordo com o formato do rosto. Os cuidados estéticos se associam com a autoestima, de modo que há vários resultados positivos justificando sua importância na melhora de aspectos psicológicos e emocionais dos pacientes, entre os quais podemos encontrar uma maior estima por si mesmo, um aumento nas relações sociais e interpessoais, e uma melhoria na qualidade de vida (MARTINS e FERREIRA, 2020). A autoestima é uma consequência, um efeito de certas práticas e que deve ser adquirida por todos os indivíduos no sentido de obterem sempre uma melhor qualidade de vida (MARTINS e FERREIRA, 2020).

Objetivo: Relatar a experiência de atividades desenvolvidas no Projeto de Extensão Estética na Comunidade.

Resultados: Durante as atividades do projeto, o design de sobrancelha é um dos mais procurados pelo público feminino, sendo uma forma de embelezamento, aumento da autoestima e do autocuidado. Embora existam diversos formatos de sobrancelhas, deve-se respeitar os traços individuais e de personalidade do cliente. Os formatos mais conhecidos são: arredondadas, arqueadas, retas, acento circunflexo, descendentes, ascendentes, juntas na raiz do nariz, afastadas, pouco espessas, curtas ou alongadas (HALLAWELL, 2010). Através dos relatos das participantes do projeto, foram obtidos efeitos positivos, dentre eles destaca-se a autoestima elevada, satisfação pessoal e confiança em si mesmo. Portanto, ressalta-se que as práticas estéticas estão intimamente associadas à autoestima, autoconfiança, bem-estar e qualidade de vida, que consequentemente se relacionam com a saúde da mulher.

Conclusão: Através da prática possibilitada pelo projeto de extensão Estética na Comunidade evidenciamos que a estética contribui positivamente para a saúde da mulher. Ressaltando, portanto, sua importância tanto em questões de aparência quanto em questões de harmonização aos traços individuais. O cuidado estético possibilita em primeiro momento um cuidado externo do indivíduo, o qual consequentemente atuará também nas questões internas. Os cuidados em saúde devem ser feitos de maneira integrada para se obter um melhor resultado.

\section{Referências}

HALLAWELL, Philip. Visagismo: harmonia e estética. 6a ed. Senac, São Paulo, 2010.

MARTINS, Roseneide da Silva Gusmão; FERREIRA, Zamia Aline Barros. A Importância dos Procedimentos Estéticos na Autoestima da Mulher/The Importance of Aesthetic Procedures in Women's Self-Esteem. ID on line. Revista de Psicologia, v. 14, n. 53, p. 442-453, 2020.

RAMTHUM, Emili Ana; SILVA, Gabriela Pasa da; PAGANINI, Tatiana. O delineamento de sobrancelha conforme a fisionomia da face. Universidade do Vale do Itajaí, 2010.2 Disponível em: http://siaibib01.univali.br/pdf/Emili\%20Ana\%20Ramthum,\%20Gabriela\%20Pasa\%20da\%20Silva.pdfv. Acesso em: 31 de ago. 2021. 
- unIPAR 50 anos:

I SALAOO DE EXTENSÃO Transformando vidas atravies da educaģso

DA UNIPAR 


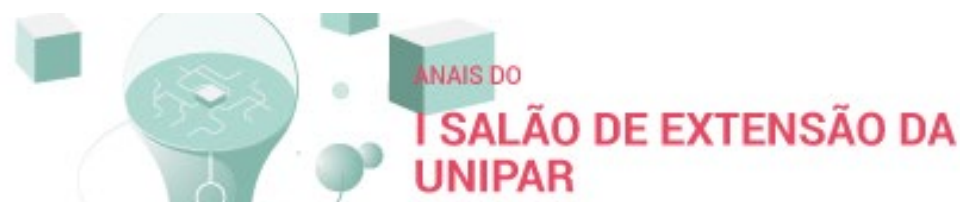 \\ - UNIPAR 50 ANOS \\ Transformando vidas através da educação \\ 27 de Outubro de 2021 \\ ISBN 978-65-87557-74-8

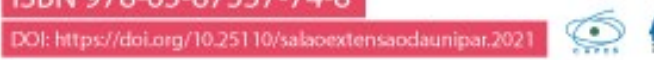

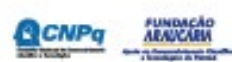

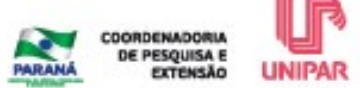 \\ ACOLHIMENTO A PACIENTES QUE BUSCAM ATENDIMENTO NA CLÍNICA ODONTOLÓGICA DA UNIPAR}

${ }^{1}$ BEATRIZ AYUMI SHIOTANI, ${ }^{2} \mathrm{HELOISA} \mathrm{GARCIA} \mathrm{FRANCOZO,}{ }^{3}$ GABRIELA ZANUTO DE LIMA, ${ }^{4}$ GABRIEL MACIEL DA SILVA, ${ }^{5}$ LAINARA ANGELO SANTOS, 6 LEISLE VERONICA PRESTES, ${ }^{7}$ ANA CAROLINE DOS SANTOS GRUNOW, ${ }^{8}$ CARINE CRISCIELE FORMAGGI SALES, ${ }^{9}$ HENDER HENRIQUE MONTEIRO DE SOUZA, ${ }^{10} \mathrm{ALICIA}$ GIOVANA ROCHA, ${ }^{11} \mathrm{ELOISA}$ PEREIRA DE SOUZA, ${ }^{12}$ ANDRESSA VENTRAMELI DE ANDRADE, ${ }^{13}$ VERUSKA DE JOAO MALHEIROS PFAU

${ }^{1}$ Acadêmica bolsista PIBEX

${ }^{2}$ Acadêmica do Curso de Odontologia da UNIPAR

${ }^{3}$ Acadêmica do Curso de Odontologia da UNIPAR

${ }^{4}$ Acadêmico do Curso de Odontologia da UNIPAR

${ }^{5}$ Acadêmica do Curso de Odontologia da UNIPAR

${ }^{6}$ Acadêmica do Curso de Odontologia da UNIPAR

${ }^{7}$ Acadêmica do Curso de Odontologia da UNIPAR

${ }^{8}$ Acadêmica do Curso de Odontologia da UNIPAR

${ }^{9}$ Acadêmico do Curso de Odontologia da UNIPAR

${ }^{10}$ Acadêmica do Curso de Odontologia da UNIPAR

${ }^{11}$ Acadêmica do Curso de Odontologia da UNIPAR

${ }^{12}$ Acadêmica do Curso de Odontologia da UNIPAR

${ }^{13}$ Docente da UNIPAR

Introdução: O acolhimento possui um papel primordial ao vincular o paciente aos serviços de necessidade, facilitando os processos e sequência de trabalho de forma a atender todos, assumindo um serviço capaz de acolher, escutar e pactuar respostas mais adequadas aos pacientes. Sendo uma das diretrizes de maior relevância na atual política de humanização do Sistema Único de Saúde - HumanizaSUS, o acolhimento visa ter o paciente como sujeito ativo no processo de produção de saúde, sendo mediada por parâmetros técnicos, éticos, humanitários e de solidariedade (RAMOS, LIMA 2003; VASCONCELOS et al., 2011). Compreendendo desde a entrada do usuário no sistema de saúde e a responsabilização integral de suas necessidades até a atenção resolutiva de todos os seus problemas, visando provocar a reorganização do serviço de forma prática, oportuna e eficiente juntamente com a sua resolutividade ao atender positivamente os entraves à saúde dos usuários de acordo com sua necessidade e individualidade, facilitando e agilizando o processo de fila de espera e atendimento para melhor acolhimento aos paciente (MOIMAZ et al., 2017).

Objetivo: Realizar o acolhimento aos pacientes que buscam atendimento na Clínica Odontológica da Unipar, bem como conduzir os devidos encaminhamentos às diversas áreas de acordo com sua necessidade individualizada em saúde bucal, proporcionando assim um serviço humanizado e dinâmico.

Resultados: Apesar do pouco tempo de projeto, é notório perceber a melhora no fluxo dos encaminhamentos de forma mais prática e eficiente para as diferentes áreas e especialidades odontológicas. Desta forma, está sendo realizada a reorganização das fichas de encaminhamento, contatos telefônicos onde podemos colher maiores informações quando necessário, além da realização de triagem presencial quando necessário, Assim, podemos avaliar a individualidade de cada paciente,e consequentemente, reduzir o tempo de espera nas filas de avaliação, bem como dos atendimentos subsequentes.

Conclusão: Diante dessa realidade, podemos perceber a importância do acolhimento em saúde bucal como um dispositivo capaz de conduzir a organização e o planejamento das atividades desenvolvidas na clínica odontológica, de forma eficiente, produtiva e humanizada, transformando-se em um importante instrumento de gestão, devendo acontecer de forma dinâmica e contínua em todos os locais e momentos do serviço.

\section{Referências}

BRASIL. Ministério da Saúde. Secretaria de Atenção à Saúde. Núcleo técnico da política Nacional de Humanização. HumanizaSUS: acolhimento com avaliação e classificação de risco, um paradigma ético-estético. Brasília: Ministério da Saúde; 2004

DINIZ, Diego Garcia. Acolhimento em saúde bucal: ferramenta facilitadora na organização do acesso às ações em odontologia 
no serviço público. 2012.

MOIMAZ, Suzely Adas Saliba et al. Qualificação do acolhimento nos serviços de saúde bucal. Cadernos Saúde Coletiva, v. 25, p. 1-6, 2017.

NUTO, Sharmênia de Araújo Soares et al. O acolhimento em saúde bucal na Estratégia de Saúde da Família, Fortaleza-CE: um relato de experiência. Revista de APS, v. 13, n. 4, 2010.

RAMOS, Donatela Dourado; LIMA, Maria Alice Dias da Silva. Acesso e acolhimento aos usuários em uma unidade de saúde de Porto Alegre, Rio Grande do Sul, Brasil. Cadernos de Saúde Pública, v. 19, p. 27-34, 2003.

VASCONCELOS, Flávia Nery; DE VASCONCELOS, Érico Marcos; DUARTE, Sebastiao Junior Henrique. O acolhimento na perspectiva das Equipes de Saúde Bucal inseridas na Estratégia Saúde da Família: uma revisão bibliográfica da literatura brasileira. Tempus Actas de Saúde Coletiva, v. 5, n. 3, p. 115-122, 2011.

WARMLING, Cristine Maria; BALDISSEROTTO, Julio; ROCHA, Evelise Tarouco da. Acolhimento \& acesso de necessidades de saúde bucal e o agir profissional na Atenção Primária à Saúde. Interface-Comunicação, Saúde, Educação, v. $23,2019$.

I SALĂOO DE EXTENSÃO

DA UNIPAR
- UNIPAR 50 ANOS:

Traneformando vidas atravéa da educaçto

27 de Outubro de 2021

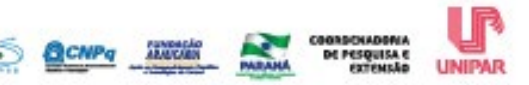




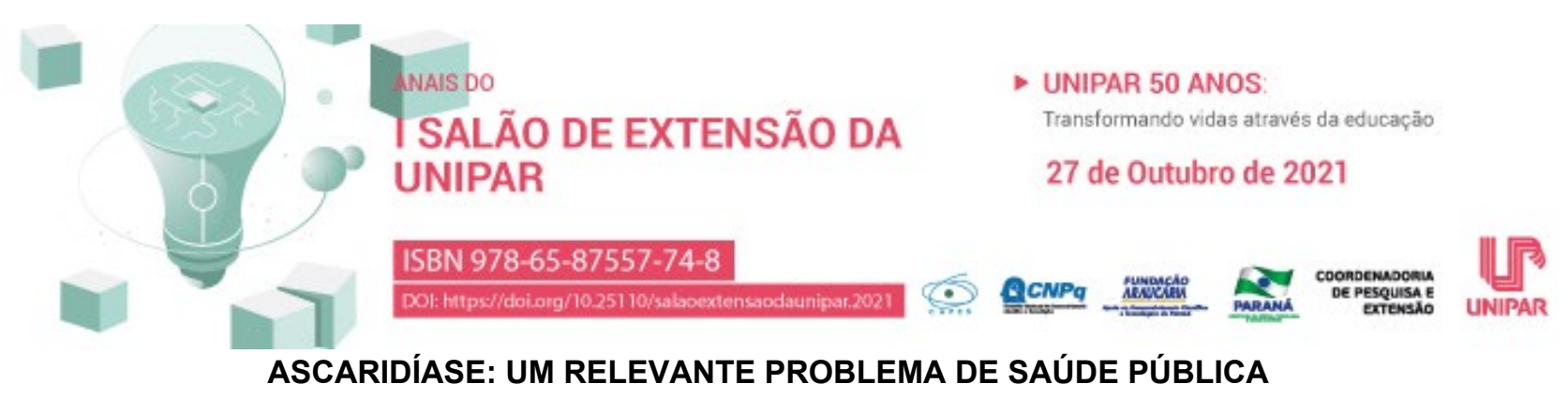

\author{
${ }^{1}$ ALLEX VITAL PEREIRA, ${ }^{2}$ LAURA RICARDA EBELING LAUTERT , ${ }^{3}$ MAISA STEFFANI ADAMCZUK, ${ }^{4}$ JULIA VALER GUERRA, \\ ${ }^{5}$ EDSON GERONIMO , ${ }^{6}$ ERIKA DE GOIS FREIRE LOPES, ${ }^{7}$ THAINARA LOURENCO DE VASCONCELLOS,${ }^{8}$ THAIS \\ EDUARDA ADAMCZUK, ${ }^{9}$ GIULIANA ZARDETO SABEC
}

${ }^{1}$ Acadêmico do Curso de Farmácia da Universidade Paranaense - UNIPAR

${ }^{2}$ Acadêmica do Curso de Farmácia da UNIPAR

${ }^{3}$ Acadêmico do Curso de Farmácia da UNIPAR

${ }^{4}$ Acadêmica do Curso de Farmácia da UNIPAR

${ }^{5}$ Acadêmico do Curso de Doutorado Em Ciencia Animal Com Enfase Em Produtos Bioativos da UNIPAR

${ }^{6}$ Acadêmica do Curso de Farmácia da UNIPAR

${ }^{7}$ Acadêmica do Curso de Farmácia da UNIPAR

${ }^{8}$ Acadêmica do Curso de Farmácia da UNIPAR

${ }^{9}$ Docente da UNIPAR

Introdução: Ascaris lumbricoides popularmente conhecida como Ascaridíase ou Lombriga, é um parasito intestinal presente em países subdesenvolvidos como o Brasil, tendo grande relevância nos problemas de saúde pública, sendo essa doença adquirida pela ingestão de água ou alimentos contaminados com ovos larvados, podendo esses ovos ser veiculados por poeira e insetos (DE ANDRADE JÚNIOR; ALVES; DE ARRUDA BARBOSA, 2020).

Objetivo: O presente estudo tem como objetivo alertar a população sobre a Ascaridíase e ressaltar as medidas protetivas para combatê-la.

Desenvolvimento: A Ascaridíase se trata de uma doença com um ciclo monoxênico, ou seja, só possui um hospedeiro, sendo o homem infectado ao ingerir água ou alimentos contaminados com ovos larvados do tipo filarioide infectante L3, que podem ser veiculados por poeira e insetos (DE ANDRADE JÚNIOR; ALVES; DE ARRUDA BARBOSA, 2020). Essa parasitose possui ação patogênica em duas etapas: durante migração das larvas e nos vermes adultos no habitat definitivo. Os vermes adultos irritam e obstruem a parede intestinal, podendo também atingir locais indevidos espontaneamente ou após medicação, como o apêndice, o canal colédoco ou serem eliminados pela boca ou narinas (DE ANDRADE JÚNIOR; ALVES; DE ARRUDA BARBOSA, 2020). Com isso, causam principalmente desconfortos abdominais, como cólicas, má digestão, aumento no volume abdominal, além de poderem afetar o sono, contribuir para o surgimento de manchas brancas na pele e o aparecimento de bruxismo (ranger dos dentes à noite) (MUNARETO et al., 2021). A epidemiologia consiste nos países de clima tropical e semitropical, com prevalência mundial de $30 \%$, sendo essa prevalência afetada pela viabilidade do ovo, disseminação por insetos e poeira, baixo nível socioeconômico e má educação sanitária, por esses motivos essa parasitose é mais presente em países subdesenvolvidos (MUNARETO et al., 2021). Para se diagnosticar a presença dos parasitos, o método mais utilizado é HPJ (Hoffmann-Pons e Janer) de sedimentação espontânea. Para realizar o diagnóstico dessas parasitoses, utiliza-se também a microscopia, que tem custo menor, possui alta especificidade e sensibilidade média (ZARDETO-SABEC et al., 2020). No tratamento da Ascaridíase é realizado, exclusivamente, por meio de fármacos atrelado a medidas prófiláticas para se evitar a reinfecção (DE ANDRADE JÚNIOR; ALVES; DE ARRUDA BARBOSA, 2020). Como maneira de profilaxia, podemos citar a melhoria das condições de saneamento básico e medidas educativas sanitárias, como lavar as mãos antes de comer/tocar alimentos, lavar os alimentos antes de consumir para proteger contra insetos, além de tratar as pessoas parasitadas, já que estas que expelem o ovo das larvas, contaminando novas pessoas (MUNARETO et al., 2021).

Conclusão: Conclui-se que as medidas de prevenção indicadas são de extrema importância, assim como a realização dos exames parasitológicos a fim de identificar possíveis casos de parasitos intestinais, não se limitando somente a ascaridíase, ademais, também é válido citar que o acesso ao saneamento básico também contribui para o não desenvolvimento dessa parasitose. Neste sentido, mais estudos acerca do assunto e conscientização da população acerca das medidas protetivas são necessárias.

\title{
Referências
}

DE ANDRADE JÚNIOR, Francisco Patricio; ALVES, Thiago Willame Barbosa; DE ARRUDA BARBOSA, Vanessa Santos. ASCARIDÍASE, HIMENOLEPÍASE, AMEBÍASE E GIARDÍASE: UMA ATUALIZAÇÃO. Educação, Ciência e Saúde, v. 7, n. 1, 2020. 
MUNARETO, Danilo da Silva et al. Parasitoses em crianças na fase pré-escolar no Brasil: revisão bibliográfica. Research, Society and Development, v. 10, n. 1, p. e1910111195-e1910111195, 2021.

ZARDETO-SABEC, Giuliana et al. Análise dos laudos do exame parasitológico de fezes de um laboratório da cidade de Umuarama-PR no ano de 2018. Brazilian Journal of Surgery and Clinical Research, v. 30, n. 3, p. 07-12, 2020.

I SALĀO DE EXTENSÃO

DA UNIPAR
- UNIPAR 50 ANOS:

Transformando vidas atravie da educaçlo

27 de Outubro de 2021

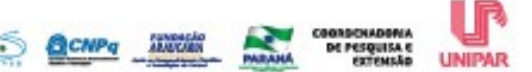




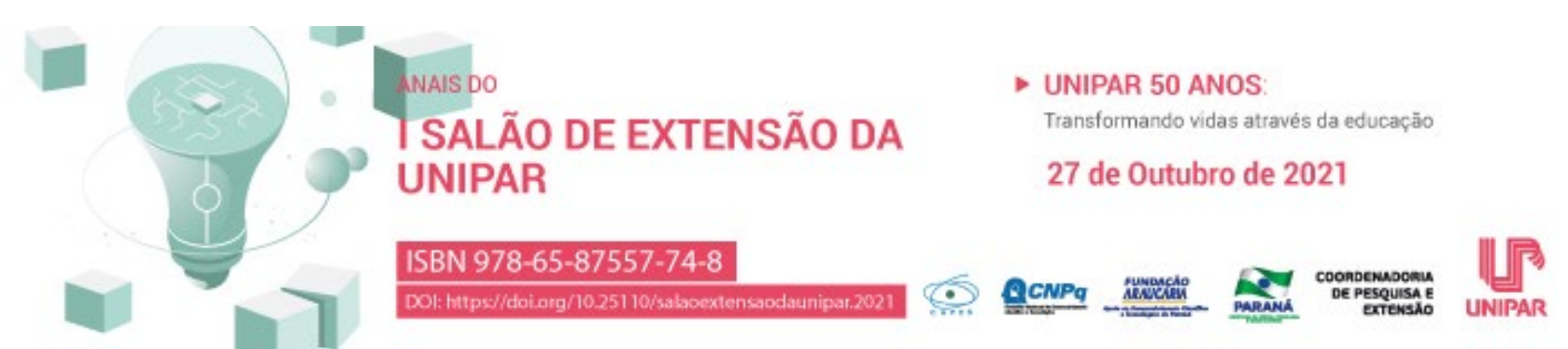

\title{
AÇÕES DE EDUCAÇÃo EM SAÚDE BUCAL PARA PACIENTES ATENDIDOS NA CLÍNICA ODONTOLÓGICA DA UNIPAR
}

\author{
${ }^{1}$ LEISLE VERONICA PRESTES, ${ }^{2}$ ANDRESSA VENTRAMELI DE ANDRADE, ${ }^{3}$ ARGEMIRO RIBEIRO DE ALMEIDA NETO , \\ ${ }^{4}$ BEATRIZ AYUMI SHIOTANI, ${ }^{5}$ GABRIELA ZANUTO DE LIMA, ${ }^{6}$ GIOVANA SOLER DOS SANTOS, ${ }^{7}$ GUSTAVO BARBOSA \\ CORREA DE MORAIS, ${ }^{8}$ HELOISA GARCIA FRANCOZO, ${ }^{9}$ IZABELLI CABRERA DE PAULA, ${ }^{10}$ JOAO MURILO GONCALVES \\ GAZOLA, ${ }^{11}$ JOAO PEDRO SILVA, ${ }^{12}$ LAINARA ANGELO SANTOS, ${ }^{13}$ LUANA HERRERO DOMENE, ${ }^{14}$ MARIANA RODRIGUES \\ VALES, ${ }^{15}$ TATIANE LORENCETO PERGO, ${ }^{16}$ VERUSKA DE JOAO MALHEIROS PFAU
}

${ }^{1}$ Discente do curso de Odontologia/UNIPAR

${ }^{2}$ Discente do Curso de Odontologia/UNIPAR

${ }^{3}$ Discente do Curso de Odontologia/UNIPAR

${ }^{4}$ Discente do Curso de Odontologia/UNIPAR

${ }^{5}$ Discente do Curso de Odontologia/UNIPAR

${ }^{6}$ Discente do Curso de Odontologia/UNIPAR

${ }^{7}$ Discente do Curso de Odontologia/UNIPAR

${ }^{8}$ Discente do Curso de Odontologia/UNIPAR

${ }^{9}$ Discente do Curso de Odontologia/UNIPAR

${ }^{10}$ Discente do Curso de Odontologia/UNIPAR

${ }^{11}$ Discente do Curso de Odontologia/UNIPAR

${ }^{12}$ Discente do Curso de Odontologia/UNIPAR

${ }^{13}$ Discente do Curso de Odontologia/UNIPAR

${ }^{14}$ Discente do Curso de Odontologia/UNIPAR

${ }^{15}$ Discente do Curso de Odontologia/UNIPAR

${ }^{16}$ Docente da UNIPAR

Introdução: O conceito de saúde não se restringe apenas a ausência de enfermidade, mas deve compreender o bem-estar físico, mental e social (CNS, 2021). Segundo Vieira et al., 2018, a saúde bucal inclui capacidades, como falar, sorrir, mastigar, engolir e transmitir diversas emoções por meio das expressões faciais, sem que haja desconforto e dor do complexo craniofacial cabeça, rosto e cavidade oral. Assim, a saúde bucal integrada à promoção de saúde, visa ações de promoção e proteção à saúde de modo a reduzir os fatores de risco que podem provocar impactos negativos à saúde das pessoas (ARANHA et al., 2021). Frente a essas condições, a educação em saúde bucal possui um importante papel no que diz respeito ao fortalecimento da autonomia dos indivíduos frente ao controle do processo saúde-doença e na condução de seus hábitos (SANTOS et al., 2015). Enquanto profissional da saúde, compreender que a saúde bucal está diretamente relacionada a certas condições, como alimentação, moradia e renda, bem como, entender a importância da disseminação de informações voltada para o coletivo, é de grande valia quando se considera a melhoria na qualidade de vida e o conhecimento que cada pessoa irá se apropriar quanto aos cuidados e a importância da higiene bucal, para manutenção da saúde geral.

Objetivos: Fornecer informações sobre a saúde bucal e a sua importância para a manutenção de uma boa qualidade de vida, para os pacientes que procuram atendimento na clínica de odontologia da UNIPAR.

Resultados: Até o momento, as ações voltadas para a educação em saúde, têm sido realizadas por meio da elaboração de materiais educativos, como vídeos, cartilhas e roteiros para palestras informativas, que serão repassadas aos pacientes, de forma presencial, quando se tratarem de palestras ou, serão transmitidas pelas televisões disponíveis nas salas de espera das clínicas. Ademais, as informações pertinentes e inerentes ao assunto, também são repassadas durante a triagem do paciente, que por sua vez, têm suas dúvidas sanadas e obtém as informações básicas para tal condição.

Conclusão: Dada importância da educação em saúde bucal, assim como o conhecimento sobre a manutenção de uma boa qualidade de vida e a relação de ambas, as ações desenvolvidas na clínica odontológica da UNIPAR é de suma relevância, considerando a abordagem e as informações que serão repassadas ao paciente, contribuindo assim, para a difusão do conhecimento, e atuando de forma preventiva nos problemas futuros. 


\section{Referências}

ARANHA, Lauramaris de Arruda Regis; et al. Condições de Saúde Bucal e acuidade visual dos estudantes em um município do Baixo Amazonas. Escola Anna Nery, v. 25, n. 3, 2021. Disponível em: https://www.scielo.br/j/ean/a/xg59chrWNCdChWfLFgb6kzk/?format=pdf\&lang=pt. Acesso em: 15 set. 2021.

CONSELHO NACIONAL DE SAÚDE. Abril da saúde de 2021: CNS mobiliza conselhos e sociedade em defesa do SUS e da vida. 29 mar. 2021. Disponível em: http://conselho.saude.gov.br/ultimas-noticias-cns/1668-abril-da-saude-2021-cns-mobilizaconselhos-e-sociedade-em-defesa-do-sus. Acesso em: 15 set. 2021.

SANTOS, Katia Simone Alves; et al. Conhecimento e percepção dos pacientes sobre saúde bucal. RFO UPF, v. 20 , n. 3, 2015. Disponível em: http://revodonto.bvsalud.org/scielo.php?pid=S1413-40122015000300003\&script=sci_arttext. Acesso em: 16 set. 2021.

VIEIRA, Paula Reginne; et al. Qualidade de vida e percepção estética da cárie dentária. Revista Brasileira em Promoção da Saúde, v. 31, n. 1, 2018. Disponível em: https://docs.bvsalud.org/biblioref/2018/04/882030/6649.pdf. Acesso em: 16 set. 2021.

\section{SALÄO DE EXTENSÃO}

DA UNIPAR
- UNIPAR 50 ANOS:

Transformando vides atraves da educaço

27 de Outubro de 2021

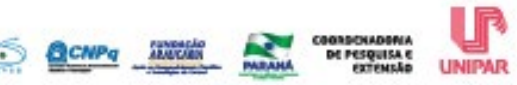




\section{(3) \\ - UNIPAR 50 ANOS: \\ Transformando vidas através da educaçào \\ 27 de Outubro de 2021

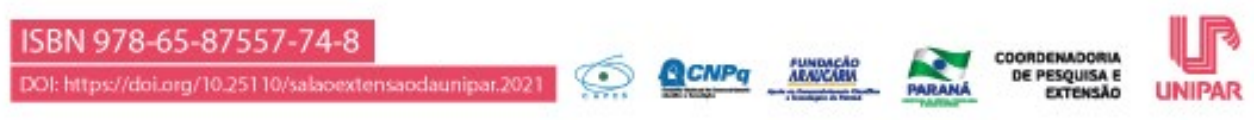 \\ RELAÇÃO ENTRE O INDICE DE MASSA CORPORAL E APTIDÃO FÍSICA RELACIONADO AO DESEMPENHO EM ESCOLARES}

${ }^{1}$ LUCAS EDUARDO BORGHESAN BORTOT, ${ }^{2}$ TAINAN PADILHA, ${ }^{3}$ MATHEUS DAL PUBEL LISE, ${ }^{4}$ RAFAELA BETTI, ${ }^{5}$ NICOLAS LUAN DESEN, ${ }^{6}$ MATHEUS KRUGER BAMPI, ${ }^{7}$ CRISTIAN MATHEUS POLETTO DALAQUA, ${ }^{8}$ GABRIEL MENDES CARVALHO, ${ }^{9} \mathrm{CHIARA}$ MUNARO, ${ }^{10}$ DURCELINA SCHIAVONI BORTOLOTI

\footnotetext{
${ }^{1}$ Acadêmico do Curso de Educação Física Bacharelado / UNIPAR

${ }^{2}$ Acadêmico do Curso de Educação Física Bacharelado / UNIPAR

${ }^{3}$ Acadêmico do Curso de Educação Física Bacharelado / UNIPAR

${ }^{4}$ Acadêmico do Curso de Educação Física Bacharelado / UNIPAR

${ }^{5}$ Acadêmico do Curso de Educação Física Bacharelado / UNIPAR

${ }^{6}$ Acadêmico do Curso de Educação Física Bacharelado / UNIPAR

${ }^{7}$ Acadêmico do Curso de Educação Física Bacharelado / UNIPAR

${ }^{8}$ Acadêmico do Curso de Educação Física Bacharelado / UNIPAR

Francisco Beltrão

Francisco Beltrão

Francisco Beltrão

Francisco Beltrão

Francisco Beltrão

Francisco Beltrão

Francisco Beltrão

${ }^{9}$ Docente do Curso de Educação Física Bacharelado / UNIPAR Francisco Beltrão

${ }^{10}$ Docente do Curso de Educação Física Bacharelado / UNIPAR Francisco Beltrão
}

Introdução: Nas últimas décadas a prática de atividade física tem diminuído e com isso, um declínio na aptidão física em crianças e adolescentes. Adicionalmente, a obesidade vem se caracterizando como um problema de saúde pública em populações cada vez mais jovens (COSTA et al., 2020). O aumento da composição corporal associa-se ao sedentarismo e a falta de atividades físicas, predispõe o aparecimento de doenças cardiovasculares (REIS et al., 2017), além disso, diminuem o desempenho em atividades esportivas. O índice de massa corporal (IMC) pode estar correlacionado a baixos níveis de AFRD (LOPES et al., 2019).

Objetivo: Avaliar a relação entre índice de massa corporal e aptidão física relacionada ao desempenho.

Resultados: Este estudo é um subprojeto do projeto de extensão universitária da UNIPAR intitulado Esporte na Universidade: Uma experiência para jovens. Para este trabalho, contamos com a participação de 75 escolares com idades de 14 a 17 anos de ambos os sexos. Foram realizadas bateria de testes propostos por Gaya e Gaya (2016) o qual avaliou-se: IMC, envergadura, velocidade, força de membros inferiores (MI) e superiores (MS), abdominal, flexibilidade, agilidade e aptidão cardiorrespiratória. Para análise dos dados empregou-se o teste de correlação de Person (significância de 5\%). Ao analisar a correlação do IMC e os diferentes componentes da AFRD encontramos que: a flexibilidade e a velocidade de rapazes e moças tiveram correlação bem fraca $(r<0,190)$, a força de MS das moças teve correlação bem fraca $(r=-0,191)$ e para os rapazes foi significativa e fraca $(r=$ $-0,365)(p<0,05)$. A força de Ml das moças teve correlação bem fraca $(r=-0,059)$ assim como a dos rapazes $(r=-0,254)$. $O$ teste do abdominal teve correlação bem fraca para os rapazes $(r=-0,116)$ e fraco para as moças $(r=-0,332)$. A agilidade teve correlação bem fraca para os rapazes $(r=0,098)$ e fraco para as moças $(r=0,283)$. A resistência cardiorrespiratória teve correlação fraca para moças $(r=-0,394)$ e moderada e significativa para os rapazes $(r=-0,514)$.

Considerações finais: Observamos que a maioria dos componentes da AFRD teve correlação fraca ou bem fraca com o IMC, e somente a resistência cardiorrespiratória dos rapazes teve uma moderada e significativa correlação com o IMC. Contudo, de maneira geral verificou-se que o IMC correlacionou-se negativamente com os componentes da AFRD dos jovens avaliados, ou seja, maiores valores de IMC podem estar relacionados a baixo desempenho físico.

\section{Referências}

COSTA, Eduardo Aleixo, et al. Relação entre testes de aptidão física, índice de massa corporal e relação cintura estatura em escolares das redes públicas e privadas. Brasilian Journal of Development, v.6, n.12, p.1024486, 2020.

n.12, p.102486-102497

GAYA, Adroaldo e GAYA, Anelise. Projeto esporte Brasil. Manual de testes e avaliação, 2016.

LOPES, Vitor Pires, et al. Body mass index and physical fitness in Brazilian adolescentes. Jornal de Pediatria, v.96, n.6, p. 667790, 2019.

REIS, Monalisa da Silva, et al. Aptidão cardiorrespiratória associada ao índice de massa corporal em escolares entre 7 a 10 anos de idade. Revista Brasileira de Prescrição e Fisiologia do Exercício, v.11, n. 64, p. 122-127, 2017. 
- unIPAR 50 anos:

I SALAOO DE EXTENSÃO Transformando vidas atravies da educaģso

DA UNIPAR 


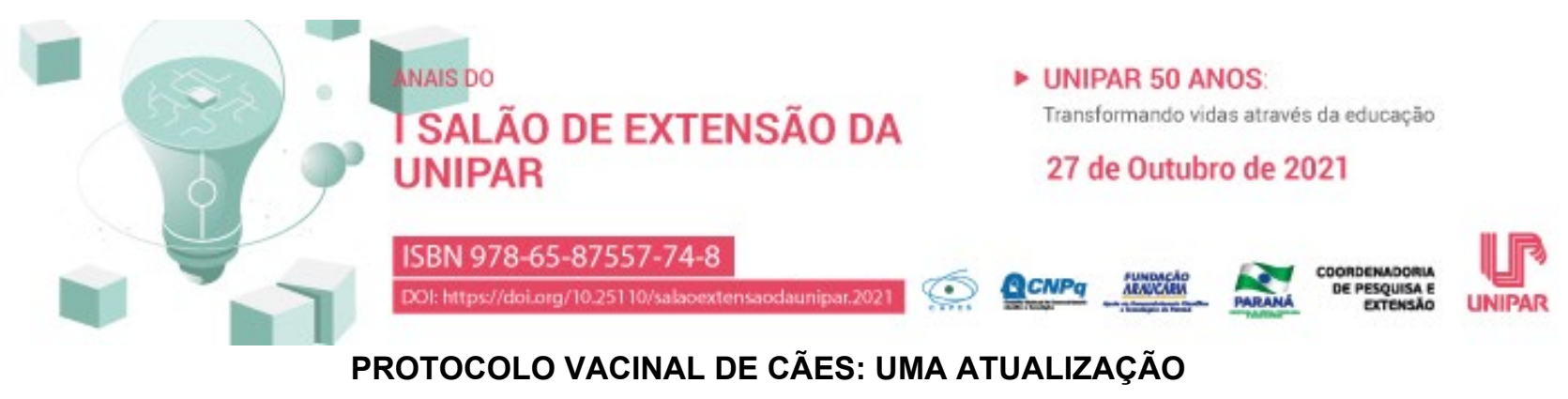

${ }^{1}$ BRUNA EDUARDA DIAS SARRANO, ${ }^{2}$ THAYS KAROLLYNI AMARAL GOMES, ${ }^{3}$ MARIA LETÍCIA LINHARES MACHADO,
${ }^{4}$ ALANA TIETE VIAJANTE, ${ }^{5}$ MARIA CLARA UCKER COSTODIO, ${ }^{6}$ JOÃO LUIS DOMINGUES FERREIRA, ${ }^{7}$ LAISA MARIAN
ROSA REY, ${ }^{8}$ MARIA EDUARDA GRAEFF, ${ }^{9}$ NATALIE BERTELIS MERLINI, ${ }^{10}$ FRANCISLAINE APARECIDA DOS REIS LIVERO

${ }^{1}$ Acadêmica do curso de Medicina Veterinária da UNIPAR, bolsista PEBEX-Fundação Araucária.

${ }^{2}$ Acadêmica do curso de Medicina Veterinária da UNIPAR, PEX.

${ }^{3}$ Acadêmica do curso de Medicina Veterinária da UNIPAR, PEX.

${ }^{4}$ Acadêmica do curso de Medicina Veterinária da UNIPAR, PEX

${ }^{5}$ Acadêmica do curso de Medicina Veterinária da UNIPAR, PEX.

${ }^{6}$ Acadêmico do curso de Medicina Veterinária da UNIPAR, PEX

${ }^{7}$ Discente do Programa de Pós-Graduação em Ciência Animal com Ênfase em Bioativos UNIPAR.

${ }^{8}$ Acadêmica do curso de Medicina Veterinária da UNIPAR, PEX

${ }^{9}$ Docente e Pesquisadora do Programa de Pós-Graduação em Ciência Animal com Ênfase em Bioativos UNIPAR.

${ }^{10}$ Docente do Mestrado Profissional em Plantas Medicinais e Fitoterápicos na Atenção Básica e do PPG em Ciência Animal UNIPAR.

Introdução: Nos últimos anos, o conceito reemergente de saúde única impactou também o campo da vacinologia. O manejo das doenças infecciosas através da interação colaborativa dos profissionais de saúde humana, animal e ambiental fornece uma meta racional e econômica em um momento em que se propõe que a maioria das doenças infecciosas humanas emergentes recentes derivam de fontes de animais domésticos e silvestres (GIBBS, 2014). Neste sentido, foram propostas diretrizes de vacinação levando-se em conta as necessidades individuais de cada espécie, sendo propostas as vacinas essenciais e não essenciais para cada região, atendendo assim à demanda local e suas características ambientais (DAY, 2016).

Objetivo: Apresentar protocolos atuais de vacinação de cães visando a proteção animal contra determinadas infecções, bem como bloqueio de transmissão de doenças.

Desenvolvimento: A vacinação de animais domésticos se baseia em conceitos científicos, dados através da compreensão dos agentes envolvidos na geração de enfermidades, introduzida por Louis Pasteur na tentativa de combater a raiva, a cólera aviária, o carbúnculo hemático e a erisipela suína. A relevância de seus resultados e o impacto social científico, principalmente no caso da raiva em cães, tornaram-se o exemplo mais emblemático da capacidade de Pasteur (TOLLIS, 2006). Há décadas há relatos do uso de vacinas inativadas e atenuadas contra cinomose e parvovirose (POVEY, 1982) e desde 1960 o protocolo padrão de vacinação recomendava vacinas anuais e contribuia para redução da incidência de algumas doenças infecciosas (COYNE et al., 2001). Entretanto, a partir da década de 90, o protocolo começou a ser questionado e foi proposta a divisão das vacinas em essenciais, opcionais e não essenciais. Além disso, foi proposto que as vacinas essenciais fossem administradas a cada 3 anos para animais adultos (ELSTON, 1998). O Vaccination Guidelines Group (VGG) considera que uma vacina essencial é aquela que deve ser aplicada em todos os cães em todo o mundo, em intervalos recomendados, para fornecer proteção perene contra doenças infecciosas de significância global. O VGG define ainda as vacinas opcionais como aquelas que são necessárias somente para os animais cuja localização geográfica, ambiente ou estilo de vida os coloca em risco de contrair infecções específicas e as vacinais não recomendadas são aquelas que não necessitam ser incluídas no programa de vacinação de rotina, mas podem ser utilizadas a critério do médico veterinário. As vacinas essenciais para o cão conferem proteção contra a infecção pelo vírus da cinomose canina (CDV), adenovírus canino (CAV) e parvovírus canino tipo 2 (CPV-2) e raiva. Ainda, em decorrência da variação das condições e geografia de alguns países podem ser administradas outras vacinas adicionais que também são consideradas opcionais. As vacinas múltiplas V8 e V10 disponíveis hoje no mercado para os cães, são utilizadas para prevenção da cinomose, parvovirose, hepatite infecciosa canina, parainfluenza, coronavirose e leptospirose. O protocolo vacinal dos cães com a vacina múltipla de acordo com o WSAVA, 2016, deve ter início entre 6-8 semanas de idade, e então uma nova dose a cada 2-4 semanas, até que o animal apresente 16 semanas (4 meses) de idade ou mais. Portanto, o número de vacinas primárias do filhote será determinado pela idade na qual a vacinação é iniciada e no intervalo selecionado entre as vacinas. Posteriormente, uma dose de reforço deve ser administrada aos 12 meses de idade e em seguida realizado reforço anual, com uma vacina multivalente, que conta com uma associação de antígenos por vezes mais orientada por protocolos comerciais do que científicos (VIDOR, 2007). Quanto à vacinação antirrábica, é determinada por lei no Brasil e deve ser 
administrada a partir das 12 semanas ( 3 meses) de idade, com reforços anuais. Finalmente, é importante destacar que desde a publicação das diretrizes de 2016 da World Small Animal Veterinary Association (WSAVA), há maior disponibilidade de kits de testes sorológicos rápidos e simples que podem ser utilizados em clínicas após a vacinação de cães, assim detectando a presença do anticorpo específico para CVD, CAV e CPV-2 de maneira individual. Esses kits de testes complementam as tradicionais modalidades padrão ouro de testes sorológicos realizados em laboratório e validados na clínica e no ambiente do abrigo (GRAY et al. 2012, Litster et al. 2012).

Conclusão: As vacinas passam por diversas intervenções e melhoramentos, levando-se em conta o paciente, seu estilo de vida, os ricos locais e os benefícios oferecidos. A administração das vacinas deve ser feita de maneira correta e consistente a fim de obter sucesso na vacinação dos animais, cabendo ao médico veterinário saber quando utilizar de maneira correta essa ferramenta que tem o poder de transformar o ambiente e trazer benefícios aos pacientes.

\section{Referências}

COYNE, Michael, et al. Duration of immunity in dogs after vaccination or naturally acquired infection. Veterinary Record, v. 149, p. 509-515, 2001.

ELSTON, Thomas. Report of the American Association of Feline Practitioners and Academy of Feline Medicine Advisory Panel of Feline Vaccines. Journal of the American Veterinary Medical Association, vol. 212, p. 227-241, 1998.

GIBBS, Paul. The evolution of One Health: a decade of progress and challenges for the future. Veterinary Record 174, p. 85-91, 2014.

GRAY, Lauren, et al. Comparison of two assays for detection of antibodies against canine parvovirus and canine distemper virus in dogs admitted to a Florida animal shelter. Journal of the American Veterinary Medical Association, p. 1084-1087, 2012.

LITSTER, Annette, et al. Accuracy of a point-of-care ELISA test kit for predicting the presence of protective canine parvovirus and canine distemper virus antibody concentrations in dogs. Journal of the American Veterinary Medical Association, 2012.

DAY, M. J, HORZINEK, M. C, SHULTZ, R. D. Diretrizes para a vacinação de cães e gatos - compiladas pelo grupo de diretrizes de vacinação (VGG) da associação veterinária mundial de pequenos animais (WSAVA). Journal of Small Animal Practice, v. 57, 2016.

POVEY, Carol. Development of a Vaccine Incorporating Killed Virus of Canine Origin for the Prevention of Canine Parvovirus Infection. Canadian Veterinary Journal, vol. 23, p. 15-21, 1982.

TOLLIS, Maria. Standardization or tailorization of veterinary vaccines: a conscious endeavour of veterinary vaccines: a conscious endeavour against infectious disease of animals. Ann Ist Super Sanitá, vol. 42, n. 4, p. 446-449, 2006.

VIDOR, Emmanuel. The nature and consequences of intra- and inter-vaccine interference. Journal of Comparative Pathology, vol. 137, p. 62-66, 2007.

\section{ISALALOOOO DE EXTENSÃO}

DA UNIPAR
- UNIPAR 50 ANOS:

Tranefformando vides atreves da educapto

27 de Outubro de 2021

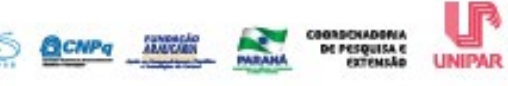




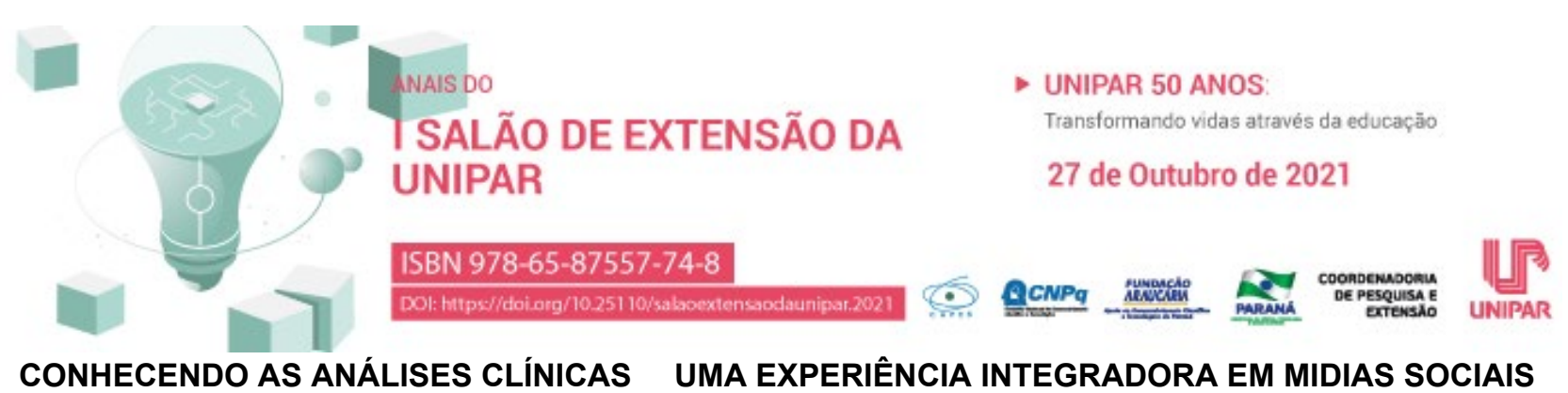

${ }^{1}$ RAPHAEL SAHD, ${ }^{2}$ MARIA FERNANDA RODRIGUES, ${ }^{3}$ JESSICA DE ARAUJO TORIANI , ${ }^{4}$ GABRIELLE PEREIRA TEMPORINI , ${ }^{5}$ FERNANDA MARIA TISCHNER DUARTE, ${ }^{6}$ CARLA KLAIS MACIEL, ${ }^{7}$ VANESSA CASAGRANDE, ${ }^{8}$ REBECA DALAVA SOARES LIMA, ${ }^{9}$ MATEUS VARELA TEXEIRA, ${ }^{10}$ JEDINA LUIZA PALAORO, ${ }^{11} \mathrm{FERNANDA}$ VALMORBIDA MOROSINI, 12IZABELA MORATELLI DE OLIVEIRA, ${ }^{13}$ AMANDA CAMILA SCHWERZ, ${ }^{14}$ LIZANGELA FERREIRA DE OLIVEIRA, ${ }^{15}$ RAPHAEL SAHD

\footnotetext{
${ }^{1}$ Professor Adjunto UNIPAR

${ }^{2}$ Acadêmica do Curso de Biomedicina da UNIPAR

${ }^{3}$ Acadêmico do Curso de Biomedicina da UNIPAR

${ }^{4}$ Acadêmico do Curso de Biomedicina da UNIPAR

${ }^{5}$ Acadêmico do Curso de Biomedicina da UNIPAR

${ }^{6}$ Acadêmica do Curso de Biomedicina da UNIPAR

${ }^{7}$ Acadêmica do Curso de Biomedicina da UNIPAR

${ }^{8}$ Acadêmica do Curso de Biomedicina da UNIPAR

${ }^{9}$ Acadêmico do Curso de Biomedicina da UNIPAR

${ }^{10}$ Acadêmico do Curso de Biomedicina da UNIPAR

${ }^{11}$ Acadêmica do Curso de Biomedicina da UNIPAR

${ }^{12}$ Acadêmica do Curso de Biomedicina da UNIPAR

${ }^{13}$ Acadêmica do Curso de Biomedicina da UNIPAR

${ }^{14}$ Acadêmica do Curso de Biomedicina da UNIPAR

${ }^{15}$ Docente da UNIPAR
}

Introdução: Não é novidade que as mídias sociais, são tendências mundiais e que apresentam um papel fundamental na disseminação de informações. Estas informações logicamente devem ser pautadas em notícias verídica, com embasamento técnico científico, de fácil leitura e com referências relevantes. No entanto as chamadas Fake News atuam de maneira antagônica, dificultando até mesmo protocolos de saúde pública e epidemiológicos, corroborando com isso que o Ministério da Saúde desenvolveu no segundo semestre de 2018 o projeto Saúde Sem Fake News , esclarecendo milhares de informações em saúde. Observa-se que mesmo antes da Pandemia COVID-19, já havia uma preocupação em relação a proliferação de notícias falsas sobre saúde, logicamente que condutas mais duras foram tomadas após a disseminação da pandemia e subsequentemente lançamento de informações equivocadas. Áreas da comunicação e da saúde sempre foram interdependentes, de forma que é impossível pensar a promoção da saúde sem a utilização dos meios de comunicação. No processo de formação educacional a valorização das Tecnologias da Informação e Comunicação (TIC) no desenvolvimento de iniciativas pedagógicas de saúde criativas, inovadoras e ousadas, desencadeiam um fortalecimento interface entre comunicação, ciência e sociedade.

Objetivo: Avaliar a utilização de mídia social por meio de projeto de extensão a promoção de informações relevantes referente ao laboratório de análises clínicas e temas relacionados a saúde.

Resultados: O projeto de extensão intitulado Conhecendo as Análises Clínicas promovido pelos cursos de Biomedicina e Farmácia da Universidade Paranaense vislumbrou a criação de um perfil no Instagram, denominado análisesclínicas_nareal tornou os acadêmicos protagonistas na elaboração de pautas, informações técnicas e formatação da plataforma. Até o momento foram realizadas 16 postagens, onde os acadêmicos realizaram a discussão dos estudos com docentes e demais membros do projeto. Tal atividade também é visualiza em outras Instituições e cursos, que buscam apresentar a formação com fontes científicas de qualidade.

Conclusão: Foi possível obter uma interação não apenas restrita a comunidade acadêmica, mas sim com a sociedade. Logicamente o projeto por estar em seu primeiro ano, necessita de amadurecimento, contudo as postagens levaram aos cidadãos um conhecimento, real e livre de viés político.

\section{Referências}

Araguão, J. M. N. O Uso Do Facebook Na Aprendizagem Em Saúde: Percepções De Adolescentes Escolares. Revista 
Brasileira De Enfermagem, [S. L.], V. 71, Ed. 2, P. 286-292, 2018.

Bernardes, V. P. Et Al. Facebook® Como Ferramenta Pedagógica Em Saúde Coletiva: Integrando Formação Médica E Educação Em Saúde. Revista Brasileira De Educação Médica, V.43, N.1, Supl.1, P.652-661, 2019.

Bueno, Maria Bethânia Tomaschewski; Bueno, Mateus Moreira; Moreira, Maria Isabel Giusti. O Uso Do Facebook Na Aprendizagem Em Saúde: Percepções De Adolescentes Escolares. Revista Thema, [S. L.], V. 20, Ed. 2, P. $181-200,2021$.

Souza, Thaís Dos Santos De Et Al. Mídias Sociais E Educação Em Saúde: O Combate Às Fakes News Na Pandemia Pela Covid-19. Enferm. Foco , [S. L.], V. 11, Ed. 1, P. 124-130, 2020.

Skura, Ivania Et Al. Mídias Sociais Digitais E A Terceira Idade: Em Busca De Uma Ferramenta Para A Promoção Da Saúde. Revista Kairósgerontologia, [S. L.], V. 16, Ed. 4, P. 237-249, 2013.

I SALALO DE EXTENSÃO $\quad$ " UNIPAR 50 ANOS:

DA UNIPAR
Transformando vides atrevita da educagto

27 de Outubro de 2021

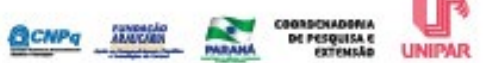




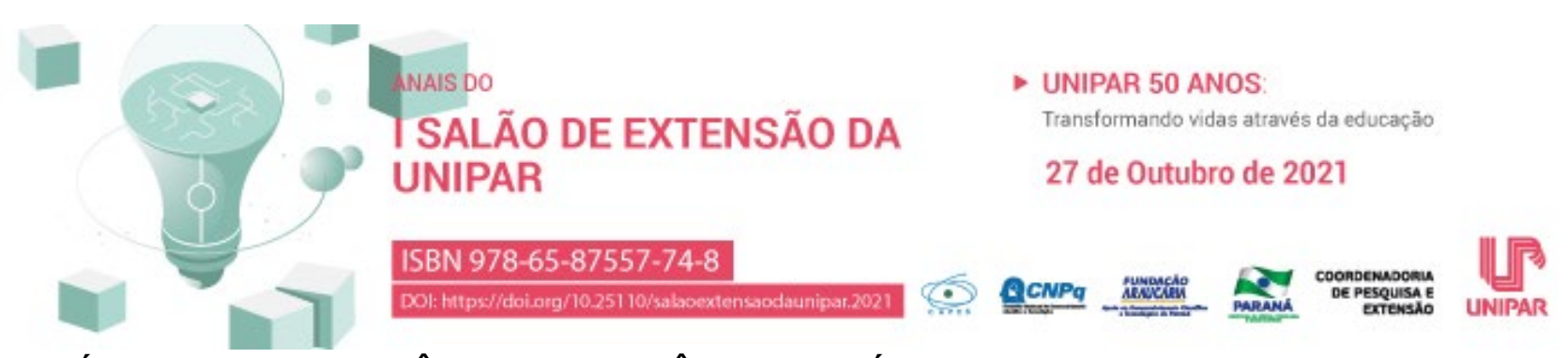

ANÁLISE DAS CONSEQUÊNCIAS DA VIOLÊNCIA OBSTÉTRICA (VO) NO PSIQUISMO DA MULHER

\author{
${ }^{1}$ ANA CLARA MILHAREZI DE SOUZA, ${ }^{2}$ ADRIANE DIEMER UECKER \\ ${ }^{1}$ Acadêmica da $2^{\mathrm{a}}$ série do curso de Psicologia - UNIPAR Cascavel \\ ${ }^{2}$ Docente da UNIPAR
}

Introdução: A Violência Obstétrica (VO), também conhecida como violência institucional na atenção obstétrica, é caracterizada por todo ato médico que viola os direitos da mulher gestante, em trabalho de parto ou durante o puerpério, podendo ter caráter físico, verbal ou psicológico, que se aproprie do corpo feminino ou prive sua capacidade arbitrária acerca de seu corpo ou sua sexualidade, além de violações da privacidade, negligências e realização de procedimentos médicos sem consentimento, segundo a OMS (Organização Mundial da Saúde). É alusiva à inserção do parto na medicina, quando perde seu cunho humanizado e natural, tornando-se medicalizado e intervencionista. Pensando acerca da exclusão do protagonismo da mãe no parto, e considerando que os danos ao psicológico podem ser mais fortes e danosos que os físicos, surge o problema que deu início e conduziu o estudo: quais as consequências psicológicas que a violência obstétrica acarreta a vida da mulher?

Objetivos: Para isso, destaca-se como objetivo geral do trabalho, apresentar as consequências psíquicas que a violência obstétrica acarreta a vida da mulher, além dos objetivos específicos que são conceituá-la, identificar os reflexos da agressão (riscos e traumas) e também apontar a atuação do psicólogo nesses casos.

Nota-se a relevância do presente trabalho para o esclarecimento do conceito de violência obstétrica, visando o reconhecimento para prevenção e denúncia, além da reflexão sobre a importância do trabalho profissional da psicologia dentro de hospitais, visando a manutenção da saúde mental da mulher durante uma vivência tão delicada. Esse estudo uma pesquisa exploratória que, segundo Selltiz et al. (1965), tem como função o entendimento de conceitos e obtenção de afinidade com o fenômeno estudado. Foram utilizados dados secundários, que Mattar (1996) afirma ser os já coletados e analisados à disposição a quem interessar, reunidos substancialmente em artigos científicos. A análise será qualitativa, onde visa-se o aprofundamento da compreensão, segundo o Goldenberg (1999). A apresentação dos dados será de forma descritiva.

Resultados: $\mathrm{O}$ atual modelo hospitalar coloca a mulher deitada em uma cama desconfortável, com as pernas abertas, sendo assistida por desconhecidos, as falas agressivas e negligências durante esse momento de vulnerabilidade criam ou reforçam sentimentos de incapacidade, inadequação e impotência da mulher e do seu corpol"(SILVA; SILVA; ARAÚJO, 2017, p 32), e potencializam a chance do aparecimento quadros de tristeza, episódios psicóticos ou depressão pós-parto, comprometendo além do bem estar psíquico da mãe, a criação de um vínculo afetivo com o recém-nascido. A VO pode ter um reflexo duradouro na vida da mulher, como por exemplo o temor a uma nova gestação ou interferência na vida sexual por conta da auto estima afetada ou incômodos físicos.

Considerações finais: Desta maneira, precisa-se pensar que esse momento traz transformações biopsicossociais, adaptações, desconforto físico e abalo emocional, logo é preciso a promoção de um ambiente acolhedor, com um elo de confiança entre médicos e gestante, além da valorização de suas decisões para a tentativa de redução dos sentimentos que tenham a tendência de trazer futuros abalos. Cabe além disso, ao profissional da psicologia, ao se deparar com feridas decorrentes da violência obstétrica, abordar temáticas de ressignificação, empoderamento e reconstituição emocional. As marcas do parto são reais e vão além das cicatrizes físicas, elas estão na memória e nos momentos revividos individualmente.

\title{
Referências
}

CONSELHO NACIONAL DOS DIREITOS HUMANOS. Recomendação n 59 de maio de 2019. Dispõe sobre sobre políticas públicas em relação à violência obstétrica. Diário Oficial da União: seção 1. jun 2019. p. 77

DA SILVA, Fabiana Laranjeira; SOUZA, Ana Lívia Siqueira; BARROS LEITE, Cláudia Daniele. REFLEXÕES SOBRE AS AGRESSÕES CAUSADAS AO PSICOLÓGICO MATERNO PELA VIOLÊNCIA OBSTÉTRICA: UM ESTUDO DE REVISÃO INTEGRATIVA. REVISTA UNINGÁ, V. $56, \quad \mathrm{n}$. S1, mar. $2019 . \quad$ Disponível em: http://revista.uninga.br/index.php/uninga/article/view/2060. Acesso em: 15 set. 2021.

DIAS, S.; PACHECO, A. Marcas do parto: As consequências psicológicas da violência obstétrica. Revista Arquivos Científicos (IMMES), v. 3, n. 1, jun. 2020. Disponível em: https://arqcientificosimmes.emnuvens.com.br/abi/article/view/232. Acesso em 14 set. 2021.

GOLDENBERG, Mirian. A arte de pesquisar: como fazer pesquisa qualitativa em Ciências Sociais. Rio de Janeiro: Record, 1999.

MATTAR, Fauze Najib. PESQUISA DE MARKETING Metodologia, planejamento, execução e análise. 7 ed. São Paulo. Elsevier Editora Ltda. 2014. p. 43. 
OLIVEIRA, Maxwell Ferreira de. METODOLOGIA CIENTÍFICA: um manual para a realização de pesquisas em administração. Disponível em: https://files.cercomp.ufg.br/weby/up/567/o/Manual_de_metodologia_cientifica_Prof_Maxwell.pdf. Acesso em: 14 set 2021.

SANTIAGO, Dayze Carvalho; SOUZA, Wanessa Kerlly Silva. VIOLÊNCIA OBSTÉTRICA: uma análise das consequências. Revista Científica da FASETE. $\mathrm{n}$ 13, fev. 2017. Disponível em: https://www.unirios.edu.br/revistarios/internas/conteudo/resumo.php?id=242. Acesso em 15 set. 2021.

SELLTIZ, Claire. Métodos de pesquisa das relações sociais: Delineamentos de pesquisa. São Paulo: EPU. 1965.

SILVA, Francisca Martins.; SILVA, Milécyo de Lima.; ARAUJO, Flávia Nunes Ferreira de. Sentimentos causados pela violência obstétrica em mulheres de Município do Nordeste Brasileiro. Revista Prevenção de Infecção e Saude, v. 3, n. 4, 2017.Disponível em: http://www.ojs.ufpi.br/index.php/nupcis/article/view/6924. Acesso em: 14 set. 2021.

\section{SALĀO DE EXTENSÃO}

DA UNIPAR
- UNIPAR 50 ANOS:

Transeformando vidas atraves da educapto.

27 de Outubro de 2021

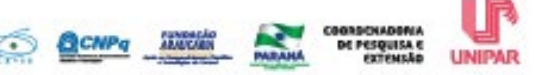




\title{
DNAIS DO UNIPAR 50 ANOS \\ SALÃO DE EXTENSÃO DA Transformando vidas através da educą̧̧̄o \\ UNIPAR \\ 27 de Outubro de 2021

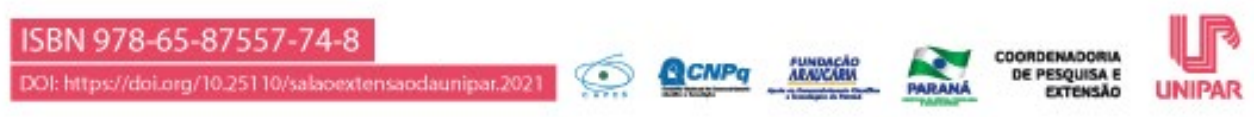 \\ DIREITO PROCESSUAL E CIDADANIA: ACESSO À JUSTIÇA E EDUCAÇÃO PARA EXERCÍCIO DA CIDADANIA PELA COMUNIDADE
}

\author{
${ }^{1}$ ALBINO GABRIEL TURBAY JUNIOR, ${ }^{2}$ FERNANDA SALES DE SOUZA, ${ }^{3}$ MATHEUS HENRIQUE RAPHAEL DE PAULA, \\ ${ }^{4}$ VITTORIA ROSANE DOS SANTOS , ${ }^{5}$ KARINNY LEAL AZEVEDO, ${ }^{6}$ MARINA SILVA RODRIGUES
}

\author{
${ }^{1}$ Docente Unipar \\ ${ }^{2}$ Acadêmica do Curso de Direito da UNIPAR \\ ${ }^{3}$ Acadêmico do Curso de Oratoria - Turma I da UNIPAR \\ ${ }^{4}$ Acadêmica do Curso de Direito da UNIPAR \\ ${ }^{5}$ Acadêmica do Curso de Direito da UNIPAR \\ ${ }^{6}$ Acadêmica do Curso de Direito da UNIPAR
}

Introdução: O espírito democrático da Constituição Federal de 1988 tem como um de seus fundamentos a cidadania, neste sentido, é preciso refletir sobre instrumentos que permitam a todos o exercício de seus direitos. O processo promove o acesso à justiça, mas é importante que as pessoas sejam educadas sobre a relação de processo e cidadania. Conforme Siqueira Jr e Oliveira (2009, p. 247) a Constituição alicerçou o Estado Democrático em dois fundamentos relacionados ao indivíduo: cidadania e dignidade da pessoa humana , completando que a cidadania se refere ao aspecto social . Assim, ter cidadania é poder participar da vida em sociedade, ou seja, é exercitar os direitos de cada cidadão. Mas o exercício dos direitos depende de conhecê-los, neste sentido, é preciso destacar o importante papel da educação, pois, a educação é que restaura a cidadania às pessoas (WANDERLEY JUNIOR, 2003, p. 18). Quando algum direito é lesado ou ameaçado, surgindo um conflito, um Estado Democrático deve ter previsão de instrumentos para que as pessoas, de forma adequada, possam provocar o exercício jurisdicional e ter uma resposta à demanda apresentada. O processo é caracterizado por esta instrumentalidade, assim, é por meio do processo que os direitos materiais em uma situação de conflito podem ser concretizados. Analisando os escopos do processo (sociais, políticos e jurídicos) novamente surge a importância da educação, pois, entre os escopos sociais, o exercício correto da jurisdição é elemento para que as pessoas sejam educadas a respeitar os direitos alheios e exercer os seus direitos (DINAMARCO, 2020, p. 165).

Objetivos: Promover de forma educativa a compreensão do processo como instrumento para o exercício da cidadania por meio de vídeos.

Resultados: O projeto está em execução com a escolha dos temas que serão objetos das gravações. O resultado que se espera é que os vídeos tenham um formato didático e conteúdo que possa contribuir para que a comunidade tenha informações sobre o processo e o exercício da cidadania.

Considerações finais: O processo é instrumento útil para que as pessoas possam exercer seus direitos, com isso, exercer cidadania, o que justifica a necessidade de que o direito processual tenha previsão de procedimentos e técnicas adequadas para que os direitos sejam concretizados, bem como, justifica a necessidade de que as pessoas, não apenas conheçam seus direitos, mas sejam educadas em como acessar instrumentos de proteção destes direitos.

\section{Referências}

BRASIL. Constituição da República Federal do Brasil. Promulgada em 05 de out. de 1988. In: Vademecum OAB e graduação. 21. ed. São Paulo: Saraiva Educação, 2021.

DINAMARCO, Cândido Rangel. Instituições de direito processual civil. 10. ed. São Paulo: Malheiros, 2020. v. 1.

SIQUEIRA JUNIOR, Paulo Hamilton; OLIVEIRA, Miguel Augusto Machado de. Direitos humanos e cidadania. 2. ed. São Paulo: Editora Revista dos Tribunais, 2009.

WANDERLEY JUNIOR, Bruno. Lições de cidadania: o caminho da democracia. In: GONÇALVES, Antônio Fabrício de Matos. Lições de cidadania. Brasília: OAB Editora, 2003. p. 13-32.

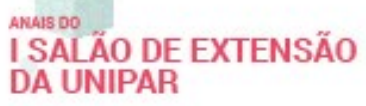

DA UNIPAR

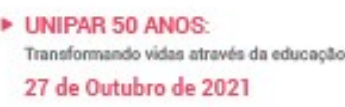

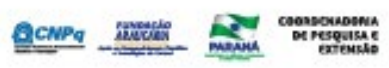




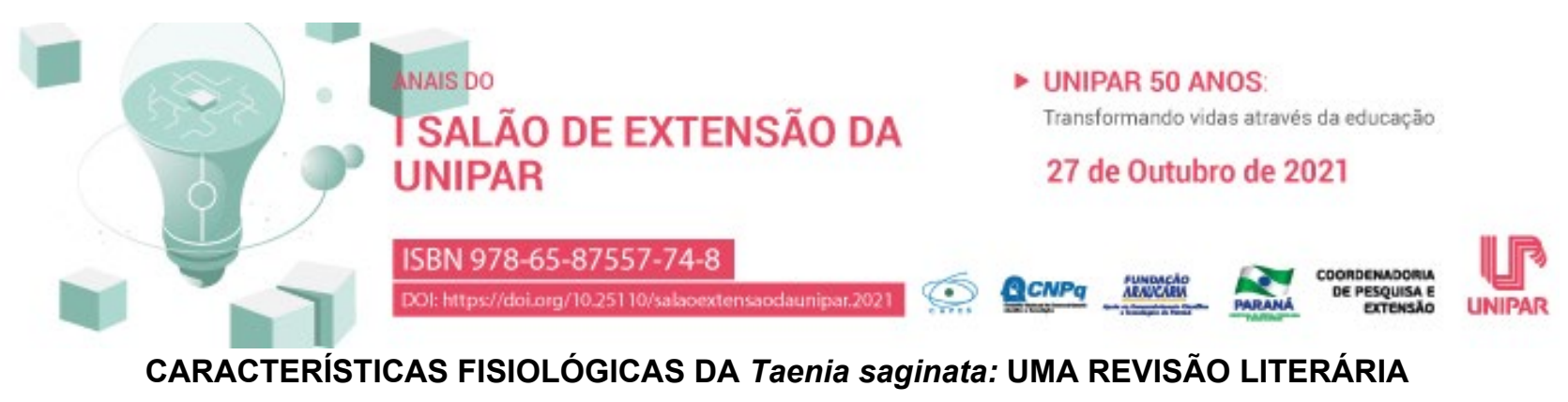

${ }^{1}$ EDSON GERONIMO , ${ }^{2}$ THAINARA LOURENCO DE VASCONCELLOS, ${ }^{3}$ JULIA VALER GUERRA, ${ }^{4}$ THAIS EDUARDA ADAMCZUK, ${ }^{5}$ LAURA RICARDA EBELING LAUTERT , ${ }^{6}$ MAISA STEFFANI ADAMCZUK, ${ }^{7}$ ALLEX VITAL PEREIRA, ${ }^{8}$ ERIKA DE GOIS FREIRE LOPES, ${ }^{9}$ DOUGLAS ROSSI JESUS, ${ }^{10}$ NATHIELLE MIRANDA, ${ }^{11}$ JAQUELINE HOSCHEID, ${ }^{12}$ GIULIANA ZARDETO SABEC

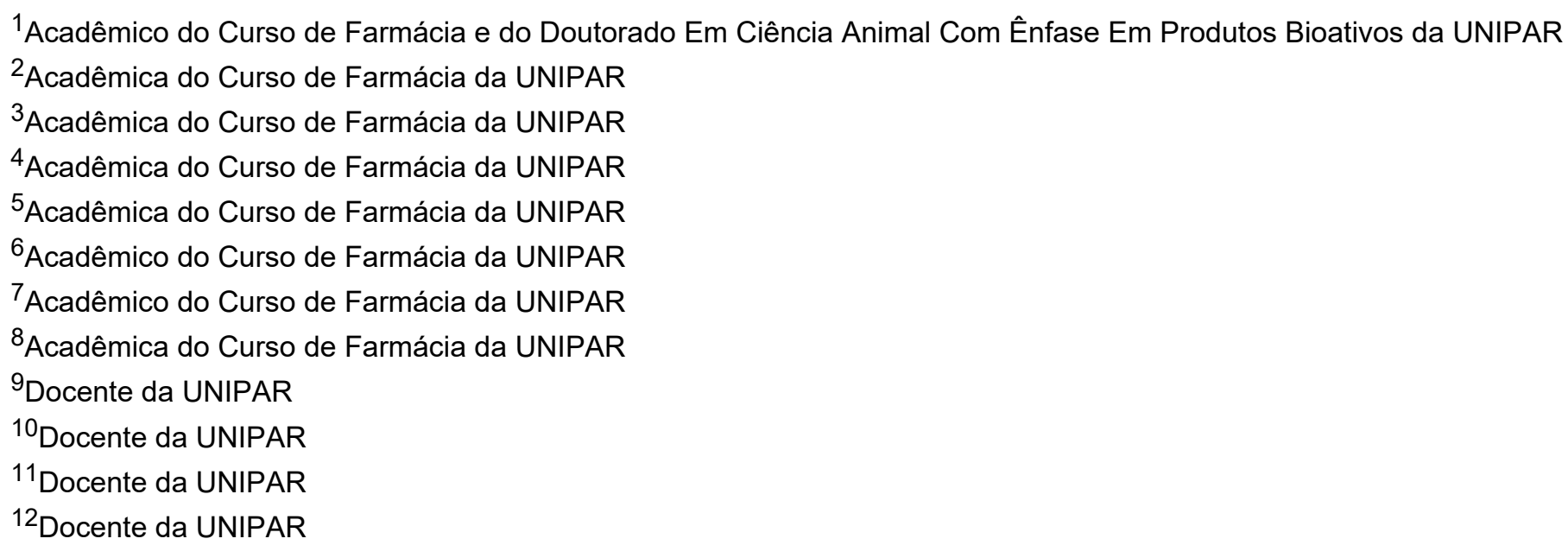

Introdução: Taenia saginata é uma tênia longa e achatada em forma de fita, de cor branca, tem cerca de 6 a 7 milímetros de largura, e quando adulta atinge geralmente cerca de 4 a 8 metros de comprimento, com cerca de 1000 segmentos chamados proglotes. O escólex tem 4 ventosas, mas não tem ganchos. É um importante cestóide de ciclo zoonótico, com distribuição mundial (CRAIG; ITO, 2007). O único hospedeiro definitivo da tênia, na fase adulta do parasito, é o homem, e o intestino delgado é o local de infestação. O hospedeiro secundário de $T$. saginata são os bovinos e bubalinos, desenvolvendo-se em sua musculatura (PFUETZENREITER; PIRES, 2000).

Objetivo: Descrever brevemente o ciclo parasitário da Taenia saginata e seu caráter zoonótico.

Resultados: A T. saginata e T. solium possuem padrões de transmissão muito semelhantes. Os humanos são os únicos hospedeiros definitivos conhecidos para $T$. saginata. O ciclo de vida começa com a ingestão de carne crua ou mal cozida contendo larvas de $T$. saginata. As larvas são digeridas da carne no sistema intestinal humano. O verme então se fixa na mucosa intestinal da parte superior do intestino delgado. A tênia digere os alimentos e cresce mais. Os proglotes são móveis e eliminam os ovos à medida que se movem. Esses ovos (contendo a oncosfera) podem permanecer viáveis por vários dias a semanas no ambiente (GARCIA et al., 2005). Os bovinos são o único hospedeiro intermediário da $T$. saginata, que ingere os ovos e as oncosferas eclodirão no duodeno sob a influência do suco gástrico. O parasito vai envaginar nas paredes intestinais e viajar através do sistema circulatório. Os embriões se espalharão por todo o corpo e desenvolverão cisticercose nos músculos estriados da vaca em 70 dias. Os seres humanos serão infectados se comerem a carne do animal neste momento (TAYLOR et al., 2016). A teníase em humanos é diagnosticada pela identificação de ovos ou proglotes grávidas das fezes do hospedeiro humano infectado. A T. saginata existe em todos os lugares do mundo onde os humanos convivem ou manejem rebanhos bovinos ou bubalinos (GRAIG; ITO, 2007). Para se diagnosticar a presença dos parasitos, o método mais utilizado é HPJ (Hoffmann-Pons e Janer) de sedimentação espontânea. Para realizar o diagnóstico dessas parasitoses, utiliza-se também a microscopia, que tem custo menor, possui alta especificidade e sensibilidade média (ZARDETO-SABEC et al., 2020).

Conclusão: Conclui-se que a infeç̧ão da $T$ saginata, é uma importante zoonose, já que causa a condenação de vísceras e carcaças de bovinos, gerando prejuízos econômicos. Além de que ocorre tanto em animais como seres humanos. Assim, se não houver a controle de carnes consumidas, saneamento básico e educação sanitária, esta infecção torna-se um grande problema de saúde pública. É importante ressaltar que para o diagnóstico e possível tratamento, o exame parasitológico de fezes torna-se fundamental. Assim, mais estudos acerca do assunto são necessários, assim como a conscientização da população acerca de medidas protetivas e preventivas.

\section{Referências}

CRAIG, Philip; ITO, Akira. Intestinal cestodes. Current opinion in infectious diseases, v. 20, n. 5, p. 524-532, 2007. 
GARCÍA, Héctor H. et al. Taenia solium cysticercosis. The lancet, v. 362, n. 9383, p. 547-556, 2003.

PFUETZENREITER, Márcia Regina; PIRES, Fernando Dias de Ávila. Epidemiologia da teníase/cisticercose por Taenia solium e Taenia saginata. Ciência Rural, v. 30, p. 541-548, 2000.

TAYLOR, M.; COOP, R.; WALL, R. Veterinary Parasitology. 4. ed. Chichester: Wiley Blackwell; 2016.

ZARDETO-SABEC, Giuliana et al. Análise dos laudos do exame parasitológico de fezes de um laboratório da cidade de Umuarama-PR no ano de 2018. Brazilian Journal of Surgery and Clinical Research, v. 30, n. 3, p. 07-12, 2020.

\section{ISALÃO DE EXTENSÃO}

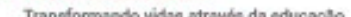

DA UNIPAR 


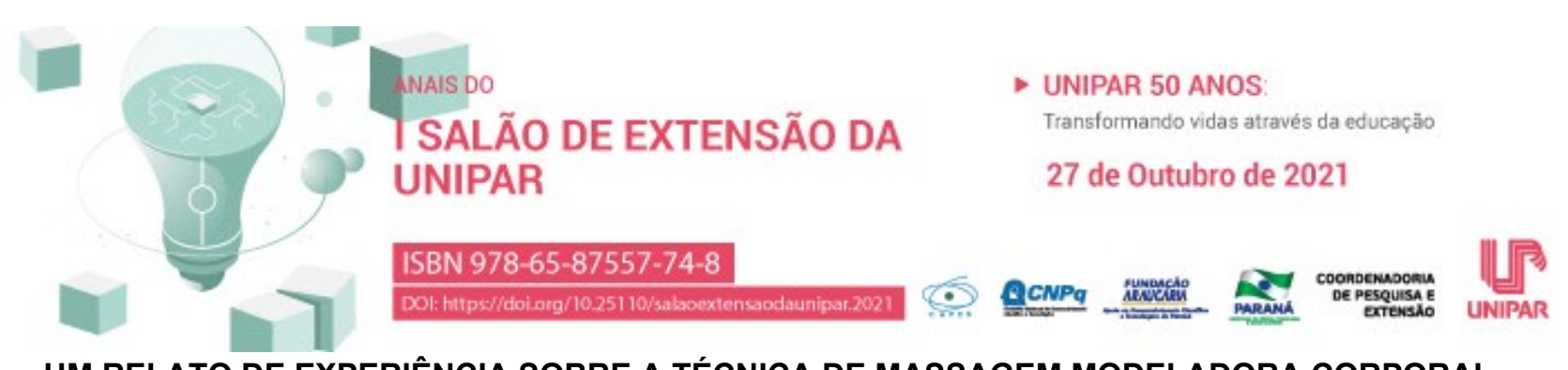

UM RELATO DE EXPERIÊNCIA SOBRE A TÉCNICA DE MASSAGEM MODELADORA CORPORAL

\author{
${ }^{1}$ MARIANE WELTER GARBOZZA, ${ }^{2}$ ANA PAOLA SILVA DE SOUZA, ${ }^{3}$ THAIS GOBBI, ${ }^{4} \mathrm{KELLI}$ KUHNEN, ${ }^{5}$ LUCIANA \\ PELLIZZARO, ${ }^{6}$ JULIANA PELISSARI MARCHI
}

${ }^{1}$ Acadêmica participante do Projeto de Extensão Estética na Comunidade, do C.S.T. em Estética e Cosmética da Universidade
Paranaense, UNIPAR.
${ }^{2}$ Acadêmica participante do Projeto de Extensão Estética na Comunidade, do C.S.T. em Estética e Cosmética da Universidade
Paranaense, UNIPAR.
${ }^{3}$ Acadêmica participante do Projeto de Extensão Estética na Comunidade, do C.S.T. em Estética e Cosmética da Universidade
Paranaense, UNIPAR.
${ }^{4}$ Responsável Técnica do Centro de Estética Escola do C.S.T. em Estética e Cosmética da Universidade Paranaense, UNIPAR.
${ }^{5}$ Docente do C.S.T. em Estética e Cosmética da Universidade Paranaense, UNIPAR.
${ }^{6}$ Docente do C.S.T. em Estética e Cosmética da Universidade Paranaense, UNIPAR.

Introdução: As atividades do projeto de extensão Estética na Comunidade foram desenvolvidas no Centro de Estética e Cosmética Escola da Universidade Paranaense, UNIPAR, Unidade de Francisco Beltrão. Dentre os diversos atendimentos realizados, o mais comum é o procedimento de Massagem Modeladora Corporal. Segundo Guirro e Guirro (2004), é uma técnica que ajuda a modelar o corpo e reduzir medidas, assim, previne e trata disfunções estéticas como a lipodistrofia localizada, a flacidez e o fibro edema ginóide (FEG), além de relaxar a musculatura e hidratar a pele.

Objetivo: Relatar a experiência de atendimentos de massagem modeladora corporal, realizados no Projeto de Extensão Estética na Comunidade.

Resultados: Os atendimentos realizados inter-relacionam teoria e prática. Promovem segurança e favorecem o desenvolvimento interpessoal e habilidades de comunicação, uma vez que para a realização do procedimento é necessário o diálogo, a explicação sobre a técnica (benefícios, indicações, contra-indicações, mecanismo de ação, cosmética e técnica manual), a desenvoltura profissional, a organização da cabine de atendimento, dentre outros (PEREZ E VASCONCELOS, 2014). A técnica de massagem modeladora corporal é aplicada nas regiões de abdômen, flancos, braços, coxas (anterior, posterior, lateral e interno), glúteos, culotes e região subescapular (RIBEIRO, 2010). O efeito desse procedimento é obtido através do estímulo mecânico por meio de pressão e estiramento rítmico aplicados ao tecido, para isso, utiliza-se de técnica manual (amassamento, friç̧ão, rolamento, pinçamento, deslizamentos) com movimentos vigorosos e rápidos, e auxílio de acessórios (pantala, bambu, rolo). Ademais, promove a mobilização da gordura, aumenta a circulação sanguínea e consequentemente eliminação de toxinas (BORGES; SCORZA, 2016; PEREZ E VASCONCELOS, 2014). Na execução utiliza-se cosméticos enriquecidos com princípios ativos redutores, descongestionantes e ativadores, atuando assim tanto na prevenção quanto no tratamento de disfunções estéticas corporais (RIBEIRO, 2010).

Conclusão: A prática de massagem modeladora oportunizou o contato com diversos clientes e a partir disso o contato com diferentes disfunções estéticas, biotipos corporais, biotipos e fototipos cutâneos, portanto, é necessário um atendimento individualizado e humanizado para atender as necessidades do cliente e promover o embelezamento, elevar autoestima e a autoconfiança, garantindo o bem-estar físico e mental.

\title{
Referências
}

BORGES, Fábio dos Santos; SCORZA, Flávia Acedo. Terapêutica em Estética: Conceitos e técnicas. São Paulo, Phorte, 2016. GUIRRO, Elaine Caldeira Oliveira; GUIRRO, Rinaldo Roberto Jesus. Fisioterapia dermatofuncional: fundamentos, recursos e patologias. $3^{\mathrm{a}}$ ed. Barueri, Manole, 2004.

PEREZ, Erika; VASCONCELOS, Maria Goreti de. Técnicas Estéticas Corporais. São Paulo, Érica, 2014.

RIBEIRO, Claúdio. Cosmetologia aplicada a dermoestética. $2^{\mathrm{a}}$ ed. São Paulo, Pharmabooks, 2010.

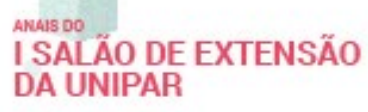

I SALÄO DE EXTENSÃO

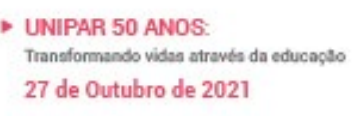

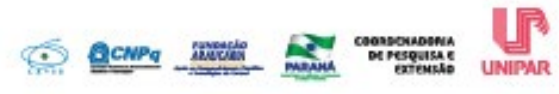




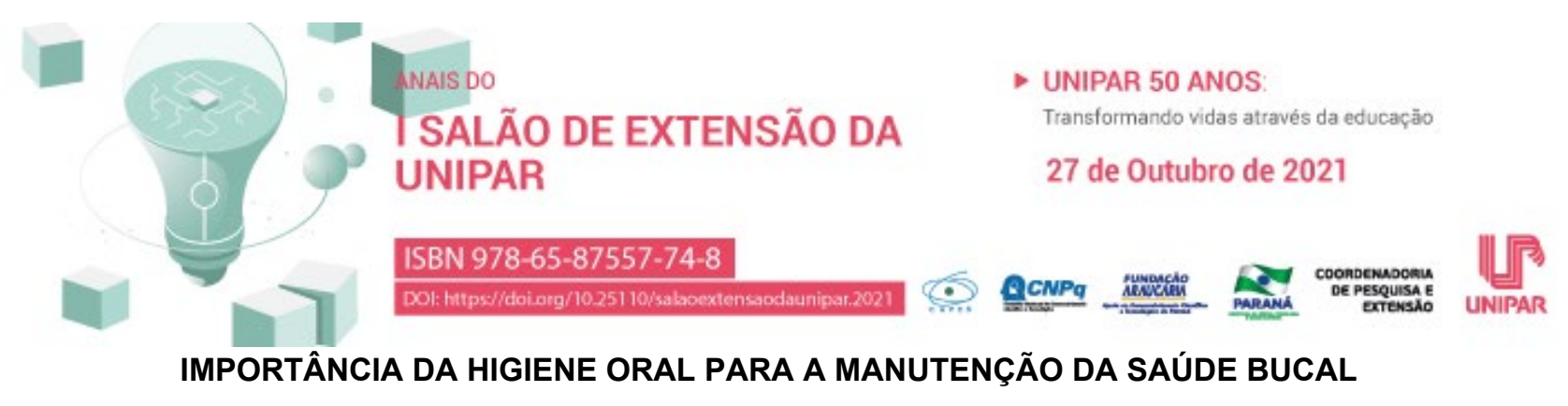

\begin{abstract}
${ }^{1}$ ROGGER RICIERI MALDONADO OLIVEIRA, ${ }^{2}$ GABRIELLY REIMAN MACHADO MARAN DA ROCHA, ${ }^{3}$ JAMILLE TOMAZINI MUSTAFA, , LUAANA MENECHINI PEREIRA, ${ }^{5}$ MARIA ANTONIELLY PEREIRA XAVIER , ${ }^{6}$ GIOVANNA OLIVEIRA CERANTO , ${ }^{7}$ PEDRO HENRIQUE LOPES NOGUEIRA , ${ }^{8}$ ARAO GASPAR PACHECO NETO, ${ }^{9}$ BIANCA FLAVIA COUTINHO BIASUZ, ${ }^{10}$ CAMILA TEIXEIRA COLUCCI , ${ }^{11}$ ARISSA AYUMI OKABAYASHI, ${ }^{12}$ GABRIELA CARDOSO DE CAMARGO, ${ }^{13}$ LETICIA DE ALMEIDA SILVA, ${ }^{14}$ ANA JULIA ROSA BORTOLOSO, ${ }^{15}$ GABRIELA NERI DE SOUZA SILVA, ${ }^{16}$ ANA CAROLINA SOARES FRAGA ZAZE
\end{abstract}

\footnotetext{
${ }^{1}$ Acadêmico do curso de Odontologia da UNIPAR

${ }^{2}$ Acadêmica do Curso de Odontologia da UNIPAR

${ }^{3}$ Acadêmica do Curso de Odontologia da UNIPAR

${ }^{4}$ Acadêmica do Curso de Odontologia da UNIPAR

${ }^{5}$ Acadêmica do Curso de Odontologia da UNIPAR

${ }^{6}$ Acadêmica do Curso de Odontologia da UNIPAR

${ }^{7}$ Acadêmico do Curso de Odontologia da UNIPAR

${ }^{8}$ Acadêmico do Curso de Odontologia da UNIPAR

${ }^{9}$ Acadêmica do Curso de Odontologia da UNIPAR

${ }^{10}$ Acadêmica do Curso de Odontologia da UNIPAR

${ }^{11}$ Acadêmica do Curso de Odontologia da UNIPAR

${ }^{12}$ Acadêmica do Curso de Odontologia da UNIPAR

${ }^{13}$ Acadêmica do Curso de Odontologia da UNIPAR

${ }^{14}$ Acadêmico do Curso de Odontologia da UNIPAR

${ }^{15}$ Acadêmica do Curso de Odontologia da UNIPAR

${ }^{16}$ Docente da UNIPAR
}

Introdução: Apesar dos esforços por meio da classe odontológica em conscientizar sobre a importância da higiene oral para a manutenção da saúde bucal, grande parte das pessoas não realizam o controle do biofilme dental satisfatoriamente, o que leva a crer que diferentes abordagens devem ser consideradas, para atingir uma maior parcela da população. Estudos mostram que a baixa qualidade da higiene oral está relacionada ao desenvolvimento das principais doenças bucais que acometem os seres humanos, a cárie e as doenças periodontais. Portanto, é necessário intensificar estratégias de motivação para realização de uma boa higiene oral, para propiciar a prevenção e controle dessas doenças, da infância até a terceira idade.

Objetivo: Apresentar a correlação existente entre a condição de higiene oral e o desenvolvimento de doenças bucais, visando a conscientização sobre a importância de sua correta realização.

Resultados: Os acadêmicos participantes do projeto de extensão I"Educação direcionada à saúde bucall" foram instruídos a desenvolver uma proposta voltada à crianças de 5 a 10 anos de idade. Apresentaram a ideia de incentivar as crianças sobre a importância da realização da higiene bucal por meio da elaboração de um teatro, a ser apresentado em escolas ou pelas redes sociais, no formato de vídeo. Foi elaborada uma história que relata a experiência de uma criança que não gostava de escovar os dentes e precisou da ajuda de um dentista para resolver seu problema, que aconteceu devido ao fato de não obedecer sua mãe, quando era incentivada a escovar os dentes. Para crianças menores, criaram uma história infantil, para ser contada com a utilização de personagens de pelúcia e fantoches para grupos pequenos, onde os personagens principais são um leão e seu dente, que não foi devidamente escovado e ficou doente. Para reforçar a compreensão do tema pelas crianças, idealizaram um jogo de pescaria, onde dentes cariados e sadios serão colocados em uma caixa de areia e os dentes cariados devem ser |"salvos।" por uma vara, em formato de escova de dentes, com a ajuda do fio dental.

Conclusão: Os acadêmicos aprenderam sobre a correlação existente entre a condição de higiene oral e o desenvolvimento de doenças bucais, bem como desenvolveram habilidades e materiais lúdicos para realizar a educação direcionada à saúde bucal, visando a promoção de saúde. 


\section{Referências}

AQUILANTE, Aline Guerra; ALMEIDA, Beatriz Simões; MARTINS DE CASTRO, Roberta Francisca.; XAVIER, Cláudio Roberto Gaião; SALES PERES, Silvia Helena Carvalho; BASTOS, José Roberto Magalhães. The importance of dental health education for preschoolchildren. Rev. Odontol. UNESP, São Carlos, v. 32, n.1, p. 39-45, Jan./Jun., 2003.

MOHAMMADI, Soudabeh; MOHAMMADI, Mohammad Ali; DADKHAH, Behroz. Dental caries prevalence among elementary school students and its relationship with body mass index and oral hygiene in Ardabil in 2019. J.Indian Soc. Pedod. Prev. Dent., v.39, n.2, 2021. Disponível em: https://pesquisa.bvsalud.org/portal/resource/pt/mdl-34341233. Acesso em 09 set. 2021.

I SALÃO DE EXTENSÃO DA UNIPAR
- UNIPAR 50 anos:

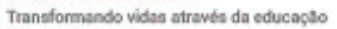

27 de Outubro de 2021

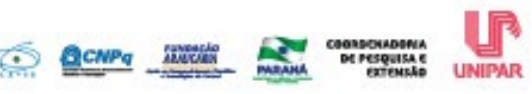




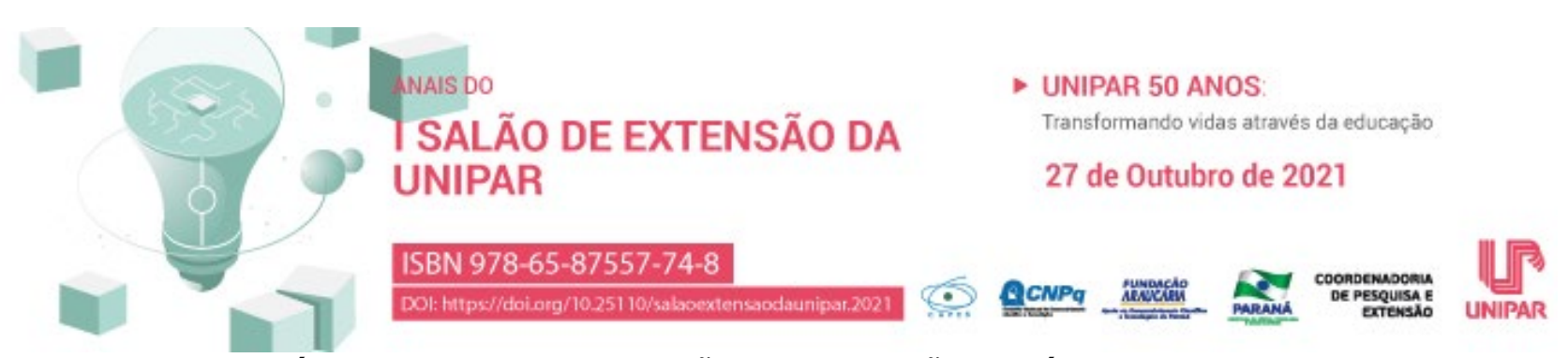

\section{ABORDAGEM LÚDICA SOBRE A TRANSIÇÃO DA DENTIÇÃO DECÍDUA PARA A PERMANENTE}

${ }^{1}$ ANNY GABRIELLI BIUDES MARQUES, ${ }^{2}$ ANA BEATRIZ MACEDO, ${ }^{3}$ BEATRIZ MARTINS GAIARI, ${ }^{4}$ BRENDA LEONARDA ALCANTARA ALDRIGUE, ${ }^{5}$ BRENDA LORENA ESCOLA PEREIRA, ${ }^{6}$ CAMILLY VITORIA GOZZI BONFIM, ${ }^{7}$ CARLA BARION , ${ }^{8}$ EMANUELY AHUENDRYA DA SILVA DOS SANTOS, ${ }^{9}$ FABIANA PEREIRA NEVES, ${ }^{10}$ GIOVANNA PICINATO CARVALHO, ${ }^{11} \mathrm{JULIA}$ DELAZARI AMERICO , ${ }^{12}$ LARISSA DE SANTANA LORENZZONI, ${ }^{13}$ PIETRA ISABELY SOUZA SALES, ${ }^{14}$ RAFAEL ANDREGUETTE ROSSI, ${ }^{15}$ VITORIA CAETANO CERVANTES, ${ }^{16}$ ANA CAROLINA SOARES FRAGA ZAZE

\footnotetext{
${ }^{1}$ Acadêmico do curso de Odontologia da UNIPAR

${ }^{2}$ Acadêmica do Curso de Odontologia da UNIPAR

${ }^{3}$ Acadêmica do Curso de Odontologia da UNIPAR

${ }^{4}$ Acadêmica do Curso de Odontologia da UNIPAR

${ }^{5}$ Acadêmica do Curso de Odontologia da UNIPAR

${ }^{6}$ Acadêmico do Curso de Odontologia da UNIPAR

${ }^{7}$ Acadêmica do curso de Odontologia da UNIPAR

${ }^{8}$ Acadêmica do Curso de Odontologia da UNIPAR

${ }^{9}$ Acadêmico do Curso de Odontologia da UNIPAR

${ }^{10}$ Acadêmico do Curso de Odontologia da UNIPAR

${ }^{11}$ Acadêmica do Curso de Odontologia da UNIPAR

${ }^{12}$ Acadêmica do Curso de Odontologia da UNIPAR

${ }^{13}$ Acadêmica do Curso de Odontologia da UNIPAR

${ }^{14}$ Acadêmico do Curso de Odontologia da UNIPAR

${ }^{15}$ Acadêmica do Curso de Odontologia da UNIPAR

${ }^{16}$ Docente da UNIPAR
}

Introdução: Os dentes decíduos geralmente iniciam seu irrompimento por volta do sexto mês de vida e possuem um ciclo de vida relativamente pequeno. Geralmente, os dentes decíduos começam a ser substituídos pelos permanentes por volta do sexto ano de vida e este período de transição se estende até os 12 anos, em média. Durante a fase de transição, as crianças enfrentam um período de instabilidade, pois a troca da dentição é um marco do crescimento físico, contudo, pode causar grande impacto emocional. Por iniciar pelos dentes anteriores, afeta a estética, o que desestabiliza emocionalmente algumas crianças que se sentem insatisfeitas com a nova aparência.

Objetivo: Conhecer a dentição decídua e como ocorre o processo de transição para a permanente, com o intuito de realizar atividades de educação em saúde, para que esta fase ocorra de maneira saudável, física e emocionalmente.

Resultados: Os acadêmicos participantes do projeto de extensão l"Educação direcionada à saúde bucall" foram instruídos a desenvolver uma proposta voltada para crianças de 5 a 10 anos. Elaboraram roteiros de teatros, onde encenaram situações vivenciadas por crianças que apresentam insegurança, medo ou vergonha durante o processo da troca dos dentes, abordando o motivo pelo qual os dentes I"de leitel" existem e precisam cair, para permitirem que um novo dente, I"maior e mais fortel" ocupe o mesmo espaço. Enalteceram que este período é transitório e que os adultos, adolescentes e crianças mais velhas já passaram por ele, que é algo normal e não precisa ser motivo de preocupação, pois logo, novos dentes estarão no mesmo lugar. Para tanto, personagens que favorecem a identificação das crianças e estimulam a imaginação foram utilizados, como l"a fada do dentel" e ।"o dentistal" que explica de forma simples como os dentes decíduos são importantes para que os permanentes consigam encontrar o caminho certo para ।"nascereml", onde ficarão fortes e saudáveis. Foi desenvolvido um jogo de perguntas e respostas, para agregar mais conhecimento, favorecendo que as crianças aprendam brincando e sintam-se mais seguras em relação ao período da troca das dentições.

Conclusão: Os acadêmicos aprenderam sobre as diferentes dentições e os aspectos fisiológicos e emocionais relacionados ao período de transição, bem como desenvolveram materiais lúdicos para realizar a educação direcionada à saúde bucal, visando uma melhor qualidade de vida para as crianças que enfrentam dificuldades no referido período. 


\section{Referências}

MENEZES, José Vitor Nogara Borges de ; ULIANA, Giovana. Perfil de crianças com dentes decíduos perdidos precocemente. J Bras Odontopediatr Odontol Bebê, Curitiba, v.6, n.31, p.196-200, maio/jun. 2003. Disponível em: https://www.dtscience.com/wp-content/uploads/2015/11/Perfi-I-de-Crian\%C3\%A7as-com-Dentes-Dec\%C3\%ADduos-PerdidosPrecocemente.pdf. Acesso em: 8 set. 2021.

RIBEIRO , Sani Santos. Quando devem cair os dentes de leite e o que fazer. Tua saúde, maio de 2020. Disponível em:https://www.tuasaude.com/quando-caem-os-dentes-de-leite/ . Acesso em: 8 set. 2021.

SANTOS, Natália dos Santos. Ocorre perda de espaço no arco dental quando um dente de leite é perdido antes do período normal. Repositório UFSC, 19 out. 2020. Disponível em: https://repositorio.ufsc.br/handle/123456789/214061 . Acesso em: 8 set. 2021.

XAVIER, Thaís Aparecida. Retenção prolongada de dentes decíduos: Possíveis fatores etiológicos locais e sistêmicos. Orientador: Sandra Yasuyo Fukada Alves. 2016. Dissertação (Mestrado Odontopediatria) - Universidade de São Paulo, Ribeirão Preto, 2016. Disponível em: https://www.teses.usp.br/teses/disponiveis/58/58135/tde-12072016165023/publico/ME_Thais_Xavier_Original.pdf. Acesso em: 8 set. 2021. 


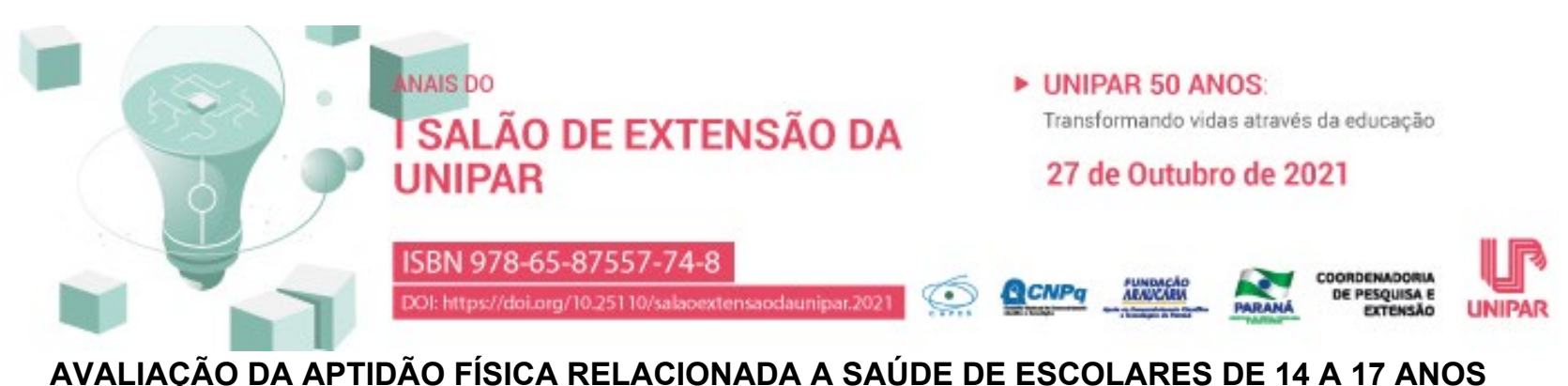

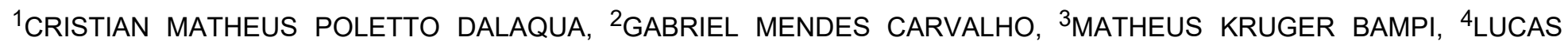 \\ EDUARDO BORGHESAN BORTOT, ${ }^{5}$ TAINAN PADILHA, ${ }^{6}$ MATHEUS DAL PUBEL LISE, ${ }^{7}$ RAFAELA BETTI, ${ }^{8}$ NICOLAS LUAN \\ DESEN, ${ }^{9}$ CHIARA MUNARO, ${ }^{10}$ DURCELINA SCHIAVONI BORTOLOTI
}

\begin{abstract}
${ }^{1}$ Acadêmico do Curso de Educação Física Bacharelado / UNIPAR
${ }^{2}$ Acadêmico do Curso de Educação Física Bacharelado / UNIPAR

${ }^{3}$ Acadêmico do Curso de Educação Física Bacharelado / UNIPAR

${ }^{4}$ Acadêmico do Curso de Educação Física Bacharelado / UNIPAR

${ }^{5}$ Acadêmico do Curso de Educação Física Bacharelado / UNIPAR

${ }^{6}$ Acadêmico do Curso de Educação Física Bacharelado / UNIPAR

${ }^{7}$ Acadêmica do Curso de Educação Física Bacharelado / UNIPAR

${ }^{8}$ Acadêmico do Curso de Educação Física Bacharelado / UNIPAR

Francisco Beltrão

Francisco Beltrão

Francisco Beltrão

Francisco Beltrão

Francisco Beltrão

Francisco Beltrão

Francisco Beltrão

${ }^{9}$ Docente do Curso de Educação Física Bacharelado / UNIPAR Francisco Beltrão

${ }^{10}$ Docente do Curso de Educação Física Bacharelado / UNIPAR Francisco Beltrão
\end{abstract}

Introdução: Evidências científicas têm sugerido significativa associação entre bons níveis de aptidão física relacionada à saúde (AFRS) e a prevenção de doenças crônicas e degenerativas. (DORNELES et al., 2016). Estudos brasileiros demonstraram que a AFRS dos adolescentes não atinge níveis adequados, chegando a reportar que cerca de $40 \%$ dos adolescentes tem um desempenho considerado fraco ou regular (MELLO et al., 2015). Destaca-se que, os baixos níveis de APFRS tendem a afastar adolescentes das práticas corporais, reduzindo as habilidades motoras, cognitivas, sociais e a oportunidades de aprimorarem a saúde (MASCARENHAS et al., 2013).

Objetivo: Avaliar o nível de aptidão física relacionada à saúde de escolares de 14 a 17 anos de idade.

Resultados: Este estudo é um sub-projeto (Parecer CEP: 4.833.478) do projeto de extensão universitária da UNIPAR intitulado Esporte na Universidade: Uma experiência para jovens. Assim, este trabalho foi realizado com a participação de 76 escolares com idades de 14 a 17 anos de ambos os sexos. Para avaliação da AFRS dos escolares foi utilizado a bateria de testes proposta por Gaya et al. (2016). Quando comparados os valores médios dos testes da AFRS entre os sexos, as moças tiveram melhor desempenho na flexibilidade e os rapazes na força abdominal e resistência cardiorrespiratória $(p<0,05)$. Não identificamos diferenças significantes entre os valores médios da AFRS nas diferentes idades. Ao verificar as tabelas normativas para as idades e sexos, os valores médios mostraram que: O IMC ambos os sexos aos 14 anos encontram-se acima do desejável; a flexibilidade dos rapazes foi desejável somente na faixa de 15 anos; na força/resistência abdominal somente a idade se 14 anos nos rapazes encontram-se desejáveis; para a resistência cardiorrespiratória, encontrou-se desejável somente as idades 14 e 15 anos para os rapazes e 14 anos para as moças.

Considerações Finais: Baixos níveis de AFRS na adolescência pode comprometer significativamente a saúde na idade adulta, com especial atenção ao surgimento ou agravo de doenças crônicas e degenerativas. Ressalta-se assim, a importância de desenvolvimento de projetos que busquem identificar junto à população jovem, as carências em relação a AFRS de acordo com sexo e idade, visto que, na idade escolar, é onde profissionais da saúde e da educação encontram-se mais próximos desta população e estratégias educativas e/ou de intervenção para um estilo de vida saudável, podem ser implementadas de maneira mais efetiva.

\title{
Referências
}

DORNELES, Rui Carlos Gomes et al. Flexibility and muscle strength/resistance indicators and screening of low back pain in adolescents. Revista Brasileira de Cineantropometria \& Desempenho Humano, v. 18, n. 1, p. 93-102, 2016.

GAYA, Adroaldo; GAYA, Anelise. Projeto Esporte Brasil. Manual de testes e avaliação, 2016

MASCARENHAS, Luis Paulo Gomes et al. Estudo comparativo da aptidão física entre crianças de escola pública e particular: uma visão regional. Cinergis, v. 14, n. 3, 2013.

MELLO, Júlio Brugnara et al. Aptidão física relacionada ao desempenho motor de adolescentes de Uruguaiana, Rio Grande do Sul. Revista Brasileira de Ciência e Movimento, v. 23, n. 4, p. 72-79, 2015. 
- unIPAR 50 anos:

I SALAOO DE EXTENSÃO Transformando vidas atravies da educaģso

DA UNIPAR 


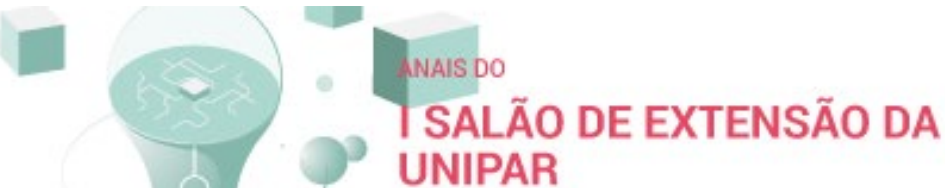

- UNIPAR 50 ANOS

Transformando vidas através da educação

27 de Outubro de 2021

ISBN 978-65-87557-74-8

DOI: hitps//doiorg/10.251 10/3aboestensadaunipar.2021

Q

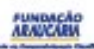

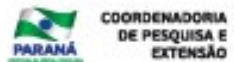

UNIPAR

\section{AVALIAÇÃO DA APTIDÃO FíSICA RELACIONADA AO DESEMPENHO DE JOVENS PARTICIPANTES DE PROJETOS ESPORTIVOS}

\author{
${ }^{1}$ MATHEUS DAL PUBEL LISE, 2 LUCAS EDUARDO BORGHESAN BORTOT, ${ }^{3}$ CRISTIAN MATHEUS POLETTO DALAQUA, \\ ${ }^{4}$ MATHEUS KRUGER BAMPI, ${ }^{5}$ TAINAN PADILHA, ${ }^{6}$ RAFAELA BETTI, ${ }^{7}$ DURCELINA SCHIAVONI BORTOLOTI
}

\begin{abstract}
${ }^{1}$ Acadêmico do Curso de Educação Física Bacharelado / UNIPAR
${ }^{2}$ Acadêmico do Curso de Educação Física Bacharelado / UNIPAR

${ }^{3}$ Acadêmico do Curso de Educação Física Bacharelado / UNIPAR

${ }^{4}$ Acadêmico do Curso de Educação Física Bacharelado / UNIPAR

${ }^{5}$ Acadêmico do Curso de Educação Física Bacharelado / UNIPAR

${ }^{6}$ Acadêmica do Curso de Educação Física Bacharelado / UNIPAR

Francisco Beltrão

Francisco Beltrão

Francisco Beltrão

Francisco Beltrão

Francisco Beltrão

${ }^{7}$ Docente do Curso de Educação Física Bacharelado / UNIPAR Francisco Beltrão
\end{abstract}

Introdução: A aptidão física (AF) pode ser definida como a capacidade de realizar atividades físicas em níveis moderados a intensos. Existem dois tipos de $\mathrm{AF}$, aquela relacionada à saúde, onde envolve os componentes da resistência cardiorrespiratória, força/resistência muscular e flexibilidade, e aquela relacionada ao desempenho físico, cujos componentes são a força/potência muscular, velocidade, agilidade e aptidão cardiorrespiratória (ACR) (MOREIRA et al., 2017). É na adolescência que ocorre grande parte do desenvolvimento de habilidades motoras, as quais são fundamentais para aprimorar os componentes da $A F$ tanto relacionada à saúde quanto ao desempenho (ALANO et al., 2011).

Objetivo: Avaliar a aptidão física relacionada ao desempenho (AFRD) de jovens participantes de projetos esportivos no município de Francisco Beltrão.

Resultados: Este estudo é um sub-projeto (Parecer CEP: 4.833.478) do projeto de extensão da UNIPAR I"Esporte na Universidade: Uma experiência para jovens de 15 a 19 anosl", que já atendeu mais de 130 adolescentes em Francisco Beltrão. Para este trabalho houve a participação de 35 jovens, com idades de 15 a 19 anos de ambos os sexos, participantes de modalidades esportivas de Vôlei (ambos os sexos) e Futsal (rapazes). Realizou-se bateria de testes propostos por Gaya e Gaya (2016) o qual se avaliou: Índice de massa corporal (IMC), envergadura, velocidade, força/potência de membros inferiores (MI) e superiores (MS), abdominal, flexibilidade, agilidade e aptidão cardiorrespiratória (ACR). Não houve diferenças significantes no IMC entre os sexos, contudo, em valores médios as moças encontram-se acima do esperado para a idade. Para a AFRD, com exceção da flexibilidade, os rapazes tiveram melhor desempenho que as moças em todos os outros componentes avaliados. Observamos ainda que, em dados médios as moças apresentam valores abaixo do desejável para a força/potência de $\mathrm{Ml}$, velocidade e ACR. Destaca-se que, a superioridade do desempenho dos rapazes já foi relatada em estudo prévio (OLIVEIRA et al., 2017).

Considerações Finais: Os aspectos físicos de adolescentes participantes de projetos esportivos devem ser rotineiramente avaliados, a fim de identificar as carências individuais ou do grupo, e direcionar o profissional de Educação Física para aprimoramento dos componentes da AFRD. Este projeto identificou que, as moças participantes da modalidade de Vôlei, podem vir a melhorar seu desempenho diante do aprimoramento dos componentes da AFRD em especial a força/potência de MI e ACR.

\section{Referências}

ALANO, Valéria da Rosa, et al. Aptidão física e motora em escolares com dificuldades na aprendizagem. Revista Brasileira de Ciência e Movimento. Florianópolis, v. 19, n.3, p.69-75, 2011.

GAYA, Adroaldo; GAYA, Anelise. Projeto esporte Brasil. Manual de testes e avaliação, 2016.

MOREIRA, Cintia Dias, et al. Nível de aptidão física para o desempenho esportivo em participantes adolescentes do projeto esporte em ação. Revista Brasileira de Prescrição e Fisiologia do Exercício, v. 11, n. 64, p. 74-82, 2017.

OLIVEIRA, Leonardo dos Santos, et al. Nível de aptidão física relacionada ao desempenho de escolares praticantes de voleibol de um município do semiárido brasileiro. Revista Brasileira de Prescrição e Fisiologia do Exercício, v. 11. n. 65. p. 156-163. 2017. 


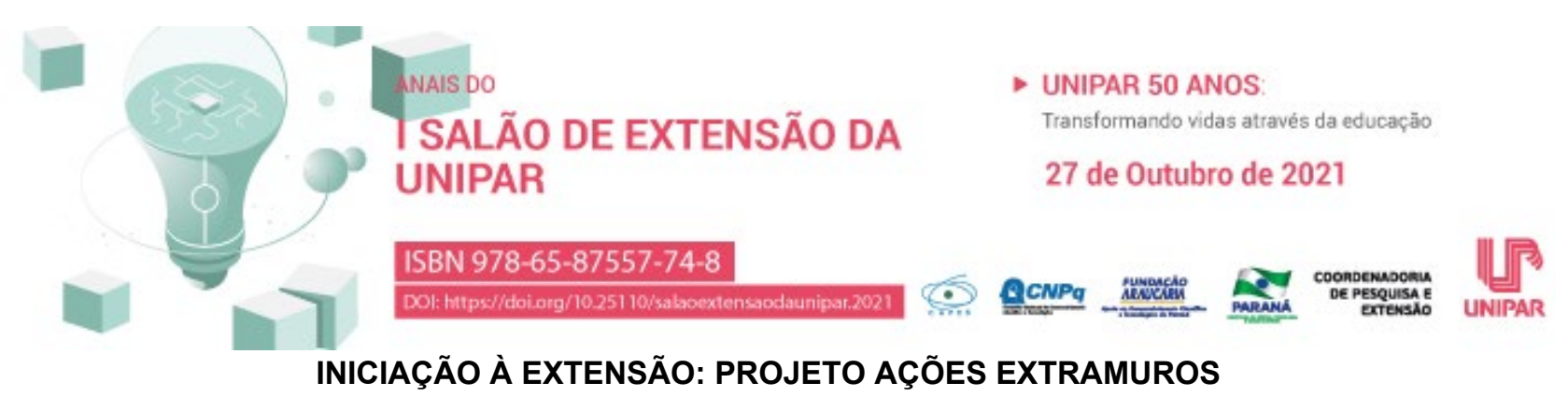

\author{
${ }^{1}$ LUANA JESSICA CAPELIN , ${ }^{2}$ ISABELA SATO ROSSI, ${ }^{3}$ JESSICA DE OLIVEIRA SILVA, ${ }^{4}$ MARIANA DUARTE MILANI DE \\ HOLANDA, ${ }^{5}$ MONICA CRISTINA MANIEZO TAVARES, ${ }^{6}$ CLAUDIA LOPES PERPETUO
}

\author{
${ }^{1}$ Acadêmica do Curso de Psicologia da UNIPAR \\ ${ }^{2}$ Acadêmica do Curso de Psicologia da UNIPAR \\ ${ }^{3}$ Acadêmica do Curso de Psicologia da UNIPAR \\ ${ }^{4}$ Acadêmica do Curso de Psicologia da UNIPAR \\ ${ }^{5}$ Psicóloga Responsável Técnica do Centro de Psicologia Aplicada da UNIPAR \\ ${ }^{6}$ Docente da UNIPAR
}

Introdução: O presente trabalho descreve de forma sucinta o desenvolvimento das atividades realizadas no Projeto de Extensão Ações Extramuros . A extensão universitária caracteriza-se pela possibilidade de desenvolver ações de cunho educativo e interdisciplinar que possibilitem a interação entre a universidade e a comunidade na qual encontra-se inserida, proporcionando a relação da teoria e a prática. Dessa forma, de acordo com o Código de Ética Profissional da Psicologia, ।"o psicólogo contribuirá para promover a universalização do acesso da população às informações, ao conhecimento da ciência psicológica, aos serviços e aos padrões éticos da profissão (CONSELHO FEDERAL DE PSICOLOGIA, 2005, p.07). Entende-se que os cursos de Psicologia formam profissionais para lidar com o cotidiano garantindo os direitos humanos e não violando seus princípios fundamentais. Assim, o Projeto Ações Extramuros nasceu com o intuito de conscientizar a população sobre movimentos que foram importantes no decorrer da história para a garantia de direitos individuais e coletivos. O projeto se iniciou a partir de reuniões com equipamentos públicos para levantamento de demandas, a fim de construir um calendário de temas pertinentes tanto à comunidade como à Psicologia, para compartilhar informações, possibilitar discussões, esclarecimentos e assim aproximar os acadêmicos das demandas sociais.

Objetivo: Promover o envolvimento dos alunos e sociedade, desenvolvendo ações voltadas à comunidade externa, a fim de divulgar datas e temas expressivos que possuem relação com a Psicologia.

Resultados: Até o presente momento foram desenvolvidas pesquisas e materiais pertinentes às datas expressivas de cada mês para serem publicados nas mídias sociais. No mês de agosto, foram produzidos materiais relacionados a Psicologia, enquanto ciência e profissão, também sobre saúde mental e, com o tema Agosto Dourado, foi trabalhado sobre o aleitamento materno. No mês de setembro, as acadêmicas produziram uma coletânea de vídeos com diversos tópicos relacionados ao suicídio, expondo suas relações com a Psicologia. A partir destas produções pretende-se compartilhar os conhecimentos da Psicologia para além da academia, buscando disseminar e produzir discussões e trocas acerca dos temas, lembrando que o Projeto ainda está sendo executado.

Conclusão: Através do projeto, que ainda está em andamento, foi possível observar a abrangente intersecção da Psicologia com os diversos temas pesquisados, e para além disto, a importância de abordar esses assuntos de forma acessível à toda comunidade externa à academia.

\title{
Referências
}

CONSELHO FEDERAL DO PARANÁ (CFP). Código de ética profissional do Psicólogo. Brasília; 2005. Disponível em: https://site.cfp.org.br/wp-content/uploads/2012/07/codigo-de-etica-psicologia.pdf. Acesso em: 8 set. 2021.

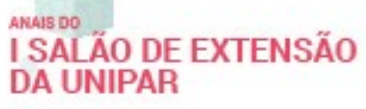

I SALÃO DE EXTENSÃO DA UNIPAR

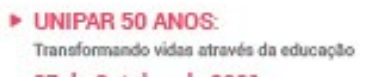

27 de Outubro de 2021

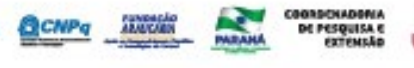




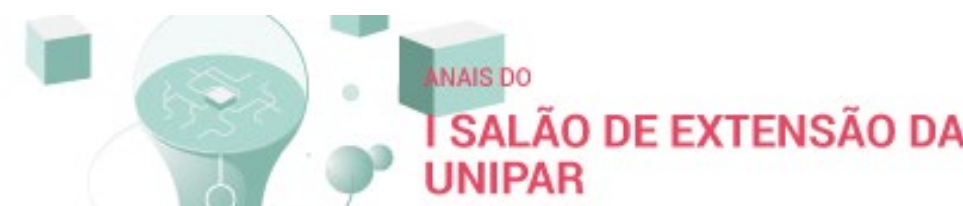 \\ - UNIPAR 50 ANOS: \\ Transformando vidas através da educaçāo \\ 27 de Outubro de 2021 \\ ISBN 978-65-87557-74-8

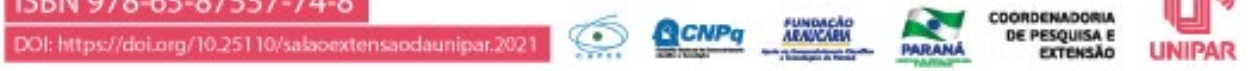 \\ A APLICAÇÃO DO BIM (BUILDING INFORMATION MODELING) NA COMPATIBILIZAÇÃO DE PROJETOS DE ENGENHARIA CIVIL ESTUDO DE REVISÃO
}

\author{
${ }^{1}$ GEYSON MARTINS RODRIGUES, ${ }^{2}$ LORENA MARCIELE VIANA ACOSTA, ${ }^{3}$ JOAO VICTOR POSSOBOM RIGOBELLO, ${ }^{4}$ IGO \\ HENRIQUE SILVA NUNES, ${ }^{5}$ VANDA ZAGO LUPEPSA
}

\author{
${ }^{1}$ Acadêmico do Curso de Engenharia Civil da UNIPAR \\ ${ }^{2}$ Acadêmica do Curso de Engenharia Civil da UNIPAR \\ ${ }^{3}$ Responsável Técnico do Escritório Modelo da UNIPAR \\ ${ }^{4}$ Docente da UNIPAR \\ ${ }^{5}$ Docente da UNIPAR
}

Introdução: No atual cenário da construção civil, devido à grande demanda de empreendimentos com curtos prazos de entrega, é recorrente a necessidade de retrabalho no canteiro de obras, isso em razão da falta de profissionais especializados em compatibilização de projetos ou à negligência na execução dos projetos. Aplicando a metodologia BIM - Building Information Modeling, o projeto deixa de ser um processo linear e paralelo e torna-se tridimensional e integrado, o que favorece a comunicação entre o projetista e o sistema construtivo (MIKALDO JR; SCHEER, 2008).

Objetivo: Apresentar algumas vantagens da aplicação do BIM em relação à compatibilização de projetos dentro da engenharia civil.

Resultados: Com necessidade de projetar sempre de forma mais prática e eficiente, o objetivo do BIM é baseado na usabilidade de softwares para a concepção de projetos em modelos 3D, o que auxilia no seu entendimento, não perdendo sua qualidade técnica, logo, no método BIM, tais modelos 3D's são unificados gerando a integração dos mesmos. Considerando que a análise de compatibilidade ocorre de forma automática, uma das melhores vantagem do uso do BIM é que ele garante agilidade e alta confiabilidade em termos de compatibilidade (MENEGARO, 2017). Outro aspecto positivo do BIM é que ele reduz custos, tempo e melhora o gerenciamento da obra. Utilizando este método, é possível antever os erros e tomar as melhores decisões de modificações ainda na concepção do projeto, pois o projetista poderá ter uma visão completamente diferente daquela quando projetada em 2D. Um grande diferencial do método BIM é a funcionalidade 5D, utilizada na composição de orçamento e análise de custo das atividades relacionadas, podendo fornecer o cronograma e o orçamento da construção por meio de uma planilha de gerenciamento. Embora as vantagens de utilização do BIM com perfeição sejam muitas, existe a necessidade do profissional se especializar em diversos softwares para ter um entendimento de suas funções, design, modelagem e criação, mas essa especialização agregará muita qualidade na elaboração e execução dos projetos (SENA, 2012).

Conclusão: Conclui-se que a aplicação do BIM nos projetos de engenharia civil traz uma maior qualidade e precisão daquilo que está sendo projetado e que será realizado em obra, além de proporcionar maior segurança de que os projetos não possuirão erros básicos de compatibilização, assim evitando o retrabalho no canteiro de obras.

\section{Referências}

MIKALDO JR, Jorge; SCHEER, Sergio. Compatibilização de projetos ou Engenharia simultânea: qual é a melhor solução?. Gestão \& tecnologia de projetos, v. 3, n. 1, p. 79-99, 2008 . Disponível em: https://www.revistas.usp.br/gestaodeprojetos/article/view/50928/55010. Acesso em: 05 Set. 2021

MENEGARO, Bruna Ferreira. Aplicação da metodologia BIM (Building Information Modeling) no processo de projeto, com foco em compatibilização. 2017. Disponível em: http://repositorio.unesc.net/bitstream/1/5878/1/BrunaFerreiraMenegaro.pdf. Acesso em: 05 Set. 2021

SENA, Thiago Silva de. A aplicaçãoda metodologia BIM para a compatibilização de projetos. Monografia, Universidade Federal da Bahia Escola Politécnica Colegiado do Curso de Engenharia Civil, Salvador, 2012. Disponível em: http://www.gpsustentavel.ufba.br/downloads/BIM\%20Compatibiliza\%C3\%A7\%C3\%A3o.pdf. Acesso em: 05 Set 2021

I SALÃ̃O DE EXTENSÃO DA UNIPAR

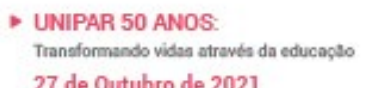

27 de Outubro de 2021

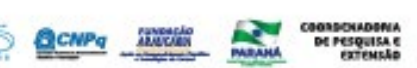




\title{
8 \\ BENEFÍCIOS DA ANÁLISE DA RELAÇÃO CUSTO/VOLUME/LUCRO NO CONTEXTO DE UMA PIZZARIA
}

\author{
${ }^{1}$ CHARLEN GABRIEL dOS SANTOS, ${ }^{2}$ EDUARDO DE QUADRA WAGNER, ${ }^{3} J E F F E R S O N ~ C A R L O S ~ R I B E I R O,{ }^{4}$ ELCIDES \\ BEZERRA PRATIS, ${ }^{5}$ GERVALDO RODRIGUES CAMPOS
}

\footnotetext{
${ }^{1}$ Acadêmico do curso de Ciências Contábeis da UNIPAR, Membro do LACUS

${ }^{2}$ Acadêmico do Curso de CiÃanncias ContÃ $;$ beis da UNIPAR, Membro do LACUS

${ }^{3}$ Acadêmico do Curso de CiÃanncias ContÃ $;$ beis da UNIPAR, Membro do LACUS

${ }^{4}$ Acadêmico do Curso de CiÃancias ContÃ $\tilde{A}^{\text {beeis }}$ da UNIPAR, Membro do LACUS

${ }^{5}$ Docente da UNIPAR, Coordenador do LACUS
}

Introdução: Dentro da ampla área de estudo da Contabilidade de Custos, uma das ferramentas mais importantes e empregadas em organizações é a análise da relação Custo/Volume/Lucro (CVL), isso ocorre em razão das informações relevantes que ela é capaz de fornecer para os gestores por meio de seus indicadores (Wernke, 2019). No entanto, esses procedimentos costumam apresentar resultados inconsistentes, prejudicando ao invés de auxiliar as análises acerca dos resultados dos produtos e as respectivas decisões a serem tomadas, como ressaltam Lembeck e Wernke (2019). Todavia, se adotada de maneira adequada, a Análise CVL conferirá benefícios informacionais fundamentais para o processo decisório, como as margens de contribuição dos produtos, isto é, a diferença entre o preço de venda e o Custo Variável de cada produto (Martins, 2010, p. 179). Tendo conhecimento do retorno potencial de cada produto, a definição do mix de produtos - segmentos priorizados devido ao maior retorno - torna-se mais simples. Sua importância se deve ao fato de que a combinação apresentada no mix garante o maior lucro possível do exercício. Por fim, a margem de contribuição contribui também para determinação do ponto de equilíbrio, que segundo Padoveze (1994, p. 255), é o momento em que o total da margem de contribuição da quantidade vendida/produzida se iguala aos custos e despesas fixas , dentre outras informações relevantes aos gestores. Ou seja, quanto deverá ser vendido para arcar com as obrigações fixas e garantir o funcionamento da fábrica.

Objetivo: Analisar o sistema de controle de custos e aplicar a técnica do ponto de equilíbrio, com o propósito de contribuir na melhoria do processo de gestão do negócio.

Resultados: Considerando as vendas no período de um mês do produto pizza, dispondo dos tamanhos P, M, G e GG, o mix de produtos vendidos no período em questão, 1.150 unidades, a margem de contribuição média de $44 \%$ do preço de venda e os custos e despesas fixos, a empresa estudada precisa vender no mínimo $R \$ 16.932,96$, para atingir o seu ponto de equilíbrio. Ela obteve receita de $R \$ 38.995,00$ e custos de $R \$ 29.375,00$, portanto, lucro líquido de $R \$ 9.620,00$.

Conclusão: A aplicação da técnica do ponto de equilíbrio consiste em um instrumento imprescindível para averiguar a saúde econômica e financeira de uma empresa, isto é, conhecendo o volume de vendas necessário para não operar no vermelho o gestor pode adotar outras estratégias na busca de maior fatia no seu mercado de atuação.

\section{Referências \\ GUERREIRO, Reinaldo. Estruturação de sistemas de custos para a gestão da rentabilidade. São Paulo: Atlas. 2011. MARTINS, Eliseu. Contabilidade de Custos. (10a. ed.). São Paulo: Atlas. 2010. \\ PADOVEZE, Clóvis Luís. Contabilidade gerencial: um enfoque em sistema de informação contábil. São Paulo: Atlas, 2010. WERNKE, Rodney. Análise de custos e preços de venda: ênfase em aplicações e casos nacionais. (2a ed.). São Paulo: Saraiva. 2019. \\ WERNKE, Rodney. Vantagens da Análise Custo/Volume/Lucro no Contexto de Pequena Fábrica de Blocos de Concreto. ABCustos, São Leopoldo, v. 16, n. 2, p. 104-132, 31 ago. 2021. Disponível em: https://revista.abcustos.org.br/abcustos/article/view/611. Acesso em: 02 set. 2021. \\ WERNKE, Rodney, \& LEMBECK, Marluce. Análise de rentabilidade dos segmentos de mercado de empresa distribuidora de mercadorias. Revista Contabilidade \& Finanças, 15(35), 68-83. 2004.}

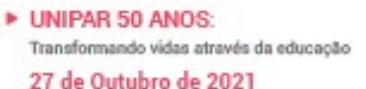

27 de Outubro de 2021
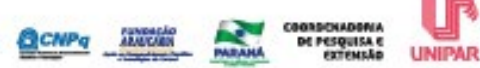


\title{
PREVENÇÃO E DIAGNÓSTICO PRECOCE DE PATOLOGIAS BUCAIS DOS PACIENTES DA CLÍNICA ODONTOLÓGICA DA UNIPAR
}

\author{
${ }^{1}$ HELOISA GARCIA FRANCOZO, ${ }^{2}$ JAMILLE CRISTINA KARWEL, ${ }^{3}$ TAIS NUNES LOPES DA SILVA, ${ }^{4}$ ANDRESSA \\ VENTRAMELI DE ANDRADE, ${ }^{5}$ GABRIELA ZANUTO DE LIMA, ${ }^{6}$ LEISLE VERONICA PRESTES, ${ }^{7}$ BEATRIZ AYUMI SHIOTANI, \\ ${ }^{8}$ GABRIEL MACIEL DA SILVA, ${ }^{9}$ PAULO NORBERTO HASSE, ${ }^{10}$ GIORDANO BRUNO DE OLIVEIRA MARSON
}

\begin{abstract}
${ }^{1}$ Discente do Curso de Odontologia da Universidade Paranaense - UNIPAR - Campus Umuarama-PR.
${ }^{2}$ Discente do Curso de Odontologia da Universidade Paranaense - UNIPAR - Campus Umuarama-PR. ${ }^{3}$ Discente do Curso de Odontologia da Universidade Paranaense - UNIPAR - Campus Umuarama-PR. ${ }^{4}$ Discente do Curso de Odontologia da Universidade Paranaense - UNIPAR - Campus Umuarama-PR. ${ }^{5}$ Discente do Curso de Odontologia da Universidade Paranaense - UNIPAR - Campus Umuarama-PR. ${ }^{6}$ Discente do Curso de Odontologia da Universidade Paranaense - UNIPAR - Campus Umuarama-PR. ${ }^{7}$ Discente do Curso de Odontologia da Universidade Paranaense - UNIPAR - Campus Umuarama-PR. ${ }^{8}$ Discente do Curso de Odontologia da Universidade Paranaense - UNIPAR - Campus Umuarama-PR. ${ }^{9}$ Docente do Curso de Odontologia da Universidade Paranaense - UNIPAR - Campus Umuarama-PR. ${ }^{10}$ Docente do Curso de Odontologia da Universidade Paranaense - UNIPAR - Campus Umuarama-PR.
\end{abstract}

Introdução: Biópsia é definida como $\circ$ ato cirúrgico de coletar o tecido alterado e encaminhá-lo para o exame anatomopatológico. Constitui-se de coleta dos tecidos alterados, com finalidade de dar o diagnóstico correto, através da análise do tecido no exame histopatológico, que é o principal e mais confiável recurso para o diagnóstico das lesões, pois estabelece as características microscópicas dos tecidos alterados, sendo na maioria das vezes o único exame capaz de estabelecer um diagnóstico conclusivo da lesão biopsiada (BRAZAO-SILVA, et al., 2018).

Objetivo: Dar suporte aos pacientes atendidos na clínica que apresentam lesões bucais, atuando de forma preventiva e/ou estabelecendo diagnóstico por meio da realização de biópsias nas clínicas de cirurgia, sob supervisão do professor orientador, e encaminhado para o exame histopatológico. Mediante laudo/diagnóstico, encaminhar para o tratamento odontológico/médico de acordo com cada necessidade.

Resultados: Até o presente momento, oito biópsias foram realizadas e encaminhadas para exame histopatológico no Departamento de Diagnóstico Bucal da UNICAMP (Universidade Estadual de Campinas, Piracicaba, SP, Brasil). Cinco desses exames já possuem resultados e o restante encontra-se sob análise. Quanto à realização das biópsias, três pacientes aguardam agendamento, recebemos encaminhamentos das Unidades Básicas de Saúde de Umuarama e região e além disso possuímos casos acompanhados na diciplina de Diagnóstico Bucal dentro do Curso de Graduação em Odontologia. Dentre esses cinco resultados, foram diagnosticadas três hiperplasias fibrosas, uma lesão fibro-óssea benigna sugestiva de displasia cemento-óssea florida e uma lesão sugestiva de queratocisto odontogênico inflamado, como todas as lesões são beningnas não houve necessidade de encaminhá-las para fora e por isso foi realizado o tratamento e acompanhamento.

Considerações finais: O projeto é de suma importância para a Universidade e também para toda a população beneficiada, uma vez que o diagnóstico e a prevenção lesões com potenciais malignos são feitos em tempo hábil para um prognóstico favorável (CIMARDI, FERNANDES 2009). Alguns autores concluíram que alunos e profissionais da Odontologia possuem conhecimento superior sobre o câncer de boca, uma vez que o cirurgião dentista e o principal responsável pela diminuição da incidência, morbidade e mortalidade do câncer bucal, bem como, o diagnóstico precoce destas patologias, tendo em vista a sua capacidade de diagnóstico frente às alterações da cavidade oral, se comparado aos demais profissionais da area da saude. (DE OLIVEIRA et al., 2013, DE MELO et al., 2008).

\section{Referências}

BRAZAO-SILVA, Marco Túlio, CARVALHO, Bianca de Oliveira, PINTO, Rodrigo Alves. A biópsia na prática odontológica: Revisão de Literatura. RvACBO, v. 7, n. 3, p. 197-203, 2018.

CIMARDI, A. C B.; FERNANDES, A. P. S. Câncer bucal- a prática e a realidade clinica dos cirurgiões-dentistas da Santa Catarina. RFO. Santa Catarina, v. 14, n. 2, p. 99-104, mai./ago. 2009.

DE MELO, Allan Ulisses Carvalho et al. Informação e comportamento de cirurgiões- dentistas do Programa Saúde da Família de Aracaju a respeito de câncer bucal. Rev. Bras. Cir. Cabeça Pescoço. Aracajú, SE, v. 37, n. 2, p. 114-119, abr./mai./jun. 2008. 
DE OLIVEIRA, Jamile Marinho Bezerra et al. Câncer de Boca: Avaliação do Conhecimento de Acadêmicos de Odontologia e Enfermagem quanto aos Fatores de Risco e Procedimentos de Diagnóstico. Revista Brasileira de Cancerologia. Natal, v. 59, n. 2, p. 211-218, 2013.

I SALALOO DE EXTENSÃO

DA UNIPAR
- UNIPAR 50 ANOS: Traneformando vidas atravta da educaço

27 de Outubro de 2021

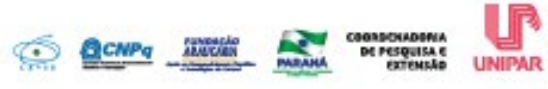




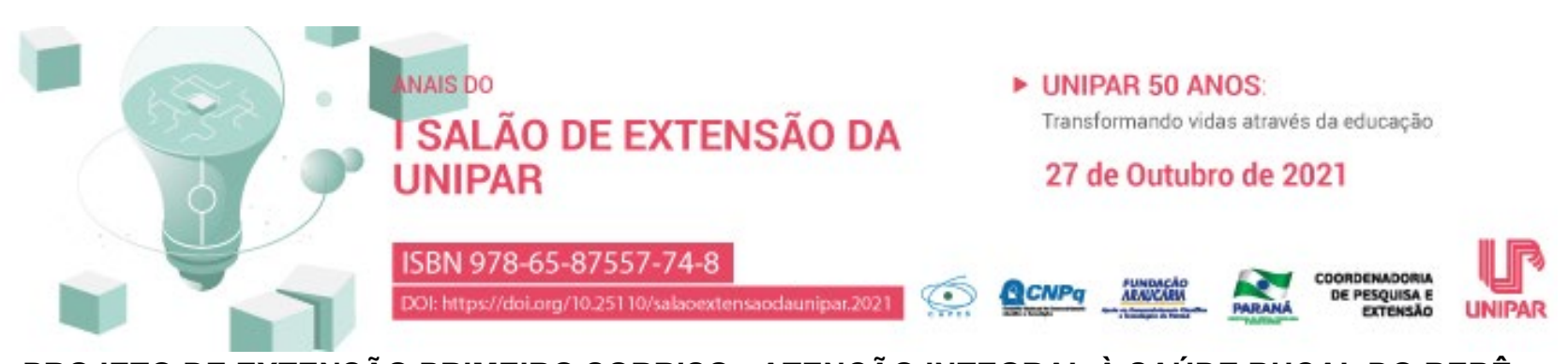

\section{PROJETO DE EXTENSÃO PRIMEIRO SORRISO - ATENÇÃO INTEGRAL À SAÚDE BUCAL DO BEBÊ}

${ }^{1}$ MILENA GEMELLI, ${ }^{2}$ DANIELY CARLA SANTIN COELHO, ${ }^{3}$ ALINE TESKER VALDAMERI, ${ }^{4}$ ANDRESSA VANDERLINDE NUENBERG DA SILVA, ${ }^{5}$ EVERTON JOSE FELIX, ${ }^{6}$ HELENA CAROLINE DA SILVA, ${ }^{7}$ HORIANA FREITAS DE VARGAS, ${ }^{8}$ FABIO LUIS FAEDO SCANDOLARA, ${ }^{9}$ JULIA GABRIELA MAZUR, ${ }^{10}$ MARIANA EDUARDA LADIK, ${ }^{11}$ NATIELE TOMASINI, ${ }^{12}$ TAYNAN DRZERMISKI DA SILVA, ${ }^{13}$ VANESSA EMANUELY GONCALVES, ${ }^{14}$ FLAVIA RUIZ BARBOSA PAGANINI

\footnotetext{
${ }^{1}$ Acadêmica do curso de Odontologia da UNIPAR

${ }^{2}$ Acadêmica do Curso de Odontologia da UNIPAR

${ }^{3}$ Acadêmica do Curso de Odontologia da UNIPAR

${ }^{4}$ Acadêmico do Curso de Odontologia da UNIPAR

${ }^{5}$ Acadêmico do Curso de Odontologia da UNIPAR

${ }^{6}$ Acadêmica do Curso de Odontologia da UNIPAR

${ }^{7}$ Acadêmica do Curso de Odontologia da UNIPAR

${ }^{8}$ Acadêmico do Curso de Odontologia da UNIPAR

${ }^{9}$ Acadêmica do Curso de Odontologia da UNIPAR

${ }^{10}$ Acadêmica do Curso de Odontologia da UNIPAR

${ }^{11}$ Acadêmica do Curso de Odontologia da UNIPAR

${ }^{12}$ Acadêmico do Curso de Odontologia da UNIPAR

${ }^{13}$ Acadêmico do Curso de Odontologia da UNIPAR

${ }^{14}$ Docente da UNIPAR
}

Introdução: A cárie dentária é uma doença crônica comum na infância, afetando cerca de um quarto delas, com aumento significativo a partir do primeiro ano de vida, influenciando negativamente a saúde oral, a saúde geral e a qualidade de vida. $O$ cuidado com a cavidade oral dos bebês é importante desde o nascimento, assim a orientação aos pais sobre como conduzir esses cuidados deve ser realizada constantemente, enfatizando orientações às gestantes, que nesse período encontram-se abertas a guardar informações. A atenção precoce visa reduzir o desenvolvimento de cárie em bebês e sua ambientação ao consultório odontológico, além da criação de hábitos de higiene bucal, pelas crianças e pelos pais, considerados a chave principal para educar e motivar. Outros cuidados devem ser tomados na atenção integral à saúde bucal do bebê: o enfoque à amamentação natural, às doenças bucais mais comuns na infância, importância da dentição decídua e prevenção de hábitos bucais deletérios.

Objetivo: Oferecer assistência odontológica integral a bebês através de atividades educativas aos pais e comunidade em geral e diagnóstico, prevenção, tratamento e controle das situações mais comuns nesta faixa etária (cárie, traumatismo, alterações de desenvolvimento, hábitos bucais deletérios), com visão interdisciplinar e multiprofissional.

Resultados: Elaboração de material educativo aos pais e responsáveis com base em literatura atual; uso da rede social

Instagram para divulgação do projeto e informações à comunidade; atendimento clínico de bebês, incluindo orientações aos responsáveis sobre saúde bucal em contexto com a saúde geral, importância da dentição decídua, hábitos de sucção nutritivos e não nutritivos, prevenção da cárie dentária, outros conforme necessidades individuais. Assim, torna-se possível ampliar o conhecimento dos pais a respeito da saúde bucal do bebê, estimulando hábitos saudáveis de higiene e dieta, reduzindo assim a necessidade de tratamentos restauradores e perdas dentárias precoces.

Considerações Finais: o projeto é uma resposta às necessidades da comunidade em educação e atenção à saúde oral das gestantes e bebês, pois os mitos que envolvem o atendimento odontológico da gestante, a alta prevalência de cárie precoce na infância, o desconhecimento dos pais e/ou cuidadores sobre as diversas questões que envolvem a saúde bucal dos bebês, evidencia a necessidade de programas voltados para a promoção de saúde e prevenção de doenças bucais na primeira infância.

\section{Referências}

ABANTO, J.; DUARTE, D.; FERES, M. Primeiros 1000 dias do bebê e saúde bucal: o que precisamos aprender! Napoleão livros. Coletânea CIOSP, vol 1.

MIRANDA DE JESUS, D. et al. A higiene bucal de bebês edêntulos e sua influência na microbiota bucal: os profissionais de 
saúde devem preconizá-la? revisão crítica. Revista da Faculdade de Odontologia de Porto Alegre, v. 62, n. 1, p. 108 120, 2021.

NAPOLEÃO, A. M. M. et al. Conhecimento Das Gestantes Sobre a Saúde Bucal Do Bebê. Revista Expressão Católica Saúde, v. 3, n. 2, p. 38, 2018.

ANâ1S Do

I SALÃOO DE EXTENSÃO

- UNIPAR 50 anOS:

DA UNIPAR

27 de Outubro de 2021

ACNPG 


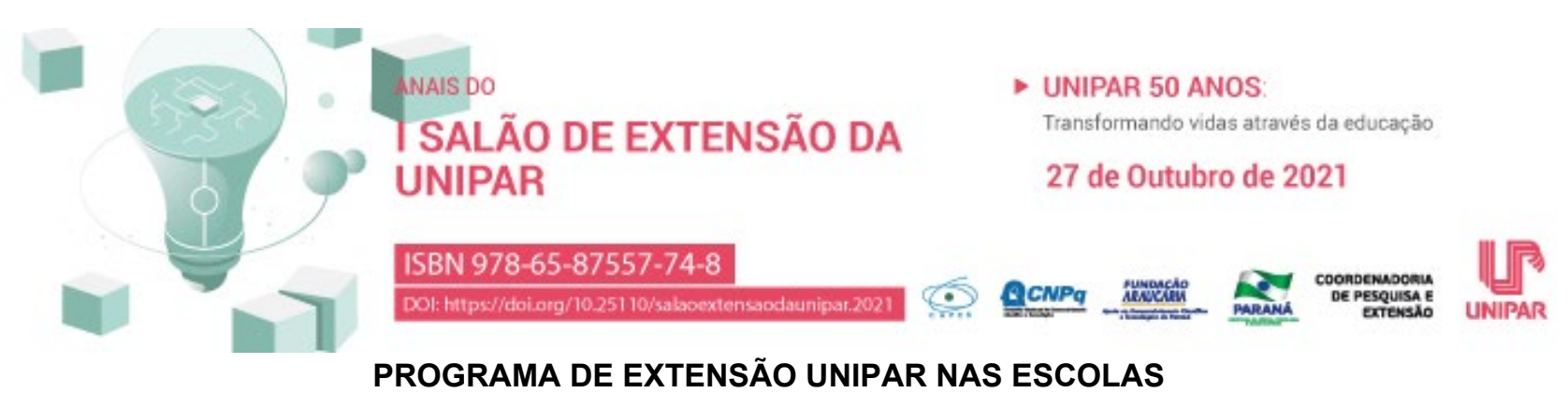

\begin{abstract}
${ }^{1}$ FABIO EDUARDO ALMEIDA SALDANHA MUNIZ, ${ }^{2}$ BaRBARA ELLEN DE ALBUQUERQUE, ${ }^{3}$ MATHEUS BISCOLA VIANA, ${ }^{4}$ MARCOS PAULO DOS SANTOS DE SA, ${ }^{5}$ MARIA FERNANDA COCULO DA COSTA, ${ }^{6}$ ROMIR RODRIGUES, ${ }^{7}$ RAQUEL COSTA MACHADO, ${ }^{8}$ CLAUDETE WERNER, ${ }^{9}$ TANIA CONCEICAO IGLESIAS, ${ }^{10}$ PAULO HENRIQUE DA SILVA PEREIRA
\end{abstract}

\author{
${ }^{1}$ Acadêmico do curso de Arquitetura e Urbanismo da UNIPAR \\ ${ }^{2}$ Acadêmica do Curso de Engenharia Civil da UNIPAR \\ ${ }^{3}$ Acadêmico do Curso de Engenharia Civil da UNIPAR \\ ${ }^{4}$ Acadêmico do Curso de Arquitetura e Urbanismo da UNIPAR \\ ${ }^{5}$ Acadêmica do Curso de EstÃ@tica e CosmÃ@tica da UNIPAR \\ ${ }^{6}$ Docente da UNIPAR \\ ${ }^{7}$ Docente da UNIPAR \\ ${ }^{8}$ Docente da UNIPAR \\ ${ }^{9}$ Docente da UNIPAR \\ ${ }^{10}$ Docente da UNIPAR
}

Introdução: A Extensão Universitária é um pilar das Universidades, sendo ela indissociável com a pesquisa e ensino, sendo assim, indispensáveis e fundamentais para uma construção de conhecimento com qualidade e produtividade (BRASIL, 1988; BORGES, ARAÚJO, 2012). De acordo com a Lei 9.394 de 1996, a extensão deve ser aberta à participação da população, visando a difusão das conquistas e benefícios resultantes da criação cultural e da pesquisa científica e tecnológica geradas na instituição (BRASIL, 1996). Nesse intuito a Extensão realiza uma grande interlocução das demandas sociais da comunidade e também o retorno de soluções com a geração substancial de conhecimento difundido para a humanidade, promovendo desenvolvimento.

Objetivo: Apresentar o projeto UNIPAR NAS ESCOLAS para os Gestores dos Colégios Públicos Estaduais do Núcleo Regional de Educação de Paranavaí.

Resultados: O contato com o Núcleo Regional de Educação de Paranavaí se deu desde o início da execução do projeto. No entanto devido a pandemia, e os trabalhos internos dos gestores da redes estadual de ensino, resultou em uma dificuldade para encontro da data mais favorável, tendo como solução o aproveitamento um evento marcado para a posse dos novos diretores, que ocorreu no dia 13 de Agosto de 2021. O Evento aconteceu presencialmente, de forma oportuna, no anfiteatro da UNIPAR Unidade de Paranavaí, sendo utilizado o início da cerimônia para a divulgação do projeto para todos os presentes. Na oportunidade foi destacado o papel fundamental da cooperação entre o ensino superior e ensino básico, no incremento da qualidade da educação e direcionamento profissional de nossa comunidade, com a possibilidade de oferta de palestras, visitas direcionadas e oficinas, entre outras possíveis demandas. Os Gestores escolares receberam o projeto e fundamentaram a importância da cooperação e a retomada desses trabalhos pós-pandemia.

Conclusão: Nesse primeiro contato, foi muito importante a informação sobre a proposta de trabalho e conhecer os atuais e novos diretores, para que assim, firme propostas e convênios para a geração de produção cooperativa entre a UNIPAR e os colégios estaduais de Paranavaí e região.

\title{
Referências
}

BRASIL. Lei de Diretrizes e Bases da Educação Nacional. n 9.394 de 20 de Dezembro de 1996.

BRASIL. Constituição da República Federativa do Brasil, de 05 de dezembro de1988.

BORGES, M.F; ARAÚJO, J.B. Ensino, pesquisa e extensão na Educação Superior: processo histórico e perspectivas futuras. EFDeportes.com, Revista Digital. Buenos Aires, Ano 17, $\mathrm{N}^{\circ}$ 172, Setembro de 2012 . Disponível em:http://www.efdeportes.com/. Acessado em: 14 de Setembro de 2021. 


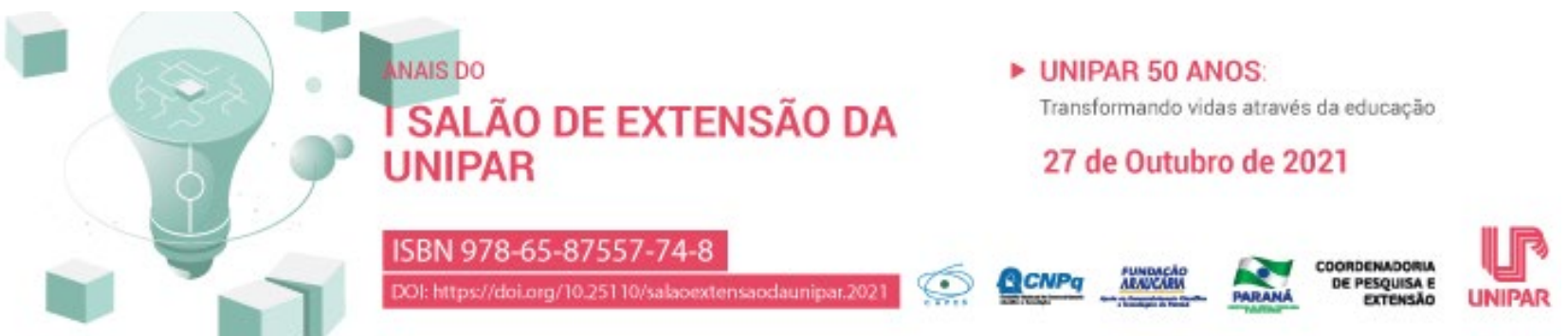

\section{A PROBLEMÁTICA DA GRAVIDEZ NA ADOLESCÊNCIA}

\author{
${ }^{1}$ FLAVIA CRISTINA RUARO, ${ }^{2}$ ALESSANDRO NEVES POPP, ${ }^{3}$ JADIELI SIMONI ROLL, ${ }^{4}$ FRANCIELE DO NASCIMENTO \\ SANTOS ZONTA, ${ }^{5}$ LEDIANA DALLA COSTA
}

\author{
${ }^{1}$ Acadêmico COPEX/UNIPAR \\ ${ }^{2}$ Acadêmico do Curso de Enfermagem da UNIPAR \\ ${ }^{3}$ Docente da UNIPAR \\ ${ }^{4}$ Docente da UNIPAR \\ ${ }^{5}$ Docente da UNIPAR
}

Introdução: A adolescência é uma fase da vida marcada por diversas mudanças no caráter físico e emocional (ALMEIDA et al. 2017).

Com a descoberta da gestação durante a adolescência tende-se a aumentar as chances de desenvolver conflitos intrínsecos em relação a medo, solidão, angústia, vergonha e abandono, levando a ocasionar um retardo na adesão ao pré-natal. Além disso outros fatores que contribuem para demora ou baixa adesão dessa população, são as condições de vida precárias, pressões psicológicas e sociais (SALDANHA, 2020). A sexualidade é tida por meio de uma construção, se baseando nas relações sociais do indivíduo durante sua infância até a puberdade. O contexto ambiental e social na qual a pessoa cresce está diretamente relacionado em como o mesmo irá lidar com sua intimidade, ou seja, alguém que cresce em um ambiente harmonioso, afetivo, onde o diálogo é uma das bases, o mesmo tenderá a ter uma sexualidade saudável. Todavia, se o jovem crescer em um ambiente cercado por agressividade, negligência e falta de afetividade, as relações tendem a ser dificultosas (FEBRASGO, 2017). Por conta da ausência do diálogo, ainda nesta fase da vida o jovem tende a ter a visão limitada aos conhecimentos sobre o uso contraceptivos para prevenção de IST e de gravidez (Nascimento et al.,2020).

Com tudo a gravidez precoce e indesejada acaba acarretando milhares de abortos clandestinos, colocando a vida de jovens em risco (BRASIL, 2018).

Objetivo: Descrever por meio de uma revisão bibliográfica as principais problemáticas da gravidez na adolescência.

Resultados: Segundo o último relatório da Organização das Nações Unidas (ONU, 2020) a taxa de fecundidade no Brasil entre meninas de 15 à 19 anos é de 64 a cada mil bebês nascidos vivos, acima da média mundial que é de 44 a cada mil. Além disso a Organização Pan-Americana de Saúde (OPAS) afirma que as adolescentes que engravidam antes de completar 15 anos, tender a ter uma maior chance de vir a óbito (FARIAS et al., 2020)

Com isso, a gravidez na adolescência tendem à gerar impactos alarmantes na saúde da adolescente e do bebê. As complicações durante a gestação se tornam mais propensas a acontecer devido ao despreparo do corpo para essa mudança como, por exemplo, o aborto espontâneo, parto prematuro, pré-eclâmpsia, mortalidade infantil entre outras (OLIVEIRA et al. 2021). Ademais a família, pode diretamente influenciar de forma positiva ou negativa essa adolescente. Estudos realizado por pesquisadores brasileiros destacam a importância da família estar preparada para apoiar essa jovem, e relatam ainda que os pontos fortes da família nessa fase são a união, o diálogo, apoio e a capacidade de resposta às necessidades de cuidado, lealdade e segurança (DOS SANTOS et al., 2020).

Conclusão: Devido ao conteúdo ser complexo e de extrema importância, ele se torna geralmente negligenciado pela sociedade. A gravidez precoce traz consigo situações permanentes como: custos econômicos, evasão escolar, além de traumas e consequências para os pais adolescentes que se sentem fora da normalidade, tendo dificuldade em retornar aos estudos, e até mesmo entrar no mercado de trabalho. Sendo assim, a educação em saúde se dá por uma estratégia de atuação diferenciada e dinâmica, integrando a equipe de saúde com a escola e a comunidade. O enfermeiro desempenha um papel fundamental para aproximação do adolescente com a temática. Portanto a gravidez na adolescência requer atenção, diálogo, apoio, tanto da sociedade quanto do ambiente familiar, dessa forma, é primordial desenvolver ações que despertem uma reflexão nos jovens referente a sexualidade, concepções e experiências prévias, a fim de transmitir a conscientização necessária acerca dos cuidados para com a experiência sexual.

\section{Referências}

ALMEIDA, R. A. A. S. Conhecimento de adolescentes relacionados as doenças sexualmente transmissíveis e gravidez. Revista Brasileira de Enfermagem. São Luiz, v. 70, n. 5, p. 1087- 1094, 2017.

BRASIL, Ministério da Saúde. Cuidando de adolescentes: orientações Básicas para a saúde sexual e a saúde reprodutiva. $2^{\mathrm{a}}$ ed. Brasília, 2018. 
DE OLIVEIRA, Maria Vitória Bertolani et al. OS IMPACTOS PSICOSSOCIAIS DA GRAVIDEZ NA ADOLESCÊNCIA. In: Anais do I Congresso Internacional de Psicologia da Faculdade América. 2021.

DO NASCIMENTO, Mariana Almendra Cavalcante et al. Eu falo, tu falas e ninguém ouve: conversas sobre sexo e sexualidade entre adolescentes e jovens no espaço escolar. Pesquisa, Sociedade e Desenvolvimento, v. 9, n. 8, pág. e386985852e386985852, 2020.

DOS SANTOS, Aline Cristina Ferraz et al. Abordagem do enfermeiro na gravidez na adolescência. Brazilian Journal of Health Review, v. 3, n. 6, p. 17438-17456, 2020.

FARIAS, Raquel Vieira et al. Gravidez na adolescência e o desfecho da prematuridade: uma revisão integrativa de literatura. Revista Eletrônica Acervo Saúde, n. 56, p. e3977-e3977, 2020.

FEBRASGO - Federação Brasileira das Associações de Ginecologia e Obstetrícia. Sexualidade na adolescente. São Paulo, v. 2 , n. 3, 2017.

SALDANHA, Bruna Lopes. Dificuldades enfrentadas por gestantes adolescentes em aderir ao pré-natal. Revista Eletrônica Acervo Saúde, v. 12, n. 9, p. e4160-e4160, 2020.

ONU. Organização das Nações Unidas. 2020. In: Taxa de gravidez na adolescência no Brasil está acima da média mundial, aponta ONU. Brasília: ONU.

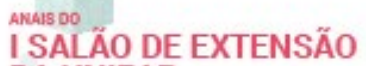

DA UNIPAR
- UNIPAR 50 ANOS:

Traneformando vides atraves da educacto

27 de Outubro de 2021

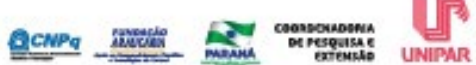




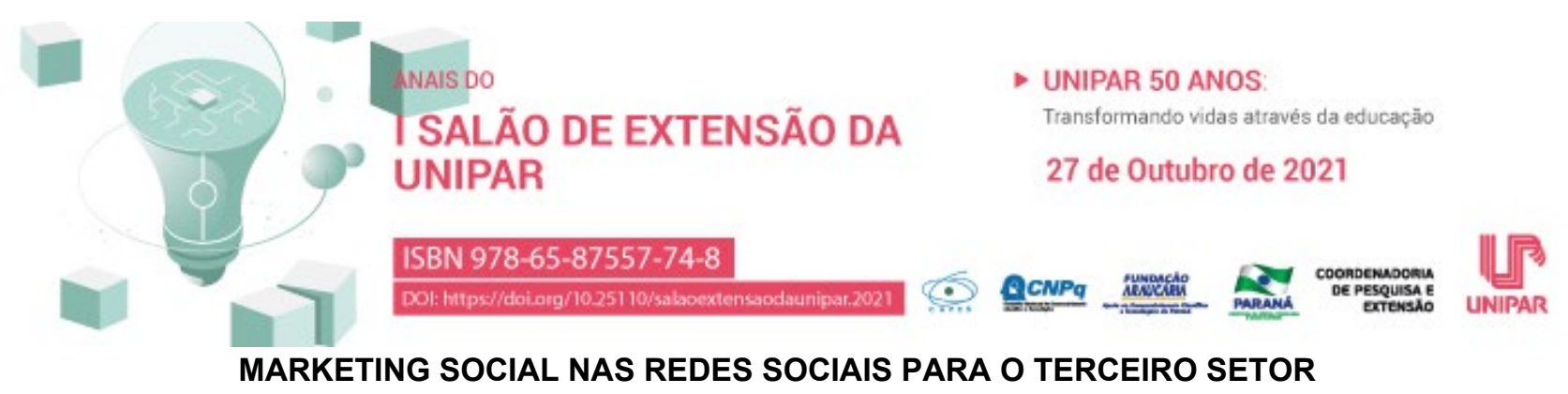

\section{${ }^{1}$ EDUARDO HENRIQUE GABIATO, ${ }^{2}$ ANA CLEIA DE OLIVEIRA CIRINO}

${ }^{1}$ Discente de Publicidade e Propaganda da UNIPAR

${ }^{2}$ Docente da UNIPAR

Introdução: Um dos aspectos mais importantes que se relacionam com o terceiro setor, isto é, instituições ou organizações sem fins lucrativos que atuam em prol da sociedade civil (PAES, 2020), é, conforme descrito, a atenção e suporte para um ou mais grupo de indivíduos, com necessidades distintas, o qual o Estado, por muitas vezes, não pode auxiliar. Isso seja por qual razão for. Uma das problemáticas principais seria, justamente, pela ausência de recursos para esses setores o quais, em sua maioria, apenas possui o voluntariado (pessoas). A segunda problemática se dá pelo fato dessas organizações/instituições não venderem um bem de consumo, algo tangível, mas sim promover a adoção de uma causa. A partir dessa real necessidade, o Projeto de Extensão, Luz e Ação - Assessoria de Comunicação para ONGS e Microempreendedores, do curso de Publicidade e Propaganda da UNIPAR - Universidade Paranaense, propõe-se a auxiliar. Diante disso, nasce o objeto de estudo do trabalho desenvolvido.

Objetivo: Auxiliar as instituições parceiras a atingirem seus objetivos de comunicação em suas redes sociais de forma a promover colaboração de empresas para o desenvolvimento das atividades e/ou causas propostas e abordar questões que se relaciona marketing social e suas estratégias para instituições/organizações do terceiro setor.

Resultados: É plausível compreender que, em um ambiente com tantos usuários como o das redes sociais, é uma excelente ferramenta para promover produtos, de forma a gerar vendas e, consequentemente, lucro. Não obstante, serve da mesma maneira às causas sociais. $O$ que difere é o sentido que se aplica, o fim que deseja atingir. Contudo, carecem de uma mesma necessidade: métodos assertivos para chegar ao resultado esperado. A partir da visão de Kotler e Zaltman (1971 apud FARIA, 2020), atribuímos o marketing social como um planejamento, de modo ordenado, para influenciar, bem como promover a aceitação de ideais sociais. Ainda nesta narrativa, salientam que isso tudo relaciona-se com planejamento de produto, preço, comunicação e distribuição de mercado. Em um sentido focal ao meio que se deseja promover a comunicação (redes sociais), o site Rock Content (2020) aborda em sentido de que o Marketing Digital para ONGS é um conjunto de estratégias desenvolvidas para fortalecer a marca e aproximar pessoas que compartilham um mesmo ideal social. Além da importância que tem uma criação de identidade visual, conforme elencado no site, é extremamente importante segmentar seu público, de forma que possa identificar quem é o seu público, onde eles estão e como alcançá-los. A partir daí surge um estreitamento com o marketing convencional, o qual atribui uma necessidade de criação de uma persona de maneira a afunilar seu público-alvo e direcionar suas estratégias.

Conclusão: $O$ marketing social voltado ao meio digital tem por objetivo promover o encontro do terceiro setor com um público interessado e engajado numa mesma causa social, de forma a colaborar com ela. Para isso, torna-se necessário um conjunto de estratégias e metas ordenadas para seu êxito. O Projeto de Extensão supracitado propôs auxiliar na criação de materiais para as redes sociais, o qual se enquadram na identidade visual, estratégia anteriormente mencionada e visando a comunicação.

\section{Referências}

FARIA, Natyelle Gonçalves de. Marketing Social no Terceiro Setor. Núcleo do Conhecimento. Disponível em: Acesso em: 05 set. 2021.

MARKETING de causa: o que é e 6 estratégias para adota-la. Rockcontent, 2018. Disponível em: < https://rockcontent.com/br/blog/marketing-de-causa/> Acesso em: 06 set. 2021.

MARKETING Digital para ONGS: como usar essa estratégia no terceiro setor. Rockcontent, 2020. Disponível em: Acesso em: 11 set. 2021.

PAES, José Eduardo Sabo. Conceito de Terceiro Setor. Escola Aberta Terceiro Setor, 2020. Disponível em: Acesso em 11 set. 2021.

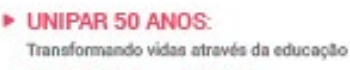

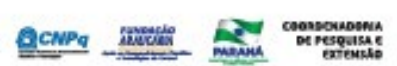

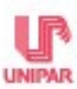




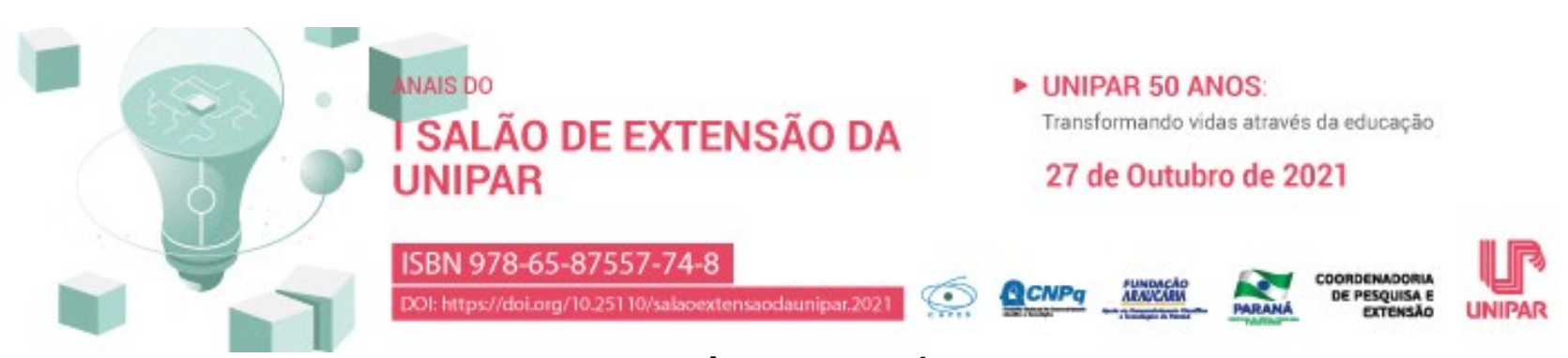

LAPSM: A IMPORTÂNCIA DA SAÚDE MENTAL

\begin{abstract}
${ }^{1}$ THAYNARA KNOPIK DECHECHI, ${ }^{2}$ AMANDA SIHNEL CORTEZ DA SILVA, ${ }^{3}$ MARIA LUIZA MARCHI SILVA, ${ }^{4}$ MIGUEL FRANCISCO FERREIRA BATISTA, ${ }^{5}$ RODRIGO HERMINIO ROPELATO , ${ }^{6}$ THALYTA CUSTODIO, ${ }^{7}$ MARILIA YUKIE TAKAKI DE OLIVEIRA ALVES, ${ }^{8}$ LEANDRO MARTINS LIMA SOUZA, ${ }^{9}$ MAYCON JORGE BRANDOLIM, ${ }^{10}$ EULLER CONDE FERNANDES , ${ }^{11}$ LORENA DE FATIMA MORETTO, ${ }^{12}$ IRINEIA PAULINA BARETTA
\end{abstract}

${ }^{1}$ Discente do curso de Medicina da Universidade Paranaense

${ }^{2}$ Discente do curso de Medicina da Universidade Paranaense

${ }^{3}$ Discente do curso de Medicina da Universidade Paranaense

${ }^{4}$ Discente do curso de Medicina da Universidade Paranaense

${ }^{5}$ Discente do curso de Medicina da Universidade Paranaense

${ }^{6}$ Discente do curso de Medicina da Universidade Paranaense

${ }^{7}$ Discente do curso de Medicina da Universidade Paranaense

${ }^{8}$ Discente do curso de Medicina da Universidade Paranaense

${ }^{9}$ Discente do curso de Medicina da Universidade Paranaense

${ }^{10}$ Discente do curso de Medicina da Universidade Paranaense

${ }^{11}$ Discente do curso de Medicina da Universidade Paranaense

${ }^{12}$ Docente do curso de Medicina da Universidade Paranaense

Introdução: Este resumo apresenta um Projeto de Extensão da Universidade Paranaense (UNIPAR), da Liga Acadêmica de Psiquiatria e Saúde Mental (LAPSM), a qual realizou durante o ano de 2021, aulas teóricas sobre a saúde mental, por meio de encontros virtuais e encontros presenciais, direcionadas para os acadêmicos do curso de Medicina, que participam da LAPSM. Esse projeto demonstra sua essencialidade ao levar conhecimento a respeito da saúde mental para os estudantes de Medicina, uma vez que, segundo Teixeira et al. (2021), através de estudo realizado, pode-se verificar que os indícios de sofrimento psíquico entre estes estão aumentados, em especial, durante a pandemia Doença de Coronavírus 2019 (COVID-19).

Objetivo: Despertar, através da LAPSM, por meio de seus professores preceptores, o conhecimento e o apreço sobre conteúdos relacionados à saúde mental para seus acadêmicos da LAPSM, auxiliando-os sobre o assunto.

Resultados: Conhecimentos sobre saúde mental estão pautados na definição da Organização Mundial da Saúde (OMS), sendo fundamental para a habilidade dos seres humanos. É um estado de bem-estar, em que as pessoas percebem suas próprias habilidades, conseguindo lidar com as tensões cotidianas, trabalhar produtivamente e colaborar com a sua comunidade (OMS, 2018). Foram discutidas e avaliadas situações sociais, como a pandemia COVID-19, em que a saúde mental pode estar fortemente impactada, podendo ocasionar transtornos de saúde mental, os quais influenciam na habilidade humana, conforme já descrito na literatura (PEREIRA et al., 2020). Ademais, a partir dos temas discutidos nos encontros da LAPSM, foi possível conhecer quando se torna uma patologia mental, e através de roda de conversa sobre saúde mental propagar esse discernimento à população. Assim, foi possível disseminar conhecimentos sobre a saúde mental para os acadêmicos do curso de Medicina, participantes da LAPSM, e através desses disseminar para as comunidades em geral.

Conclusão: Portanto, a saúde mental é essencial para todos os indivíduos, sobretudo para conseguirem encontrar-se em um estado de bem-estar consigo mesmos e com o próximo. A LAPSM desenvolveu esse projeto, visto que é de extrema importância para a formação pessoal e profissional dos estudantes de Medicina, principalmente em tempos de pandemia. Além disso, os acadêmicos podem expandir esse conhecimento para outras pessoas ao seu redor e, futuramente, para seus pacientes.

\title{
Referências
}

ORGANIZAÇÃO MUNDIAL DA SAÚDE (OMS). Saúde mental: fortalecendo nossa resposta. 30 mar. 2018. Disponível em: https://www.who.int/en/news-room/fact-sheets/detail/mental-health-strengthening-our-response. Acesso em: 15 ago. 2021.

PEREIRA, Mara Dantas; et al. A pandemia de COVID-19, o isolamento social, consequências na saúde mental e estratégias de enfrentamento: uma revisão integrativa. Revista Research, Society and Development, v. 9, n. 7, 2020. Disponível em: https://preprints.scielo.org/index.php/scielo/preprint/download/493/version/503/625/640. Acesso em: 15 ago. 2021.

TEIXEIRA, Larissa de Araújo Correia; et al. Saúde mental dos estudantes de Medicina do Brasil durante a pandemia da coronavirus disease 2019. J. bras. psiquiatr., v. 70, n. 1 , januar 2021 . Disponível em: 
https://www.scielo.br/j/jbpsiq/a/yjxwLdpJ6q5CJJCpPNxKr5R/?lang=pt\&format=html. Acesso em: 15 ago. 2021.

ANALA DO D UNIPAR 50 ANOS:

I SALÃO DE EXTENSÃO Transformando vides atraves da educoces

DA UNIPAR

27 de Outubro de 2021

Q.5. ACNPQ 


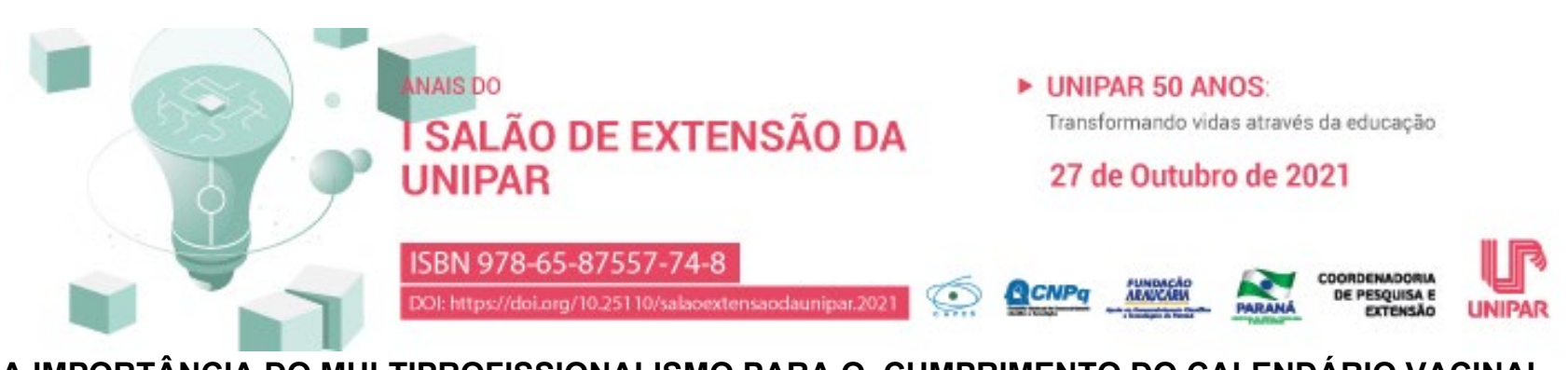

\title{
A IMPORTÂNCIA DO MULTIPROFISSIONALISMO PARA O CUMPRIMENTO DO CALENDÁRIO VACINAL
}

\author{
${ }^{1}$ MARIA BEATRIZ TIJOLIN, ${ }^{2}$ JENIFER KAROLINE SILVA STANTE, ${ }^{3}$ KATIA BIAGIO FONTES
}

${ }^{1}$ Acadêmica do Curso de Medicina da UNIPAR

${ }^{2}$ Enfermeira da UNIPAR

${ }^{3}$ Docente da UNIPAR

Introdução: A cobertura de vacina tríplice viral no Brasil caiu significativamente de 2015 a outubro de 2018. Dados da Organização Mundial de Saúde demonstraram que foram notificados casos de sarampo e o crescimento mundial nos primeiros meses de 2019 foi muito preocupante comparando-se aos períodos anteriores (VIEIRA et al., 2020). No Brasil, nos últimos anos, especialmente durante a pandemia de COVID-19, houve uma diminuição da cobertura da terceira dose da vacina contra difteria, tétano e coqueluche (DTP 3) (OMS, 2021). Outrossim, é comprovado que ação de campanhas de vacinação atreladas a valorização dos profissionais, são capazes de reverter a realidade exposta (VIEIRA et al., 2020).

Objetivo: Identificar na literatura científica ações multiprofissionais de promoção para o cumprimento do calendário vacinal.

Resultados: Entre 2015 e outubro de 2018 os índices vacinais brasileiros, sofreram com a queda da cobertura da primeira dose da tríplice viral, ademais, tal cenário só foi convertido à partir da campanha nacional de vacinação, que ocorreu em setembro de 2018, na qual meta do Plano Nacional de Imunizações (PNI) foi cumprida conforme o idealizado anteriormente (VIEIRA et al., 2020). Desse modo, a relevância das intervenções de profissionais da área da prática clínica não contemplam somente o cuidado da aplicação da vacina nos indivíduos, mas sim, um trabalho integrado, do qual é capaz de produzir indicadores de vigilância e monitorização de saúde das populações (OMS, 2021). Além disto, o fator estrutural das unidades prestadoras de serviços tratase de um importante influenciador na distribuição de doses, sendo estes componentes estruturais imprescindíveis: geladeira exclusiva para vacinas, caixas térmicas para vacinas sempre disponíveis, sala de vacinação exclusiva para ações imunizantes, cartões de vacinação disponíveis e impressos (VIEIRA et al., 2020). Sendo assim, torna-se imprescindível a compreensão dos profissionais sobre calendário vacinal, as datas da aplicação das vacinas, seguidas da fórmula vacinal recebida; para mais, essas informações servem de base fundamentadora para a disseminação de dados vacinais em sua prática profissional, a fim de incentivar o cumprimento das metas propostas pelo PNI (FRADE; HENRIQUES; FRADE, 2019).

Conclusão: Pode-se concluir que ações multiprofissionais como, vigilância e monitorização da saúde, campanhas de incentivo à vacinação, estruturação dos serviços de saúde, capacitação profissional e divulgação de informações sobre vacinação podem contribuir para a promoção à cobertura vacinal.

\section{Referências}

FRADE, João Manuel Graça; HENRIQUES, Carolina Miguel Graça; FRADE, Fátima. Registos vacinais de enfermagem: importância para a vigilância da saúde das populações. Revista de Enfermagem Referência, v. 4, n. 20, p. 107-116, 2019.

VIEIRA, Ed Wilson et al. Estrutura e localização dos serviços de vacinação influenciam a disponibilidade da tríplice viral no Brasil. Revista Mineira de Enfermagem, v. 24, p. 1-6, 2020.

ORGANIZAÇÃO PAN-AMERICANA DE SAÚDE. Organização Mundial de Saúde. Atualização epidemiológica: Difteria. 25 de junho de 2021. Disponível em:https://pesquisa.bvsalud.org/portal/resource/pt/phr2-54474 Acesso em: 20 ag. 2021.

ANals Do

I SALÃO DE EXTENSÃO DA UNIPAR

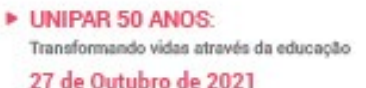

Traneformando vides atravta
27 de Outubro de 2021

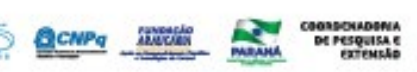




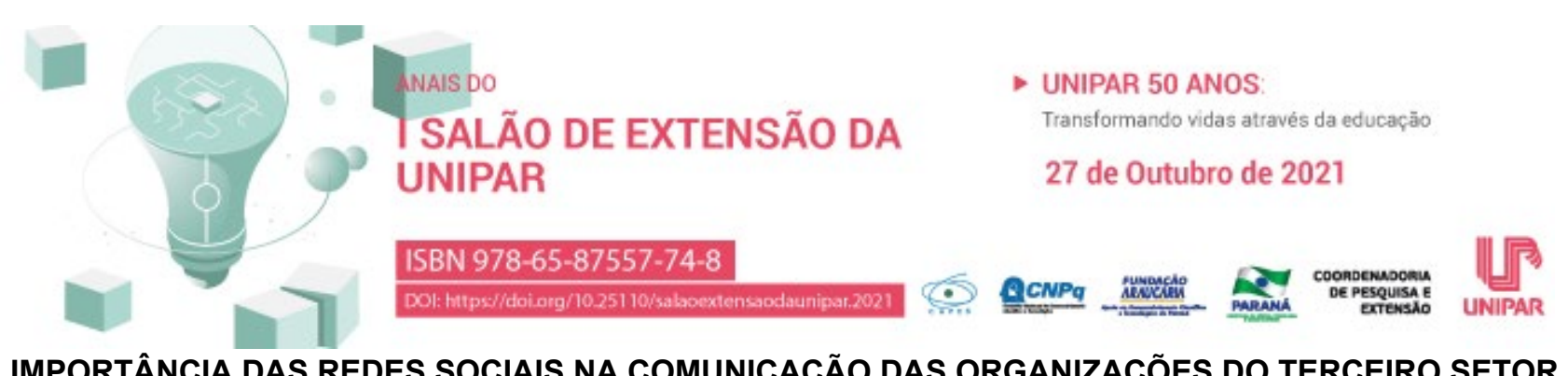

A IMPORTÂNCIA DAS REDES SOCIAIS NA COMUNICAÇÃO DAS ORGANIZAÇÕES DO TERCEIRO SETOR

\author{
${ }^{1}$ YSLA DA SILVA FUJIWARA, ${ }^{2}$ ANA CLEIA DE OLIVEIRA CIRINO \\ ${ }^{1}$ Discente de Publicidade e Propaganda da Unipar. \\ ${ }^{2}$ Docente da UNIPAR
}

Introdução: No atual momento em que as questões de ordem social ganham cada vez mais importância é necessário conhecer as contribuições do marketing e da comunicação para o terceiro setor. Essas organizações têm uma necessidade diferente das empresas com fins lucrativos, pois não vendem produtos ou serviços, elas propagam ideias e defendem as causas na qual acreditam. As informações deste estudo partem do Projeto de Extensão, Luz e Ação - Assessoria de Comunicação para ONGs e Microempreendedores, do curso de Publicidade e Propaganda da Universidade Paranaense UNIPAR.

Objetivo: Abordar com base em estratégias comunicacionais, como organizações do terceiro setor podem se destacar nos meios digitais, com o intuito de promover engajamento social.

Resultado: As redes sociais promovem no meio internet a conexão entre os indivíduos e as interações entre eles. Essas plataformas oferecem serviços que todos podem criar perfis públicos, de acordo com suas preferências e necessidades. Por meio delas, os usuários se conectam de modo voluntário com outros indivíduos do sistema. O site de conteúdos Rock Content (2020), aborda o Marketing Digital para ONGs como um conjunto de estratégias focadas no meio online, com o objetivo de fortalecer a marca e atrair pessoas com o mesmo propósito social. Fazer as pessoas se envolverem pela causa é o ponto mais importante ao estabelecer uma estratégia de Marketing Digital para ONGs, e as redes sociais são ferramentas que auxiliam nesse processo. Para isso, o desenvolvimento de um layout padronizado para as publicações, respeitando a identidade visual da marca, se vê necessário, na qual pertence ao estudo de programação visual, que [...] é um conjunto de teorias e técnicas que nos permite ordenar a forma pela qual se faz a comunicação visual, afirma Strunck (2003, p. 53) em seus estudos. Sequeira (2013) ainda defende que a identidade visual não está apenas atrelada a escolha das cores, logotipo, e seu significado. Cabe ainda definir a harmonização da composição gráfica e a questão visual da imagem ou qualquer material que estará presente junto ao símbolo e a tipografia, contribuindo com eficiência as necessidades da comunicação. As redes sociais digitais passaram a fazer parte do cotidiano das pessoas e, dessa forma, impactaram de modo significativo os valores e comportamentos dos indivíduos. A internet se tornou uma ferramenta imprescindível para a vida das pessoas, na sociedade e no ambiente organizacional, portanto as organizações sem fins lucrativos também precisam utilizar essas ferramentas e plataformas para atender aos seus objetivos de marketing e comunicação.

Conclusão: O Marketing digital destinado para causas sociais pode ser considerado como um instrumento estratégico e de posicionamento que integra uma organização ou marca a uma questão ou causa social relevante. O projeto Luz e Ação conseguiu articular ensino e extensão ao estimular a experimentação de formatos comunicacionais e possibilitar a troca desses conhecimentos, contribuindo para planejar e executar soluções comunicacionais para as entidades atendidas.

\title{
Referências
}

ROCKCONTENT. Marketing Digital para ONGs: como usar essa estratégia no terceiro setor. RockContent, 2020. Disponível em: https://rockcontent.com/br/blog/marketing-digital-para-ong. Acesso em: 11 ago. 2021.

SEQUEIRA, A. M. S. M. Identidade visual: O simbolismo na identidade organizacional. 2013. Disponível em: https://recipp.ipp.pt/bitstream/10400.22/1780/1/PP_ArmindaSequeira_2013.pdf. Acesso em: 06 out. 2019.

STRUNCK, Gilberto Luiz Teixeira Leite. Como criar identidades visuais para marcas de sucesso: um guia sobre o marketing das marcas e como representar graficamente seus valores. 2. ed. Rio de Janeiro: Rio Books, 2003.

\section{SALÃO DE EXTENSÃO DA UNIPAR}

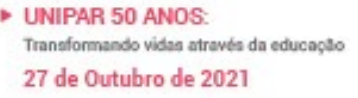

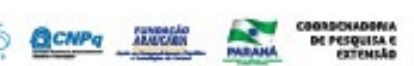

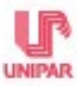



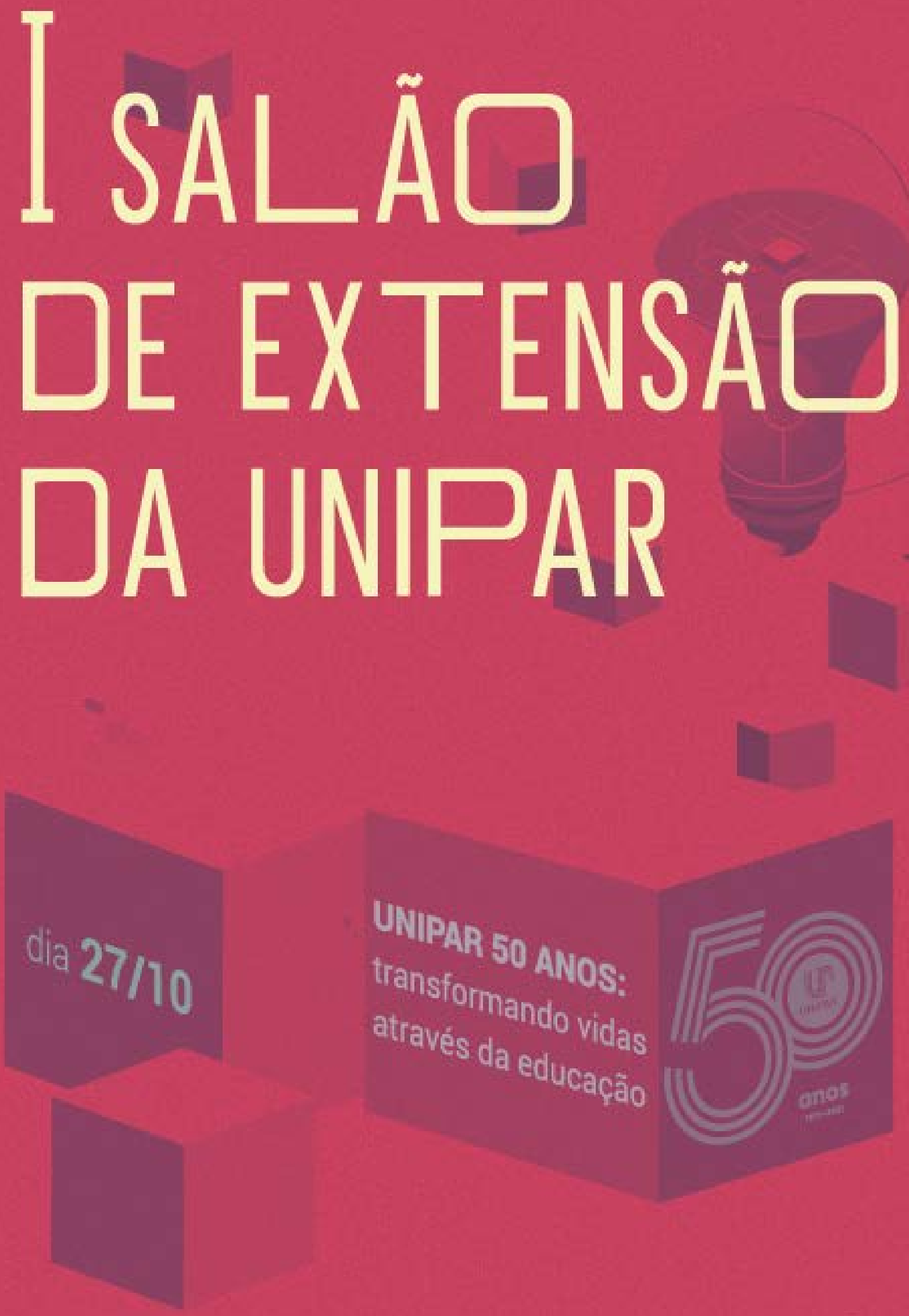

$\lessdot$ PㄷPㅁ
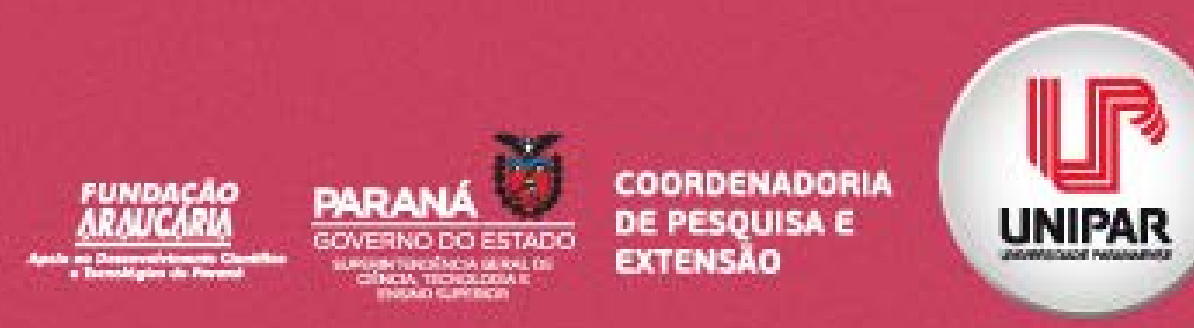